
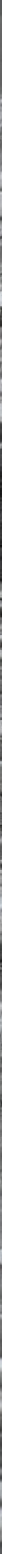

Marion Sauter (Hrsg.)

\title{
SURENENPASS Archäologie und Geschichte in Attinghausen
}

Mit Beiträgen von Ulrike Gollnick, Jean Nicolas Haas, Walter Imhof, Urs Leuzinger, Christine Pümpin, Jochen Reinhard, Marion Sauter und Peter Spillmann 
Marion Sauter (Hrsg.)

\section{SURENENPASS Archäologie und Geschichte in Attinghausen}

Mit Beiträgen von Ulrike Gollnick, Jean Nicolas Haas, Walter Imhof, Urs Leuzinger, Christine Pümpin, Jochen Reinhard, Marion Sauter und Peter Spillmann 
Lucerne University of

Applied Sciences and Arts

\section{HOCHSCHULE}

LUZERN

Technik \& Architektur

$\mathrm{FH}$ Zentralschweiz

Dieser Band wurde gedruckt mit Unterstützung von:

Stiftung zur Förderung der Hochschule Luzern - Technik \& Architektur Hochschule Luzern - Technik \& Architektur: Abteilung Architektur Hochschule Luzern - Technik \& Architektur: Forschung

Kanton Uri, Otto-Gamma-Stiftung und Gemeinde Attinghausen

Herzlichen Dank! 


\section{Inhalt}

Zum Geleit

Hans Stadler-Planzer

Vorwort

Marion Sauter

\section{Landschaft und Umwelt}

Geologie des Surenenpasses

Peter Spillmann

Links und rechts des Surenenpasses: Klima- und Vegetationsverlauf seit der letzten Eiszeit

Jean Nicolas Haas, Notburga Wahlmüller, Sara Altstätter, Benjamin

Dietre, Anton Stefan Schwarz und Irka Hajdas

\section{Archäologie in Attinghausen}

Wüstungsforschung im Kanton Uri - Katalog der Gemeinde

Attinghausen

Marion Sauter

Die Restaurierung der Burgruine Attinghausen - Bauforschung

Ulrike Gollnick

\section{Das Forschungsprojekt Surenenpass}

Höhlen und Balmen - Natürliche Schutzräume am Surenenpassweg

Walter Imhof

Wege zum Surenenpass

Marion Sauter

Siedlungsplatz Geissrüggen - Ein hallstattzeitliches Gebäude

Urs Leuzinger

Das archäologische Fundmaterial entlang des Surenenpasswegs

Urs Leuzinger

Mikromorphologische Untersuchungen an einem hallstattzeitlichen

Siedlungsplatz

Christine Pümpin

3D-Dokumentation mit Drohne

Jochen Reinhard

Strukturwandel - Die Alpnutzung auf Surenen

Urs Leuzinger und Marion Sauter

\section{Anhang}

Autoren

Pressespiegel 


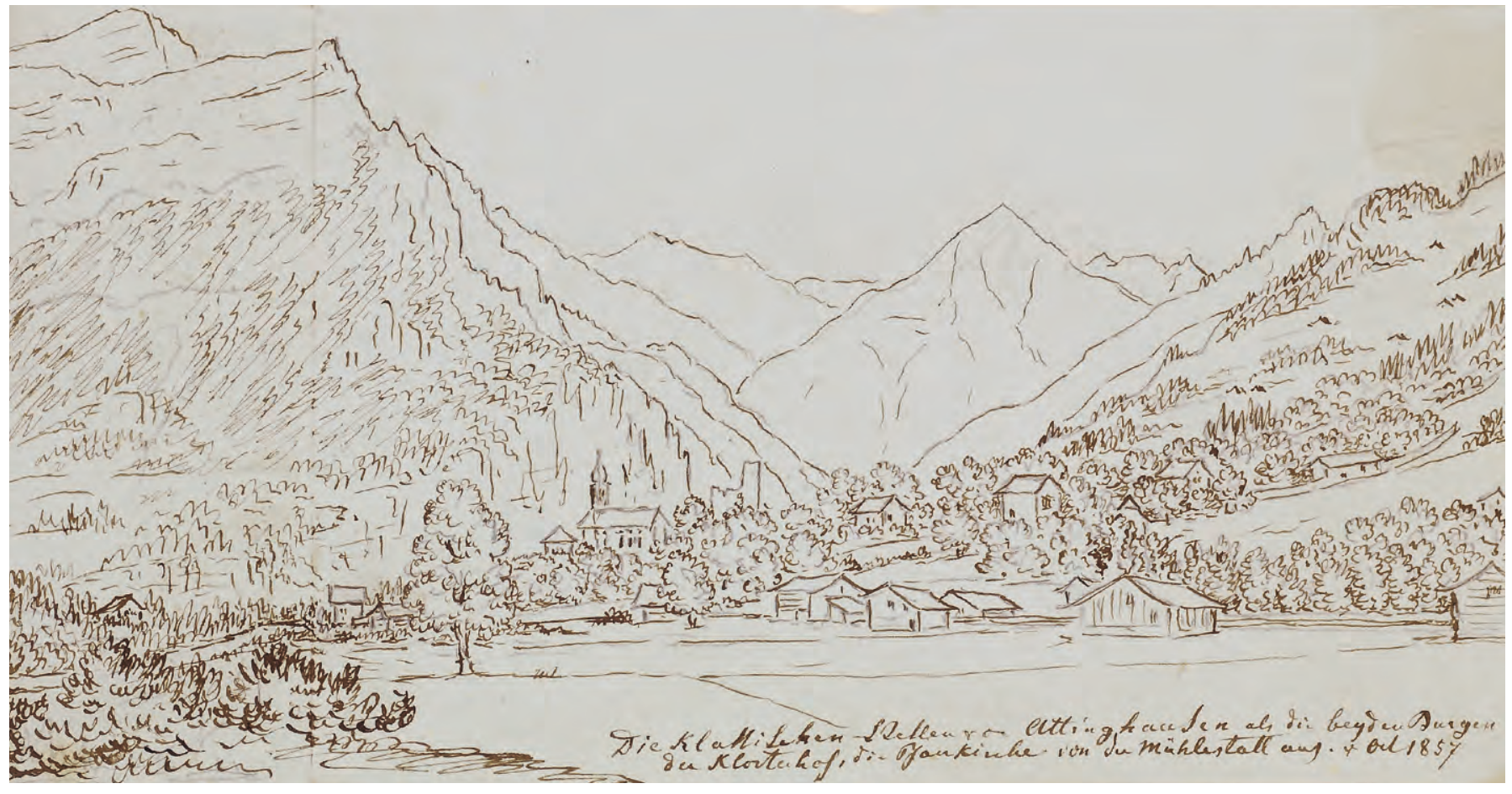




\section{Zum Geleit}

Das Gebirgsland Uri war wirtschaftlich bis ins 20. Jahrhundert hinein in stärkstem Masse von der Land- und Alpwirtschaft geprägt. Die Siedler hatten seit prähistorischer Zeit der Natur überall dort, wo die Topografie es ermöglichte, Kulturland abgewonnen. Dies war vor allem an den Talflanken der Fall, weniger hingegen in der Reussebene, wo sich Sümpfe ausbreiteten. Auch entlang des Surenenpasswegs entstanden Berggüter und Alpen.

Doch wie war es um die Alpwirtschaft in diesen frühen Epochen bestellt? Die schriftlichen Quellen setzen erst am Übergang vom Hoch- zum Spätmittelalter ein. Sie berichten von Nutzungskonflikten zwischen den Urnern und dem Kloster Engelberg und der mühsam errungenen Grenzziehung. Diesseits der Wasserscheide, auf dem Grat, lagen die Oberstafel der Alpbetriebe des Gitschentals, die Grossbauern und dem Kloster St. Lazarus in Seedorf gehörten. Intakte Alpinfrastrukturen aus diesen Epochen fehlen. Die Wissenslücken sind gross. Vor allem ist unbekannt, wann die Alpwirtschaft einsetzte und wie sie anfänglich organisiert war.

Wie kann die Forschung weiterkommen? Es gibt zahlreiche Alpwüstungen: entlang des Surenenpasswegs, vor allem auf dem Geissrüggen und im Talkessel von Blacken. Es ist das Verdienst von Marion Sauter, sich mit Forscherblick, Fleiss und grossem technischen wie organisatorischen Aufwand diesen wüst gefallenen Gebäuden zugewandt zu haben.

In der vorliegenden Publikation sind fundierte Beiträge verschiedener Autorinnen und Autoren versammelt. Sie behandeln die Geologie, die Balmen und Höhlen, die alpinen Wüstungen und die archäologischen Einzelfunde im Surenengebiet. Für die Geschichtswissenschaft sehr gewichtig sind die Ausführungen über die Burgruine Attinghausen und über die Wege. Für den Surenenpassweg von Seedorf durch das Gitschental auf den Grat wird für früher eine grössere Bedeutung postuliert. Die These lässt sich aus der aktenmässigen Überlieferung erhärten. Als ursprünglicher Passwegverlauf von den Eggen abwärts gegen Surenen wird - für heutige Vorstellungen überraschend - der schmale Weidweg von Uf den Seewen durch die Steilflanke unter dem Turm nach Gritschen vermutet.

Holzkohlesedimente aus einer Wüstung auf dem Geissrüggen liessen sich ins frühe 6. Jahrhundert v.Chr. datieren. Die geheimnisvollen Mauern sind somit Überreste des einzigen bislang bekannten Urner Gebäudes im Alpwirtschaftsgebiet aus der Hallstattzeit. Seine Verwendung bleibt allerdings mangels erhellender Kleinfunde unsicher. Die vielen Wüstungen im weiten Talkessel von Blacken - Überreste von Hütten und Ställen, Pferchen und Unterständen - können anhand einiger Holzkohlefunde mit Mittelalter oder Neuzeit datiert werden. Die Forschungen beweisen, dass auf der Blackenalp die Einzelalpung herrschte, bevor in der Frühen Neuzeit der Hirtebetrieb Platz griff. Die Entwicklung verlief in Surenen somit ähnlich wie in Fiseten (Urnerboden) und Alplen (Unterschächen).

Der Forschungsansatz erwies sich als fruchtbar. Die Arbeit des Teams um Marion Sauter zeitigte wichtige Ergebnisse und formulierte beachtenswerte Thesen. Sie stellen für die Geschichte des Landes Uri einen bedeutenden Fortschritt dar. Sie bereichern auch allgemein die archäologischen Kenntnisse über den Alpenraum.

hausen als die beyden Burgen

der Klosterhof, die Pfarrkirche [...]" (Bildunterschrift).

Zeichnung K. F. Lusser, 1857 (Staatsarchiv Uri)

Hans Stadler-Planzer 


\section{Vorwort}

Mit grosser Freude darf ich die Abschlusspublikation des Projekts "Wüstungsforschung im Kanton Uri» vorstellen, das meine Arbeit als Urner Denkmalinventarisatorin und Dozentin für Architektur- und Siedlungsgeschichte an der Abteilung Architektur der Hochschule Luzern über sieben Jahre lang begleitet hat. Der Titel des vorliegenden Bands, "Surenenpass. Archäologie und Geschichte in Attinghausen", verdeutlicht den Arbeitsprozess von der Feldforschung in einer ganzen Region hin zur wissenschaftlichen Fokussierung auf ein besonders vielversprechendes Fundgebiet.

Im hochpreisigen Kulturland rund um die Schweizer Siedlungsschwerpunkte werden nicht mehr benötigte Gebäude in der Regel eingeebnet und/oder überbaut. Anders im Alpenraum: Hier wird Ungenutztes meist dem Verfall preisgegeben. Die Überreste, die sogenannten Wüstungen, dokumentieren somit die Baukultur vieler Jahrhunderte und lassen Rückschlüsse auf die Siedlungsentwicklung, auf das Klima und die damit einhergehende Vegetation sowie auf die jeweils vorherrschenden Wirtschaftsformen zu.

Der heutige Forschungszweig "Alpine Wüstungsforschung" startete Ende des 19. Jahrhunderts mit der volkskundlichen Erfassung sogenannter Heidenhüttli. Seit dem ausgehenden 20. Jahrhundert findet die Dokumentation abgegangener Alphütten und anderer baulicher Überreste zunehmend Verbreitung und gewinnt an Systematik. Herausragend sind das engagierte Höhlen- und Wüstungsforschungsteam um Walter Imhof im Schwyzer Muotatal, die Prospektionsprojekte im Berner Oberland in den Jahren 2003/04 und 2006 sowie in Graubünden 2007 bis 2012. Letzteres mündete in aufsehenerregende Grabungen in der Silvretta. Derzeit wird hauptsächlich in den Kantonen Schwyz und Nidwalden geforscht.

1983 konnten in Hospental-Blumenhütte ein mittelalterlicher Alpweiler ausgegraben und einige benachbarte Baufragmente dokumentiert werden. Auf Anregung von Walter Imhof wurde die Urner Feldforschung ab 2008 unter meiner Federführung fortgesetzt. Über 700 weitere Objekte - HöhIen, Balmen, Gebäude- und Mauerreste sowie Überreste der Infrastruktur - dokumentieren inzwischen die bevorzugten Aufenthaltsorte prähistorischer Jäger, die Bautätigkeit mittelalterlicher Schafhirten oder neuzeitlicher Milchviehhalter und ihrer Familien. Das Urner Wüstungsinventar hat damit einen vorbildlichen Stand erreicht.

Die Grundlagen, die personalaufwendige Feldforschung, legten 28 Studierende der Abteilung Architektur in ihrer Freizeit. Die Arbeit der jungen Planerinnen und Planer wurde in der Fachwelt zuerst skeptisch, dann erstaunt und schliesslich anerkennend betrachtet. Neben dem Gewinn für die Archäologie half die Feldforschung den Studierenden, den Alpenraum als Siedlungsgebiet wahrzunehmen und den Blick für günstige Ortslagen zu schärfen. Der Kanton Uri erwies sich als vorbildlicher Gastgeber und finanzierte den engagierten Nachwuchsforscherinnen und Nachwuchsforschern Kost und Logis, ebenso anschliessend den Profis: Kolleginnen und Kollegen von den Universitäten Basel, Zürich und Innsbruck sowie den kantonalen Archäologiefachstellen der Kantone Thurgau, Bern, Zug und Zürich, die 2013/14 die Kampagnen auf dem Geissrüggen und auf Blacken sowie die wissenschaftliche Auswertung in höchstem Masse interdisziplinär, dem aktuellen Forschungsstand der Archäologie entsprechend, übernahmen ehrenamtlich! 


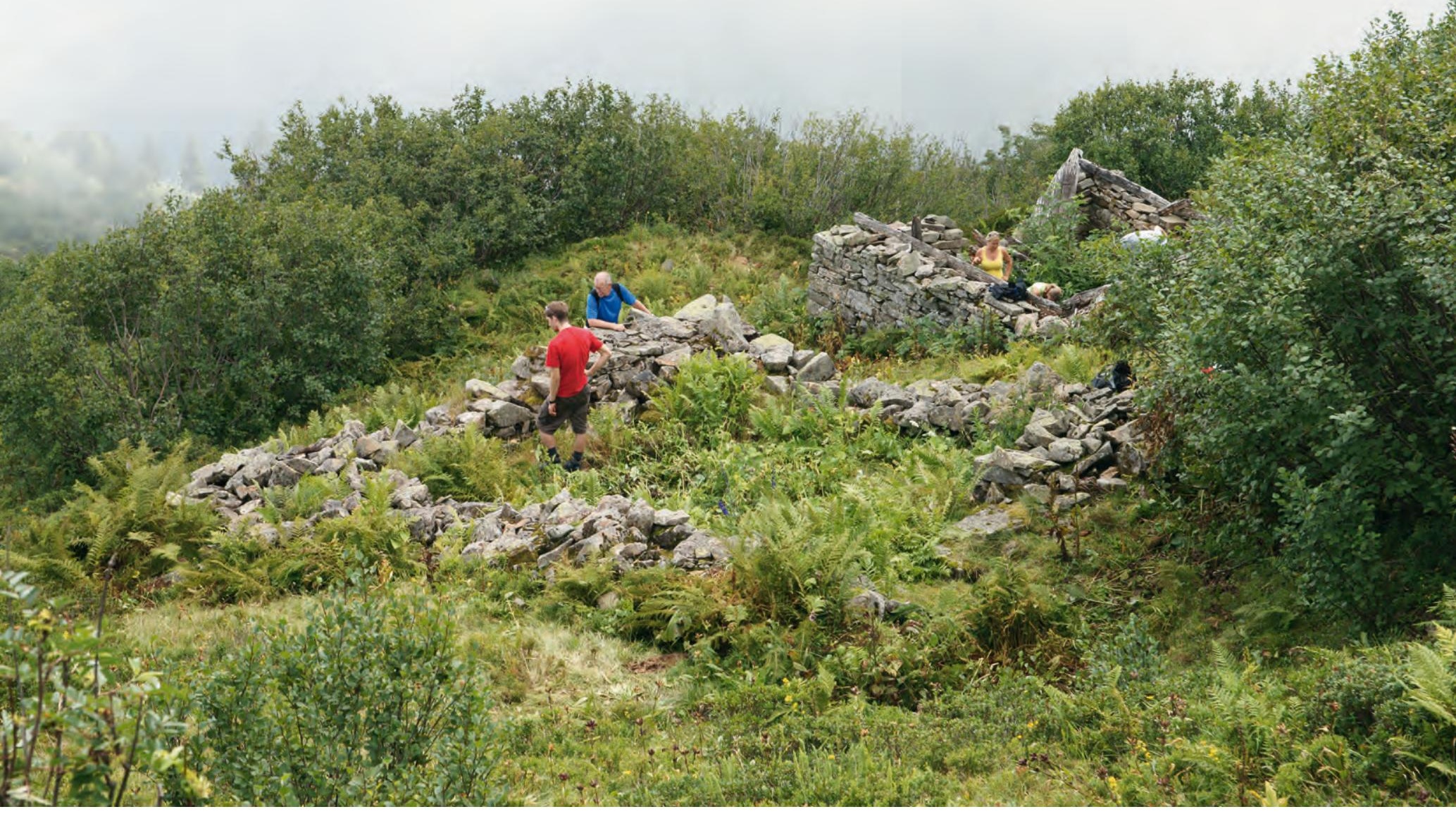

At.029 / At.043

Zwei Heuställe (Übersicht) Attinghausen-Gratgädemli LK 1191 - 687 587/188 719 1802 m ü.M.

Foto T. Künzle, 2009
Unsere Feldforschungsergebnisse finden eine gewinnbringende Ergänzung in einem Bericht über die zeitgleich durchgeführte Sicherung der Burgruine Attinghausen. Entstanden ist ein archäologisches und historisches Gesamtbild, wie es in dieser Form wohl für kaum eine andere Schweizer Berggemeinde vorliegt.

Ich bin dem Kanton Uri, meinen Studierenden und allen Kolleginnen und Kollegen - besonders unserem Grabungsleiter Urs Leuzinger sowie Walter Imhof - zu grossem Dank verpflichtet. Es hat mich sehr gefreut, dass die Hochschule Luzern, die Abteilungen Forschung und Architektur sowie die Stiftung zur Förderung der Hochschule Luzern den Grundstock zur Finanzierung dieser Abschlusspublikation gelegt haben. Die Hochschule Luzern stellt sich damit in eine Reihe mit namhaften Universitäten: Die GraubündenForschung wurde von der Universität Zürich initiiert, das aktuelle Prospektionsprojekt im Kanton Nidwalden, das als nächster Band in der neu konzipierten LIBRUM-Reihe "Archäologische Prospektion - Archaeological Survey" erscheinen wird, wird von der Universität Basel getragen. Zum Gelingen des Forschungsprojekts und dieser Publikation trugen ausserdem die Korporation Uri, die Surenenhirtekommission, die Otto-Gamma-Stiftung und die Gemeinde Attinghausen bei. Grabungsmaterial - vom Spaten bis zur Fotodrohne - steuerten die Abteilung Zivilschutz des Kantons Uri beziehungsweise das Amt für Denkmalpflege und Archäologie Zug bei.

Hoffentlich beschert der Abstecher in die alpine Archäologie in Buchform den Lesern ebenso gewinnbringende Erkenntnisse wie unsere unvergesslichen Ausflüge in die Berge den Studierenden und dem Archäologenteam! 



\section{Landschaft und Umwelt}




\section{Summary: Geology of the Surenen Pass}

The rocks that occur along the Surenen Pass represent different stages of the earth's history. The oldest rocks crop out in the Reuss Valley near Erstfeld and in the rearmost part of the Engelberg Valley. They consist mostly of high-grade metamorphic gneisses that exhibit imprints of several pre-Mesozoic orogenic cycles. They are stratigraphically overlain by Mesozoic carbonates indicating the onset of marine sedimentation from the Lower Triassic period onwards. Crystalline basement rocks and their sedimentary cover make up the Aarmassif, representing a section of European crust near a passive continental margin. The main rock type accompanying the trail along the Surenen Pass is a well banked sandstone with thin shaly intercalations. These synorogenic flysch deposits (North-Helvetic Flysch) were formed during the Tertiary in a narrow basin facing the Alpine mountain chain. During ongoing Alpine orogeny the Aarmassif and the North-Helvetic Flysch also became incorporated in the Alpine nappe edifice. The thrusting of sedimentary units which were detached from their crystalline substratum and forced northwards resulted in the units in the Surenen area being buried to mid-crustal levels. Subsequent uplift and erosion led to the formation of the actual relief. The distribution of valleys and mountains in the actual relief was strongly influenced by periodic Quaternary glaciations. The last glacial maximum occurred about 24000 years ago. The subsequent retreat of the glaciation to its actual extension is attested to by the traces of erosional and sedimentological processes left in the modern landscape. 


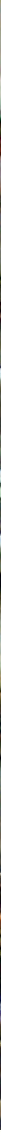

\section{Geologie des Surenenpasses}

Die Gesteine am Surenenpass repräsentieren ganz unterschiedliche Abschnitte der Erdgeschichte. In Erstfeld oder im Talhintergrund von Engelberg liegen sehr alte kristalline Gesteine vor. Darüber bildeten sich mit dem Vorrücken des Meers kalkige Ablagerungen, welche überlagert werden von Sandsteinen. Diese entstanden in einem schmalen Meeresarm im Vorfeld der anrückenden Alpen. Im Zuge der fortschreitenden Alpenfaltung wurde diese Abfolge von Gesteinspaketen überschoben und in grössere Tiefe versenkt. Hebungsbewegungen und Abtrag führten dann zum heutigen Landschaftsbild, welches durch die eiszeitlichen Vergletscherungen sein abschliessendes Gepräge fand und schliesslich die Bühne bereitete für die menschlichen Aktivitäten entlang des Passes.

\section{Steine am Wegrand}

\section{Flysch - Der Schutt der heranrückenden Alpen}

Der Wanderer, der den Surenenpass begeht, bewegt sich über eine grosse Wegstrecke auf einer einheitlichen Gesteinsformation. Er erkennt in den Felsaufschlüssen und im Schutt entlang des Wegs eine recht monotone Abfolge von mehrheitlich grobbankigen grauen und grünlichen Sandsteinen mit dünnen Zwischenlagen von Tonschiefern und Mergeln.

Diese Gesteinsformation bildete sich vor rund 35 Millionen Jahren in einem schmalen Meeresarm, welcher den Schutt aus dem Abtrag der von Südwesten vorrückenden Alpen aufnahm. Man nennt Meeresablagerungen, welche sich in diesem geografischen Umfeld am Rande eines aktiven Gebirges bildeten, Flysche. Entsprechend ihrer Lage im Alpenbau werden die Gesteine, welche entlang des Surenenpasswegs aufgeschlossen sind, als Nordhelvetischer Flysch bezeichnet. 


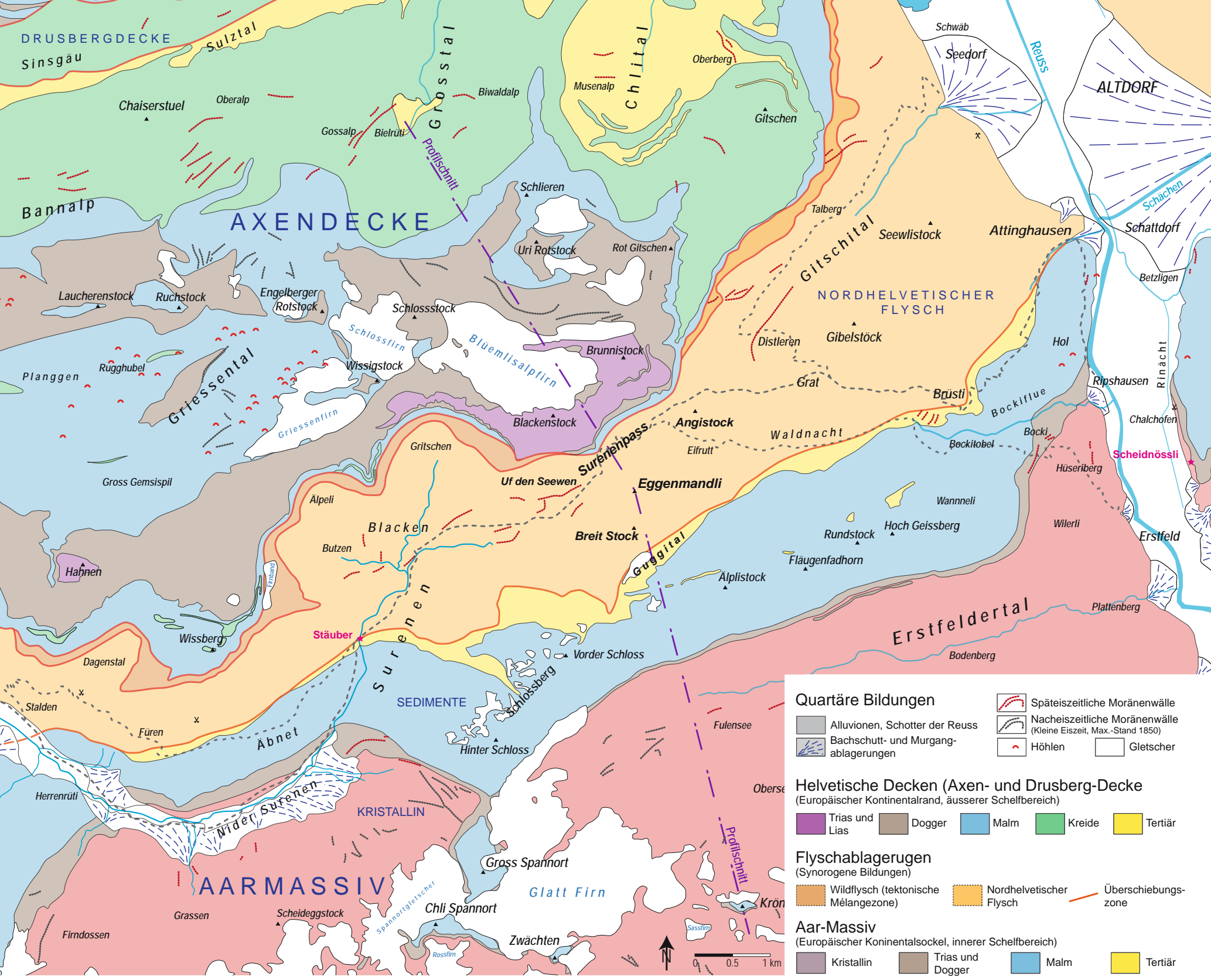

Die Bezeichnung Flysch steht für Gesteinsabfolgen, die typischerweise in Gebieten mit "schlechtem" beziehungsweise schiefrigem Gestein auftreten. Der Nordhelvetische Flysch ist zwar häufig gekennzeichnet durch sehr harte Gesteine, die beispielsweise nördlich von Attinghausen als Hartsteine zur Gewinnung von Bahnschottern abgebaut werden; gleichzeitig setzt aber der Flysch der Erosion nur eine geringe Widerstandskraft entgegen. Das Gestein ist wenig wasserdurchlässig, was zu sumpfigen Vernässungen im Gelände und zu ausgeprägten Rutschgebieten führen kann. Flyschgebiete sind daher eher durch Passübergänge als durch markante Gipfel geprägt. Das gilt insbesondere auch für den Surenenpass. Die Berggipfel auf der Urner Seite des Passes, der Seewlistock (1546 m ü.M.), die Gibelstöck (1887 m ü.M.) und der Angistock (2070 m ü.M.) stehen im Schatten der steil aufragenden Kalkgipfel der Uri-Rotstock-Gruppe im Norden und der Geissberg-Schlossberg-Kette im Süden, ebenso das Eggenmandli (2447 m ü.M.) und der Breit Stock (2464 m ü.M.) im Gebiet des Passübergangs.

Auch das Gebiet westlich der Passhöhe bildet eine sehr typische Flyschlandschaft. Kennzeichnend sind weiche Geländeformen mit sumpfigen Mulden und tiefgründig verwitterter Fels mit Rutschgebieten und tief greifenden Erosionsfurchen.

Titelbild: Aufschluss von Sandsteinen des Nordhelvetischen Flyschs (Altdorfer Sandstein) an der Strasse ins Gitschital oberhalb von Seedorf.

Foto C. Gisler, 2009

Geologische Karte des Surenenpasses und seiner Umgebung.

Zeichnung P. Spillmann, 2015 
De Quervain 1984

Der Attinghauser Steinbruch in der Anfangszeit der Hartsteinproduktion. Foto, um 1900 (Staatsarchiv Uri)
Die Lage des Übergangs zwischen dem Urner Reusstal und dem Tal der Engelberger $\mathrm{Aa}$ ist durch das Auftreten des Nordhelvetischen Flysches gegeben. Die geringe Höhe des Übergangs und die Tendenz zu eher weichen Geländeformen erlaubten die Erschliessung von Alpgebieten und das Anlegen von Wegverbindungen ( - S. 102-121). Die unmittelbar nördlich und südlich angrenzenden Übergänge zwischen den Tälern der Reuss und der Engelberger Aa führen bis in die heutige Zeit über hochalpines, vergletschertes Gelände.

\section{Flysch als Baumaterial}

Dank einer plattigen Ausbildung und einer guten Spaltbarkeit eignet sich der Nordhelvetische Flysch ausgezeichnet zur Erstellung von Natursteinmauerwerk, aber auch zur Gewinnung von Dachplatten. Lokal aus Aufschlüssen und aus dem Gehängeschutt gewonnenes Material diente vor Ort der Erstellung von landwirtschaftlichen Bauten. Auf der Engelberger Seite wurde bei der Fürenalp und im Dagenstal Flysch in Gruben abgebaut und beispielsweise beim Bau des Klosters Engelberg für Boden- und Ofenplatten sowie als Dachschiefer verwendet. Das Dach der Engelberger Kapelle St. Jakob in Espen ist aus Steinen aus diesen Gruben gefertigt, ebenso das ursprüngliche Dach des Herrenhauses in Grafenort. ${ }^{1}$

In Attinghausen bietet seit vielen Jahrzehnten der Abbau von Nordhelvetischen Flyschen, sogenannten Altdorfer Sandsteinen, zahlreiche Arbeitsplätze. Das gewonnene Gestein wird zu Hartsteinprodukten (Schotter, Split und Wuhrsteinen) verarbeitet.

\section{Kalkige Hindernisse}

Dem aufmerksamen Wanderer wird nicht entgehen, dass beim Aufstieg auf das Brüsti entlang des Wegs gelegentlich auch hell anwitternde Kalkfelsen auftreten. Diese sind insbesondere auch in das Pflaster und in die seitlichen Stützmauern der Gasse bei Mettlen eingearbeitet.

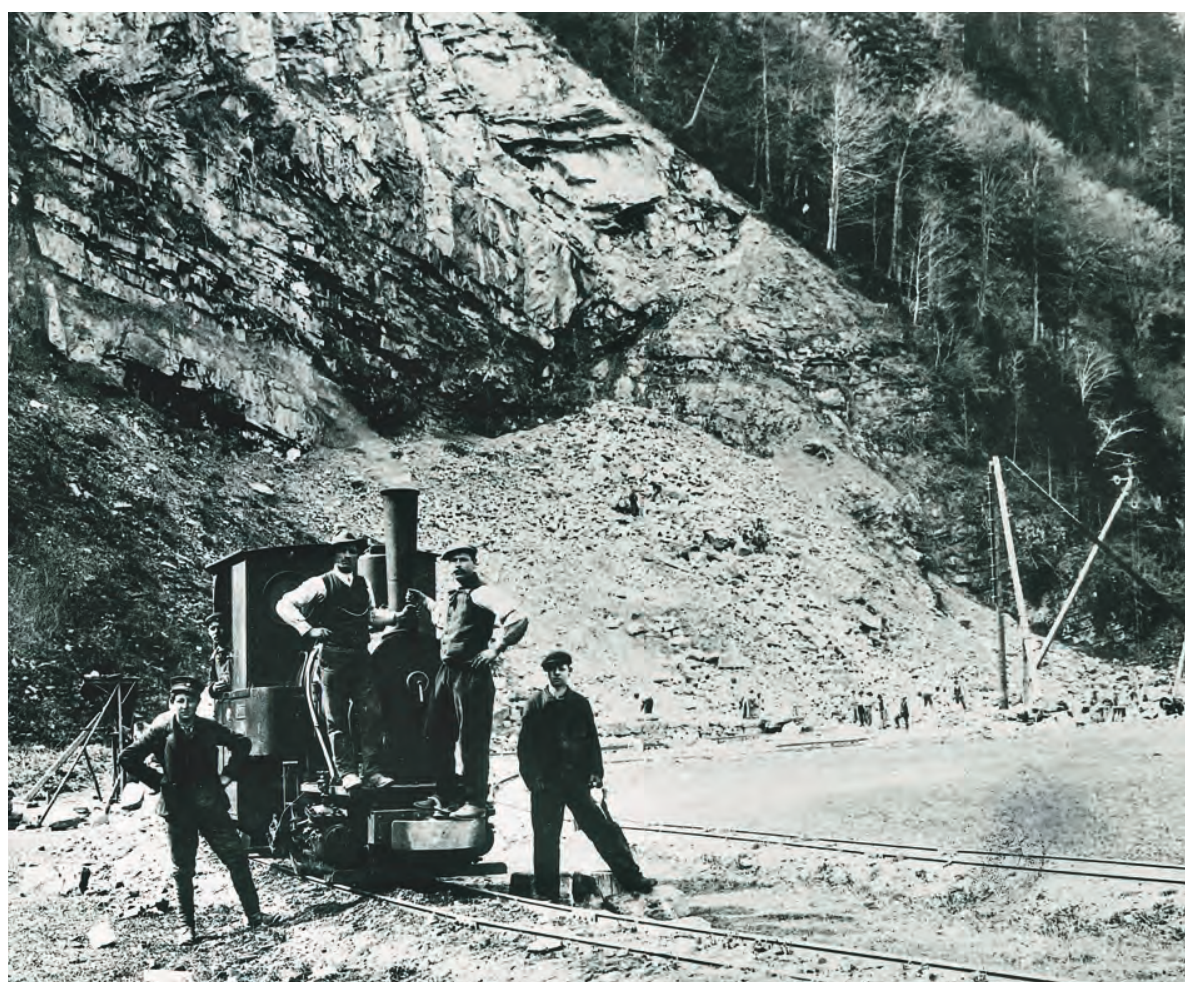


Besonders auffällig sind diese in der Anwitterung hellgrauen, im frischen Bruch aber dunkelgrauen bis schwarzen Kalkgesteine beim Passieren des linken Reussufers zwischen Attinghausen und Ripshausen. Da die Reuss hier an den steil aufragenden Talrand drängt, wurde der Weg am östlichsten Ausläufer der Bockiflue in einen Tunnel gelegt. Ein etwas höher gelegener, nicht mehr gebräuchlicher Weg überwindet diese Stelle mittels einer in den Fels eingehauenen spektakulären Halbgalerie ( $\rightarrow$ Abb. S. 109).

Besonders beeindrucken wird diese mächtige Kalkabfolge den von Erstfeld Richtung Surenenpass Wandernden. Die im Oberen Jura (Malm), vor rund 160 Millionen Jahren, in einem relativ tiefen, schlecht belüfteten Meeresbecken abgelagerten Kalke bilden den bis 500 m hohen, schroff aufragenden Riegel der Bockiflue, der sich gegen Südwesten in der markanten Bergkette zwischen Hoch Geissberg und Schlossberg fortsetzt. Dieser Riegel wird oberhalb des Bockitobels über einen ausgesetzten Pfad überwunden, bevor in der Waldnacht und beim Brüsti der oben beschriebene Nordhelvetische Flysch erreicht wird. Der Kontrast zwischen der durch Kalk und der durch Flysch geprägten Landschaft ist hier sehr ausgeprägt erlebbar.

\section{Kristallines Urgebirge}

Beim Aufstieg von Erstfeld her sind zunächst entlang des Weges in kleineren Felswänden oder in der Form von gletschergeschliffenen Höckern graue Gneise mit steil einfallender Schieferung aufgeschlossen. Hier handelt es sich um sehr alte Gesteine, die geprägt sind durch Gebirgsbildungen, die sich lange vor der Bildung der Alpen, im Paläozoikum und noch früher, ereigneten.

\section{Das Vorrücken des Meers}

Gegen Ende des Paläozoikums, nach der vollständigen Einebnung des sogenannten Variskischen Gebirges, drang in der Trias, also vor rund 250 Millionen Jahren, das Meer vor und es lagerten sich in einem flachen Meer Plattformkarbonate ab. ${ }^{2}$ Diese Vorgänge sind auf der gegenüberliegenden Talseite am Scheidnössli beim Nordportal des Gotthard-Basistunnels sehr anschaulich aufgeschlossen.

Im Unteren Jura (Lias), vor rund 200 Millionen Jahren, fiel dieses Meer trocken. Es bildete sich Festland (Alemannisches Land), welches im Mittleren Jura (Dogger) wiederum überflutet wurde, was zur Ablagerung von geringmächtigen, teilweise stark eisenhaltigen Sedimenten führte. Erst im Oberen Jura (Malm) formten sich dann vor rund 160 Millionen Jahren die mehrere $100 \mathrm{~m}$ mächtigen, oben beschriebenen kalkigen Meeresablagerungen.

Während der Kreide bildeten sich weitere marine Sedimente in einem inneren, periodisch trocken fallenden Schelfbereich, unweit des europäischen Kontinentalrandes. Diese Schichten fehlen heute, sie wurden im frühen Tertiär bis in den Malm hinunter aberodiert, was zu eisenhaltigen Bohnerzlagern in den verkarstenden Malmkalken führte. Diese alte Landoberfläche wird diskordant überlagert durch tertiäre flachmarine Sandsteine und Mergel.

Das kristalline Grundgebirge und die aufgelagerten Sedimente der Trias bis ins Tertiär bilden im alpinen Gebirgsbau das sogenannte Aarmassiv, welches das Urner Reusstal zwischen Schattdorf und Schöllenenschlucht prägt.

2 Gisler/Hochuli/Ramseyer et al. 2007 - Gisler/Spillmann 2011. 


\section{Kalk als Baustoff}

Die Malm-Kalke, welche den Hauptteil der Sedimente des Aarmassivs aufbauen, wurden zur Gewinnung von Mörteln in Kalköfen gebrannt, beispielsweise am Fuss der Rinächtflue bei der Lokalität Chalchofen nördlich von Erstfeld.

Aus grösseren Sturzblöcken und Findlingen dieser Kalke wurde ausserdem ein Baumaterial gewonnen, welches im geschliffenen Zustand wie ein weiss durchaderter schwarzer Marmor erscheint. Diese Bausteine wurden häufig für sakrale Bauten verwendet, beispielsweise für die Taufsteine in der Pfarrkirche Silenen und in der Klosterkirche Engelberg. Auch die Hauptportale der Klöster Engelberg und Seedorf und die Altäre der Kirche St. Martin in Altdorf und der Kapelle St. Jakob in Espen bestehen aus diesem Gestein. ${ }^{3}$

\section{Stäuber}

Im Abstieg vom Surenenpass gegen Engelberg verläuft der Weg bis unterhalb Blacken durchgehend in Flyschgesteinen mit den entsprechenden typischen Geländeformen. Der Stierenbach, welcher dieses Gebiet entwässert, markiert mit einem markanten Wasserfall das Ende dieser Flyschlandschaft. Der Stäuber fällt über dunkelgrau-grüne Sandsteine des Tertiärs und frisst sich dann in Malmkalke der Sedimentbedeckung des Aarmassivs. Der Surenenpasswanderer kann nun diesen Malmkalken folgen und in der Höhe über Äbnet und die Fürenalp oder direkt in den flachen Talboden absteigen. Dort, im Gebiet Nidersurenen, besteht der Untergrund wieder aus Kristallingesteinen des Aarmassivs. Diese werden jedoch im Talgrund von Bachgeröll überlagert, welches aber viel Kristallinschutt aus der südlichen Talflanke enthält. Der weitere Marsch nach Engelberg auf zunehmend flachem Talboden verläuft durchgehend auf Schottern der Engelberger Aa oder auf Schuttfächern der Seitenbäche. In den Aufschlüssen der Seitenhänge ist aber erkennbar, dass bei Herrenrüti die Sedimentbedeckung des Aarmassivs wieder überschritten wird, und etwas später wird bei Stalden wiederum der Nordhelvetische Flysch erreicht.

Kalk aus dem Oberen Jura (Malm). Im frischen Bruch dunkelgrau, mit hellgrauer bis weisser Anwitterungsfarbe. Foto C. Gisler, 2009

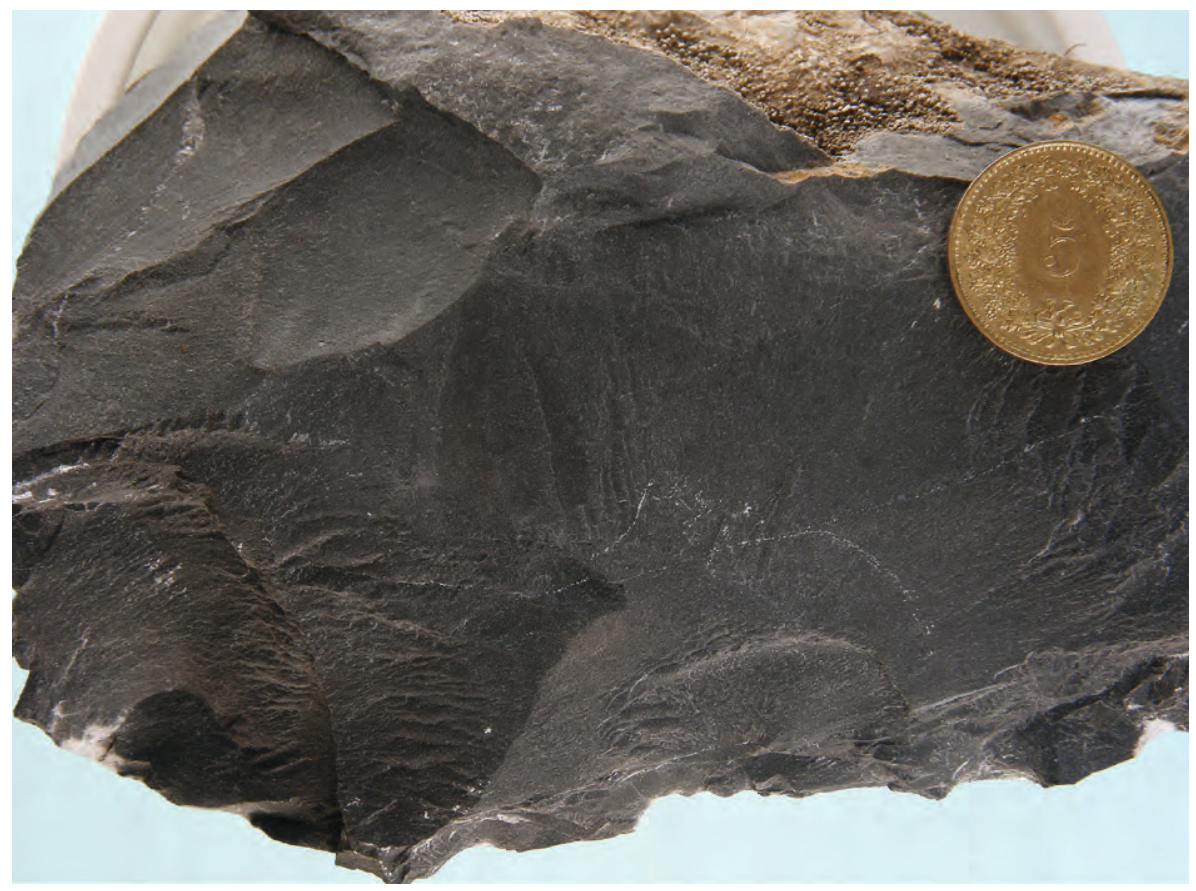




\section{Gebirgsbildung - Die Entstehung des Surenenpasses}

\section{Erdgeschichte und Relief}

Der Wanderer begegnet auf dem Weg zum Surenenpass Zeugen einer lange zurückliegenden geologischen Vergangenheit. Die Gesteine des kristallinen Sockels belegen das Entstehen und Vergehen von Gebirgen im Verlaufe der Erdgeschichte. Die darauf abgelagerten kalkigen Sedimente bezeugen das Vordringen des Meeres und die Flyschablagerungen erzählen schliesslich vom Vorrücken des alpinen Gebirges und dessen laufender Abtragung.

Noch nicht erzählt ist hingegen die Geschichte der Bildung des heutigen Gebirges und dessen Abtrag, der dazu führte, dass sich das heutige Relief und damit der Surenenpass überhaupt formte und die oben beschriebenen Gesteine für die Beobachtung freilegte.

\section{Überschiebungsdecken}

Zum Verständnis der gebirgsbildenden Prozesse wendet der von Attinghausen oder Seedorf her kommende Surenenpasswanderer seinen Blick nach rechts gegen die Kulisse im Nordwesten. Das von den Flyschablagerungen geprägte Gelände mit seinen typischen weichen Formen wird in der Bergkette vom Gitschen über Brunnistock und Blackenstock bis zum Hahnen von einer schroffen, bis $1000 \mathrm{~m}$ hohen Felswand überragt.

Die in den Felswänden aufgeschlossene kalkige Schichtreihe umfasst Meeresablagerungen, die einen sehr langen Zeitraum abbilden (TriasTertiär). Die stark verfalteten Sedimente im Gebiet zwischen Urner See und Engelberg sind Teil der Axendecke, welche im Zuge der alpinen Gebirgsbildung von ihrem kristallinen Sockel abgeschert und von Süden auf die jüngeren Flyschablagerungen überschoben wurde. ${ }^{4}$

4 Arbenz 1918. - Arbenz 1921. - Spörli 1966. - Menkveld 1995. 



\section{SSE}

Krönten

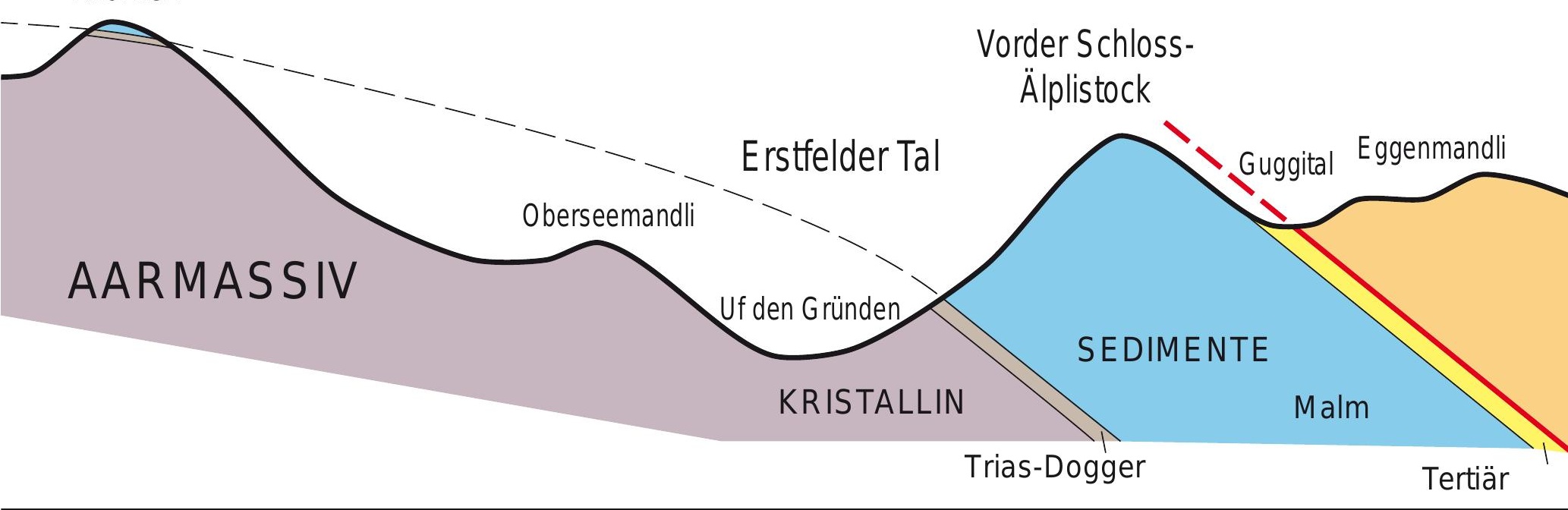

Über der Axendecke liegen weitere tektonische Elemente. Die DrusbergDecke entstammt einem Ablagerungsraum südlich der Axendecke am äusseren europäischen Kontinentalrand. Darüber liegen weitere Decken, die von noch sehr viel südlicherer Herkunft sind - bis hin zu Elementen, die dem südlichen Kontinentalrand entstammen.

Im Zuge der alpinen Überschiebungen wurden die tektonischen Einheiten, die heute am Surenenpass an der Oberfläche auftreten, in grosse Tiefe versenkt (10 bis $12 \mathrm{~km}$ ). Die Gesteine waren dadurch hohem Druck ausgesetzt und erwärmten sich auf circa $350^{\circ} \mathrm{C}$. Unmittelbar im Anschluss an die Verdickung der Kruste durch Überschiebungen setzten aufgrund der Tendenz zum isostatischen Ausgleich Hebungsbewegungen ein, begleitet vom Abtrag des Gebirges. Der Schutt aus dem Abtrag lagerte sich in den Molassebecken beidseits der Alpen ab, während sich in den Alpen im Laufe der Zeit durch Erosion das heutige Relief herausbildete.

Die Prozesse von Hebung und Abtrag dauern bis heute an. Vor rund 2,6 Millionen Jahren veränderte sich mit dem Beginn des Quartärs das globale Klima zu deutlich tieferen Temperaturen mit markanten zeitlichen Schwankungen. Rund 15 Eiszeiten mit Gletschern, die bis ins Flachland vordrangen, wechselten sich mit Zwischeneiszeiten ab, während deren sich die Gletscher in die höchsten Gebirgsregionen zurückzogen. Das heutige Gelände erfuhr im Verlaufe dieser Eiszeiten sein heutiges Erscheinungsbild.

Das Reusstal und das Tal der Engelberger Aa wurden durch die vorstossenden und zurückweichenden Gletscher auf ihre aktuelle Tiefe ausgehobelt, dazwischen bildete sich die uns heute bekannte Gebirgslandschaft mit Gipfeln, Seitentälern und Übergängen.

Die Erosionskraft der eiszeitlichen Gletscher wirkte auch in die Tiefe. Die aus den alpinen Tälern fliessenden Eisströme vereinigten sich am Alpenrand zu einer einheitlichen Eisoberfläche. Im Untergrund formten sie übertiefte Becken, in denen sich der Vierwaldstättersee und die weiteren Alpenrandseen bildeten. Im Querschnitt bei Seedorf beispielsweise erodierte der Gletscher bis unter den heutigen Meeresspiegel hinunter. ${ }^{5}$

Im Zuge der Bildung des heutigen Reliefs bildeten sich in den Kalken des Malms ausgedehnte Karstgebiete mit Karrenfeldern an der Oberfläche und weitläufigen Höhlensystemen im Untergrund ( $\rightarrow$ S. 82-101).
Geologisches Profil zwischen der Kröntengruppe und dem Isentaler Grosstal.

Grafik P. Spillmann, 2015 


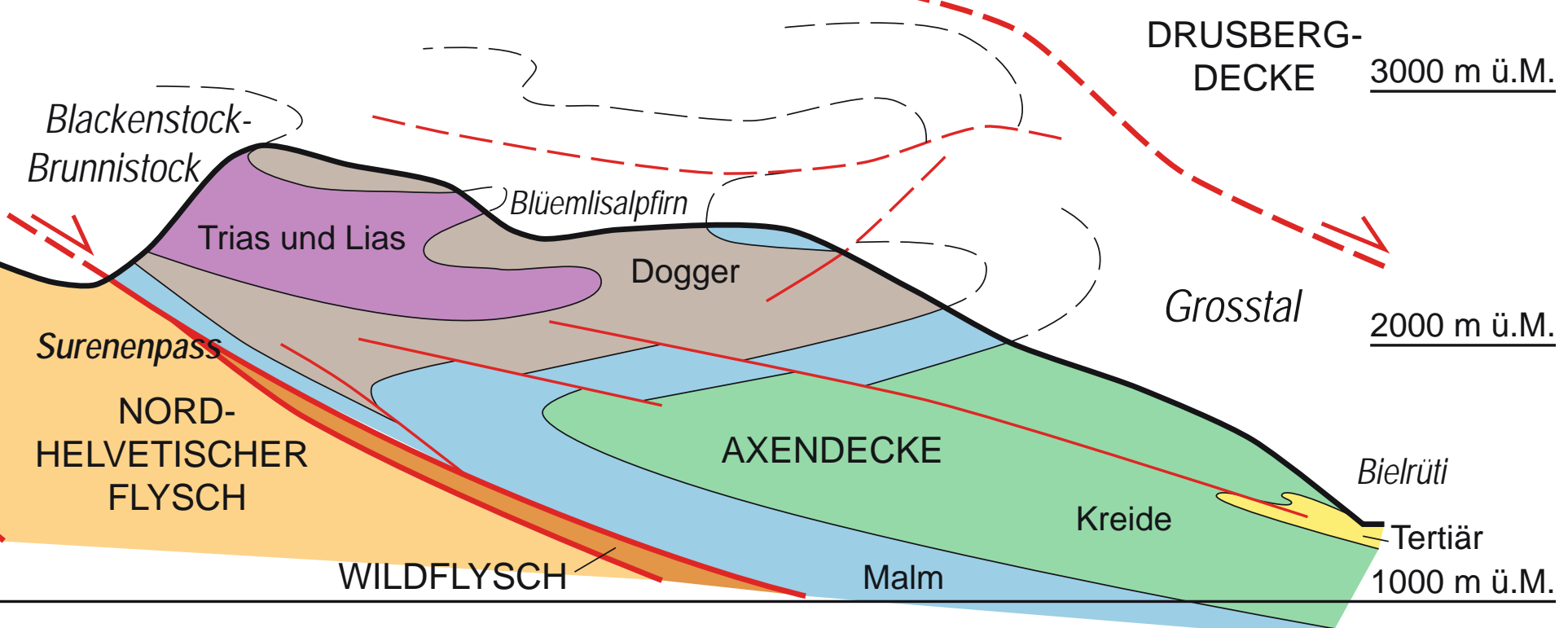

\section{Kaltzeit (Jüngstes Pleistozän)}

\section{Das Maximum der letzten Eiszeit}

Das Maximum der Vergletscherung der letzten Eiszeit liegt rund 24000 Jahre zurück. Die Gletscherzunge des Reussgletschers befand sich damals bei Mellingen im Kanton Aargau. Im Urner Reusstal lag zu jener Zeit die Eisoberfläche auf circa 1800 m ü.M. ${ }^{6}$ Die Waldnacht und das Gitschital waren mit Eis gefüllt, dazwischen ragten die Gibelstöcke als Nunataker knapp aus dem Eis. Der Grat (Geissrüggen) bildete eine flache Firnkuppe, die sich ganz knapp über die Eisfläche erhob.

Auf Engelberger Seite lag eine fast kreisförmige, flache Gletscherebene auf circa 2100 m ü.M., aus der das Eis zunächst gegen Südwesten und dann über Engelberg nach Norden abfloss, wo sich der Engelbergergletscher mit dem Reussgletscher und einem über den Brünig strömenden Arm des Aaregletschers vereinigte. Die heute noch vergletscherten Gipfel der Uri-Rotstock-Gruppe, des Schlossbergs und der Krönten-Spannort-Gruppe überragten diese Eisflächen um rund $1000 \mathrm{~m}$. Die Gipfelbereiche unterschieden sich dabei nur geringfügig vom heutigen Landschaftsbild.

Das Gebiet zwischen Reusstal und Engelberg befand sich zur Zeit der grössten Vergletscherung durchgehend über der Gleichgewichtslinie, also im Nährgebiet der eiszeitlichen Gletscher. Ein früher hypothetischer Wanderer über den Surenenpass hätte zwar eine geringere Höhendifferenz zu bewältigen gehabt, er wäre aber durchgehend im verfirnten Gebiet unterwegs gewesen. In den Flanken des Surenenpasses hätte er ausserdem steile, durch Gletscherspalten zerrissene Gebirgsgletscher zu traversieren gehabt.

Es gibt zwar Hinweise auf die Wanderung von Menschengruppen über ausgeaperte eiszeitliche Gletscherzungen, ein Vordringen des Menschen in grössere Höhen kann jedoch weitgehend ausgeschlossen werden.

\section{Der Rückzug der Gletscher im Spätglazial}

Im Anschluss an die letzteiszeitliche maximale Vergletscherung begannen sich die Gletscher aus dem Mittelland in die Alpen zurückzuziehen, unterbrochen von kurzen Wiedervorstössen, welche durch Moränenwälle im Gelände angezeigt werden. ${ }^{7}$ Vor rund 19500 Jahren fluktuierte die

Bini/Buoncristiani/Coutterand et al. 2009.

7 Renner/Zgraggen 2011.
Gletscherzunge des Reussgletschers bei Bremgarten, vor circa 18000 Jahren am Alpenrand bei Gisikon. 


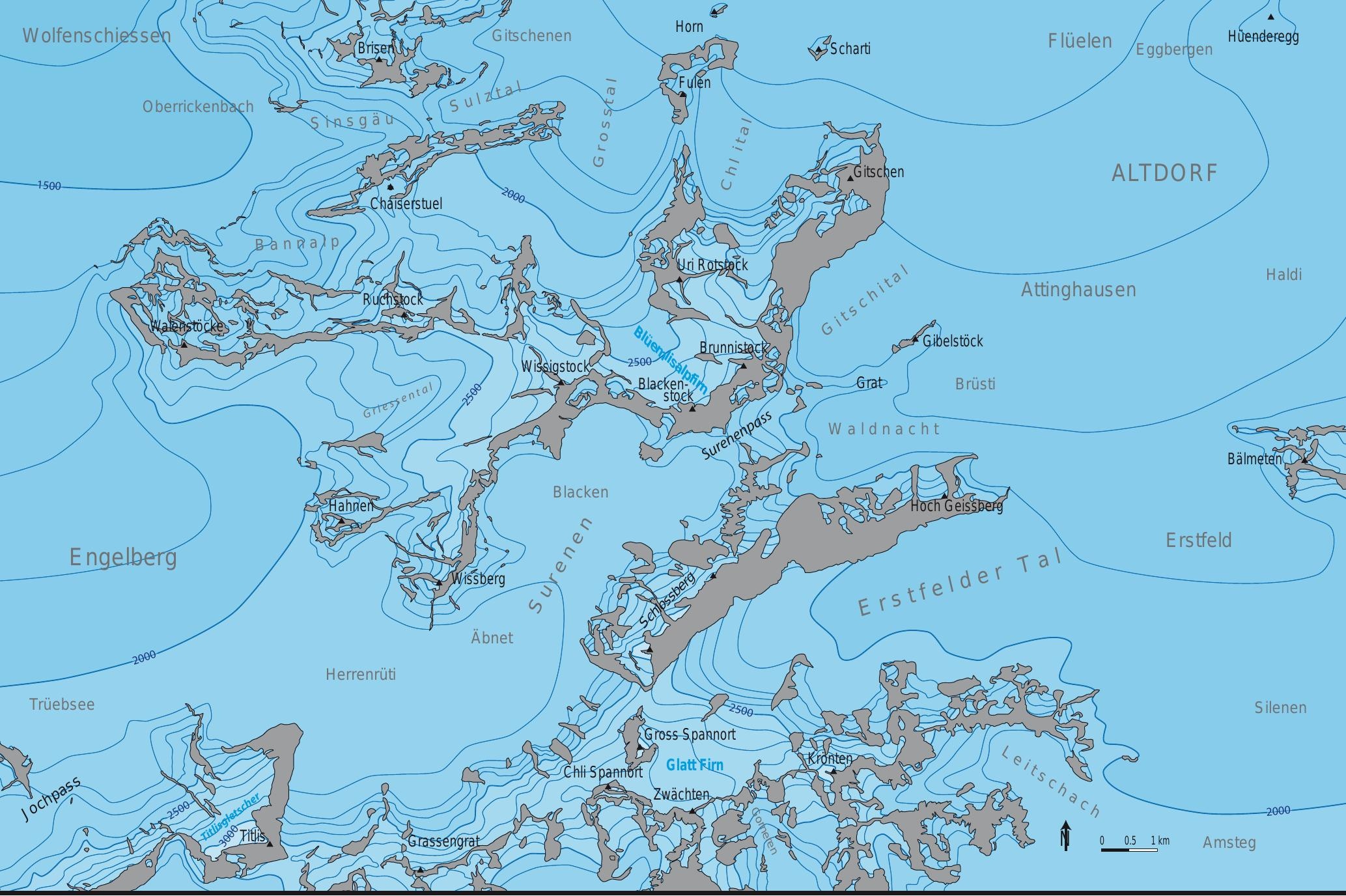

Periodische Wiedervorstösse beim weitergehenden Rückzug der eiszeitlichen Gletscher hinterliessen in Form unterseeischer Moränen ihre Spuren im Vierwaldstättersee. Im Zuge dieses Rückzugs zerfiel das einst zusammenhängende Eisstromnetz entlang der nördlichen Voralpen. Der Brünig-Arm des Aaregletschers und später auch der Engelberger Gletscher trennten sich vom Reussgletscher.

Sehr markant ist der unterseeische Moränenwall der Nas bei Vitznau. Als vor etwa 17000 Jahren die in den See kalbernde Zunge des Reussgletschers an dieser Seeenge über längere Zeit stagnierte, hatte sich der Engelberger Gletscher bereits weit in das Tal der Engelberger Aa, wahrscheinlich bis Wolfenschiessen, zurückgezogen. Im Urner Reusstal lag zu dieser Zeit die Gletscheroberfläche auf rund 1200 bis 1300 m ü.M., angezeigt durch markante Seitenmoränen auf dem Haldi bei Schattdorf. ${ }^{8}$ Das Gebiet des unteren Reusstals befand sich damals bereits im Zehrgebiet des Reussgletschers, also unterhalb der Firnlinie. Auf der im Sommer ausgeaperten Gletscheroberfläche wurde Schutt abtransportiert, es bildeten sich Seiten- und Mittelmoränen.

Der Reussgletscher drang damals noch weit in das Gitschital hinein, wo er sich im Hintergrund mit einem Lokalgletscher vereinigte. Ein örtlicher Gletscher strömte auch aus dem Gebiet Waldnacht dem Reussgletscher zu, gespeist durch Eismassen aus dem Gebiet des Surenenpasses, dem Guggital und dem Wanneli. Auch auf der Engelberger Seite vereinigten sich Gebirgsgletscher aus den deutlichen Karstrukturen bei Uf den Seewen, Gritschen und Älpeli zu einem zusammenhängenden Eisstrom, der gegen Engelberg abfloss.
Die Umgebung des Surenenpasses zur Zeit der letzten maximalen Vergletscherung vor rund 24000 Jahren.

Grafik P. Spillmann, 2015

8 Hier wird der Interpretation in Renner/Zgraggen 2011 gefolgt. Hantke/Brückner 2011 korrelieren die Moränenwälle auf dem Haldi mit dem älteren Stadium bei Honau. 
Nach einem weiteren Zwischenhalt bei Gersau (Chindlimoräne) zog sich der Reussgletscher weit zurück. An seiner Stelle bildete sich im Reusstal der Urner See, der sich zeitweise wahrscheinlich bis gegen Amsteg hinein erstreckte.

Auch der Engelberger Gletscher schmolz bis hinter Engelberg zurück. Durch den Eiszerfall wurden die steilen Seitenhänge instabil und zwischen Obermatt und Niederberg wurde das Tal durch einen gewaltigen Bergsturz verschüttet. ${ }^{9}$ Hinter dem Bergsturzschutt staute sich im Talboden von Engelberg ein See auf.

Vor rund 16000 Jahren stiess der Reussgletscher wiederum vor und bildete im Urner Reusstal bei Hüseriberg und bei Schattdorf (Betzligen) deutliche Moränenwälle, die eine in den Urner See kalbernde Gletscherstirn des Reussgletschers auf der Höhe von Attinghausen belegen. Die Eismassen aus dem Erstfeldertal vereinigten sich bei Erstfeld mit dem Reussgletscher. Im Gitschital lag ein Lokalgletscher; und Moränenwälle bei Bocki zeigen, dass aus dem Gebiet Surenenpass - Waldnacht - Wanneli Gebirgsgletscher Gletscherzungen bis in den Talgrund hinunter sandten, wo sie sich mit dem Reussgletscher verbanden.

Zur selben Zeit stiess auch der Engelberger Gletscher noch einmal in das Tal der Engelberg Aa vor. Belegt wird dies durch Moränenmaterial, welches das Bergsturzmaterial bei Engelberg überlagert.

Anschliessend, am Ende des Pleistozäns, begann der endgültige Rückzug der Gletscher in das Hochgebirge. Periodische Wiedervorstossphasen während dieses Rückzugs sind durch Moränenwälle angezeigt, zum Beispiel ausgangs der Waldnacht oder im Vorfeld der Karstrukturen im Gebiet Surenen oder im oberen Gitschital.

Der Rückzug der eiszeitlichen Gletscher und das Ansteigen der Permafrostgrenze destabilisierten die übersteilen Talflanken, was zu zahlreichen Sackungen, Fels- und Bergstürzen führte. Das Lockermaterial in den Hängen (Moränenmaterial und Gehängeschutt) wurde durch die Niederschläge ausgespült, über Runsen abgeführt und im Talgrund in ausgedehnten Murgangkegeln abgelagert.

\section{Warmzeit (Holozän)}

\section{Nacheiszeitliche Vergletscherung}

Vor rund 11600 Jahren begann die heute noch andauernde Warmzeit (Holozän). Der Surenenpass und seine Umgebung wurden nun endgültig eisfrei. Einzig im schattigen Guggital und in der Nordabdachung des Schlossbergs verblieben kleinere Gletscher und aus Lawinenschnee gebildete ganzjährige Firnflächen. Die südexponierten Flanken sind heute, mit Ausnahme des schattigen Firnbands nordöstlich des Wissbergs, vollständig eisfrei. Lawinenschnee aus der Südwand des Brunnistocks führt jedoch dazu, dass der Passwanderer östlich der Passhöhe im Gebiet Langschnee bis weit in den Sommer hinein Schneefelder zu überqueren hat.

In den angrenzenden höheren Regionen schwanken die Gletscher seit Beginn des Holozäns in einer engen Bandbreite zwischen Maximalständen, die etwa dem Stand Mitte des 19. Jahrhunderts am Ende der sogenannten Kleinen Eiszeit entsprechen, und Minimalständen, mit Gletschern, die deutlich kleiner waren als die uns heute bekannten. 


\section{Der Urner See und seine Ufer}

Der Talgrund des Reusstals war nach dem Rückzug der Gletscher im späten Pleistozän erfüllt vom Urner See, der sich fjordartig bis etwa in das Gebiet von Erstfeld hinein erstreckte. Das Geschiebe des Schächens aus dem Schächental und des Palanggenbachs aus dem Gitschital baute mächtige seitliche Schuttkegel in diesen verlängerten Urner See hinein. Die Zwischenräume wurden allmählich von Süden nach Norden durch das Geschiebe der Reuss zugelandet. ${ }^{10}$ Die Ebene zwischen Erstfeld und Attinghausen dürfte bereits vor rund 9000 Jahren vollständig verlandet gewesen sein. Vor etwa 7000 Jahren lag dann das Ufer des Urner Sees etwa beim Bahnhof Altdorf, wo sich die Reuss zwischen den Schuttfächern des Schächens und des Palanggenbachs durchschlängelte und zunächst ein Delta gegen Flüelen aufbaute. Vor rund 1000 Jahren verlagerte sich das Mündungsgebiet der Reuss gegen Westen in das Gebiet zwischen Schwäb und Schanz. Am Rand dieses Deltas bildete sich allmählich das flache Ufer zwischen dem ursprünglich am Seeufer erbauten Turm beim Kreisschulhaus Seedorf und dem heutigen Seeufer.

Seit rund 150 Jahren sind diese natürlichen Prozesse anthropogen stark überprägt durch künstlichen Aufstau beim Seeausfluss in Luzern, durch Hochwasserschutzmassnahmen (Reusskorrektur) und Meliorationen sowie durch Kiesentnahmen und Materialablagerungen (Tunnelausbruch) am Seeufer.

\section{Ein See in Engelberg}

Nach dem Rückzug der eiszeitlichen Gletscher staute sich im flachen Talboden von Engelberg wiederum ein See auf, der aber durch die Schotter der Engelberger Aa und deren Seitenbäche in kurzer Zeit verlandete.

\section{Die Vegetation und der Mensch}

Die beschriebenen kontinuierlichen und episodischen landschaftsbildenden Prozesse begleiten uns bis in unsere heutige Zeit. Die episodischen Prozesse (Überschwemmungen, Murgänge, Bergstürze, Rutschungen und Lawinen) bedrohen seit jeher Siedlungen, Verkehrswege und Kulturland. Das Urner Reusstal und das Gebirge im Allgemeinen waren auch nach dem Rückzug der Gletscher ein unwirtliches Gebiet. Auf den allmählich entstehenden Böden wuchs eine Pioniervegetation mit Steppen- und Tundra-Charakter. Später bildeten sich boreale Nadelwälder. Die grosse Dynamik der landschaftsformenden Prozesse führte aber zu einer laufenden Vernichtung allfällig vorhandener Spuren des Menschen.

Indirekte Spuren auf die Landnahme durch zuwandernde Menschen liefern Untersuchungen eines Hochmoors am Grat westlich des Brüsti beim Berggasthaus Z'Graggen (1587 m ü.M.). Eine etwa 1,8 $\mathrm{m}$ mächtige Torfschicht enthält Informationen zur Entwicklung der Vegetation über die letzten 7400 Jahre ( $\Rightarrow$ S. 24-45). ${ }^{11}$

Arbenz, P. (1913). Bericht über die Exkursion der Schweiz. Geolog. Gesellschaft in die Obwaldner Alpen vom 10.-13. September 1913. In: Eclogae Geologicae Helveticae $12 / 5,689-721$.

Arbenz, P. (1918). Geologische Karte der Urirotstockgruppe 1:50'000. Spezialkarte 84 (= Beiträge zur Geologischen Karte der Schweiz N.F. 26). Bern.

Arbenz, P. (1921). Über den geologischen Bau der Urirotstockgruppe. In: Mitteilungen der Naturforschenden Gesellschaft Bern (1920), Sitzungsber. VII-XIV. Bern.

10 Eberli 1997.

11 Zusammengefasst in: Haas 2015. 
Bini, A. / Buoncristiani, J.F. / Couterrand, S. et al. (2009). Die Schweiz während des letzteiszeitlichen Maximums (LGM) M 1:50000. Bern.

De Quervain, F. (1984). Gesteinsarten an historischen Bau- und Bildwerken der Schweiz. Aufzeichnungen 1954-1982 (Bd. 5). Zürich.

Eberli, U. (1997). Untersuchung der geologischen Bohrkerne aus der Region AltdorfErstfeld, Kanton Uri. Bericht für das Amt für Umweltschutz, Kanton Uri. Altdorf.

Gisler, C. / Hochuli, P.A. / Ramseyer, K. et al. (2007). Sedimentological and palynological constraints on the basal Triassic sequence in Central Switzerland. In: Swiss Journal of Geosciences 100, 263-272.

Gisler, C. / Spillmann, P. (2011). Die mesozoisch-alttertiäre Sedimentbedeckung. In: Spillmann, P. / Labhart, T. / Brücker, W. et al. Geologie des Kantons Uri (= Naturforschende Gesellschaft Uri 24). Altdorf. 49-78.

Haas, J.N. (2015). Waldgeschichte der Waldstätte. In: Sauter, M. (Hrsg.).Ausflug in die Vergangenheit. Archäologische Streifzüge durch die Urschweiz. Hochwald, 54-63. Hantke, R. / Brückner, W. (2011). Geologischer Atlas der Schweiz 1:25000 (BI. 1192 Schächental, Erläut. 83). Bern.

Hess, P. (1986). Der prähistorische Bergsturz von Engelberg. Engelberger Dokumente 19. Engelberg.

Menkveld, J. (1995). Der geologische Bau des Helvetikums der Innerschweiz. Bern. Renner, F. /Zgraggen, A. (2011). Auf den Spuren des Reussgletschers von der Eiszeit bis zur Gegenwart. In: Spillmann, P. / Labhart, T. / Brücker, W. et al. Geologie des Kantons Uri (= Naturforschende Gesellschaft Uri 24). Altdorf, 97-134 (Kartenbeilage). Spillmann, P. (2011). Der Bau des Gebirges und die Entwicklung der Landschaft des Kantons Uri. In: Spillmann, P. / Labhart, T. / Brücker, W. et al. Geologie des Kantons Uri (= Naturforschende Gesellschaft Uri 24). Altdorf, 79-96.

Spörli, B. (1966). Geologie der östlichen und südlichen Urirotstock-Gruppe. In: Mitteilungen des Geologischen Instituts der ETH und der Universität Zürich N.F. 62. Zürich. 
Summary: Left and right of the Surenen Pass: Climate and vegetation development since the last lce Age

The Surenen Pass in Canton Uri, Switzerland, connects the areas and settlements of the Reuss and Engelberg Valleys. Although, at nearly $2300 \mathrm{~m}$ a.s.l., the pass was often snow-covered all-year-round in the past (e.g. during the Little Ice Age AD 1350-1850), it constituted an important economic pathway from east to west (and vice versa). In addition, and according to written sources, the Alpine pasture at Blackenalp south-west of the Surenen Pass was intensively used by Uri farmers for grazing sheep, goats, and cattle at least since the High Middle Ages. The vegetation on both sides of the Surenen Pass is therefore the result of past climatic change and the millennial, long-term impact of humans and their livestock. 


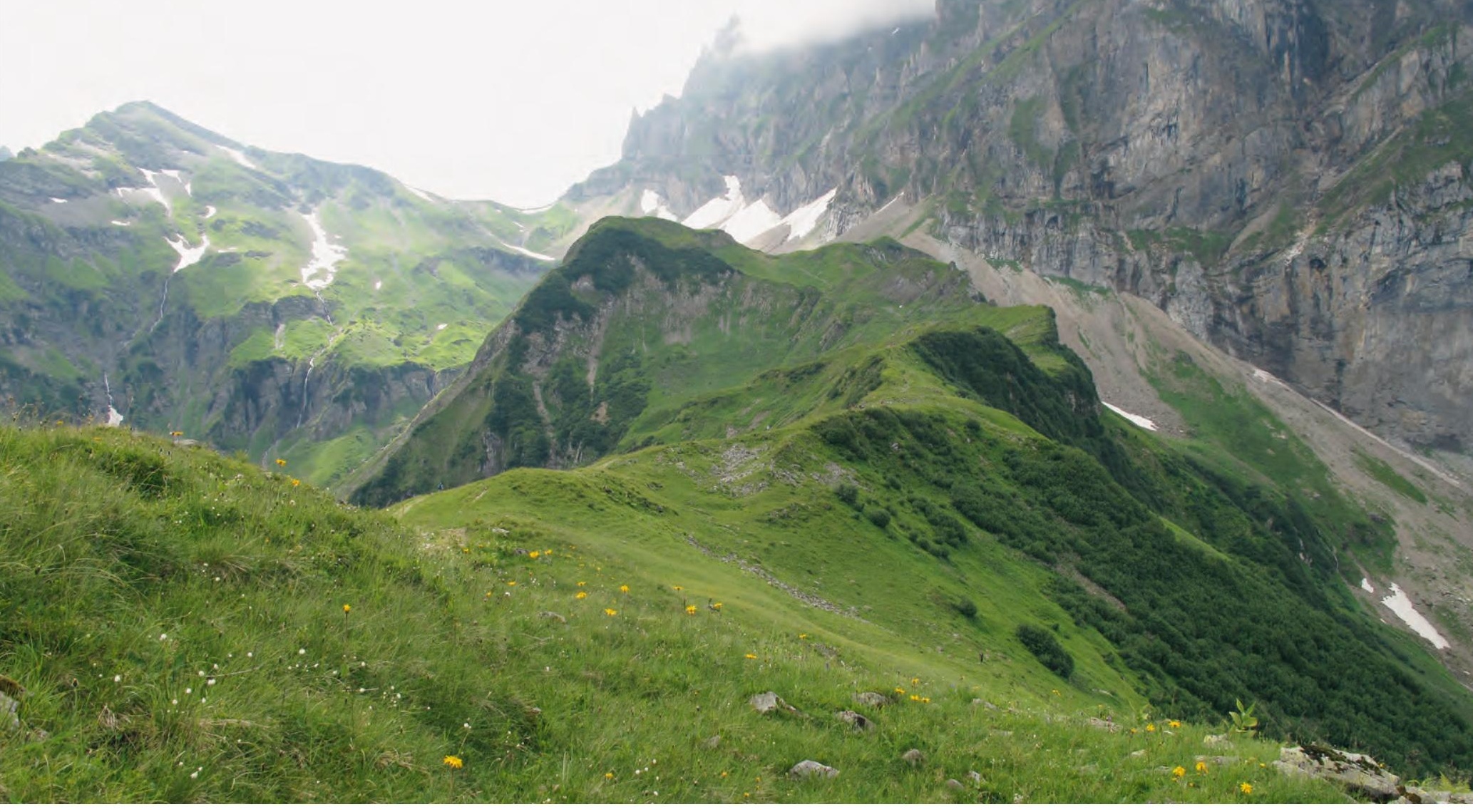

\section{Links und rechts des Surenenpasses: Klima- und Vegetationsverlauf seit der letzten Eiszeit}

Haas/Altstätter/Dietre et al. 2015. Haas/Wahlmüller/Vaccaro et al. 2014. - Leuzinger/Sauter/Haas et al. 2014.
Der Surenenpass im Kanton Uri verbindet die Gebiete und Siedlungen des Urner Reusstals und des Engelbergertals. Obwohl dieser knapp $2300 \mathrm{~m}$ ü.M. hohe Passübergang früher, etwa während der sogenannten Kleinen Eiszeit, klimatisch bedingt oft das ganze Jahr über schneebedeckt blieb, stellte er eine zentrale Handelsachse von Ost nach West (und umgekehrt) dar. Zudem werden gemäss schriftlicher Quellen die südwestlich des Surenenpasses gelegenen Alpweiden der Blackenalp mindestens seit dem Hochmittelalter von der Urner Talseite her intensiv mit Schafen, Ziegen und Kühen bestossen. Die beidseits des Surenenpasses heute vorhandene Flora und Vegetation sind daher das Resultat vergangener Klimaänderungen sowie des jahrtausendealten Einflusses des Menschen und seiner Haustiere.

\section{Regionaler Kontext}

In den letzten Jahren konnte dank einer regionalen Forschungsinitiative und der grosszügigen Unterstützung durch den Kanton Uri die Urner Vegetations- und Klimageschichte seit dem Abschmelzen der würmeiszeitlichen Gletscher vor circa 16000 Jahren wissenschaftlich aufgearbeitet und beleuchtet werden. ${ }^{1}$ Im Vergleich zu anderen Gebieten der Schweiz war bisher für den Kanton Uri wenig über die spät- und nacheiszeitliche Florenentwicklung unter dem Einfluss des prähistorischen beziehungsweise historischen 
Die geschützte und relativ seltene Hochmoorpflanze Rundblättriger Sonnentau (Drosera rotundifolia) auf dem Z'Graggen-Moor auf Brüsti.

Foto J.N. Haas, 2011

Blick auf Blackenalp-Oberes Moor in Richtung Engelbergertal.

Foto J.N. Haas, 2014

Torfkern aus dem Z'Graggen-Moor auf Attinghausen-Brüsti.

Foto J.N. Haas, 2011
4 Gobet/Tinner 2012. - Küttel 1990a. - Küttel 1990b. - Küttel/Lotter 1987. - Renner-Aschwanden 2014. - Sidler 2001.

5 Blaauw 2010. - Hajdas 2008. - R Core Team 2015. - Reimer/Bard/Bayliss et al. 2013. - Synal/Stocker/Suter 2007. mit einbezogen wurden. Es handelt sich bei den wissenschaftlich bearbeiteten Mooren um folgende Lokalitäten:

- $\quad$ Z'Graggen-Moor (informeller Name gemäss dessen Lokalität) auf Brüsti östlich des Surenenpasses (Gemeinde Attinghausen, 1587 m ü.M) mit Ablagerungen der letzten 7300 Jahre,

- Blackenalp-Moor (informeller Name: Blackenalp-Oberes Moor) südwestlich des Surenenpasses (Gemeinde Attinghausen, 1820 m ü.M.) mit Ablagerungen der letzten 2000 Jahre,

- Hospental-Moos zwischen Andermatt und Hospental (Gemeinde Hospental, 1480 m ü.M.) mit Ablagerungen der letzten 7000 Jahre sowie Schattgaden-Moor auf Silberen (Gemeinde Muotathal, 1886 m ü.M.) mit Ablagerungen der letzten 12800 Jahre.

Gute Vergleichsmöglichkeiten ergaben sich zudem durch das Einbeziehen wichtiger Ergebnisse von weiteren Studien zur spätglazialen und nacheiszeitlichen Vegetations- und Klimageschichte der Innerschweiz. ${ }^{4}$ Die genaue Bestimmung der in Moor- und Seesedimenten erhaltenen Pflanzen- und Tierreste stellte dabei die Grundlage für die Rekonstruktion der lokalen Landschaftsentwicklung seit der letzten Eiszeit. Die zeitliche Einordnung der untersuchten Torfkörper wird hierbei durch die Radiokarbondatierung von einzelnen Pflanzenfunden aus unterschiedlichen Torfschichten ermöglicht. ${ }^{5}$
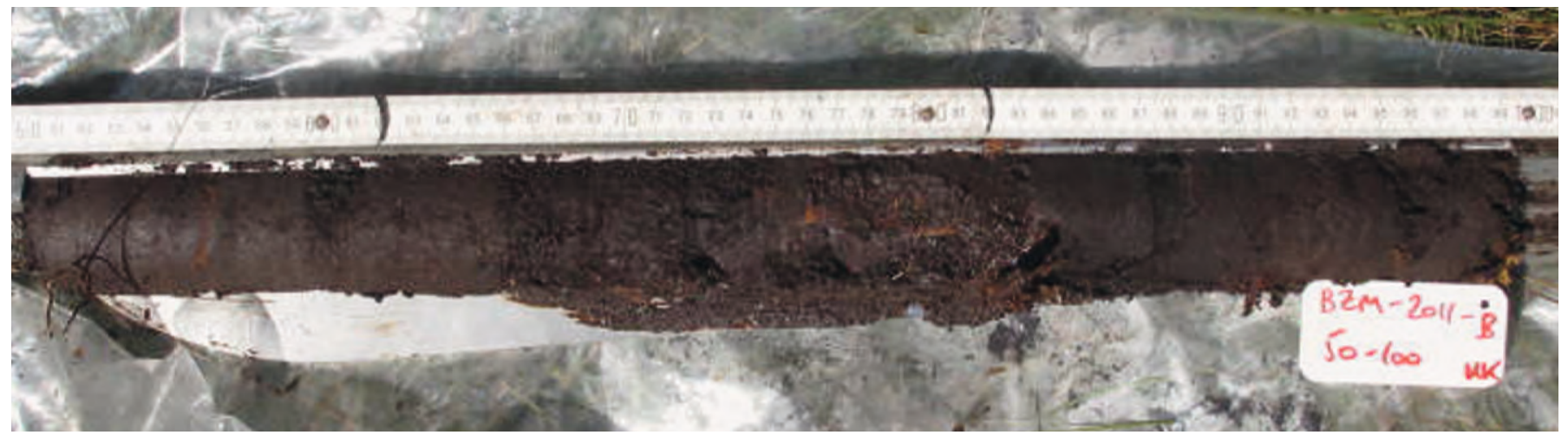


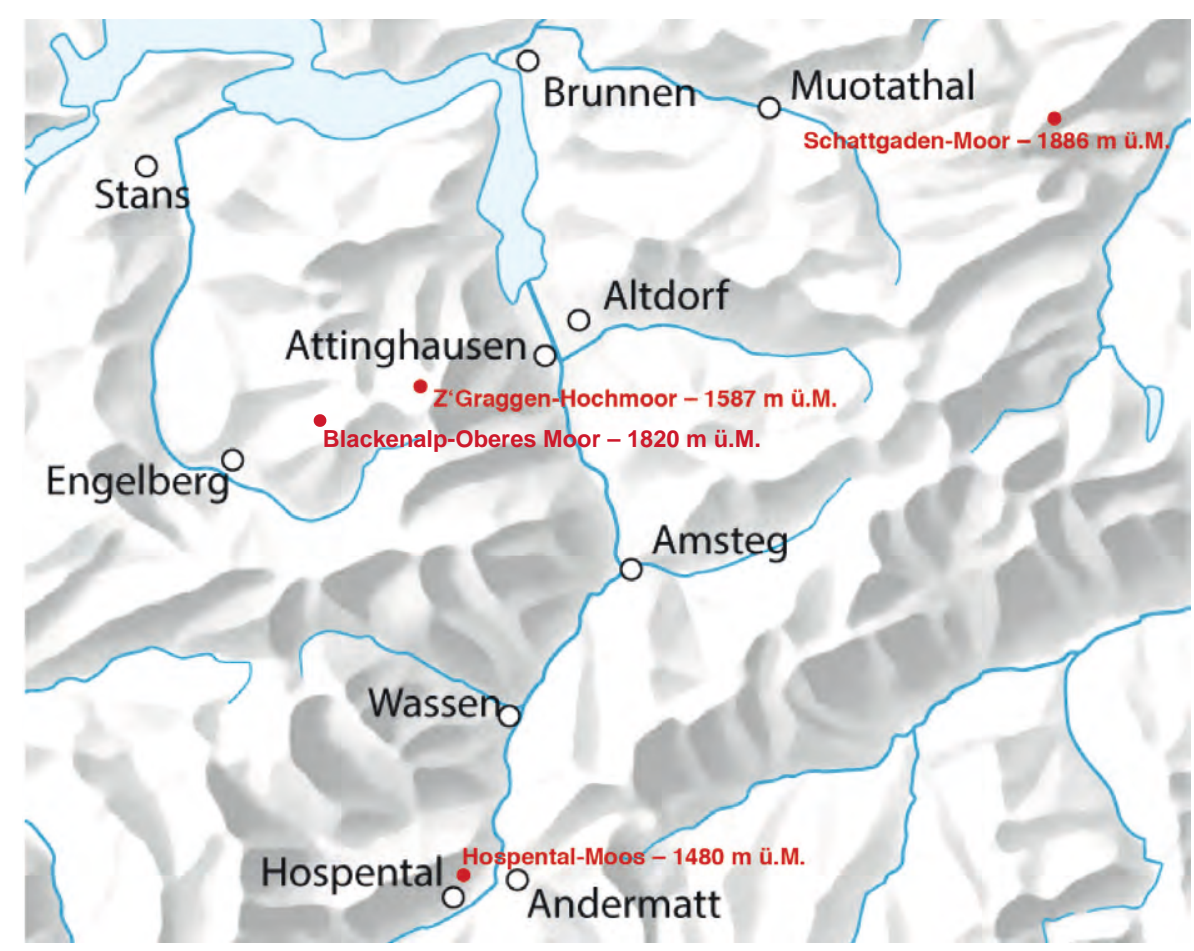

Feld- und Labormethoden

Bevor jedoch diese datierten Pflanzenreste erfolgreich bestimmt werden konnten, brauchte es für jede Lokalität die Entnahme von Bohrkernen. Diese wurden mithilfe eines sogenannten Russischen Kammerbohrers entnommen, wobei die einzelnen Segmentstücke jeweils $50 \mathrm{~cm}$ lang waren und einen Durchmesser von $5 \mathrm{~cm}$ aufwiesen, sodass aufgrund des geringen Bohrerdurchmessers keine bleibenden Schäden am jeweiligen Moor verursacht wurden. Die erhaltene Sedimentsäule konnte danach im Labor systematisch mit einem Probenstecher beprobt werden, um die aus den entsprechenden Tiefen entnommenen Torfproben chemisch aufzubereiten. Bei dieser Extraktion der Mikroreste wurde zuerst ein Siebprozess mit einem 250- $\mu \mathrm{m}$-Sieb durchgeführt, gefolgt von einem weiteren Siebprozess mit einem 7- $\mu \mathrm{m}$-Sieb. Die erhaltene Fraktion 7-250 $\mu \mathrm{m}$ wurde dann der eigentlichen chemischen Behandlung unterzogen, gemäss den üblichen Standardmethoden. ${ }^{6}$ Es wurde hierbei auf eine möglichst schonende chemische Behandlung geachtet, um auch empfindliche Pflanzenteile und Mikrofossilien zu erhalten. Der für die palynologischen (pollenanalytischen) Analysen notwenige Laborprozess umfasste hierbei die Entwässerung der Sedimente mit konzentrierter Essigsäure, eine 1-minütige Acetolyse, die Behandlung von ton-/silthaltigen Proben mit 10-prozentiger Flusssäure sowie die Aufnahme und Fuchsin-Färbung der Probenreste in Glycerin. Zu guter Letzt erfolgte die Fundanalyse am Mikroskop, mit dem Fokus die Pollen (Blütenstaub) von Bäumen, Sträuchern und Kräutern sowie die Sporen von Farnen, Moosen und Pilzen, Holzkohlepartikel, Algenzysten oder tierische Reste (z.B. Wurmeier) möglichst genau zu bestimmen.

Ein Kubikzentimeter Torf beinhaltet hierbei oft mehr als 100000 Mikroreste. Aus Zeit- und Finanzierungsgründen konnte nur ein kleiner, jedoch statistisch signifikanter Teil dieser Mikroreste (z.B. 1000 pro Probe) bestimmt und ausgezählt werden. Zur Bestimmung der Mikrofossilien wurden die umfangreiche Vergleichssammlung des Instituts für Botanik der Universität Innsbruck und entsprechende Bestimmungsliteratur verwendet. ${ }^{7}$
Übersicht über die untersuchten Moore der Innerschweiz: Z'Graggen-Hochmoor UR (688 750/188 763), Blackenalp-Oberes Moor UR (682 560/186 780), Hospental-Moos UR (686 649/164 434) und Schattgaden-Moor SZ (713 123) 205 193).

Karte swisstopo (BA16018), Grafik M. Sauter, 2016
6 Moore/Webb/Collinson 1991. - Stockmarr 1971.

7 Punt 1976. - Punt/Clarke 1980-1988. - Van Geel 1978. - Van Geel 2001. Fægri/lversen 1989. - Moore/Webb/ Collinson 1991. - Beug 2004. 
8 Grimm 1987. - Grimm 1991.

9 Leuzinger-Piccand 1996. - LeuzingerPiccand/Leuzinger-Piccand 2012.
Zusammenstellung der an Pflanzenresten aus Bohrkern BZM-2011-B durchgeführten Radiokarbondatierungen. Grafik J.N. Haas, 2016
Erhaltene Zählwerte werden in der Folge grafisch dargestellt, ${ }^{8}$ beispielsweise in Form von Prozentdiagrammen. Dazu, beziehungsweise zur Unterscheidung zwischen der lokalen und der regionalen Flora und Vegetation, wird für jede ausgezählte Tiefenstufe eine 100-prozentige Berechnungssumme aus sämtlichen Pollen (Bäume, Sträucher, Kräuter und Süssgräser) gebildet. Lokal am Moorstandort wachsende Arten wie Pollen von Sauergräsern (Cyperaceae), Sumpf- und Wasserpflanzen, Sporen von Farnen und Pilzen, Algenzysten oder Mikroreste von Tieren werden dabei zur Berechnung ihrer Bedeutung in Bezug zu dieser 100-Prozent-Summe gesetzt.

Des Weiteren wurde auch Wert auf das Schlämmen von Torfproben und auf die Analyse der darin enthaltenen Pflanzen- und Tiergrossreste - Samen, Früchte, Blätter und Nadeln > $250 \mu \mathrm{m}$ - gelegt. Mithilfe eines Binokulars können somit die Grossreste bestimmt und die palynologischen Untersuchungen ergänzt werden, um ein möglichst genaues Abbild der lokalen Vegetations- und Klimaentwicklung zu erhalten.

\section{Der Surenenpass im Verlaufe der wichtigsten Epochen seit der Würmeiszeit}

\section{Die Altsteinzeit (14000-9600 v.Chr.)}

Auch wenn die Sedimente der Moore im Surenenpassgebiet nicht so weit zurückreichen, so erlauben vegetationsgeschichtliche Untersuchungen aus der Innerschweiz Einblicke in diese Periode nach der Eiszeit.

Nach dem Abschmelzen der letzten Gletscher aus der Würmeiszeit vor circa 16000 Jahren kam auf den eisfreien Böden rund um den Surenenpass eine Steppen- und Tundrenvegetation mit diversen Pionierpflanzen auf. Nach einer ersten Warmphase gegen 12700 v.Chr. - nach klassischen dänischen Lokalitäten auch Bølling/Allerød-Phase genannt - konnte sich in Europa, auch im Kanton Uri, vor allem die Waldföhre (Pinus sylvestris) auf den humoser gewordenen Böden ansiedeln. Für die erweiterte Region um den Kanton Uri herum gibt es bisher nur wenige archäologische Zeugnisse, etwa die auf circa 12000 v.Chr. datierten menschlichen Aktivitäten am Ufer des Sihlsees. ${ }^{9}$ Um 10500 v.Chr. bewirkte eine neuerliche Kaltphase, genannt Jüngere Dryaszeit, eine Reduktion des zuvor entstandenen Nadelwaldes und ein Wiederaufkommen von Steppenpflanzen wie Beifussarten (Artemisia).

\begin{tabular}{|l|c|c|c|l|c|c|}
\hline Labor-Nr. & Tiefe $(\mathbf{c m})$ & ${ }^{14}$ C-Alter & Delta ${ }^{13} \mathbf{C}$ & Kalibration 2-sigma (95\%) & Mittelwert & Mittelwert \\
\hline & & & & & BC/AD & cal. BP (AD 1950) \\
\hline ETH-54075 & 22 & $621 \pm 26$ & -29.8 & $1290 A D-1400 A D$ & $1345 \pm 55$ AD & $605 \pm 55$ \\
\hline ETH-52811 & 34 & $1156 \pm 31$ & -26.3 & $770 A D-980 A D$ & $875 \pm 105$ AD & $1075 \pm 105$ \\
\hline ETH-54076 & 52 & $1586 \pm 27$ & -26.8 & $410 A D-550 A D$ & $480 \pm 70$ AD & $1470 \pm 70$ \\
\hline ETH-52812 & 67 & $2787 \pm 33$ & -28.8 & $1020 B C-840 B C$ & $930 \pm 90$ BC & $2880 \pm 90$ \\
\hline ETH-54077 & 82 & $2879 \pm 27$ & -26.0 & $1190 B C-940 B C$ & $1065 \pm 125$ BC & $3015 \pm 125$ \\
\hline ETH-54078 & 98 & $3706 \pm 31$ & -30.9 & $2200 B C-1980 B C$ & $2090 \pm 110$ BC & $4040 \pm 110$ \\
\hline ETH-52813 & 115 & $5075 \pm 36$ & -26.3 & $3970 B C-3790 B C$ & $3880 \pm 90$ BC & $5830 \pm 90$ \\
\hline ETH-52814 & 151 & $5792 \pm 37$ & -30.9 & $4730 B C-4540 B C$ & $4635 \pm 95$ BC & $6585 \pm 95$ \\
\hline ETH-52815 & 167 & $6147 \pm 37$ & -29.8 & $5220 B C-4990 B C$ & $5105 \pm 115$ BC & $7055 \pm 115$ \\
\hline
\end{tabular}




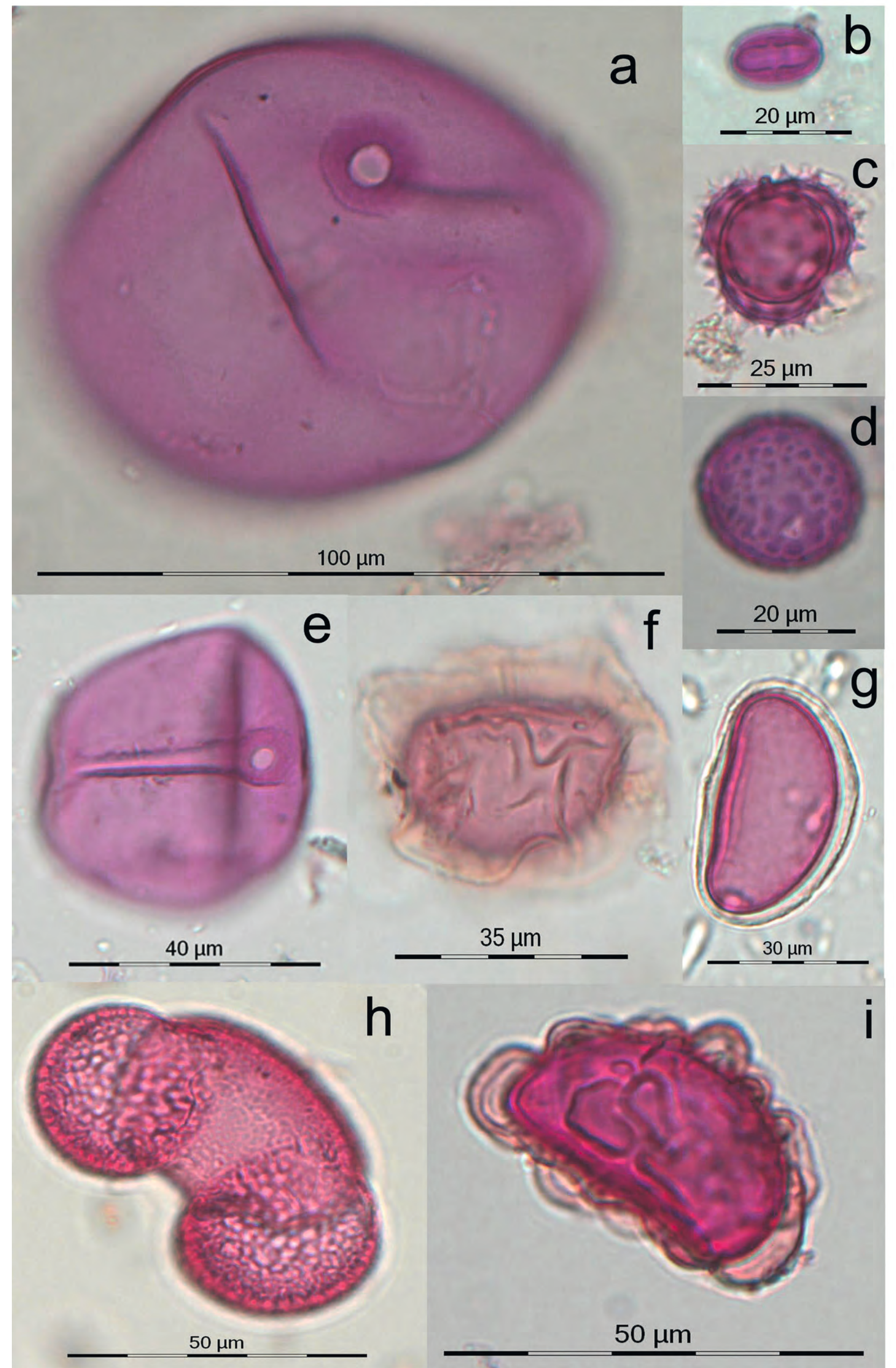


Beispiele der Mikrofossilien aus den Blackenalp-Torfproben: a: Mais (Zea mays), b: Edelkastanie (Castanea sativa), c: Beifussblättriges Traubenkraut (Ambrosia artemisiifolia), d: Alpen-Wegerich (Plantago alpina), e: Getreide (Cerealia), f, g, i: Farnsporen mit Exospor (Pteridophyta), h: Arve (Pinus cembra).

Fotos N. Wahlmüller, 2016

Eine räuberisch lebende Schalenamöbe (Nebela collaris-Artengruppe) aus den Blackenalp-Torfproben.

Foto N. WahImüller, 2016

Zeit-Tiefen-Modell für das Z'GraggenMoor, erhalten durch die absolute Radiokarbondatierung von Pflanzenresten aus neun Tiefenschichten an der ETH Zürich und der Kalibrierung bzw. Modellberechnung mithilfe von CLAM-Software.

Grafik B. Dietre, J.N. Haas, 2016

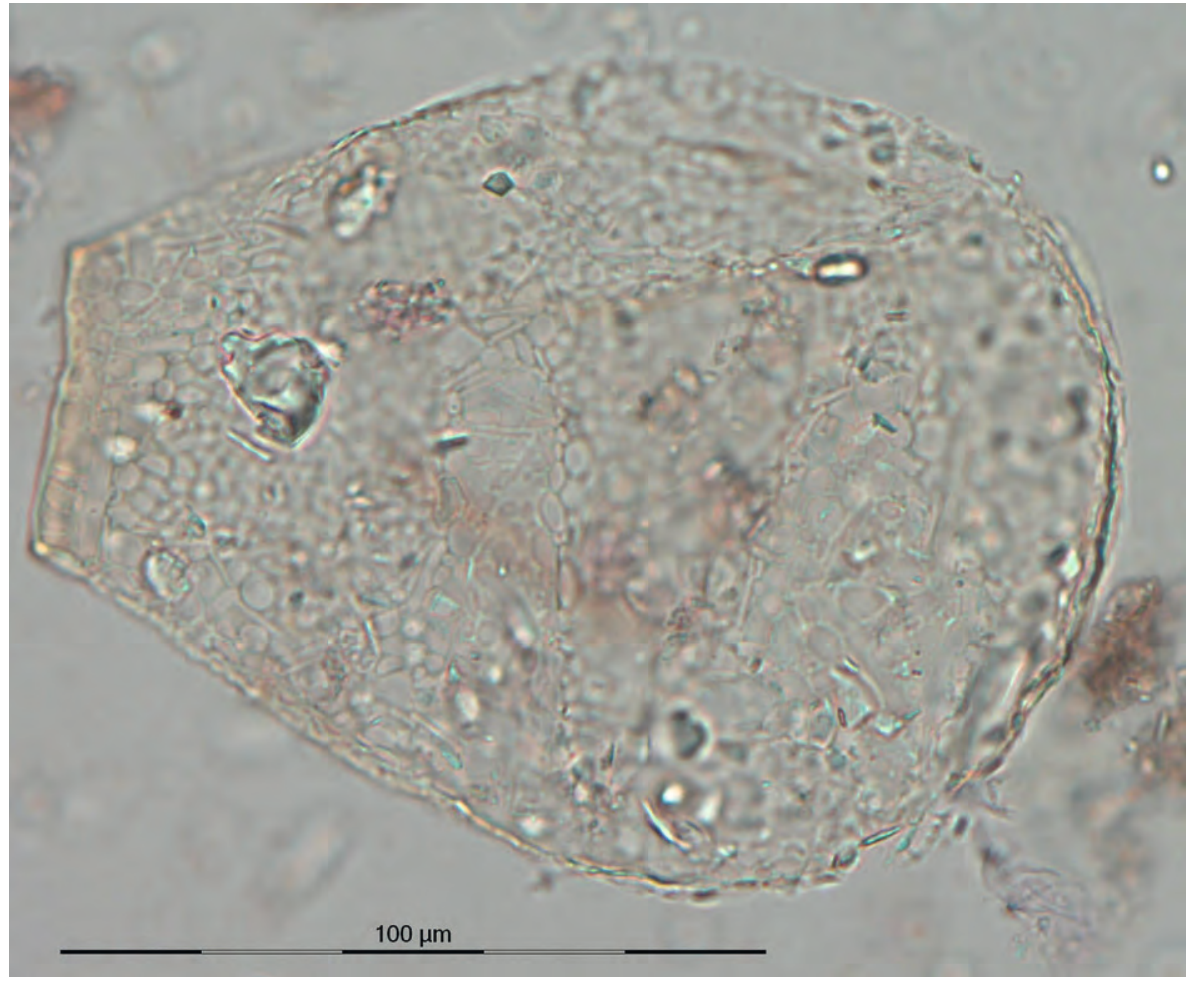

\section{Mittelsteinzeit (9600-5500 v.Chr.)}

Mit dem Beginn der Nacheiszeit, auch Holozän genannt, veränderte sich das damalige Klima drastisch. Innert weniger Jahrzehnte stieg die Jahresmitteltemperatur auch im Kanton Uri um mehrere Grad Celsius auf Werte leicht höher oder vergleichbar mit heute, sodass es zu einer Verdrängung der Föhren durch die Hasel (Corylus avellana) kam, gefolgt vom Einwandern der Eichenmischwaldarten: Ulme - Ulmus, Linde - Tilia, Ahorn - Acer, Esche - Fraxinus und Eiche - Quercus. Um 8100 v.Chr. konnten auch für die Innerschweiz mittelsteinzeitliche Jäger- und Sammlergesellschaften nachgewiesen werden, wie die archäologischen Untersuchungen von der Bergli-

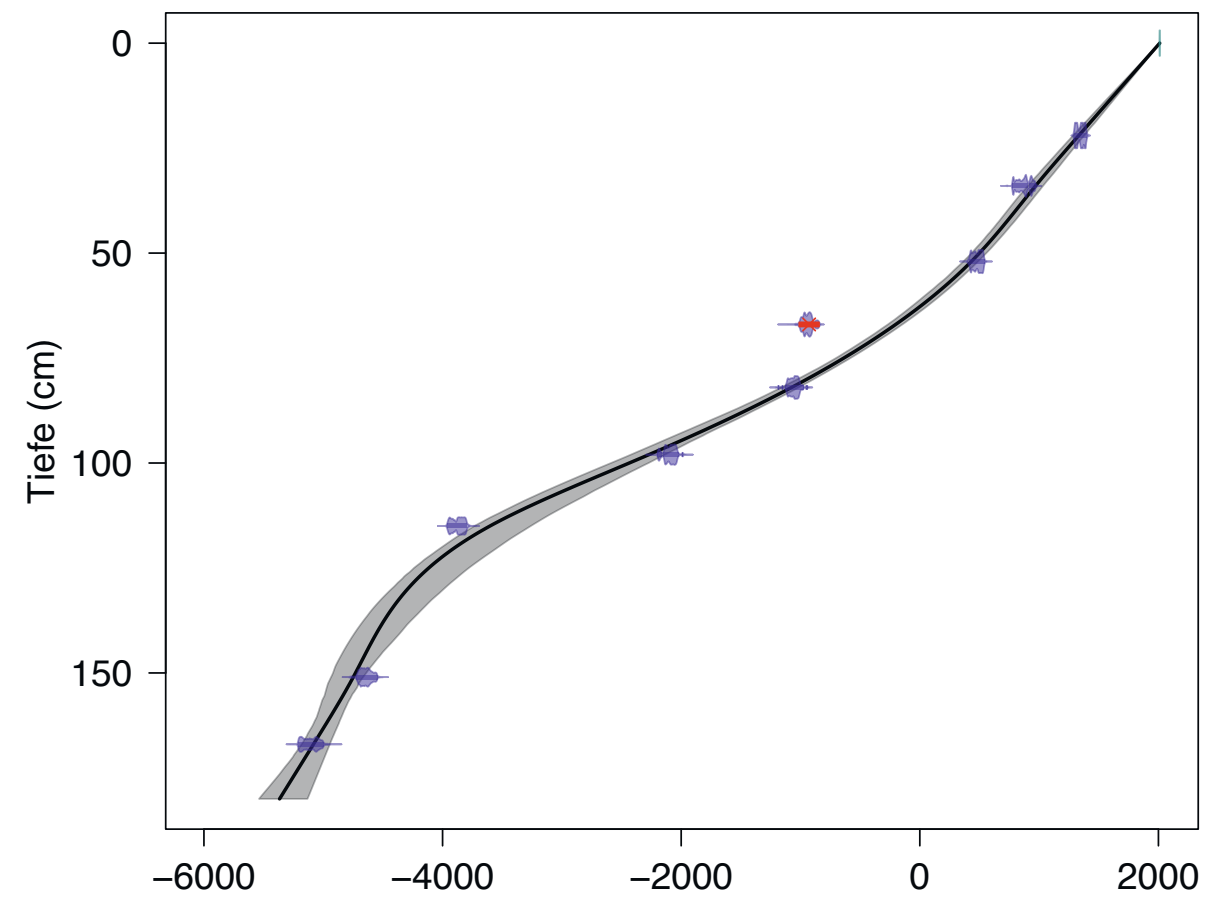




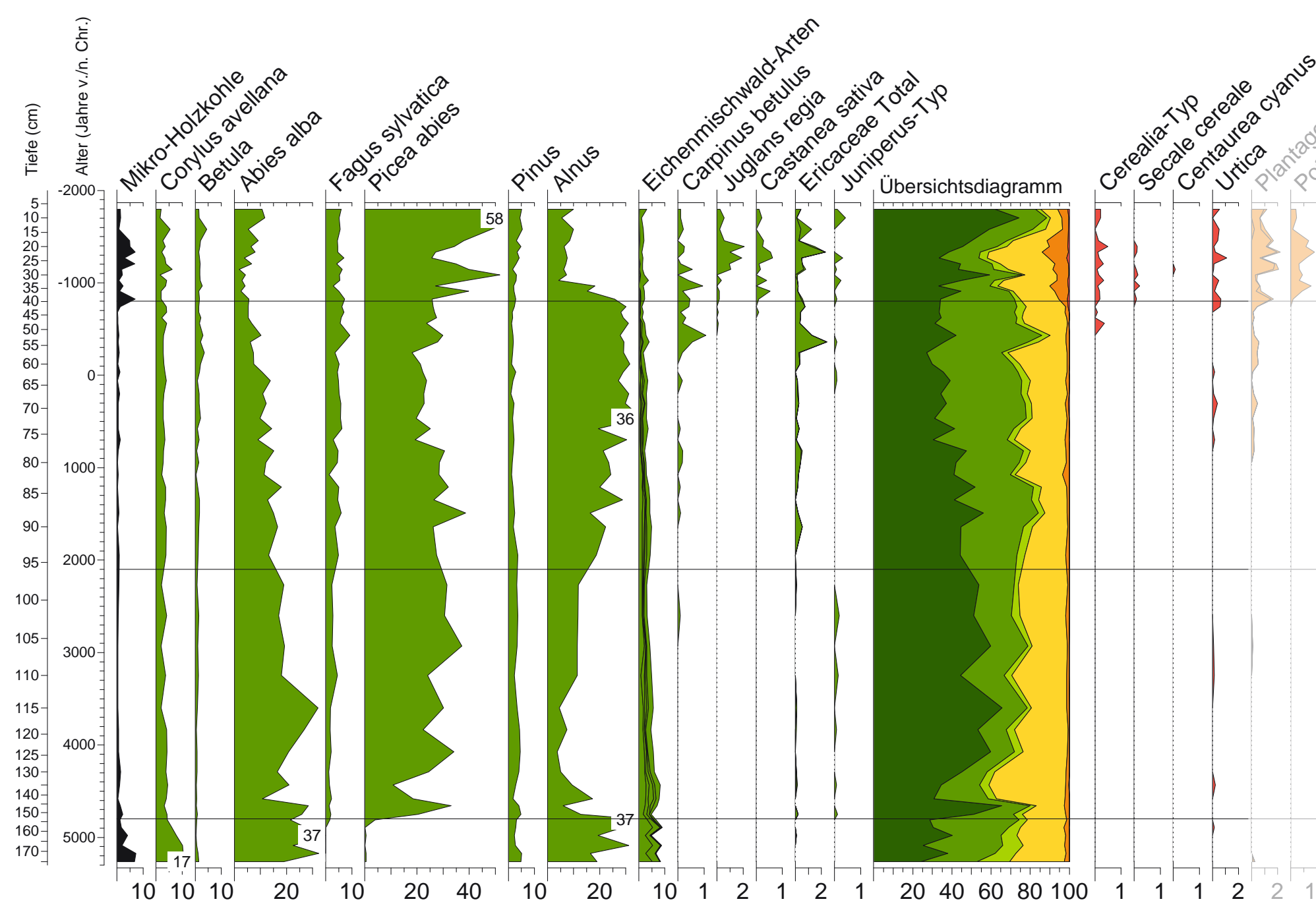

balm im Bisistal südlich von Muotathal zeigen. ${ }^{10}$ Allerdings finden sich in den Tallagen zu dieser Zeit immer noch ausgeprägte dichte, vor allem durch Laubbaumarten geprägte Urwälder. ${ }^{11}$ Gleichzeitig fanden sich an der auf mehr als 2300 m ü.M. liegenden Baumgrenze je nach Exposition und Bodenbeschaffenheit vor allem Arven (Pinus cembra), Lärchen (Larix decidua), Latschen (Pinus mugo) und Grünerlen (Alnus alnobetula). Erst gegen 7000 v.Chr. begann sich das Bild zu ändern, da von Südwesten her die Weisstanne (Abies alba) aus ihren eiszeitlichen Rückzugsgebieten in Südfrankreich und dem westlichen Norditalien dank kontinuierlicher Tier- und Windverbreitung ihrer Samen in die Innerschweizer Wälder «zurückwanderte». ${ }^{12}$ Die Weisstanne verdrängte dabei vor allem die in den montanen Lagen zuvor von den mittelsteinzeitlichen Jägern und Sammlern auch wegen ihrer Nüsse als Nahrungsquelle geschätzte und daher geförderte lichtliebende Hasel. Die relativ konkurrenzschwache Waldföhre wurde zudem auf ihre noch heute vorhandenen Sonderstandorte wie untiefe, trockenheitsgefährdete Böden zurückgedrängt. ${ }^{13}$

\section{Jungsteinzeit (5500-2200 v.Chr.)}

Während dieser neuen Zeitepoche, in der in Mitteleuropa die Landwirtschaft eingeführt und der Mensch sesshaft wurde, fand sich im Kanton Uri im Grossen und Ganzen noch immer ein natürlicher Waldbestand. In Lagen unterhalb von 2000 m ü.M. dominierte ein Weisstannenwald das Gebiet und

Palynologische Auswertung der Torfsedimente aus dem Z'Graggen-Moor mit zeitlinearer Darstellung der relativen Prozentkurven ausgewählter Pflanzenarten sowie den Funden von mikroskopischen Holzkohlepartikeln, Pilzsporen und Turbellariereiern.

Grafik N. Wahlmüller, B. Dietre und J.N. Haas, 2016

10 Leuzinger/Affolter/Beck et al. 2016.

11 Zoller/Haas 1995.

12 Van der Knaap/Van Leeuwen/Finsinger et al. 2005. - Van der Knaap/Van Leeuwen/Sperisen 2005.

13 Oechslin 1927. 


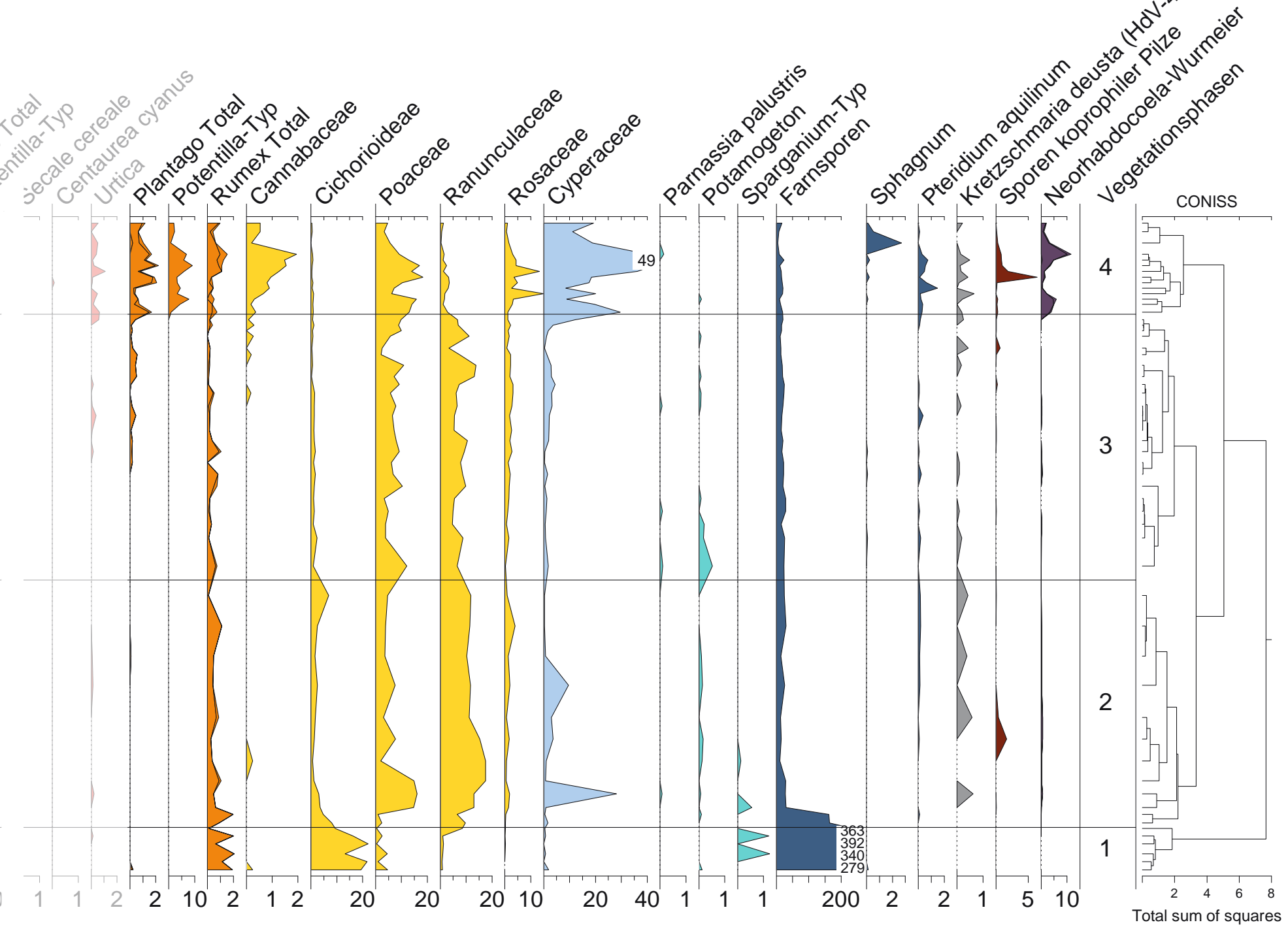

die Umgebung des Kantons Uri. Die heute reichlich im Gebiet vorhandene Fichte (Picea abies) war aufgrund ihrer weit im Südosten der Alpen, unter anderem im Prosecco-Gebiet nördlich von Venedig, ${ }^{14}$ gelegenen eiszeitlichen Rückzugsgebiete noch gar nicht bis in den Kanton Uri gelangt. Über $2000 \mathrm{~m}$ ü.M. und bis zur Baumgrenze nahm der Anteil an Lärchen und Arven stetig zu. Die beiden letztgenannten Baumarten bildeten auch die Waldgrenze.

Um 5300 v.Chr. setzte nun das Torfwachstum im Z'Graggen-Moor auf dem Brüsti ein, sodass aufgrund des Pollenniederschlags detailliert über die nun folgenden Vegetationsveränderungen berichtet werden kann.

Um 4800 v.Chr. veränderte sich das Aussehen der lokalen Urner Flora und Vegetation nachhaltig, da nun die Fichte ganz massiv von Osten via Arlberggebiet und von Norden her über das bayerische Alpenvorland in die Innerschweiz gelangte. ${ }^{15}$ Die Fichte "wanderte» damals relativ schnell und gleichzeitig in das Gebiet um Attinghausen, ins Urserntal, sowie ins Muota-

14 Monegato/Ravazzi/Culiberg et al. 2015.

15 Haas/Wahlmüller/Vaccaro et al. 2014. - Haas/Wahlmüller/Kappelmeyer et al. 2013. - Haas/Altstätter/Dietre et al. 2015. - Van der Knaap/Van Leeuwen/Finsinger et al. 2005. - Van der Knaap/Van Leeuwen/Sperisen 2005. tal ein, wo sie zwar überall in direkter Konkurrenz zur Weisstanne stand, dabei aber vor allem die Standorte der in den Tallagen zuvor vorhandenen Eichenmischwaldarten (Eichen, Linden, Ahorn, Eschen, Ulmen) sukzessive besiedelte. Hohe Fichten- und Weisstannen-Pollenwerte in den verschiedenen untersuchten Torfsedimenten sowie deren Nadel- und Zapfenteile belegen die ausgeprägte Dominanz dieser Nadelhölzer während der zweiten Hälfte der Jungsteinzeit. Ebenfalls neu im Gebiet von Attinghausen trat 


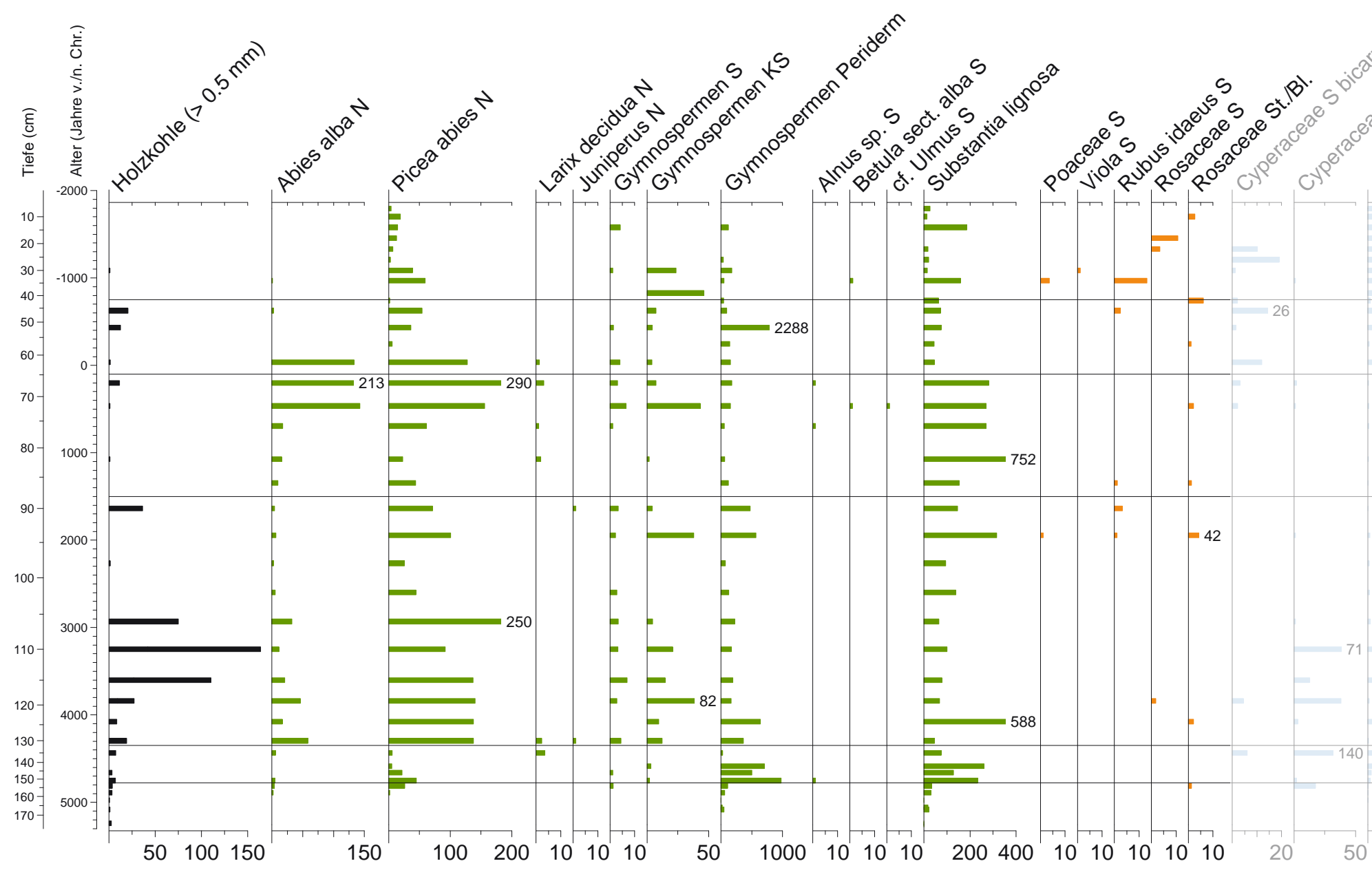

ab 4800 v.Chr. die Buche (Fagus sylvatica) auf. Deren regionale Präsenz unterhalb dem Brüsti während der Jungsteinzeit lässt sich auch indirekt über die nun im Torf des Z'Graggen-Moores einsetzenden Funde von Sporen des Brandkrustenpilzes (Kretzschmaria deusta) nachweisen, ein Pilz, der mit Vorliebe saprobiontisch oder parasitisch auf Buchen wächst. Erst mit dem Übergang von der Jungsteinzeit zur Bronzezeit ab 2200 v.Chr. wurden weitere Baumarten wie die Erle (Alnus) im Gebiet des Surenenpasses wichtiger. Obwohl lokal immer wieder grössere Feuerereignisse auf dem Brüsti zu verzeichnen waren, wurde das regionale Landschaftsgefüge wohl noch nicht sehr stark vom Menschen verändert. Archäologisch bekannt sind für diese Zeitepoche nur wenige Siedlungsstellen, Funde und Befunde, ${ }^{16}$ auch wenn bereits erste Pfahlbaugesellschaften ab circa 3450 v.Chr. die nahen Ufer des Vierwaldstättersees auf Nidwaldner Seite in Stansstad-Kehrsiten besiedelten. ${ }^{17}$

\section{Bronzezeit (2200-800 v.Chr.)}

Mit dem Beginn der Bronzezeit änderte sich vorerst die Vegetationszusammensetzung in unserem Untersuchungsgebiet nicht grundsätzlich. Die Fichtenpollenwerte zeigen eine stabile Fichtenpopulation auf dem Brüsti an, bei gleichzeitig leicht zurückgehender Bedeutung der Weisstanne und dem verstärkten Aufkommen von Erlen. Dieses verstärkte Erlenaufkommen könnte durchaus auch mit klimatischen Faktoren beziehungsweise feuchteren Klimabedingungen zu tun haben, da gleichzeitig auch eine Zunahme an Wasser- und Sumpfpflanzen wie Laichkräutern (Potamogeton) oder Herzblatt (Parnassia palustris) im Z'Graggen-Moor festzustellen ist, was auf
Grossrestanalytische Auswertung der Torfsedimente aus dem Z'Graggen-Moor mit zeitlinearer Darstellung der Absolutwerte ausgewählter Pflanzenarten pro $10 \mathrm{~g}$ Torf. Abkürzungen: $\mathrm{B}=\mathrm{Blätter,}$ $\mathrm{BB}=$ Blattbasis, $\mathrm{BI} .=\mathrm{Blütenboden,}$ FK=Fruchtkörper, KS=Knospenschuppen, $\mathrm{N}=$ Nadeln, $\mathrm{S}=$ Samen, St. $=$ Stacheln, V=vegetativ.

Grafik S. Altstätter, B. Dietre und J.N. Haas, 2016
16 Leuzinger/Affolter/Beck et al. 2016.

17 Hügi 2006. - Michel 2014. - Michel/ Bleicher/Brombacher et al. 2012. Michel-Tobler/Brombacher/Rehazek 2010. 
22 Haas/Rasmussen 1993. - Haas 2002. - Oechslin 1927.

Blick auf die Alp Waldnacht und den Surenenpass. Rechts oben ist der Grat des Geissrüggens zu erkennen.

Foto, 1918 (Staatsarchiv Uri)

\section{Römerzeit (15 v.Chr.-400 n.Chr.)}

Während der Römerzeit ändert sich das Waldbild rund um das Z'GraggenMoor auf dem Brüsti. Es ist gemäss dem Pollenbild von einem starken Rückgang der Weisstanne auszugehen, wobei sich dieser Rückgang auch regional zeigte. Die Resultate der Grossrestuntersuchungen aus dem Z'GraggenMoortorf widerspiegeln diesen Rückgang der Weisstanne gut, finden sich doch aus der Zeit nach 50 n.Chr. fast gar keine Nadelfunde mehr. Die Reduktion der Weisstannenbestände wurde gemäss den Pollenanalysen durch leicht höhere Werte an Birken (Betula) und Fichten kompensiert. Bei gleichzeitigem Fehlen von mikroskopischer Holzkohle ist es unwahrscheinlich, dass Feuer bei dieser Walddynamik eine Rolle spielte. Es ist somit eher von menschlichen Aktivitäten respektive selektiver Bewirtschaftung des Waldes während der Römerzeit auszugehen und der gezielten Nutzung von Weisstannen, wie dies auch später bis weit ins Hochmittelalter hinein geschehen sein dürfte. Mögliche Nutzungsformen des Weisstannenholzes könnten im Zusammenhang mit einer verstärkten Stammholznutzung für den Hausbau stehen oder beispielsweise auch mit der Herstellung von Schindeln, wofür sich Weisstannenholz speziell gut eignet. Eine weitere Möglichkeit wäre die Verwendung von Weisstannen-Reisig als Winterfutter für die eingestallten Haustiere der Region, was - aus Mangel an Futteralternativen - bis in die historische Zeit für den Kanton Uri belegt ist. ${ }^{22}$ Gemäss dem pollenanalytischen Bild und der geringen Anzahl an typischen Zeigerpflanzen scheinen jedoch die römerzeitlichen Bewohner der Region zu dieser Zeit kaum Alpwirtschaft betrieben zu haben. Dieses Phänomen ist auch aus anderen Regionen der Schweiz bekannt und deutet auf ein gewisses Desinteresse an den Alpgebieten. Die Transit- und Handelswege über die Alpenpässe wurden hingegen weiterhin rege benutzt, was zum Beispiel durch verschiedene römerzeitliche Münzfunde auf der Blackenalp jenseits des Surenenpasses evident wurde ( - S. 136-155).

\section{Völkerwanderungszeit/Frühmittelalter (400-800 n.Chr.)}

Nach der Römerzeit wandelte sich das Vegetationsbild erneut, und zwar sowohl in der Umgebung des Brüsti wie auch auf der südwestlichen Seite des Surenenpasses auf der Blackenalp. Die Buche und auch die Fichte nahmen nun vermehrt die Standorte der reduzierten Weisstannenbestän-

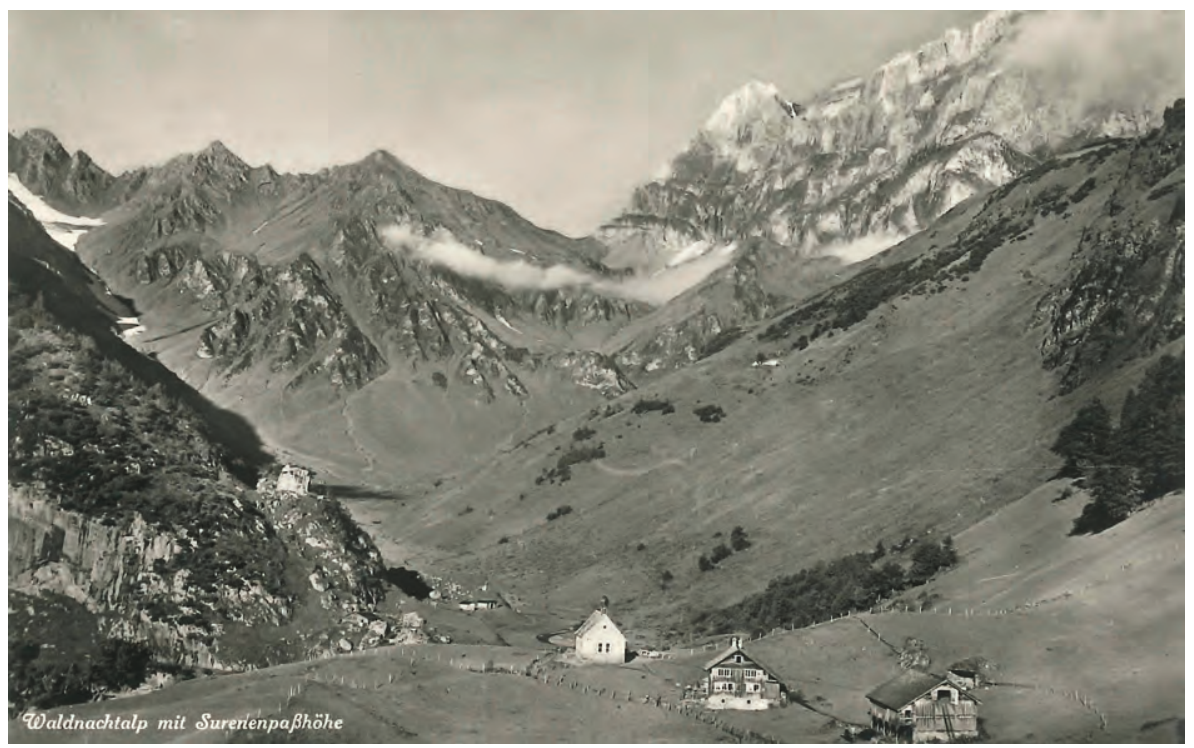




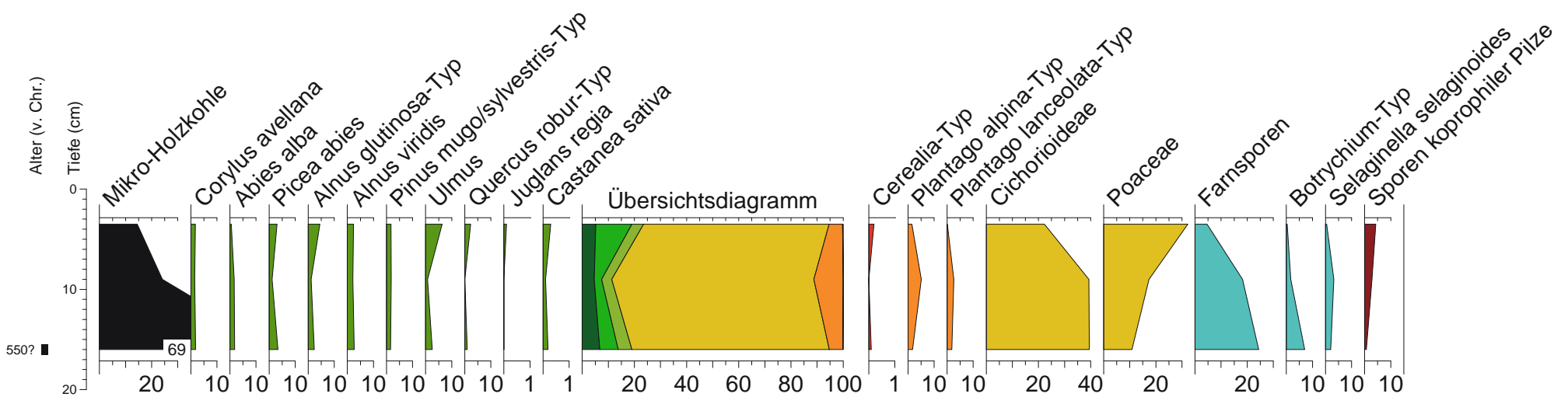

de ein, wobei in etwas wärmeren Lagen nun auch die Hainbuche (Carpinus betulus) verstärkt auftrat sowie erste Walnussbäume (Juglans regia) vorkamen. Auch finden sich in den enstprechenden Torfschichten des Z'Graggen- und Blackenalp-Moores erstmalig und durchgängig Getreide(Cerealia) und Hanfpollen (Cannabaceae), was auf das Heraufwehen des Blütenstaubs aus den Anbaugebieten dieser Kulturpflanzen zurückzuführen ist und den Kulturpflanzenanbau in den hangseitigen Tallagen um Attinghausen und im Urner Reusstal ausdrückt. Diese Zeitperiode war auch durch Holzkohlevorkommen in den Torfablagerungen gekennzeichnet, was auf lokale beziehungsweise regionale Feuer hinweist. Gleichzeitig konnten im Z'Graggen-Moor für das Ende des Frühmittelalters die ersten Roggenpollennachweise (Secale cereale) getätigt werden - ein für das Gebiet damals neues Getreide, das in den Urner Tallagen vor allem dann im Hochmittelalter grosse Bedeutung erlangte. Wie in vielen anderen Alpentälern wird dieses Getreide - seit jeher - bevorzugt von der römisch-katholischen Bevölkerung verwendet.

\section{Hoch- und Spätmittelalter (800-1500 n.Chr.)}

Im Hoch- bis Spätmittelalter fanden erneut grössere Vegetationsveränderungen im Gebiet rund um den Surenenpass statt. In den Urner Talschaften kann von einem stetig zunehmenden extensiven Roggen-, Getreide- und Hanfanbau ausgegangen werden. Dass während dem Hochmittelalter auch reichlich Ackerunkräuter vorgekommen sein müssen, wird durch den Fund von Kornblumenpollen (Centaurea cyanus) im Z'Graggen-Moor klar, ein heute auf der roten Liste stehendes, sehr seltenes Element von Roggenund Getreideäckern, vor allem von Wintergetreidefeldern. Sehr interessant ist auch der zu jener Zeit offensichtlich in den Tallagen stark ausgebaute Hanfanbau. Im Urner Reusstal, im Engelbergertal und in den weiteren umliegenden Tälern der Waldstätten dürfte damals viel Hanf (Cannabis sativa) als Medizinalpflanze angebaut worden sein, vor allem auch für die Gewinnung von Fasern zur Textilherstellung. Aus der Zeit ab dem Hochmittelalter findet sich sowohl im Z'Graggen-Moor wie auch im Blackenalp-Moor reichlich Blütenstaub von Edelkastanien (Castanea sativa) und auch stark zunehmende Walnusswerte ab dem Spätmittelalter. In den Tallagen rund um den Surenenpass muss es demzufolge zur regelmässigen Nutzung dieser Fruchtbäume gekommen sein, vor allem im Urner Reusstal, wo sie noch heute vorkommen; oder auch in den nahen Südalpengebieten, etwa dem Tessin. Auch die Alpwirtschaft fand nun links und rechts des Surenenpasses während dieser Zeit eine neue Blüte. Zeigerpflanzen für Trittrasengesellschaften wie Spitzwegerich und für Alpbewirtschaftung wie Fingerkraut ( $P O$ tentilla), Ampfer (Rumex) oder Süssgräser (Poaceae) sowie für Nährstoffeintrag - zum Beispiel Brennessel - erreichten Höchstwerte. Gleichzeitig
Palynologische Auswertung der Kulturschichtsedimente aus dem hallstattzeitlichen Gebäude auf dem Geissrüggen mit tiefenlinearer Darstellung der relativen Prozentkurven ausgewählter Pflanzenarten sowie den Funden von mikroskopischen Holzkohlepartikeln und von Sporen koprophiler Pilze. Grafik B. Dietre und J.N. Haas, 2016 
23 Renner-Aschwanden 2014.

Blick auf die Blackenalp mit der Alpkapelle und einem Älpler mit seiner Schafherde.

Foto, 1960er Jahre (Staatsarchiv Uri) . verlor die Weisstanne weiterhin an Boden und zeigte gegen 1200 n.Chr. ihre niedrigsten Pollenwerte respektive ihre geringste Verbreitung seit Jahrtausenden, wohl aufgrund starker Holznutzung. Vergleichbar verlief auf dem Brüsti auch die Häufigkeit der Erle zu dieser Zeit, von reichlichen Beständen um 800 n.Chr. zu einer sehr geringen Bedeutung um 1100 n.Chr., bei gleichzeitiger Zunahme der Fichte. Möglicherweise stand dieser Artenwechsel im Zusammenhang mit dem mittelalterlichen Klimaoptimum und den im Vergleich zu heute etwas wärmeren Sommertemperaturen, doch könnte auch das gezielte Fällen von Erlen rund um das Z'Graggen-Moor dafür verantwortlich gewesen sein. Diese generellen Umwälzungen in der Zusammensetzung des Waldes dürften zudem - zumindest regional - mithilfe von Feuer verursacht geworden sein, worauf ein verstärktes Vorhandensein von mikroskopischer Holzkohle hinweist. Diese Feuerereignisse drückten sich auch im vermehrten Aufkommen von Adlerfarn aus, ein Farn der erst nach pflanzenphysiologischen Stresssituationen wie etwa einem grossflächigen Feuer überhaupt Sporen bilden kann. Wie einige aus dem Hospental-Moos im Urserntal entnommene, angekohlte und auf den Zeitraum 820 bis 1010 n.Chr. datierte Weisstannen- und Fichtenstämme gezeigt haben, dürfte das Legen von Feuer damals zur alltäglichen Technik der Weidegewinnung gehört haben. ${ }^{23}$ Extrem häufig vorkommende Sporen von Pilzen, die nur auf Exkrementen wachsen, vervollständigen dieses Bild einer intensiven Alpwirtschaft mit vielen Haustieren rund um den Surenenpass. Sicherlich hatte dieser spätmittelalterliche Ausbau der lokalen Alpwirtschaft in den subalpinen Gebirgshochlagen mit einer generellen Bevölkerungszunahme zu tun. Diese führte im Tal zu stark vergrösserten Ackerflächen für den Kulturpflanzenanbau und zwang wohl auch zum Ausbau der Alpwirtschaft. So wurden neue Alpweiden jenseits des Surenenpasses, auf der Blackenalp beziehungsweise in Niedersurenen, erschlossen.

Allerdings dürfte dieser generelle alpwirtschaftliche Umschwung auch mit einer Strukturänderung in der damaligen Viehwirtschaft zu tun haben. Ab dem frühen 14. Jahrhundert verlor die Schmalviehhaltung (Schafe/Ziegen) in den subalpinen Lagen der Zentralschweiz stark an Bedeutung und wurde durch Rinderwirtschaft abgelöst, selbst wenn die Schafhaltung noch bis ins 20. Jahrhundert von Bedeutung war $(\rightarrow$ S. 184-201).

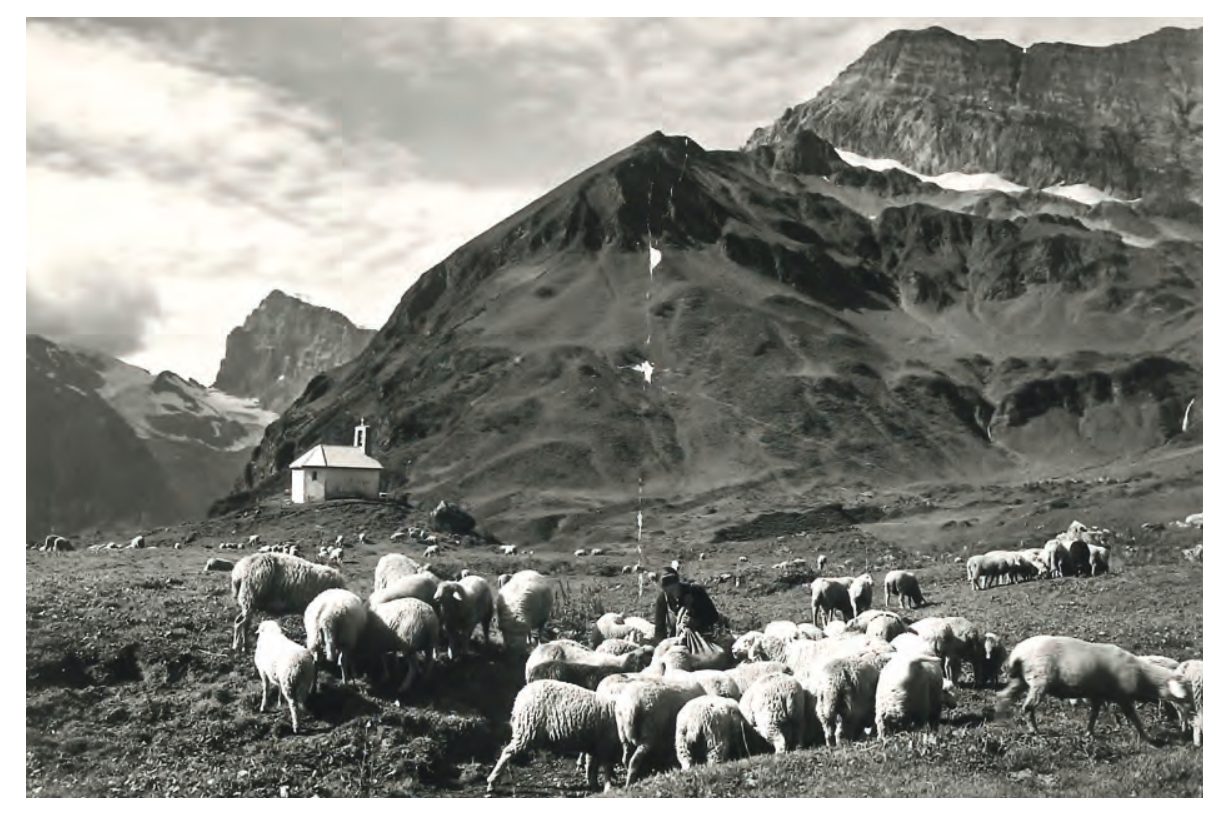




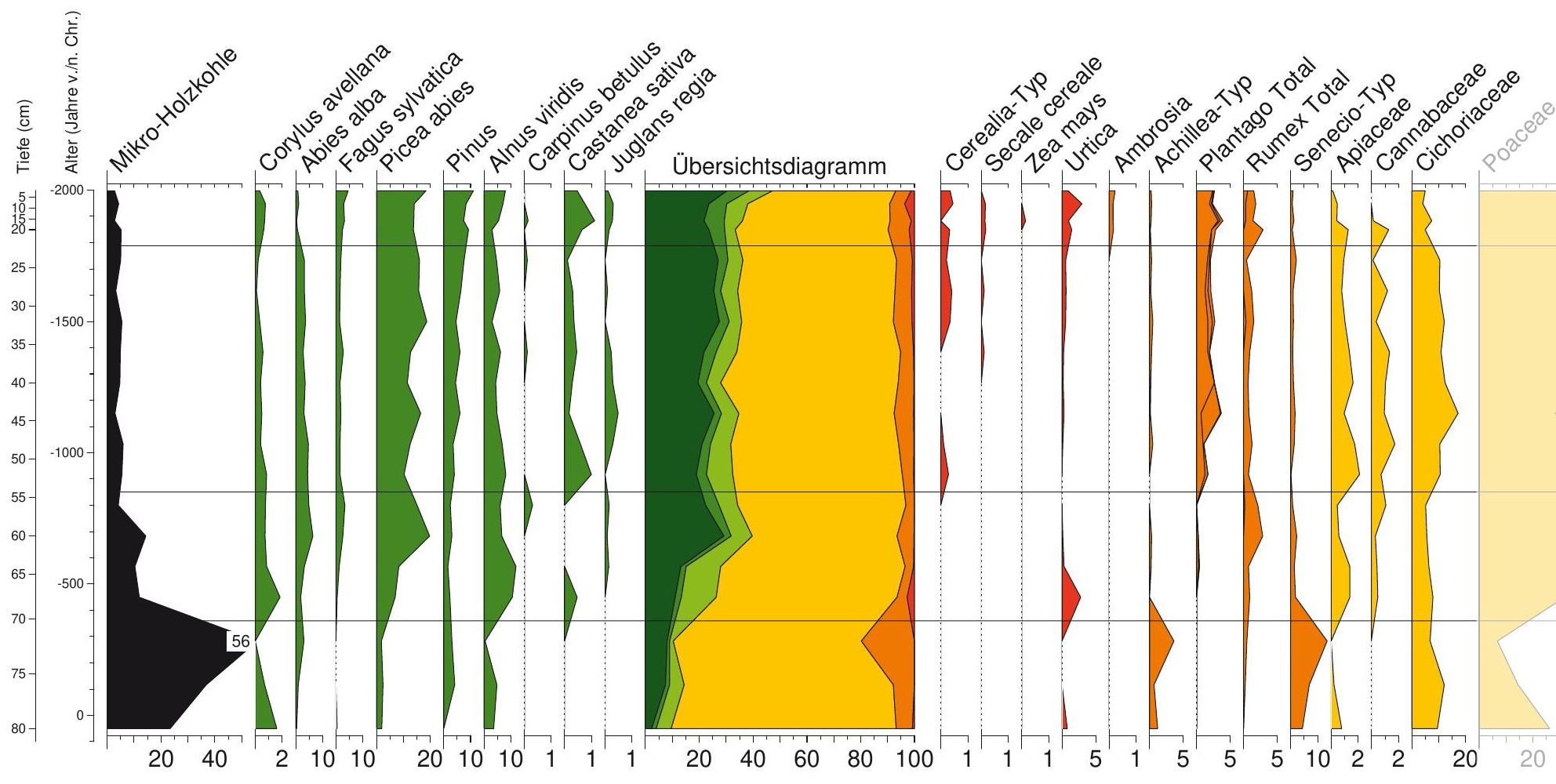

Die sogenannte Kleine Eiszeit mit mehreren Kälteschüben zwischen 1350 und 1850 n.Chr. scheint dabei im Zeitraum des Spätmittelalters jedoch kaum Auswirkungen auf die Alpwirtschaft gehabt zu haben, wie es die Pollenmaximalwerte von entsprechenden Kräutern (Plantago, Urtica, Potentilla, Rumex) zeigen. Zudem bestätigt eine Vielzahl von Wüstungen auf der Blackenalp zwischen Engelberg und dem Surenenpass, dass auch die über 1800 m ü.M. gelegenen Alpen intensiv beweidet wurden und von grosser Bedeutung blieben.

Widmen wir uns hier noch kurz der naturschutzrelevanten Geschichte der lokalen Flora des Z'Graggen-Moores, so kann festgehalten werden, dass die für Hochmoore typischen Torfmoose (Sphagnum) und Wollgräser (Eriophorum) erst ab dem Hochmittelalter verstärkt auftraten. Typische zoologische Vertreter von Hochmooren sind ebenfalls in grösseren Beständen im Torf des Z'Graggen-Moores zu registrieren, zum Beispiel Turbellarier-Würmer (Neorhabdocoela ${ }^{24}$ ). Das heutige Bild vom Übergangsmoor mit Hochmooraspekt und seine trotz der sehr kleinen Fläche sehr schützenswerte Hochmoorvegetation entstanden also vor etwa 1200 Jahren.

\section{Neuzeit (seit 1500 n.Chr.)}

Die jüngsten Torfschichten und Pflanzenreste aus dem Z'Graggen-Moor und dem Blackenalp-Moor entsprechen in ihrer botanischen Zusammensetzung den heutigen Vegetationsbeständen auf den jeweiligen Mooroberflächen weitgehend. Auf dem Brüsti wächst somit der von Alpweiden durchzogene, heute lockere Fichten-Tannen-Wald wohl in ähnlicher Zusammensetzung wie vor einigen wenigen Jahrhunderten. In den obersten Torfschichten des Z'Graggen-Moores finden sich jedoch auch minerogene Partikel (Sand), was vermutlich auf die rege Bautätigkeit in der Umgebung, zum Beispiel den Bau des Berggasthauses Z'Graggen, zurückzuführen ist. Der Grossteil des ehemals viel grösseren Brüsti-Moorkomplexes beziehungsweise Z'Graggen-Moores wurde dabei leider unwiderruflich zerstört, sodass es

Palynologische Auswertung der Torfsedimente aus dem Blackenalp-Oberes Moor mit zeitlinearer Darstellung der relativen Prozentkurven ausgewählter Pflanzenarten sowie den Funden von mikroskopischen Holzkohlepartikeln, von Pilzsporen und von diversen Tierresten.

Grafik N. Wahlmüller, B. Dietre und J.N. Haas, 2016 
Blick auf die Blackenalp. Im Vordergrund sind Tausende von Alpenampfern, auch Alpen-Blacken genannt (Rumex alpinus), zu erkennen die wohl namengebend für das Gebiet südwestlich des Surenenpasses waren.

Foto M. Sauter, 2014 eingeschleppten Arten. Diese Funde erlauben somit den Nachweis von erstmaligem Maisanbau in den Tallagen rund um den Surenenpass respektive den Nachweis der für Allergiker heute sehr problematischen Ambrosie, die somit wohl auch in der Innerschweiz bereits seit mehr als 100 Jahren als Ackerunkraut vorhanden gewesen sein muss. ${ }^{27}$

\section{Fazit}

Die am Z'Graggen- und Blackenalp-Moor durchgeführten paläoökologischen Untersuchungen erlauben einen guten Einblick in die jahrtausendealte Klima-, Wald- und Vegetationsentwicklung rund um den Surenenpass. Auch wenn das Blackenalp-Moor beziehungsweise wohl alle dort vorhandenen Moore mit um die $80 \mathrm{~cm}$ Torftiefe eher jüngeren Alters sein dürften und erst seit der Römerzeit oder dem Frühmittelalter entstanden sind, müssen diese Moorflächen als sehr schützenswerte Archive bezeichnet werden. Hier stellt sich natürlich durchaus die Frage, ob diese Moore auf der Blackenalp erst mit der verstärkten Alpwirtschaft selbst entstanden sein könnten. Dies ist durchaus vorstellbar, denn grössere Wasserflächen sind auch heute noch Mangelware im Gebiet. Trotz dem tosenden und reissenden Stierenbach wäre es für die seit dem Mittelalter auf der Blackenalp weilenden Älpler sicherlich sinnvoll gewesen, an geeigneten Stellen Boden auszuheben, um Wasserstellen für ihre Haustiere zu schaffen. Sukzessive dürften diese Stellen jedoch später verlandet sein, was die Grundlage für das Aufkommen der relativ artenreichen Kleinstmoore rund um die Blackenalp gewesen sein dürfte, ohne die wir keinen Einblick in die vergangene Klima-, Floren-, Vegetations- und Alpgeschichte bekommen hätten.
27 Vgl. Van der Knaap/Van Leeuwen/ Fankhauser et al. 2000. 
Beug, H.-J. (2004). Leitfaden der Pollenbestimmung für Mitteleuropa und angrenzende Gebiete. München.

Blaauw, M. (2010). Methods and code for "classical" age-modelling of radiocarbon sequences. In: Quaternary Geochronology 5/5, 512-518.

Fægri, K. / Iversen, J. (1989). Textbook of pollen analysis. Chichester.

Gobet, E. / Tinner, W. (2012). Von der Ur-zur Kulturlandschaft. In: Geschichte des Kantons Schwyz 1, 37-57.

Grimm, E.C. (1987). CONISS: a FORTRAN 77 program for stratigraphically constrained cluster analysis by the method of incremental sum of squares. In: Computers \& Geosciences 13, 13-35.

Grimm, E.C. (1991). TILIA and TILIAGRAPH. Springfield.

Haas, J.N. (1996). Neorhabdocoela oocytes - palaeoecological indicators found in pollen preparations from Holocene freshwater lake sediments. In: Review of Palaeobotany and Palynology 91, 371-382.

Haas, J.N. (2002). 6000 years of tree pollarding and leaf-hay foddering of livestock in the Alpine Area. In: Centralblatt für das gesamte Forstwesen / Austrian Journal of Forest Science 119, 231-240.

Haas, J.N. / Rasmussen, P. (1993). Zur Geschichte der Schneitel- und Laubfutterwirtschaft in der Schweiz - Eine alte Landwirtschaftspraxis kurz vor dem Aussterben. In: Brombacher, C. / Jacomet, S. / Haas, J.N. (Hrsg.). Festschrift Zoller. Cramer. In: Dissertationes Botanicae 196. Berlin/Stuttgart, 469-489.

Haas, J.N. / Richoz, I. / Tinner, W. et al. (1998). Synchronous Holocene climatic oscillations recorded on the Swiss Plateau and at timberline in the Alps. In: The Holocene 8, 301-309.

Haas, J.N. / Wahlmüller, N. / Kappelmeyer, T. et al. (2013). Zur Vegetationsgeschichte der Silberenalp im Muotatal SZ an Hand der paläoökologischen Untersuchung der Schattgaden-Moorsedimente. In: Mitteilungen des Historischen Vereins des Kantons Schwyz 105, 11-32.

Haas, J.N. / Wahlmüller, N. / Vaccaro, C. et al. (2014). 7000 Jahre Vegetationsgeschichte des Urserntals anhand palynologischer und grossrestanalytischer Untersuchungen an den Torfsedimenten aus der Flur Moos zwischen Andermatt und Hospental. In: Historisches Neujahrsblatt Uri N.F. 68, 85-103.

Haas, J.N. / Altstätter, S. / Dietre, B. et al. (2015). Waldgeschichte der Waldstätte. In:

Sauter, M. (Hrsg.). Ausflug in die Vergangenheit. Archäologische Streifzüge durch die Urschweiz. Hochwald, 54-63.

Hajdas, I. (2008). Radiocarbon dating and its applications in Quaternary studies, In: Quaternary Science Journal - Eiszeitalter und Gegenwart 57, 2-24.

Hügi, U. (2006). Stansstad NW-Kehrsiten - Neolithische Seeufersiedlungen am Alpennordrand. In: Jahrbuch Archäologie Schweiz 89, 7-23.

Küttel, M. (1990a). Zur Vegetationsgeschichte des Gotthardgebietes. In: Mitteilungen der Naturforschenden Gesellschaft Luzern 31, 99-111.

Küttel, M. (1990b). Der subalpine Schutzwald im Urserental - ein inelastisches Ökosystem. In: Botanica Helvetica 100, 183-197.

Küttel, M. / Lotter, A. (1987). Vegetation und Landschaft der Zentralschweiz im Jungpleistozän. In: Mitteilungen der Naturforschenden Gesellschaft Luzern 29, 251-272. Leuzinger, U. / Sauter, M. / Haas, J.N. et al. (2014). Eine hallstattzeitliche Gebäudestruktur auf 1911 m ü.M. am Weg zum Surenenpass, Attinghausen UR, Siedlungslatz Geissrüggen. In: Jahrbuch Archäologie Schweiz 97, 153-168.

Leuzinger, U. / Sauter, M. / Haas, J.N. et al. (2015). Spätmittelalterliche und neuzeitliche Alpnutzung zwischen dem Surenenpass und der Blackenalp, Gemeinde Attinghausen UR. In: Jahrbuch Archäologie Schweiz 98, 145-153. 
Leuzinger, U. / Affolter, J. / Beck, C. et al. (2016). Der frühmesolithische Abri Berglibalm im Bisistal, Gemeinde Muotathal SZ. In: Jahrbuch Archäologie Schweiz 99, 7-26.

Leuzinger-Piccand, C. (1996). Einsiedeln SZ-Langrüti: eine spätmagdalénienzeitliche und mesolithische Freilandstation in den Voralpen. Grabungsbericht und Sammlungsstudie. In: Jahrbuch der Schweizerischen Gesellschaft für Ur- und Frühgeschichte 79, 7-26.

Leuzinger-Piccand, C. / Leuzinger-Piccand, U. (2012). Alt- und mittelsteinzeitliche Jäger und Sammlerinnen. In: Geschichte des Kantons Schwyz 1. Zürich, 59-73.

Meisner, F. (1823). Reise durch Unterwalden, Uri und Ursern über die Furca und Grimsel nach Interlachen; für die Jugend beschrieben. Bern.

Michel, C. (2014). Pfahlbauten am Vierwaldstättersee - der steinzeitliche Siedlungsplatz in Kehrsiten. In: Der Geschichtsfreund (= Mitteilungen des Historischen Vereins Zentralschweiz) 167, 71-98.

Michel, C. / Bleicher, N. / Brombacher, C. et al. (2012). Pfahlbauten am Vierwaldstättersee - der steinzeitliche Siedlungsplatz in Kehrsiten. In: Archäologie Schweiz 32/2, $56-77$.

Michel-Tobler, C. / Brombacher, C. / Rehazek, A. (2010). Stansstad-Kehrsiten - Neolithische Seeufersiedlungen hart am Alpenrand. In: Matuschik, I. / Strahm, C. I Eberschweiler, B. et al. (Hrsg.). Vernetzungen - Festschrift für Helmut Schlichtherle. Freiburg, 287-296.

Monegato, G. / Ravazzi, C. / Culiberg, M. et al. (2015). Sedimentary evolution and persistence of open forests between the south-eastern Alpine fringe and the Northern Dinarides during the Last Glacial Maximum. In: Palaeogeography, Palaeoclimatology, Palaeoecology 436, 23-40.

Moore, P.D. / Webb, J.A. / Collinson, M.E. (1991). Pollen analysis. London.

Oechslin, M. (1927). Die Wald- und Wirtschaftsverhältnisse im Kanton Uri. In: Beiträge zur geobotanischen Landesaufnahme 14. Bern.

Primas, M. / Della Casa, P. / Schmid-Sikimić, B. (1992). Archäologie zwischen Vierwaldstättersee und Gotthard. Siedlungen und Funde der ur- und frühgeschichtlichen Epochen (= Universitätsforschungen zur prähistorischen Archäologie 12). Bonn. Punt, W. (Hrsg.) (1976). The Northwest European Pollen Flora I. Amsterdam.

Punt, W. / Clarke, G.C.S. (Hrsg.) (1980-1988). The Northwest European Pollen Flora II-V. Amsterdam.

R Core Team (2015). R: A language and environment for statistical computing. Wien. https://www.R-project.org/.

Reimer, P. / Bard, E. / Bayliss, A. et al. (2013). Intcal13 and Marine13 radiocarbon age calibration curves 0-50,000 years cal BP. In: Radiocarbon 55, 1869-1887.

Renner-Aschwanden, F. (2014). Landschafts- und Waldgeschichte des Urserntals. In: Historisches Neujahrsblatt Uri N.F. 68, 11-36.

Scheuchzer, J.J. (1716). Helvetiae Stocheiographia, Orographia et Oreographia. Zürich (deutsche Übersetzung: Sulzer, J.G. (1746). Natur-Historie des Schweitzerlandes. Zürich.

Sidler, C. (2001). Spätglaziale und holozäne Vegetationsgeschichte des Bödmerenwaldes, Gemeinde Muotathal/SZ (Pollenanalyse). In: Berichte der Schwyzerischen Naturforschenden Gesellschaft (Urwaldreservat Bödmeren) 13, 51-64.

Stockmarr, J. (1971). Tablets with Spores used in absolute pollen analysis. In: Pollen et Spores 13, 615-621.

Synal, H.-A. / Stocker, M. / Suter, M. (2007). MICADAS: a new compact radiocarbon AMS system. In: Nuclear Instruments and Methods in Physics Research Section B: Beam Interactions with Materials and Atoms 259, 7-13. 
Van der Knaap, W.O. / Van Leeuwen, J.F.N. / Fankhauser, A. et al. (2000). Palynostratigraphy of the last centuries in Switzerland based on 23 lake and mire deposits: chronostratigraphic pollen markers, regional patterns, and local histories. In: Review of Palaeobotany and Palynology 108, 85-142.

Van der Knaap, W.O. / Van Leeuwen, J.F.N. / Finsinger, W. et al. (2005). Migration and population expansion of Abies, Fagus, Picea, and Quercus since 15000 years in and across the Alps, based on pollen percentage threshold values. In: Quaternary Science Reviews 24, 645-680.

Van der Knaap, W.O. / Van Leeuwen, J.F.N. / Sperisen, C. (2005). Vegetationsgeschichte des Bödmerenwaldes. In: Stiftung Urwald-Reservat Bödmeren (Hrsg.). Urwaldcharakteristiken des Bödmerenwaldes. Lenzburg, 69-93.

Van Geel, B. (1978). A palaeoecological study of Holocene peat bog sections in Germany and The Netherlands, based on the analysis of pollen, spores and macro- and microscopic remains of fungi, algae, cormophytes and animals. In: Review of Palaeobotany and Palynology 1/25, 1-120.

Van Geel, B. (2001). Non-pollen palynomorphs. In: Smol, J. / Birks, H.J.B. / Last, W. (Hrsg.). Tracking environmental change using lake sediments. Vol. 3: Terrestrial, algal and silicaceous indicators. Dortrecht, 99-109.

Zoller, H. / Haas, J.N. (1995). War Mitteleuropa ursprünglich eine halboffene Weidelandschaft oder von geschlossenen Wäldern bedeckt? In: Schweizerische Zeitschrift für Forstwesen 146, 321-354. 

Archäologie in Attinghausen 


\section{Summary: Settlement archaeology in Canton Uri - Catalogue of the municipality of Attinghausen.}

Between 2009 and 2015 deserted settlements throughout Canton Uri were systematically catalogued with the aim of researching the Alpine region from the points of view of archaeology and architectural heritage and in order to extend our knowledge of the settlement development and architectural typology of past eras. The fieldwork began throughout the entire canton under the leadership of Marion Sauter and Walter Imhof. The surveys were carried out with help from students from the Lucerne School of Engineering and Architecture. The numerous deserted buildings and infrastructures were documented and gathered in a database using digital photographs, GPS coordinates, sketches and brief descriptions. The efforts soon began to focus on the municipality of Attinghausen amongst others, which offers a good basis for research because of its Alpine pass, wide-ranging alp levels and ruined castle. The study summarises the history of Attinghausen, outlines the areas of former settlement along the Surenen Pass trail that have yielded the most numerous finds and presents the most important types of architecture found in the area. The buildings range from very small structures to Alpine huts, which were apparently still in use up to the $20^{\text {th }}$ century. A number of former pens were also found, as were areas of meadowland which were once used to harvest hay and had therefore been fenced off to create the so-called "Heurütenen", and so-called "Tristbetten", stone settings that served as substructures for stacks of wild hay. Mountain farming families, having lived in the area for several generations, proved a valuable source of information for the researchers. The entire list of deserted buildings in the municipality of Attinghausen is attached in the form of a table at the end of the study. 


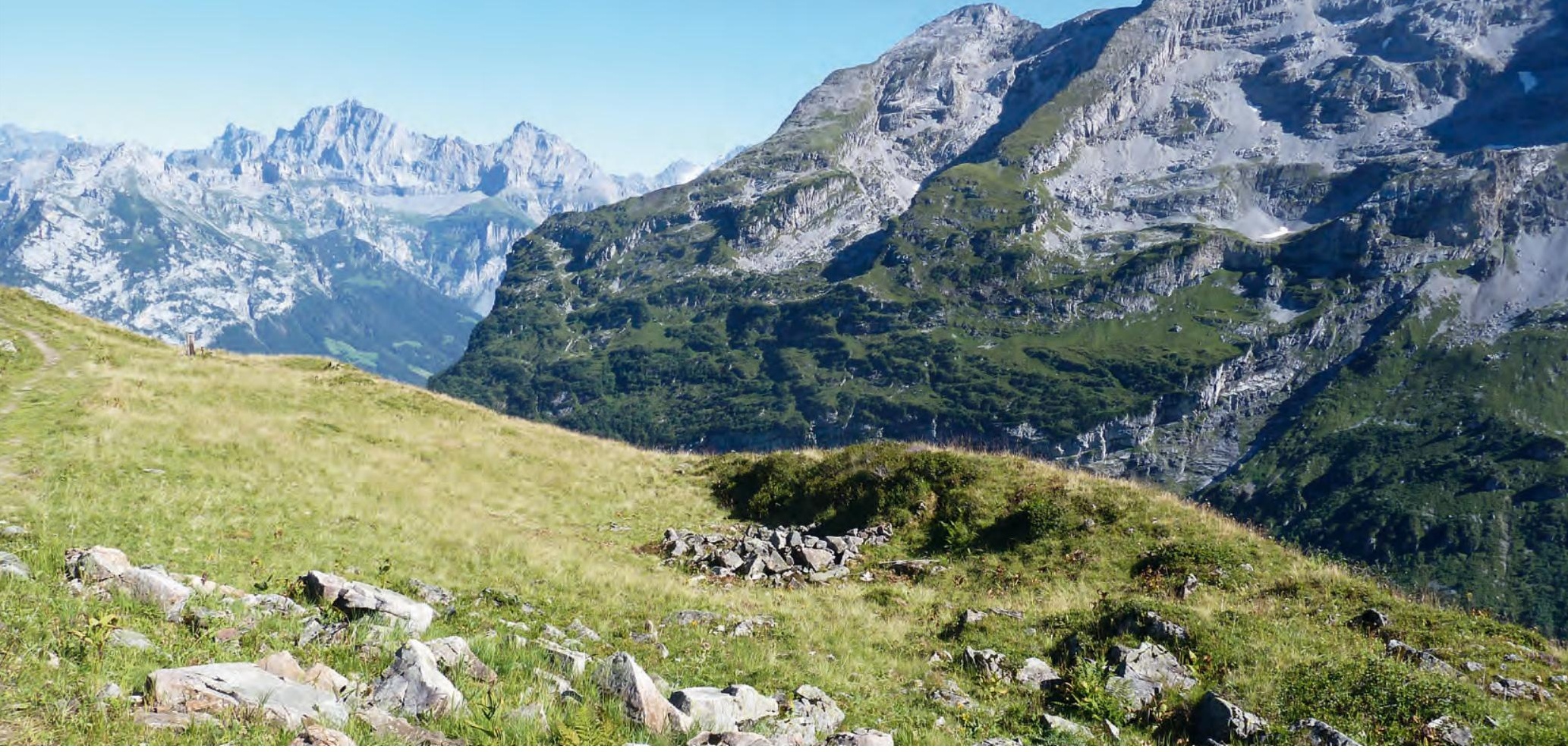

\section{Wüstungsforschung im Kanton Uri - Katalog der Gemeinde Attinghausen}

Die Urner Wüstungsforschung hat sich zum Ziel gesetzt, den Alpenraum archäologisch und bauhistorisch zu erforschen und damit die Kenntnisse um die Siedlungsentwicklung vergangener Epochen zu erweitern. Die Feldforschung startete im ganzen Kanton, schon bald folgte eine Fokussierung - vor allem auf die Gemeinde Attinghausen, die mit einem seit der Bronzezeit genutzten Passübergang, weitläufigen Alpstafeln und einer Burgruine gute Forschungsgrundlagen bietet.

\section{Wüstungsforschung im Kanton Uri}

Auf Anregung und mit unermüdlicher Unterstützung des Muotathaler Speläologen Walter Imhof startete die Urner Denkmalinventarisation im Jahr 2008 mit der systematischen Wüstungsforschung, die sich im Kanton Uri bis dahin auf die archäologische Grabung in Hospental-Blumenhütte im Jahr 1983 durch Werner Meyer und Jakob Obrecht sowie einige Zufallsfunde in der näheren Umgebung beschränkt hatte.

Wüstungen - im Alpenraum sind dies meist Überreste von Schutz- oder Alphütten, Ställen und Speichern, aber auch Infrastrukturen oder von Menschen aufgesuchte Höhlen und Balmen - werden im Rahmen von Prospektionskampagnen inventarisiert und dokumentiert. Der gezielten Geländebegehung gehen Luftbild- und Landeskartenanalysen sowie Literatur- und Archivrecherchen voraus. Die Prospektionskampagnen finden im Idealfall Unterstützung durch ein Netzwerk von Gewährsleuten (= oral history). Herzlicher Dank gebührt hier deshalb vor allem Werner Arnold, Alois Gisler ( $\dagger$ ), Benno Furrer, Familie Martin Furrer, den Familien Max und René Herger, Kari Kempf, Karl Marty ( $t$ ), Joseph Muheim, Kari Muheim, den Familien Leo und Felix Püntener, Walter Renggli, Julius Stadler, Rosemarie Stampfli, Luzia Walker, Toni Walker und Thomas Ziegler.

Die so gewonnenen Erkenntnisse zur Siedlungstätigkeit vergangener 
die damit zusammenhängende Vegetations- und Klimaentwicklung, die in weiterführenden, interdisziplinären Untersuchungen Bestätigung und/ oder Ergänzung finden können ( $\rightarrow$ S. 24-45). Es sind Erkenntnisse, die sich nur in seltenen Fällen archivalisch niedergeschlagen haben und somit die Geschichtsforschung enorm bereichern.

\section{Prospektion mit Studierenden}

Schnell wurde klar, dass für die Prospektion in den weitläufigen Arealen grössere Forscherteams erforderlich sind. Diese konnten - freiwillig - unter den Studierenden der Hochschule Luzern - Technik \& Architektur gewonnen werden. Anfänglich betrachtete die archäologische Fachwelt das Engagement der zukünftigen Architekten recht skeptisch. Es stellte sich jedoch heraus, dass die Studierenden sehr schnell ein gutes Gespür für geeignete Ortslagen und günstige Rahmenbedingungen entwickelten und so zahllose bauliche Überreste dokumentieren konnten.

Das alpine Gelände ist geneigt, die winterlichen Schneelasten sind enorm: In der Regel wurden deshalb kleine, eingetiefte Steinbauten errichtet, die sich in die Falllinie des Hangs ducken oder sich an schützende Felsblöcke schmiegen. Verbaut wurde Trockenmauerwerk und wenig Holz, vor allem in den Arealen, die deutlich oberhalb der Waldgrenze liegen. Neben Steinplatten ist von Schindeldachdeckungen, bei peripheren Schutzhütten möglicherweise jedoch lediglich von einem temporären Regenschutz aus Ästen und/oder Viehhäuten auszugehen. Die Materialisierung und die Konstruktion der Alphütten veranschaulichten eindrucksvoll einfachste, aber solide Bauweisen, die gänzlich ohne die Inanspruchnahme technischer Hilfsmittel entstanden sind. ${ }^{2}$ Die Kampagnen brachten den Studierenden somit wertvolle Erfahrungen zu vernakulären Bauweisen - bewegen sich ihre eigenen Projekte doch stets in definierten Baufenstern auf vorgegebenem Baugrund und entsprechen höchsten technischen Ausbaustandards.

Eine erste mehrtägige Prospektionskampagne führte 2009 in die Gemeinden Unterschächen und Spiringen, eine zweite auf das Haldi, das auf Schattdorfer und Bürgler Gemeindegebiet liegt, und eine dritte auf den

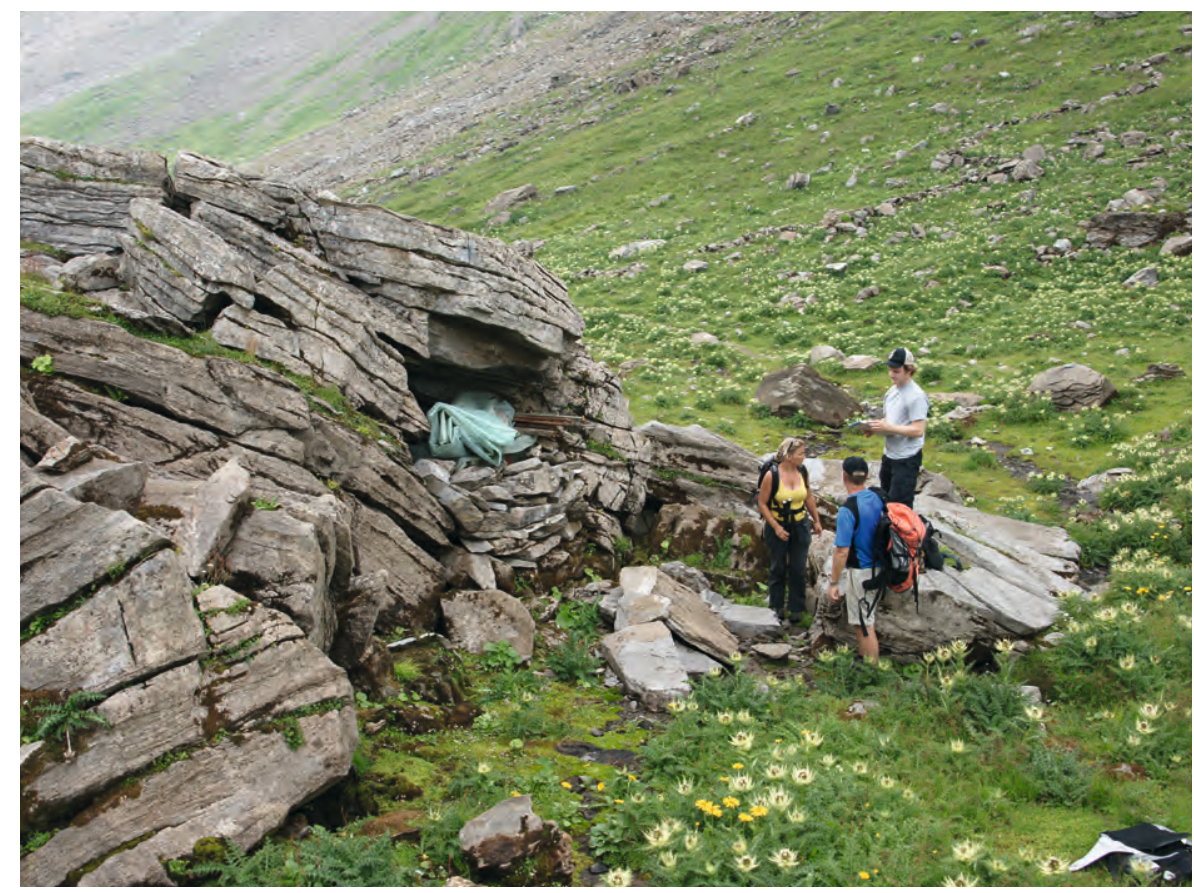

2 Vgl. Furrer 2015.

Titelbild: At.044

Hüttli am Surenenpassweg (Übersicht)

Attinghausen-Geissrüggen

LK 1191 - 687 527/188 646

$1894 \mathrm{~m}$ ü.M.

3,3 x 3,9 m

Foto M. Sauter, 2012

At.036

Kühlkeller (Ansicht)

Attinghausen-Brunnifurggi

LK 1191 - 685 464/188 465

$2030 \mathrm{~m}$ ü.M.

$2 \times 1,3 \mathrm{~m}$

Foto T. Künzle, 2009 


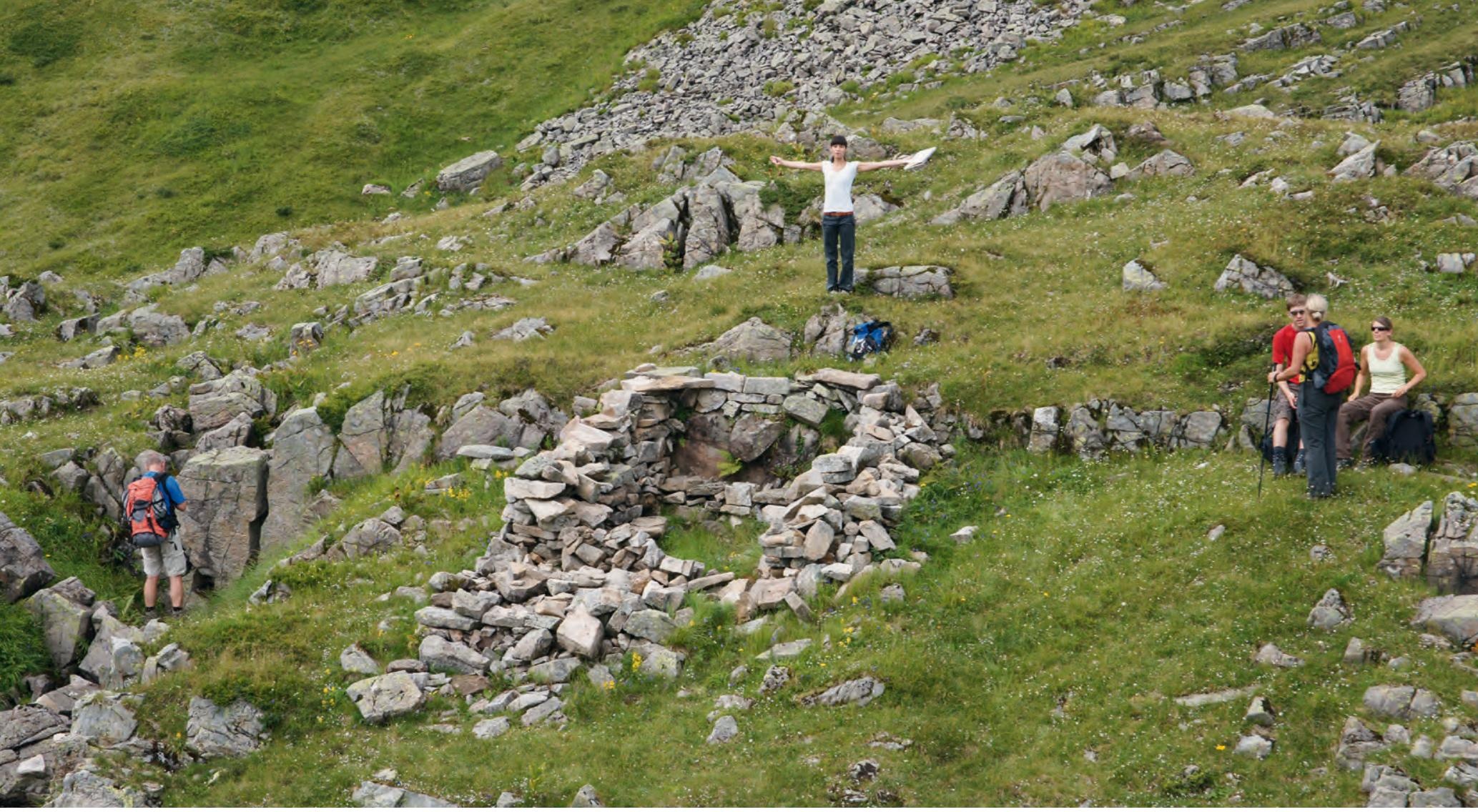

At.046

Zweiräumiges Hüttli (Ansicht)

Attinghausen-Nussfruttli

LK 1191 - 685 975/188 693

$1947 \mathrm{~m}$ ü.M.

4,7 x 3,5 m

Foto T. Künzle, 2009
3 Sauter 2009. - Sauter 2010. - Sauter 2011.
Attinghauser Surenenpass. 2010 konnten dann der Zingel auf dem Urnerboden und Teile Urserns in Augenschein genommen werden. Insgesamt nahmen 28 Studierende an den Prospektionskampagnen teil, einige davon mehrfach, sogar über ihre Bachelorstudienzeit hinaus. Die Prospektionsteams fanden ausserdem durch Arbeitskollegen der berufsbegleitend Studierenden Unterstützung. Euch allen, vor allem einmal mehr Walter Imhof, der auch einige Prospektionskampagnen begleitet hat, sei für das grosse Engagement sehr herzlich gedankt! Wie schon die Kampagnen - Kost und Logis - finanzierte der Kanton Uri freundlicherweise auch den anschliessenden Druck der kleinen Dokumentationen, die Interessierten einen ersten Einblick in die archäologische Feldforschung bieten und sich als wertvolles Mittel für die Öffentlichkeitsarbeit erwiesen haben. ${ }^{3}$

PROSPEKTIONSTEAM UNTERSCHÄCHEN/SPIRINGEN 2009: Tobias Ammann, Fabian Brunner, Dominik Frey, Barbara Häfliger, Martin Janser, Simon Jauch, Miriam Landwehr, Nicole Lipp, Lea Riechsteiner, Lukas Sager, Evelyne Tejada und Samuel Vyletal. PROSPEKTIONSTEAM HALDI 2009: Liwen Gehrig, Thomas Gugger, Michael Hurni, Marco Knüsel und Tommaso Pace.

PROSPEKTIONSTEAM ATTINGHAUSEN 2009: Franziska Flückiger, Kevin Jans, Tobias Künzle, Stephanie Osusky und Patrizio Welti.

PROSPEKTIONSTEAM ZINGEL (URNERBODEN) 2010: Simone Dania Schmid-Traber und Aldo Schmid (Studienarbeit).

PROSPEKTIONSTEAM URSERN 2010: Franziska Flückiger, Kevin Jans, Seline Koch, Tobias Künzle, Stephanie Osusky und Severin Walpen sowie Caudia Mühlebach und Claudio Waser.

LUFTAUFNAHMETEAM ATTINGHAUSEN 2012: Franziska Flückiger, Markus Käch, Severin Walpen sowie Andreas Heierle und Cristina Trofin. Die Messpunkte lieferte ProSpect GmbH, Aarau: Brigitte Andres, Christian Auf der Maur und Georg Matter. PROSPEKTIONSTEAM ATTINGHAUSEN 2013: Valentin Hobi und Matthias Elmiger (inkl. Grabungsassistenz). 


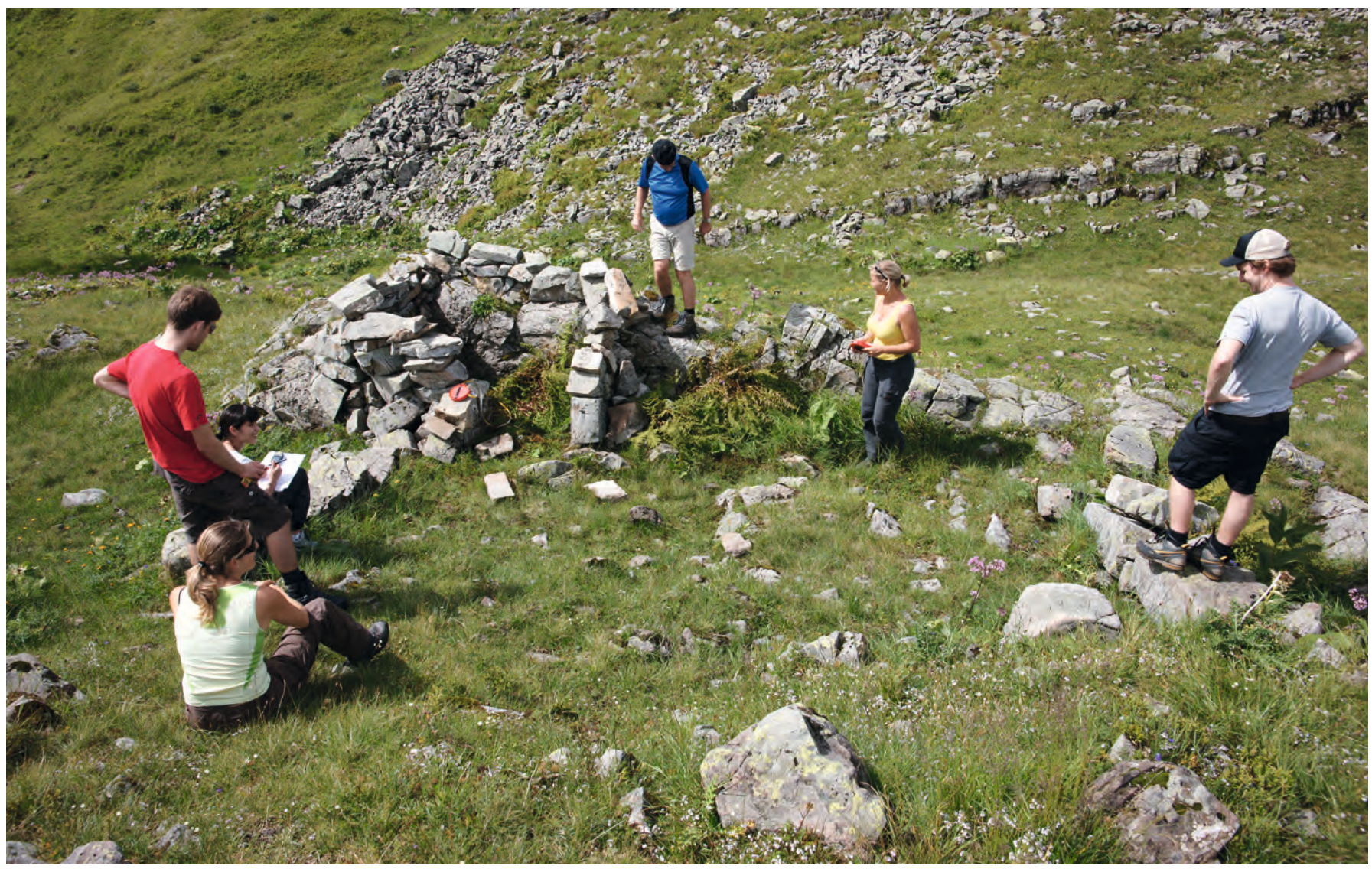

\section{Dokumentation}

Der Forschungsstand zum derzeitigen Projektende der Urner Wüstungsforschung ist ein über 700 Objekte umfassendes Inventar. Es beinhaltet im kollegialen Austausch auch sämtliche Daten der Ostschweizer Gesellschaft für Höhlenforschung (OGH), die zusammen mit Kollegen der Arbeitsgemeinschaft Höllochforschung (AGH) in den letzten Jahren mehrere Urner Höhlen vermessen und untersucht hat $(\rightarrow$ S. 82-101). Auch den Speläologen Dieter Betschart, Dominik Imhof, Walter Imhof, René Scherrer und Franz Suter sei an dieser Stelle natürlich sehr herzlich gedankt!

Ein Wüstungsinventar ist niemals vollständig, auch nicht der Katalog von Attinghausen. Bewuchs, Sediment und manchmal auch Überbauungen sorgen dafür, dass die Spuren vielerorts schwierig zu finden oder leicht zu übersehen sind. Schlussendlich waren auch die zeitlichen Ressourcen begrenzt.

Aufgrund der Vielzahl an Fundstellen im Kanton Uri war das Hauptziel, eine Übersicht über den Bestand zu gewinnen. Die einzelnen Fundstellen sind mit Fotos, GPS-Koordinaten, einfachen Skizzen und Kurzbeschreibungen in einer Datenbank erfasst, die im Staatsarchiv Uri Altdorf geführt wird. Die Fundorte wurden häufig individuell bezeichnet: "Dornröschenschloss" (At.055) beschreibt etwa einen ungewöhnlich runden, vollständig mit Alpenrosen überwachsenen Bau. "Ginger City" (At.104) würdigt den das Archäologenteam stets treu begleitenden Hund einer Hüttenwirtin und "Katzenburg" (At.003) verweist auf die heutigen Bewohner einer Wüstung. Zumindest für die Beteiligten lassen sich die vielen Hundert Hüttli so gut unterscheiden.

Für den nächsten Schritt, die Erstellung erster Übersichtspläne und massstäblicher Grundrisse, wurde die Luftaufnahme gewählt. Die beschei-
At.047

Hüttli mit Sitzstein und Pferch?

(Übersicht)

Attinghausen-Nussfruttli

LK 1191 - 685 967/188 699

$1950 \mathrm{~m}$ ü.M.

1,7 x 2,4 m / 5,7 x 4,7 (Pferch?)

Foto T. Künzle, 2009 


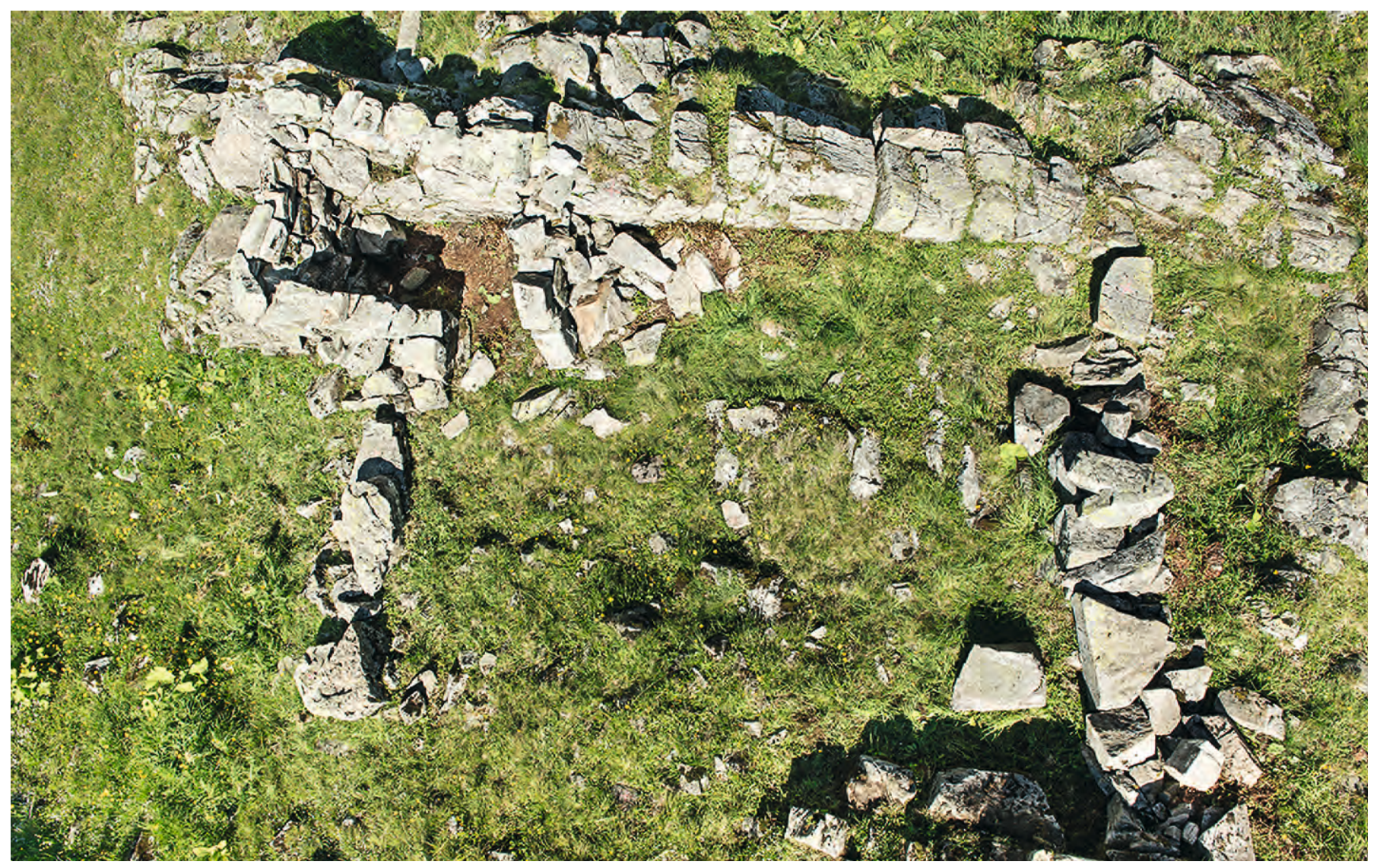

Dieselbe Wüstung (At.047), fotografiert mit dem Teleskopstativ. Die entzerrte Luftaufnahme entspricht einem steingerecht gezeichneten Grundriss. Foto M. Käch, S. Walpen, 2012 denen Mittel erlaubten im Jahr 2010 noch nicht den Einsatz der heute etablierten Drohnen. Stattdessen konstruierten Fotodozent Markus Käch und Severin Walpen in der Abteilung Architektur der Hochschule Luzern ein Teleskopstativ, das nach einem überraschenden Schneeeinbruch Ende August 2011 jedoch erst im Folgejahr zum Einsatz kam. Mit einer Nikon D800 (Nikkor 24-70 mm) und einer Canon EOS 5D Mark II (Canon 17-40 mm) wurden sämtliche Wüstungen auf dem Attinghauser Grat dokumentiert, nachdem sie vollständig vom Bewuchs befreit worden waren und damit bereits erste neue Erkenntnisse geliefert hatten. Die entzerrten Luftaufnahmen bildeten eine wertvolle Plangrundlage für die Grabung am Geissrüggen im Sommer 2013 ( $\rightarrow$ S. 122-135). Markus Käch und Severin Walpen unterstützten das Forschungsprojekt bis zur Drucklegung - ein grosses Dankeschön geht somit last but not least nach Luzern!

Schwierig gestaltet sich in der Regel die augenscheinliche Interpretation der ehemaligen Funktion der vielfältigen Steinsetzungen. Zuerst muss die vorherrschende Wirtschaftsweise - Einzelalpung oder genossenschaftliche Strukturen, Milch- oder Viehwirtschaft - analysiert werden. Ehemalige Kühlkeller können ob ihrer schattigen Lage, ehemalige Pferche ob ihres meist rudimentären Mauerverbands spezifiziert werden. In der Neuzeit etablierten sich zunehmend gedeckte Ställe, deren Mauerreste sich nicht wesentlich von denen einer Alphütte unterscheiden. Anhaltspunkte geben hier allenfalls die Dimension oder die Einbauten, etwa Wandnischen (= Wohnräume) oder Lager (= Ställe).

Warum jedoch wurden die Bauten aufgegeben? Hier finden sich grundlegende Zäsuren, etwa Strukturwandel in der Land- und Alpwirtschaft, der Übergang von der dominierenden Schmalviehhaltung (Schafe, Ziegen) zur vermehrten Rindvieh- und Pferdehaltung um 1300 oder zur Einrichtung von 
dezidierten Rinder- und Schafhirten auf peripheren Alpweiden im 16. bis 18. Jahrhundert $\left(\Rightarrow\right.$ S. 184-201). ${ }^{4}$ Aber auch einzelne Betriebe durchliefen Entwicklungsprozesse, die eine Anpassung der Wohn- und Wirtschaftsbauten nach sich zogen, zuletzt meist bedingt durch Infrastrukturmassnahmen wie etwa den Bau von (Transport-)Seilbahnen. Auch die klimatischen Verhältnisse, etwa die Kaltphasen der Kleinen Eiszeit, oder lokale Naturkatastrophen wie Lawinenabgänge oder Steinschläge sind zu berücksichtigen.

Die folgenden Ausführungen ergänzen die Dokumentation von $2009^{5}$ und erläutern einige exemplarische Bautypen. Der aktuelle Stand des Attinghauser Wüstungsinventars - 88 Objekte - ist tabellarisch angefügt und aufgrund der Surenen-Thematik dieses Bands um die Erstfelder Fundorte auf der Alp Waldnacht ergänzt. Die Fundorte der archäologischen Forschungskampagne 2014 - 30 Wüstungen auf Surenen ( $\Rightarrow$ S. 184-201) sowie die Höhlen und Balmen auf dem Gebiet der Gemeinde Attinghausen $\Leftrightarrow$ S. 82-101) sind separat beschrieben.

\section{Attinghausen}

Die Gemeinde Attinghausen umfasst $47 \mathrm{~km}^{2}$, liegt am linken Ufer der Reuss und hat ihren Schwerpunkt im Mündungsgebiet des Kummetbachs auf $468 \mathrm{~m}$ ü.M. Dieser teilt die Gemeinde in ein sogenanntes Herrschaftszentrum im Norden und in einen bäuerlichen Dorfkern im Süden des Bachlaufs. Mehr als die Hälfte des Gemeindegebiets entfällt auf die weitläufigen Alpweiden jenseits des Surenenpasses auf 2291 m ü.M.

Der 1210 erstmals überlieferte Begriff Suranum ${ }^{6}$ ist keltischen Ursprungs und deckt sich mit der Zeitstellung des ältesten archäologischen Streufunds. Als Suranum bezeichnete man ursprünglich lediglich einen Bach (heute: Stierenbach bzw. Engelberger Aa), um 1300 wurde der Begriff auf das gesamte Alpgebiet jenseits der Wasserscheide übertragen. ${ }^{7}$ Attinghausen findet erstmals im Jahr 1240 Erwähnung. ${ }^{8}$ Die Ortsbezeichnung, welche den althochdeutschen Rufnamen Atto beinhaltet, deutet jedoch auf eine
4 Stadler-Planzer 2013, 17-18.

5 Sauter 2009, 56-81.

6 Schiess 1933, 109-110.

7 Stadler-Planzer 1993, 24.

8 Schiess 1933, 195.
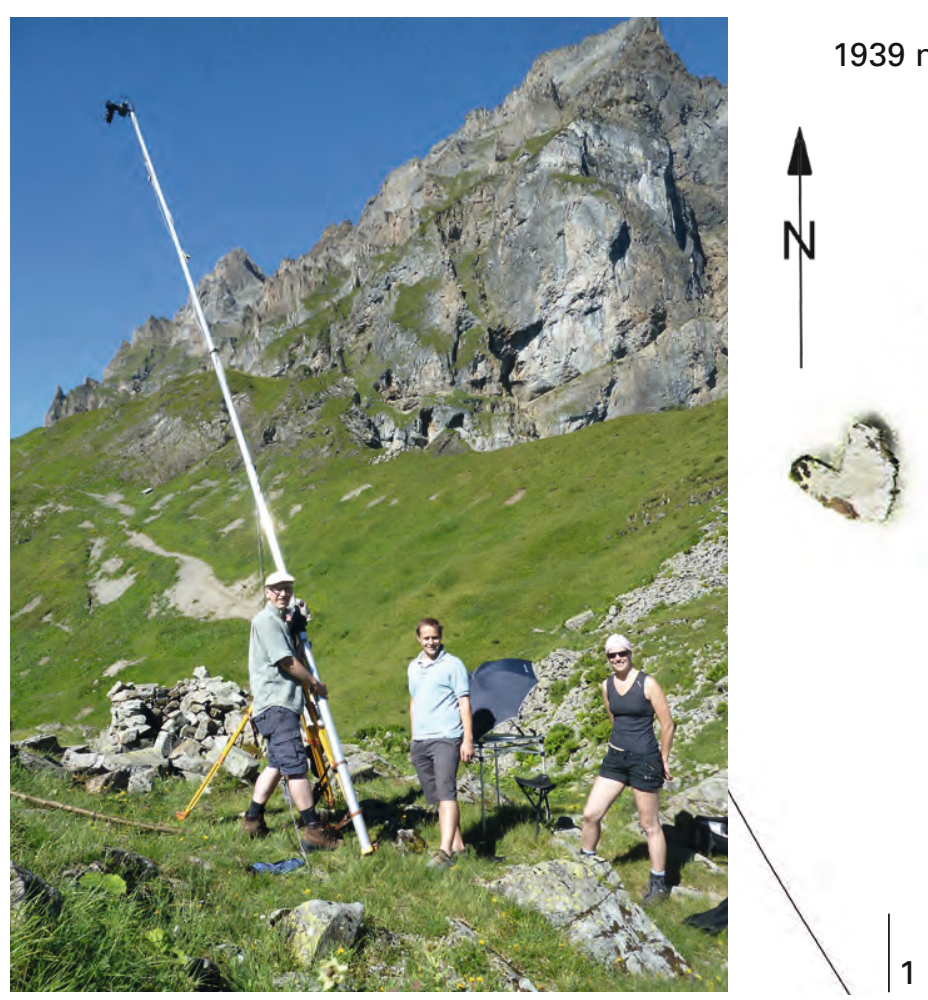

Das Teleskopteam der Hochschule Luzern - Technik \& Architektur im Einsatz am Surenenpass.

Foto M. Sauter, 2012 
9 Gasser 1979.

10 Lehner 1983. - Meyer/Obrecht/ Schneider 1984, 37-62.

11 Stadler-Planzer 1993, 68-75.

12 Sauter 2017 (im Druck).

Entzerrte und digital vom Bewuchs befreite Teleskopaufnahmen:

At.048

Mehrräumige Anlage (Aufsicht)

Attinghausen-Nussfruttli

LK 1191 - 685 956/188 792

$1940 \mathrm{~m}$ ü.M.

$1,7 \times 2,5 \mathrm{~m}$ (Hauptraum)

At.049

Farnhüttli (Aufsicht)

Attinghausen-Nussfruttli

LK 1191 - 685 950/188 703

$1939 \mathrm{~m}$ ü.M.

2,6 $63 \mathrm{~m}$

At.046

Zweiräumiges Hüttli (Aufsicht)

Attinghausen-Nussfruttli

LK 1191 - 685 975/188 693

$1947 \mathrm{~m}$ ü.M.

$4,7 \times 3,5 \mathrm{~m}$

Bearbeitete Fotos M. Käch, S. Walpen, 2012 deutlich frühere Gründung hin: Verbindungen mit der Endung «inghausen» tauchen im Gegensatz zu den «ingen»-Bildungen in der Schweiz ausgesprochen selten auf und werden von der Etymologie dem 7. oder 8. Jahrhundert zugeordnet. $^{9}$

Spätestens ab dem frühen 12. Jahrhundert erhoben sich bei der Siedlung Attinghausen eine Kapelle und eine Burg - die grösste Festungsanlage im Kanton Uri ( $\Rightarrow$ S. 66-79). ${ }^{10}$ Zeitgleich nahmen die Urner wohl auch das jenseits der Passhöhe gelegene Surenen als Alpweide in ihren Besitz. Die Notwendigkeit, tiefer gelegene Schneefluchtareale zu unterhalten sowie Bau- und Brennholz zu gewinnen, stand dem Bestreben entgegen, den Besitz des 1120 gegründeten Benediktinerklosters Engelberg weiter auszudehnen. Daraus resultierte ein zäher Konflikt mit den Klöstern Engelberg und Muri, die das Areal um die Fürenalp beanspruchten. Schiedssprüche folgten in den Jahren 1275, 1309, 1320 und 1471. Erst ein Abkommen im Jahr 1513, das von einem Gebietsabtausch begleitet war, brachte eine Einigung. ${ }^{11}$ Die Dokumente zu den Gebietsstreitigkeiten gehören zu den frühesten schriftlichen Zeugnissen über die Alpnutzung auf Surenen, die mittelalterlichen Zinsrodel beziehen sich in der Regel auf die deutlich tiefer gelegenen Hauptbetriebe.

Mit den Freiherren von Attinghausen rückte Attinghausen für einige Dekaden in den Fokus der (Inner-)Schweizer Politik. Die Ära endete mit dem Tod des Johannes von Attinghausen um 1358/59. Da zwischenzeitlich auch der Flüeler Hafen die ältere Seedorfer Anlage abgelöst und sich die Gotthardroute am rechten Reussufer etabliert hatte, verlor Attinghausen zunehmend an Bedeutung. Die Gründung des Kapuzinerinnenklosters Maria zu allen Engeln im Jahr 1608 bildet einen der letzten Höhepunkte der Dorfgeschichte. Nach einem Brand im Jahr 1676 wurde das Kloster nach Altdorf verlegt. Mangels grösserer Flächen in der Reussebene partizipierte Attinghausen kaum an der Industrialisierung und ist bis heute landwirtschaftlich beziehungsweise als Wohnsiedlung geprägt. ${ }^{12}$

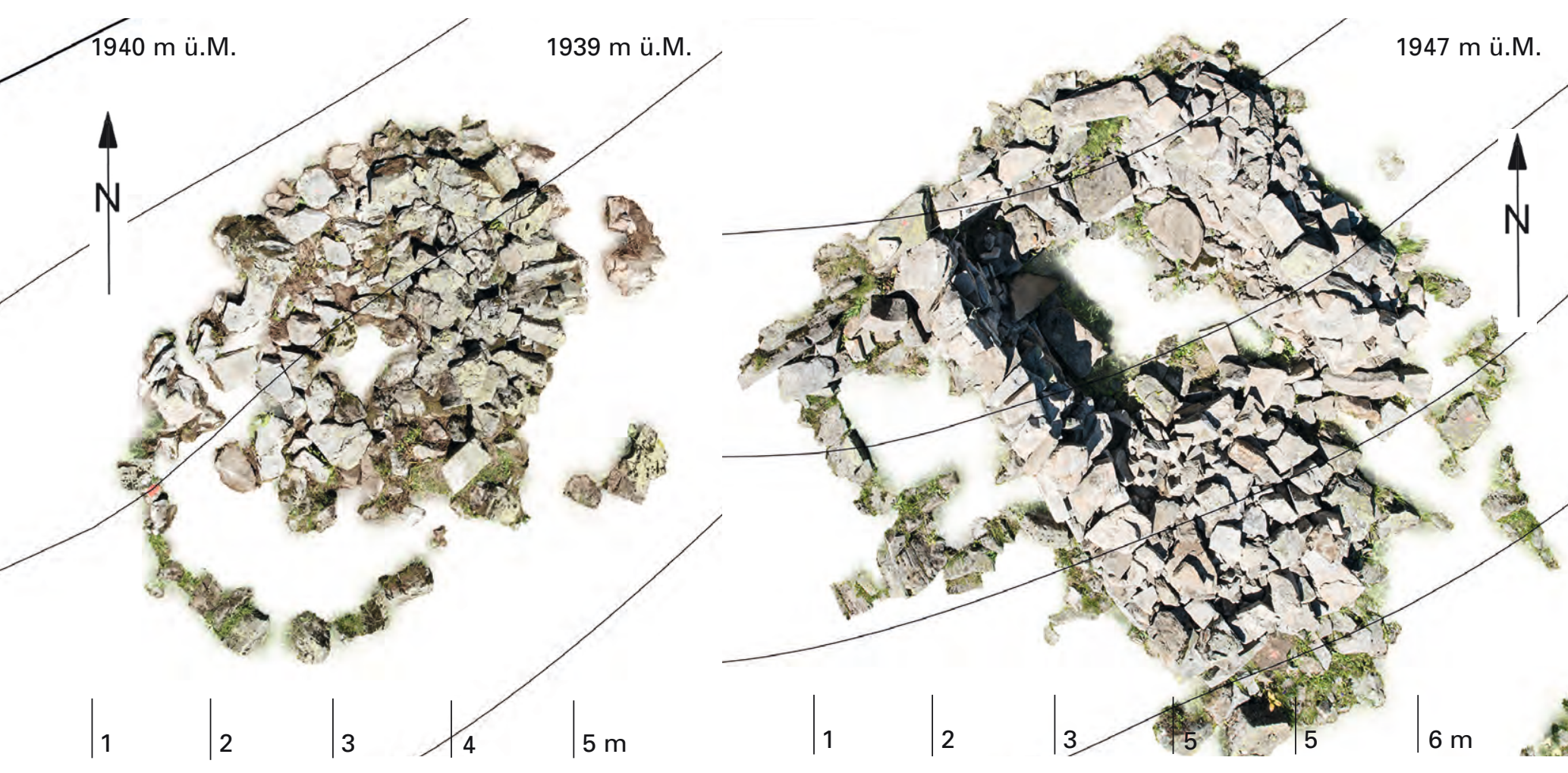




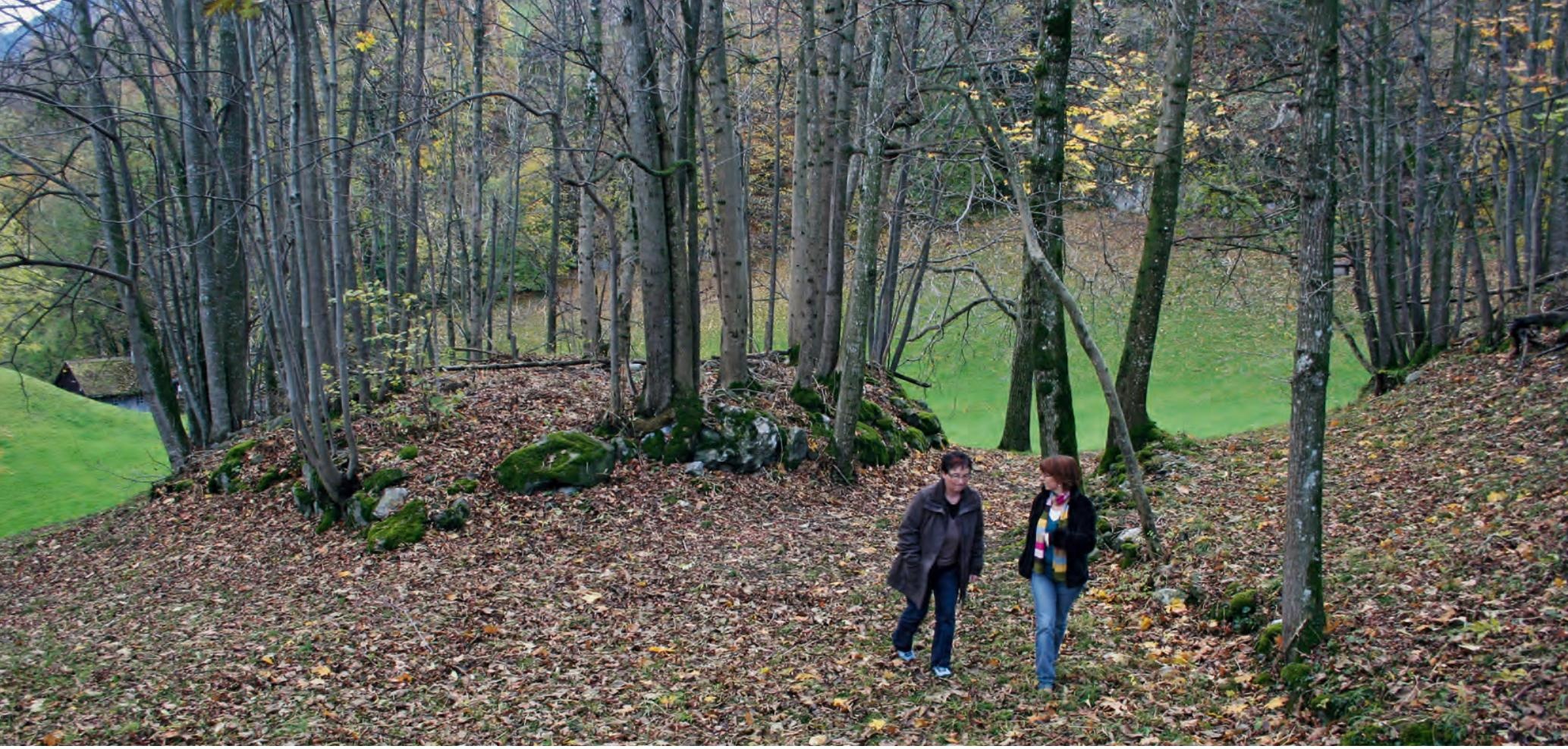

\section{Talacher - Tschingel - Mettlen (500 bis 700 m ü.M.)}

Die Streusiedlung Attinghausen zieht sich südlich des Kummetbachs über die Flure Langacher, Tschingel und Mettlen den Hang hinauf. Das Areal wird vom Surenenpassweg, dem Streckenabschnitt Mettlengasse ${ }^{13}$, durchzogen und vom ehemaligen Hochweg gequert. Der eingeebnete, einst $11 \times 10$ m (Aussenmass) ${ }^{14}$ umfassende Turm im Schatzbödeli (heute: Areal der Pferdestallungen Islern) stand im Zusammenhang mit der historischen Hauptverkehrsachse in Richtung Süden ( $\rightarrow$ S. 102-121).

Die Wüstungsforschung bewegt sich aufgrund der Erfahrungswerte zur Zahl der Fundstellen und der Übersichtlichkeit halber in der Regel im (sub-) alpinen, waldfreien Gelände. Dem Hinweis von Luzia Walker ist es zu verdanken, dass im Bereich des Langachers, in der kultivierten und stark bewachsenen montanen Geländestufe, eine äusserst interessante Wüstung dokumentiert werden konnte: Ein Geländesporn auf $580 \mathrm{~m}$ ü.M. mit Blick auf die Reussebene ist mit einer Trockenmauer aus groben Steinbrocken gefasst. Die Bezeichnung "Magischer Ort» durch die Gewährsfrau bildet die hügelige Lage und den wilden Baumbewuchs dieser Wüstung gut ab. Eine weiter gehende Untersuchung wird durch das Wurzelwerk erschwert, das Mauerreste im Inneren der Einfassung - falls vorhanden - gesprengt haben dürfte. Über den Zweck der baulichen Fassung einer Kuppe kann bislang nur spekuliert werden. Eine ähnliche Situation findet sich auch auf Blacken $(\rightarrow$ S. 192-194). Für einen Pferch scheint die erhöhte Lage ungeeignet. Vorstellbar wäre die Einfassung eines Aussichtspostens - ein möglicher weiterer Beleg für die Sicherung der über den Hochweg führenden ehemaligen Hautverkehrsachse. In kurzer Distanz ist das hügelige Gelände mit einer weiteren Bastion versehen.

\section{Waldnachter Berge - Waldnacht (1414 m ü.M.)}

Die Waldnachter Berge markieren ohne grosse Höhendifferenz den Übergang von der Ganzjahres- beziehungsweise Maiensässsiedlung hin zur Alp. Die Alp Waldnacht öffnet sich in einem weiten, ost-west-orientierten Taleinschnitt. Sie gehört zu den wenigen Eigenalpen im Kanton Uri, ihre Geschichte lässt sich bis zu einem Marchbrief aus dem Jahr 1457 zurück-
At.076

"Magischer Ort" (Ansicht)

Attinghausen-Talacher

LK 1192 - $690805 / 190080$

$525 \mathrm{~m}$ ü.M.

Foto M. Sauter, 2009
13 Mettlengasse: IVS UR 1998, 290.1.1 (inkl.Beschrieb).

14 Grundrissskizze und Beschreibung von A. Regli-Nager, 1956 (Eidgenössisches Archiv für Denkmalpflege, 69550). 
15 Hug/Weibel 1990, 899-900. - Eine ausführliche Aufstellung aller Quellen findet sich bei Furrer/Furrer 2000, 42-43.

16 Furrer/Furrer 2000, 148.

17 Gasser 1979.

18 Freundl. Hinweis von Martin Furrer. Historische Fotos vgl. Furrer/Furrer 2000.

19 Obrecht 1999, 9. - Püntener 1908. verfolgen. ${ }^{15}$ Die Waldnacht wird vom Angibach durchquert, der die Grenze zwischen den Gemeinden Erstfeld und Attinghausen markiert. Eine gravierende topografische Veränderung stellt die Einrichtung eines Ausgleichbeckens für das Wasserkraftwerk Bocki II im Jahr 1970 dar. ${ }^{16}$

Es ist davon auszugehen, dass die Waldnacht im Mittelalter sechs bis zehn Betriebe umfasste. Im Lauf der Jahrhunderte besassen verschiedene Familien und Institutionen Alprechte auf Waldnacht, unter anderem auch das Attinghauser Kapuzinerinnenkloster. ${ }^{17}$ Die geringe Zahl der vorgefundenen Wüstungen spiegelt dies jedoch nicht mehr wider - nach dem grossen Unwetter von 1910 erfolgte ein subventioniertes Abräumungsprojekt der Trümmer und Ruinen.

Seit Menschengedenken wird die Alp Waldnacht von drei Betrieben, der Langen Hütte, der Grossen Hütte und der Hinteren Hütte, genutzt. Die auf 1523 m ü.M. liegende Krähenalp wurde 1944 ausgeschieden. Von 1972 bis 2015 wurde die gesamte Milch der Waldnachter Alpbetriebe in der Langen Hütte verarbeitet. In den Folgejahren wurden die historischen, teilweise aus dem Spätmittelalter datierenden Alphütten erneuert, die Vorgängerbauten überbaut. Erhalten haben sich lediglich die drei zugehörigen Käsespeicher unweit der Bachhütte. Sämtliche historischen Gebäude waren/sind Blockbauten, obwohl die Waldnacht seit mehreren Hundert Jahren waldlos ist. Das Bauholz stammte aus den Waldnachter Bergen. ${ }^{18}$

Die Hintere Hütte ist um eine grosse Einfassung aus Steinbrocken ergänzt. Derartige Einfassungen wurden ursprünglich als Wiesland und werden heute häufig als Abendweide genutzt. Sie finden sich im Kanton Uri mehrfach. Eingefasst waren/sind nicht die Viehherden, sondern die zur Heugewinnung genutzten Matten, Heurütenen genannt. Die beiden wohl bekanntesten Heurütenen befinden sich auf der Unterschächener Sittlisalp - es sind zugleich die einzigen, die in der digitalen Landeskarte (swisstopo) verzeichnet sind. Abendweiden ersparen dem Vieh die weiten Wege zwischen dem morgendlichen und dem abendlichen Melken, haben sich - wie auch die Trennung von Milchkühen und Jungvieh auf den Weiden - jedoch erst in jüngerer Zeit als Rationalisierungsmassnahme etabliert.

Seit dem 15. und 16. Jahrhundert werden zunehmend gedeckte Ställe errichtet, mit einiger Verzögerung auch auf den Alpstafeln. Der Alpinspektionsbericht von 1908 mahnt hier fast durchgehend Verbesserungen an. ${ }^{19}$ Zuvor wurde das Vieh über Nacht eingepfercht - zu gross war die Gefahr seitens Bär, Wolf und Luchs. Neben der Nutzung durch die angrenzenden Alpbetriebe mussten auch die Schafherden, die auf Surenen gesömmert

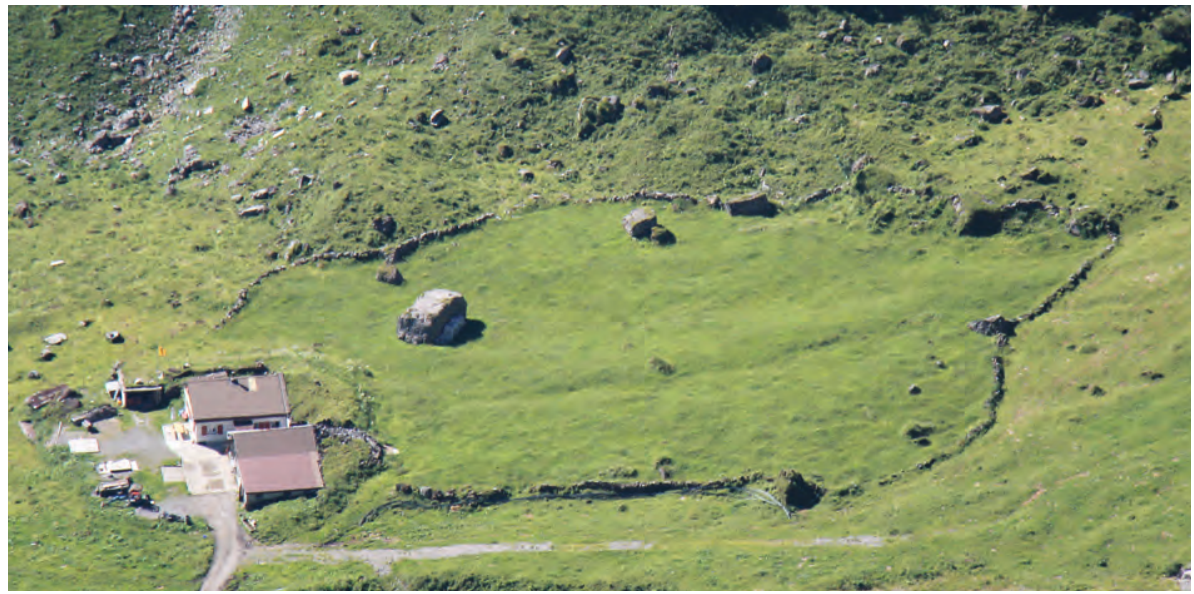

Einfassung Hintere Hütte (Aufsicht)

Erstfeld-Waldnacht

LK 1191 - 687 020/187 791

$1435 \mathrm{~m}$ ü.M.

Foto M. Sauter, 2013 


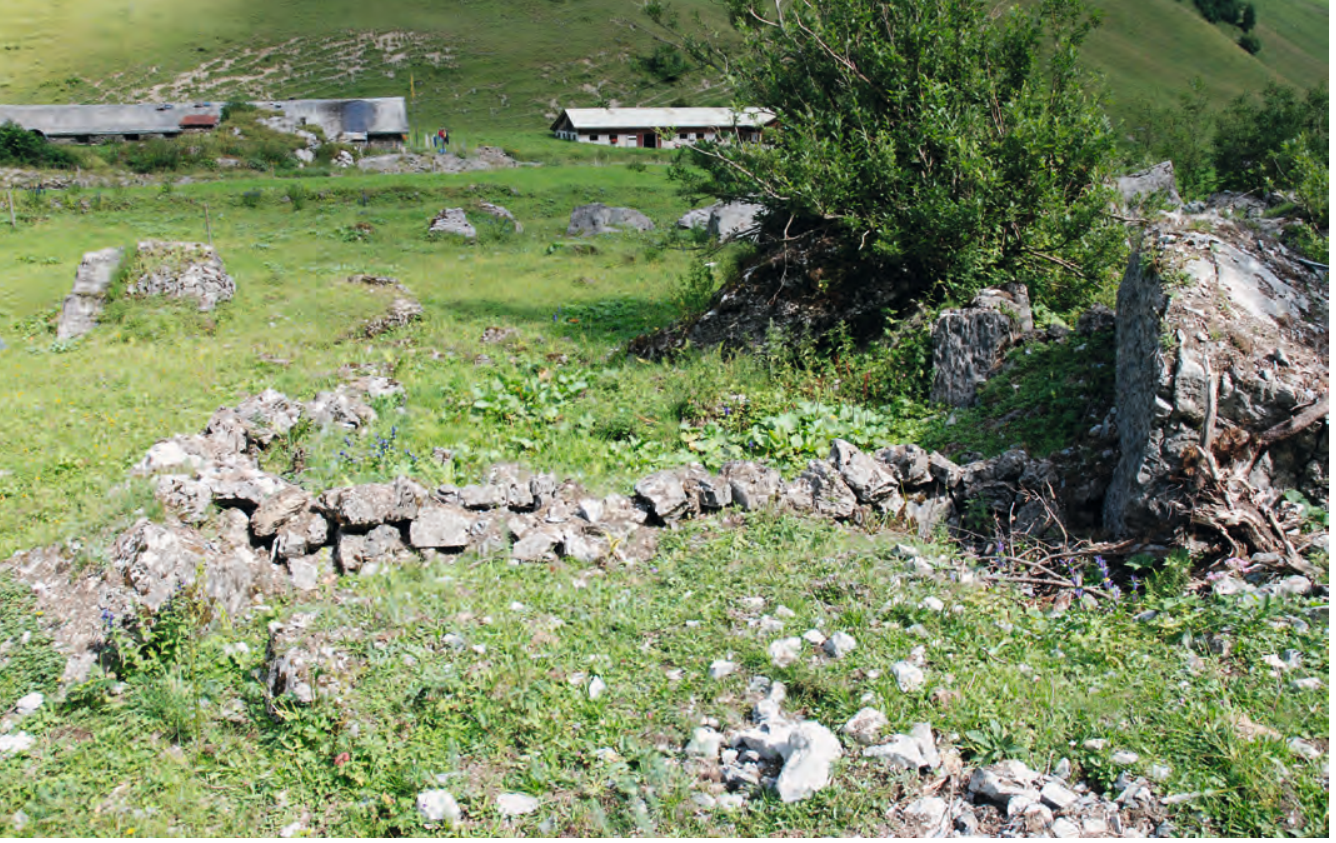

wurden, im Herbst wieder ihren Besitzern übergeben werden. Dieses sogenannte Ausziehen der Schafe fand ursprünglich ebenfalls in Steinfassungen statt, im Jahr 2010 letztmals neben der Langen Hütte in einer modernen Einzäunung.

\section{Geissberg (1832 m ü.M.)}

Der Geissberg erhebt sich im Süden der Waldnacht. Das steile Gelände diente bis 1936 als Ziegenweide - die Waldnacht kennt keinen Bestoss mit Ziegen. Die zuletzt 40 bis 50 Tiere umfassende Herde wurde tagtäglich von der Bachhütte aus über den Geissenweg in Richtung Guggital getrieben. ${ }^{20}$ Da der Geissberg nicht mehr bewirtschaftet wird, wachsen inzwischen reichlich Buschwerk und Bäume nach. Im Unterschied zu dem lediglich Wolle und Fleisch liefernden Schaf galt die Ziege als «Kuh des kleinen Mannes". ${ }^{21} 1823$ wurde im Kanton Uri ein Höchststand von über 15000 Ziegen erreicht, was die schwierigen Wirtschaftsverhältnisse am Ende der Kleinen Eiszeit widerspiegelt. ${ }^{22}$

Das Prospektionsteam erwartete, einige rudimentäre Abri-Situationen vorzufinden, wurde jedoch von einer immer noch provisorisch gedeckten Hütte und einem zugehörigen Siedlungsplatz überrascht. Zuletzt wurde das Bauensemble wohl von den Bewohnern des Höchibergs genutzt, die auf

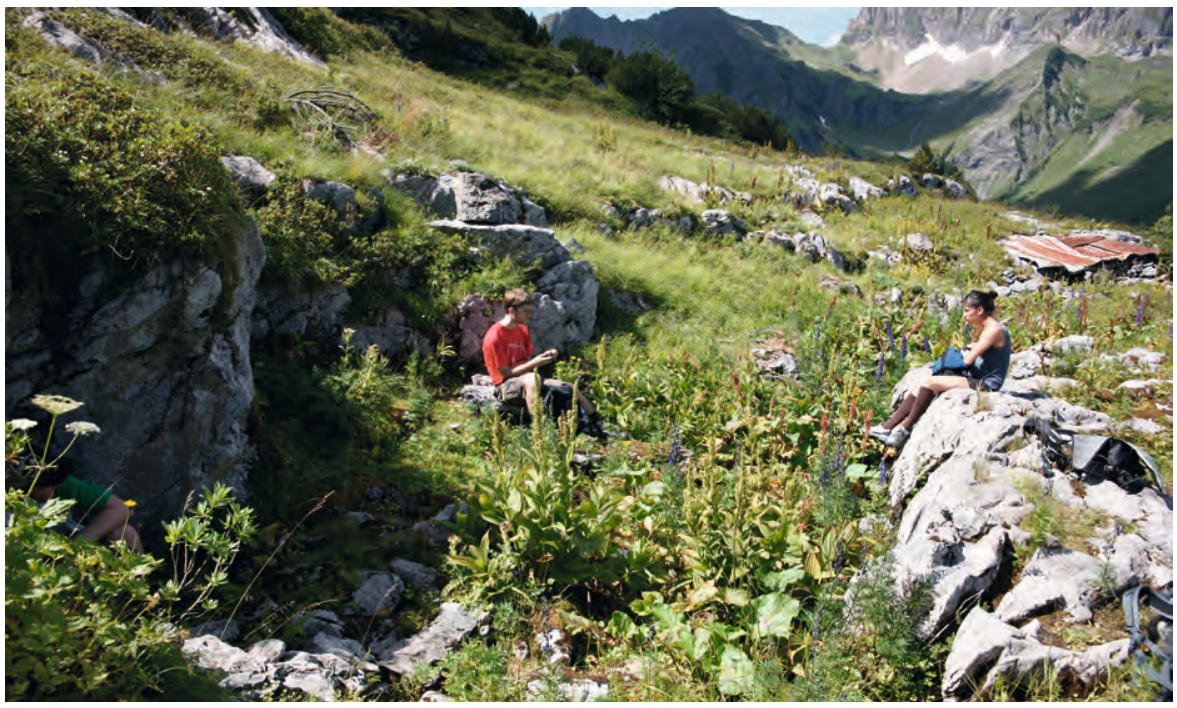

At.047

Pferch

Attiinghausen-Waldnacht (Aufsicht)

LK 1191 - 687 609/187 887

$1411 \mathrm{~m}$ ü.M.

$7,4 \times 8 \mathrm{~m}$

Foto M. Sauter, 2009

Er.026

Siedlungsplatz Geissberg (Übersicht) Erstfeld-Geissberg

LK 1191 - 688 275/187 740

$1791 \mathrm{~m}$ ü.M.

Foto T. Künzle, 2009
20 Furrer/Furrer 2000, 13.

21 Obrecht 1999, 8.

22 Oechslin 1927, 162. - Kunz 2010. 
Er.034

"Püntener schläft» (Ansicht)

Erstfeld-Guggital

LK 1191 - 686 028/187 105

$1760 \mathrm{~m}$ ü.M.

Foto M. Sauter, 2010
23 Püntener 2015, 199.

24 Püntener 1908, 103.

25 Freundl. Hinweis von Martin Furrer.

- Furrer/Furrer 2000, 30-32.

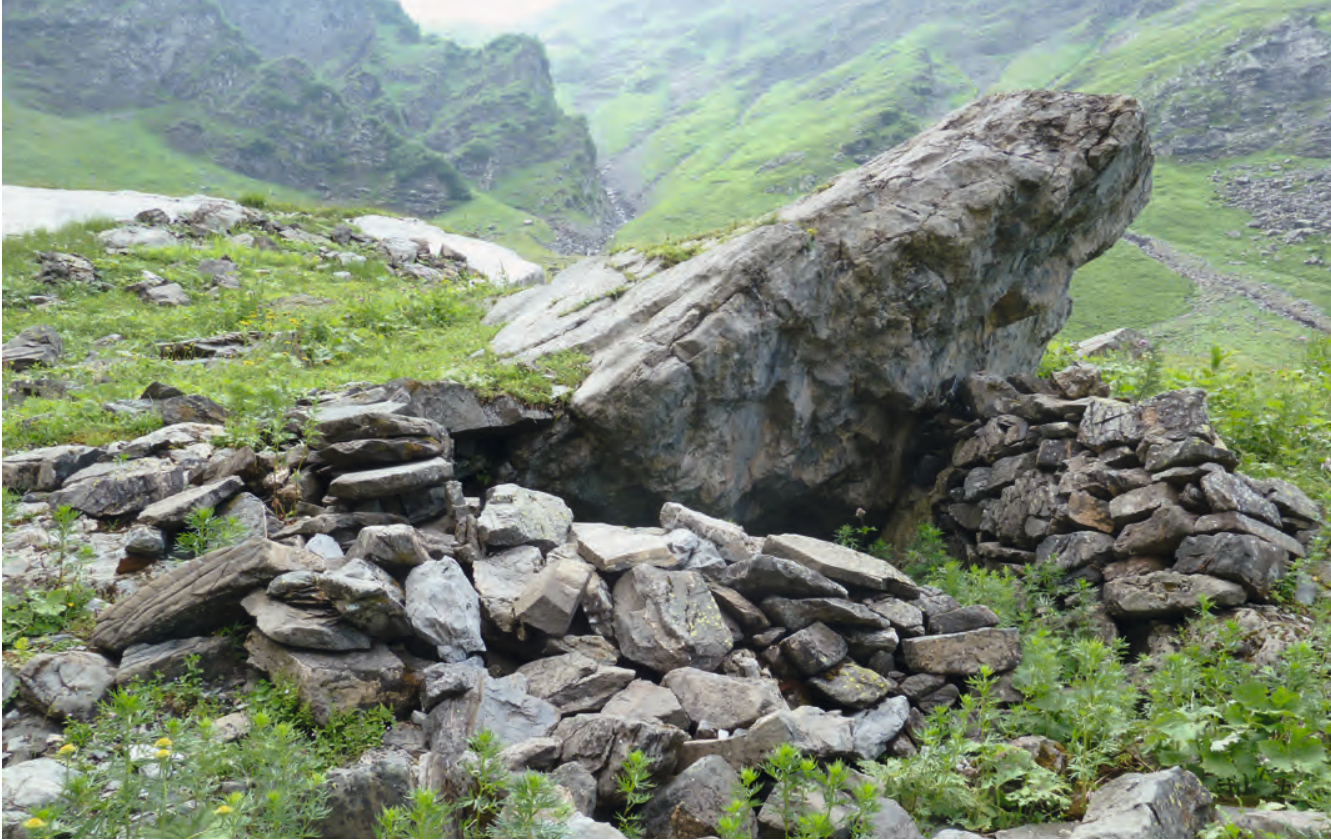

dem Geissberg Streu sammelten und dieses via Lastseil abtransportierten. Wahrscheinlich handelt es sich jedoch um einen deutlich älteren Siedlungsplatz.

\section{Guggital (1750 m ü.M.)}

Das sogenannte Stäfeli im abgeschiedenen Erstfelder Guggital wird als Oberstafel der Alpen Grosse Hütte und Hintere Hütte genutzt und heute ausschliesslich mit Rindern und Jungvieh bestossen, Gebäude werden nicht unterhalten. Die südliche, steil ansteigende Talflanke des Stäfelis liegt im Schatten des Fläugenfadhorns (2710 m ü.M.) und ist in der Regel ganzjährig mit Firn bedeckt - das Areal muss während der Kaltphasen der Kleinen Eiszeit äusserst unwirtlich gewesen sein.

Der periphere Oberstafel überrascht jedoch mit zwölf Fundstellen und ist damit ein gutes Beispiel für lokalen Strukturwandel. Die Anpassungen, die den individuellen Bedürfnissen der Betriebe Rechnung tragen, sind hier für das 20. Jahrhundert gut nachzuvollziehen: Bis 1960 weideten im Guggital noch Milchkühe. Die Milch wurde während der kurzen Bestosszeit tagtäglich in die Waldnacht hinabgetragen. Diese Wirtschaftsform bedingte Schutzhütten für Hütebuben und Hirten, Melkplätze und Pferche. Die umfangreichen baulichen Überreste und die Erinnerungen der Bergbauernfamilie Püntener ${ }^{23}$ erlauben eine entsprechende Zuordnung sowie die These, dass hier ein älterer (mittelalterlicher?), intensiver genutzterer Siedlungsplatz zum Oberstafel umgewandelt wurde.

\section{Eifrutt (1781 m ü.M.)}

Eifrutt gehört zu den wenigen Urner Alpstafeln, die bis heute lediglich zu Fuss zu erreichen sind - der Serpentinenweg vor Eifrutt gehört zu den pittoresksten Partien des Surenenpasswegs ( - S. 110-111).

Der Oberstafel der Langen Hütte wird bis heute jeweils drei Wochen pro Jahr mit Milchkühen bestossen und umfasst neben der Alphütte auch einen Stall. ${ }^{24}$ Dieser wurde nach einem Lawinenabgang im Jahr 1935 neu errichtet und 1951 um einen moderneren Wohn- und einen Wirtschaftsteil ergänzt. Hinweise auf weitere ehemalige Hüttenplätze sind auf Eifrutt nicht auszumachen. Massgeblich für die Fortführung der Milchwirtschaft war die Einrichtung einer Transportseilbahn im Jahr 1972. Bis 1971 ist auf Eifrutt noch gekäst worden. ${ }^{25}$ 


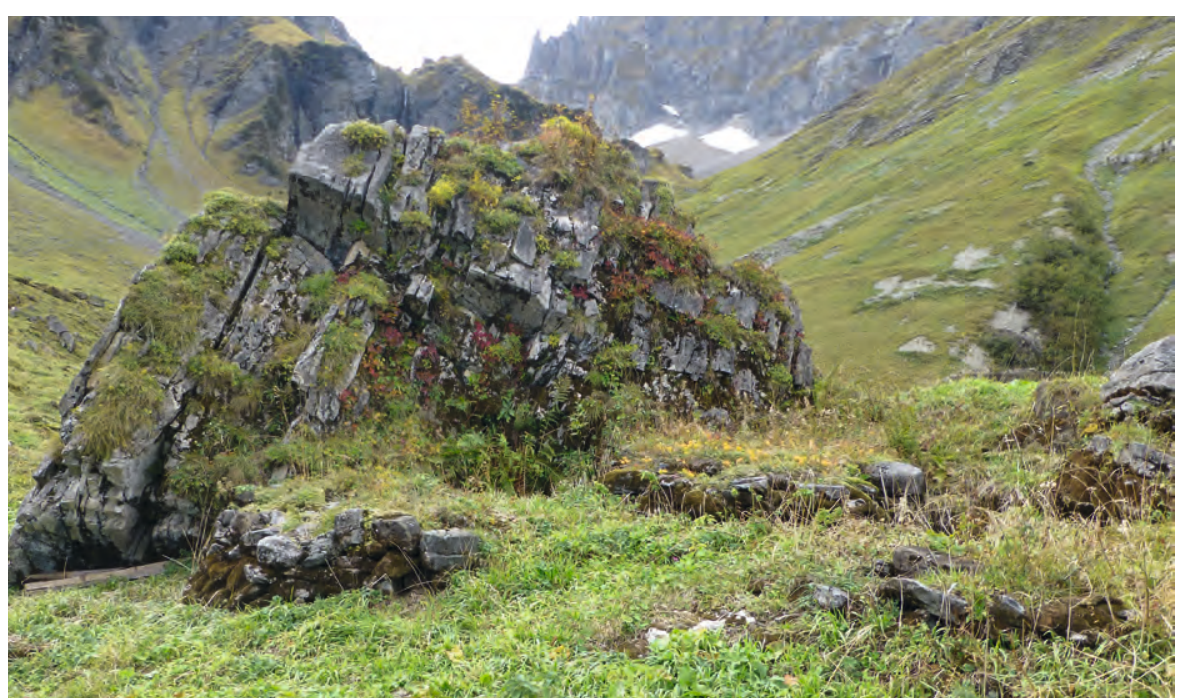

In der Nähe der Alphütte liegen im Schutz eines Felsblocks mehrere kreisrunde Steinsetzungen - Fundamente ehemaliger Tristbetten, welche die Wildheuerei im angrenzenden steilen Gelände bezeugen.

\section{Gratalp (1810 m ü.M.)}

Auf der Gratalp kreuzen sich die vom Seedorfer Gitschital und vom Attinghauser Chulm herführenden historischen Surenenpasswege sowie der heutige Wanderweg, der an der Bergstation der Luftseilbahn Brüsti startet ( $\rightarrow$ S. 114-115). Die Alp wird von der Bergbauernfamilie Herger bewirtschaftet, die eine Alphütte, einen Stall und ein kleines Lager unterhält und sich auf Agrotourismus spezialisiert hat. Die heutigen Gebäude entstanden in den Jahren 1996/97 und 2011.

Im Norden der Gratalp, in Richtung Gibelstöck und Chli Laucheren, befinden sich ein weiterer Stall sowie weitläufige Ruinenfelder. Mehrere Mauergevierte und Steinsetzungen zeugen von einer intensiven wie veränderlichen Nutzung dieses Areals. Die Siegfriedkarten der Jahre 1875 bis 1924 dokumentieren hier drei gedeckte Gebäude, um 1936 kamen zwei weitere Hütten hinzu. Der Alpinspektionsbericht zählte 1907 jedoch lediglich einen Stall, demzufolge wurden zwei vorhandene Bauten zwischenzeitlich nicht genutzt. Dominierend sind zwei mächtige, aus zweihäuptigem Mauerwerk gefügte Gevierte, die den Quellen zufolge wohl die raschen Veränderungen des 19. und 20. Jahrhunderts abbilden. Die "Katzenburg" (At.003) misst 7 × 6,5 m, das «Hüttli mit Bastion» (At.002) 6,7 x 8,3 m (Aussenmasse). Ohne umfassende und aufwendige archäologische Untersuchungen können die Entstehungszeit, die Abfolge und die ehemalige Funktion der vielfältigen Wüstungen auf dem Grat jedoch nicht näher gefasst werden.

Ein anschauliches Bild zur ehemaligen Nutzung und zur Bautypologie liefern hingegen die beiden Stallscheunenruinen auf dem nahen Gratgädemli, die in sämtlichen Versionen der Siegfriedkarte verzeichnet sind. Die untere Stallscheune ist erst vor wenigen Jahrzehnten eingestürzt: Die in die 1960er Jahre zurückreichenden, geritzten Inschriften der Mauersteine belegen, dass der Bau auch als Schutzhütte genutzt wurde. Stallscheunen dokumentieren die Nutzung der umliegenden Matten zur Heugewinnung. Diese werden auf dem Gratgädemli jedoch seit Jahrzehnten nicht mehr bewirtschaftet. Die wüst gefallenen Bauten sind von dichtem Grünerlengebüsch umgeben. 1907 sömmerten 32 Kühe, 6 Rinder und 8 Kälber auf 
der Gratalp, heute sind es nur noch 20 Tiere. ${ }^{26}$ Entsprechend erobert sich die Natur einst kultiviertes Land zurück.

Die beiden Stallscheunen unterscheiden sich mit ihrem eingetieften, massiven Sockelgeschoss und einem ehemals locker gewandeten Blockaufsatz typologisch nicht von den Stallscheunen im Tal. Fast alle Bauten auf dem Attinghauser Grat weisen ein ausserordentlich qualitätvolles Mauerwerk auf.

\section{Geissrüggen - Nussfruttli (1936 bis 1953 m ü.M.)}

Der Surenenpass kann auch über den an die Gratalp anschliessenden Grat erreicht werden - abseits der Hauptviehtriebroute über die Waldnacht (- S. 114-115). Die Südflanke des Grats fällt steil in Richtung Waldnacht ab und wird von Wildheuern bewirtschaftet. Die Nordflanke ist gegen das Gitschital geneigt. Hier liegen die Fluren Geissrüggen und Nussfruttli. Von ihrer einst dichten Besiedlung zeugen insgesamt zehn Wüstungen.

Zwei Bauten fallen besonders ins Auge: Das Ensemble "Hüttli mit Pferch" (At.032) ist stark einsedimentiert, der Grat jedoch baumlos und nicht lawinengefährdet. Eine entsprechende Überdeckung benötigt demzufolge viel Zeit. Die Wüstung wurde zum Kern des Forschungsprojekts (- S. 122-135). Der zweite bemerkenswerte Bau ist ein Kühlkeller (At.033), der im Schutz eines senkrecht aufragenden Felsens errichtet wurde und ein akkurat gefasstes Bassin aufweist - bislang der einzige bekannte Bau dieses Typs im Kanton Uri. Vorstellbar ist, dass der letzte Schnee und Eis in das Bassin gefüllt wurden und der schattig gelegene Lagerraum so über weitere Wochen die erforderlichen niedrigen Temperaturen lieferte.

Die anderen wüst gefallenen Gebäude auf dem Grat sind allesamt aussergewöhnlich klein, was die Interpretation der ehemaligen Funktionen erschwert. Zwei Ruinen weisen mehrere Lagen aufgehendes Mauerwerk auf und sind mit einem Steinplattenboden ausgestattet, der kleinere Bau (At.031) umfasst jedoch lediglich 0,6 0 0,9 cm (Innenmass). Zwei Wüstungen sind mit Steinbänken versehen, die an Milchbänke erinnen - allerdings befinden

Übersicht über das Ruinenfeld auf dem Attinghauser Grat. Im Vordergrund liegt die "Katzenburg" (At.003)

Foto M. Peters, 2012 sich beide Bauten (At.041, At.048) nicht in schattiger Lage. Da keines der Gebäude in den Siegfriedkarten dokumentiert ist, muss der Grat spätestens im 19. Jahrhundert als Siedlungsplatz aufgegeben worden sein.

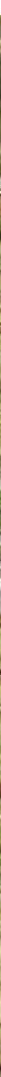




\section{Von der Prospektion zum Forschungsprojekt}

Die Beispiele verdeutlichen die grosse Schwierigkeit, die Wirtschaftsgeschichte einzelner Täler im Alpenraum exakt zu rekonstruieren. Die Wüstungen dokumentieren nämlich zahlreiche Veränderungen, die das Bild der vermeintlich althergebrachten, auf festgefügten Traditionen beruhenden Alpwirtschaft korrigieren. Die Prospektion ist die einzige Möglichkeit der Annäherung - das wertvolle Wissen der teilweise betagten Gewährsleute ausnutzend. Hoffentlich findet die alpine Wüstungsforschung im Kanton Uri eine Fortsetzung und kann die in den Jahren 2009 bis 2014 erarbeiteten Grundlagen nutzen.

Die durch die Prospektionskampagnen gewonnene Übersicht bildete die Grundlage für weiterführende, detaillierte Untersuchungen: so geschehen an einem Dammwegfragment auf dem Urnerboden, an ehemaligen Siedlungsplätzen im Studenbergliwald auf Haldi, dem Geissrüggen $\left(-\right.$ S. 122-135) und auf Surenen $\left(\rightarrow\right.$ S. 184-201). ${ }^{27}$

Furrer, B. (2015). Vom Steinhaufen zum Molkenbad. Spurensuche in Urner Alpgebäuden. In: Hirtler, C. (Hrsg.). Hirt, Tinner und Fugibootschä. Urner Berglandwirtschaft früher, heute, morgen. Altdorf, 13-59.

Furrer, F. / Furrer, M. (2000). Unsere schöne Alp. Eine kleine Kulturgeschichte der Eigenalp Waldnacht. Solothurn.

Gasser, H. (1979). Die Kunstdenkmäler der Schweiz. Pilotmanuskript der Gemeinde Attinghausen. Altdorf.

Hug, A. / Weibel, V. (1988-1991). Urner Namenbuch. Die Orts- und Flurnamen des Kantons Uri (4 Bde). Altdorf.

IVS UR (1998). Inventar Historischer Verkehrswege der Schweiz. Dokumentation Kanton Uri. Bearb. von Loepfe, A. / Müller, U.A. / Bösch, R. et al. (provisorische Fassung).

Bern.

Kunz, R. (2010). Die Ziegen um den Geissberg. Altdorf.

Lehner, H. (1983). Die Ausgrabungen in der Pfarrkirche St. Andreas in Attinghausen. In: Historisches Neujahrsblatt Uri, 113-154.

Leuzinger, U. / Sauter, M. / Haas, J.N. et al. (2014). Eine hallstattzeitliche Gebäudestruktur auf 1911 m ü.M. am Weg zum Surenenpass, Attinghausen UR, Siedlungsplatz Geissrüggen. In: Jahrbuch Archäologie Schweiz 97, 153-168.

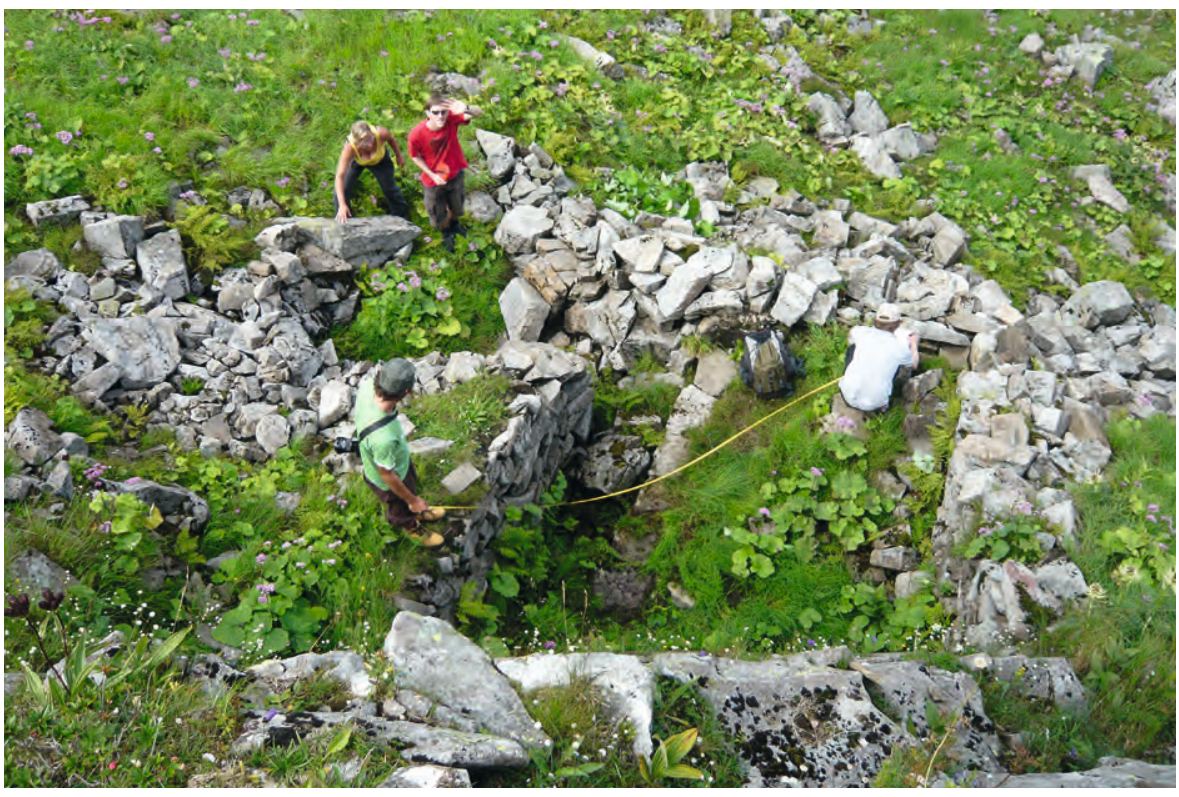

27 Sauter 2013. - Sauter/Auf der Maur 2014. - Leuzinger/Sauter/Haas et al. 2014. - Leuzinger/Sauter/Haas et al. 2015.
At.033

Kühlkeller mit Bassin (Aufsicht) Attinghausen-Nussfruttli LK 1191 - 685 990/188 713 $1948 \mathrm{~m}$ ü.M. 4,2 x 4,2 m (Hauptraum) Foto F. Flückiger, 2009 

At.067

Felsblock mit Doppelsteinlegung (Ansicht)

Attinghausen-Chli Laucheren

LK 1191 - 687 075/189 437

$1565 \mathrm{~m}$ ü.M.

Foto F. Flückiger, 2009

At.053

Terrassenhausanlage (Aufsicht) Attinghausen-Gibelstock

LK 1191 - 688 082/189 373

$1807 \mathrm{~m}$ ü.M.

Foto M. Sauter, 2009

\begin{tabular}{|c|c|c|c|c|}
\hline At.087 & Ehem. Kapuzinerinnenkloster & Dorfkern & 690433 / 190875 & 500 \\
\hline At.048 & Dreiräumige Anlage & Geissrüggen & $685956 / 188702$ & 1950 \\
\hline At.031 & Kleines Hüttli mit Pferch & Geissrüggen & 686507 / 188681 & 1894 \\
\hline At.032 & Alpiner Siedlungsplatz Geissrüggen & Geissrüggen & $686366 / 188706$ & 1905 \\
\hline At.034 & Pferch an der Felskante & Geissrüggen & $685939 / 188725$ & 1945 \\
\hline At.044 & Pferch an der Steilhangkante & Geissrüggen & 686527 / 188646 & 1894 \\
\hline At.045 & Hüttli & Geissrüggen & $686377 / 188714$ & 1904 \\
\hline At.046 & Zweiräumiges Hüttli neben Felsspalt & Geissrüggen & $685975 / 188693$ & 1947 \\
\hline At.047 & Gaumerhüttli mit Pferch und Sitzstein & Geissrüggen & $685967 / 188699$ & 1950 \\
\hline At.049 & Zweiräumiges Farnhüttli & Geissrüggen & $685950 / 188703$ & 1949 \\
\hline At.058 & Massives Hüttli mit Pferch & Gibelstock & 687614 / 189201 & 1783 \\
\hline At.009 & Pferch & Gibelstock & 688082 / 189399 & 1742 \\
\hline At.053 & Terrassenhausanlage & Gibelstock & 688082 / 189399 & 1742 \\
\hline At.054 & Eingeebnetes Gaumerhüttli & Gibelstock & 687726 / 189373 & 1807 \\
\hline At.055 & «Dornröschenschloss» mit Pferch & Gibelstock & $687589 / 189195$ & 1782 \\
\hline At.056 & Grosser Pferch & Gibelstock & 687614 / 189201 & 1783 \\
\hline At.057 & Kleiner Pferch & Gibelstock & 687614 / 189201 & 1783 \\
\hline At.029 & Heustall & Gratgädemli & 687582 / 188726 & 1807 \\
\hline At.001 & Zweiräumiges (?) Gaumerhüttli & Gratgädemli & 687727 / 188660 & 1740 \\
\hline At.030 & Aussichtspunkt & Gratgädemli & $687511 / 188735$ & 1825 \\
\hline At.039 & Gratgädemli Stall & Gratgädemli & $687705 / 188657$ & 1758 \\
\hline At.041 & Materialhüttli (?) & Gratgädemli & 687803 / 188716 & 1751 \\
\hline At.042 & Hüttli & Gratgädemli & $687603 / 188747$ & 1792 \\
\hline At.043 & Inschriften-Heuschopf & Gratgädemli & $687587 / 188719$ & 1802 \\
\hline At.123 & Abri sous bloc «Gritschen 2» & Gritschen & $682000 / 187740$ & 1941 \\
\hline At.122 & Schutzhütte und Pferch & Gritschen & $682150 / 187845$ & 1928 \\
\hline At.124 & Jägerstand & Gritschen & $682330 / 188190$ & 1971 \\
\hline At.128 & Hermis-Hüttli & Hermisalp & 682272 / 185656 & 1950 \\
\hline At.075 & Holloch & $\mathrm{Hol}$ & $690590 / 189034$ & 890 \\
\hline At.004 & S Hol-Höhle & $\mathrm{Hol}$ & $690730 / 189170$ & 730 \\
\hline At.077 & Rote Balm & $\mathrm{Hol}$ & $690740 / 189090$ & 730 \\
\hline At.097 & Sandbalm & $\mathrm{Hol}$ & $690740 / 189090$ & 730 \\
\hline At.037 & Achtung Einsturzgefahr-Hüttli & Restibiel & $685356 / 188276$ & 1964 \\
\hline At.020 & Mauerreste: Terrassierung und Wegfassung & Schweinsberg & $690250 / 190950$ & 500 \\
\hline At.115 & Abri Surenenpass & Surenenpass & 684409 / 187976 & 2320 \\
\hline At.107 & Wasserwüstung & Teif Boden & $681740 / 186500$ & 1750 \\
\hline At.076 & «Magischer Ort» im Langacher & Tschingel & & \\
\hline At.010 & Ehem. Hofstatt Aegerlueli & Tschingel & & \\
\hline At.026 & «Holzers Baracke» & Tschingel & & \\
\hline At.027 & Quellfassung & Tschingel & & \\
\hline At.078 & Ehem. Turmruine Schatzbödeli (Isleren) & Tschingel & $690950 / 190390$ & 520 \\
\hline At.121 & Abri sous bloc / Gaumerhüttli & Uf den Seewen & $688740 / 187623$ & 2139 \\
\hline At.129 & Zweiräumiger Bau & Uf der Lauwi & $681467 / 185523$ & 1669 \\
\hline At.023 & Hochweg von Attinghausen & & $690889 / 189117$ & 550 \\
\hline
\end{tabular}


Summary: The restoration of the Attinghausen castle ruins - An architectural survey

Attinghausen Castle was built in two phases, the first around 1100 and the second in the first half of the $13^{\text {th }}$ century. Measuring just under $25 \times 27 \mathrm{~m}$, the castle consisted of a separate tower, $12 \times 12 \mathrm{~m}$ in size and originally just under $25 \mathrm{~m}$ high, which was enclosed by a curtain wall with residential buildings. After the castle had been abandoned as a result of a natural conflagration in 1370, it fell into ruin. Today's appearance of the castle ruins is the result of several restoration projects. One in particular, carried out in 1897/98, had involved a very hard type of mortar, which had encased the walls in a kind of corset. Neither capillary nor rain water could escape the masonry, and as a result the original mortar was washed out, which led to the entire construction becoming unstable. Massive cracks in the masonry and sections breaking off made it necessary to carry out further restoration work in 2011. At the same time an architectural survey was mounted in order to gain new insight into how the walls had been constructed and into the various phases of construction and restoration. The investigation was based on the combination of various strands of evidence retrieved from the study of the masonry and mortar and from comparing historical photographs of the edifice with its current state. Furthermore, detailed studies of the masonry were made, including the number of courses and their types, the size of the stones, the occurrence of red discolouration due to fire etc.; the mortar and grouting were also examined by carrying out test excavations and coring. 


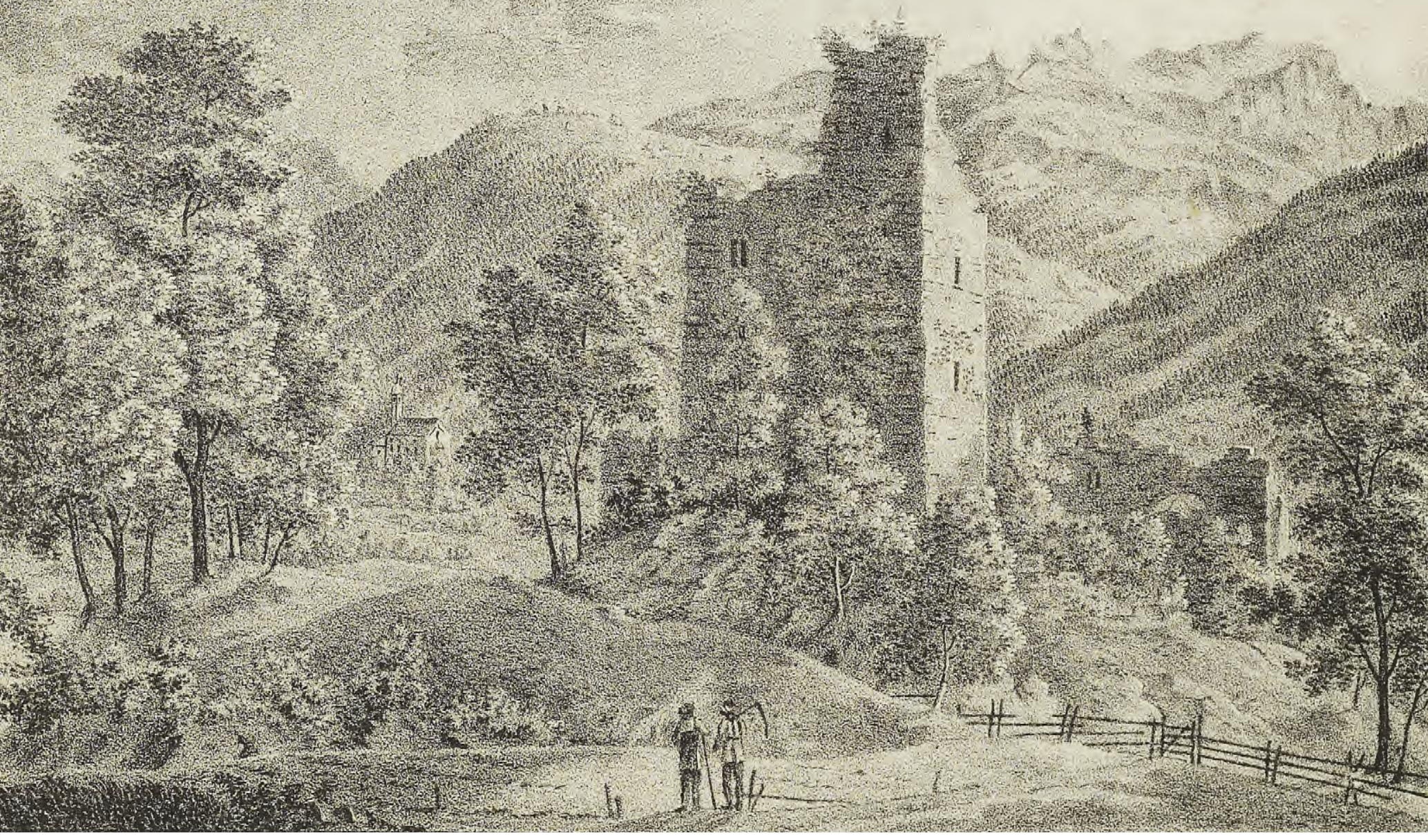

\section{Die Restaurierung der Burgruine Attinghausen - Bauforschung}

Die Burg Attinghausen wurde zu Beginn des 12. Jahrhunderts, zeitgleich mit dem ältesten Vorgängerbau der heutigen Pfarrkirche, von einem wohl aus dem Umfeld der Zähringer stammenden Hochadeligen errichtet und im 13. Jahrhundert erweitert. Nach der Aufgabe der Burg im 14. Jahrhundert erfuhr die Burgruine mehrere Restaurierungsmassnahmen, wovon vor allem diejenigen des ausgehenden 19. Jahrhunderts das heutige Erscheinungsbild prägen. Im Rahmen der Restaurierungsmassnahmen in den Jahren 2011/12 konnte die Bauforschung neue Einblicke in die Entstehungsgeschichte der Burganlage gewinnen.

\section{Die Situation}

Massive Rissbildungen im Mauerwerk und Mauerabbrüche am Turm machten 2011 Restaurierungsmassnahmen an der Burgruine Attinghausen unumgänglich. ${ }^{1}$ Die Projektleiterin Barbara Vogt vom Architekturbüro Iwan Bühler, Luzern, beauftragte das atélier d'archéologie médiévale (AAM), Moudon, mit der Plandokumentation und der Bauforschung. Während der ersten gemeinsamen Begehung der Burgruine am 26. Mai 2011 wurden die Aufgaben der Bauforschung wie folgt definiert: Erarbeitung der "Erkenntnisse wie restauriert werden soll», die Unterscheidung von Original- und

Gollnick 2012b.

2 Protokoll der Sitzung vom 26. Mai 2011.
Restaurierungsmauerwerk und die Klärung architektonischer Besonderheiten, beispielsweise des horizontalen Nordmauerabschlusses des Turms. ${ }^{2}$ 


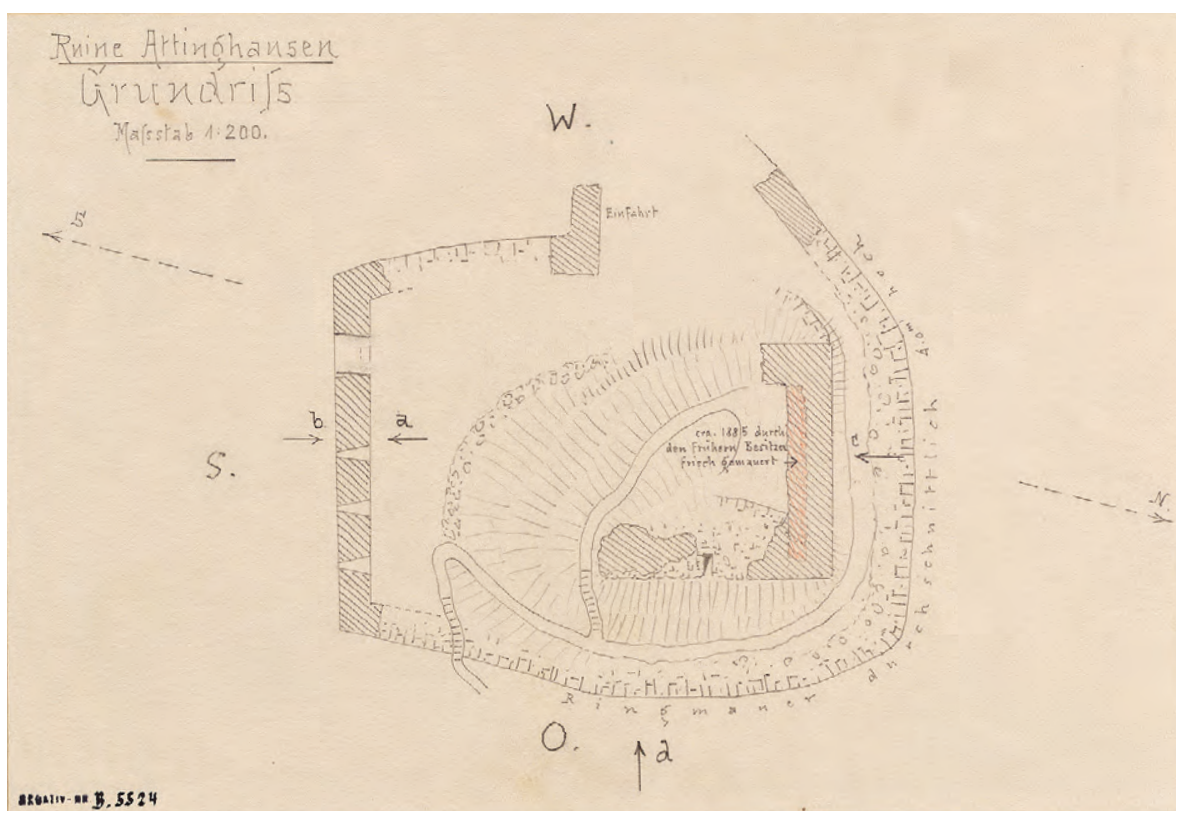

Ruine Artinóhausen
Massstab 1:200.

fusicht a

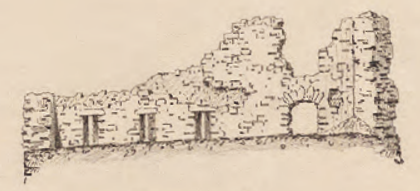

Ansictit b.

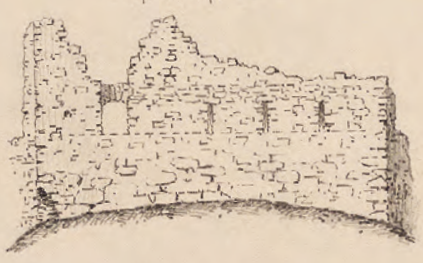

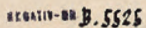

Ruine Attincótansen.

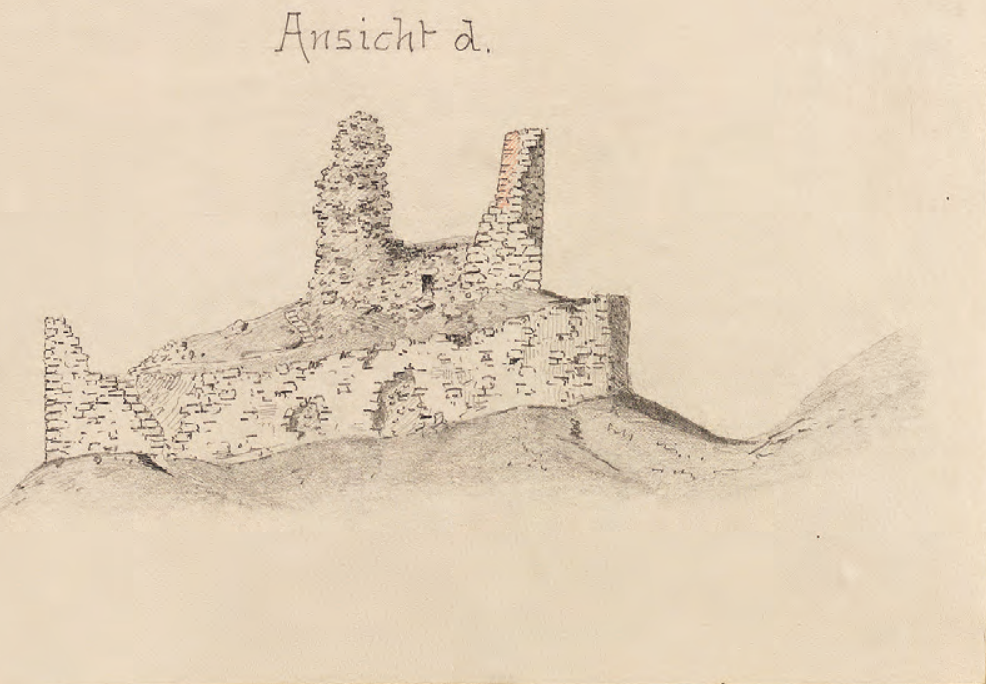

Titelbild: Ansicht der Burgruine Attinghausen von Nordwesten.

Stich nach einer Zeichnung F. X. Triners, um 1800 (Staatsarchiv Uri, 13-02-N-669)

Grundriss, Ansicht der Mauern 8A, 8B und $1 A$ sowie der Gesamtanlage gegen Südwesten vor der Restaurierung der Burgruine 1896.

Zeichnung J.C. Kunkler, 1896 (Eidgenössisches Archiv für Denkmalpflege, 564) 
3 Zeller-Werdmüller 1884.

Boschetti-Maradi 2004, 58.

5 LM 3205/34. - Gasser 1979, 14.

6 Durrer 1898, 50.

7 Eidgenössisches Archiv für Denkmalpflege, 564.

8 Mehrere Zeichnungen zeigen deutlich den Ringgraben, etwa das "Blatt Burg Attinghausen, 12 Juny 1835" aus dem Skizzenbuch des Altdorfer Arztes und Naturforschers Karl Franz Lusser, der ab 1820 wiederholte Male die Burgruine zeichnete (Staatsarchiv Uri, 150.1-448).

\section{Die Restaurierungen}

\section{Pfarrer Anton Denier, 1894}

Die aktuelle Restaurierung stellt den vierten bekannten Eingriff an der Burgruine Attinghausen dar. Im Jahr 1894 fand eine erste Grabung in der Burgruine unter der Leitung des Attinghauser Pfarrers Anton Denier statt. ${ }^{3}$ Bei dieser Gelegenheit kam vermutlich das bedeutende "Attinghauser Kästchen ${ }^{4}$ in den Besitz Deniers, bis es schliesslich 1898 mit der Sammlung Denier vom Schweizerischen Landesmuseum erworben wurde. ${ }^{5}$ Gleichzeitig mit dieser Grabung dürfte auch die Aufmauerung der um $1880^{6}$ eingestürzten Mauer M1 einhergehen, die laut einer handschriftlichen Eintragung auf dem Bestandsplan Johann Christoph Kunklers «ca. 1885 durch den früheren Besitzer frisch gemauert" worden war. Die Kampagne wurde nicht dokumentiert.

\section{Johann Christoph Kunkler, 1897/98}

Im Jahr 1896 erwarb der Verein für Geschichte und Altertümer des Kantons Uri die Burgruine Attinghausen. Der St. Galler Architekt Johann Christoph Kunkler fertigte in der Folge eine skizzenhafte Aufnahme des Grundrisses, der Mauern 8 A, 8 B, 1 A sowie der Gesamtanlage gegen Südwesten im M 1:200.7 Aus diesem Plan geht hervor, dass der Verlauf der südlichen Ringmauer vermeintlich verändert worden ist. Sie soll ehemals in einem spitzeren Winkel zur Mauer M8 verlaufen sein und wies im Westen eine "Einfahrt» auf - vermutlich der ehemalige Brückenzugang über den Ringgraben. ${ }^{8}$ Besonders von Bedeutung sind die Einträge zur Umfassungsmauer "Ringmauer durchschnittlich $4 \mathrm{~m}$ hoch" sowie, wie oben bereits erwähnt, zur abgebrochenen Mauer M1. Die aktuellen Untersuchungsergebnisse zeigen jedoch, dass die Aufnahmen Kunklers nur zum Teil dem Zustand der Burgruine von 1896 entsprechen.

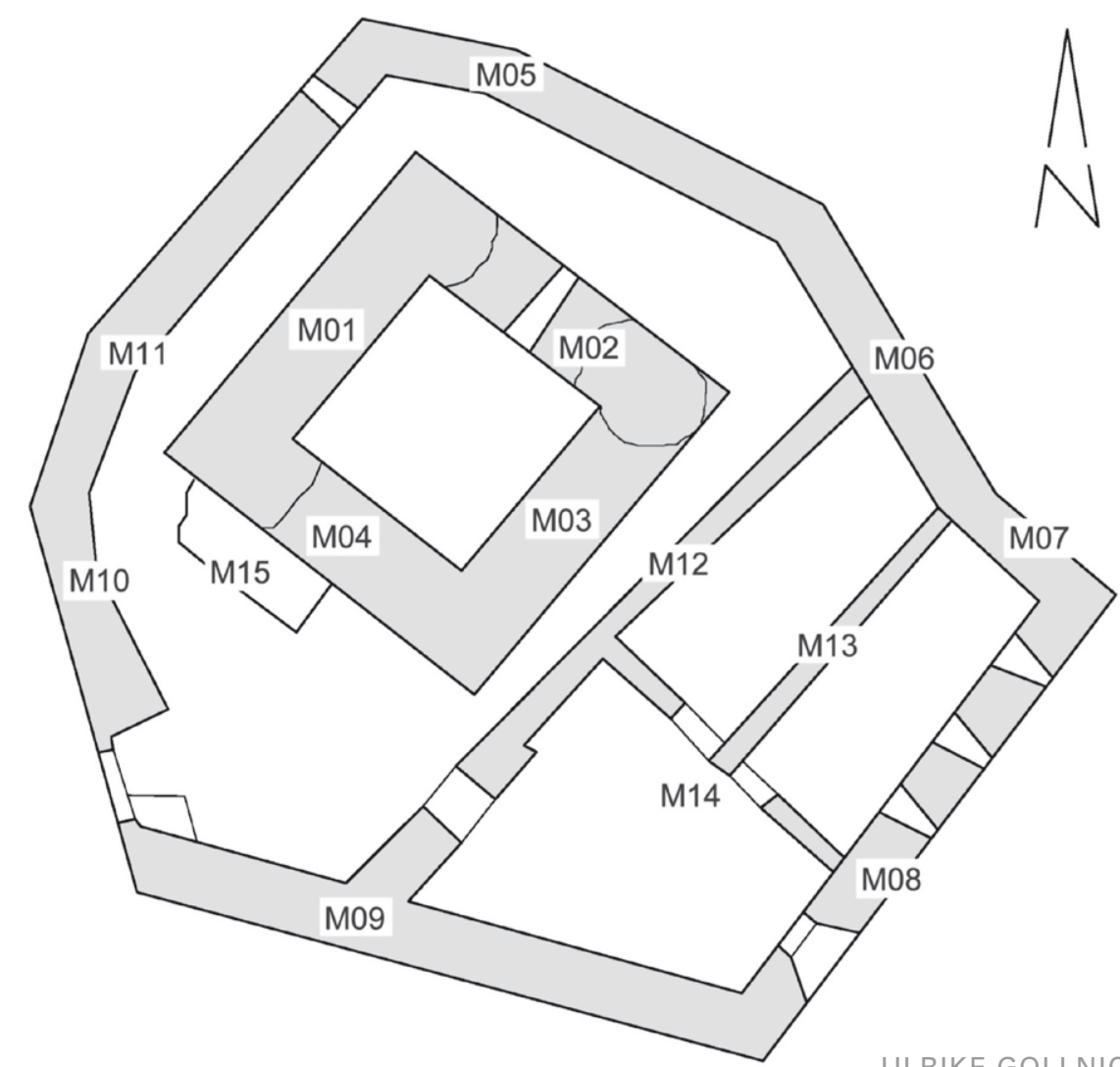

Planübersicht. Zeichnung AAM, 2012 
Eine umfassende, die heutige Gestalt der Burgruine bestimmende Restaurierung erfolgte in den Jahren 1897/98. Beteiligt waren der Urner Kantonsbaumeister Johann Müller und die Eidgenössische Kommission zur Erhaltung historischer Baudenkmäler. Für die praktischen Instandstellungsarbeiten war Johann Christoph Kunkler verantwortlich, die Restaurierungsarbeiten blieben jedoch ebenfalls undokumentiert. ${ }^{9}$

Der bedeutende Kunsthistoriker und Historiker Robert Durrer kritisierte die tief greifende Sanierung aufs Schärfste: Der wissenschaftliche Anspruch sei bei diesen Arbeiten verkümmert, da man - durch den erwachsenden Tourismus beeinflusst - anstrebte, eine "Renommierruine" zu schaffen. ${ }^{10}$ Besonders bedauerte er, dass es unterlassen worden war, die Grenze zwischen "altem» und "neuem» Mauerwerk zu markieren - wie es etwa gleichzeitig unter der Leitung von Albert Naef im Schloss Chillon in Form von eingelegten Ziegeln geschehen sei. Ferner bemängelte Durrer das Fehlen einer Dokumentation des freigelegten Originalzustandes. Dieser Punkt mag die Bauleitung veranlasst haben, Gedeon Berger mit der Erstellung von Plänen zu beauftragen, die den Zustand "vor und nach der Restauration" zeigen sollen. Die elf Zeichnungen von Fassadenmauern und Grundriss markieren anhand von dunkler getönten Flächen die Eingriffe und Ergänzungen. Aber auch selbige fanden bei Durrer keine Gnade: «Die nachträglich aufgenommenen und im Archiv der schweizerischen Gesellschaft für Erhaltung hist. Kunstdenkmäler [Eidgenössisches Archiv für Denkmalpflege EAD] niedergelegten Pläne und Aufrisse ${ }^{11}$ muss ich gestützt auf eine sorgfältige Kontrolle an Ort und Stelle leider als unzulänglich und in Bezug auf die Unterscheidung alten und neuen Mauerwerks geradezu irreführend bezeichnen. ${ }^{12}$

Die auf dem Berger-Plan als Erneuerung farblich markierten Flächen machen etwa ein Drittel der Gesamtfläche aus. Ob es sich dabei um den vollständigen Wiederaufbau, das Ausflicken oder das Verputzen des Bereiches handelt, ist nicht zu erkennen. Die Ergebnisse der aktuellen Bauforschung bieten näheren Aufschluss über die Stimmigkeit der Berger-Pläne und die Berechtigung der Durrer-Kritik. Das Ausmass der Restaurierungsarbeiten schlägt sich unter anderem in einem nahezu vollflächig 2 bis $15 \mathrm{~cm}$ dick aufgebrachten, sehr harten Zementverputz nieder. Lediglich ein $18 \mathrm{~m}^{2}$ grosser Bereich an der Aussenmauer $5 \mathrm{~A}$ blieb unverändert.

\section{Werner Meyer, 1979}

Die bis dato letzte Restaurierung fand im Sommer/Herbst 1979 im Rahmen von Sondierungs- und Sicherungsarbeiten unter der Leitung von Prof. Werner Meyer, Basel, statt. Die Arbeiten Meyers erbrachten den Nachweis für einen Vorgängerbau, der sich typologisch nur sehr summarisch bestimmen lässt. Charakteristisch ist dabei die Trennung zwischen einer Kernburg mit einem isolierenden, etwa $10 \mathrm{~m}$ breiten Ringgraben und einer Vorburg. Zeitlich darf dieser Vorgängerbau aufgrund der Keramikfunde C1-C3 in die Zeit um 1100 gesetzt werden. Gemäss Meyer folgte zwischen 1230 und 1250 eine zweite Anlage beziehungsweise eventuell bereits gegen 1200 der Bau des Hauptturms und zwischen 1230 und 1250 die Errichtung der Ringmauer mit dem Südosttrakt, der anschliessend mindestens einmal umgestaltet worden ist - wahrscheinlich in den Jahren 1250 bis 1350 . Der Niedergang der Burg ist nicht auf eine gewaltsame Zerstörung zurückzuführen, sondern eher auf eine natürliche Brandkatastrophe gegen 1370. Diese Datierung bezieht sich auf die zeitliche Einordnung der späten Funde. ${ }^{13}$
9 Gasser 2012, 45-47.

10 Durrer 1898, 47.

11 Der Plan Bergers ist bezeichnet mit "Zürich, im Dezember 1897» (Eidgenössisches Archiv für Denkmalpflege, 567).

12 Durrer 1898, 47.

13 Meyer 1979. - Meyer 1984. - Gasser 1979, 37. 


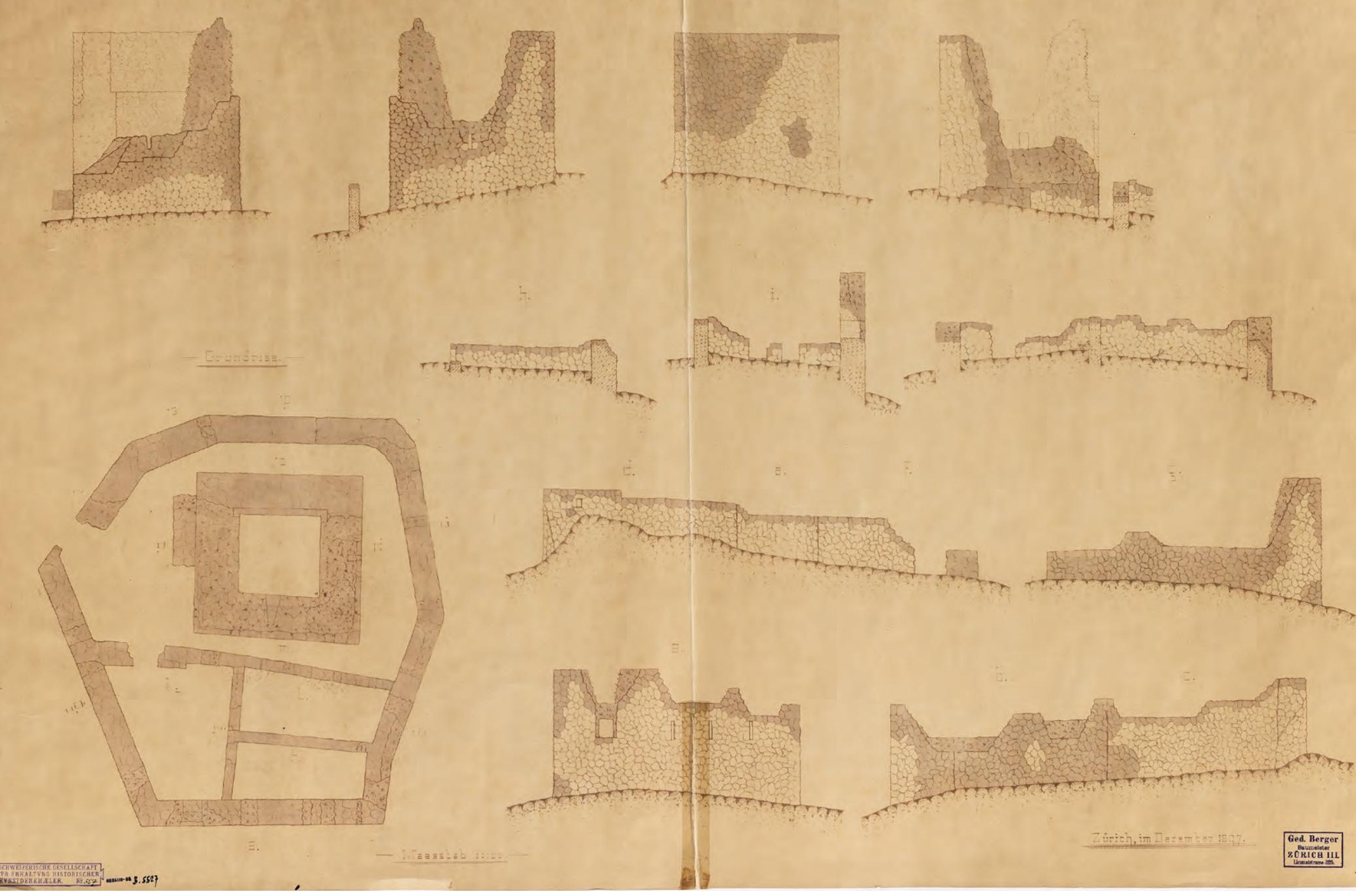

Grundriss und Fassaden, die dunkler getönten Flächen zeigen die Eingriffe ins Mauerwerk.

Übersichtsplan G. Berger, 1897 (Eidgenössisches Archiv für Denkmalpflege, 567)

14 Stöckli AG 2010, 3.

\section{Bauforschung 2011/12}

\section{Vorgehensweise}

Die Bauuntersuchung erfolgte unter der vom Restaurator Wendel Odermatt vorgegebenen Prämisse, dass der 1897/98 und 1979 eingeführte Mörtel erhalten bleibt soll, da dessen Rückbau "zu aufwendig und mit zu grossem Substanzverlust für die alte Mauer verbunden» wäre. Nur schadhafte Stellen sollten konsolidiert werden, ${ }^{14}$ grossflächige, der Bauforschung dienliche Sondierungen waren zu Untersuchungszwecken nicht vorgesehen. Da der zementhaltige Verputzmörtel der Restaurierungskampagne von 1897/98 fast ausnahmslos alle Maueroberflächen bedeckt, war diese Prämisse nicht nur ein richtungsweisendes, sondern auch ein äusserst erschwerendes Kriterium für die Untersuchung.

Eine seriöse historische Bauforschung bedingt den vollständigen Zugang zum Mauerwerk, um es in seiner Gesamtheit betrachten, den Mörtel Fuge für Fuge verfolgen und eventuelle Mörtelgruppen in unmittelbarer Nachbarschaft vergleichen zu können. Das Ziel war daher - trotz des fast vollständig verdeckten Fugenapparates -, befriedigende und glaubhafte Ergebnisse zu erzielen, abgestützt auf eine Verflechtung mehrerer Indizienstränge. Die Beobachtungen konzentrieren sich daher in erster Linie auf Stellen, die bereits durch Wasserschäden vom Zementverputz befreit vorgefunden wurden und 


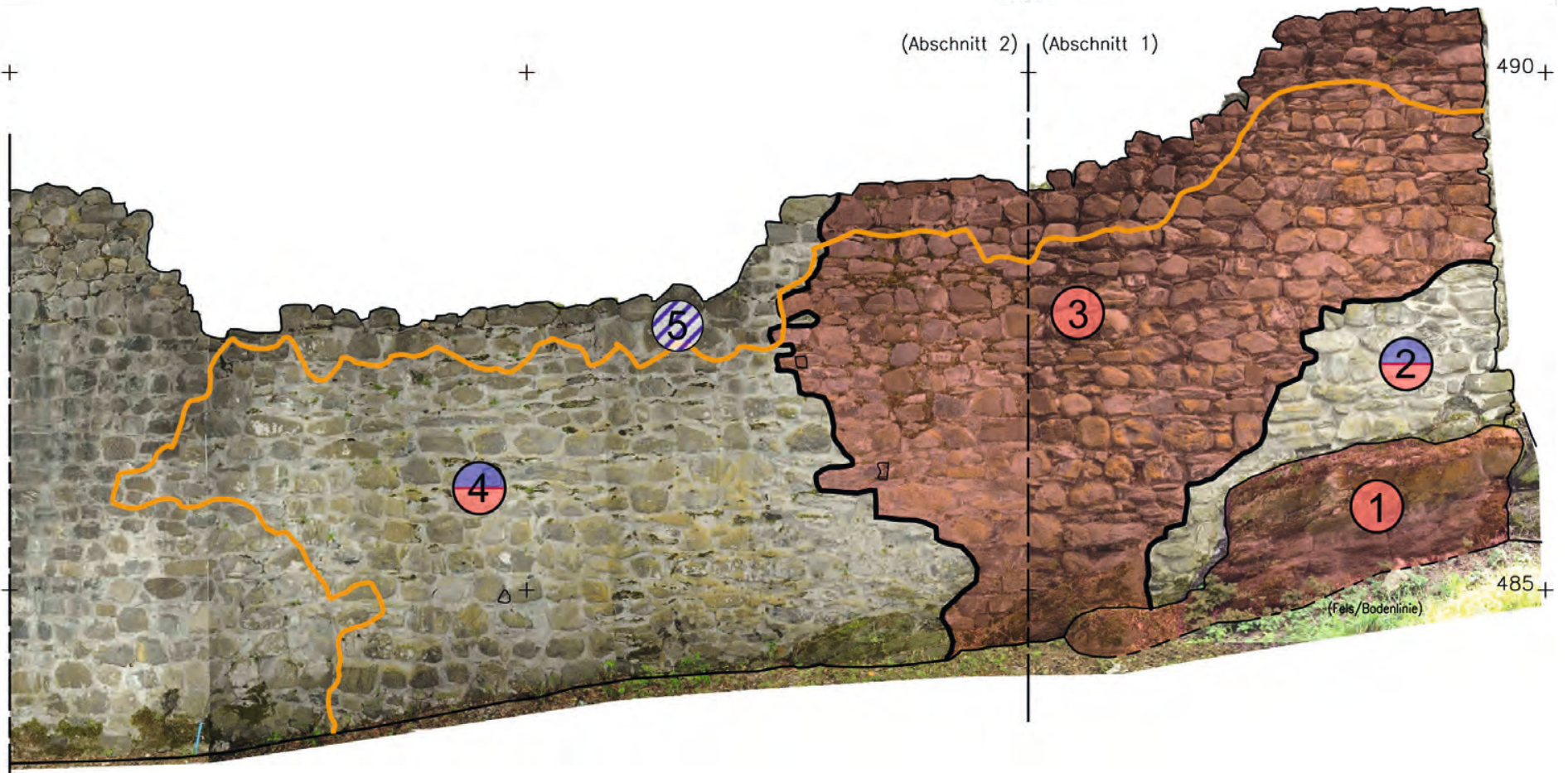

auf Stellen, an denen Steine ausgebrochen waren. Ergänzung fanden die Beobachtungen durch Sondierungen mit dem Kernbohrer und dem Bohrhammer.

\section{Grundlagen}

Grundlage der Bauforschung bildete eine Plandokumentation, die 2011 in Form einer tachymetrischen Vermessung erfolgt war. ${ }^{15}$ Die verschiedenen Mauerabschnitte - Ecke zu Ecke - wurden nummeriert, die äussere Mauerschale wurde zusätzlich mit dem Buchstaben A, die innere Schale mit dem Buchstaben $B$ gekennzeichnet. Dies erleichtert die präzise Benennung der einzelnen Mauerteile, die aufgrund der zu den Himmelsrichtungen um $53^{\circ}$ nach Westen verdrehten Burganlage ansonsten sehr komplex und missverständlich wäre.

\section{Erste Beobachtungen}

Der erste Teil der Bauuntersuchung erfolgte 2011 aus der Ferne, weitgehend ohne Gerüst - lediglich die Turmmauer M1 war aufgrund partiell aufgetretener Mauerschäden eingerüstet. ${ }^{16}$ Das übrige Mauerwerk wurde im Frühjahr 2012 eingerüstet und somit aus der Nähe zugänglich.

Die Beobachtungen an 22 Fehlstellen im Verputzmörtel von 1897/98 ${ }^{17}$ lieferten folgendes Bild: Hinter dem sehr harten Mörtel folgte ein etwa $20 \mathrm{~cm}$ tiefer Bereich mit versandetem Originalmörtel, dahinter der mehr oder weniger gut erhaltener Originalmörtel. An einigen Stellen konnte der absolut intakte harte Originalmörtel bis zur Mauerflucht festgestellt werden.

Der Mörtel war immer deutlich feucht, meist mit modrigem Geruch, oftmals war im Mauerinneren eine Humusschichteinlagerung mit Bewuchs von Moosen und Farnen (Waldbodenvegetation) anzutreffen. An der Mauerschale stellen Moose und Farne einen Indikator für Löcher im Zementmörtel dar. Nach starkem Regen war sogar zu beobachten, dass Wasser in Rinnsalen aus Öffnungen des Mauerwerks lief.
Umfassungsmauer, Mauer M5A, Blick gegen Süden. Intaktes Originalmauerwerk (rot), nicht betroffen von der Restaurierung 1897/98.

Bildplan AAM, 2012

Legende:

(1) Positionsnummer

originales Mauerwerk / Setzmörtel

originales Mauerwerk / Setzmörtel, Verputz 1897/98

möglicherweise $1897 / 98$ errichtet, Verputz 1897/98

1897/98 errichtet, Verputz $1897 / 98$

(1) 1979 ersetzt, verfült etc., Verputz 1979

Befundgrenze

...... vermutete Befundgrenze

___ vermutete Grenze gemäss Plan Berger 1897

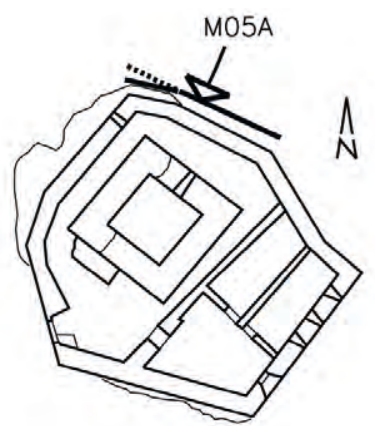

15 Plandokumentation: 29 Umrisszeichnungen und Bildpläne M 1:50 (Staatsarchiv Uri).

16 Gollnick 2012a.

17 Am gesamtem Mauerwerk waren immer wieder bis zu $8 \times 8 \mathrm{~cm}$ grosse Löcher im Zementverputz zu beobachten. Gollnick 2012a, Abb. 19. 


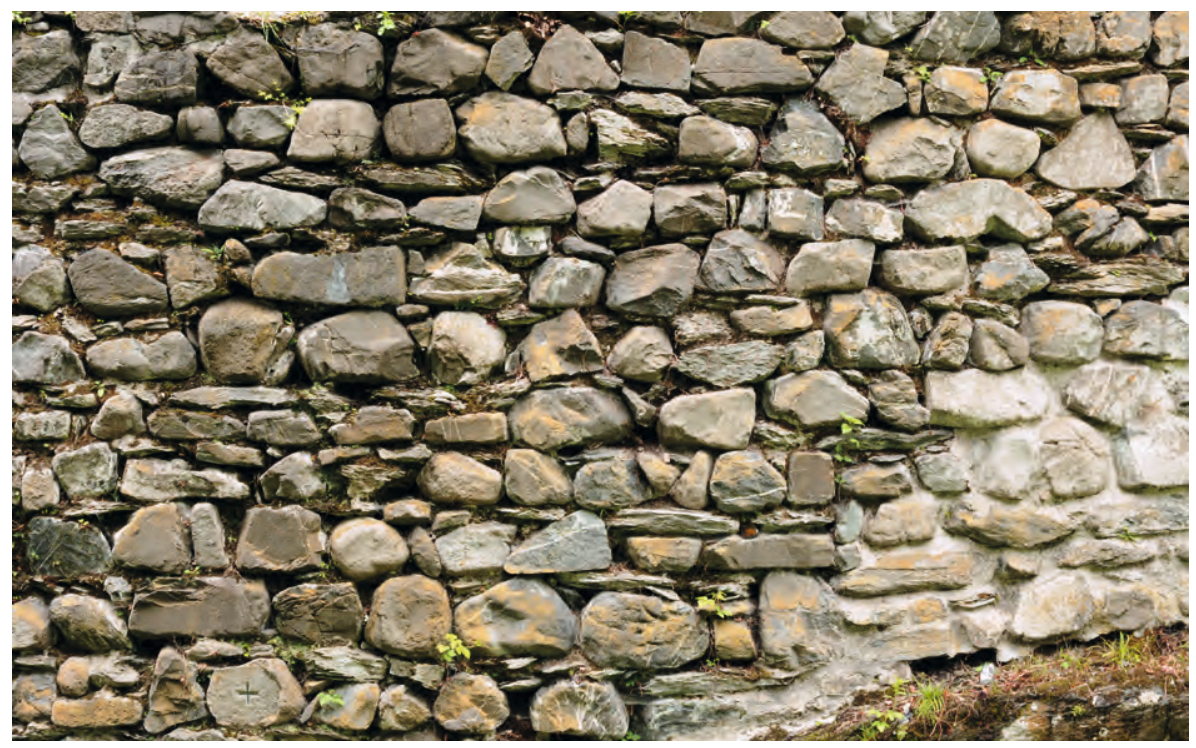

Insgesamt halfen 60 vom Gerüst aus genommene Mörtelproben und Abgleiche, die Befundgrenzen zu bestimmen und damit die verschiedenen Mauerwerke der Burgruine zu differenzieren.

Das Mauerwerk wurde vom Gerüst aus Mauerabschnitt für Mauerabschnitt nach Kriterien wie Lagenhaftigkeit, Materialgrösse des Mauerwerks, Auftreten von Brandröte oder Erscheinungsbild des Mauerwerk untersucht, und die jeweiligen Analogien und Indizien wurden festgehalten. Die Ergebnisse wurden in Positionsnummern aufgeteilt in die Bildpläne eingetragen und, wenn möglich, einer Entstehungsphase zugeordnet. Im Gegensatz zum sonst üblichen Verfahren wurde jedoch von einer vollständigen Kolorierung abgesehen, da die Beobachtungen oftmals zu ungenau schienen, um feste Aussagen treffen zu können.

Ausserdem erfolgte ein Abgleich der Fotos der Kampagne Meyer im Jahr 1979 mit der angetroffenen Situation. Weitere Hinweise auf neu aufgeführtes Mauerwerk ergab eine massstabsgerechte Übertragung der summarisch angegebenen Befundgrenzen der Berger-Pläne auf die neu erstellten Bildpläne.

Umfassungsmauer, Mauer M5A, Blick gegen Süden. Intaktes Originalmauerwerk mit zum Teil bis zu den Steinköpfen reichendem Mörtel.

Foto AAM, 2012

Umfassungsmauer, Mauer M7, Blick gegen Südwesten. Rinnsal an stark durchnässtem Mauerwerk.

Foto AAM, 2012

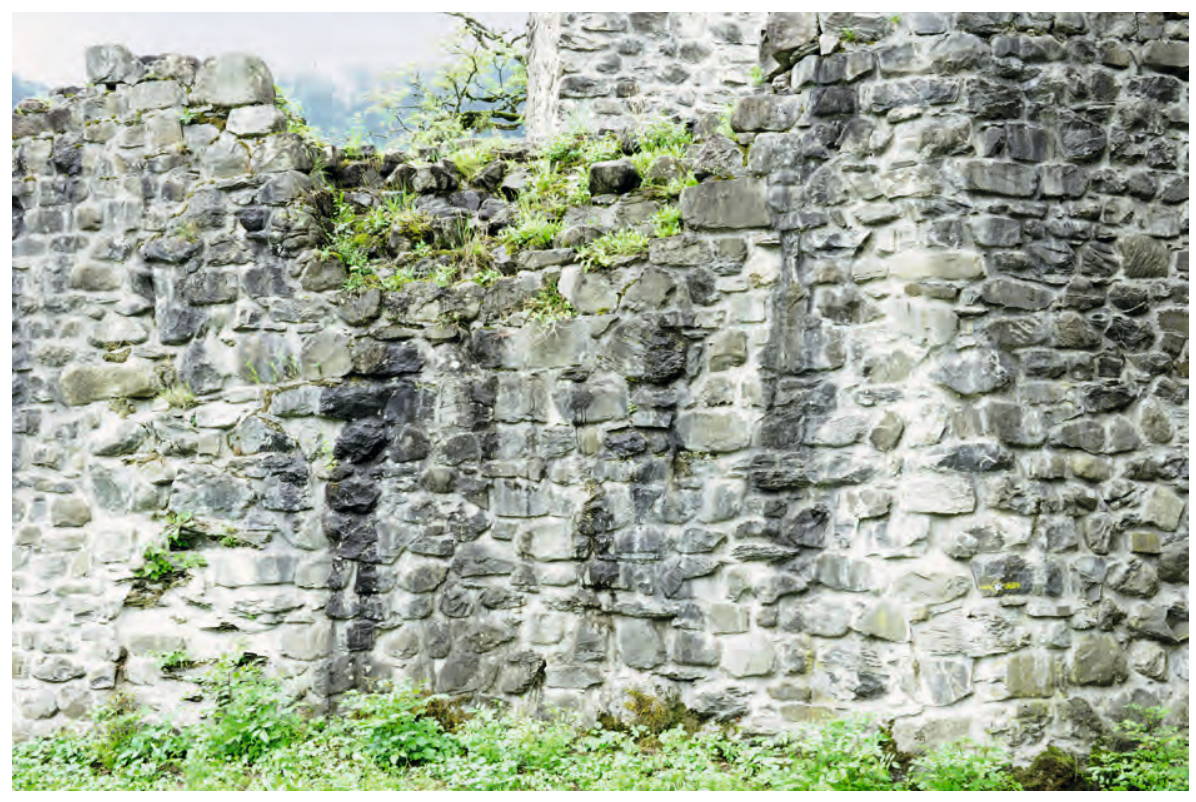



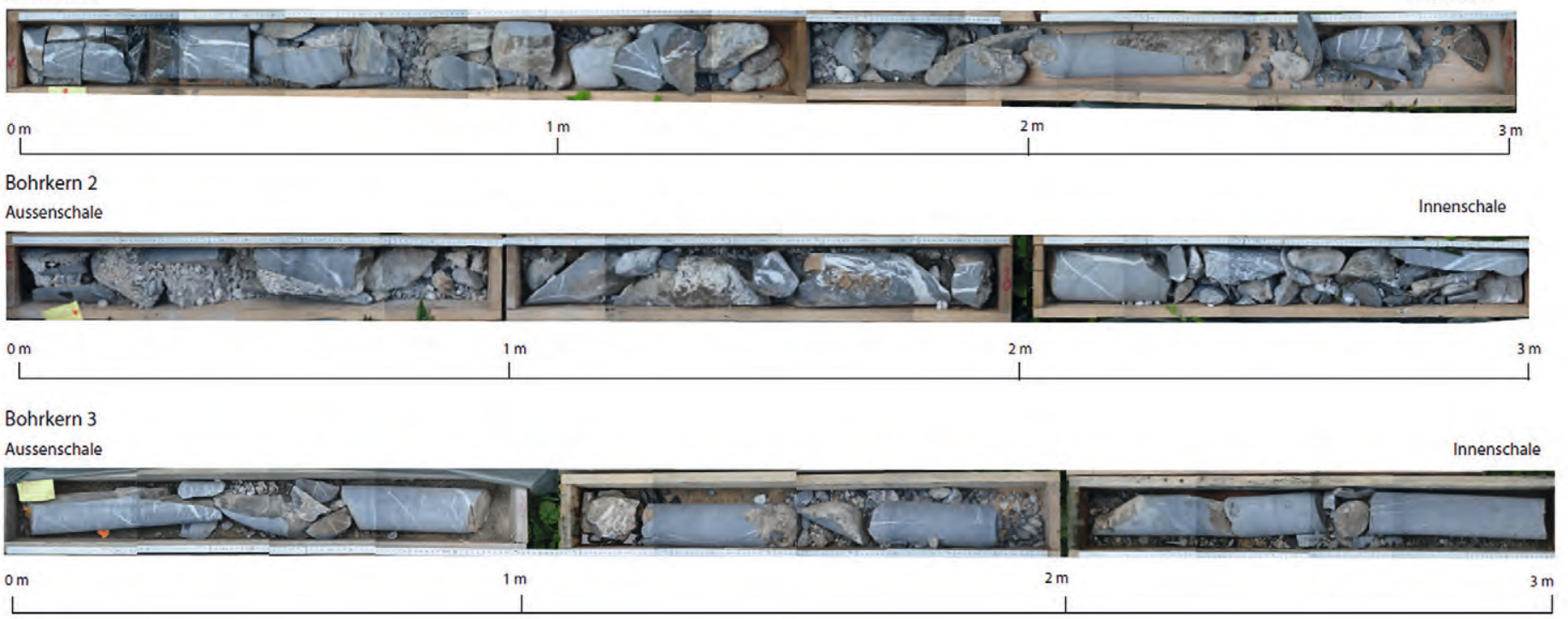

\section{Kernbohrungen und Sondierungen}

Ende Juli 2011 erfolgten Kernbohrungen in der Mauer M1 zur Abklärung des Zustands des Mauerkerns. In einer Höhe von etwa $1 \mathrm{~m}$ ab Boden wurden insgesamt drei Bohrungen an den Aussenseiten der Mauern M1 und M2 angesetzt, wobei die südliche Bohrung an Mauer M1 nach dem Abbrechen der Bohrkrone beendet werden musste. Der Durchmesser der Bohrkerne beträgt $12 \mathrm{~cm}$. Der Zustand der Kerne ist stark fragmentiert, was dafür spricht, dass die Adhäsion zwischen Stein und Mörtel meist nicht mehr gewährleistet ist. Dennoch war das Ergebnis zum Teil überraschend, da einige grosse zusammenhängende Originalmörtelbrocken, zwischen Steinen haftend, entnommen werden konnten. Der Originalmörtel der Kernbohrung 1 (Kiste 13) ist in maximal $5 \times 5 \mathrm{~cm}$ grosse Fragmente zerfallen. Zwischen zwei Steinen der Kernbohrung 2 (Kiste 10) klebte ein $20 \times 7 \times 11 \mathrm{~cm}$ grosses hartes Mörtelstück.

Im September 2011 wurden mit einem Mitarbeiter des Bauunternehmens Brun unter Zuhilfenahme eines Bohrhammers einige Sondierungen am Mauerwerk durchgeführt. Zusammen mit der Entnahme von weiteren 21 Bohrkernen mit einem Durchmesser von 2,7 cm im Rahmen der Ankerinstallation im Frühjahr 2012, konnten damit die Mauerwerksstrukturen der Wohntraktmauern noch präziser gefasst werden.

\section{Ergebnisse der Bauforschung}

Die zahlreichen Einzelindizien ergeben ein Gesamtbild der Burggenese mit folgenden bauarchäologischen Ergebnissen:

- Die heute noch knapp 25 × 27 m messende Burgruine beinhaltet den separat stehenden Turm, von der Umfassungsmauer eingeschlossen. Diese bildet im Süden die Aussenmauern des Palasgebäudes. Der Ringgraben und der Bereich der Vorburg sind im Gelände noch erahnbar. ${ }^{18}$

- Der Turm und das Palasgebäude sind, wie schon von Werner Meyer postuliert, in zwei Phasen entstanden. Dies liess sich anhand mehrerer Unterschiede im Mauerwerk, im Mörtel und in Geländehöhen feststellen.

Der Turm misst 11,6 $\mathrm{m} \times 11,6 \mathrm{~m}$ mit einer Mauerstärke von $3 \mathrm{~m}$, seine ursprüngliche Höhe dürfte knapp $25 \mathrm{~m}$ betragen haben. ${ }^{19}$ Das Fundament-
Bohrkerne.

Fotos AAM, 2012
18 Meyer 1979, 100.

19 Dies ergibt sich aus Abbildungen des 19. Jahrhunderts, etwa Franz Xaver Triner, Ansicht NW (Staatsarchiv Uri, 13.02-N-3393). 
mauerwerk (1) besteht aus mächtigen Granit- und Kalksteinblöcken bis $70 \times 100 \mathrm{~cm}$, die zum Teil auf das anstehende plattige Material gesetzt worden sind. Es wurde kurz nach dem Bau des Turms bedingt durch das extreme Gefälle freigespült, was auch statische Probleme im Mauerwerk ausgelöst haben dürfte. Der wohl mittelalterliche Treppenunterbau stösst gegen das Fundamentmauerwerk der Mauer M15.

Das aufgehende Mauerwerk besteht aus sorgfältig in Lagen gesetzten Flusskieseln und zum Lagenausgleich zum Teil aus Kalkplatten. Der Eckverband ist abwechselnd aus Bindern und Läufern von etwa $30 \times 60 \times 30 \mathrm{~cm}$ Grösse ohne speziellen Behau gesetzt. Das gesamte Steinmaterial ist nur grob hammerrecht zugeschlagen. Als Wandflucht wurde sorgsam ausgewähltes Material mit ebenen Oberflächen gesetzt. Wie die Bohrkerne und einige Mauerabbruchsstellen zeigen, handelt es sich nicht um ein klassisches Zweischalenmauerwerk. Vielmehr fand gleichformatiges Material von circa $20 \mathrm{~cm}$ x $35 \mathrm{~cm}$ Grösse Verwendung für Mantel und Kern. Der Befund fand Anfang Juli 2012 durch eine eher zufällige Maueröffnung der Mauer M3 Bestätigung, bei der Kernmauerwerk über $2 \mathrm{~m}$ zu sehen war.

Der originale Turmmörtel ist ein weisser, harter Kalkmörtel, reib- und brechbar. Sehr nasser beigegelber Kalk umfloss bei der Mischung Flusssandkörner von 0,5 bis $5 \mathrm{~mm}$ Grösse. Die Sandkörner sind hellgrau bis schwarz, zum Teil haben die Kiesel bis zu $2 \mathrm{~cm}$ Durchmesser. Die schwarzen Sandkörner sind oftmals platt, sehr selten kommen ziegelfarbige Elemente vor. Genässt saugt der Mörtel sehr schnell das Wasser auf und erscheint dunkler.

Das originale, 1897/98 verputzte Mauerwerk (2) ist im Südwesten fast bis zur aktuellen Turmhöhe erhalten, im Nordosten etwa 2,7 m hoch, was Mörtel aus Kernbohrungen und Mörtelabgleich belegen. Die etwa $30 \mathrm{~cm}$ hohen Lagen sind aus Steinen mit zumeist runden Steinköpfen gebildet, die Fugenbreite beträgt $4 \mathrm{~cm}$. Die Wandflucht weicht etwa $2 \mathrm{~m}$ vor der südwestlichen Ecke gegen Süden ab, der obere Bereich der Mauer kippt im Verhältnis zum Mauerfuss um mindestens $10 \mathrm{~cm}$ nach aussen. Mindestens vier

Turm, Mauer M1A, Blick gegen Südosten. Bildplan AAM, 2012
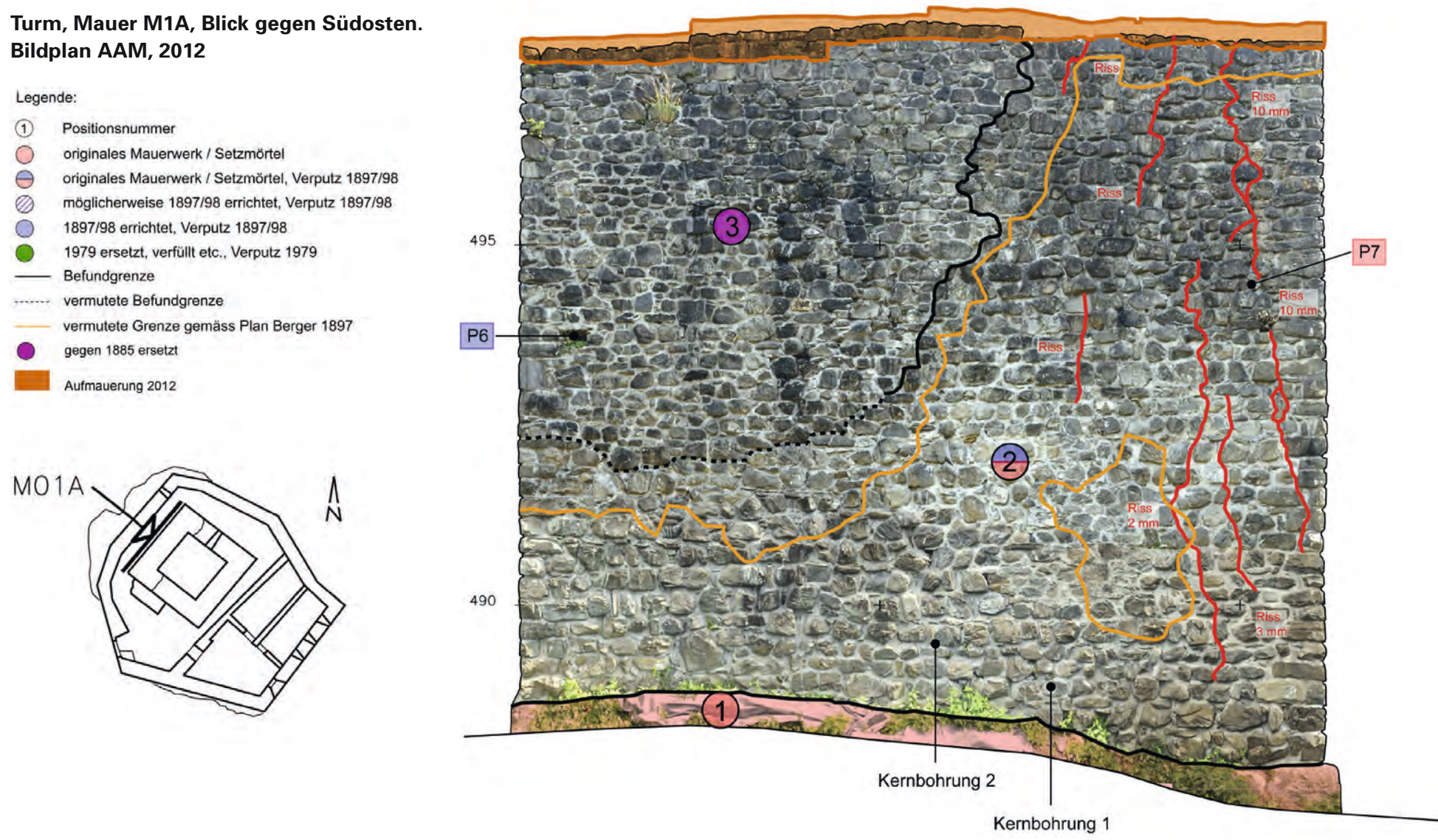


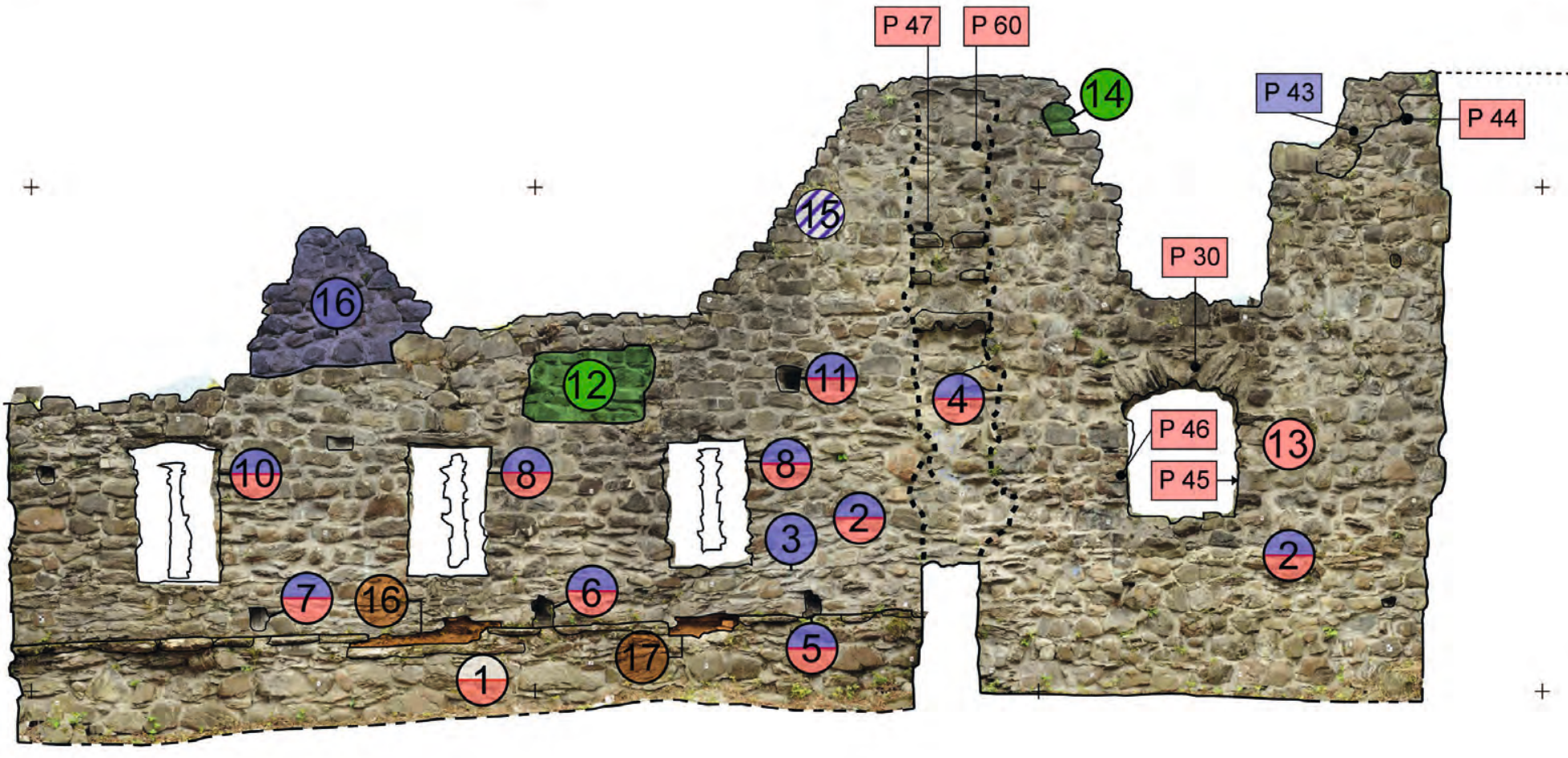

2 bis $10 \mathrm{~mm}$ starke Risse, zum Teil durch Steine hindurch, liegen in dieser Wandfläche in der Nähe der Ecke. Sie beginnen als Risse in der Mauerkrone und durchziehen meist die gesamte Wandhöhe.

Eine Befundgrenze zum Mauerwerk (3) zeichnete sich erst aus der Höhe betrachtet ab. Das Mauerwerk (3) wurde entsprechend einer Notiz Johann Christoph Kunklers um 1885 errichtet und 1897/98 verputzt. Es besteht aus einigermassen lagig gesetzten Kieseln, die Steingrössen der jeweiligen Lagen sind wenig regelmässig, die Lagenhöhe beträgt etwa $20 \mathrm{~cm}$, die Fugenhöhe im Durchschnitt $2 \mathrm{~cm}$. Die Flucht wirkt aufgrund des auffällig flachen Steinmaterials sehr eben, der Verputz reicht meist an den glatten Steinkopf. Die Flucht liegt etwa $10 \mathrm{~cm}$ hinter der Flucht des Mauerwerks (2) und ist senkrecht. Der Verlauf der unteren Befundgrenze ist aufgrund des Zementmörtels von 1897/98 nicht genau bestimmbar, Mauerwerksbeobachtung und Linie aus dem Berger-Plan liegen relativ nah beieinander. Robert Durrer befand zu dieser Fassade: «Die Nordwand war nach dem erwähnten Bilde von einem rundbogigen Fensterpaar im obern und einem einfachen Rundbogenfenster im untern Stock durchbrochen, heute erscheint sie als völlig geschlossen, denn nachdem sie in den achziger Jahren [des 19. Jahrhunderts] zusammengestürzt war, ist sie beinahe ganz neu aufgeführt worden. ${ }^{20}$ Die Fensteröffnung des ersten Wohngeschosses dürfte gemäss der Zeichnung Franz Xaver Triners und im Abgleich mit der Wandinnenseite frühestens in einer Höhe von 4,95 m zu erwarten sein.

Gegen 1250 erfolgte der Bau des Wohntrakts und der 1,6 m starken Umfassungsmauer. Dies geschah offensichtlich gleichzeitig, wie es die Wartesteine in der Mauer M8 nahe legen; ansonsten stossen die Binnenwände an die Umfassungsmauer.

Auf Höhe des Erdgeschosses gab es mindestens drei Räume mit trapezförmigem Grundriss. Der nördliche Raum ist mit drei Schartenfenstern ausgestattet, die möglicherweise durch einen auf den Mauerabsatz abgestellten Wehrgang zu begehen waren. Im Südosten lag ein Raum, der ein Fenster mit Bogenfensteröffnung besass. Die aus der Gewölbemitte entnommene Mörtelprobe (P30) und die Brandröte aufweisende Wandoberfläche legen
Wohntrakt, Mauer M8, Blick gegen Südosten.

\section{Bildplan AAM, 2012}
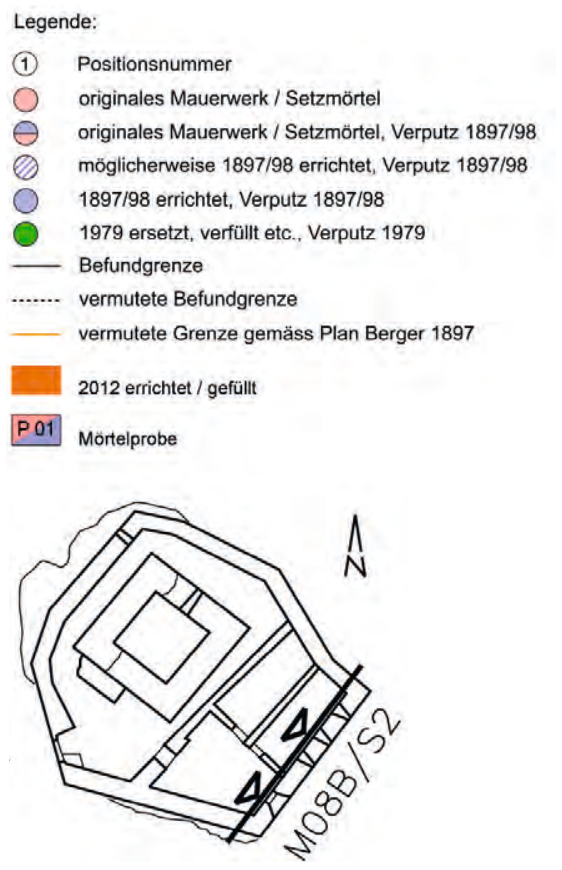

20 Durrer 1898, S. 50. 
21 Gollnick 2012a, Abb. 2-14.

22 Der Setzmörtel von 1897/98 wird durch das Nässen dunkelgrau.
Turm, Mauer M3, Blick gegen Nordosten. Freigelegtes Originalmauerwerk sowie Mauerwerk der Restaurierungen 1897/98 und 2012.

Foto AAM, 2012 nahe, dass es sich um eine originale Öffnung handelt. Der Abgleich des Fotos der Kampagne 1979 mit der angetroffenen Situation ermöglichte ferner die Identifikation neu hinzugefügten Mauerwerks (12) und (14).

Der Aufbau des Mauerwerks und des Mörtels des Wohntrakts unterscheidet sich von demjenigen des Turms: Es besteht aus sorgfältig in Lagen gesetztem Kieselsteinmaterial mit grob bearbeiteten Oberflächen, teilweise wurde plattiges Material zum Ausgleich der Lagenhöhe verwendet. Die Lagenhöhe beträgt im Durchschnitt $30 \mathrm{~cm}$. Im Gegensatz zum Turmmauerwerk unterscheidet sich hier die grossformatige Schale vom kleineren Kernmaterial - $20 \times 13 \mathrm{~cm}$ grosse Kiesel, gebrochenes, plattiges Material von $3 \times 15 \mathrm{~cm}$ Grösse sowie $8 \times 50 \mathrm{~cm}$ grosser schiefriger Kalkstein, alles zum Teil lagig gesetzt. Der Mörtel ist ein weisser Kalkmörtel, sehr hart, zerreibbar, mit einem hohen, fast hälftigen Kalkanteil, gerolltem, hell bis dunkelgrauem Feinsand von bis zu $3 \mathrm{~mm}$ Durchmesser. Der Mörtel enthält wenige ziegelfarbige Elemente (Ziegelsplitt?) und wenige beige Kalklinsen (bis $2 \mathrm{~m}$ Grösse). Zum Teil zeigt der Mörtel Luftblasen von bis zu 0,5 mm Durchmesser.

Ein letztes Indiz für die Zweiphasigkeit ist der auffällige Unterschied zwischen der Oberkante (= Terrainhöhe) des Fundamentmauerwerks des Turms und derjenigen der Mauer M12 des Wohntrakts von über $80 \mathrm{~cm}$. Es ist daher zu vermuten, dass die Mauer M12 erst gebaut wurde, als das Fundament des Turms schon freigespült war.

Gegen 1370 soll die Burg laut Werner Meyer durch ein natürliches Brandereignis aufgegeben worden sein. Die Abbildungen des 19. Jahrhunderts zeigen den Zerfall der Mauern. ${ }^{21}$ Es folgten die erwähnten Restaurierungsmassnahmen. Es ist auffallend, dass die Restaurierung der Jahre 1897/98 nach detailliertem und intensivem Studium des Originalmauerwerks inklusive Mörtel erfolgt zu sein scheint. Das vorliegende Steinmaterial kam zur Verwendung - ob durch logistische und finanzielle Sparmassnahmen oder durch ideologische Gründe motiviert, muss offen bleiben. Diese beiden Faktoren bedingen eine Entsprechung der Lagenhöhe zwischen Original- und Restaurierungsmauerwerk, was die Unterscheidung des Steinmaterials erschwert.

Der Setzmörtel ist im trockenen Zustand ${ }^{22}$ dem Originalmörtel der Umfassungsmauer optisch sehr ähnlich. Es ist ein gräulich weisser, harter und

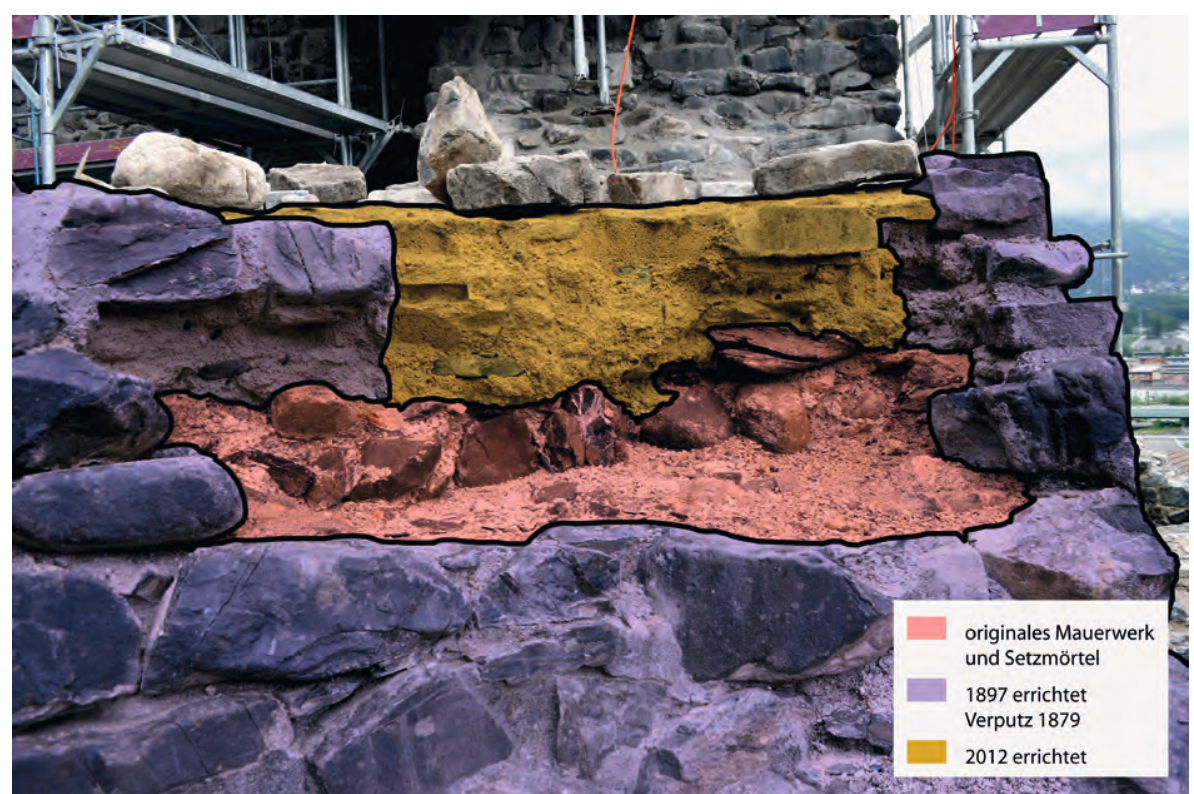


nicht mit weicherem Mörtel saniert, sondern mit einem ähnlich harten Mörtel, um eine neuerliche Rissbildung zu verhindern. Die Risse im Mauerwerk wurden injiziert und verfugt, für die Stabilität des Mauerwerks wurden Zugstangen eingefügt. Metallene Regenrinnen sorgen für den gezielten Abfluss des Regenwassers. Diese Massnahmen sollen den weiteren Verfall für die nächsten circa 30 Jahre weitgehend verhindern. Für zukünftige Massnahmen und Wartung wurde eine ausführliche Dokumentation erstellt, welche die erfolgten Eingriffe kartiert und den aktuellen Zustand festhält.

Am 22. und 23. September 2012 wurde die Burgruine der Öffentlichkeit im Rahmen einer festlichen Eröffnung übergeben.

Dieser Artikel beruht in leicht abgeänderter Form auf dem 2012 erschienenen Artikel im Historischen Neujahrsblatt des Kantons Uri, das der Restaurierung der Burgruine Attinghausen gewidmet ist (Gollnick 2012b, 74-90).

Die Gesamtkoordination der Restaurierung oblag der Welcome Immobilien AG unter der Leitung von Ernst Widmer, Bauökonom. Die Fachkommission bestand aus: Lukas Högl, Bundesexperte; Edi Müller, kantonaler Denkmalpfleger; Josef Müller, Schubiger AG, Luzern, Baustatik; Vroni Raab, Historischer Verein als Vertreterin der Bauherrschaft; und Ulrike Gollnick, AAM, Moudon, Bauforschung.

Bär-Vetsch, W. (2012). Die Restaurationen der Burgruine Attinghausen. In: Historisches Neujahrsblatt des Kantons Uri, 63-73.

Boschetti-Maradi, A. (2004). Höfische Sachkultur - archäologische Zeugnisse aus dem Kanton Bern, Mittelalter. In: Zeitschrift des schweizerischen Burgenvereins, 57-65.

Durrer, R. (1898). Die Ruine Attinghausen. In: Anzeiger für schweizerische Altertumskunde, 7-52 und 79-92.

Gasser, H. (1979). Pilotmanuskript der Gemeinde Attinghausen. Altdorf.

Gasser, H. (2012). Die Burgruine Attinghausen. In: Historisches Neujahrsblatt des Kantons Uri, 11-62.

Gollnick, U. (2012a). Burgruine Attinghausen. Zwischenbericht der Bauforschung (Textund Abbildungsteil). Moudon (Typoskript).

Gollnick, U. (2012b). Die Restaurierung der Burgruine Attinghausen in den Jahren

2011/12 - Bericht der Bauforschung. In: Historisches Neujahrsblatt des Kantons Uri, 74-90.

Meyer, W. (1979). Gesamtdokumentation (Staatsarchiv Uri, R-400-15/Prof. Dr. W. Meyer. Attinghausen, Burgruine, archäologische Bodenfunde und Grabungs-Dokumentation). Meyer, W. (1984). Die Untersuchungen auf der Burgruine Attinghausen. In: Meyer, W. / Obrecht, J. / Schneider, H. (Hrsg.). Die bösen Türnli. Archäologische Beiträge zur Burgenforschung in der Urschweiz (= Schweizer Beiträge zur Kulturgeschichte und Archäologie des Mittelalters). Olten/Freiburg, 7-36.

Stöckli AG (2010). Bericht zur geplanten Restaurierung. Stans.

Zeller-Werdmüller, H. (1884). Denkmäler aus der Feudalzeit im Lande Uri (Das Kästchen von Attinghausen). In: Mitteilungen der Antiquarischen Gesellschaft 5/21. 

Das Forschungsprojekt Surenenpass 
Summary: Caves and rock shelters - Naturally protected areas on the Surenen Pass trail.

The Muotathal speleologist Walter Imhof explains the geological conditions that are required to provide areas of natural protection and describes the advancement of the earliest humans into the Alpine region in Central Switzerland. Besides the fieldwork, which was supported by the Ostschweizer Gesellschaft für Höhlenforschung (OGH) [Speleological Society of Eastern Switzerland] and the Arbeitsgemeinschaft Höllochforschung (AGH) [Hoelloch Cave Research Association], written records such as the Uri Book of Names provided information on numerous caves and rock shelters, some of which were located in the municipality of Attinghausen. Some of these caves and rock shelters have since been forgotten and can no longer be located, whilst others have now been archaeologically examined, sampled and surveyed. The results form the basis for an annotated catalogue. The largest cave, the Hölloch above the centre of the village of Attinghausen, and two rock shelters located directly on the Surenen Pass and at Surenen-Gritschen were the most outstanding features recorded. Although no prehistoric traces have so far been found in the naturally protected areas around Attinghausen despite the sometimes extraordinarily advantageous locations, the inventory of Attinghausen caves and rock shelters nevertheless offers an interesting overview of a variety of natural features, enhanced by bone finds and today's fauna. 


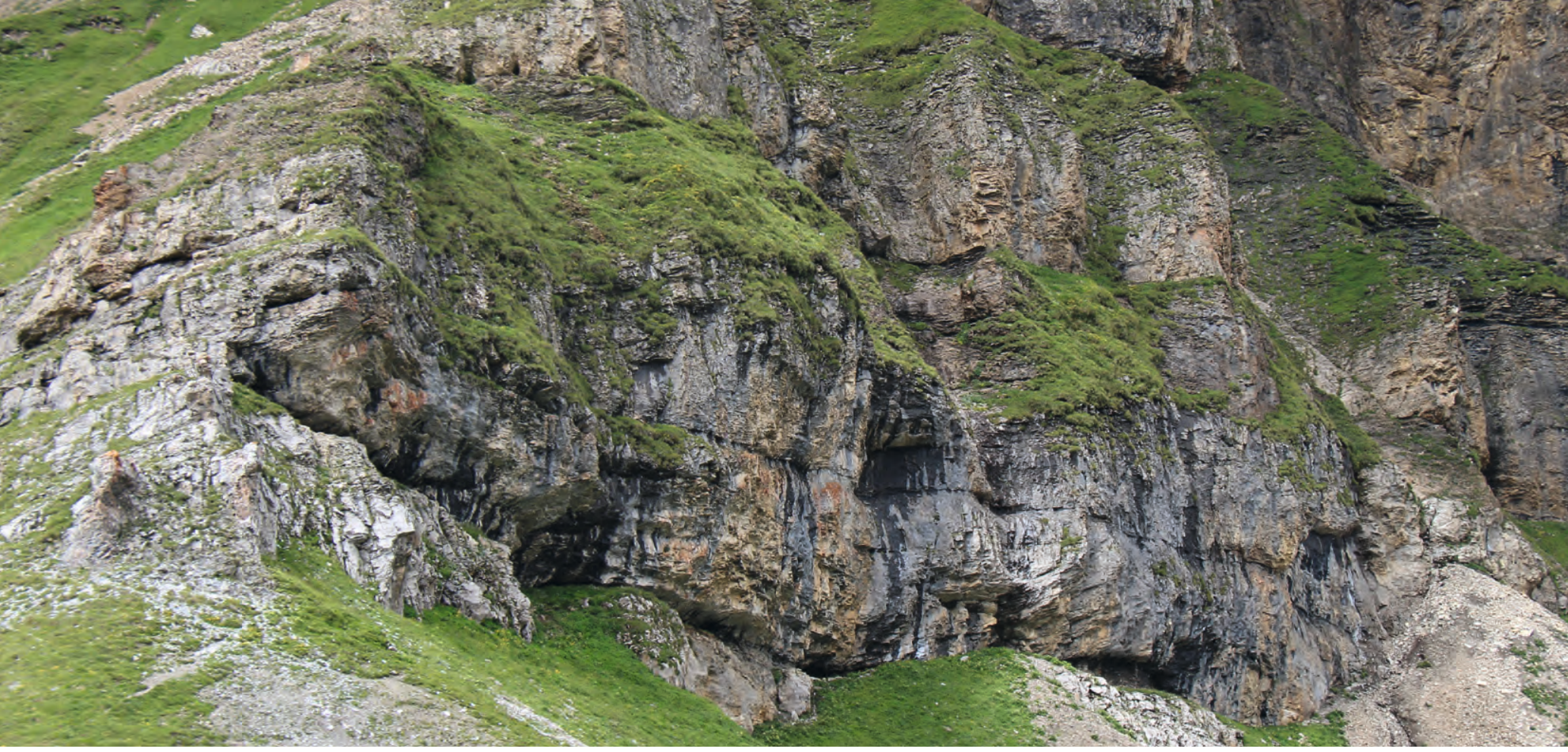

\section{Höhlen und Balmen - Natürliche Schutzräume am Surenenpassweg}

Entlang des Surenenpasswegs finden sich nur wenige natürliche Schutzräume - umso wichtiger waren diese Orte für die Passgänger in den vergangenen Jahrhunderten. Neben der Feldforschung wurde auch das Urner Namenbuch ausgewertet, das immerhin neun Balmen auf dem Attinghauser Gemeindegebiet verzeichnet, des Weiteren wurden die Datenbestände der Ostschweizer Gesellschaft für Höhlenforschung (OGH) konsultiert.

\section{Geologische Voraussetzungen}

Zu den Naturgegebenheiten einer Landschaft gehören vor allem ihre Lage und ihre Beschaffenheit. Es macht einen Unterschied, ob Menschen in einer ebenen, einer gebirgigen Landschaft oder am Meer leben. Auch das Klima spielt eine entscheidende Rolle. Die Geschichte der Innerschweiz wird im Wesentlichen von ihren Raumverhältnissen bestimmt. Den ersten Siedlern boten sich in den abgeschlossenen, karstreichen Tälern in den Gebirgen um den Vierwaldstättersee unzählige natürliche Unterstände, seien es Höhleneingänge, Balmen oder Felsblöcke. ${ }^{1}$

Das Verschwinden der Gletscher verminderte den Druck auf die Bergflanken und Felswände, was mancherorts zu Erdrutschen und Felsabbrüchen führte. Natürliche Unterstände unter Felsblöcken, auch Abri sous bloc genannt, finden sich somit vorwiegend in Gebieten, die mit Geröll und mit Steinblöcken übersät sind, die von nacheiszeitlichen Felsabbrüchen oder kleinen Bergstürzen stammen. Grössere nutzbare Hohlräume zwischen Felsblöcken werden als Versturzhöhlen bezeichnet. Balmen dagegen befinden sich vorwiegend am Fuss von Felswänden und können in unterschiedlichem Gestein, sehr häufig aber im Kalkgestein, auftreten. Grosse Höhlensysteme entstanden phreatisch, sie wurden vom Schmelzwasser der Eiszeit ausgewaschen. 


\section{Die Eroberung des Alpenraums}

Nach dem Rückzug der Gletscher wurden die freigegebenen Gebiete rasch von ersten Pionierpflanzen und allmählich auch von der Vegetation zurückerobert. Das war Voraussetzung für die Einwanderung von Tieren, die prähistorischen Jägergruppen als Beute dienten. Schon bald danach wagten sich die ersten Jäger ins Gebirge, um vor allem den Steinböcken, Gämsen, Hirschen, Rehen und Murmeltieren nachzustellen. Sie standen dabei überall vor den gleichen Schwierigkeiten: Unter anderem mussten sie für sich Schutz suchen sowie einen geeigneten Aufbewahrungsort für ihre Produkte finden. Instinktiv wurden Höhleneingänge oder Balmen aufgesucht. ${ }^{2}$ Flavio Zappa schrieb dazu sehr treffend: "Es besteht kein Zweifel, dass sich der Mensch von den Räumen, die die Natur ihm zur Verfügung stellte, angezogen fühlte, doch ist es eher unwahrscheinlich, dass er sie immer bezugsbereit vorfand. Um einen ebenen Boden und nutzbares Volumen zu erhalten, musste er im Gegenteil oft Erde und Schutt wegräumen, Steine entfernen und das Terrain nivellieren ${ }^{3}{ }^{3}$ Es brauchte weiterhin Mauern, Schutzdächer oder Ablage- und Arbeitsflächen. Oft waren solche Eingriffe massiv, andere Baumassnahmen sind hingegen kaum noch zu erkennen.

Die Jägergruppen besassen ein Netz von Jagdstationen in den einzelnen Geländekammern, die sie mit sicherem Instinkt auswählten und auf ihren Beutezügen immer wieder aufzusuchen pflegten: Funde beweisen, dass diese Plätze über Jahrtausende hinweg immer wieder genutzt wurden. Die sommerliche Jagdsaison dauerte lediglich ein paar Monate, danach kehrten die Jäger in ihre Basislager in den Haupttälern zurück. ${ }^{4}$

Es gab mit Sicherheit auch Freilandstationen an Wasserstellen, Bachläufen oder anderen exponierten Stellen, von denen in der Urschweiz aber bislang nur wenige bekannt sind. Sie zu finden, ist äusserst schwierig, da sie meist entweder erodiert oder mit gewaltigen Sedimentschichten überdeckt sind. Eine Ausnahme bildet die Freilandstation in Einsiedeln-Langrüti, die in die ausgehende Altsteinzeit datiert. ${ }^{5}$
2 Amrein 1939, 47-60. - Curdy/Praz 2002, 69-88.

3 Zappa 2005, 69.

4 Curdy/Praz 2002, 69-88. - Leuzinger/ Affolter/Beck et al. 2016.

5 Leuzinger-Piccand 1996, 7-26.
Titelbild: At.115

Balmwand am Surenenpass (Ansicht) Attinghausen-Surenenpasshöhe LK 1191 - 687 075/189 437

$2291 \mathrm{~m}$ ü.M.

Foto M. Sauter, 2014

Erdrutsche und Felsabbrüche formten Trümmerlandschaften. Die Felsblöcke konnten mit wenig Aufwand als Unterschlupf hergerichtet werden. Im Mittelpunkt ist der Abri sous bloc "Gritschen 2" (At.123) zu erkennen. Foto W. Imhof, 2014

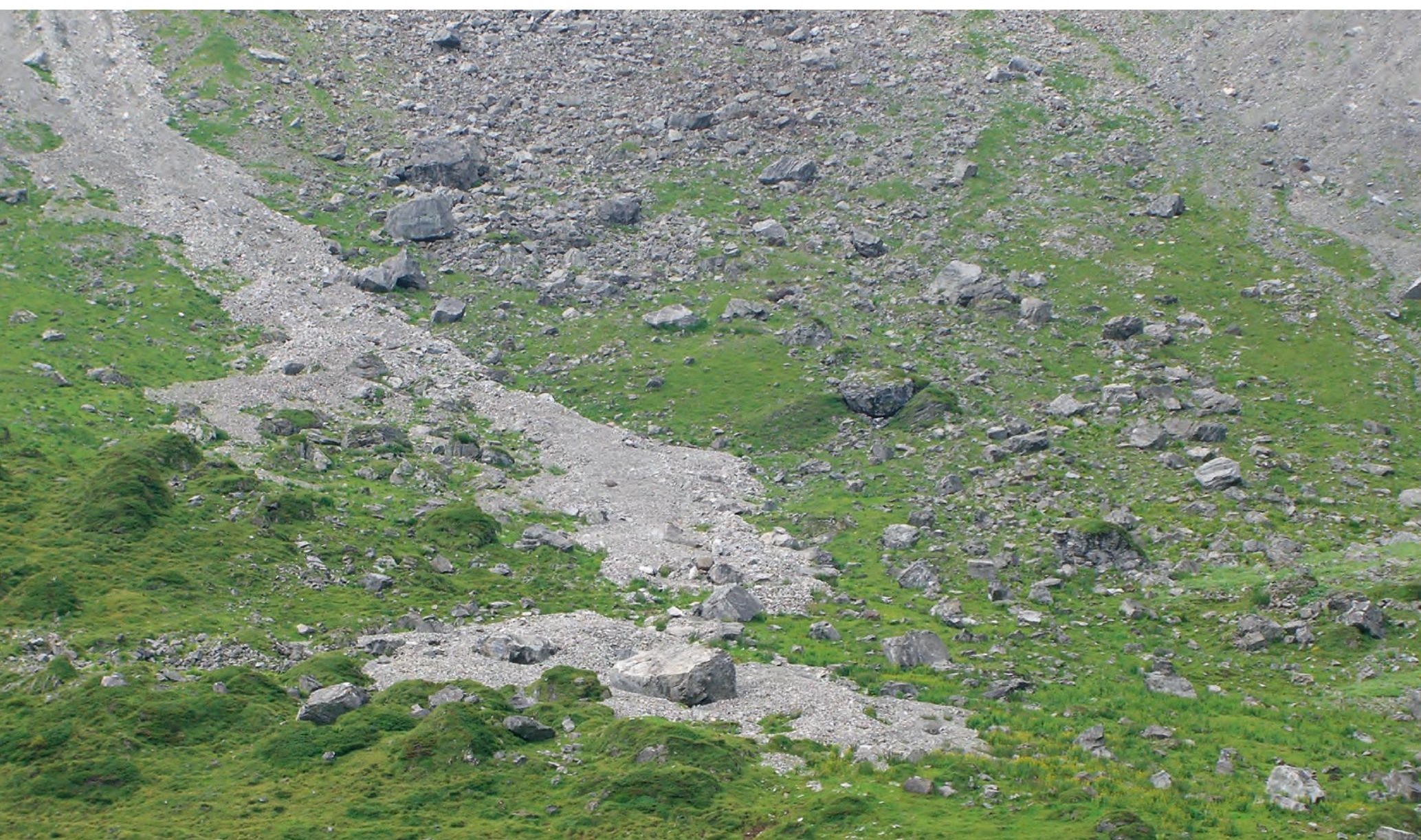


Um eine lichte Höhe zu erreichen, wurde der Eingangsbereich dieses Abris abgetieft und mit Sitzgelegenheiten ausgestattet.

At. 123

Abri sous bloc "Gritschen 2" (vorderer

Raum)

Attinghausen-Gritschen

LK 1191 - 682 000/187 740

$1941 \mathrm{~m}$ ü.M.

Foto M. Sauter, 2014

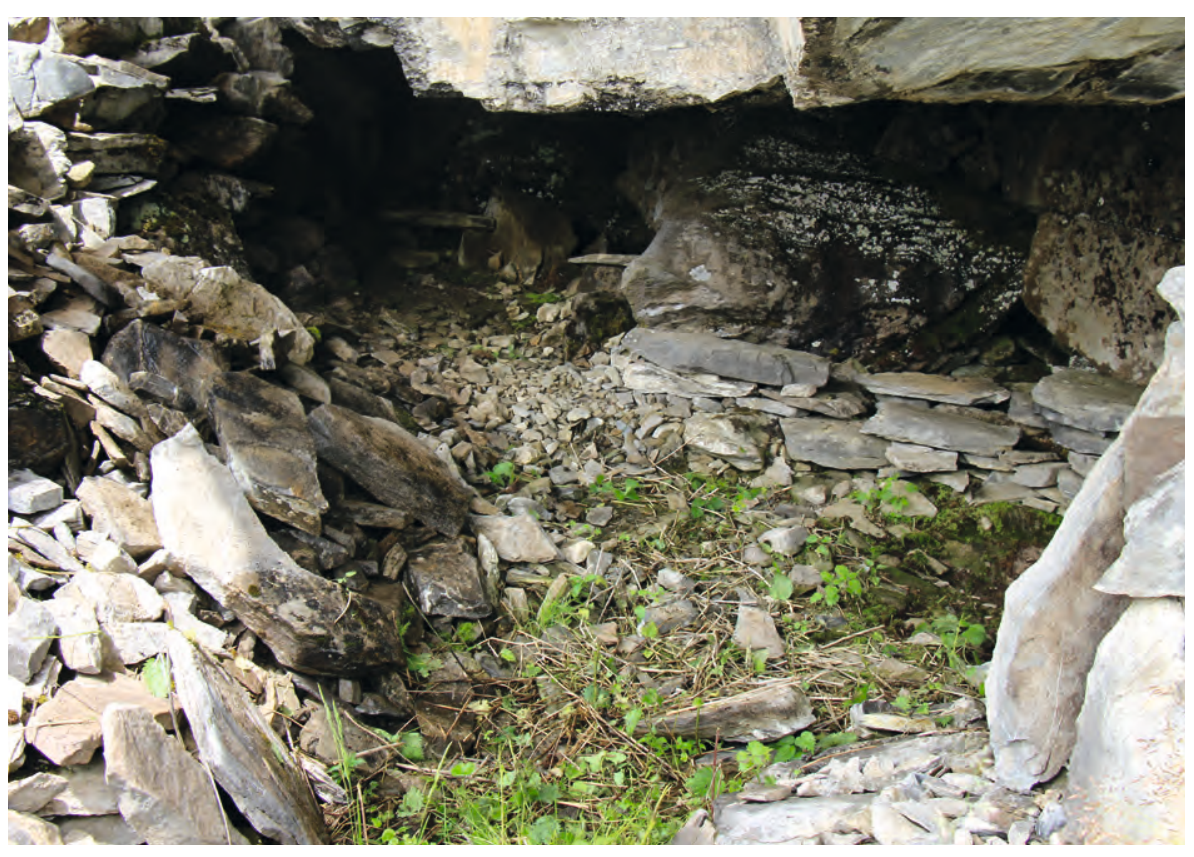

Die jagdstrategischen Punkte im Gelände erfüllten eine wichtige Funktion in der Jagdtechnik urzeitlicher Menschen. Schlachtabfälle - meist Knochen von Rothirsch oder Steinbock - wurden in Karstschächten oder Höhlen entsorgt, um nicht in der Umgebung lebende Raubtiere auf den Lagerplatz aufmerksam zu machen. Die Höhlen- und Balmnutzer hinterliessen somit Spuren, die Rückschlüsse auf ihr Alltagsleben zulassen. Spuren, die in Gebirgsregionen und Alpgebieten jedoch spärlich und teilweise recht unscheinbar sind, etwa Reste von Feuerstellen oder Bearbeitungsspuren an Knochen im Glücksfall Steinwerkzeuge, Bronzebeile oder Scherben von Gefässen. Wie bei einem Puzzle ergeben viele Stücke zusammen jedoch ein recht detailliertes Bild der Lebensweise unserer Vorfahren. ${ }^{6}$ Neben Mauerresten und Feuerstellen handelt es sich bei den allermeisten Funden aus Höhlen und Balmen um Knochen einer bemerkenswert vielfältigen prähistorischen Fauna, die Anzeiger für Vegetation und Klimaentwicklung sind. ${ }^{7}$

\section{Forschungsgrundlagen}

Das Urner Namenbuch, ein Lexikon historischer Orts- und Flurbezeichnungen, kann als Grundlage einer systematischen Erforschung der natürlichen Unterstände dienen. ${ }^{8}$ Es verzeichnet über 140 Balmen, die neuerlich vor Ort überprüft werden sollten. Die Ostschweizerische Gesellschaft für Höhlenforschung $(\mathrm{OGH})$ führt in ihrem Höhleninventar über den Kanton Uri zudem mehr als 70 Höhlen. Viele Höhleneingänge übten ebenfalls eine natürliche, den Balmen ähnliche Schutzfunktion aus, und sollten daher auch näher untersucht werden.

Selbst wenn die Namensgebung vieler natürlicher Unterstände mittelalterlich oder neuzeitlich ist, kann davon ausgegangen werden, dass bei vielen die Nutzung bedeutend früher einsetzte. Ein kürzlich gemachter Holzfund sowie Reste eines Reh- und eines Rothirschgeweihs in einer Balm am Übergang vom Maderaner- ins Hinterrheintal datieren aus der Zeit um 6000 v.Chr. Es ist zu vermuten, dass prähistorische Jäger für die Deponierung dieser Geweihreste verantwortlich sind. ${ }^{9}$ Die Stremlücke dürfte als inneralpiner Sekundärpass damals eine gewisse Bedeutung gehabt haben. ${ }^{10}$ Auch die Suche nach Kristallen darf im Zusammenhang mit der 2800 m ü.M.
6 Imhof/Obrecht 2005, 30-35. - Imhof 2013, 23-30.

Imhof 2012, 16-20.

Hug/Weibel 1988-1991.

ETH-59449: $7030 \pm 28$ BP, 5988-5871 BC.

10 Imhof 2015. 
gelegene Fundstelle nicht ausser Acht gelassen werden. Die Balm dient heutzutage Strahlern (= Kristallsuchern) als Zustieg in eine Kluft. ${ }^{11}$ Dieses Zeitfenster passt mit den Forschungsergebnissen, die im benachbarten Muotatal gemacht wurden, überein. Dort haben systematische Untersuchungen von Balmen und Höhleneingängen über 12000 Jahre alte Spuren prähistorischer Jäger zutage gefördert. ${ }^{12}$

\section{Höhlen am Surenenpassweg - Katalog}

\section{Holloch (At.075/AGH-Plan 3030)}

LK 1192, 690 590/189 034, 890 m ü.M.

Der Begriff Hol bedeutet Loch oder Höhle. Die Höhle Holloch befindet sich südlich der Hofgebäude eines Heimwesens am Fusse einer kleinen Felswand oberhalb von Attinghausen und war namensgebend für die Flur und den landwirtschaftlichen Betrieb. Die Vermessung durch Mitglieder der Arbeitsgemeinschaft Höllochforschung (AGH) und der Höhlengruppe Muotathal (HGM) ergab eine Länge von insgesamt $81 \mathrm{~m}$. Das erste Aufmass von 1892 brachte bereits ein sehr ähnliches Ergebnis. ${ }^{13}$

Der imposante, etwa $4 \mathrm{~m}$ messende Eingangsbereich dieser phreatischen Höhle ist annähernd rund geformt und vorteilhaft nach Südosten ausgerichtet. Der Höhlengang führt fast parallel zur Aussenwand nach Nordwesten. Er steigt zuerst leicht an und fällt nach etwa $20 \mathrm{~m}$ bis über $30^{\circ}$ steil ab. Auf dem höchsten Punkt befindet sich eine etwa $4 \mathrm{~m}$ hohe und ebenso lange und breite Halle. Bis hierhin ist der Gang aufrecht begehbar. Nach etwa $60 \mathrm{~m}$ teilt sich der Gang. Linkerhand ist er noch etwa $1 \mathrm{~m}$ hoch und über $2 \mathrm{~m}$ breit und endet $10 \mathrm{~m}$ weiter, indem der Gang bis zur Decke mit Sedimenten gefüllt ist. Rechterhand führt er steil nach unten und endet nach etwa $12 \mathrm{~m}$ an einem Siphon.

Im Inneren der Höhle trifft man im abwärts führenden Teil auf der ganzen Gangbreite auf viel Sinter - Kalk, der aus dem Wasser ausgeschieden wurde und Ablagerungen gebildet hat. An zwei Stellen ist die 15 bis $20 \mathrm{~cm}$ mächtige Sinterschicht durchbrochen, darunter liegt Geröll. Das Gangprofil muss demzufolge ursprünglich einem runden Stollen mit mindestens 1,5 m Durchmesser entsprochen haben. Der viele Sinter zeigt, dass hier
11 Entdecker der Balm und Finder der Geweihstangen ist Heinz Infanger, Attinghausen.

12 Imhof 2012, 21-26.

13 Suter/Imhof 2010, 13-19. - Ein Ausflug nach dem "Hohlloch" in Attinghausen. In: Urner Wochenblatt 23/1892.
At.075

Holloch

Attinghausen-Hol (Grundriss/Schnitt)

LK 1192 - 690 590/189 034

$890 \mathrm{~m}$ ü.M.

Skizze D. Betschart, 2009

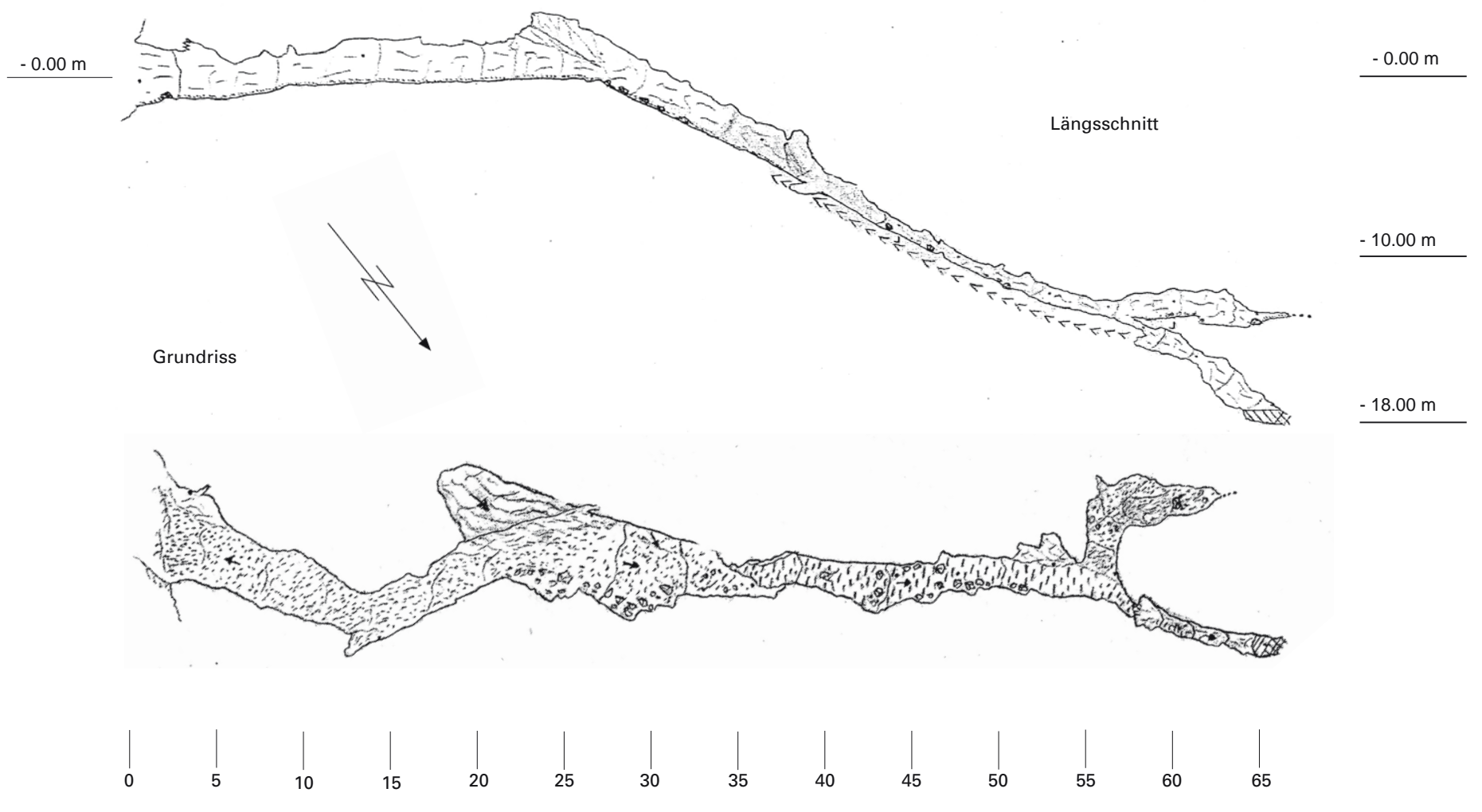



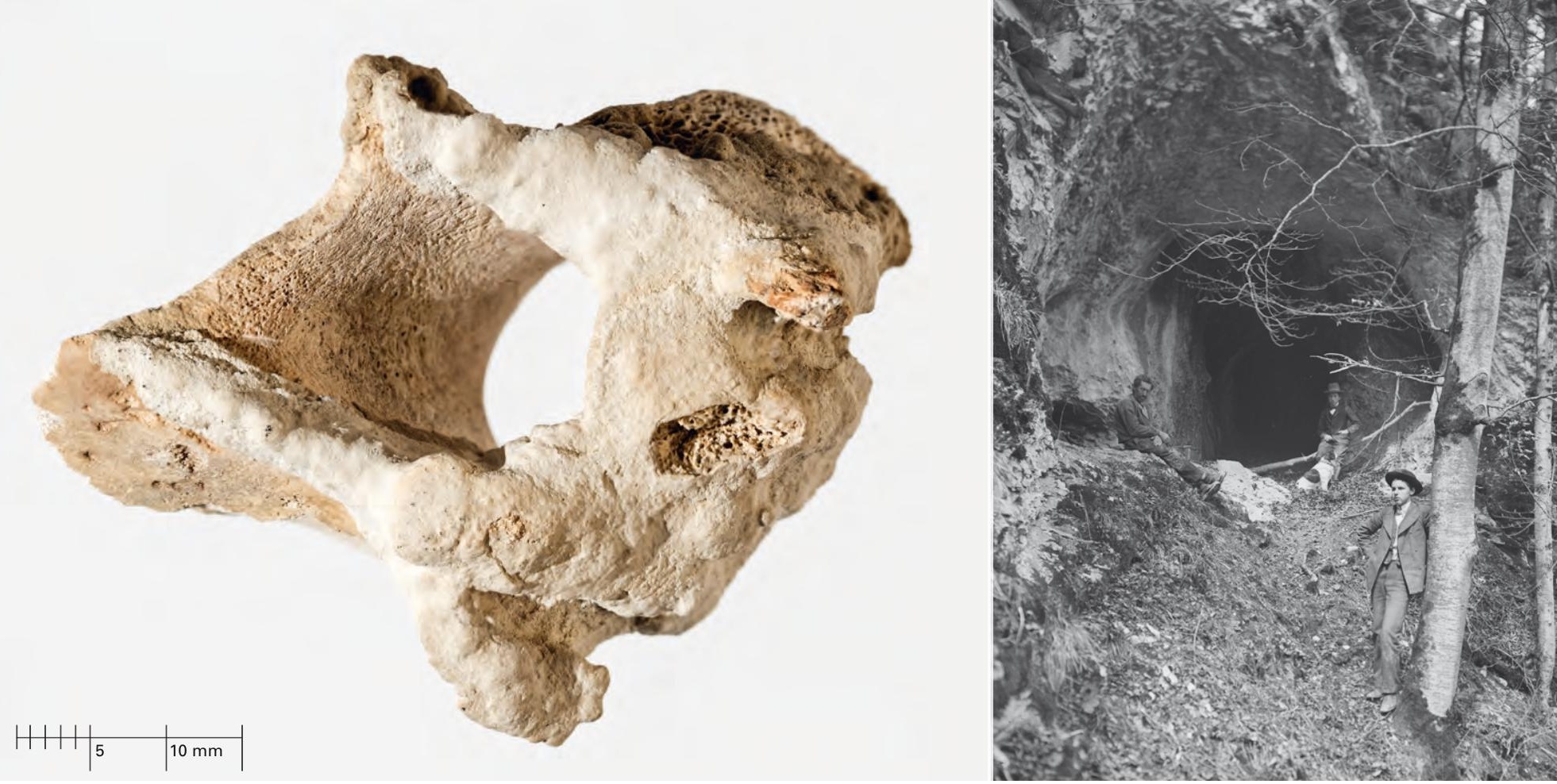

Dieser stark versinterte Wirbel eines Rothirschs dürfte aus einer Schlachtung stammen und datiert gemäss Radiokarbondatierung aus dem Zeitraum 1220 bis 1285 n.Chr.

Foto M. Käch, 2015

Eingang des Hollochs mit Besuchern. Foto M. Aschwanden, um 1890 (Staatsarchiv Uri)
14 Die Knochen wurden in den 1930er Jahren durch Johannes Hürzeler vom Naturhistorischen Museum Basel bestimmt

15 Freundl. Mitteilung von Casparina Aschwanden, Kantonsmittelschule Uri. das Wasser langsam einwärts abgeflossen ist. Die Fliessfacetten sind nicht eindeutig erkennbar, aber der phreatische Gang hat auch schnelle Wasser gesehen. Dieses Wasser muss Richtung Eingang geflossen sein, denn die Geröllmassen unter der Sinterschicht wären ansonsten wohl nach unten, ins Höhleninnere, geschwemmt worden. Insgesamt weist das Holloch ausserordentlich viele verschiedene Sinterformationen auf.

Im ebenen Eingangsbereich des Hollochs sind menschliche Aktivitäten nachweisbar: in Form von Feuerstellen, zudem liegt angekohltes Holz herum. Die in der Höhle verstreut zu findende Holzkohle dürfte von Fackeln stammen. Herumliegende Flaschen, Batteriereste, Kerzen usw. sind Zeugnisse einer starken Verschmutzung der Höhle - im Sinne des Höhlenschutzes wäre es wünschenswert, den Abfall zu entfernen.

Die Wände am Höhlenende zieren unzählige Inschriften von Besuchern, die ältesten datieren aus dem 16. Jahrhundert. Viele Namen und Anfangsbuchstaben sind gut lesbar, andere leider nicht (mehr) zu entziffern. Erstaunlicherweise hat es ganz unten beim Siphon auch Inschriften an der Höhlendecke. Diese hätte man beim heutigen Wasserstand nicht anbringen können, ohne nass zu werden - ein Hinweis, dass der Wasserspiegel dieses Siphons durchaus tiefer liegen kann.

Es gibt auch Leben im Holloch. Der waagrechte Eingangsbereich bietet vielen Höhlen-Kreuzspinnen (Meta menarii L.) an Wänden und Decke einen geschützten Lebensraum. Die Höhle beherbergt auch den Weberknecht (Phopilio alangium Zimmermann) und den sogenannten Höhlenspanner (Triphosa dubitata L.), eine weit verbreitete Schmetterlingsart, die vornehmlich Höhleneingänge aufsucht.

In der Naturhistorischen Sammlung der Kantonsmittelschule Uri lagern zahlreiche Knochen von längst verstorbenen Tieren und Menschen aus Grabungen und Höhlen des Kantons Uri. ${ }^{14}$ Darunter ist auch eine Schachtel mit Knochen aus dem Holloch, die von einem Fuchs (Vulpes vulpes), einem Hase (Lepus europaeus), einem unbestimmten Vogel, einem kleinen Wiederkäuer und einer Erdkröte (Bufo bufo) stammen. ${ }^{15}$

Ein Besuch in der Höhle brachte einen weiteren Knochenfund zu Tage: Es handelt sich um einen stark versinterten Wirbelknochen eines Rothirschs 


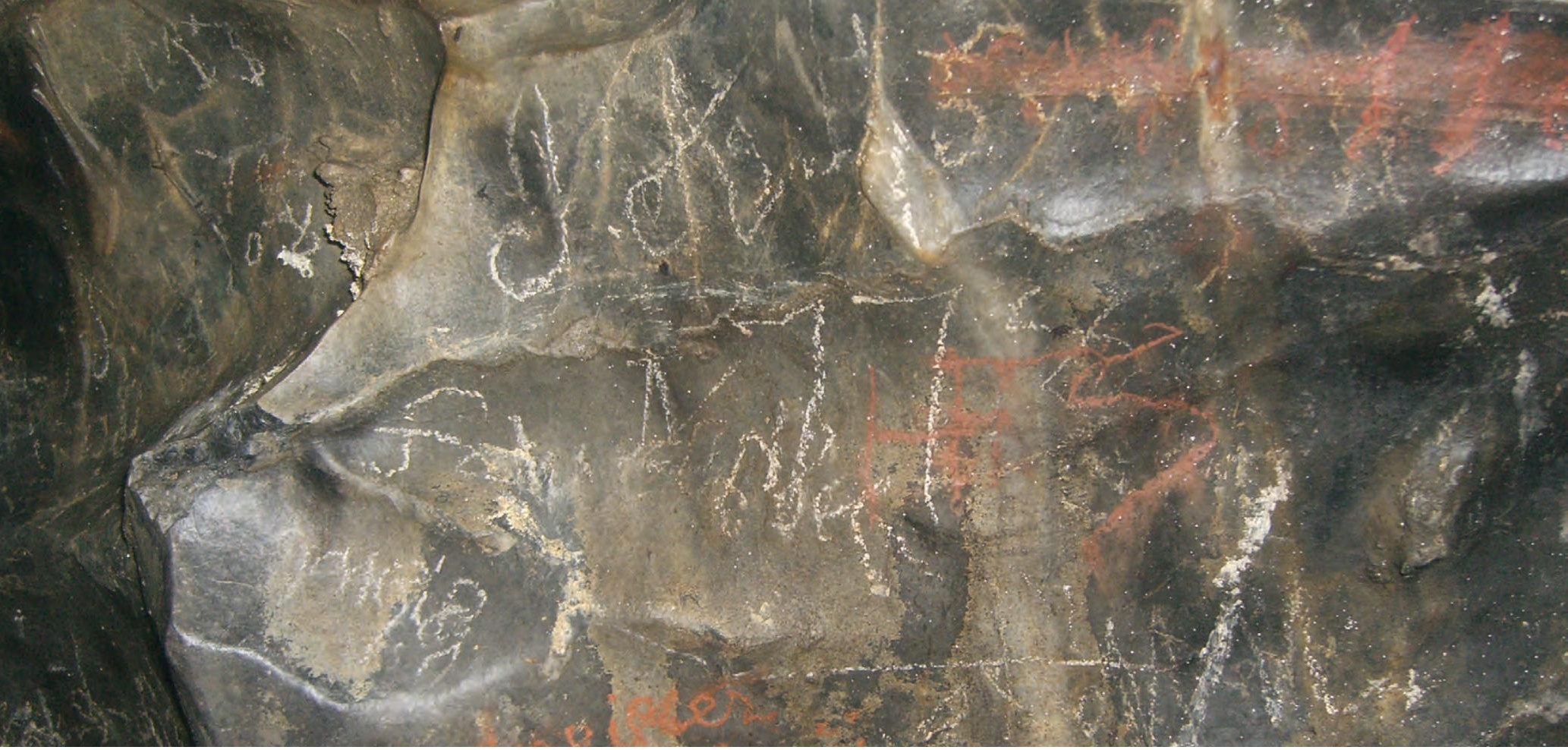

(Cervus elaphus). Knochen von Rothirschen in Höhlen sind mit grösster Wahrscheinlichkeit eingeschleppt worden, da Rothirsche Höhlen nicht freiwillig aufsuchen. Der Wirbelknochen lag im hinteren, steilen Höhlenteil und war aufgrund der Versinterung im umgebenden Gestein kaum zu erkennen. Im Allgemeinen stammen Rothirschknochen in Höhlen fast immer von Schlachtungen. Die Rothirschprobe wurde mittels der Radiokarbonmethode im Labor für lonenstrahlphysik der ETH Zürich gemessen: Sie datiert aus der Zeit um 1220 bis 1285 n.Chr. ${ }^{16}$ - an der bereits erwähnten prähistorischen Abfallentsorgung wurde offensichtlich bis in die letzten Jahrhunderte hinein festgehalten.

Der Eingangsbereich des Hollochs bietet ausreichend geschützten, vor Tropfwasser sicheren Raum. Die Aktivitätszone erstreckt sich dank des hohen Eingangsportals, das viel Licht in die Höhle lässt, weit ins Höhleninnere. Zudem erleichtert der hohe und waagrecht verlaufende Höhlengang über etwa $20 \mathrm{~m}$ den Aufenthalt. Die Höhle ist - wie die Altersanalyse des Rothirschknochens zeigt - mindestens seit dem Mittelalter bekannt.

Das Holloch wurde bislang nicht archäologisch untersucht. Das steil abfallende Vorgelände und der Eingangsbereich sind leider zu wenig tiefgründig, nach wenigen Zentimetern erscheint bereits der anstehende Fels. Eine Spurensuche in diesem Gelände wäre sehr aufwendig und wenig erfolgversprechend. Demgegenüber ist der Höhlenboden auf den ersten $20 \mathrm{~m}$ reichlich sedimentiert. In diesem Bereich liessen sich problemlos Sondierungen anlegen. Eine archäologische Untersuchung wäre wünschenswert, da ein dermassen gut erreichbarer und geschützter Raum prähistorischen Menschen sicher nicht entgangen sein dürfte.

\section{Höhle S-Hol (At.098, SGH 31597)}

LK 1192, 690 730/189 170, 725 m ü.M.

Die Höhle S-Hol befindet sich ebenfalls auf dem Heimwesen Hol, unmittelbar unterhalb der Sandbalm. Der Höhleneingang liegt am Fuss einer nahen Felswand und ist recht schwer zu finden: Der Weg führt über das Weideland am Stall unterhalb des Heimwesens Hol weiter bis zum südlichsten Zipfel der Wiese, die hier bis in den Wald hinein reicht.
At.075

Holloch (Inschriften)

Attinghausen-Hol

LK 1192 - 690 590/189 034

$890 \mathrm{~m}$ ü.M.

Foto W. Imhof, 2010 
17 Höhlenpost 29/1972.

18 ETH-61961: 148 24 BP, 1667-1777 AD.
Der Eingang von S-Hol ist nach Osten orientiert. Bei der Höhle handelt es sich um eine inaktive Wasserhöhle, die 1972 durch René Scherrer von der $\mathrm{OGH}$ untersucht und vermessen wurde. Der etwa $4 \times 3$ m messende Eingang führt im Quinterkalk in den Berg. Der leicht ansteigende Eingangsbereich ist mit verwittertem Fels und Frostbruchschutt bedeckt. Die lichte Höhe des Höhlengangs nimmt kontinuierlich ab. Nach etwa $15 \mathrm{~m}$ erschweren mit Lehm überzogene Felsbrocken das Weiterkommen. Die Höhle ist noch etwa 10 m kriechbar, führt dann leicht abwärts weiter und kann nicht mehr weiterverfolgt werden. Die Vermessung ergab eine Länge von 28,5 m. Der Eingangsbereich von S-Hol bietet Schutz und lädt zusammen mit dem kleinen, begrenzten Vorplatz zum Verweilen ein. ${ }^{17}$

An den Höhlenwänden sind Spinnen (Meta menardi), Stechmücken (Culicidae), Weberknechte (Phopilio alangium) und Tausendfüssler (Niphargus sp.) auszumachen, ausserdem vermutlich die Spuren eines Fuchses (Vulpes vulpes). Hinweise auf eine Anwesenheit von Menschen sind jedoch nicht zu finden.

Am 5. Mai 2014 wurde direkt an der nordöstlichen Eingangswand eine eng begrenzte Kellensondierung von $20 \times 20 \mathrm{~cm}$ angelegt. Die anfänglich zahlreichen verwitterten Steine nehmen bereits nach $10 \mathrm{~cm}$ deutlich ab. Darunter folgt eine sandige, mit kleinen kantigen Steinen durchsetzte Schicht. Bis auf eine Tiefe von $-50 \mathrm{~cm}$ bleibt diese Schicht gleich. In dieser Tiefe zeigte sich etwas Holzkohle, die zur Datierung entnommen wurde. Die Sondierung wurde auf dem Niveau der Holzkohle abgebrochen. Die entnommene Holzkohleprobe datiert in die Neuzeit. ${ }^{18}$

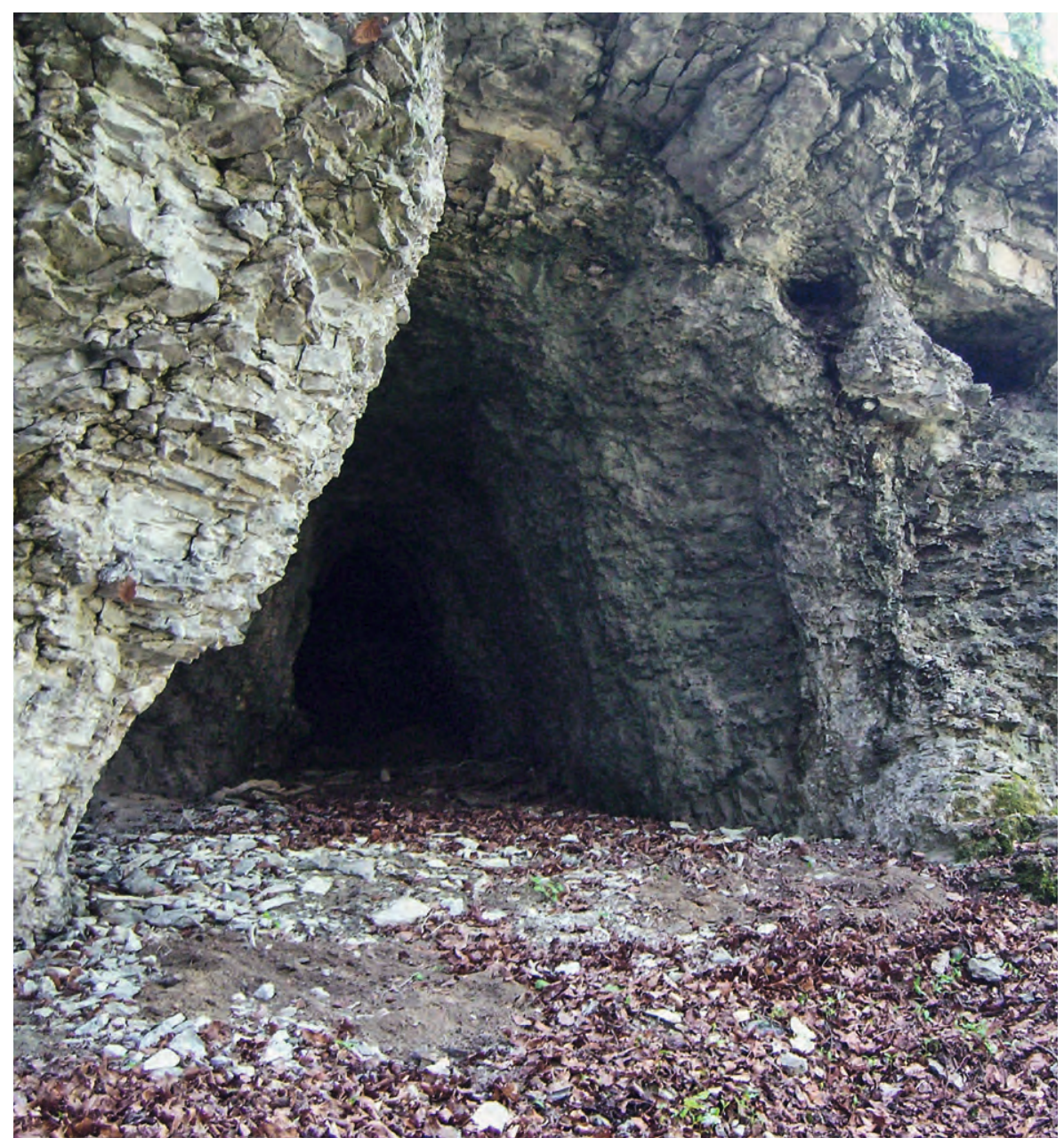

At.098

Höhle S-Hol (Eingangsbereich)

Attinghausen-Hol

LK 1192 - 690 730/189 170

725 m ü.M.

Foto W. Imhof, 2010 


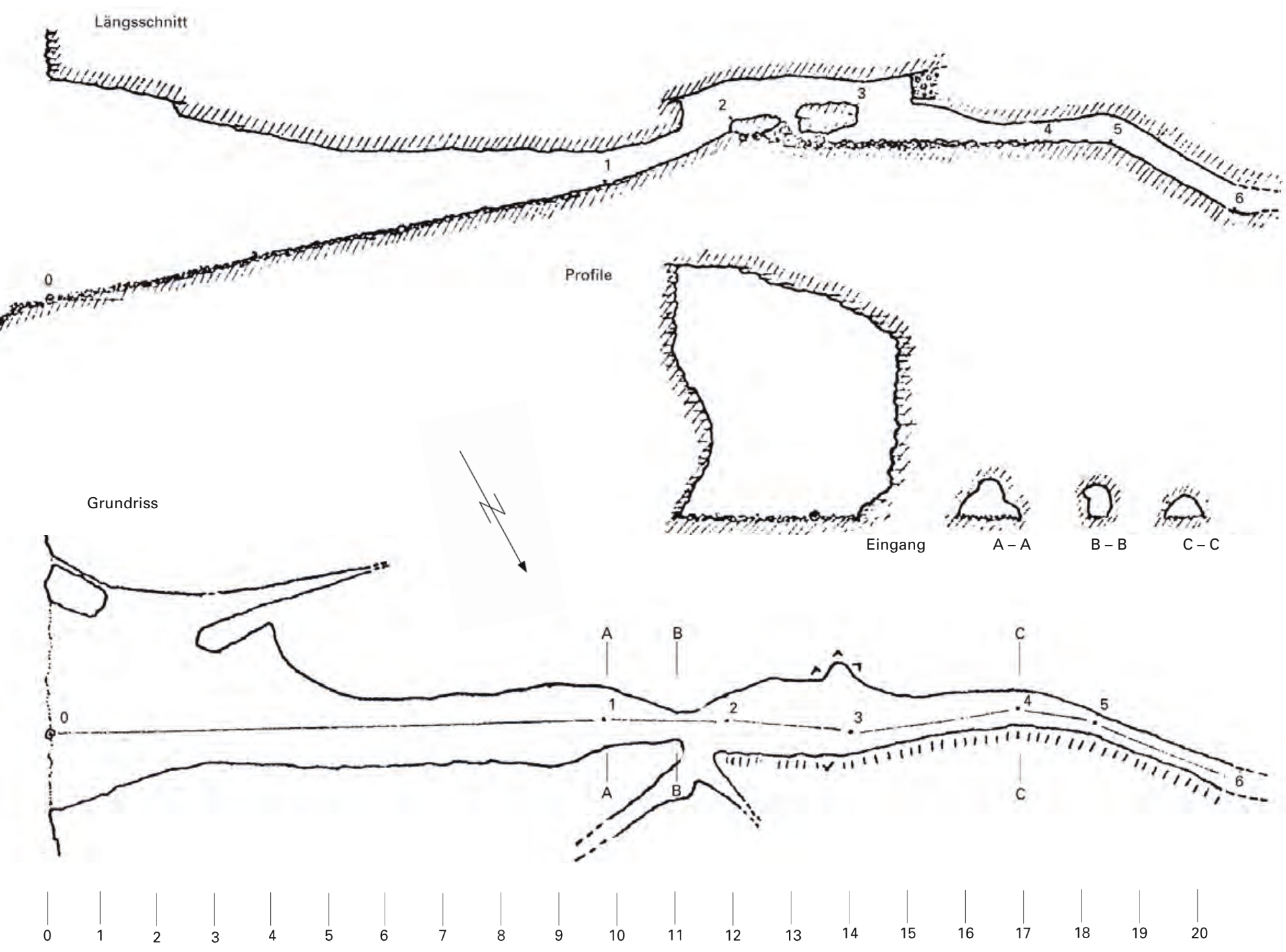

Aufgrund der Fundsituation ist das Resultat enttäuschend: Bei einer Sondierung auf $-50 \mathrm{~cm}$ in einem Höhleneingang darf ein älteres Datum erwartet werden. Wahrscheinlich wurde der Höhleneingang auch in den letzten paar Hundert Jahren von Jägern, Waldarbeitern oder von Bewohnern des angrenzenden Heimwesens regelmässig aufgesucht. Da im Rahmen der Sondierung keine Störung in der Sedimentstruktur festgestellt werden konnte, ist zu vermuten, dass die neuzeitliche Holzkohle durch Kleinsäuger in die tieferen Bodenschichten gelangte.

\section{Zibegghöhle (At.024/SGH 31596)}

LK 1192, 691 051/190 215, 452 m ü.M.

Die ebenfalls phreatisch entstandene Zibegghöhle liegt unmittelbar am Weg, der vom Restaurant Krone hinunter zum Attinghauser Reussdamm führt und heute - entgegen der historischen Streckenführung $(\rightarrow$ S. 102-121) - als Hochweg bezeichnet wird. Direkt neben dem Eingang befindet sich eine Bank, die den Wanderer zum Verweilen einlädt. Die Benennung der Höhle erfolgte nach dem Heimwesen, das sich oberhalb des Höhleneingangs befindet.

Der Eingang der Zibegghöhle befindet sich knapp $20 \mathrm{~m}$ oberhalb des Niveaus des Talbodens der Reussebene, der nacheiszeitlich durch die Reuss und die umliegenden Gebirgsbäche aufgeschüttet wurde. Daher muss sich der Höhleneingang in prähistorischer Zeit - bis etwa 7000 v.Chr. - an exponierter Lage am Ufer des Urner Sees befunden haben.

At.098

Höhle S-Hol (Grundriss/Schnitte) Attinghausen-Hol

LK 1192 - $690730 / 189170$

$725 \mathrm{~m}$ ü.M.

Skizze R. Scherrer, 1972 
19 Höhlenpost 8/1965.

20 Pater Franz Xaver Muheim (18941946) war ein eifriger Höhlenforscher, der etliche der damals bekannten Urner Höhlen erforscht und dabei viele Tierknochen ausgegraben hat: 1934/35 unter anderem die Bärenhöhle am Klausenpass, in der er mehrere Braunbär- (ETH-40289: 6160 \pm 35 BP, 5220-5000 BC), Wolf(ETH-40285: 3915 \pm 35 BP, 2490-2290 $B C)$ sowie Steinbockknochen (ETH40286: 2455 \pm 35 BP, 670-410 BC) geborgen hat. Das Fundmaterial befindet sich in der Naturhistorischen Sammlung der Kantonsmittelschule Uri.

21 Max Oechslin (1893-1979) absolvierte die Industrieschule in Zürich und studierte anschliessend Forstingenieurwesen an der ETH Zürich. Von 1930 bis 1960 war er Vorsteher des Kantonsforstamts und des Kulturamts Uri. Er war Ehrenbürger von Isenthal, der Korporation und des Kantons Uri.

22 Pater Fintan Amstad (1888-1973), Naturforscher und Universalgelehrter, wirkte als Lehrer und Bibliothekar am Kollegium Karl Borromäus in Altdorf.
Bei der Zibegghöhle handelt sich um eine periodisch aktive Wasserhöhle im Malmkalk, die nur nach ergiebigen Regenfällen und einer gleichzeitigen Schneeschmelze durch Druck aus dem Berginnern überflutet wird. Die Arbeit des Wassers ist besonders an den Fliessfacetten an der Decke gut sichtbar. Es gibt nur wenige Tropfstellen. Die Höhle neigt sich nach innen leicht abwärts und verjüngt sich stetig. Der Boden ist durchgehend mit sandigem Lehm bedeckt, vermischt mit rundlichen Steinen. Nach etwa $23 \mathrm{~m}$ taucht der an dieser Stelle sehr enge Höhlengang ins Grundwasser ein.

Die Höhle wurde 1965 von René Scherrer von der Ostschweizerischen Gesellschaft für Höhlenforschung (OGH) vermessen: Sie umfasst bis zum Siphon eine Länge von $23 \mathrm{~m} .{ }^{19} \mathrm{Im}$ Jahr 1990 unternahm die OGH einen ersten Versuch, den Siphon zu durchtauchen. Eine Engstelle im Grundwasser der Höhle verhinderte jedoch ein Durchkommen.

Wie der Anrainer, Alt-Landammann Hans Zurfluh (Jg. 1927) zu berichten weiss, haben in den 1930er Jahren Pater Franz Xaver Muheim²0, Max Oechslin $^{21}$ und Pater Fintan Amstad ${ }^{22}$ in der Zibegghöhle Grabungen vorgenommen. Aufgrund der engen Platzverhältnisse wurden Sand und Steine entfernt. Dabei sollen neben Tierknochen auch menschliche Skelette zum Vorschein gekommen und in die Naturhistorische Sammlung der Kantonsmittelschule Uri verbracht worden sein. Eine Kontrolle sämtlicher Knochenfunde brachte jedoch keine Bestätigung. In der Sammlung fehlen leider noch weitere Knochenfunde, deren Abgabe dokumentiert ist und die im Volksmund meist der Franzosenzeit zugeschrieben werden.

Hans Zurfluh bestätigte auch, dass nach intensiven Niederschlägen und der Schneeschmelze mehrfach grosse Wassermengen aus dem Eingang der

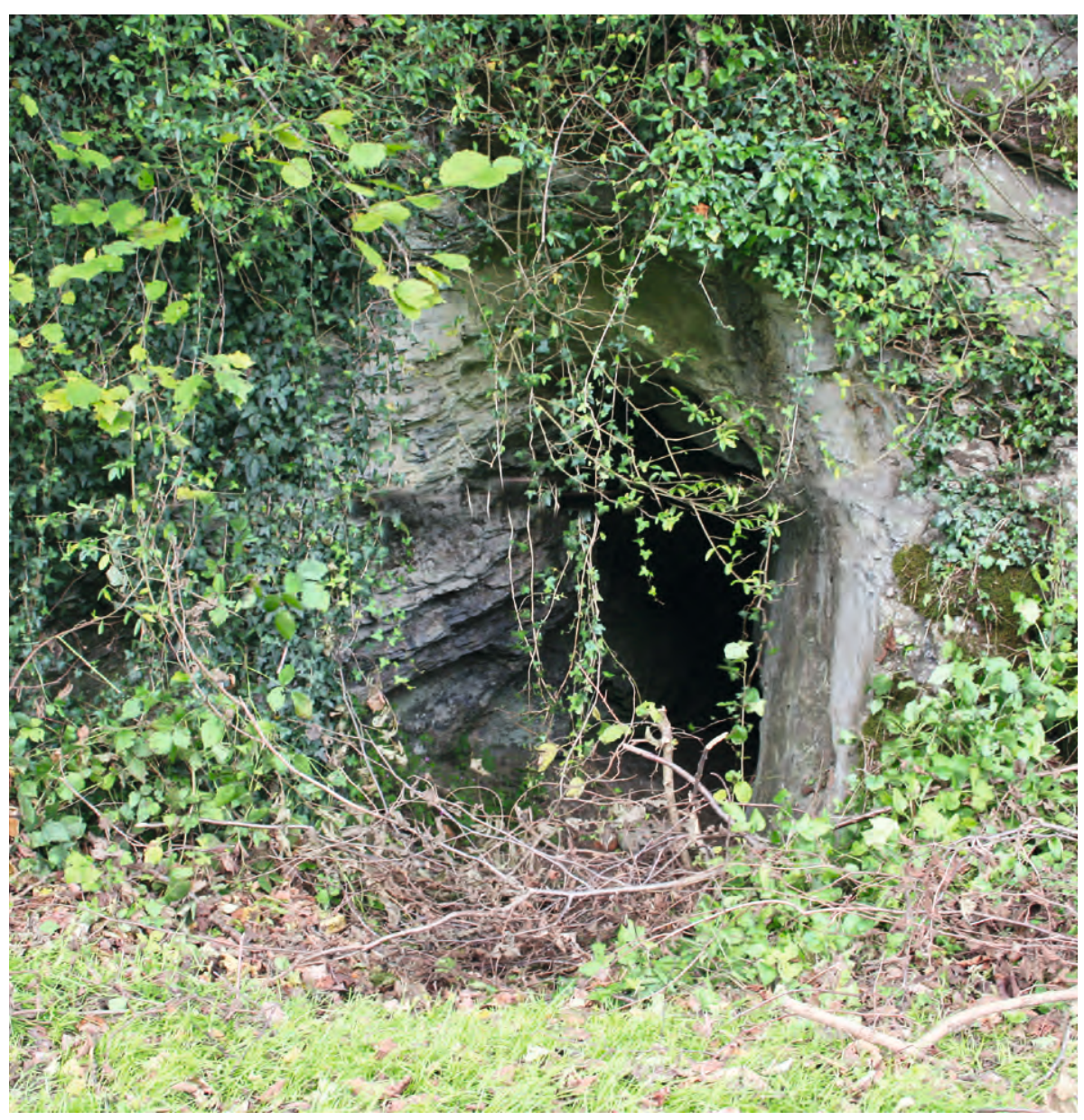

At.024

Zibegghöhle (Ansicht) Attinghausen-Zibeggi LK $1192-691051 / 190215$ $452 \mathrm{~m}$ ü.M.

Foto M. Sauter, 2009 

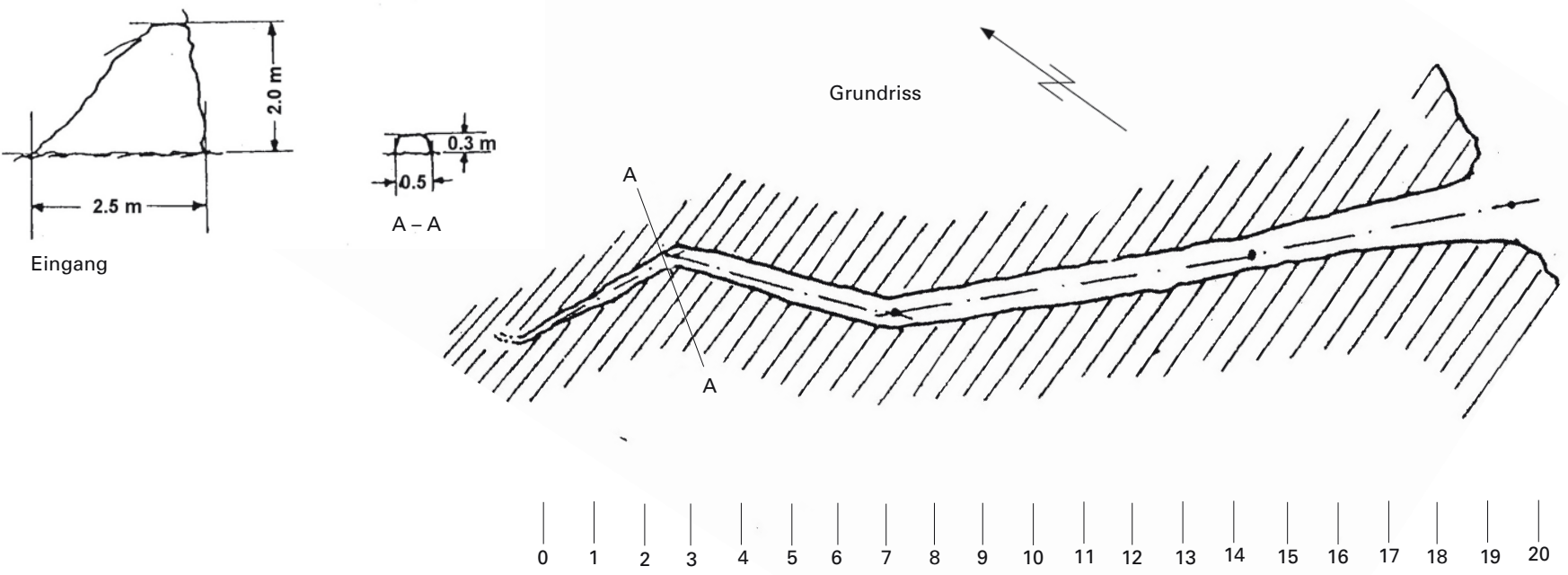

Zibegghöhle geflossen sind - dies wohl schleichend und langsam, da sonst die leichten, sandig-lehmigen Sedimente und sämtliche andere Hinterlassenschaften aus der Höhle geschwemmt worden wären.

Die Zibegghöhle beherbergt zahlreiche Insekten und Schnecken. Im hinteren Teil, kurz vor dem Siphon, konnten einige Knochen ausgegraben werden. Ein Knochenstück stammt von einem Reh (Capreolus capreolus) und weist Schnitt- oder Sägespuren auf, die mithilfe einer hochauflösenden Aufnahme dokumentiert werden konnten: Benutzt wurde ein neuzeitliches Werkzeug. Bei den anderen Funden handelt es sich um die Speiche (Radius) eines Fuchses (Vulpes vulpes) mit starker Arthrose sowie zwei Bruchstücke der Elle (Ulna), wohl zu der Speiche gehörend, sowie ein unbestimmtes Langknochenstück. ${ }^{23}$ Zudem wurde moderner Abfall vorgefunden - im Sinne des Höhlenschutzes sollte dieser entfernt werden.

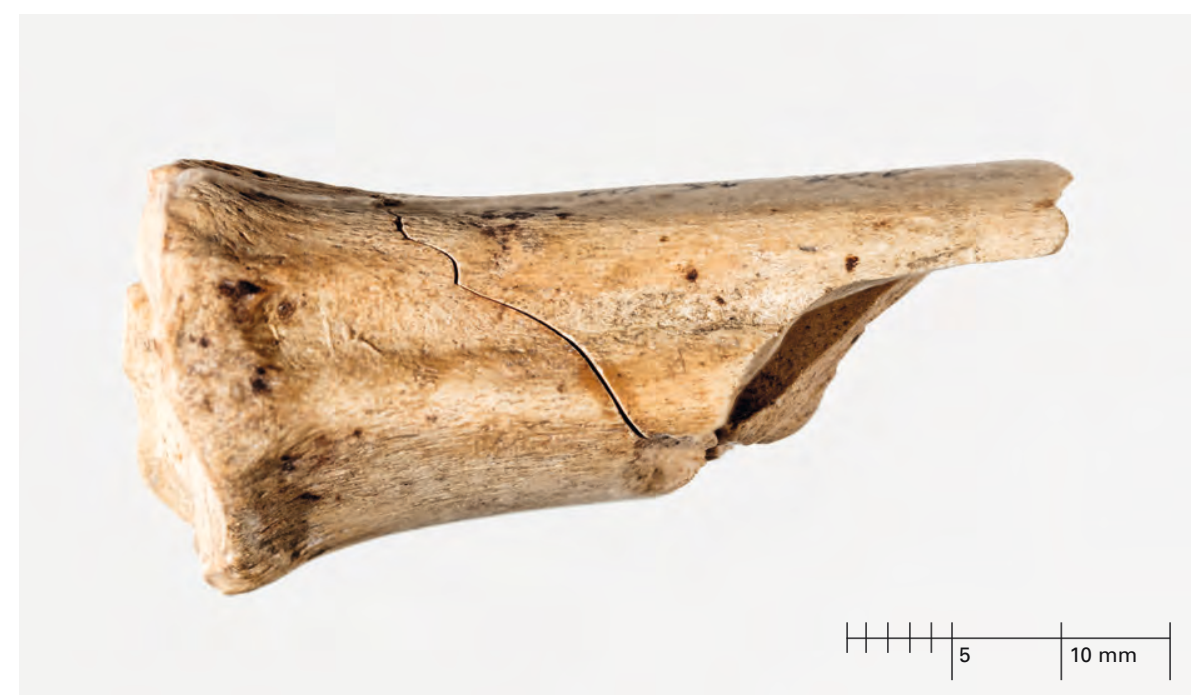

23 Bestimmung durch Werner Müller vom archäozoologischen Labor der Universität Neuenburg.

At.024

Zibegghöhle (Grundriss/Schnitte) Attinghausen-Zibeggi

LK $1192-691$ 051/190 215

$452 \mathrm{~m}$ ü.M.

Skizze R. Scherrer, 1965

Dieser Mittelfussknochen (Metacarpalia) mit Bearbeitungsspuren gehörte einem Reh. Die Spuren stammen von einem Metallwerkzeug und lassen auf eine neuzeitliche Schlachtung des Tieres schliessen.

Foto M. Käch, 2015 
24 Hug/Weibel 1988, 249-267.

25 Mündliche Bestätigung der Namengebung durch Leo Zurfluh, Landwirt auf dem nahen Hof Hol.

26 Leuzinger/Sauter/Haas et al. 2014. Sauter 2009, 56-81.
Balmen und Abris am und westlich des Surenenpasses: 1 Abri Surenenpass 2 Gritschen 2 - 3 Munggenbälmli 4 Staldenbalm - 5 Heuwbalm - 6 Geissbalm - 7 Stigibalm.

Karte swisstopo (BA16018)

\section{Balmen und Abris sous bloc - Katalog}

Im Urner Namenbuch sind für die Gemeinde Attinghausen neun Balmen aufgeführt, von denen die Heretswiibalm und die Herrenbalm abgegangen sind und die Lokalisierung der Schindelbalm fraglich ist. Bekannt und lokalisiert sind die Geissbalm (680 400/183 820), die Heuwbalm (680 580/184 880 ), die als Tristplatz diente, das Munggenbälmli (681 880/188 260), die Staldenbalm (681 460/185 350) und die Stigibalm (679 630/183 540). ${ }^{24}$ Diese Balmen befinden sich allesamt auf der Engelbergerseite des Surenenpasses zwischen Gritschen und Alpenrösli, unweit der Kantonsgrenze zu Obwalden. Die sogenannte Rot Balm im Gebiet Stock konnte noch nicht lokalisiert werden. Bekannt ist dagegen die äusserst imposante Sandbalm, die aber im Namenbuch keine Erwähnung findet. ${ }^{25}$ Sie befindet sich auf dem Heimwesen Hol, wo auch das Holloch und die Höhle S-Hol liegen.

Im Rahmen der Prospektionstouren mit den Studierenden der Hochschule Luzern - Technik \& Architektur im Jahr 2009 und den Forschungskampagnen in den Jahren 2013 und 2014 konnten weitere Balmen und Abrisous-bloc-Situationen auf dem Gebiet der Gemeinde Attinghausen und im Erstfelder Teil der Alp Waldnacht ins Inventar der alpinen Wüstungen im Kanton Uri aufgenommen werden, bislang leider ohne prähistorische Funde $\left(\rightarrow\right.$ S. 136-155). ${ }^{26}$

Etliche Unterstände sind unscheinbar und noch nicht näher untersucht worden, verweisen jedoch auf die vielfältige Nutzung - teilweise bis heute. Der folgende Katalog umfasst die untersuchten Balmen, weitere Fundorte siehe Inventar ( - S. 64-65).

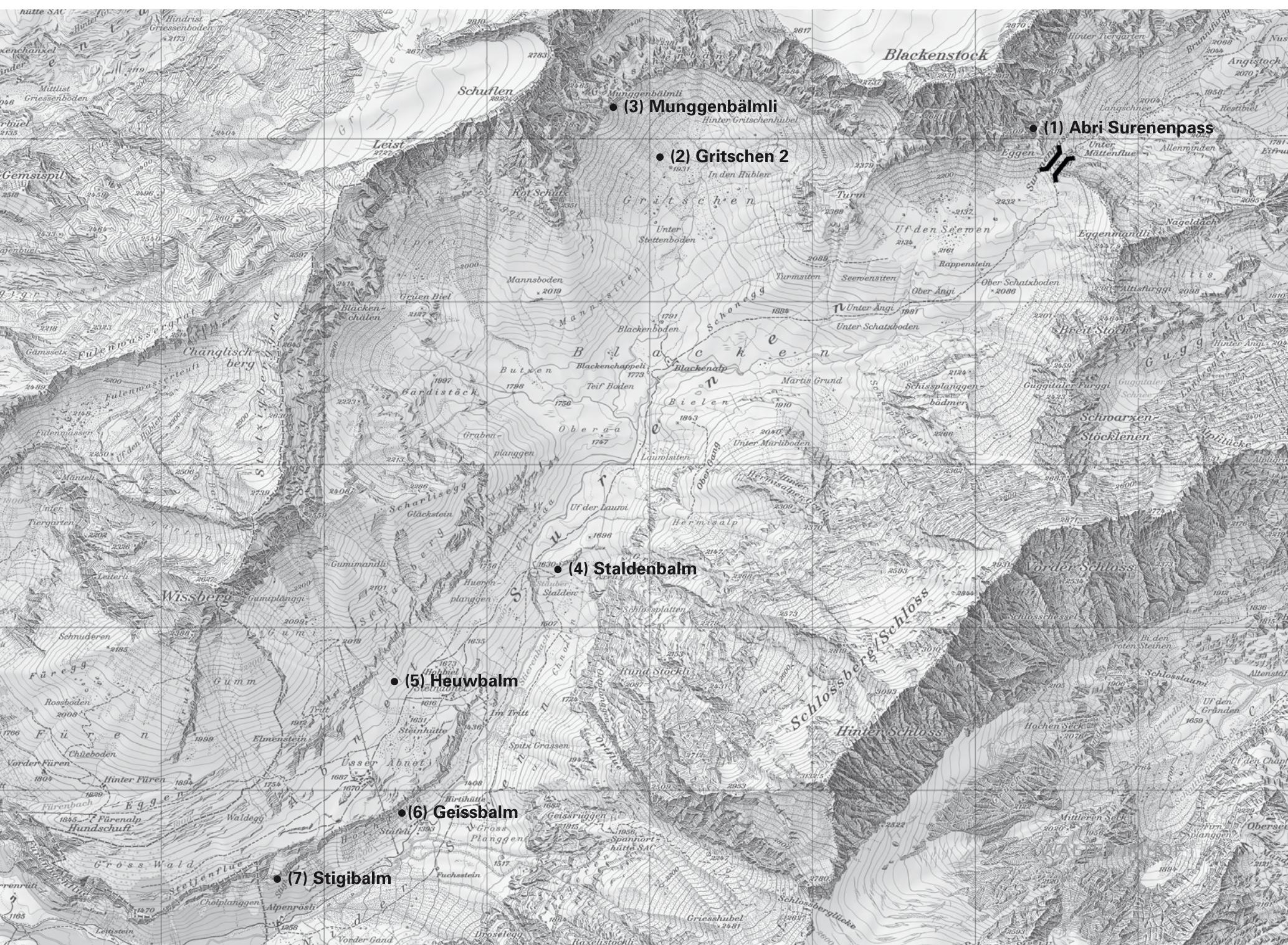




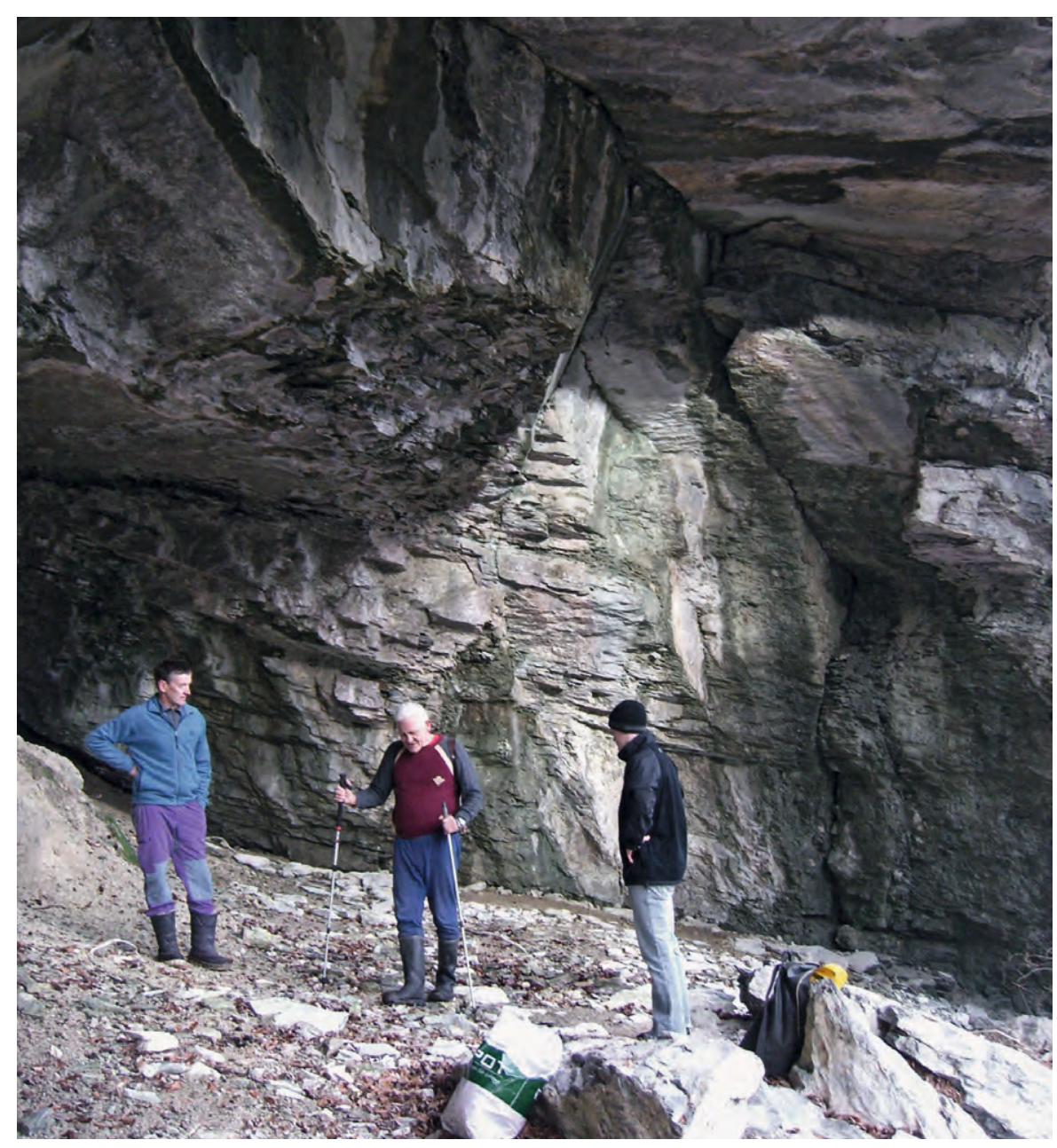

\section{Sandbalm (At.097)}

LK 1192, 690 740/189 090, 730 m ü.M.

Die Sandbalm ist mit ihren Dimensionen und mit der grossräumig überdachten Fläche der eindrücklichste natürliche Unterstand auf Attinghauser Boden. Sie befindet sich im bewaldeten Gebiet und ist nicht einfach zu finden: Der Zustieg ist identisch mit demjenigen zu S-Hol, der Weg führt an der Höhle vorbei. Das letzte kurze Stück hinauf zur Sandbalm ist recht steil, was jedoch für eine Nutzung durch den Menschen in vergangenen Zeiten keinen Hinderungsgrund darstellte. Die Sandbalm ist im Namenbuch der Ortsund Flurnamen des Kantons Uri nicht aufgeführt. In der näheren Umgebung befinden sich weitere namenlose Balmen, deren Zustieg nur über Wildwechsel ${ }^{27}$ und Steilhänge erfolgt, was gefährlich ist und gegen eine Nutzung durch den Menschen spricht.

Die Sandbalm ist nach Osten ausgerichtet und bietet daher hervorragend Schutz vor schlechter Witterung. Der Grossteil des Balmbodens ist wenig tiefgründig, da er mehrheitlich aus anstehendem, leicht abfallendem Fels besteht. Dies sind schlechte Voraussetzungen für eine archäologische Untersuchung: Spuren werden in diesem Fall nicht einsedimentiert und verschwinden sehr bald im abschüssigen Gelände. Eine Sondierung wurde deshalb an der Südostseite, am Ausläufer der Sandbalm, angelegt. Nachdem die etwa handtellergrossen kantigen Verwitterungssteine an der Oberfläche entfernt waren, zeigte sich ein sandiger, mit kleineren kantigen Steinen durchsetzter Untergrund, der unverändert bleibt und $50 \mathrm{~cm}$ abgetieft werden konnte. Die Sondierung lieferte kein Fundmaterial.
At.097

Sandbalm (Ansicht)

Attinghausen-Hol

LK 1192 - $690740 / 189090$

$730 \mathrm{~m}$ ü.M.

Foto W. Imhof, 2010 
28 Gisler/Spillmann 2011, 57-62.

29 Leuzinger/Sauter/Haas et al. 2015, 153-168.

\section{At.115}

Abri Surenenpass (Ansicht) Attinghausen-Surenenpass LK 1191 - 684 409/187 976 $2320 \mathrm{~m}$ ü.M.

Foto W. Imhof, 2014

\section{Abri Surenenpass (At.115)}

LK 1191, 684 409/187 976, 2320 m ü.M.

Die Balm befindet sich auf der Höhe und nordwestlich des Surenenpassübergangs. Das überhängende, nach Osten orientierte, mehrere Hundert Meter lange Felsband bietet über eine längere Strecke verschiedene Schutzmöglichkeiten. Dass die Balm noch heute ihre Funktion als Schutzraum erfüllt, ist daran zu erkennen, dass hier Werkzeuge für den Wegunterhalt und aufgerüstetes Brennholz gelagert werden. Wie Kotreste zeigen, suchen sowohl Wildtiere wie Gämsen und Steinböcke als auch Schafe die Balm auf.

Das schutzbietende Felsdach liegt im Schichtwechsel zwischen Dogger und Malm. An der Basis des gebankten Malmfelsens befindet sich die schiefrig-mergelige Schilt-Formation, die ausgewittert ist und in ihrer nordwestlichen Hälfte den Abri bildet. ${ }^{28}$ Der optimal geschützte Bereich ist von einer zweilagigen, stark einsedimentierten Trockenmauer zum Abhang hin begrenzt. Ein Eingangsbereich mit Steinschwelle ist noch erkennbar. Der flache Balmboden ist bestens geeignet für einen Lager- oder Rastplatz, auch für einen längeren Aufenthalt. Wasser und Schneefelder, die bis in den Sommer hinein Bestand haben, sind in unmittelbarer Nähe vorhanden. Der Blick in Richtung der Alpgebiete, der Reussebene und auf den nahen Passübergang ist optimal und erlaubt zudem sowohl eine Kontrolle des Alpviehs als auch des Personen- und Warenverkehrs.

Insgesamt wurden drei Sondierungen durchgeführt. Die Sondierungen 1 und 2 waren steril. In Sondierung 3, einem $50 \times 50 \mathrm{~cm}$ umfassenden Schnitt, kamen in 25 und $31 \mathrm{~cm}$ Tiefe in einer Feuerstelle mit brandgeröteten Steinen grosse, gut erhaltene Holzkohlestücke von dünnen Zweigen zum Vorschein. In $38 \mathrm{~cm}$ Tiefe konnte zudem eine lagige Steinsetzung beobachtet werden, die allenfalls den Plattenboden der Feuerstelle bildete. ${ }^{29}$ Die Probe wurde mittels der Radiokarbonmethode gemessen und datiert aus der Zeit um

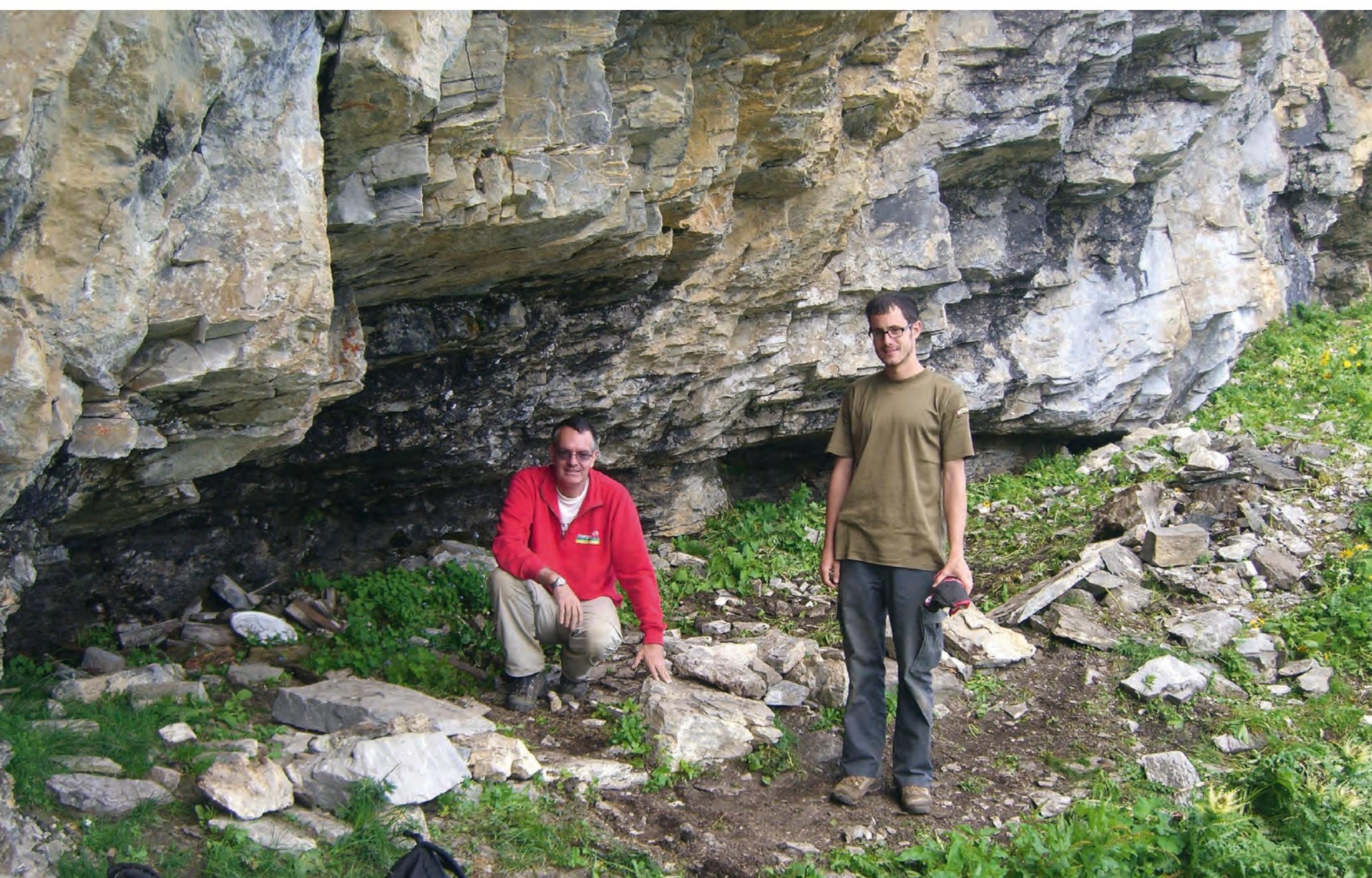




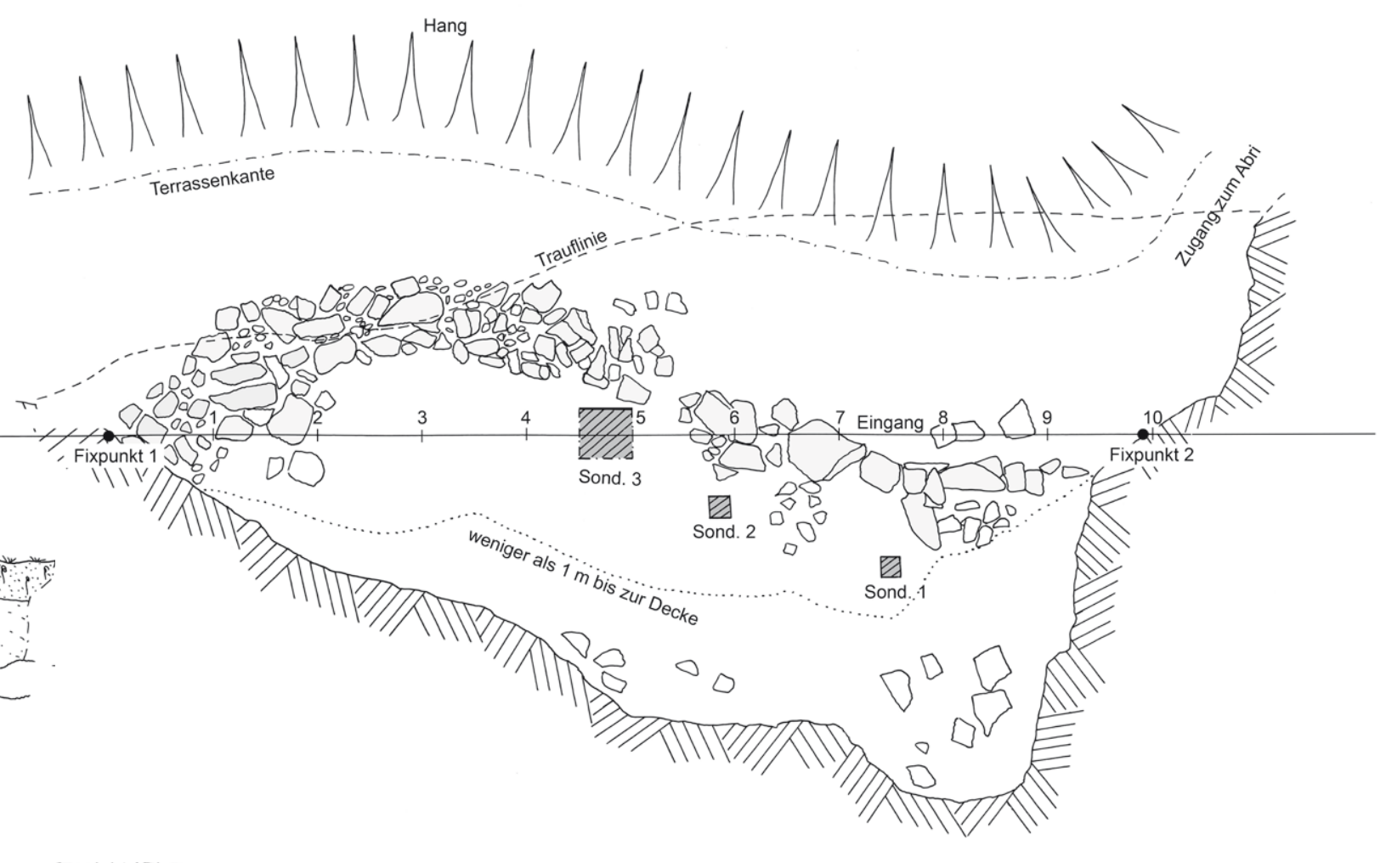

1660 bis 1950 n.Chr. ${ }^{30}$ - ein aufgrund der Bodenbeschaffenheit zu erwar30 ETH-57591: 188 22 BP, 1660-1950 AD. tendes Ergebnis der Altersanalyse. Wegen des sehr steinigen Untergrunds - bestehend aus von der Felswand herabgefallenen und durch Frostsprengung zerkleinerten Steinen - war eine tiefere Sondierung nicht möglich. Diese würde mit grösster Wahrscheinlichkeit noch ältere Spuren liefern. Die Schutzfunktion der Balm, auch in prähistorischer Zeit, ist offensichtlich.

\section{Chli-Laucheren-Balm (At.064)}

LK 1191, 687 300/189 100, 1780 m ü.M.

Die Balm am Chli Laucheren wurde 2009 inventarisiert ( $\Rightarrow$ S. 64-65) und 2013 im Zusammenhang mit den Grabungen auf dem Geissrüggen untersucht. Sie ist auf dem markierten Wanderweg, der von der Gratalp ins Gitschital führt, in etwa einer Viertelstunde zu erreichen. Nach dem Übergang von der Gratalp ins Gitschital wird das Gelände steil. Der ehemalige Saumpfad nach Seedorf schlängelt sich in mehreren Kehren hinab zu einer Felswand, die sich nach Süden, in Richtung des Geissrüggens, zieht. Die Balm befindet

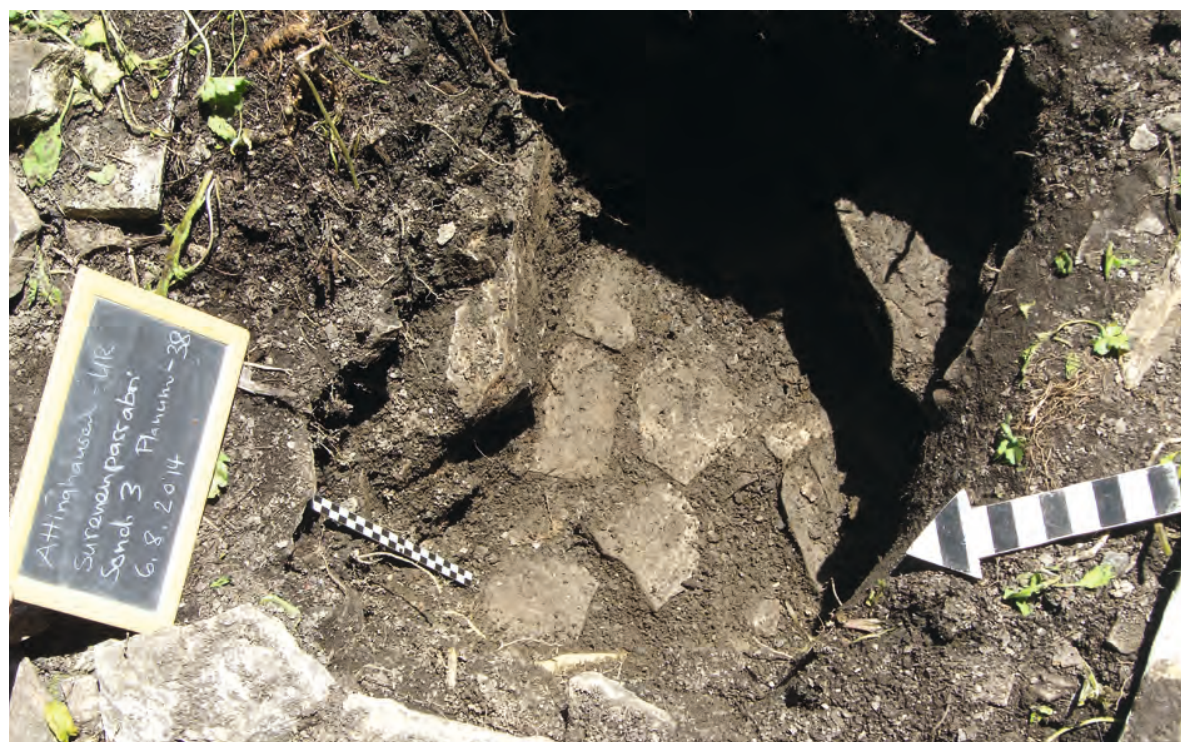

At. 115

Abri Surenenpass (Grundriss/Schnitt)

Attinghausen-Surenenpass

LK 1191 - 684 409/187 976

$2320 \mathrm{~m}$ ü.M.

Zeichnung U. Leuzinger, E. Belz, 2014

Sondierung 6.8.2014

Foto U. Leuzinger, 2014 


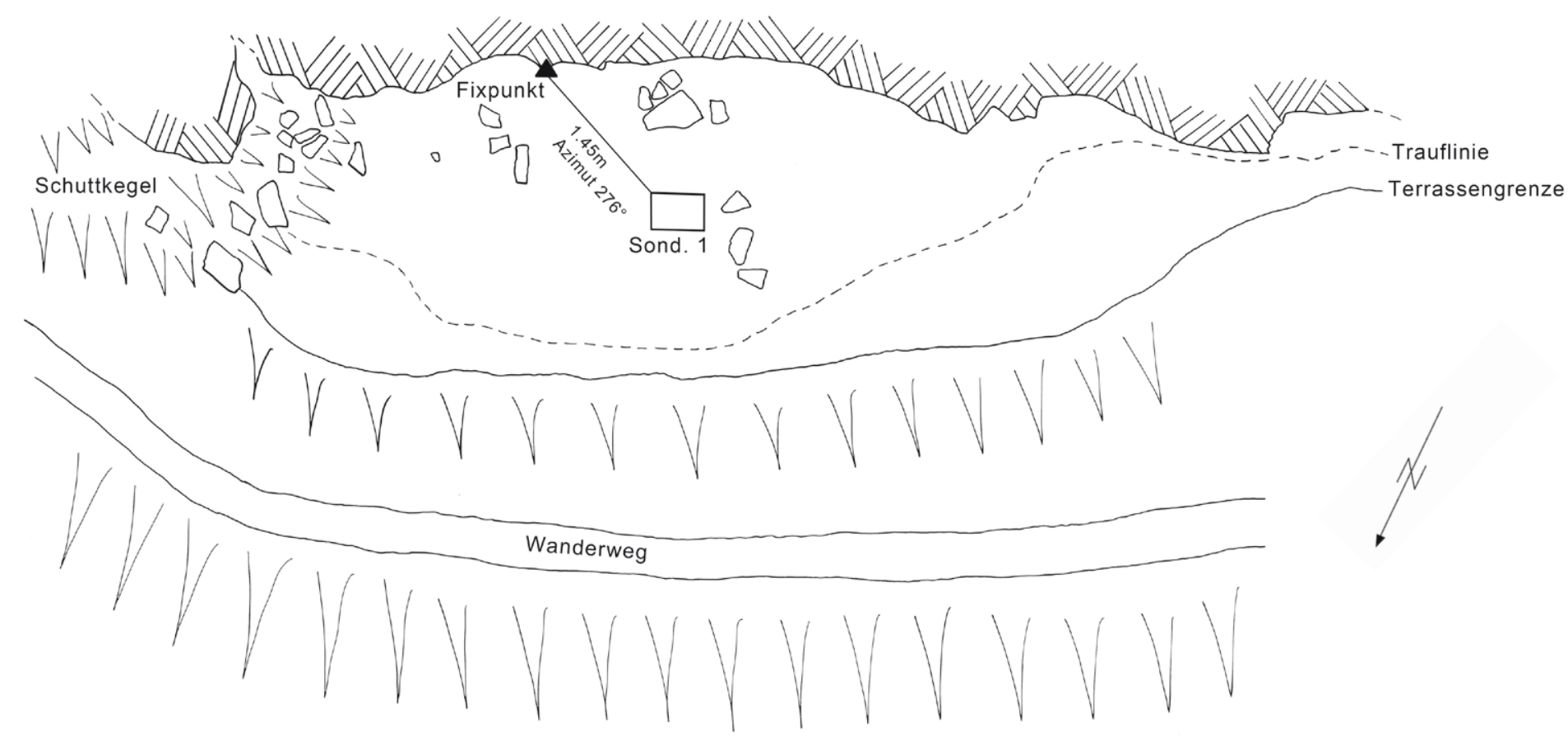

At.064

Chli-Laucheren-Balm (Grundriss) Attinghausen-Chli Laucheren LK 1191 - $687300 / 190100$ $1780 \mathrm{~m}$ ü.M.

Zeichnung U. Leuzinger, E. Belz, 2013

Dokumentation, 12.8.2013

Foto W. Imhof, 2013 sich am Fusse des nördlichen Ausläufers dieser Felswand, direkt am Weg, und ist während der Vegetationszeit mit stickstoffliebenden Blacken und Brennnesseln überwachsen.

Die stark geklüftete Felswand besteht aus grobkörnigem Quarzsandstein. Ein Überhang schützt die flache, $9 \mathrm{~m}$ lange und $3 \mathrm{~m}$ tiefe Terrasse. Unmittelbar davor fällt das Gelände steil gegen Norden in eine unwegsame Geröllhalde ab. Die günstige Lage am ehemaligen Saumpfad und die einfache Zugänglichkeit dürften den Unterstand als Schutzplatz prädestinieren. Die Chli-Laucheren-Balm liegt allerdings bis in den Nachmittag hinein im Schatten, weshalb auch an einem hochsommerlichen Tag im August 2013 um 11.30 Uhr lediglich eine Temperatur von $13^{\circ} \mathrm{C}$ gemessen wurde.

Im Zentrum der Terrasse ist die Steinlegung einer Feuerstelle mit umgebenden Sitzsteinen, wie sie auf Rastplätzen gang und gäbe ist, zu sehen. An dieser Stelle wurde 2013 eine kleine Sondierung von $20 \times 40 \mathrm{~cm}$ angelegt. Es gelang, das Sondierloch bis in eine Tiefe von $-37 \mathrm{~cm}$ zu öffnen. Unter einer flachen Steinplatte folgten dunkelgraue, lehmige Sedimente mit Holzkohle-

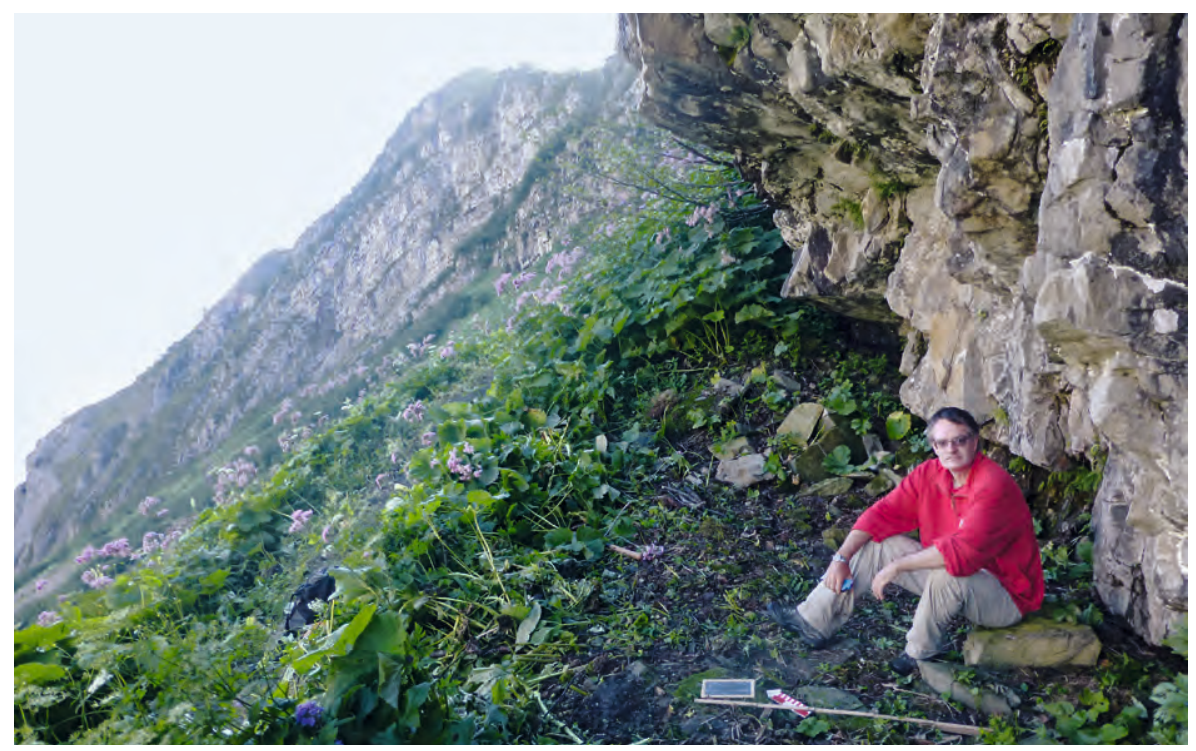


33 Leuzinger/Sauter/Haas et al. 2015, 147.

34 ETH-57595: 129 \pm 23 BP, 1670-1940 AD.

35 Imhof 2013, 31.

\section{At.123}

Abri sous bloc Gritschen 2 (hinterer Raum)

Attinghausen-Gritschen

LK 1191 - 682 000/187 740

$1941 \mathrm{~m}$ ü.M.

Foto M. Sauter, 2014 eine weitere Mauer im hinteren Bereich unterteilt. Es macht den Anschein, dass es sich hier um zwei Bauphasen handelt. Der Eingangsbereich ist jünger, sicher neuzeitlich einzustufen. Allfällige ältere Spuren sind im Rahmen der Erweiterungsarbeiten und des Einbaus mehrerer Sitzplätze aus sorgfältig gesetzten Steinplatten zerstört worden. Der hintere, deutlich niedrigere Abri-Bereich dürfte den ursprünglichen Zustand anzeigen. Hier befindet sich eine steinerne Sitzbank.

Unter einer grösseren Steinplatte fand sich eine Feuerstelle, im Umfeld sind zudem oberflächig Aschen- und Holzkohleablagerungen nachweisbar. Im Bereich der Feuerstelle wurden zwei kleine Sondierungen von $10 \times 10 \mathrm{~cm}$ angelegt. Sondierung 1 zeigte eine etwa $10 \mathrm{~cm}$ mächtige, durchgehende Aschen- und Holzkohleschicht mit verkohlten Wacholdernadeln (Juniperus communis) und Alpenrosenstauden (Rhododendron sp.). Sondierung 2 wurde etwa $50 \mathrm{~cm}$ südwestlich angelegt und zeigte in $10 \mathrm{~cm}$ Tiefe ebenfalls grosse Mengen an Holzkohle. ${ }^{33}$ Die Alpenrosen-Holzkohleprobe wurde mittels der Radiokarbonmethode gemessen und datiert in die Zeit um 1670 bis 1940 n.Chr. ${ }^{34}$ Obwohl die Radiokarbondatierung der Feuerstelle sehr jung ausgefallen ist, dürfte der Abri sous bloc jedoch bereits im Mittelalter oder früher genutzt worden sein. Dafür sprechen seine Grösse, seine günstige Lage und die starke Einsedimentierung des Felsblocks im spärlich bewachsenen Gelände. Das Resultat der Altersbestimmung und die Fundumstände legen die Vermutung nahe, dass der Unterstand hauptsächlich neuzeitlichen Jägern als Aufenthaltsort und als Versteck diente. Als Hütehütte eines Hirten ist der Unterstand zu weit vom Weidegebiet entfernt. Auf der Engelberger Seite des Surenenpasses befinden sich einige weitere ähnliche Unterstände unter Felsblöcken, darunter auch solche, die - wie Jäger berichten - heute noch benutzt werden.

Aufgrund der hohen Holzkohlekonzentration im hinteren Teil müssen hier verschiedene grosse Feuer unterhalten worden sein. Das Vorkommen von verkohlten Alpenrosen und vor allem Wacholdernadeln dürfte ein Hinweis sein, dass hier eventuell Fleisch geräuchert und somit haltbar gemacht wurde. Der für Blockunterstände grosse Hohlraum im hinteren Teil bietet dafür genügend Platz. Dafür sprechen auch die erhöhte Lage, der zum vorderen

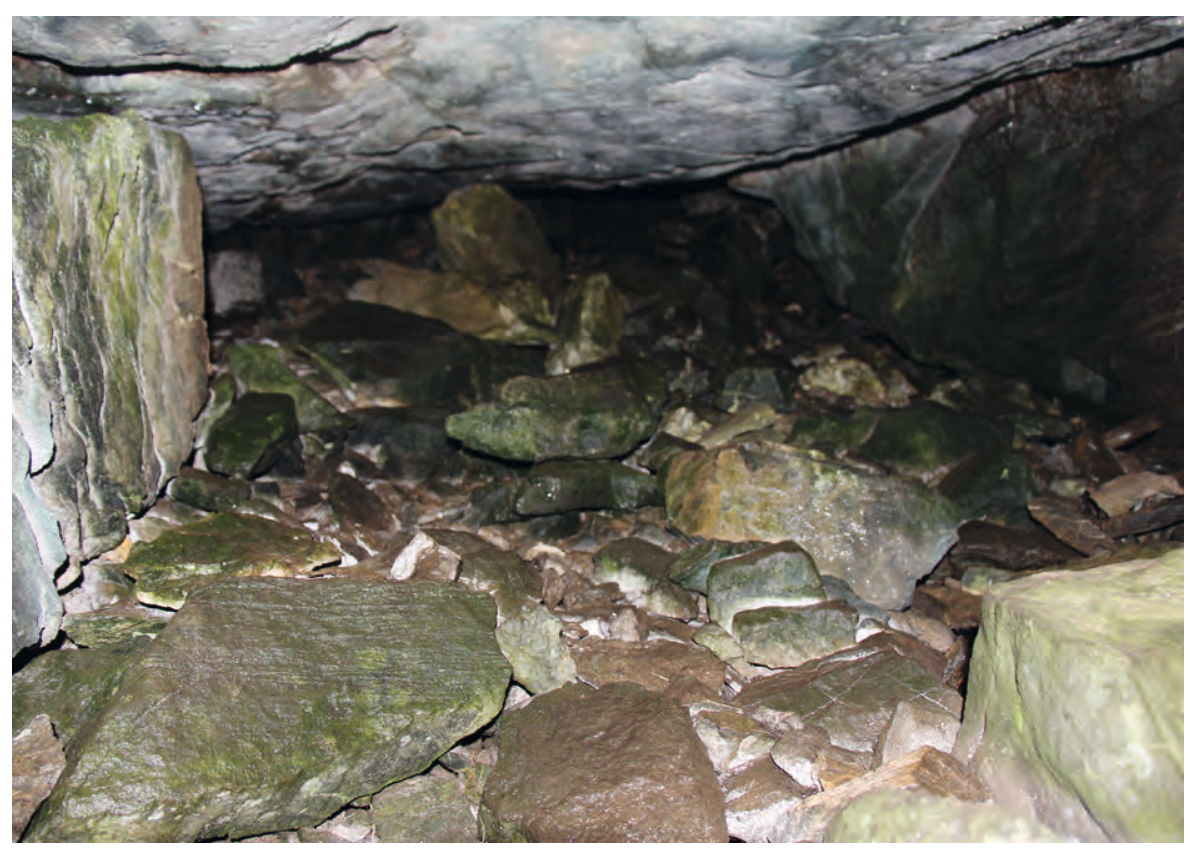


Teil des Unterstands mit einer Mauer abgegrenzte Bereich und die Tatsache, dass im Eingangsbereich keine Feuerstelle ausgemacht werden kann. Da der Höhlenraum oberhalb der Feuerstelle nach aussen gut abgedichtet ist, kann der Rauch nur schwer abziehen und bietet so ideale Verhältnisse für einen Rauchfang. Die starke Rauchentwicklung dürfte daher den vorderen, tiefer angelegten Eingangsbereich in seiner Aufenthaltsqualität kaum beeinträchtigt haben.

Beim Vorgang der Fleischräucherung wird nur ein schwelendes, lang anhaltendes kleines Feuer unterhalten, das möglichst lange und viel Rauch produziert. Dazu sind Holzarten mit Nadeln besonders gut geeignet. Rauch verhindert zudem, dass Fliegen ans Fleisch gelangen. Wacholderstauden sind für die Räucherung von Fleisch beliebt. Wacholder wird allgemein eine desinfizierende Wirkung nachgesagt. Der würzige Rauch verleiht dem Fleisch eine angenehme und appetitanregende Note. Der Autor hat selbst noch Wacholderstauden zum Räuchern von Fleisch gesammelt und kann bestätigen, dass auf diese Weise nicht nur Fleisch von Haustieren, sondern beispielsweise auch solches von Murmeltieren haltbar gemacht werden kann.
At.123

Abri sous bloc Gritschen 2

(Grundriss/Schnitt)

Attinghausen-Gritschen

LK 1191 - 682 000/187 740

1941 m ü.M.

Zeichnung U. Leuzinger, E. Belz, 2014

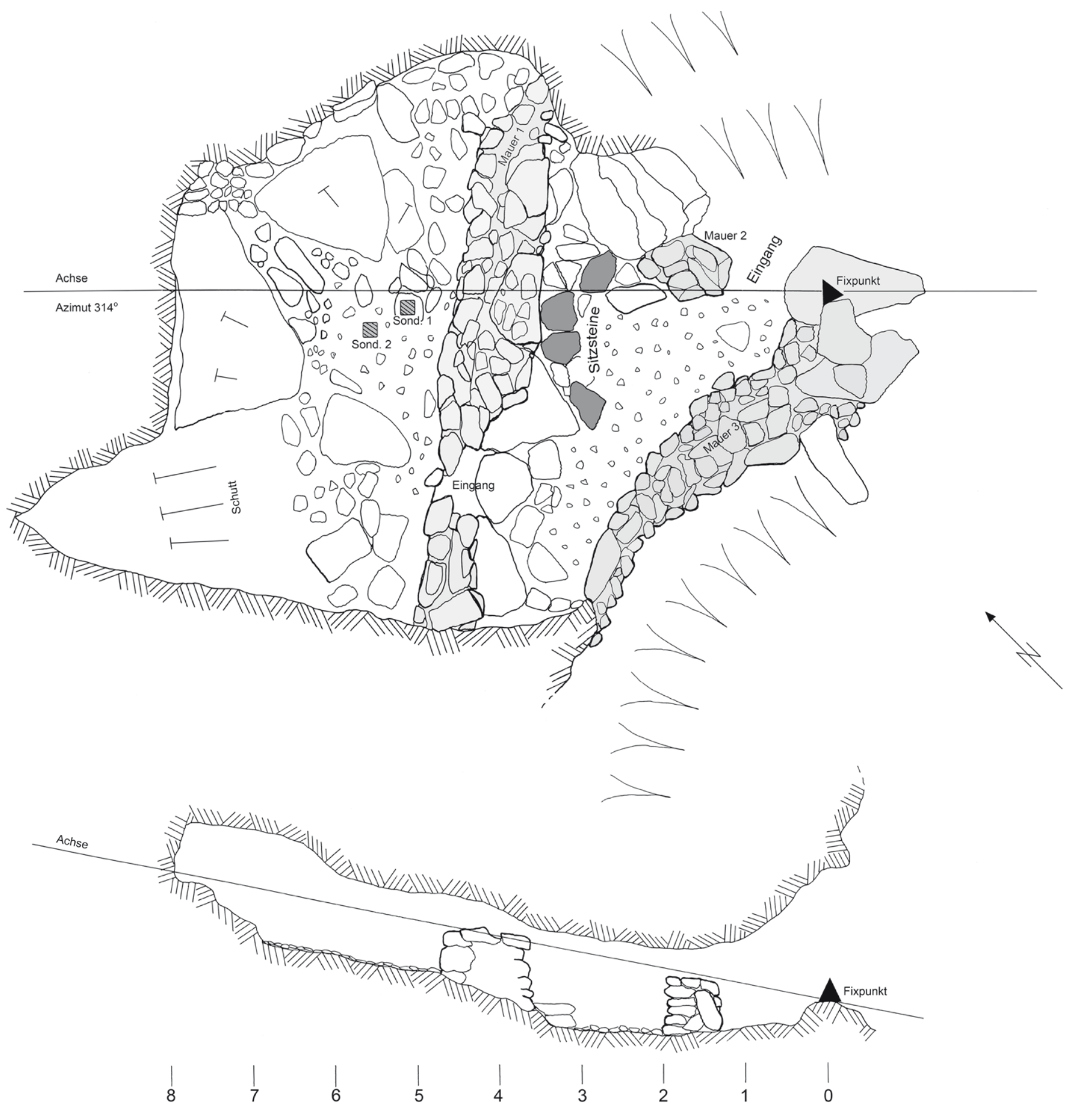


35 Imhof 2013, 31.
Die zahlreichen oberflächlichen, vermutlich rezenten Faunenreste von Rind (Bos taurus), Schaf/Ziege (Ovis/Capra), Gämse (Rupicapra rupicapra) und Murmeltier (Marmota marmota) - Schlachtabfälle oder von Tieren eingeschleppte Knochen - wurden nicht aufgesammelt, sondern in situ belassen.

\section{Fazit}

Ein Grund, die Fokussierung des Wüstungsforschungsprojekts an den Surenenpass zu legen, war die augenscheinlich geringe Zahl natürlicher Unterstände. Daraus resultierte die These, dass besonders früh Schutzhütten errichtet worden sein müssen, was in den Grabungsergebnissen Bestätigung fand ( $\rightarrow$ S. 122-135). Die weiterführende Recherche zur Höhlen- und Balmsituation ergab dennoch ein recht breites und interessantes Spektrum, wenngleich sich die Fund- und Datierungserfolge aus dem nahen Muotatal leider nicht einstellten. ${ }^{35} \mathrm{Da}$ es plausibel ist, Parallelen zu ziehen, sind die Aufenthaltsorte prähistorischer Menschen entlang des Surenenpasses wohl dennoch dokumentiert.

Amrein, W. (1939). Urgeschichte des Vierwaldstätter Sees und der Innerschweiz. Aarau. Curdy, P. / Praz, J.-C. (2002). Die ersten Menschen im Alpenraum. Von 50000 bis 5000 vor Christus. Ausstellungskatalog. Sitten.

Gisler, C. / Spillmann, P. (2011). Die mesozoisch-alttertiäre Sedimentbedeckung. In: Spillmann, P. / Labhart, T. / Brücker, W. et al. Geologie des Kantons Uri (=Naturforschende Gesellschaft Uri 24). Altdorf, 49-78.

Hug, A. / Weibel, V. (1988-1991). Urner Namenbuch. Die Orts- und Flurnamen des Kantons Uri (4 Bde). Altdorf.

Imhof, W. (2012). Bär, Wolf und Luchs im Muotatal, Knochenfunde aus Höhlen. Muotathal. Imhof, W. (2013). Die ersten Muotataler - Spuren ur- und frühgeschichtlicher Jäger und Hirten aus Höhlen und Balmen. Muotathal.

Imhof, W. (2015). Ein glücklicher Fund für die Urner Urgeschichte. Urner Wochenblatt 13.5.2015.

Imhof, W. / Obrecht, J. (2005). Mesolithische Wildbeuter im Alpgebiet der Gemeinde Muotathal (SZ). Archäologie Schweiz 3/28, 30-35.

Leuzinger, U. / Sauter, M. / Haas, J.N. et al. (2014). Eine hallstattzeitliche Gebäudestruktur auf 1911 m ü.M. am Weg zum Surenenpass, Attinghausen UR, Siedlungsplatz Geissrüggen. In: Jahrbuch Archäologie Schweiz 97, 153-168.

Leuzinger, U. / Sauter, M. / Haas, J.N. et al. (2015). Spätmittelalterliche und neuzeitliche Alpnutzung zwischen Surenenpass und der Blackenalp, Gemeinde Attinghausen UR. In: Jahrbuch Archäologie Schweiz 98, 145-153.

Leuzinger, U. / Affolter, J. / Beck, C. et al. (2016). Der frühmesolithische Abri Berglibalm im Bisistal, Gemeinde Muotathal SZ. In: Jahrbuch Archäologie Schweiz 99, 7-26.

Leuzinger-Piccand, C. (mit Beiträgen von Haas, J.N. / Hantke, R. / Leuzinger, U. / Rentzel, P. (1996). Einsiedeln SZ-Langrüti: eine spätmagdalénienzeitliche und mesolithische Freilandstation in den Voralpen. Grabungsbericht und Sammlungsstudie. In: Jahrbuch der Schweizerischen Gesellschaft für Ur- und Frühgeschichte 79, 7-26.

Sauter, M. (2009). Wüstungsforschung im Kanton Uri. Brunni- und Schächental, Haldi und Surenenpass. Altdorf.

Suter, F. / Imhof, W. (2010). Holloch Attinghausen/UR. In: Höhlenpost 136, 13-19.

Zappa, F. (2005). Genutzte Felshöhlen im Muotatal - Milchbalm-Höhle, Eiskeller und

Siten Balm. Ein Vergleich mit den "splüi» südlich der Alpen. In: Auf der Maur, F. I

Imhof, W. / Obrecht, J. (Hrsg.). Alpine Wüstungsforschung, Archäologie und Speläologie auf den Alpen Saum bis Silberen. Muotatal, 69-73. 


\section{Summary: Ways to reach the Surenen Pass.}

Several roads lead to the Surenen Pass. On one hand this is due to the topographical situation, on the other due to the passage of time. The different sections of track were adapted to the needs that prevailed at the time and thus reflect the history of transport and the economy. Until a few decades ago, before the inauguration of the A2 national road in 1980, the Surenen Pass was mainly used for cattle drives. This article describes the various historical routes that lead from the three Uri valley locations of Erstfeld, Attinghausen and Seedorf to the summit of the pass and on towards Engelberg. The core of the Surenen Pass trail is the crossing of the Waldnacht Alp, which once served as a place where large herds could be rested along the way. The discovery of a stretch of path and the results of an archaeological research project on Surenen in the summer of 2014, which uncovered numerous new settlement sites, allowed us to reconstruct an earlier trail over the Surenen Pass. The fact that the route had been altered showed that a structural change had taken place within Alpine farming in the $18^{\text {th }}$ century from proprietary Alpine pastures to cooperative organisations that hired herdsmen. Parts of the Surenen Pass trail were already included in the Inventar der historischen Verkehrswege der Schweiz (IVS) [Inventory of Historical Routes in Switzerland], and others have now been added. Whilst the infrastructure in meadowland areas is characterised by hollow ways with earth banks on both sides, and some of the particularly steep stretches in forested areas are fortified and other tracks even cobbled, the paths through Alpine pastureland, however, are simple dirt tracks. The mountain trail at Attinghausen and the Bockitobel ravine just beneath the Alpine pasture of Waldnacht were historically the most exposed passages en route to the Surenen Pass. The fact that the Seedorf Driangel had to be crossed using ladders, however, is now in the "annals" of oral history. 


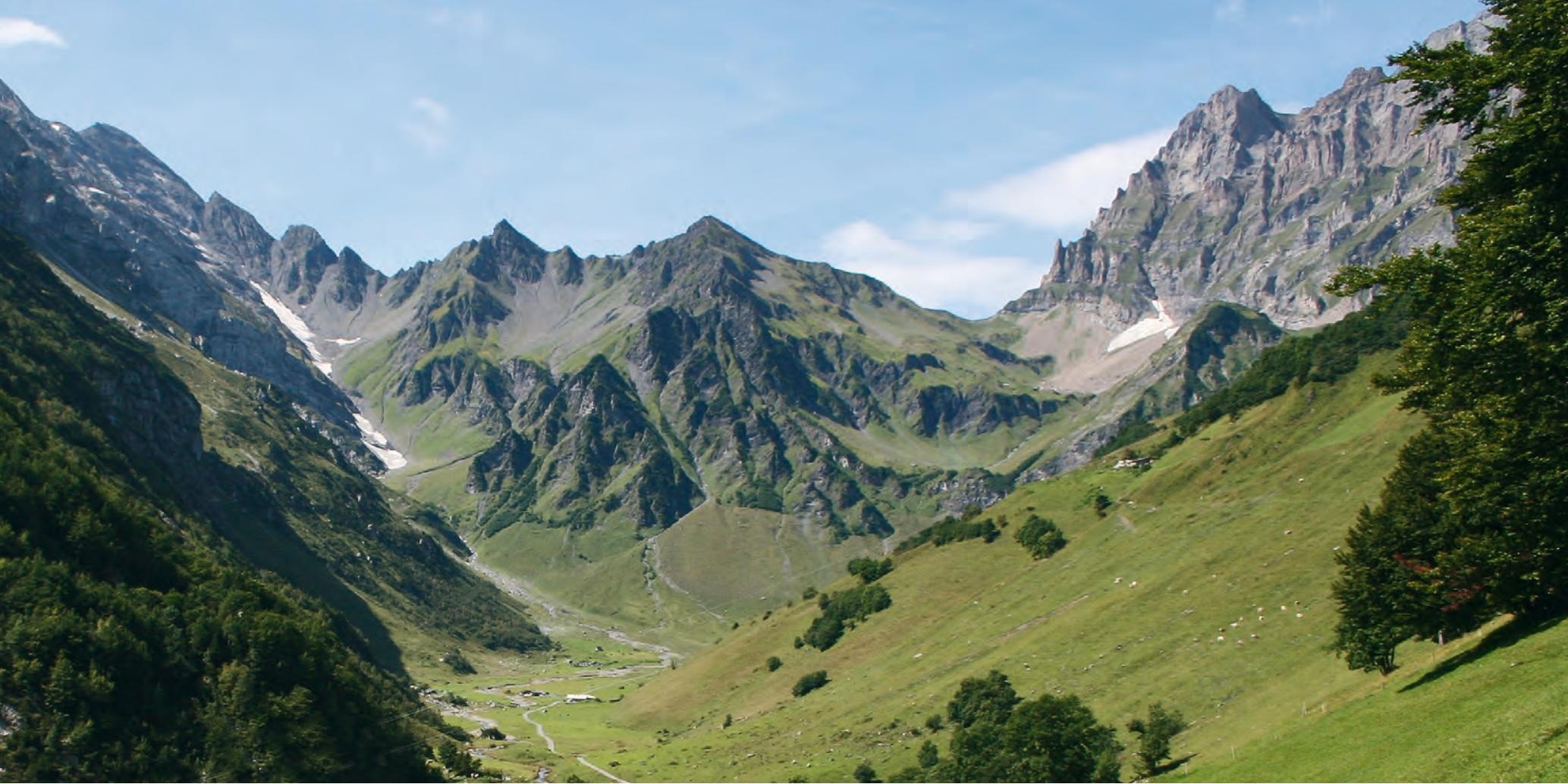

\section{Wege zum Surenenpass}

Zum Surenenpass führen mehrere Wege. Dies ist einerseits der Topografie, andererseits dem Lauf der Zeit geschuldet: Die Streckenabschnitte wurden stets den jeweiligen Bedürfnissen angepasst. Im Rahmen der Urner Wüstungsforschung konnte das Schweizer Inventar der historischen Verkehrswege (IVS) um einige interessante Passagen und Thesen rund um den Surenenpassweg ergänzt werden.

\section{Topografie und Erschliessung}

Der Surenenpass liegt auf $2291 \mathrm{~m}$ ü.M. in einer Senke unterhalb des Blackenstocks (2931 m ü.M.). Er verbindet das Urner Reusstal mit dem Obwaldner Klosterdorf Engelberg und erschliesst die weitläufige Alp Surenen. Um vom Urner Reusstal nach Engelberg zu gelangen, müssen $25 \mathrm{~km}$ und 1935 Höhenmeter bewältigt werden. $18 \mathrm{~km}$ dieses Wegs liegen im Kanton Uri: Der Surenenpass markiert ebenso wie der Klausen, die Chinzig- und die Ruosalper Chulm nicht die Kantonsgrenze. Das Urner Gebiet umfasst jenseits der Wasserscheiden jeweils noch ausgedehnte Alpgebiete, auf der Glarner Seite des Klausenpasses mit dem Urnerboden sogar eine Ganzjahressiedlung.

Der Surenenpassweg wurde im Jahr 1888 als Kantonsstrasse eingestuft und 2009 der Gemeinde Attinghausen übertragen. Er und die Route über die Ruosalper Chulm, die das Schächental mit dem Muotatal verbindet, sind die beiden letzten lediglich fussläufig erschlossenen Passwege im Kanton Uri. Das Inventar der historischen Verkehrswege der Schweiz (IVS) misst

Hauptstrecke: IVS UR 1998, 290.1. Mettlengasse: IVS UR 1998, 290.1.1 (inkl. Beschrieb). - Loepfe 2007, 50-51.

2 Strecke Höchiberg-Grat IVS UR 1998, 290.2. - Bockitobelroute IVS UR 1998, 290.3. - Akten zum Surenenzoll, um 1848 (Staatsarchiv Uri, R-270-13/39). dem Surenenweg von Attinghausen über die Waldnacht und Surenen nach Engelberg regionale Bedeutung zu, der Teilabschnitt Mettlengasse besitzt nationale Bedeutung. ${ }^{1}$ Als Varianten wurden der Wegabschnitt vom Höchiberg über den Grat bis Langschnee sowie der Abstieg durch das Bockitobel nach Erstfeld inventarisiert, wo bis 1848 auch die Surenenzollstation angesiedelt war. $^{2}$ 

7 Primas/Della Casa/Schmid-Sikimić 1992, 228.

8 Sauter 2017 (im Druck).

9 Stadler-Planzer 1993, 68-75.
1949 wurde die Luftseilbahn Attinghausen-Brüsti eröffnet, 1979 folgte eine Seilbahn auf die Engelberger Fürenalp. Wie vielerorts veränderte dies die Erschliessung nachhaltig: Auf der Engelberger Seite etablierte sich ein neuer, teilweise als Naturstrasse ausgebauter Wanderweg. Die historische Gasse oberhalb von Attinghausen, welche die ersten 1000 Höhenmeter der historischen Routen ausmacht, wird seitdem kaum noch frequentiert, die Surenenpasswege von Seedorf und Erstfeld werden als solche kaum noch wahrgenommen. Die Überquerung des Surenenpasses, die Wanderung von der Bergstation der Luftseilbahn Brüsti bis zur Fürenalp, dauert gut 6 Stunden und gehört zu den populärsten Innerschweizer Tagestouren. Die meisten angrenzenden alpwirtschaftlichen Betriebe bieten Agrotourismus an.

\section{Historische Eckdaten}

Der Surenenpass wird nachweislich seit 1450 v.Chr. begangen - Beleg dafür ist eine bronzene Gewandlochhalsnadel, die 1951 oberhalb des Weilers Stäfeli in Nidersurenen gefunden wurde $\left(\boldsymbol{s}\right.$ S. 138-139). ${ }^{7}$ In der Hallstattzeit wurde auf dem Geissrüggen ein Kontrollposten eingerichtet $(\rightarrow$ S. 122-135). Streufunde häufen sich zeitlich wie örtlich zur gallo-römischen Epoche rund um die im Kern mittelalterliche Blackenalpkapelle St. Antonius und Wendelin - wahrscheinlich war hier zuvor eine heidnische Kultstätte angesiedelt. ${ }^{8}$

Spätestens im ausgehenden 11. Jahrhundert nahmen die Urner Surenen in Besitz: Der terminus ante quem ist die Gründung des Bendiktinerklosters Engelberg im Jahr 1120 mit den folgenden zähen Grenzstreitigkeiten. ${ }^{9}$

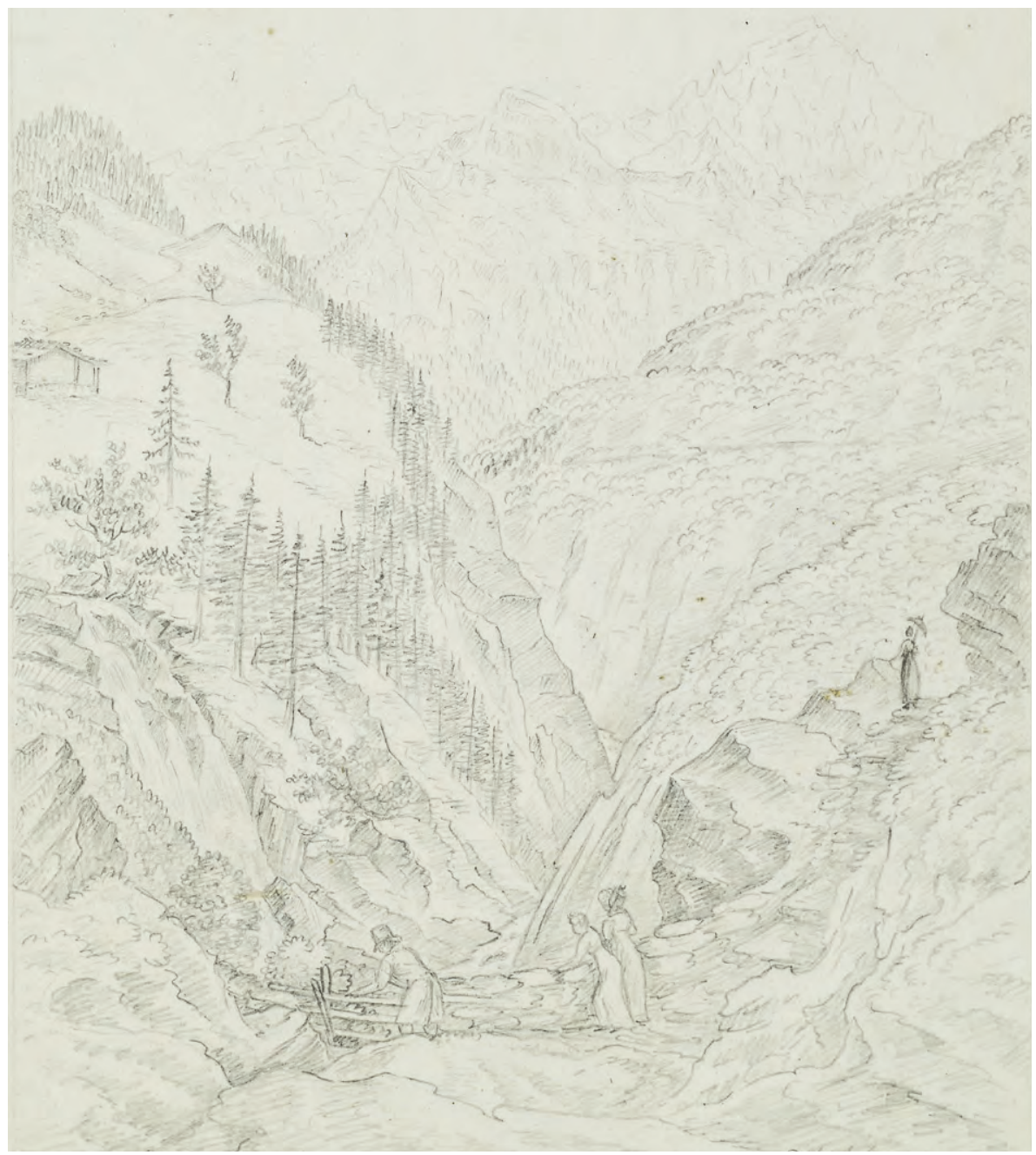

Bockitobel - die ausgesetzte Passage wurde auch von Spaziergängern im Sonntagsstaat frequentiert. Zeichnung K. F. Lusser, 1818 (Staatsarchiv Uri) 
Seither ist von einer alpwirtschaftlichen Nutzung des gesamten Geländes auszugehen, die für die Eigenalp Waldnacht in Marchbriefen und Urkunden ab 1457 einzigartig dicht dokumentiert ist. ${ }^{10}$

\section{Alpwirtschaft}

Der Weg über den Surenenpass diente über Jahrhunderte vornehmlich der Urner Alpwirtschaft. Der Transport der Engelberger Produkte in Richtung Süden erfolgte stets über den Vierwaldstättersee, gegebenenfalls weiter über den Gotthard.

Das Gebiet nördlich der Schöllenen ist seit jeher von Einzelalpung geprägt und - mit wenigen Ausnahmen wie der Eigenalp Waldnacht - im Besitz aller Alpgenossen, heute: der Korporation Uri. Die Verbreitung des Hausrinds setzte erst im ausgehenden Mittelalter ein. Damit verbunden war eine umfassende Urbarmachung der Alpweiden, die auch im Rahmen der palynologischen Untersuchungen nachgewiesen werden konnte ( S. 24-45). Die Nutzungsmöglichkeit der Alpen war an die Höhenlagen, die Bestossdauer und ob des grossen Bedarfs an Bau- und Brennholz an die Waldgrenzen geknüpft sowie von den Kaltphasen der sogenannten Kleinen Eiszeit in den Jahren 1340-1380, 1570-1640, 1765-1771, 1812-1817 sowie 1851-1854 beeinträchtigt. Besonders warme und trockene Sommer prägten hingegen die Dekaden 1380-1420, 1530-1660 sowie 1718-1730.11

Alle Surenen-Alpfahrer haben das verbriefte Recht auf der Eigenalp Waldnacht zu nächtigen - Grundlage, um den Pass überhaupt mit Viehherden überqueren zu können. Die Waldnacht kann von Attinghausen und von Erstfeld aus erreicht werden. Den Seedorfern fehlt ein entsprechender Rastplatz. Über die Gitschital-Route wurden wahrscheinlich auch in der Vergangenheit nur Schafe über den Surenenpass getrieben.

Seit der Eröffnung der A2 beziehungsweise des Seelisbergtunnels im Jahr 1980 werden die Viehherden in der Regel auf dem deutlich kürzeren Weg von Engelberg aus auf die Alp Surenen getrieben, insgesamt fast 1200 Tiere. Lediglich 30 Rinder, die vor der Alpzeit auf der Attinghauser Seite des Surenenpasses im Maiensäss auf Chulm und Brüsti auf $1550 \mathrm{~m}$ ü.M. gesömmert werden, queren derzeit noch den Surenenpass über die Gratroute.

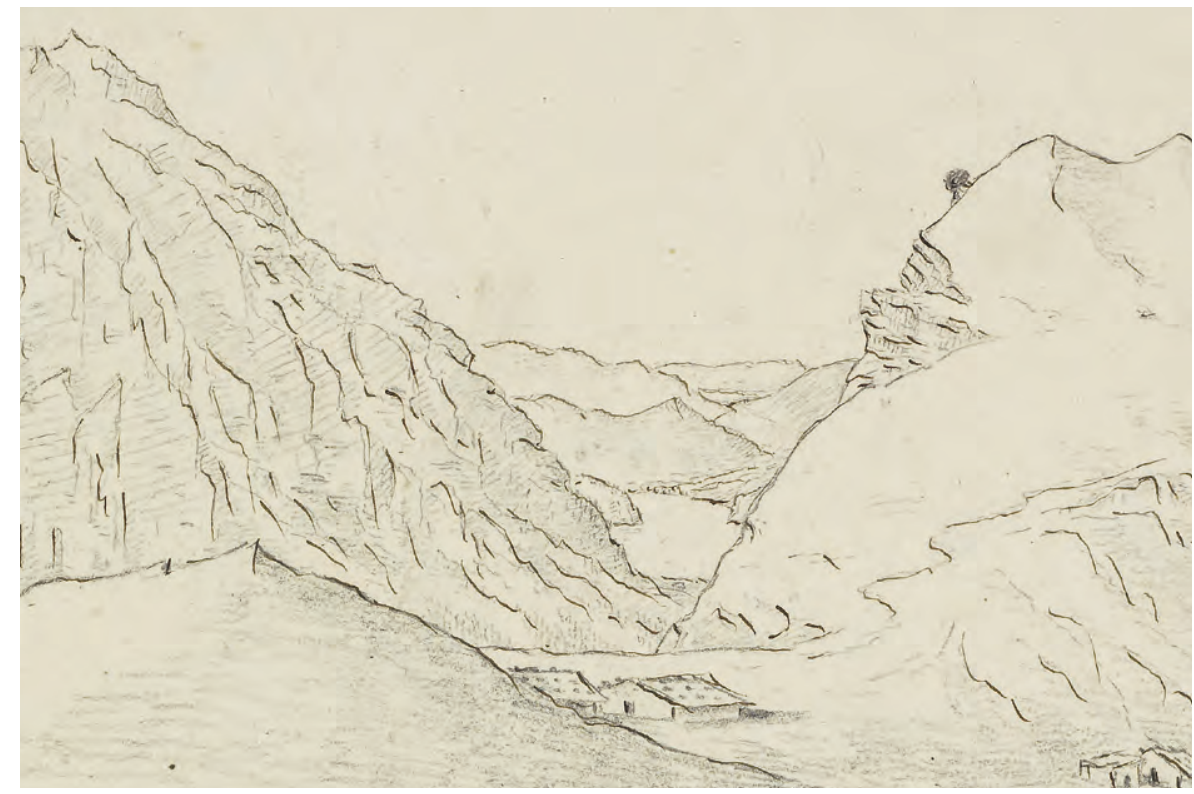

10 Furrer/Furrer 2000.

11 Pfister, C. Kleine Eiszeit. In: www.h/s. ch (30.11.2015).
«Der GratStaffel in Attinghausen zwischen Waldnacht $u$. Gitschenthal mit einem Wildheuer in Gefahren dass mir graute» (Bildunterschrift).

Zeichnung K. F. Lusser, 1826 (Staatsarchiv Uri) 
Klosterneubau und die Kuppelkirche St. Lazarus ragen bis heute aus der bescheidenen ländlichen Siedlung hervor. ${ }^{16}$

Im Süden folgt Attinghausen. Es besticht ebenfalls durch ein «Herrschaftszentrum», bestehend aus vier repräsentativen Solitärbauten: der Burg und der Pfarrkirche St. Andreas, dem Wohnturm Schweinsberg sowie dem im Jahr 1676 vom Feuer zerstörten Kapuzinerinnenkloster Maria zu allen Engeln. Die erste Befestigung der Burg datiert ebenso wie die erste Kapelle (heute: Pfarrkirche St. Andreas) ins 11. Jahrhundert. ${ }^{17}$ Auch das 1909 von Theiler \& Helber errichtete Schulhaus ist hier angesiedelt. Der bäuerliche Dorfkern von Attinghausen liegt südlich des Kummetbachs.

Flussaufwärts folgen die Weiler Ripshausen, Hofstetten und Niderhofen, schliesslich der Erstfelder Dorfkern, der sich aus Taubach und Spätach zusammensetzt. Der reiche Bestand an historischen Bauernhäusern lässt sich bis ins 15. Jahrhundert zurückverfolgen: Die Taubachhofstatt entstand etwa im Jahr 1480. ${ }^{18}$ Die Erstfelder Pfarrkirche St. Ambros und Otmar gründet auf einer Kapelle des 13. Jahrhunderts, der Vorgängerbau der frühbarocken Jagdmattkapelle auf einer Kapelle des 11. Jahrhunderts. ${ }^{19}$ Der Surenenpassweg zweigte im Mittelalter demzufolge von einem für Innerschweizer Verhältnisse dicht besiedelten Landstrich ab - zwischen Seedorf und Erstfeld liegen lediglich 7,5 km.

Gegenüber, am rechten Reussufer, finden sich hingegen keine historische Bausubstanz oder archäologische Siedlungsspuren. Das Reusstal war bis zur Melioration zwischen Erstfeld und Flüelen in den Jahren 1919 bis 1924 sumpfig und wird im Osten von der nahezu senkrecht aufragenden Rynächtfluh jäh begrenzt. Ein ausgesetzter Pfad auf 1000 m ü.M., der sogenannte Brandtritt, stellte die einzige Verbindung zwischen Schattdorf und Erstfeld während der regelmässigen Überschwemmungen dar und wurde bis weit ins 20. Jahrhundert hinein rege genutzt. Am Fusse der Brandtritt-Route fand sich im Jahr 1962 auch der keltische Goldschatz von Erstfeld.

Die heutigen Strassen von Seedorf nach Attinghausen und von Ripshausen nach Spätach folgen mit geringfügigen Veränderungen dem historischen Streckenverlauf. Die Strecke von Seedorf nach Attinghausen wurde vom IVS als national bedeutend eingestuft - hauptsächlich, weil ihr Trassee nie begradigt wurde und teilweise bis heute von historischen
16 Gasser 1986, 168-252.

17 Meyer/Obrecht/Schneider 1984, 7-36. - Lehner 1983.

18 Furrer 1985, 88-89.

19 Sauter 2017 (im Druck).
Die Siegfriedkarte von 1880 (BI. Altdorf) dokumentiert mehrere Zubringer zum ausgesetzten "Hohweg». Das lokale Wegenetz war weit verzweigt. Karte swisstopo (BA16018)

Der Hochweg von Attinghausen und die kurvige Route durch die Reussebene bildeten die Nord-Süd-Achsen durch den Kanton Uri im Mittelalter und der Neuzeit.

Zeichnung F. X. Triner, um 1800 (Zentralbibliothek Zürich)

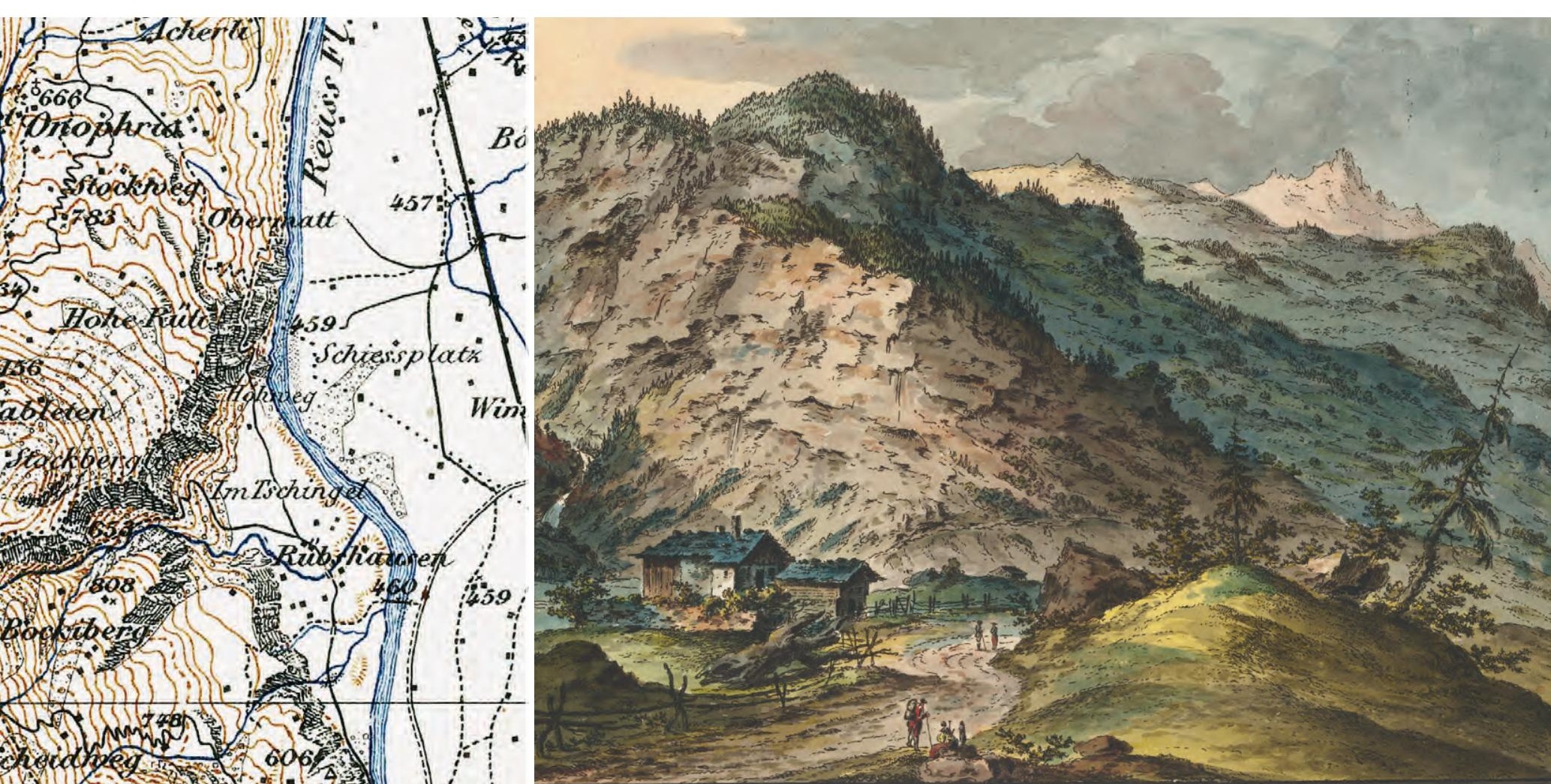


Die ausgesetzte Halbgalerie des Hochwegs von Attinghausen ist das letzte Zeugnis der historischen Passage. Foto M. Sauter, 2011
20 IVS UR 1998, 12 (inkl. Beschrieb).

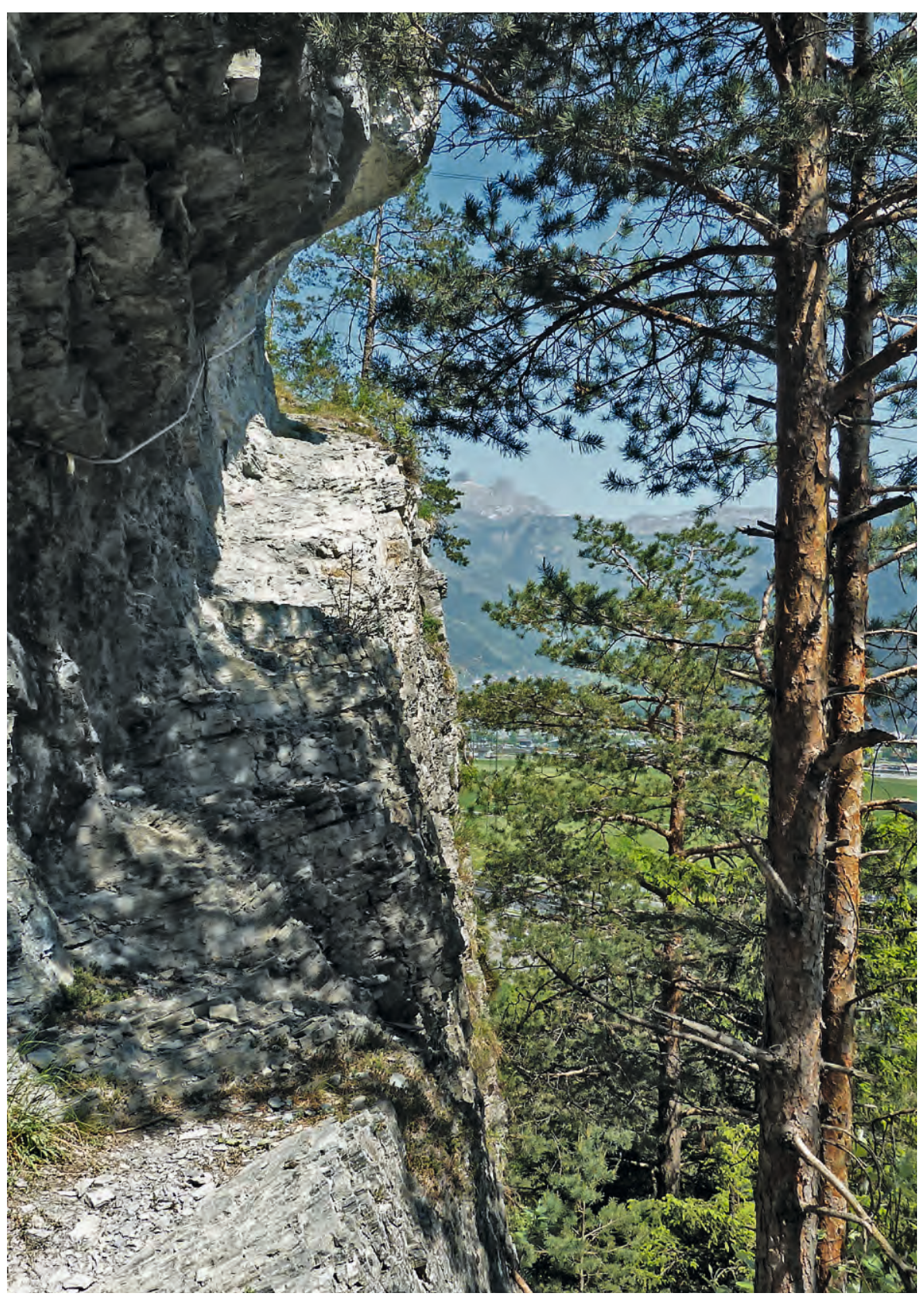

Trockenmauern gefasst ist. In der Eielen verläuft die inzwischen geteerte Strasse auf einem aufgeschütteten Damm.

Nördlich von Attinghausen existiert eine alternative Route über Spälten und Schweinsberg, wo das Relikt einer Gasse erhalten geblieben ist. Der geschotterte, gut $1 \mathrm{~m}$ breite Weg hat bergseitig eine etwa $40 \mathrm{~m}$ lange Stützund talseitig eine $10 \mathrm{~m}$ lange Begrenzungsmauer, Überreste des einst weit verzweigten lokalen Wegenetzes.

Das IVS misst der Strecke von Seedorf nach Attinghausen eine grosse politische Bedeutung zu. Das Zürcher Fraumünsterkloster war ab 853 als kirchliche Obrigkeit und als Eigentümer zahlreicher Urner Anwesen am Ausbau der Erschliessung interessiert. ${ }^{20}$ Diese endete jedoch sicher nicht in Attinghausen, sondern führte weiter in Richtung Süden über eine Geländeterrasse bei Isleren, etwas oberhalb des bäuerlichen Dorfkerns von Attinghausen und vorbei am ehemaligen Turm im Schatzbödeli. Im Wald querte der Weg die von der Reuss unterspülte, steil aufragende Bockifluh auf dem sogenannten Hochweg, einer künstlich ausgebrochenen Halbgalerie. 


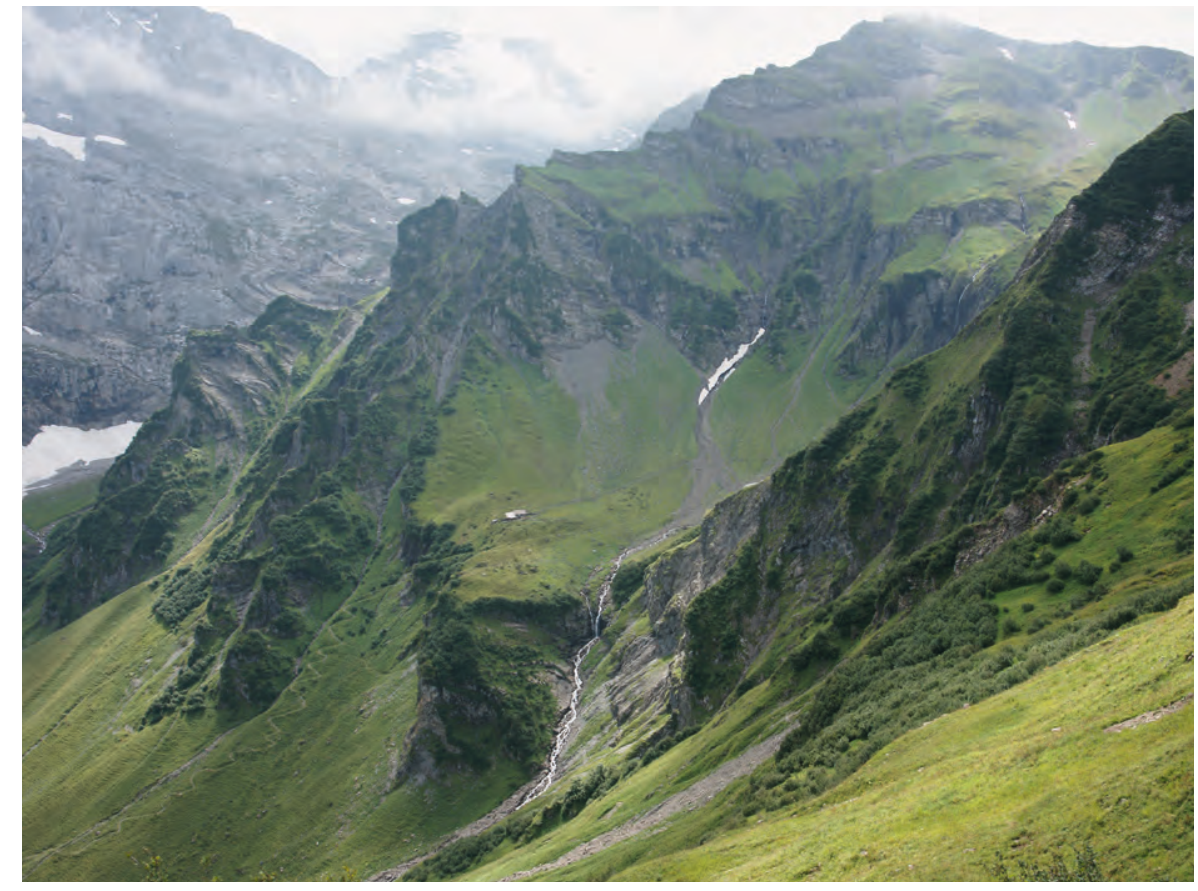

Die ausgesetzte Felspassage ist $12 \mathrm{~m}$ lang und kaum mehr als 0,5 m breit. Sie war und ist somit für Mensch und Schmalvieh problemlos, für Grossvieh - unter Berücksichtigung der deutlich geringeren Grösse der Tiere im Mittelalter - durchaus begehbar. ${ }^{21} 1321$ fand der "Honwege» im Urbar der Zürcher Fraumünsterabtei erstmals Erwähnung. ${ }^{22}$ Der Urner Künstler Franz Xaver Triner skizzierte den Weg um $1800 .{ }^{23}$ Sowohl der Dufouratlas von 1859 als auch die Siegfriedkarte von 1880 bilden die ausgesetzte Passage $a b$, unter den charakteristischen Bezeichnungen "Stockweg" beziehungsweise "Hohweg".

Da die Hochweg-Partie nicht mit Karren zu befahren ist, etablierte sich im Zusammenhang mit dem Ausbau des Flüeler Hafens im ausgehenden Mittelalter eine befahrbare Strecke am rechten Reussufer. Die rechtsufrige Route führte bis weit in die Neuzeit hinein über Bürglen und war somit deutlich länger als der Hochweg, der bis ins 20. Jahrhundert hinein von den Anwohnern rege frequentiert wurde.

Nachdem 1959 eine Galerie in die Bockiflue gesprengt und am Ufer der inzwischen mit einem Damm gefassten Reuss ein bequemer Fussweg eingerichtet worden war, geriet der ausgesetzte Hochweg in Vergessenheit. ${ }^{24}$ Die Spazierroute - von Spaziergängern liebevoll mit unzähligen kleinen Engelsfigürchen dekoriert - veränderte den unmittelbaren Zugang zur historischen Felspassage. Im Süden führen heute einige Eisentritte zum Hochweg hinauf. Im Norden verliert sich das ehemalige Trassee im Wald. ${ }^{25}$

Der Weg von Ripshausen bis zum Dorfkern von Erstfeld beziehungsweise zur Erstfelder Reussbrücke führt schliesslich an einigen historischen Bauern- und an zwei Schulhäusern des 19. Jahrhunderts vorbei. Die frequentierte Dorfstrasse selbst weist keine historischen Besonderheiten mehr auf.

\section{Der Surenenpassweg bis zum 18. Jahrhundert}

Der Surenenweg führt von Attinghausen am linken Ufer des Chummetbachs entlang bergauf beziehungsweise quert die Streusiedlungen Langacher und Tschingli. Bei Mettlen, unweit der im Kern aus dem ausgehenden 16. Jahrhundert datierenden Kapelle St. Onofrio, treffen sich die beiden Routen. Der
Der Serpentinenweg von der Waldnacht zur Alp Eifrutt (linke untere Bildhälfte). Foto M. Sauter, 2011
21 Zu den Thesen über einen abgegangenen Weg entlang des Reussufers vgl. Sauter 2011.

22 Kläui 1943, 262.

23 Blick von Rinächt gegen das Bockitobel. Zeichnung F. X. Triner, um 1800 (Zentralbibliothek Zürich, Graphische Sammlung 9172).

24 IVS UR 1998, 13.0.1.

25 Zum Hochweg vgl. Sauter 2011. 
26 Scheuchzer 1716, 218-219.

27 Freundl. Hinweise von Martin Furrer und Kari Muheim.

Der Surenenpassweg erschloss bis zum alpwirtschaftlichen Strukturwandel die Siedlungsplätze auf Gritschen. Die heutige Route etablierte sich wahrscheinlich erst im 18. Jahrhundert.

Foto M. Sauter, 2014
Weg geht weiter über das Wiesland bei Obermatt, bevor er bei Tafleten in den Wald hineinführt. Die letzte Etappe vor der Eigenalp Waldnacht ist der Stückiberg. Eine Senke auf 1436 m ü.M. unterhalb des Höchibergs bietet den Blick auf das ausgedehnte Hochtal der Waldnacht. Knapp 2,5 km geht es nun fast eben voran, vorbei an der 1931/32 errichteten Alpkapelle St. Wendelin.

Der letzte Anstieg zur Passhöhe beginnt hinter dem sogenannten Sennenstein bei Gletti, führt in Serpentinen auf Eifrutt weiter über Restbiel. Die in engen Serpentinen angelegte Passage nach Eifrutt gehört zu den schönsten Streckenabschnitten des Surenenpasswegs. Angesichts der Topografie ist eine andere Wegführung an dieser Stelle kaum vorstellbar. Die Datierung der permanent instand gesetzten Anlage ist nicht möglich.

Der mit viel Geröll durchsetzte Hang unmittelbar unterhalb der Surenenpasshöhe auf der Urner Seite ist ein Schneeloch, gekennzeichnet durch die Flurbezeichnung Langschnee. Häufig liegt dort bis weit in den Juli hinein Schnee, so beispielsweise auch während der Vorbereitungen für die Grabungskampagne auf dem Geissrüggen im Sommer 2013. Die Witterungsverhältnisse gestalteten sich während der Kleinen Eiszeit noch erheblich schlechter. Reisebeschreibungen des 18. Jahrhunderts notieren über eine Stunde dauernde Querungen von Schneefeldern auf dem Weg nach Engelberg. ${ }^{26}$ Zuletzt schmolz der Langschnee in den heissen Sommern der Jahre 1947 und 1949 vollständig ab. Der Auftrieb der Viehherden über den Pass variierte im 20. Jahrhundert entsprechend vom 10. Juni bis zum 15. Juli. ${ }^{27}$

Diesseits der Passhöhe führt der Surenenweg vorbei an der Surenenschutzhütte in den Taleinschnitt eines Stierenbachzuflusses. Ab hier ist von einer ursprünglich anderen Wegführung auszugehen. Der historische Pfad zweigte nach Westen ab und querte die auf $2161 \mathrm{~m}$ ü.M. liegende Terrasse Uf den Seewen, die mit mehreren kleinen Seen zur Rast einlud. Einige grössere, teilweise um Mauerzüge ergänzte Felsbrocken boten/bieten Schutz im ansonsten vollständig ausgesetzten, baumfreien Gelände.

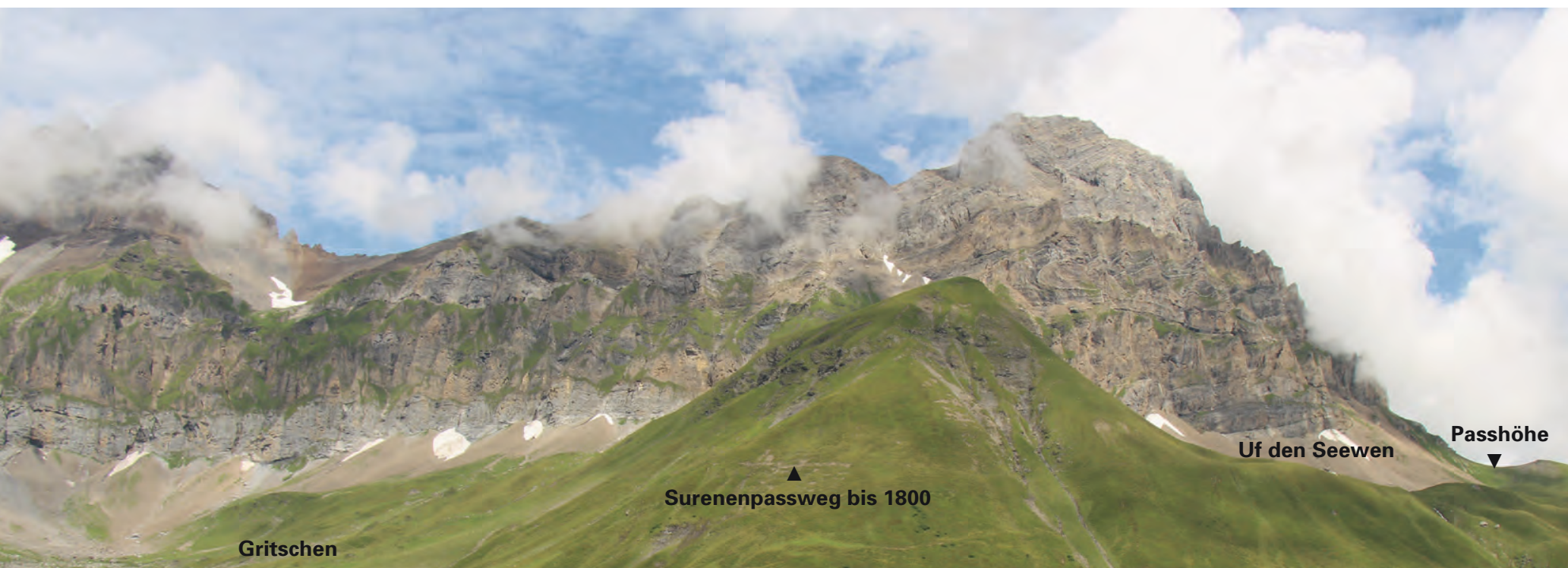

Blackenboden 


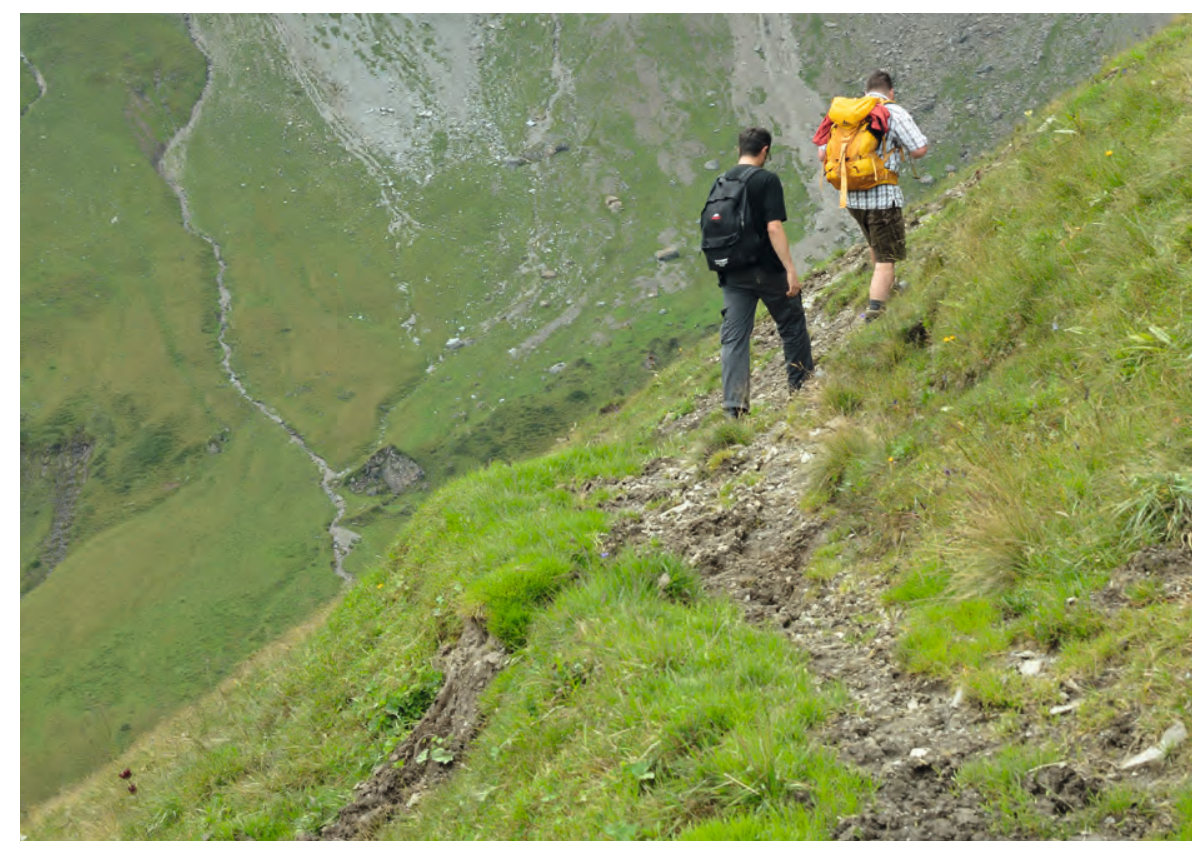

Unterhalb des Turms (2368 m ü.M.), der die Terrasse Uf den Seewen überragt, findet sich bis heute ein Wegfragment. Die isolierte Passage ist sogar in der aktuellen Landeskarte (LK 1191) verzeichnet und belegt - zusammen mit den Ergebnissen der Prospektionskampagne 2014 ( $\Rightarrow$ S. 184-201) - die historische Streckenführung: Der ehemalige Surenenweg muss das $100 \mathrm{~m}$ tiefer liegende ehemalige alpwirtschftliche Zentrum Surenens auf Gritschen erschlossen haben. Das Wegfragment unterhalb des Turms führt von Osten auf die ehemaligen Alpstafel von Gritschen zu und ist demzufolge spätestens im Mittelalter angelegt worden. Der Weg weist keine Substruktionen auf und ist heute lediglich noch als breiter Viehtritt zu erkennen, der nicht mehr unterhalten wird und an mehreren Stellen durch Hangrutschungen unterbrochen ist. Der ehemalige Surenenweg querte den Blackenboden wahrscheinlich entlang des Stierenbachs, Überreste sind jedoch keine mehr zu erkennen.

Um 1700 wurde Surenen im Rahmen eines Strukturwandels von der Einzelalpung auf eine grosse Rinder- und Schafhirte umgestellt. ${ }^{28}$ Die teilweise aus dem Mittelalter datierenden Betriebe auf Gritschen wurden aufgegeben und ein neues Alpzentrum, die heutige Blackenalp auf 1773 m ü.M., wurde eingerichtet. Möglicherweise führte auch eine verheerende (Schnee-)Lawine oder ein Erdbeben zur definitiven Zerstörung der noch vorhandenen Gebäudestrukturen und zur Verlagerung des alten Surenenpasswegs auf die gegenüberliegende, östliche Hangseite - den heutigen Weg. Der frühere Passweg zerfiel in der Folge und ist heute im Gelände nahezu spurlos verschwunden. Entlang des heutigen, rege frequentierten Wanderwegs von der Surenenpassschutzhütte zur Blackenalp - eine Strecke von gut $3 \mathrm{~km}$ finden sich keinerlei bauliche Überreste, was eindeutig für eine Einrichtung dieser Route nach dem alpwirtschaftlichen Strukturwandel spricht.

Im Rahmen der Prospektionskampagne 2014 konnte ein weiteres Alpzentrum mit sieben Wüstungsplätzen auf Butzen, auf 1800 m ü.M., dokumentiert werden ( $\rightarrow$ S. 184-201). Es ist daher anzunehmen, dass der historische Surenenpassweg an der nordwestlichen Talflanke, am rechten Ufer des Stierenbachs entlang talwärts führte. Fragmente einer alternativen Streckenführung finden sich unmittelbar hinter der Blackenalpkapelle. Es
Die Überreste des ursprünglichen Surenenpasswegs zwischen Uf den Seewen und Gritschen. Foto R. Gubler, 2014 
Der Surenenweg von Erstfeld in Richtung Waldnacht. Die ausgesetzte Passage am Bockitobel ist aufwendig unterfangen.

Foto M. Sauter, 2015 ist vorstellbar, dass der Weg südlich von Butzen entlang der heutigen Weidmauer verlief. In der Fortsetzung, zwischen der Flur Unteraa und der Alp Hobiel, verläuft ein Pfad, der auch die Alpen Steinäbnet, Steinhütte und Usser Äbnet erschliesst. Von Steinäbnet führt ein steiler Pfad durch die Fluh Im Tritt in Richtung Engelberg hinab, vorbei an den Alpweilern Stäfeli und Alpenrösli.

Wahrscheinlich besteht seit jeher jene Wegalternative, die auf direkte Weise von Surenen in die Engelberger Herrenrüti, das Urner Schneefluchtareal, führt. Hierzu muss der Stierenbach oberhalb des Stäubers gequert werden. Es ist anzunehmen, dass die Hirtihütte an der Ostflanke Nidersurenens zeitnah zur Einrichtung der Rinderhirte Surenen erstellt wurde. Sie dient dem Rinderhirten als Maiensäss beziehungsweise als Übergabeort der Viehherden. Die Hirtihütte, bestehend aus einem Wohnhaus und einem Gaden, ist das einzige Bauensemble an der sanft geneigten, jedoch von Steinschlägen aus dem Schlossbergmassiv stark bedrohten östlichen Talflanke Nidersurenens.

Die Erschliessung der Alp Surenen wurde nach der Einrichtung der Seilbahn von Stäfeli nach Usser Äbnet im Jahr 1997 für landwirtschaftliche Nutzfahrzeuge fahrbar gemacht, der Surenenweg zur Naturstrasse ausgebaut und in sanftem Schwung an der östlichen Talflanke in Richtung Blackenalp weitergeführt, was die Errichtung einer weiteren Steinbrücke erforderlich machte.

\section{Der Weg von Erstfeld zum Bockitobel}

Auf der Siegfriedkarte besitzt der Erstfelder Surenenpassweg die gleiche Wertigkeit wie der Attinghauser Weg. Ein Anstieg startet in Hofstetten, eine Wegalternative führt in Ripshausen am linken Ufer des Bockibachs bergauf. ${ }^{29}$ Die beiden Strecken treffen sich auf dem Bockiberg. Die Streusiedlungen auf dem Wisligberg und dem Zieriberg werden von einer Gasse gequert, was regelmässige und grössere Viehtriebe über den Erstfelder Surenenweg belegt.

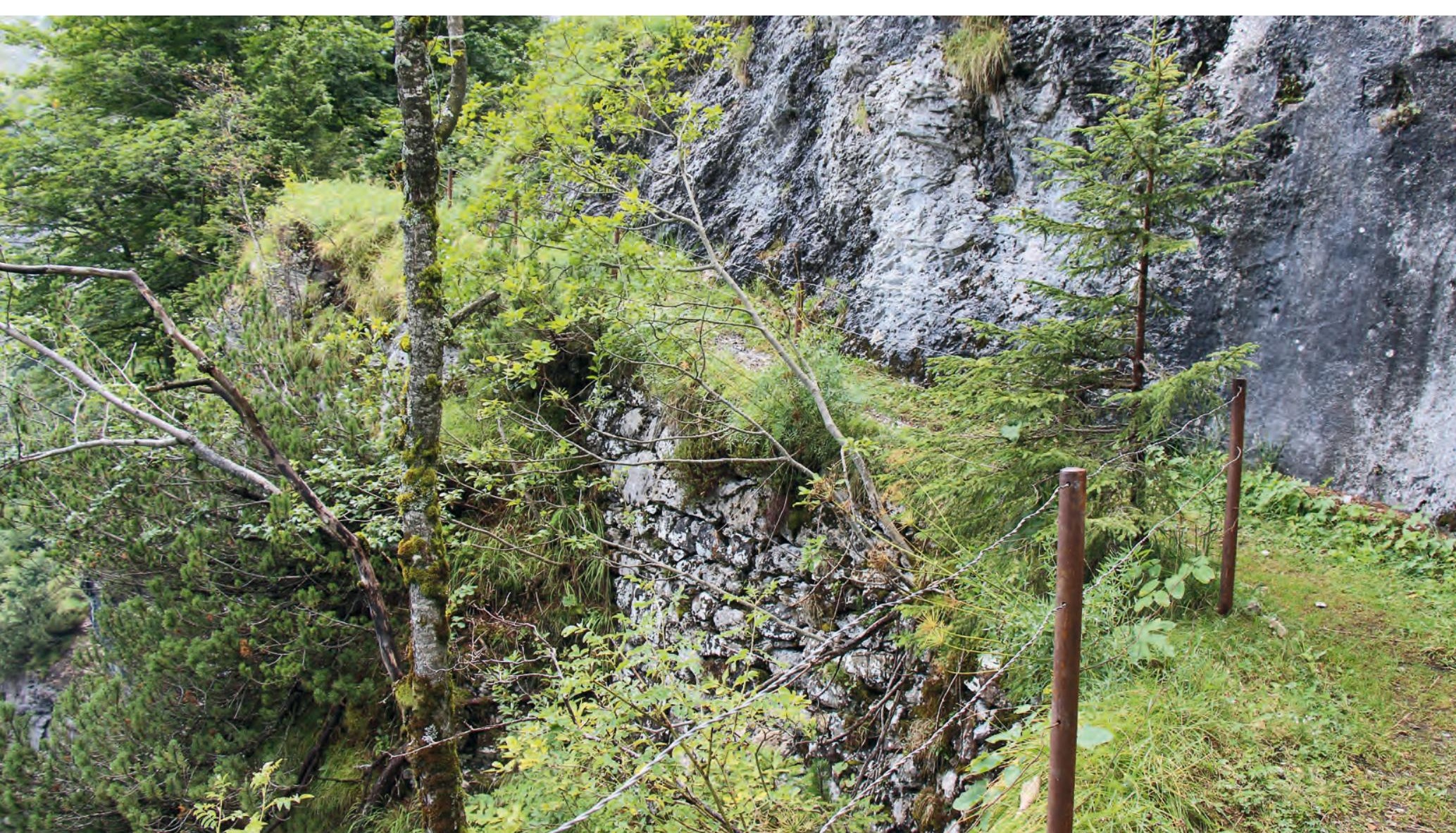




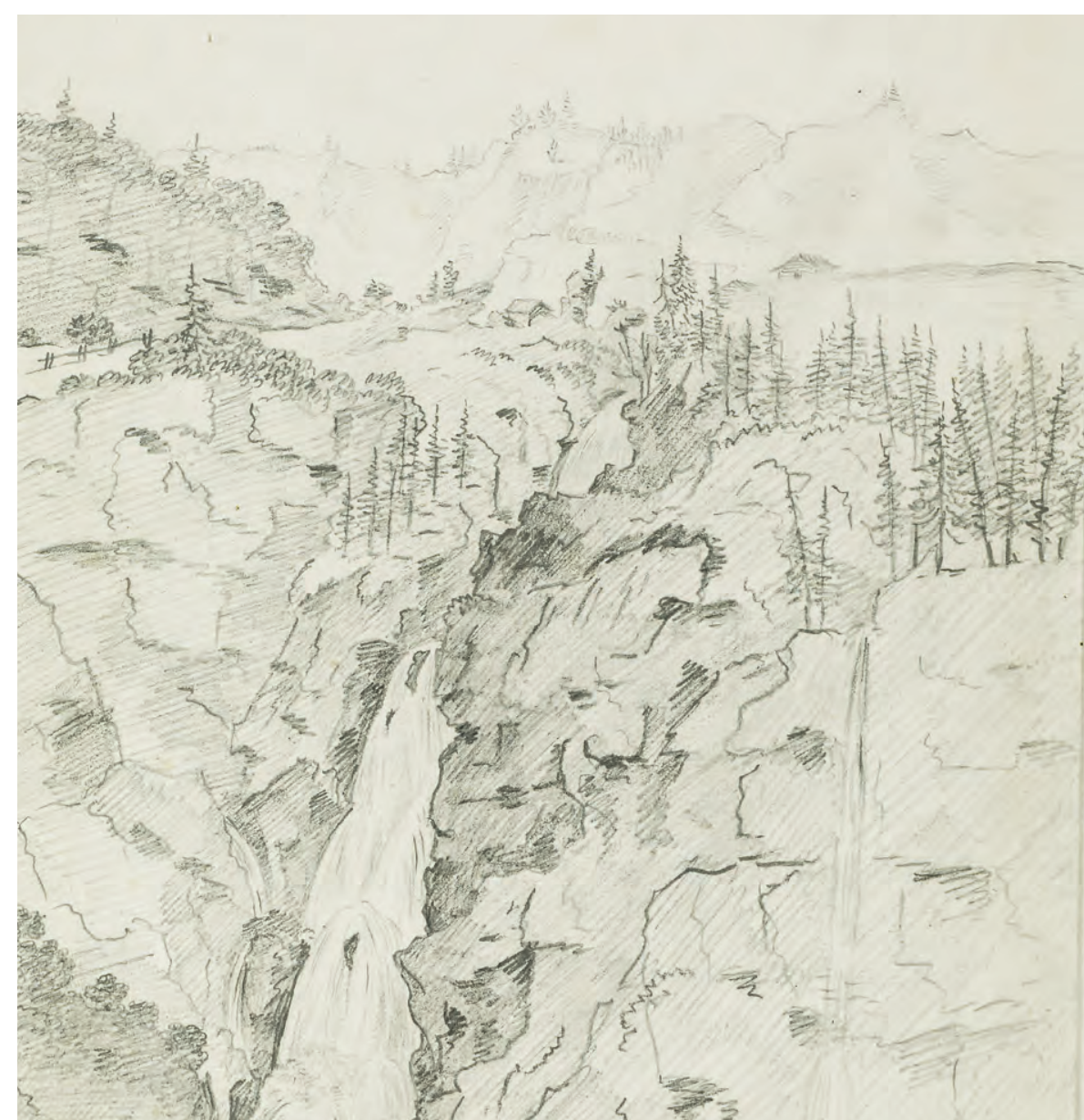

Auf 1000 m ü.M. quert der Surenenweg die Bergflanke in Richtung Nordwesten und bietet atemberaubende Ausblicke auf die hoch aufragenden Felsmassen der Bockifluh beziehungsweise auf das steil eingetiefte Tobel. Auf den letzten Metern vor dem Tobel ist der Surenenweg terrassiert angelegt und mit hohen Stützmauern unterfangen. Bau- oder Unterhaltsarbeiten zu dieser Passage sind nicht dokumentiert. Wahrscheinlich datieren die ersten Substruktionen jedoch ins Mittelalter. Der Erstfelder Surenenweg stösst an der Waldnachter Bachhütte auf die Attinghauser Route.

\section{Der Weg über Chulm und Grat}

Die Betriebe rund um den Attinghauser Chulm auf $1500 \mathrm{~m}$ ü.M. dienen als Maiensäss, sie werden demzufolge bereits einige Wochen vor der eigentlichen Alpfahrt bestossen. Es ist anzunehmen, dass in dieser moderaten Höhenlage zeitweise auch ganzjährig gewirtschaftet wurde. Die Erschliessung des Chulms erfolgt ab Attinghausen-Port vornehmlich durch den Wald, der von mehreren eingetieften Bachläufen durchzogen ist. So verfügen die Liegenschaften Rietli, Bittmändi, Ruberli (heute: Kohlplatz) und Schwandenberg jeweils über einen eigenen steil ansteigenden Zugang. Der letzte Aufstieg nach Chulm startet am Schwandenberg. Von Chulm führte der Weg über Chäserli in Richtung Gratgädemli, von dort weiter in Richtung Grat - südlich des heutigen Wanderwegs. Am Grat trifft die Chulmroute auf den Seedorfer Surenenweg.

Von Gratgädemli aus kann man auch in die Waldnacht hinabsteigen. Die Wegpartie wird jedoch nicht mehr unterhalten und lediglich noch von Wildheuern begangen. Die heutige Querverbindung zwischen dem Surenenweg
Der exponierte Streckenabschnitt am Bockitobel ist seit jeher mit Geländern gesichert - links oben zu erkennen. Zeichnung K. F. Lusser, um 1820 (Staatsarchiv Uri) 
Der Seedorfer Surenenweg (rot) führte über den Gitschenberg. Der Streckenabschnitt zwischen Rüti und Honegg (blau) konnte abgekürzt werden - allerdings nur mit Schmalvieh. Der Weg durch das Driangel (gelb) führte über Leitern und empfahl sich nur für erfahrene Berggänger.

Karte swisstopo (BA16018), Grafik M. Sauter, 2016 über die Waldnacht und der Passage über den Grat entstand erst nach der Eröffnung der Luftseilbahn Brüsti. Der ausgesetzte wie pittoreske Weg über das Furggeli ist nicht mit Vieh zu begehen.

Der weitere Weg in Richtung Surenenpass über den Geissrüggen, Nussfruttli und Brunnifurgi folgt weitgehend der Topografie und hat sich daher in seiner Streckenführung in den letzten Jahrhunderten wahrscheinlich kaum verändert. Das Areal rund um den Grat wird heute nur noch von einem alpwirtschaftlichen Betrieb genutzt. Entlang des Passwegs finden sich jedoch zahlreiche Ruinen, die weitere historische Alpstafel bezeugen, sowie die Überreste des hallstattzeitlichen Kontrollpostens auf dem Geissrüggen (- S. 122-135). Bei Langschnee, 200 m unterhalb der Passhöhe, stösst die Gratpassage auf den Hauptweg.

Die Landeskarte (LK 1191) verzeichnet auf 2100 m ü.M. einige Wegfragmente. Möglicherweise führte der Passweg ursprünglich oder zeitweise oberhalb der Schneefelder vorbei, was die Bedeutung der Grat-Route stärkt.

\section{Der Weg von Seedorf zum Grat}

Die steile Seedorfer Surenenroute erschliesst in erster Linie die Alpstafel des Gitschitals. Hier wirtschaften heute drei Betriebe. Wie auch auf dem Grat kann jedoch aufgrund der Vielzahl der Wüstungsplätze von weiteren historischen Alpstafeln ausgegangen werden. Die alpwirtschaftliche Verbindung zum Attinghauser Surenenweg über den Grat liegt in der Nutzung von Oberstafeln auf dem Grat sowie im ehemaligen Schaftrieb nach Surenen. Bis weit ins 20. Jahrhundert hinein wurden in der sumpfigen Ebene im Reussdelta bei Seedorf vornehmlich Schafe gehalten. Die Gitschitaler Rinder werden vor Ort gesömmert, vorherrschend ist die Einzelalpung.

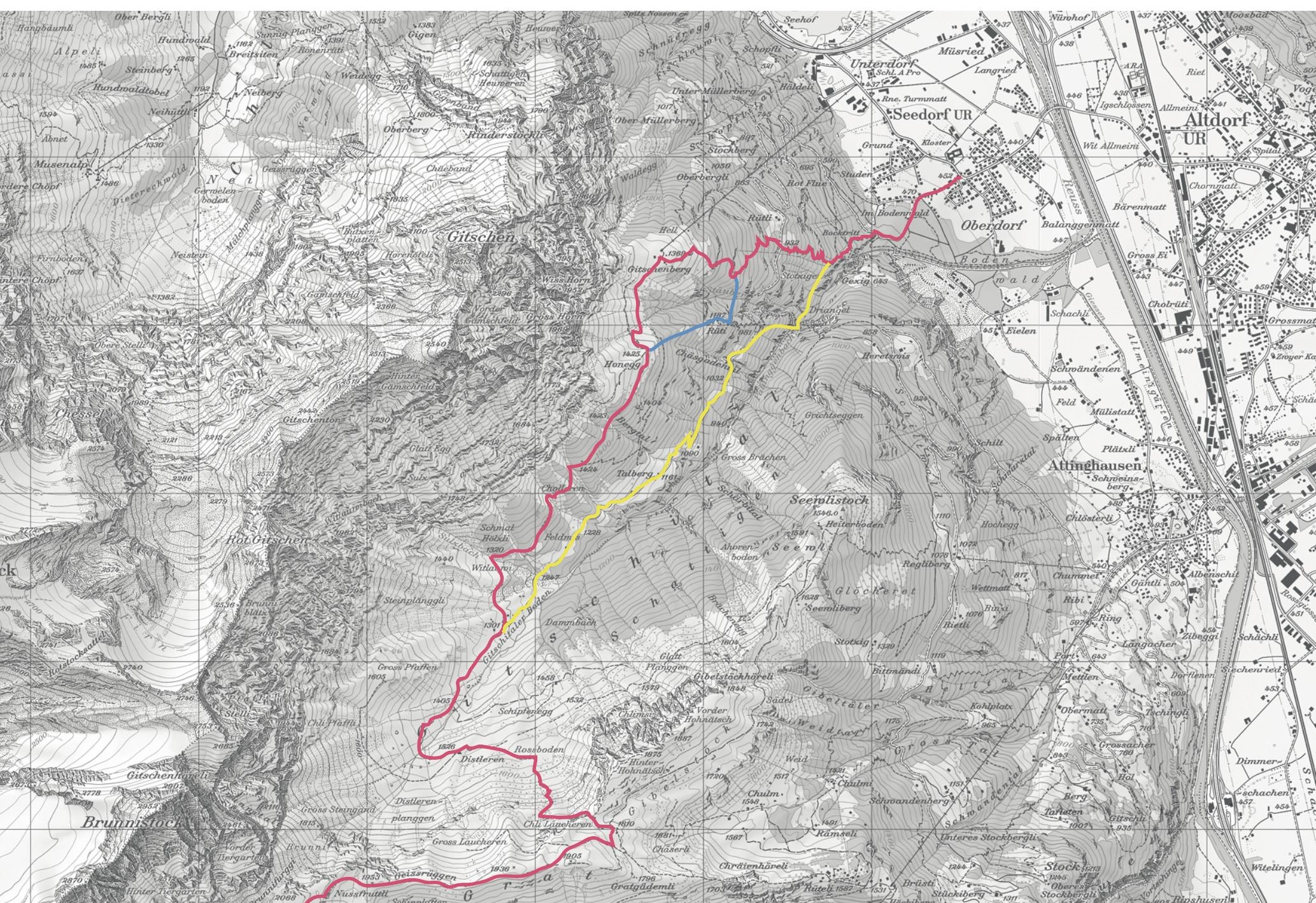



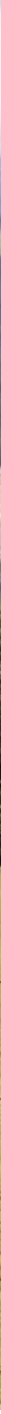

Das Gitschital wurde/wird von mehren Wegen durchzogen: Partien, die mit Vieh gerade noch zu begehen sind, sowie enorm steile Abkürzungen durch das sogenannte Driangel, die etwa die Holzfäller früher nutzten. Auf $800 \mathrm{~m}$ ü.M. fliessen der Stäuber und der Palanggenbach zusammen. Die tiefen Einschnitte der beiden Wildbachläufe bilden das Driangel, das nur mithilfe von Leitern auf direktem Weg zu queren war.

Das Vieh wurde durch den steilen Bodenwald ins Rüttli auf die auf 1369 m ü.M. gelegene Alp Gitschenberg getrieben. Der Weg führt über Honegg und Cholleren weiter in Richtung Distleren, zum hintersten Alpstafel des Gitschitals. Parallel dazu etablierte sich eine Route, die oberhalb des Palanggenbachs über den Talberg auf 1161 m ü.M. führt. Diese Route wurde 1963 durch eine Seilbahn bis Stotzigen verbessert, eine weitere Seilbahn erschliesst seit 1971 den Gitschenberg. Mithilfe polnischer Internierter wurde in den 1940er Jahren der Weg in Richtung des zeitweise ganzjährig besiedelten Stockbergs zu einem Waldweg ausgebaut - die ersten vier Kehren der heutigen Strasse. Diese wurde 1980 in Betrieb genommen, sie erforderte Sprengungen ob der Rot Flue, die zuvor nicht zu überwinden war. Nach der Untertunnelung des Stäubers im Jahr 1987 konnte auch der zwischenzeitlich ausgebaute Alpfahrweg oberhalb des Flusslaufs an die Fahrstrasse angebunden werden.

Die Steilheit des stark bewaldeten Geländes rund um das Driangel wird auf mehreren Aussichtsbalkonen deutlich, die atemberaubende Ausblicke auf den Vierwaldstättersee erlauben. Das Vieh wurde häufig nur über das Gitschital auf-, jedoch über Attinghausen abgetrieben, um die Gefahren auf
Die Mettlengasse oberhalb von Attinghausen wurde in den Jahren 1896 bis 1899 ausgebaut.

Foto M. Sauter, 2011

Die Gasse im Wiesland am Erstfelder Wisligberg dürfte hingegen noch dem Ausbaustandard der frühen Neuzeit entsprechen.

Foto M. Sauter, 2015 
30 Oechslin 1927, 127.

31 Freundlicher Hinweis von Werner Arnold und Julius Stadler, Seedorf.

32 Das IVS weist auf die Differenz in der Verortung auf der Siegfriedkarte hin. Derartiges konnte im Kanton Uri mehrfach festgestellt werden und entspricht wohl einer ungenauen Aufnahme und nicht einer einschneidenden Verlegung des Saumpfads 1896. Vgl. Loepfe 2007, 50-51.

33 GPA vom 15. Dezember 1895 und P 1-171 (Auszüge aus den Rechenschaftsberichten der Regierung, Attinghausen betreffend.)

34 Gasser 1979, 113.
Der Surenenpassweg ist im Bereich der Waldnachter Berge als Gasse ausgebildet und partiell gepflastert.

Foto M. Sauter, 2015 den steilen Pfaden zu verringern. Nichtsdestotrotz wurden auf 1424 m ü.M., bei Cholleren, einst Kohlemeiler betrieben, "wo jede Wegsame für die Holzbringung fehlte ${ }^{30}$ und die Produktion auf steilen Pfaden ins Tal transportiert werden musste. ${ }^{31}$

Hinter dem Gitschitaler Boden beschreibt der Pfad eine weite Kurve über Distleren in Richtung Grat. In der Siegriedkarte ist diese Erschliessung lediglich gestrichelt dargestellt und hinter dem Gitschitaler Boden gar unterbrochen, obwohl in "Tischleren» (= Distleren) und Schipfenegg zahlreiche Alpgebäude verzeichnet sind. Die im Wesentlichen auf das Gitschital beschränkte Bewirtschaftung und die anspruchsvolle Route mag Ende des 19. Jahrhunderts zu einer "Abwertung" dieser Surenenroute geführt haben.

\section{Die Infrastrukturbauten}

Der Surenenpassweg ist wie viele andere historische Passagen im Bereich des Wieslands meist als hohle Gasse ausgebaut, um die angrenzenden Matten vor Flurschäden beim Viehtrieb zu schützen. Bekannt ist vor allem die Attinghauser Mettlengasse, die neben der Burgli-Hofstatt in sanftem Schwung bergauf führt. ${ }^{32}$ Pendants finden sich aber auch auf der Erstfelder Strecke am Wisligberg, der Bedeutung als alternativer Alpfahrweg und ehemaliger Standort der Surenen-Zollstation entsprechend. Wahrscheinlich entspricht die heutige Gestalt der Erstfelder Gasse der Ausführung der alten Mettlengasse, die in den Jahren 1896 bis 1899 umfassend ausgebaut wurde. ${ }^{33}$ Auch in den Waldnachter Bergen wurde das Vieh durch eine beidseitig gefasste Gasse am Ausbrechen gehindert und konnte somit geordnet auf den Rastplatz getrieben werden.

Die typischen Viehtriebgassen sind bis zu 1,8 $\mathrm{m}$ breit angelegt, bis zu 1,2 $\mathrm{m}$ eingetieft und häufig beidseitig mit Trockenmauerwerk eingefasst. Vielerorts finden sich Pflasterungen, sogenannte Bsetzi, oder Stufen. Es ist anzunehmen, dass die aufwendigen Fassungen spätestens im 16. Jahrhundert entstanden sind und die wachsende Zahl von Rindviehherden widerspiegeln. Die Pflasterungen am Attinghauser Surenenpassweg fanden im Rahmen der Regelung der Unterhaltsarbeiten im Jahr 1562 erstmals Erwähnung. ${ }^{34}$ Die Gassen ziehen sich auf direktem Weg oder in engen Kurven bergauf - entsprechend den Bedürfnissen der berggängigen Älpler.

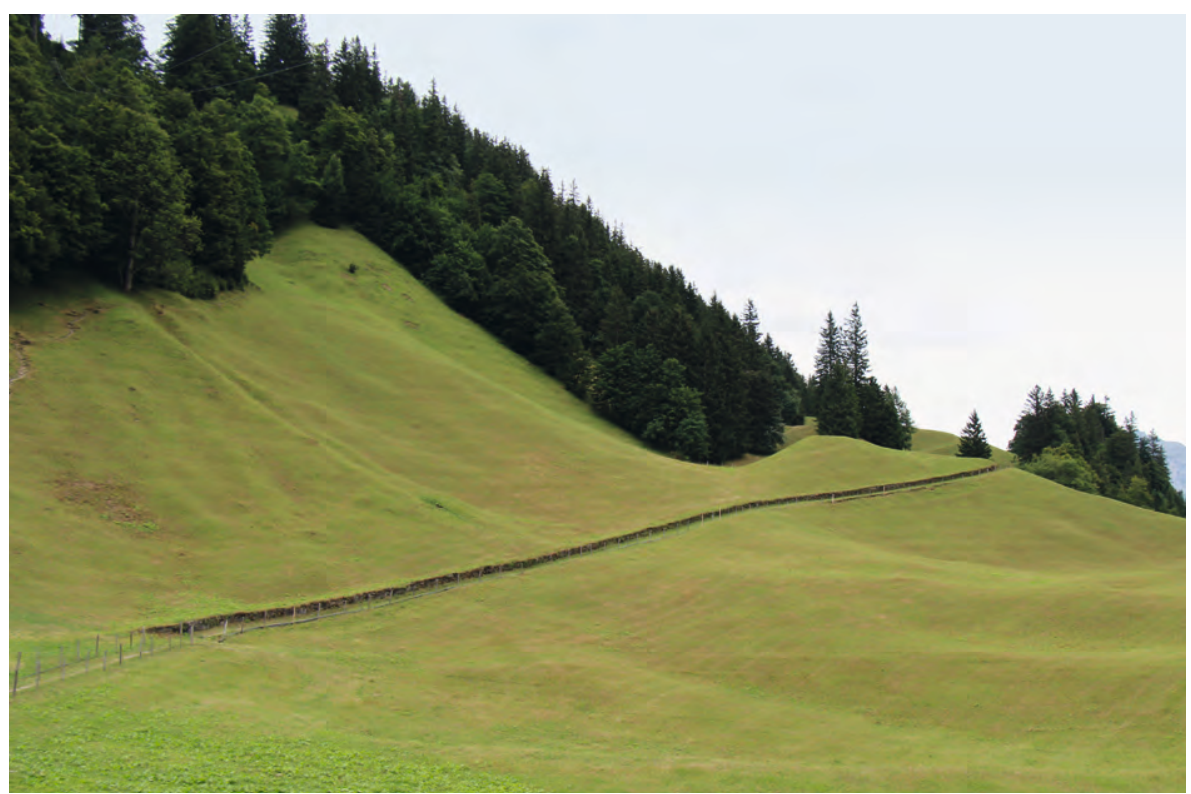


Im Wald wurde das Trassee der Passwege bei Bedarf mit gepflasterten Partien oder Trittstufen ausgebaut sowie mit Randsteinen oder Stützmauern befestigt. Hier war keine seitliche Begrenzung erforderlich, da das Vieh kaum Flurschaden anrichten konnte. Die steilste Waldpassage auf dem Weg zum Surenenpass quert den Seedorfer Stäuber und setzt sich unterhalb des heutigen Tunnels fort.

Der steile Verlauf der Gassen und der Passagen durch den Wald bedingte, dass die neu erbauten fahrbaren Strassen im 20. Jahrhundert anderweitig geführt werden mussten und sich die historischen Wegfassungen somit vielerorts erhalten haben. Die Erschliessung des Surenenpasswegs durch bequeme Luftseilbahnen hat jedoch dazu geführt, dass diese historischen Wege heute kaum noch frequentiert werden und daher zunehmend verfallen und überwachsen.

Die Pfade oberhalb der Waldgrenze sind - bis auf die Serpentinen der Eifruttpassage - hingegen kaum ausgebaut. Sie entstanden durch regelmässige Begehung, können nach Jahreszeit variieren und im Fall von Naturkatastrophen - Erdrutsche oder Steinschläge - recht einfach verlagert werden. Einzig am Abstieg nach Niedersurenen, unterhalb des Stäubers, finden sich mehrere gepflasterte Partien.

Eine Besonderheit bilden die Stege, die über die zahlreichen Bachläufe führen. Neben einfachen Provisorien oder ausgetüftelten Stegen, erstellt durch die jeweiligen Anrainer, sind hier vor allem die Steinbogenbrücken an der Blackenalp und am Stäuber zu erwähnen, die in ihrer heutigen Gestalt ins frühe 20. Jahrhundert datieren.

\section{Fazit}

Zwei Aspekte kennzeichnen den neuen Stand der SurenenpasswegForschung: einerseits die Aufwertung der Erstfelder Route, die ganz ähnliche Passagen wie die als national bedeutend eingestufte Attinghauser Mettlengasse aufweist und damit auch den bislang eher rätselhaften
Auf den Waldnachter Bergen verlängerten Zäune die eingetieften Gassen. Zeichnung K. F. Lusser, 1819 (Staatsarchiv Uri) 
35 Schiller, Friedrich. Wilhelm Tell. 2. Aufzug, 2. Szene.

Im Wald unterhalb des Erstfelder Wisligsbergs ist eine steile Kurve gepflastert. Die Steine sind hochkant gesetzt und ergeben so einen rutschfesten Belag.

Foto M. Sauter, 2015

Dieser Wegabschnitt zwischen dem Seedorfer Rüti und Stotzingen wird seit dem Bau des Tunnels unter dem Stäuber nicht mehr genutzt. Es ist die wohl steilste Viehtriebpassage auf dem Weg zum Surenenpass.

Foto M. Sauter, 2015
Surenenzollstandort in Erstfeld erklärt; andererseits die historische Wegführung zwischen der Surenenpasshöhe und Blacken, beziehungsweise zwischen Blacken und Hobiel, die aufgrund der neuen Erkenntnisse zu den Siedlungsschwerpunkten der Alpwirtschaft für die Zeit vor dem 18. Jahrhundert rekonstruiert werden konnte.

Die bislang nicht dokumentierte Erschliessung durch das Gitschital mit Leiterwegen verdeutlicht einmal mehr, mit welcher Selbstverständlichkeit und Routine die autochtone Bevölkerung im Alpenraum schwierige Passagen zu bewältigen vermochte beziehungsweise zeitaufwendige Umgehungen mied.

Mit der Eröffnung des Seelisbergtunnels im Jahr 1980 hat der Surenenpassweg seine Bedeutung als Alpfahrweg, als Verbindung zwischen den Weiden diesseits und jenseits der Passhöhe, verloren. Die Nutzung hat sich auf die Begehung durch Wanderer (oder Archäologen) beziehungsweise auf die Befahrung durch Mountainbiker reduziert. Der Surenenpassweg gehört aber immer noch zu einem Weitwanderwegenetz, das die Ost- mit der Westschweiz verbindet. Damit hat er zumindest eine gewisse grossräumige Bedeutung behalten.

Historisch gesehen spielte der Tourismus kaum eine Rolle. Es lassen sich jedoch zumindest zwei illustre Wanderer dokumentieren: Der Komponist Felix Mendelssohn-Bartholdy querte den Pass im Jahr 1842 und dokumentierte seine Reise in einer Skizze sowie einem kurzen Brief an seine Mutter. Der exzentrische bayrische König Ludwig II. reiste 1881 mit seinem Lieblingsschauspieler Josef Kainz in die Urschweiz, um sich an den Originalschauplätzen Schillers Tell rezitieren zu lassen. Um den jungen Schauspieler einen Eindruck zu vermitteln, welchen Gefühlen Arnold von Melchtal auf seiner Flucht ins Urnerland ausgesetzt war, schickte er inn "durch der Surennen furchtbares Gebirg» ${ }^{35}$ - geleitet vom Rütlipächter Michael

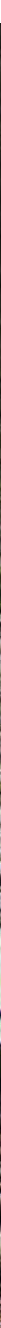




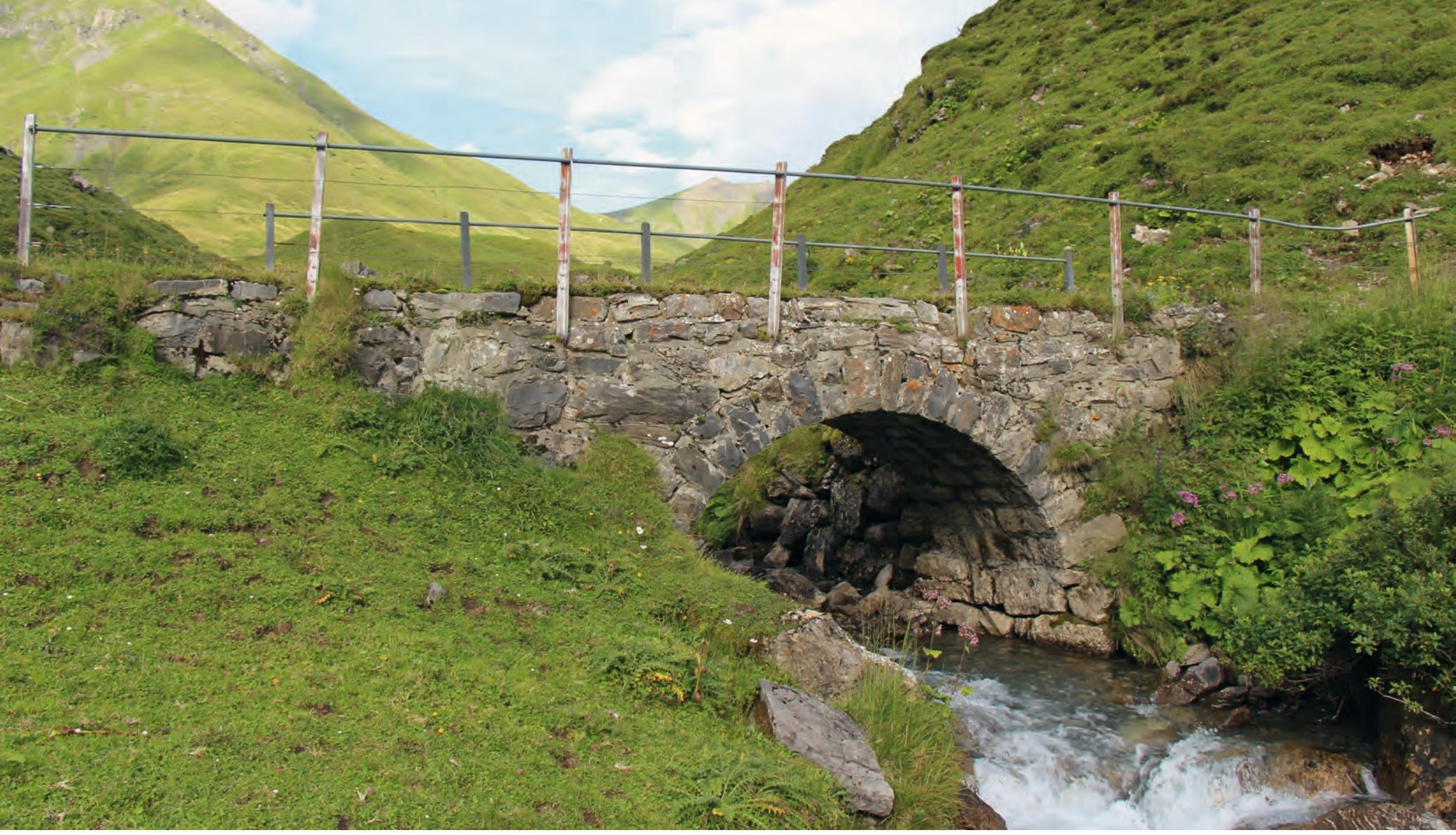

Aschwanden, einem königlichen Beamten sowie drei Trägern, die neben dem Proviant auch reichlich Moselwein und Champagner den Berg hinauf schleppen mussten. Der Tross kam nach 12 Stunden völlig erschöpft in Engelberg an. ${ }^{36}$

Das IVS wurde für den Kanton Uri nur auf der Ebene "national bedeutend" detailliert ausgearbeitet, die lediglich lokal relevanten Passagen etwa im Seedorfer Gitschital - sind ohne Berücksichtigung der komplexen historischen Zusammenhänge aufgenommen. Die Fortsetzung und die Vertiefung der vom IVS begonnenen Infrastrukturdokumentation ist wichtig,

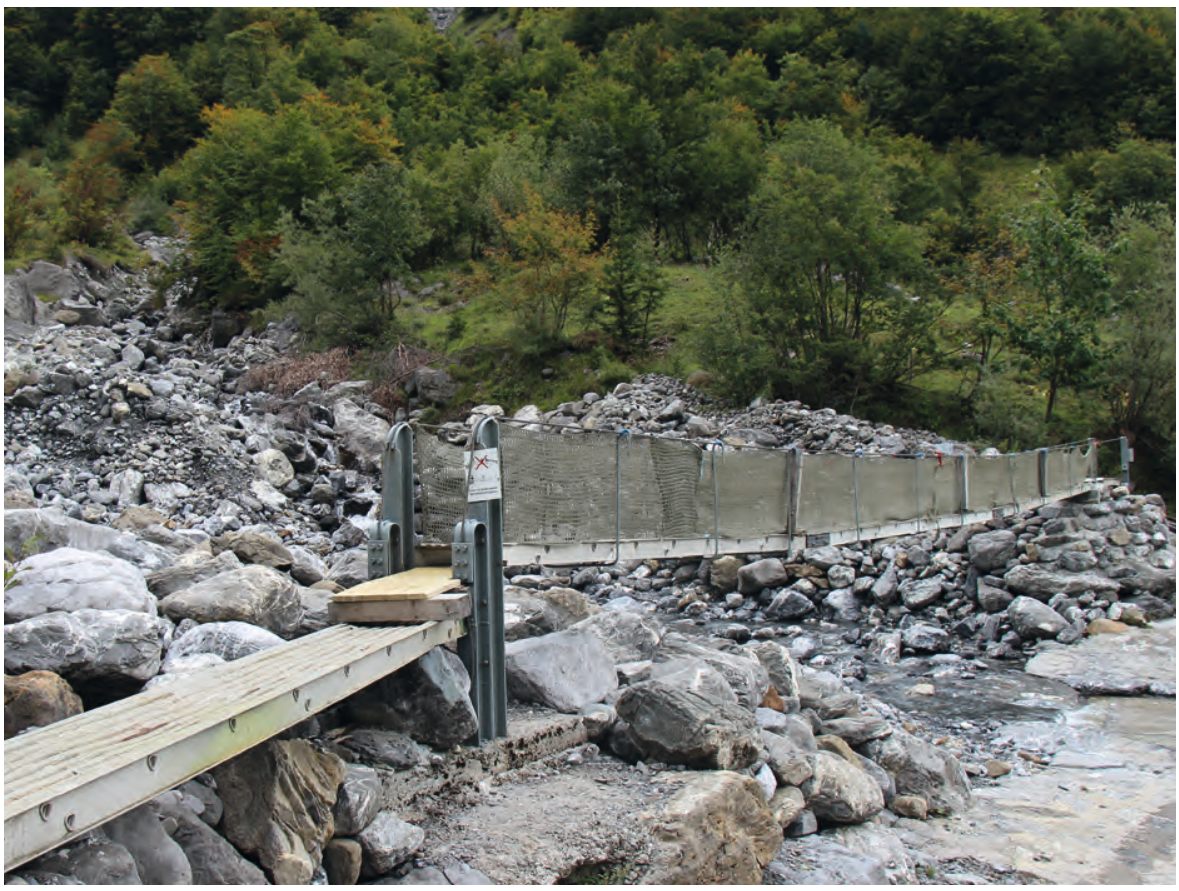

36 Baumann/Fryberg 1999, 3-4.

1905 wurde im Urner Amtsblatt die Errichtung einer Steinbogenbrücke in Surenen ausgeschrieben. Es ist unklar, welche der beiden sehr ähnlichen Brücken auf Surenen damit gemeint war. Hier: Querung des Stierenbachs unterhalb der Blackenalp.

Foto M. Sauter, 2014

Der Steg über das Geröllfeld des Seedorfer Sulzbachs, einem Zufluss des Palanggenbachs, wurde von Julius Stadler konzipiert. Die gespannte Aluminiumkonstruktion wird jeden Winter abgebaut.

Foto M. Sauter, 2015 
da vor allem nicht mehr oder nur noch selten begangene historische Wegpartien von Verfall oder Einebnung bedroht sind: Entsprechende Fragmente finden sich in Uri zuhauf. Als unabdingbare "Lebensadern" bezeugen Wege Siedlungstätigkeit und Wirtschaftsformen und sind daher ein wesentliches Geschichtszeugnis, das von der Seilbahn oder gar dem Helikopter aus zunehmend weniger wahrgenommen wird.

Baumann, H. / Fryberg, S. (1999). Verkehrswege in Uri-Surenen, Chinzig Chulm und Krüzlipass (Bd. 7). Altdorf.

Brunner, T. (2008). Die Kunstdenkmäler des Kantons Uri. Oberes Reusstal und Ursern (Bd. 4). Bern.

Eberli, U. (1997). Gutachten der geologischen Bohrkerne aus der Region AltdorfErstfeld, Kanton Uri. Zürich (Ms.).

Furrer, B. (1985). Die Bauernhäuser des Kantons Uri (= Die Bauernhäuser der Schweiz 12). Basel.

Furrer, F. / Furrer, M. (2000). Unsere schöne Alp. Eine kleine Kulturgeschichte der Eigenalp Waldnacht. Solothurn.

Gasser, H. (1979). Die Kunstdenkmäler der Schweiz. Pilotmanuskript der Gemeinde Attinghausen. Altdorf.

Gasser, H. (1986). Die Kunstdenkmäler des Kantons Uri. Die Seegemeinden (Bd. 2). Basel. IVS UR (1998). Inventar Historischer Verkehrswege der Schweiz. Dokumentation Kanton Uri. Bearb. von Loepfe, A. / Müller, U.A. / Bösch, R. et al. (provisorische Fassung). Bern. Kläui, P. (1943). Quellenwerk zur Entstehung der Schweizerischen Eidgenossenschaft. Abteilung II: Urbare und Rödel bis zum Jahre 1400. Aarau.

Kocher, A. (1951). Der alte St. Gotthardweg. Verlauf, Umgehung, Unterhalt. Altdorf. Lehner, H. (1983). Die Ausgrabungen in der Pfarrkirche St. Andreas in Attinghausen. In: Historisches Neujahrsblatt Uri, 113-154.

Leuzinger, U. / Sauter, M. / Haas, J.N. et al. (2014). Eine hallstattzeitliche Gebäudestruktur auf 1911 m ü.M. am Weg zum Surenenpass, Attinghausen UR, Siedlungsplatz Geissrüggen. In: Jahrbuch Archäologie Schweiz 97, 153-168.

Loepfe, A. (2007). Historische Verkehrswege im Kanton Uri (= Inventar historischer Verkehrswege der Schweiz IVS). Bern (2. Aufl.).

Meyer, W. / Obrecht, J. / Schneider, H. (1984). Die bösen Türnli. Archäologische Beiträge zur Burgenforschung in der Urschweiz. Olten/Freiburg.

Oechslin, M. (1927). Die Wald- und Wirtschaftsverhältnisse im Kanton Uri. Bern. Primas, M. / Della Casa, P. / Schmid-Sikimić, B. (1992). Archäologie zwischen Vierwaldstättersee und Gotthard. Siedlungen und Funde der ur- und frühgeschichtlichen Epochen (= Universitätsforschungen zur prähistorischen Archäologie 12). Bonn.

Sauter, M. (2011). Der Hochweg von Attinghausen - Auf den Spuren einer historischen Passage. In: Via Storia 1, 19-25.

Sauter, M. (2017, im Druck). Die Kunstdenkmäler des Kantons Uri. Schächental und unteres Reusstal. Bern.

Scheuchzer, J.J. (1716). Helvetiae Stoicheiographia. Orographia et Oreographia. Oder Beschreibung der Elementen/Grenzen und Bergen des Schweitzerlands. Der NaturHistori des Schweitzerlands. Zürich.

Stadler-Pflanzer, H. (1993). Geschichte des Landes Uri: Von den Anfängen bis zur Neuzeit. Schattdorf.

Stadler-Planzer, H. (2013). Die Urner Allmendgenossenschaft von den Anfängen bis 1888. In: Korporation Uri (Hrsg.). Korporation Uri. Altdorf, 9-21. 


\section{Summary: The settlement site at Geissrüggen - A building from the}

Hallstatt period.

In the course of the Uri settlement archaeology project a stone feature, which was particularly deeply embedded in the sediment, was found directly on the current Surenen Pass trail. A team of archaeologists partially excavated the feature between $2^{\text {nd }}$ and $12^{\text {th }}$ August 2013. The excavation brought to light part of a building from the Hallstatt period - the first known prehistoric building in the Alpine region of Central Switzerland. The feature measured $8.5 \times 11 \mathrm{~m}$ (exterior measurements) and was dug into the ground towards the slope of the mountain. Up to 5 courses of stone walls measuring c. $1.3 \mathrm{~m}$ in thickness had survived. Collapsed rubble from the western façade had been reused to construct a later wall. This had destroyed the features around the entrance and it was no longer possible to reconstruct its original appearance. The dating of several radiocarbon samples suggested that the building had been used in the Hallstatt period, from the $8^{\text {th }}$ to $6^{\text {th }}$ centuries $B C$. The ground-plan appears to be a little too big for a building used for Alpine farming; any medieval or post-medieval buildings in the region were considerably smaller. It may have been a checkpoint on the way to the Surenen Pass, which we know to have been used since the Bronze Age. The archaeological excavation was carried out on an interdisciplinary basis and besides the natural sciences, drone photography was also employed. The results achieved by these means are also outlined in this volume. 


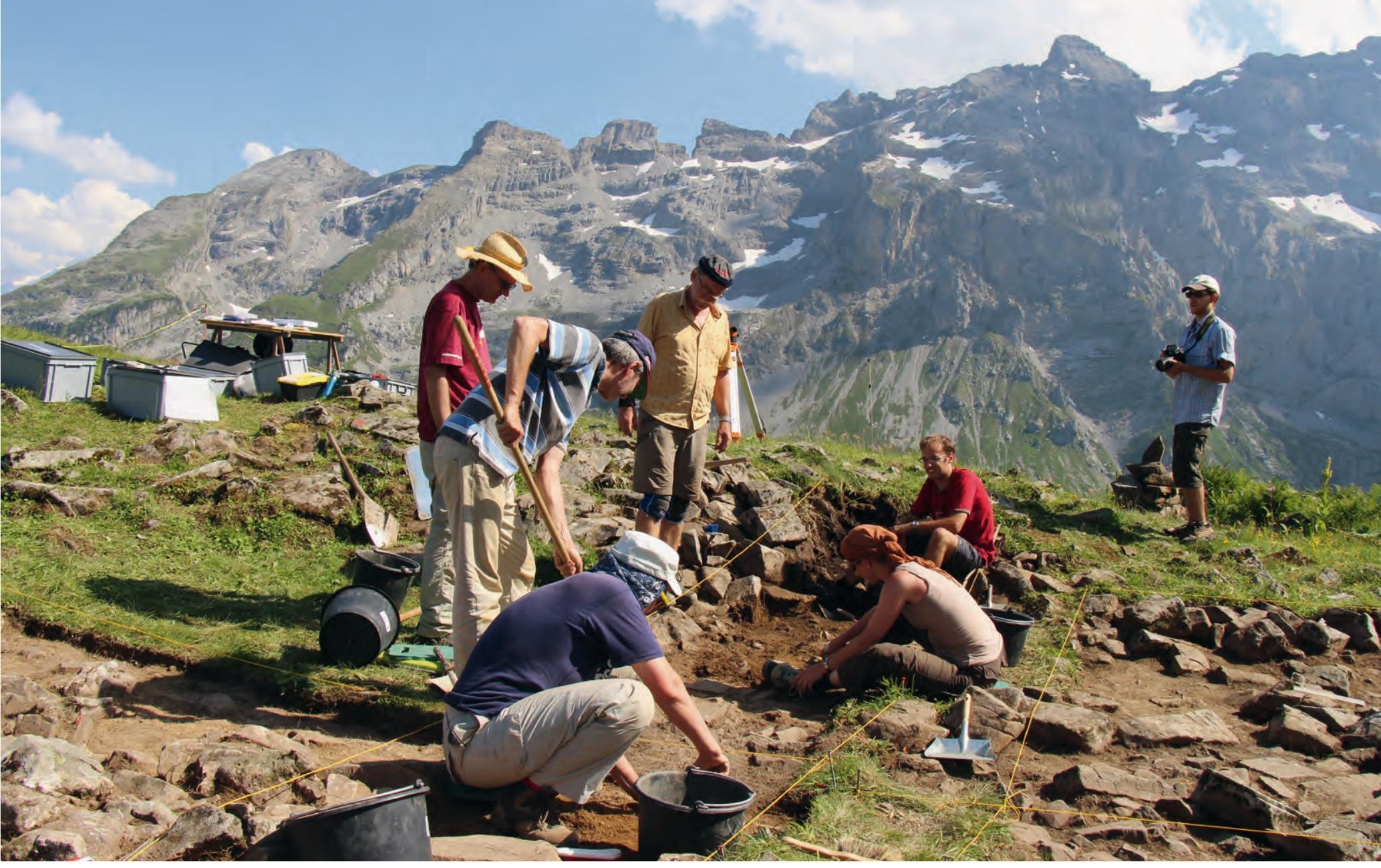

Sauter 2009. - Sauter 2010. - Sauter 2011. - Sauter 2012.

2 Primas/Della Casa/Schmid-Sikimić 1992, 221-228. - Leuzinger/Sauter/ Haas et al. 2014, 153-168. - Leuzinger/Sauter/Haas et al. 2015, 45-153.

3 Sauter 2009, 62-63.

\section{Siedlungsplatz Geissrüggen - Ein hallstattzeitliches Gebäude}

Auf dem Attinghauser Geissrüggen befindet sich eine stark einsedimentierte Steinsetzung unmittelbar am heutigen Surenenpassweg. Diese wurde vom 2. bis 12. August 2013 von einem Archäologenteam bei optimalen Wetterbedingungen teilweise ausgegraben und dokumentiert. Zum Vorschein kam ein hallstattzeitliches Gebäudefragment - der erste bekannte prähistorische Bau im Innerschweizer Alpenraum.

\section{Ausgangssituation}

Im Rahmen archäologischer Prospektionstouren mit Studierenden der Hochschule Luzern - Technik \& Architektur konnten seit 2008 über 700 Wüstungsplätze inventarisiert werden $\left(\rightarrow\right.$ S. 48-65). ${ }^{1}$ Die Attinghauser Alp Grat und der angrenzende Geissrüggen gehören zu den am dichtesten mit Ruinen bestandenen Arealen - obwohl sie weit abseits des historischen Surenenpasswegs, der über die Alp Waldnacht führt, liegen ( $\Rightarrow$ S. 102-121). Archäologische Bodenfunde belegen, dass der Surenenpass spätestens ab der Mittleren Bronzezeit begangen wurde. ${ }^{2}$ Da entlang des Passwegs nur wenige natürliche Schutzräume vorhanden sind $(-S$. 82-101), dürften einige dieser Hütten bereits sehr früh errichtet worden sein.

Aus diesem Grund wurde die offensichtlich älteste Wüstung am Geissrüggen für eine archäologische Sondierung ausgewählt. Zu erkennen ist eine stark einsedimentierte, verstürzte Steinsetzung. ${ }^{3}$ Unmittelbar östlich 


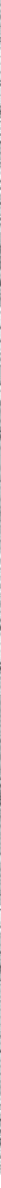

davon befinden sich eine gewinkelte, rechteckige Trockenmauer sowie eine ovale Struktur von ebenfalls stark einsedimentierten und überwachsenen Blöcken aus silikatischem Sandstein. Das Ensemble (At.032) war im Rahmen der Prospektionstour 2009 augenscheinlich als kleines «Hüttli mit Pferch" bewertet worden. Ein im Sommer 2011 zwischen den Mauerresten des Pferchs aus $12 \mathrm{~cm}$ Tiefe geborgenes Holzkohlestück lieferte mittels Radiokarbonanalyse im Labor für lonenstrahlphysik der ETH Zürich eine Datierung in die Hallstattzeit. ${ }^{4}$

Das hohe Alter der Probe veranlasste die Verantwortlichen der Denkmalpflege Uri ${ }^{5}$, eine archäologische Sondiergrabung an diesem Fundplatz zu initiieren, um zu weiterführenden Erkenntnissen über diesen bemer-

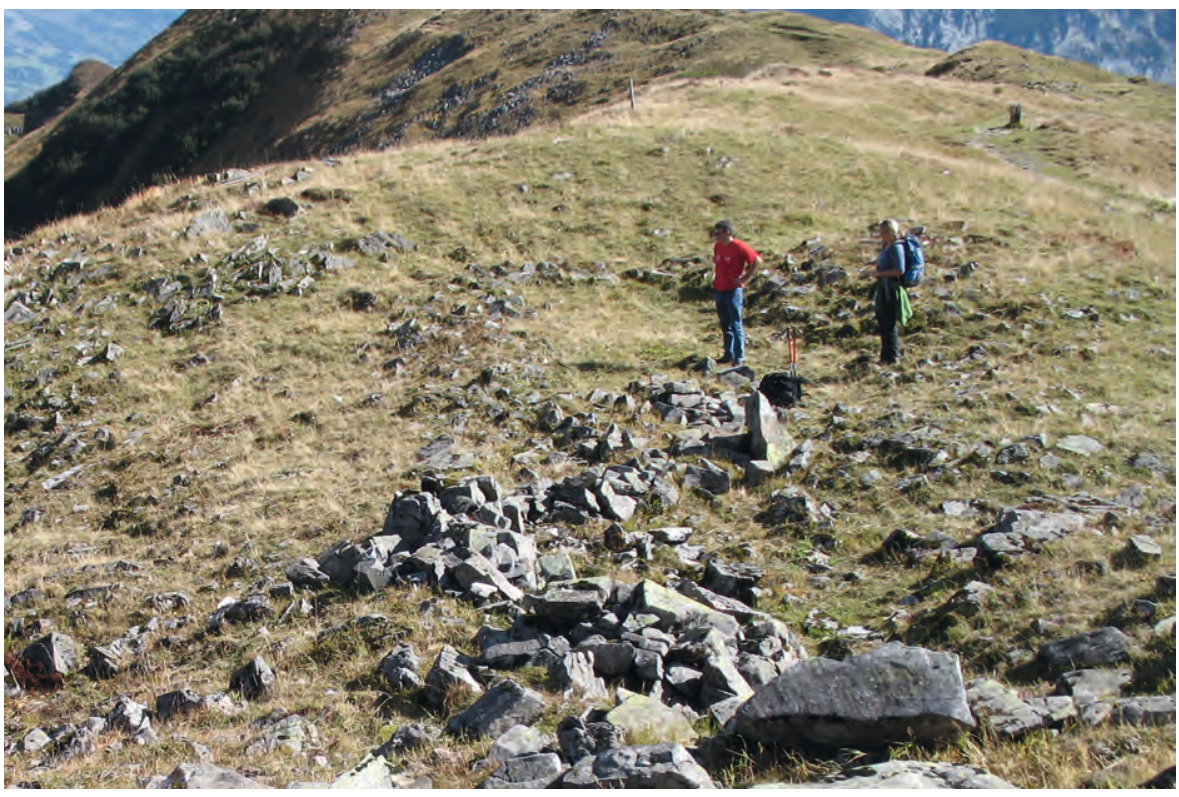

4 ETH-43714: 2450 \pm 35 BP, 670-400 BC.

5 Dem ehemaligen Leiter der Urner Denkmalpflege, Eduard Müller, sei für sein entgegengebrachtes Vertrauen und seine Unterstützung herzlich gedankt.

Titelbild: Das Grabungsteam bei der Arbeit am Siedlungsplatz Geissrüggen. Foto M. Sauter, 2013

Übersicht: Das Surenenpassareal mit dem Grabungsort Geissrüggen (»), den Metallfunden an der Blackenalpkapelle $(\Delta)$ und den entnommenen Torfstratigrafien $(+)$.

Karte swisstopo (BA16018)

Geländebegehung mit dem Grabungsleiter Urs Leuzinger, 6.10.2012. Dank des warmen Herbstlichts und der abgegrasten Alpweiden waren die Strukturen besonders gut zu erkennen.

Foto M. Peters, 2012 
Das Grabungsteam bei der Arbeit. Foto U. Leuzinger, 2013
6 Team 2013: Claudia Beck, Simone Benguerel, Marcel Cornelissen, Matthias Elmiger, Regula Gubler, Jean Nicolas Haas, Valentin Hobi, Walter Imhof, Reto Jagher, Urs Leuzinger, Christine Pümpin, Jochen Reinhard und Marion Sauter.

7 Spillmann/Labhart/Brücker et al. 2011.

8 Hinweis des Gratalp-Bergbauern Max Herger.

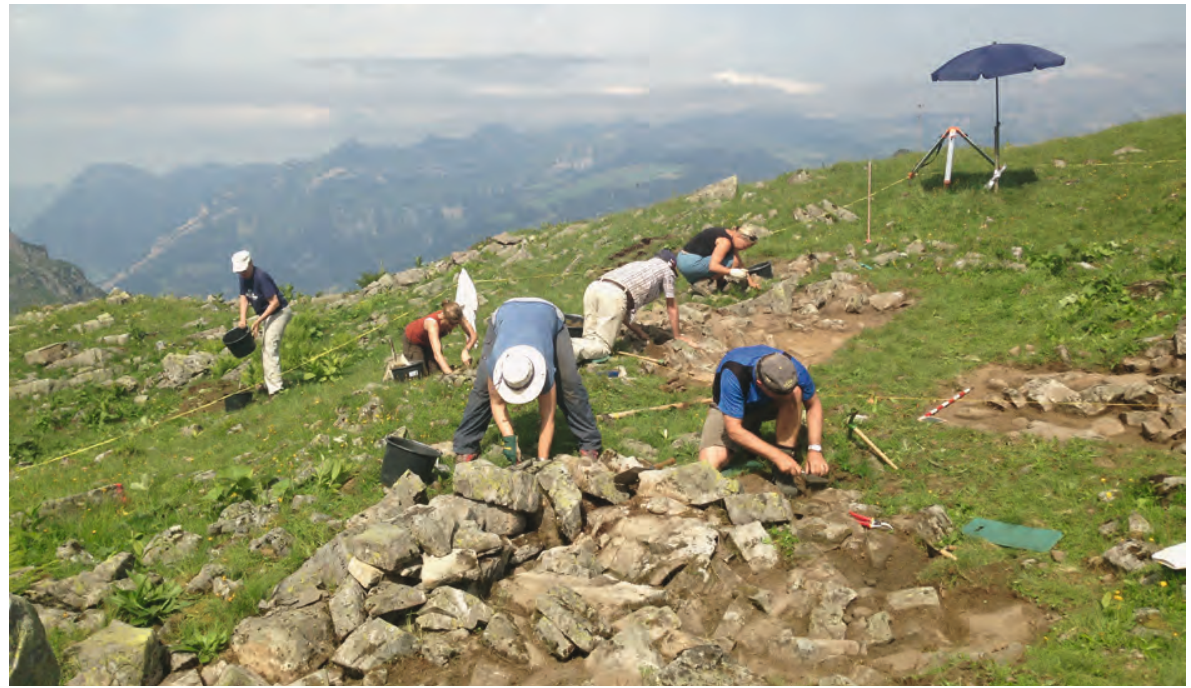

kenswerten Befund zu gelangen. 2012 fertigte ein Team der Hochschule Luzern - Technik \& Architektur mithilfe eines Teleskopstativs massstäbliche Luftaufnahmen der Fundorte auf dem Geissrüggen an. 2013 konnten schliesslich zahlreiche freiwillige Archäologen und Helfer gewonnen werden, die vom 2. bis 12. August unter der wissenschaftlichen Leitung von Marion Sauter und Urs Leuzinger die Ausgrabung durchführten. ${ }^{6}$

Finanziert wurde die Grabungskampagne am Geissrüggen vom Kanton Uri. Weitere Unterstützung erfuhr das Forschungsprojekt dankenswerterweise durch die Korporation Uri als Landeignerin, durch die Abteilung Zivilschutz des Kantons Uri, das Amt für Archäologie des Kantons Thurgau, das Amt für Denkmalpflege und Archäologie Zug, das Institut für prähistorische und naturwissenschaftliche Archäologie der Universität Basel (IPNA), das Institut für Botanik der Universität Innsbruck, die swiss helicopter AG Erstfeld sowie durch die Arbeitsgemeinschaft Höllochforschung (AGH). Das Grabungsteam logierte auf der nahegelegenen Gratalp, wo sich auch das improvisierte Grabungsbüro befand - an dieser Stelle sei auch der Bergbauernfamilie Herger ganz herzlich für ihre Gastfreundschaft gedankt.

Die Ergebnisse der Grabungskampagne und die naturwissenschaftlichen Untersuchungen werden im Folgenden vorgestellt.

\section{Lage und Topografie}

Die Fundstelle Attinghausen-Siedlungsplatz Geissrüggen befindet sich bei den Landeskoordinaten 686 366/188 706 auf 1911 m ü.M. Der schmale, in Ost-West-Richtung verlaufende Grat wird durch stark gefaltete, steil gestellte Decken des Infrahelvetikums (Eozän bis frühes Oligozän) gebildet. ${ }^{7}$ Der anstehende Untergrund besteht aus grobkörnigen Sandstein- und Mergelschichten. Der Platz liegt heute deutlich über der Wald- beziehungsweise der Baumgrenze, in unmittelbarer Nachbarschaft wachsen jedoch Grünerlenbüsche. Obwohl das Gelände eine schwach ausgeprägte Mulde bildet, ist der Fundplatz stark der Witterung ausgesetzt. Besonders bei Föhnstürmen sowie bei Gewittern, die in der Regel vom westlich gelegenen Passübergang her aufziehen, waren und sind Personen und Vieh, die sich auf dem Grat aufhalten, unmittelbar gefährdet. Die windexponierte Lage des Fundplatzes führt jedoch auch dazu, dass im Winter die Schneehöhe und somit die Last über einem allfälligen hölzernen Gebäudedach vergleichsweise gering gewesen sein dürfte. ${ }^{8}$ 


\section{Die Grabungsfläche}

In einem ersten Arbeitsschritt wurde über das gesamte Grabungsareal ein nach den Himmelsrichtungen orientiertes Vermessungsnetz angelegt und anschliessend wurden drei Felder abgesteckt. Prämisse war, mit einer möglichst kleinen Grabungsfläche ein Maximum an Informationen zu gewinnen. Da es sich nicht um eine Notgrabung handelte, wurde versucht, den Ruinenbestand möglichst zerstörungsfrei zu erfassen.

Nach den Vermessungsarbeiten wurden zunächst die Pflanzendecke und die dünne Humusschicht über der obersten Steinlage entfernt. Anschliessend konnten die freigelegten und mit Bürsten gereinigten Strukturen fotografiert und im Massstab 1:20 steingerecht gezeichnet werden.

Nach dem ersten Abtrag wurde rasch ersichtlich, dass sich ein aussergewöhnlich grosses Trockenmauergeviert im Boden versteckt. Dieses ist besonders in Richtung des nach Norden abfallenden Geländes sowie im Bereich der südöstlichen Innenecke stark verstürzt. Die nördliche Mauer führt in einem schwachen Bogen nach Südwesten. Die Biegung steht im Zusammenhang mit einer Sandsteinrippe, die hier beinahe bis an die heutige Oberfläche aufstösst. Die Ostmauer ist gegen den natürlichen Hang gesetzt, der nordöstliche Gebäudewinkel im Inneren klar erkennbar. Trotz des massiven Versturzes in der südöstlichen Raumecke ist davon auszugehen, dass die Mauer auf dem höchsten Punkt des im Gelände gut sichtbaren Walls einen Winkel in Richtung Osten bildet. Auch die Südmauer wurde im unteren Bereich gegen den Hang gesetzt. Angesichts des massiven Versturzes und des humosen Erdmaterials zwischen den obersten Steinlagen ist davon auszugehen, dass die Mauer ursprünglich im oberen Teil freistehend aufgesetzt war.

Der Eingang ist im Nordwesten oder Westen des Befunds zu suchen. Dort ist die Struktur jedoch durch den Einbau einer jüngeren Trockenmauer (At.032) stark gestört, sodass die Vorstellung über den westlichen Abschluss des Gebäudes auch nach der Grabung vage bleibt. Die Mächtigkeit der freigelegten Steinsetzung spricht nicht für eine Nutzung als Pferch, sondern vielmehr für ein ursprünglich gedecktes Gebäude.

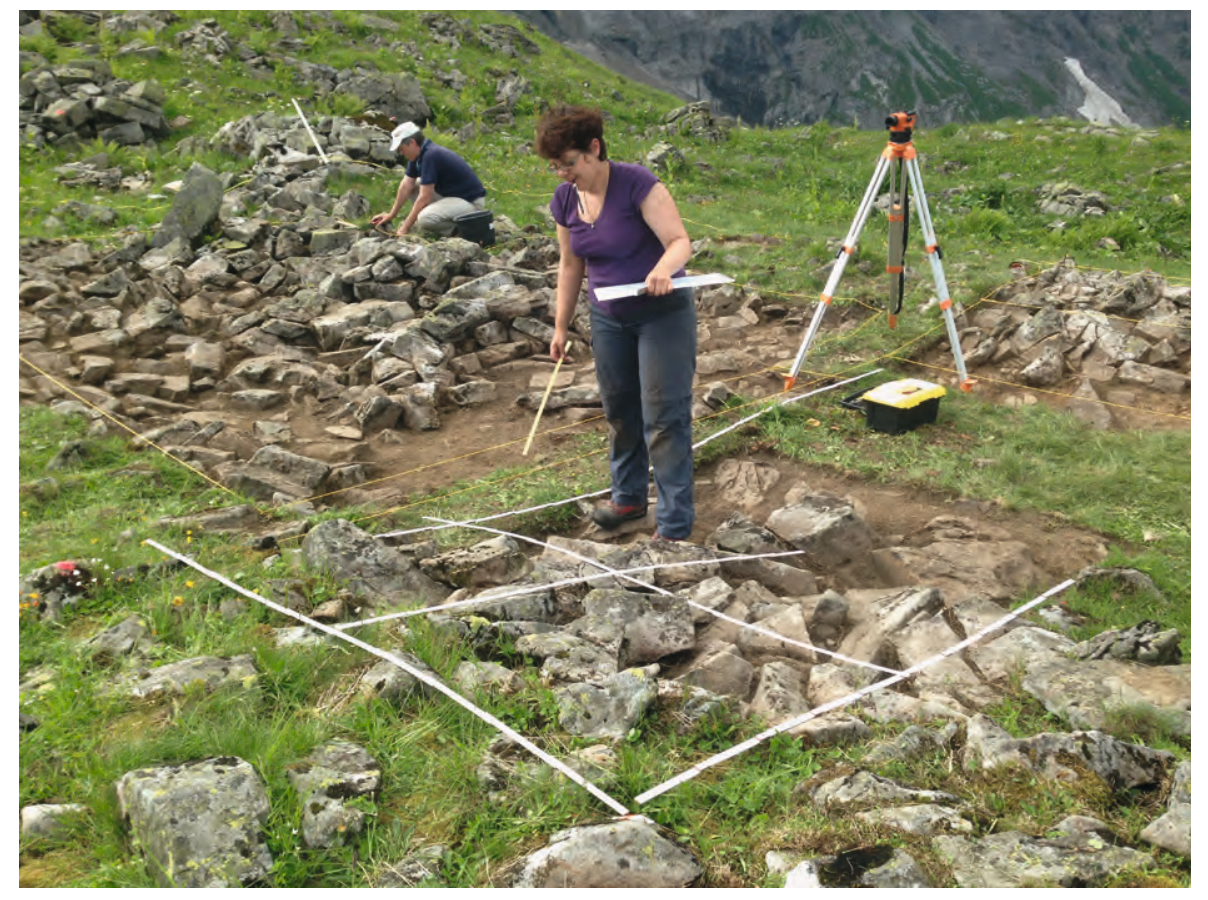

Das Grabungsteam bei der Arbeit. Foto U. Leuzinger, 2013

Steingerechter Plan der Steinsetzungen nach dem 1. Abstich. Der Quadratmeterstreifen $\mathbf{5 0 . 0 0 - 5 1 . 0 0 ~ v o n ~ L a u f m e t e r ~}$ 97.60-104.00 gibt die Strukturen nach dem 2. Abstich wieder. Dadurch werden die Mächtigkeit der nördlichen Trockenmauer sowie die Versturzlage der südlichen Mauer in diesem Bereich besser ersichtlich. Das Profil wurde auf der Achse 50.00/96.60-105.00 angelegt. Die Wandabwicklung zeigt den Schichtaufbau auf der Achse 104.00. Zeichnung U. Leuzinger, E. Belz, 2013 


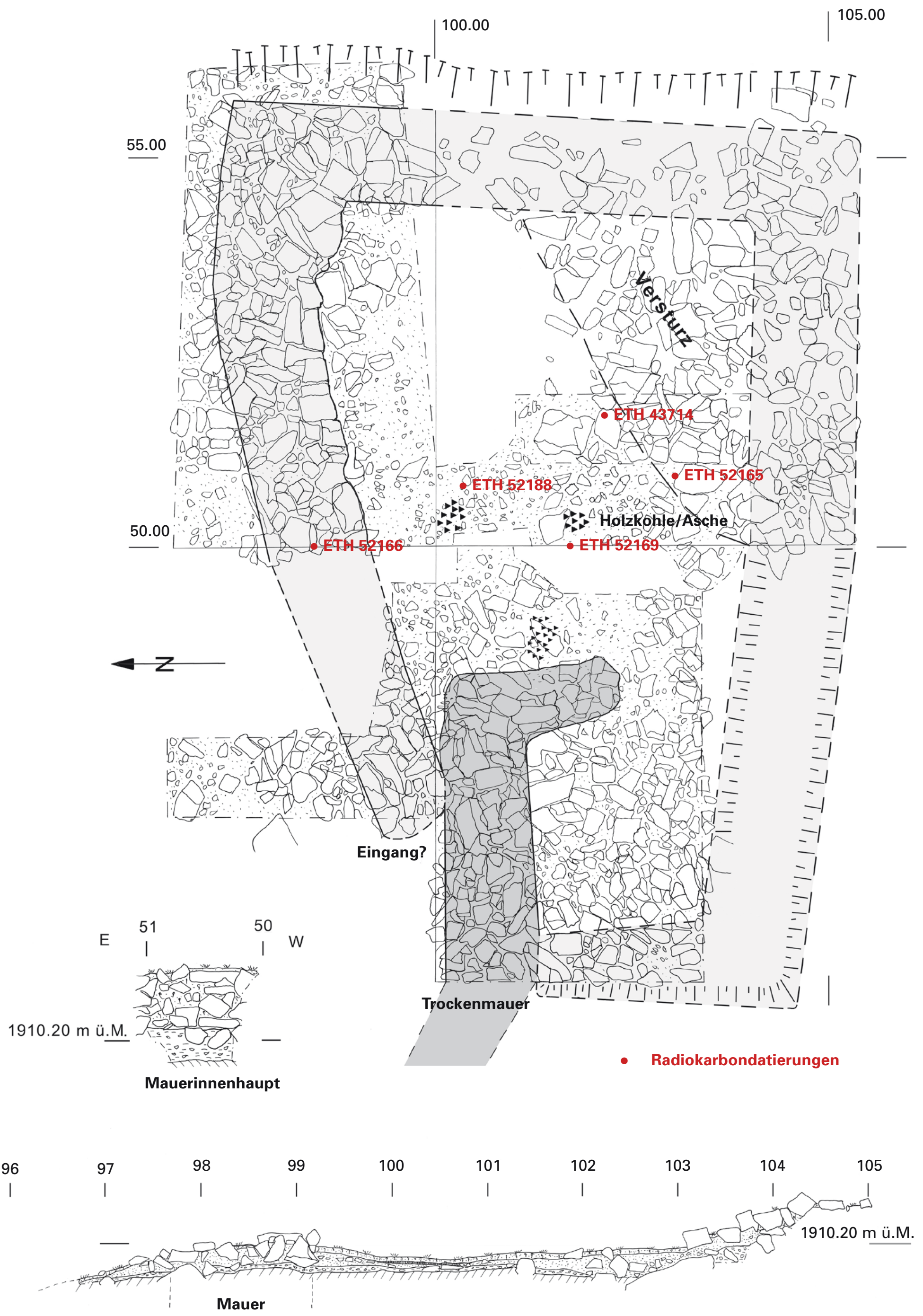




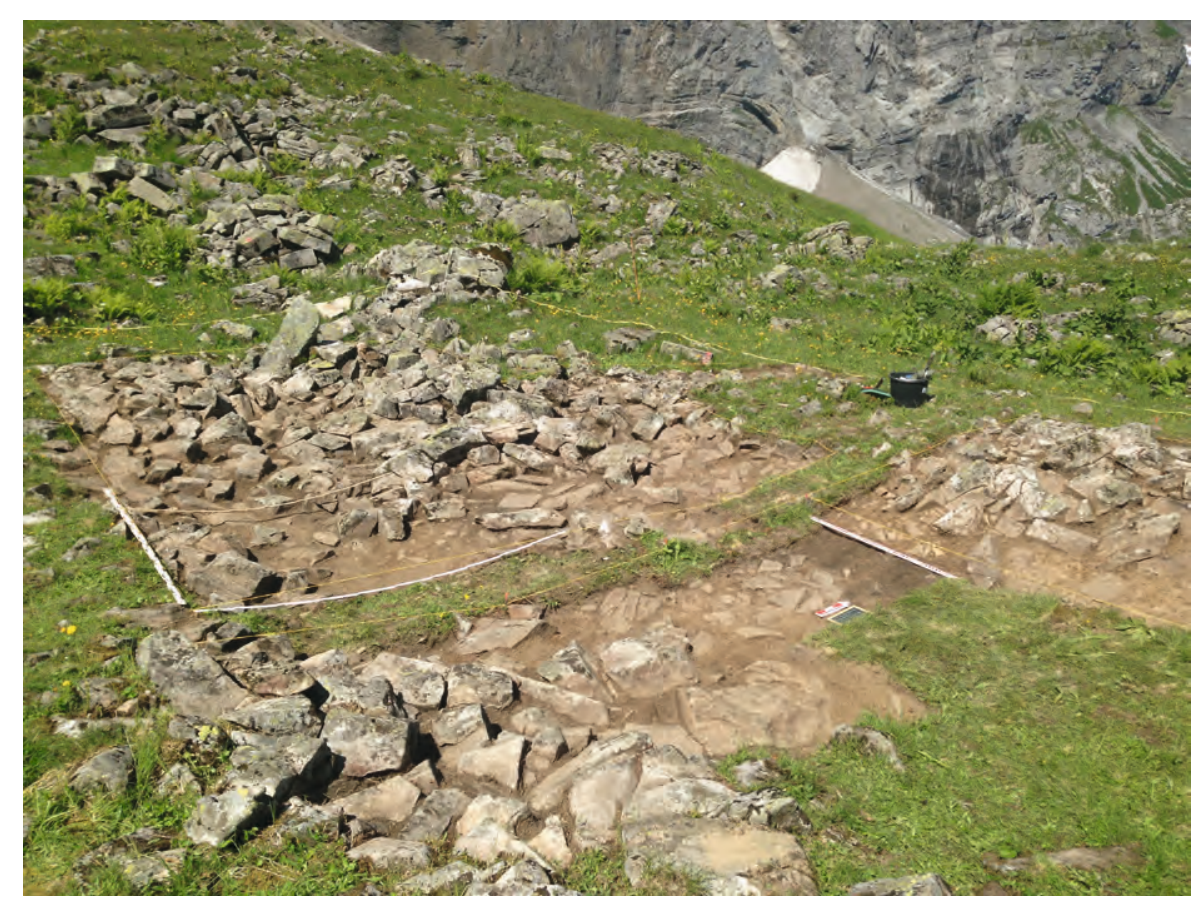

\section{Das Nord-Süd-Profil}

Das Grabungsteam legte entlang der Nord-Süd-Achse 50.00 einen $1 \mathrm{~m}$ breiten Profilschnitt an. In zwei Abstichen wurde anschliessend die oberste Steinlage abgetragen. Dies machte die Stärke der nördlichen Trockenmauer offensichtlich: Der Versturz ist nur in einer Lage erhalten, die eigentliche Mauer jedoch noch zwei- bis dreilagig. An der Basis dürfte sie gemäss Befund etwa 1,3 m dick gewesen sein. Es ist nicht auszuschliessen, dass sich die auf eine gelbliche, sandig-lehmige Schicht gesetzten Sandsteinblöcke im Lauf der Zeit in einem gewissen Umfang bewegt haben.

Das gelbliche, sandig-lehmige Sediment, bei dem es sich ursprünglich um ein Verwitterungsprodukt des anstehenden Felsuntergrunds handeln dürfte, zeichnet sich im Innern des Steingevierts unmittelbar unter der circa $5 \mathrm{~cm}$ dicken Humusschicht sowohl in der Fläche als auch im Nord-Süd-Profil entlang der Achse 50.00 ab $(\Rightarrow$ S. 156-171). An der Oberkante dieser Schicht sind kleine Sandsteinplatten eingebettet, die einen ebenen Gehhorizont bilden. Zwischen diesen Steinplatten und der darüber folgenden Humusschicht sind

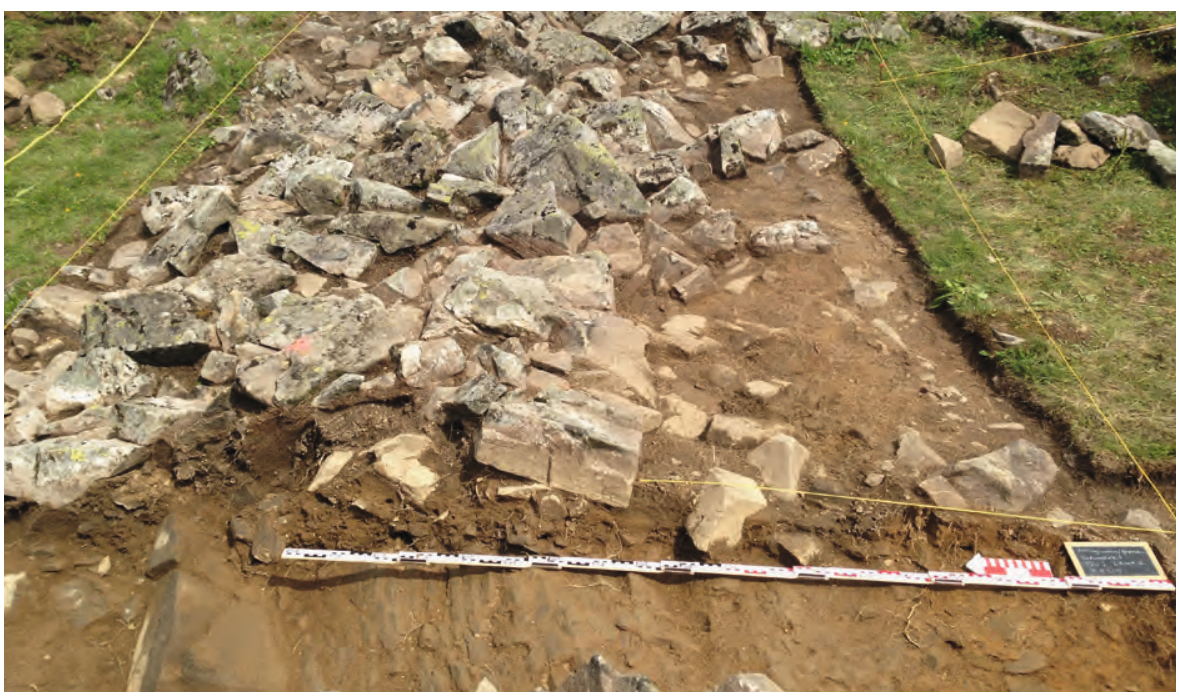

Übersicht über die drei Grabungsfelder. Foto U. Leuzinger, 2013

Schnitt durch die nördliche Trockenmauer, Blick in Richtung Osten. Unter der Steinsetzung ist eine etwas mächtigere Schicht aus gelblichem, sandigem Lehm zu erkennen.

Foto U. Leuzinger, 2013 
9 Taramarcaz/Curdy 2013, 20.

10 In Mals/Schnals (I) - Langgrubenjoch im Vinschgau entdeckte man im Sommer 2013 auf 3017 m ü.M. in einer Gebäudestruktur ein spätbronzezeitliches Schindelbrett mit Loch aus Lärche (Larix decidua). Steiner 2015, 17-18.
Mithilfe einer ferngesteuerten Drohne wurden mehrere Luftbilder aufgenommen. Deutlich zu sehen sind der ursprüngliche Grundriss (links) sowie die jüngeren Interventionen (rechts). Foto J. Reinhard, 2013 schwarz gefärbte Holzkohlekonzentrationen zu erkennen. Diese stammen wahrscheinlich von aufgelassenen oder umgelagerten Feuerstellen. Hinweise auf Feuerstellen liefern in dieser Schicht auch mehrere grosse Holzkohlestücke sowie hitzegerötete Sandsteine. Unter der Nordmauer nimmt die Mächtigkeit der sandig-lehmigen Schicht etwas zu. Vermutlich wurde überschüssiges Sediment beim Ausebnen des Bauplatzes und bei der Steinsetzung als "Fundament» angeschüttet. Darunter folgt rötlicher Lehm mit angewitterten Muttergestein-Stückchen, der fliessend in den anstehenden Sandstein beziehungsweise den Flysch-Mergel übergeht.

Im Süden des Profilschnitts zeichnete sich bei Quadratmeter 50.00-51.00/ 104.00 klar das Innenhaupt einer mindestens noch fünflagig erhaltenen Trockenmauer ab. Deren Stärke kann anhand des im Gelände sichtbaren «Mauerwalls» auf ebenfalls etwa 1,3 m geschätzt werden.

\section{Rekonstruktionsversuch}

Der ehemalige Grundriss des Gebäudes lässt sich somit ziemlich genau fassen. Einerseits lieferten die drei Grabungsfelder Aufschluss über den Aufbau und Verlauf der Mauern, andererseits sind die stark überwachsenen Mauerstrukturen im Gelände als Wälle noch gut erkennbar.

Das Aussenmass des Baus betrug ursprünglich etwa $8,5 \times 11 \mathrm{~m}$, die Innenfläche lässt sich auf circa 5,5 $\times 8,5 \mathrm{~m}$ rekonstruieren. Eine Unterteilung des Innenraums ist nicht zu erkennen. Der Eingangsbereich dürfte im Nordwesten oder Westen gelegen haben. Über die ehemalige Dachbedeckung kann man nur spekulieren. Am sinnvollsten erscheint ein von Süden nach Norden geneigtes Pultdach. Da innerhalb der Gebäudestruktur relativ wenig flache Steinplatten gefunden wurden, kann eine steinerne, im Alpenraum durchaus etablierte Dachdeckung wohl ausgeschlossen werden. ${ }^{9}$ Wahrscheinlich war das Dach mit Schindeln gedeckt. ${ }^{10}$ Hölzerne Stützpfosten im Gebäudeinneren sind auf jeden Fall wegen der

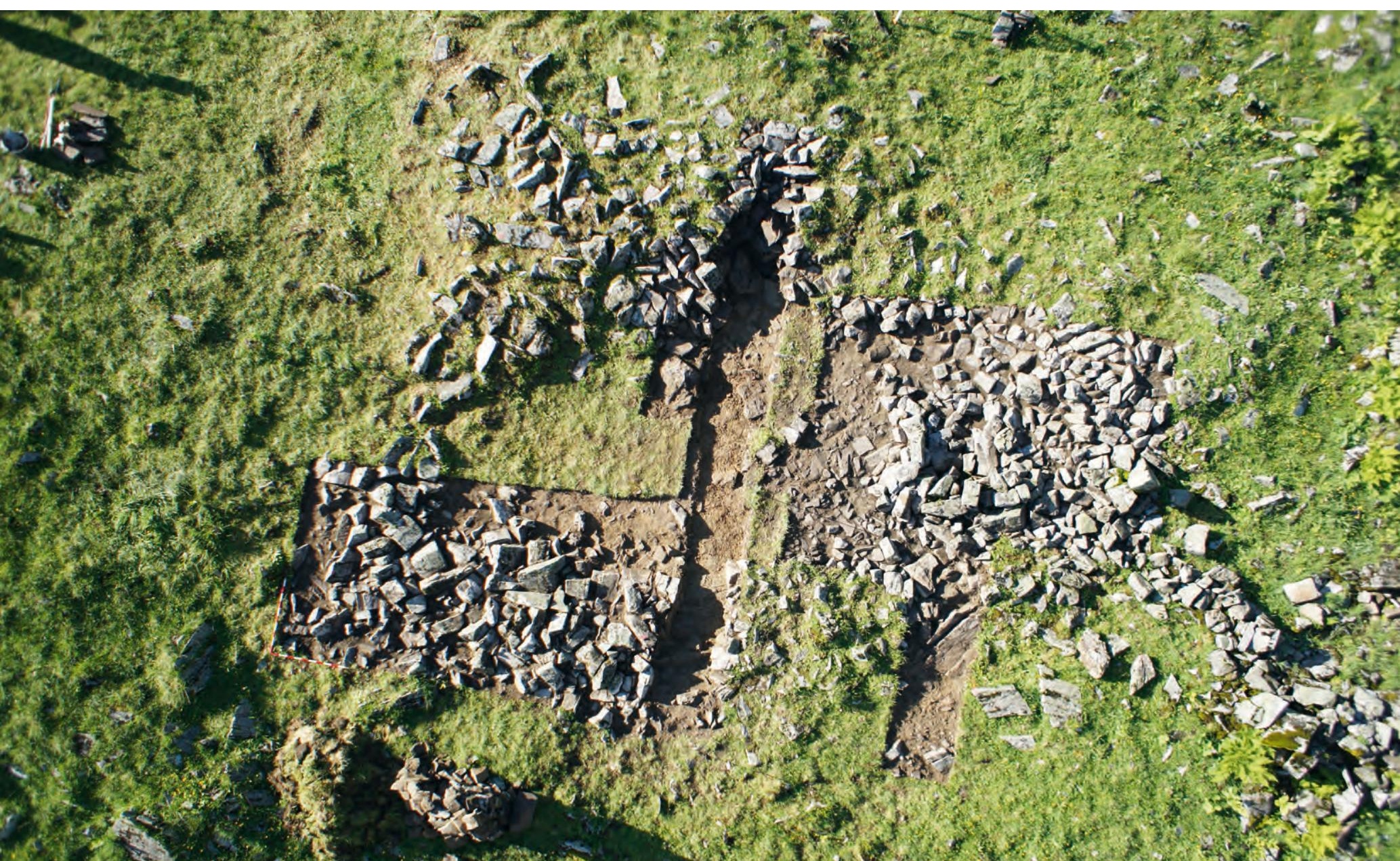




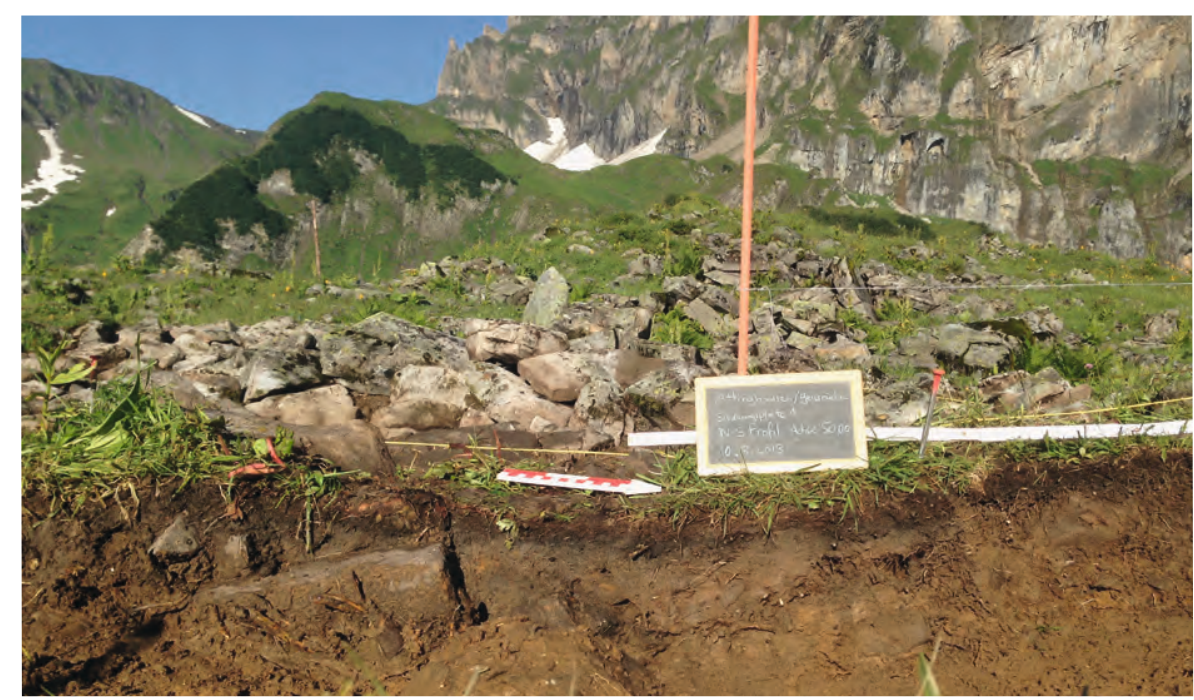

winterlichen Schneelast wahrscheinlich. Auflageplatten eines Ständers oder Pfostenlöcher solcher Verstrebungen fanden sich in der begrenzten Grabungsfläche allerdings keine.

Mithilfe einer Drohne wurden zudem aufschlussreiche Orthofotografien gemacht ( $\rightarrow$ S. 172-183), die eine Lokalisierung des Gemäuers wesentlich vereinfachten und auch den Grössenunterschied zum angrenzenden mittelalterlichen oder frühneuzeitlichen Gebäudegrundriss eindrucksvoll demonstrieren. Während in der Vorbereitung, in den Jahren 2011/12, ein Drohnenflug an der peripheren Fundstelle noch zu teuer erschien und die einfachere Teleskopfotografie zum Einsatz kam, haben sich die ferngesteuerten Fluggeräte mit Kamera mittlerweile als Hilfsmittel bei archäologischen Prospektionen im Alpenraum - auch im Kanton Uri - durchgesetzt. ${ }^{11}$

\section{Datierung}

Verschiedene Indizien sprechen bereits augenscheinlich für ein hohes Alter des ausgegrabenen Gebäudes. Das vorliegende Mauerwerk ist im Unterschied zur Bausubstanz der umliegenden Strukturen von der Vegetation bereits flächendeckend überwuchert und vollständig einsedimentiert, was oberhalb der Baumgrenze viele Jahrhunderte dauert. Im Inneren der Struktur konnte keine charakteristische Lägerflora beobachtet werden. Der Phosphatgehalt unterscheidet sich hier somit nicht von der Umgebung. Dies spricht dafür, dass der Bau nicht nur sehr alt ist, sondern auch schon seit sehr langer Zeit nicht mehr genutzt wurde. Im Vergleich zu den bekannten mittelalterlichen und frühneuzeitlichen alpinen Strukturen ist das untersuchte Gebäude ausserdem sehr gross.

Da während der Grabung kein archäologisches Fundmaterial geborgen wurde, lässt sich eine absolute Zeitstellung des Siedlungsplatzes Geissrüggen nur mithilfe der Radiokarbonanalyse von Holzkohlen erzielen. Es liegen insgesamt fünf Altersbestimmungen an eindeutig stratifizierten Holzkohlen aus den Sedimenten im Gebäudeinneren, aus dem nördlichen Mauerfundament und unter dem Mauerversturz vor. ${ }^{12}$ Eine direkte Verknüpfung von Holzkohledatierungen und Baubefund scheint vertretbar, da alle Proben aus unterschiedlichen Befundsituationen - Mauerbasis, Mauerversturz und Gebäudeboden - in denselben Zeithorizont datieren.

Alle Proben wurden von Irka Hajdas im Labor für lonenstrahlphysik der ETH Zürich gemessen. Alle fünf Holzkohleproben liegen zeitlich eng bei-
Profil der Feuerstelle - Blick nach Westen, in Richtung Surenenpass. Foto U. Leuzinger, 2013
11 Andres/Walser 2013, 107-109. Reinhard 2013, 177-188.

12 Drei weitere an das Labor für lonenstrahlphysik der ETH Zürich eingereichte Proben (ETH-52163, ETH52164 und ETH-52167) wurden nicht untersucht, da zu wenig oder gar keine Holzkohle vorhanden war. 
13 Leuzinger/Sauter/Haas et al. 2014, 159.

14 Bronk Ramsey 2013. - Reimer/Baillie/ Bard et al. 2009.

15 Holzhauser/Magny/Zumbüh/ 2005. Holzhauser 2009.

16 Magny 2013.
Gegenüberstellung der kalibrierten Radiokarbondatierungen aus Attinghausen-Geissrügen und der Kalibrationskurve Intcal09 sowie der Klimadaten der Göschenen-I-Kaltphase, dem Hochstand der Seespiegel der Alpenrandseen und der archäologischen Chronologie (Abszisse: kalibriertes Alter in Jahren BC; Ordinate: unkalibrierte Radiokarbonjahre BP).

Grafik R. Jagher, 2013 einander. Sie datieren in die Ältere Eisenzeit (750 bis 450 v.Chr.). Wegen des sogenannten Hallstatt-Plateaus auf der Radiokarbon-Kalibrationskurve ist das Gebäude damit jedoch nur relativ ungenau in den Zeitraum zwischen dem 8. und 5. Jahrhundert v.Chr. einzuordnen. Reto Jagher versuchte, die Gebäudestruktur auf dem Geissrüggen trotz Hallstatt-Plateau modellhaft in einem interdisziplinären Ansatz chronologisch noch etwas genauer zu bestimmen. ${ }^{13}$ Zur besseren Visualisierung wurden dabei die Messwerte mit dem Programm OxCal4.2.3 kalibriert und auf die Kalibrationskurve Intcal09 projiziert. ${ }^{14}$ Dabei wird klar ersichtlich, dass alle Datierungen übereinstimmend innerhalb der Zeitspanne von circa 750 bis 420 v.Chr. liegen, die nur eine sehr geringe Auflösung im Radiokarbonalter aufweist (senkrechte Achse). Zu Beginn dieser Periode lässt sich ein deutlicher Vorstoss der alpinen Gletscher feststellen. Diese breiteten sich ab dem 10. Jahrhundert v.Chr. stetig und zwischen 730 und 600 v.Chr. (cal.), während der Göschenen-I-Kaltphase, massiv aus. ${ }^{15} \mathrm{Ab} 750$ v.Chr., in der Phase einer deutlichen Klimaverschlechterung, kann man auch eine markante Transgression der Seespiegel im Alpenvorland beobachten. ${ }^{16}$ Die exponierte Höhenlage auf $1911 \mathrm{~m}$ ü.M. für das Gebäude auf dem Geissrüggen und dessen offensichtlicher Bezug auf den Surenenpassübergang auf $2291 \mathrm{~m}$ ü.M. legen es deshalb nahe, die relativ geringe Auflösung der Datierungen mit diesen Ereignissen zu kombinieren. Modellhaft lässt sich somit eine Datierung in die etwas günstigere Klimaphase nach 600 v.Chr. postulieren, die durchaus im Einklang mit den Ergebnissen der Radiokarbonanalyse steht. Somit lässt sich auf eine Bauzeit im frühen 6. Jahrhundert v.Chr. und eine Benutzung der Anlage bis in die 1. Hälfte des 5. Jahrhunderts v.Chr. schliessen. Dies erlaubt eine wahrscheinliche Einordung der Fundstelle auf dem Geissrüggen in die HaD-Stufe der Älteren Eisenzeit.

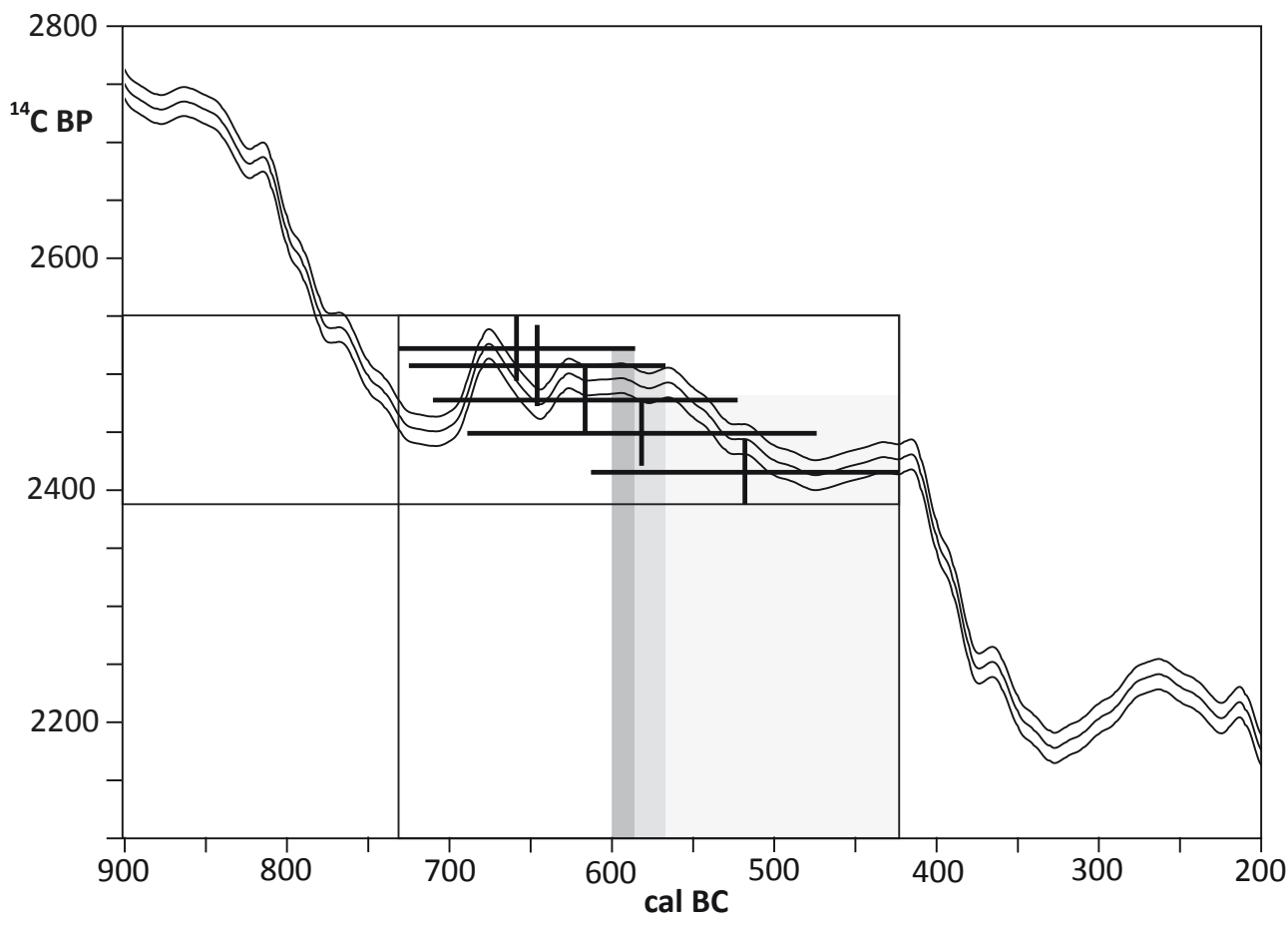

Klima

Göschenen 1 Hauptvorstoss 730-600 BC

Archäologie 


\begin{tabular}{|c|c|c|c|c|c|c|c|}
\hline PROBE & BESCHREIBUNG & MATERIAL & ${ }^{14}$ C ALTER & & KALIBRIERTES ALTER BC & $\sigma^{13} \mathrm{C} \%$ & \pm \\
\hline ETH-43714 & SONDIERPROBE 2011 & Holzkohle & $2450 \mathrm{BP}$ & 35 & $\begin{array}{c}68.2 \% \text { probability } \\
\text { 750BC }(20.9 \%) 680 \mathrm{BC} ; 670 \mathrm{BC}(6.2 \%) 640 \mathrm{BC} ; \\
\text { 560BC (24.4\%) 480BC; 470BC }(16.7 \%) 410 \mathrm{BC} \\
95.4 \% \text { probability } \\
\text { 760BC }(23.8 \%) 680 \mathrm{BC} ; 670 \mathrm{BC}(71.6 \%) 400 \mathrm{BC}\end{array}$ & -23.6 & 7 \\
\hline ETH-52165 & $\begin{array}{l}\text { PROBE } 9 \\
\text { Schnitt } 1 \\
\text { unter Versturz der südlichen Mauer }\end{array}$ & Holzkohle & $2508 \mathrm{BP}$ & 29 & $\begin{array}{c}68.2 \% \text { probability } \\
770 \mathrm{BC}(10.7 \%) 740 \mathrm{BC} ; 690 \mathrm{BC}(11.6 \%) 660 \mathrm{BC} ; \\
650 \mathrm{BC}(45.9 \%) 550 \mathrm{BC} \\
95.4 \% \text { probability } \\
790 \mathrm{BC}(95.4 \%) 520 \mathrm{BC} \\
\end{array}$ & -25.4 & \\
\hline ETH-52166 & $\begin{array}{l}\text { PROBE } 19 \\
\text { Schnitt } 2 \\
\text { im Erdwall unter der nördlichen Mauer }\end{array}$ & Holzkohle & $2479 \mathrm{BP}$ & 29 & $\begin{array}{c}68.2 \% \text { probability } \\
\text { 760BC }(21.7 \%) 680 \mathrm{BC} ; 670 \mathrm{BC}(46.5 \%) 530 \mathrm{BC} \\
95.4 \% \text { probability } \\
770 \mathrm{BC}(91.1 \%) 480 \mathrm{BC} ; 470 \mathrm{BC}(4.3 \%) 410 \mathrm{BC}\end{array}$ & -22.6 & \\
\hline ETH-52168 & $\begin{array}{l}\text { PROBE } 21 \\
\text { Schnitt } 1 \\
\text { Gebäude-Inneres }\end{array}$ & Holzkohle & $2523 \mathrm{BP}$ & 29 & $\begin{array}{c}68.2 \% \text { probability } \\
\text { 780BC }(19.5 \%) 740 \mathrm{BC} ; 690 \mathrm{BC}(14.4 \%) 660 \mathrm{BC} ; \\
650 \mathrm{BC}(28.9 \%) 590 \mathrm{BC} ; 580 \mathrm{BC}(5.4 \%) 560 \mathrm{BC} \\
95.4 \% \text { probability } \\
800 \mathrm{BC}(28.4 \%) 720 \mathrm{BC} ; 700 \mathrm{BC}(67.0 \%) 540 \mathrm{BC}\end{array}$ & -23.9 & \\
\hline ETH-52169 & $\begin{array}{l}\text { PROBE } 22 \\
\text { Schnitt } 1 \\
\text { Gebäude-Inneres }\end{array}$ & Holzkohle & $2417 \mathrm{BP}$ & 29 & $\begin{array}{c}\text { 68.2\% probability } \\
530 \mathrm{BC}(68.2 \%) 400 \mathrm{BC} \\
95.4 \% \text { probability } \\
750 \mathrm{BC}(14.0 \%) 680 \mathrm{BC} ; 670 \mathrm{BC}(3.3 \%) 640 \mathrm{BC} ; \\
560 \mathrm{BC}(78.1 \%) 390 \mathrm{BC} \\
\end{array}$ & -25.1 & \\
\hline
\end{tabular}

\section{Interdisziplinäre Auswertung}

Die archäologischen Arbeiten auf dem Attinghauser Geissrüggen wurden von Anfang an von naturwissenschaftlichen Nachbarsdisziplinen begleitet. So führten Forscher des Instituts für Botanik der Universität Innsbruck im nahen Z'Graggen-Hochmoor paläoökologische Untersuchungen durch (- S. 24-45). Diese Analysen erlaubten es, die Umwelt und Vegetationsentwicklung im Bereich des Fundplatzes im Verlauf der Zeit zu rekonstruieren.

Die anthrakologischen Forschungen lieferten interessante Erkenntnisse zur prähistorischen Brennholzversorgung. ${ }^{17}$ Mehrere Holzkohlestücke aus dem Innern der hallstattzeitlichen Gebäudestruktur - wahrscheinlich Überreste von Herdfeuern - wurden von Werner Schoch (Labor für quartäre Hölzer, Langnau a.A.) sowie von Angela Schlumbaum (IPNA, Universität Basel) auf das Taxon bestimmt. Die untersuchten Proben lieferten vorwiegend Hölzer von Erle (Alnus sp.), standortbedingt handelt es sich dabei vermutlich um die Grünerle (Alnus viridis). Zudem fanden sich verkohlte Holzreste von Nadelhölzern: in einem Fall von Fichte (Picea abies) oder Lärche (Larix decidua). Die geringe Anzahl geborgener Holzkohlen gibt wahrscheinlich nicht das gesamte Artenspektrum der eisenzeitlichen Brennhölzer wieder. Die vorliegenden Hölzer entsprechen jedoch der zu erwartenden Zusammensetzung und sind beispielsweise vergleichbar mit Fundstellen im Muotatal. ${ }^{18}$

Die mikromorphologischen Proben erbrachten weiterführende Erkenntnisse zur Schichtgenese im Innern des Gebäudes ( $\rightarrow$ S. 158-173).

\section{Synthese}

Alle archäologischen und naturwissenschaftlichen Untersuchungen lieferten wichtige, sich schlüssig ergänzende Informationen, um den prähistorischen Befund zu beschreiben und in sein natürliches Umfeld zu stellen. Eine wichtige Frage kann allerdings nur als These formuliert, nicht aber abschliessend beantwortet werden: die ehemalige Funktion oder die Funktionen dieses hallstattzeitlichen Gebäudes am Geissrüggen. Grundsätzlich
Die im Labor für lonenstrahlphysik der ETH Zürich durchgeführte Radiokarbondatierungen (AMS-Technik) für den Geissrüggen in der Übersicht. Das Radiokarbonalter basiert auf der in der Probe gemessenen und für Delta ${ }^{13} \mathrm{C}$ korrigierten Radiokarbonkonzentrationen. Das kalibrierte Alter bezieht sich auf 1950 n.Chr.: BP (Stuiver/Polach 1977). Für die Kalibrierung wurden OxCal v3.10 (Bronk Ramsey 2005) und IntCal09 calibration curve (Reimer/ Baillie/Bard et al. 2009) verwendet. Daten I. Hajdas, Grafik U. Leuzinger, 2013

17 Leuzinger/Sauter/Haas et al. 2014, 163.

18 Leuzinger/Auf der Maur/Cornelissen et al. 2007, 120-122. 
Mikroskopaufnahme eines Holzkohlefragments von Grünerle (Alnus viridis) aus Schnitt 1 (2. Abstich).

Foto W. Schoch, 2013
19 Reitmaier/Lambers/Walser et al. 2013

20 Kalzinierte Knochen müssten sich auch im sauren Bodenmilieu erhalten haben, wie Knochenfunde aus dem hochalpin gelegenen Abri Zermatt-Alp Hermettji belegen. Curdy/Leuzinger-Piccand/Leuzinger 2003, 79.

21 Reitmaier/Lambers/Walser et al. 2013.

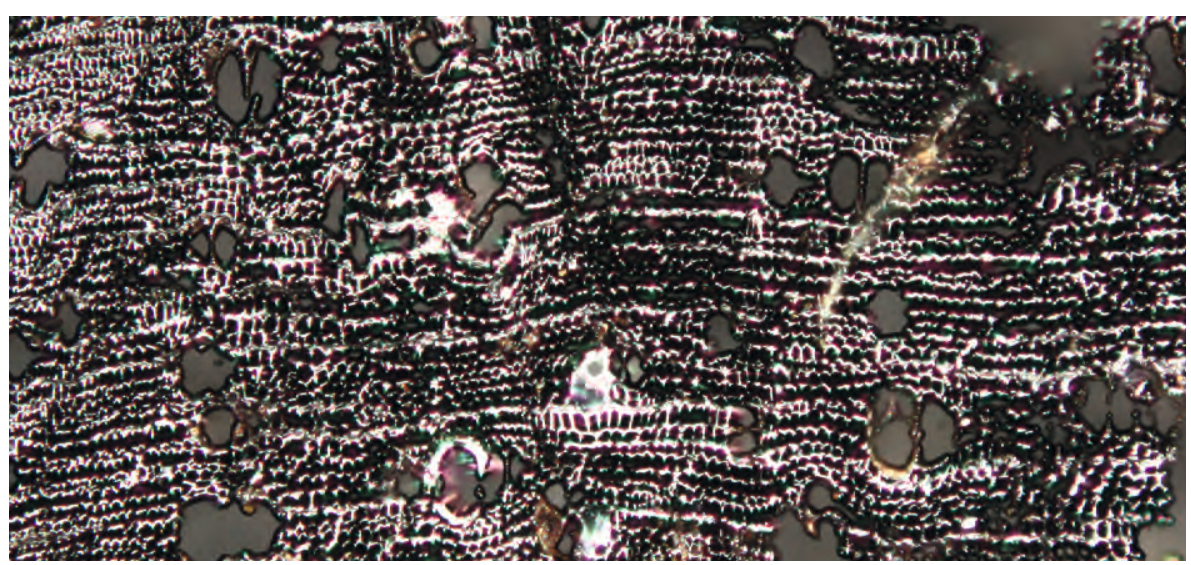

sind drei Nutzungsformen denkbar, die auch gleichzeitig existiert haben können, andere sind auszuschliessen:

- Auf der Passroute von der Reussebene bis nach Engelberg bieten nur relativ wenige Stellen wie überhängende Blöcke oder Abris-sous-blocSituationen einen effektiven Schutz vor Unwettern. Das hallstattzeitliche Gebäude wurde daher als Schutzhütte konzipiert. Dagegen sprechen einerseits seine Grösse und andererseits die exponierte Lage mitten auf dem Grat. Es gäbe in unmittelbarer Nähe wesentlich geeignetere Stellen, beispielsweise in der Geländemulde Nussfruttli oberhalb der untersuchten Fundstelle.

- Das Gebäude wurde in der Hallstattzeit tatsächlich als saisonal genutzte Alphütte verwendet. Damals befand sich die natürliche Waldgrenze wohl noch in unmittelbarer Nähe, sodass genügend Holz zum Bauen und Heizen zur Verfügung stand. Trotz der entsprechenden Interpretation einer eisenzeitlichen Hütte in der Silvretta-Grabung ist über die prähistorische Alpwirtschaft bislang zu wenig bekannt - vor allem was die erstaunliche Gebäudegrösse des Befunds auf dem Geissrüggen anbelangt. ${ }^{19}$

- Denkbar wäre schliesslich, dass das äusserst massive Gebäude an der exponierten Lage auf dem Grat des Geissrüggens mit freiem Blickfeld in Richtung Urner See und mit guter Sicht auf die Surenenpasswege über den Grat und über die Alp Waldnacht zu Kontrollzwecken errichtet wurde. Vielleicht versuchte eine hallstattzeitliche Elite aus dem Tal mit diesem hochgelegenen Posten einen herrschaftlichen Anspruch auf den Pass- beziehungsweise den Handelsweg (Steuern, Schutz) zu erheben oder die Kontrolle über die oberhalb der Waldgrenze gelegenen Urweiden in den Geländekammern dies- und jenseits des Passes zu festigen.

- Eine Nutzung als Höhenheiligtum oder als militärische Anlage ist klar auszuschliessen, da die dafür charakteristischen Funde wie Weihegaben, kalzinierte ( $=$ hitzeversehrte) Tierknochen ${ }^{20}$ und Waffen vollständig fehlen

Somit ist mit dem aktuellen Forschungsstand nicht definitiv abzuklären, in welcher Form das 8,5 × $11 \mathrm{~m}$ grosse Bauwerk tatsächlich genutzt wurde.

\section{Vergleichsbeispiele im Alpenraum}

Forscher der Universität Zürich entdeckten im Jahr 2007 einen Gebäuderest aus dem 1. Jahrtausend v.Chr. auf $2283 \mathrm{~m}$ ü.M. in dem zur Gemeinde Valsot gehörenden Fimbertal im Graubündner Silvrettagebiet. ${ }^{21}$ Die bislang älteste alpine Hütte der Schweiz ist $7 \times 7 \mathrm{~m}$ gross (Aussenmass). Versturzlagen wie beim Befund vom Siedlungsplatz Geissrüggen fehlen.

Das Silvretta-Forschungsprojekt bezog sich auf bereits bekannte Siedlungsplätze der inneralpinen Bronze- und Eisenzeit im Talbereich des Un- 
Leuzinger, U. / Sauter, M. / Haas, J.N. et al. (2014). Eine hallstattzeitliche Gebäudestruktur auf 1911 m ü.M. am Weg zum Surenenpass, Attinghausen UR, Siedlungsplatz Geissrüggen. In: Jahrbuch Archäologie Schweiz 97, 153-168.

Leuzinger, U. / Sauter, M. / Haas, J.N. et al. (2015). Spätmittelalterliche und neuzeitliche Alpnutzung zwischen Surenenpass und der Blackenalp, Gemeinde Attinghausen UR. In: Jahrbuch Archäologie Schweiz 98, 145-153.

Magny, M. (2013). Orbital, ice-sheet, and possible solar forcing of Holocene lake-level fluctuations in westcentral Europe: A comment on Bleicher. In: The Holocene 23/8, 1202-1212. Mandl, F. (2006). Königreich, spätbronzezeitliche Siedlung, Dachsteingebirge, Gemeinde Gröbming, Steiermark. Vorbericht über ein interdisziplinäres Projekt im Sommer 2005. In: Mandl, F. (Hrsg.). Alpen. Archäologie, Geschichte, Gletscherforschung. Festschrift 25 Jahre ANISA Verein für alpine Forschung. Haus i.E., 149-158.

Patzelt, G. (2013). Datierung von Feuerstellen in prähistorischen Hirtenhütten im Waldgrenzbereich ostalpiner Gebirgsgruppen (= Praearchos 4). Innsbruck.

Primas, M. / Della Casa, P. / Schmid-Sikimić, B. (1992). Archäologie zwischen Vierwaldstättersee und Gotthard. Siedlungen und Funde der ur- und frühgeschichtlichen Epochen (= Universitätsforschungen zur prähistorischen Archäologie 12). Bonn.

Putzer, A. (2012). Eine prähistorische Almhütte auf dem Schwarzboden im Maneidtal, Südtirol/Vintschgau. In: Archaeologica Austriaca 93, 33-43.

Reimer, P.J. / Baillie, M.G.L. / Bard, E. et al. (2009). IntCal09 and Marine09 Radiocarbon Age Calibration Curves, 0-50,000 years cal BP. In: Radiocarbon 51/4, 1111-1150.

Reinhard, J. (2013). Structure from Motion, Drohnen \& Co. Neue Wege in der Dokumentation archäologischer Ausgrabungen. In: Tugium 29, 177-188.

Reitmaier, T. (Hrsg.) (2012). Letzte Jäger, erste Hirten. Hochalpine Archäologie in der Silvretta. Chur.

Reitmaier, T. / Lambers, K. / Walser, C. et al. (2013). Alpine Archäologie in der Silvretta. In: Archäologie Schweiz 36/1, 4-15.

Sauter, M. (2009). Wüstungsforschung im Kanton Uri. Brunni- und Schächental, Haldi und Surenenpass. Altdorf.

Sauter, M. (2010). Wüstungsforschung im Kanton Uri. Ursern. Altdorf.

Sauter, M. (2011). Wüstungsforschung im Kanton Uri. Urnerboden-Zingel. Altdorf.

Sauter, M. (2012). Auf dem Weg zum Surenenpass - Einblicke in die aktuelle Wüstungsforschung. In: Archäologie Schweiz 35/2, 17-23.

Spillmann, P. / Labhart, T. / Brücker, W. et al. (2011). Geologie des Kantons Uri (= Naturforschende Gesellschaft Uri-Bericht Nr. 24). Altdorf.

Steiner, H. (2015). Aufgetaut-Gletscherfunde am Langgrubenjoch (Matsch/Schnalstal). Antiquitates Tyrolenses. Festschrift für Hans Nothdurfter zum 75. Geburtstag (= Veröffentlichungen des Südtiroler Landesmuseums Schloss Tirol 1). Innsbruck, 11-30.

Stuiver, M. / Polach, H.A. (1977). Discussion: reporting of 14 C data. In: Radiocarbon 19/3, 355-363.

Taramarcaz, T. / Curdy, P. (2013). Là-haut dans la montagne ... des îtres et des hommes. Inventaire des ruines d'alpage dans le Val de Bagnes. In: Archäologie Schweiz, 36/3, 16-25. Walsh, K. / Mocci, F. (2011). Mobility in the Mountains: Late Third and Second Millenia Alpine Societies' Engagements with the High-Altitude Zones in the Southern French Alps. In: European Journal of Archaeology 14/1-2, 88-115.

Walsh, K. / Court-Picon, M. / De Beaulieu, J. L. et al. (2014). A historical ecology of the Ecrins (Southern French Alps): Archaeology and palaeoecology of the Mesolithic to the Medieval period. Quaternary International 353, 52-73.

Die Grabungsergebnisse wurden erstmals in Leuzinger/Sauter/Haas et al. 2014 publiziert. Der vorliegende Bericht ist überarbeitet und um einige Abbildungen ergänzt. 


\section{Summary: The archaeological finds recovered along the Surenen Pass}

trail.

Because excavations in the Alpine region usually yield few finds, it was decided to run a metal detector survey in tandem with the excavation work carried out at Geissrüggen in 2013. As part of this two-day survey, Romano Agola retrieved numerous objects, including a denarius of Tiberius (AD 14-37), a Roman signet ring and a bronze bracelet. Numerous post-medieval coins were discovered around the Blackenalp Chapel, which had already yielded many finds on previous occasions. The coins attested to the practice followed for many centuries of giving thanks and of making votive offerings. As part of the comprehensive publication of all the results obtained by the research project it was also possible to show and comment on the finds that had been made earlier and on the less "valuable" new finds, including (hob)nails and lead balls. These are actually important pieces in the historical puzzle, although very few similar finds are usually published. Besides the metal finds, a number of bones and ceramic sherds were also found during test excavations carried out on Surenen in the summer of 2014. Although the finds were not very numerous by Swiss standards, they did constitute progress for the archaeological research in Canton Uri, which is still in its infancy. 
Dabei sollte man sich aber nicht nur auf technische Hilfsmittel verlassen. Oberflächig freigewitterte Funde lassen sich auch mit einem geübten Auge ausfindig machen und können so das Fundspektrum um Keramik, Glas oder Knochen erweitern.

Trotz intensiver Oberflächenprospektionen entlang des Surenenpasswegs während der archäologischen Kampagnen in den Jahren 2013 und 2014 konnte hier jedoch nur wenig Fundmaterial geborgen werden. ${ }^{3}$ Dies ist vorwiegend auf die geringen offen liegenden Flächen im Untersuchungsgebiet - Aufschlüsse wie etwa Kuhtrittpfade, Alpwege oder Erosionsrinnen zurückzuführen. Einige wenige kleinflächige archäologische Sondierungen lieferten Holzkohlefragmente.

\section{Bronzezeit}

Der älteste Fund am Surenenpassweg datiert aus der Bronzezeit, die im Kanton Uri bislang nur in einigen wenigen Stücken vertreten ist: ein Bronzedolch aus der Zeit um 1500 v.Chr. vom Urnerboden; ein Fundensemble aus der Zeit um 1300 v.Chr, das auf eine zerstörte Grabstelle hindeutet und während der Bauzeit der Klausenstrasse nahe der Pfarrkirche St. Peter und Paul in Bürglen gefunden wurde; ein Messer mit Antennengriff, das seit Jahrhunderten Teil des Kapellenschatzes der Jagdmattkapelle in Erstfeld ist; sowie Siedlungsspuren im Kontext der Zwing Uri bei Amsteg-Flüeli. ${ }^{4}$

\section{Kat.-Nr. 1: Gewandlochhalsnadel}

Bisheriger terminus post quem für die Begehung des Surenenpasses ist eine bronzezeitliche Gewandlochhalsnadel. Das Objekt kam 1951 oberhalb der Flur Im Tritt am Weg Richtung Alp Steinäbnet im Geröll einer kleinen Runse zum Vorschein (LK 1191, 681 000/184 500, 1470 m ü.M.). Die Nadel ist in der Dauerausstellung des Historischen Museums Altdorf zu sehen.

Das Exemplar ist sehr gut erhalten, dunkelgrün patiniert und nur im Spitzenbereich leicht korrodiert. Die Nadel ist $218 \mathrm{~mm}$ lang und hat einen Kopfdurchmesser von $5 \mathrm{~mm}$, das Stück ist $18,84 \mathrm{~g}$ schwer. Der schwach verdickte Nadelschaft weist eine horizontale ovale Durchlochung auf. Der sechsfach gerippte konische Nadelkopf wird durch ein schräg gekerbtes Band von der ebenfalls horizontal gerippten oberen Schaftpartie abgetrennt. Das Schaftloch liegt mittig in einer Zierzone aus schräg umlaufenden Leiterbändern, die unten durch drei umlaufende Rippen begrenzt sind. Typologisch datiert die Lochhalsnadel in die Mittlere Bronzezeit, das heisst in die Phase Bz C1 (circa 1480 bis 1420 v.Chr.). Das Fundstück belegt eine Begehung des südlichen Passwegabschnitts seit spätestens der Mittleren Bronzezeit. Ob die Nadel als Weihegabe in den Boden gelangte oder zufäl-
Titelbild: Urs Leuzinger und Walter Imhof bei einer Sondierung im Abri am Surenenpass (At.115), 2320 m ü.M. Foto P. Stöckli, 2014

Kat.-Nr. 1

Gewandlochhalsnadel, bronzezeitlich Zeichnung M. Primas, 1992 / Foto M. Käch, 2016
3 Leuzinger/Sauter/Haas et al. 2014. Leuzinger/Sauter/Haas et al. 2015.

4 Primas/Della Casa/Schmid-Sikimić 1992, 228-235. 
5 Hochuli 1998, 327-336.

6 Leuzinger/Sauter/Haas et al. 2015, 151-152.

7 Pászthory 1985, Taf. 170, 2031-2034. - Riha 1990, Taf. 18 und 528-531.

Kat.-Nr. 2

Armreif, bronzezeitlich bis römisch Zeichnung U. Leuzinger, 2013, Foto M. Käch, 2015 lig verloren ging, lässt sich nicht mit Sicherheit sagen. Deponierungen von Schmuck oder Gerätschaften aus Bronze sind in dieser Zeit aber durchaus typisch (Abb. Kat.-Nr. 1). ${ }^{5}$

Jahrbuch der Schweizerischen Gesellschaft für Urgeschichte 43/1953, 60. - Primas/Della Casa/Schmid-Sikimić 1992, 221, 228 (U2).

\section{Kat.-Nr. 2: Armreif}

Während der Metalldetektorprospektion entdeckte Romano Agola in der "Pferchartigen Struktur" auf Blacken (At.100) einen Armreif aus Bronze (2013.014.6) (LK 1191, 681 859/186 467, 1770 m ü.M.). Ein Zusammenhang mit der grossen ringförmigen Steinsetzung, deren Funktion noch nicht abschliessend geklärt werden konnte, ist jedoch nicht zwingend - eine weitere, kleine Sondierung blieb 2014 erfolglos $\left(-\right.$ S. 193-194) ${ }^{6}$

Das Objekt ist aussen $79 \mathrm{~mm}$ breit und $58 \mathrm{~mm}$ hoch; innen $72 \mathrm{~mm}$ breit beziehungsweise $54 \mathrm{~mm}$ hoch. Der Durchmesser des im Querschnitt beinahe runden, gegossenen Reifs beträgt in der Mitte $6 \mathrm{~mm}$, gegen beide Enden verjüngt sich das Objekt zu einem leicht abgeflachten Durchmesser von $3 \mathrm{~mm}$. Beide Enden sind wahrscheinlich leicht fragmentiert. Das Schmuckstück ist noch 18,72 g schwer. Die ehemals unverzierte glatte Oberfläche ist teilweise von einer krustigen Patina überzogen. Am einen Ende ist die Korrosion stark fortgeschritten.

Der Armreif lässt sich typologisch nur unsicher datieren, da charakteristische stilistische Merkmale fehlen. Vergleichbare Schmuckstücke finden sich in der Schweiz von der Bronze- bis in die Römerzeit. ${ }^{7}$ Das Schmuckstück dürfte als Weihegabe deponiert worden sein (Abb. Kat.-Nr. 2).

\section{Römerzeit}

Im unmittelbaren Umfeld der peripheren Blackenalpkapelle kamen vier römische Münzen sowie ein römerzeitlicher Siegelring zum Vorschein (Kat.Nr. 3 bis 7). Diese Häufung dürfte nicht zufällig sein. Es ist denkbar, dass die Stelle der heutigen Kapelle bereits in vorgeschichtlicher Zeit als heidnische Kultstätte genutzt wurde. Somit könnte es sich bei den Münz- und Schmuckfunden um Weihegaben handeln. Möglicherweise errichtete man die heutige, im Kern mittelalterliche Blackenalpkapelle anstelle eines älteren Kultorts. Die Lage über einer markanten Geländestufe nahe dem Stierenbach mit spektakulärem Blick in Richtung Süden unterstützt diese Vermutung.
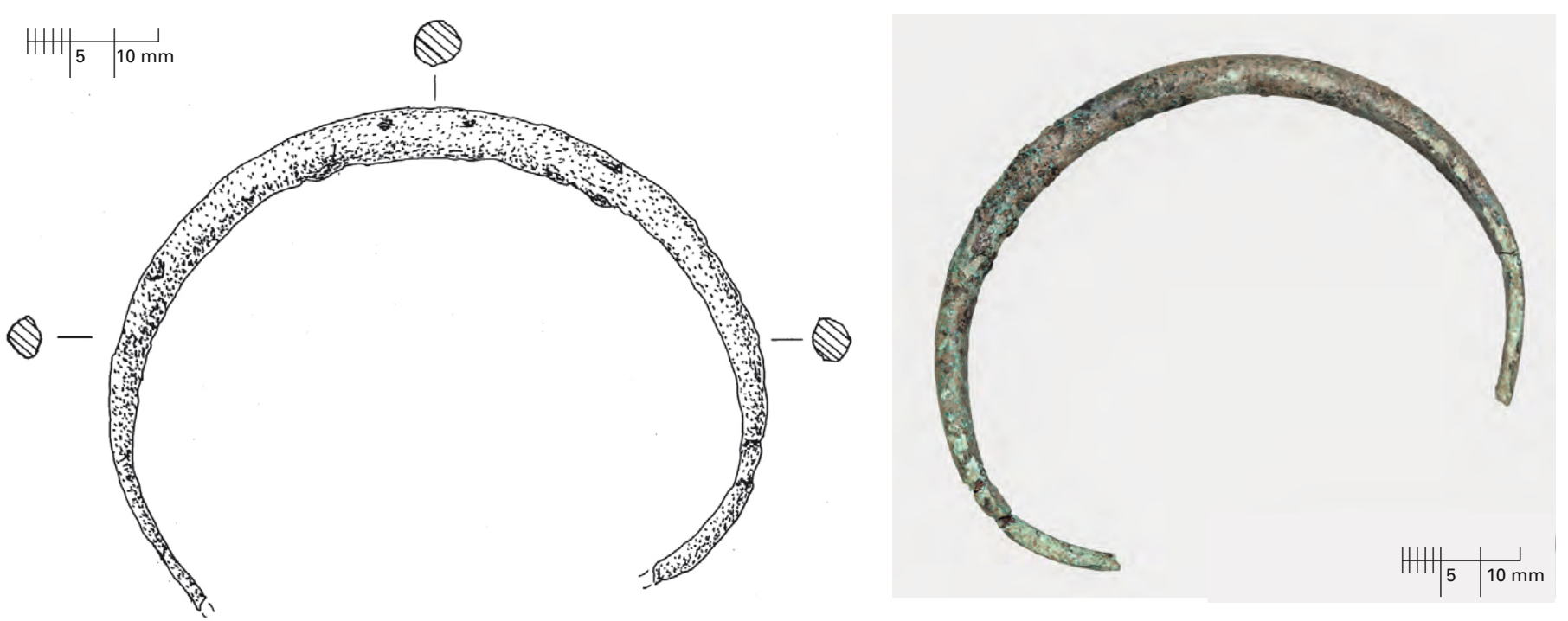


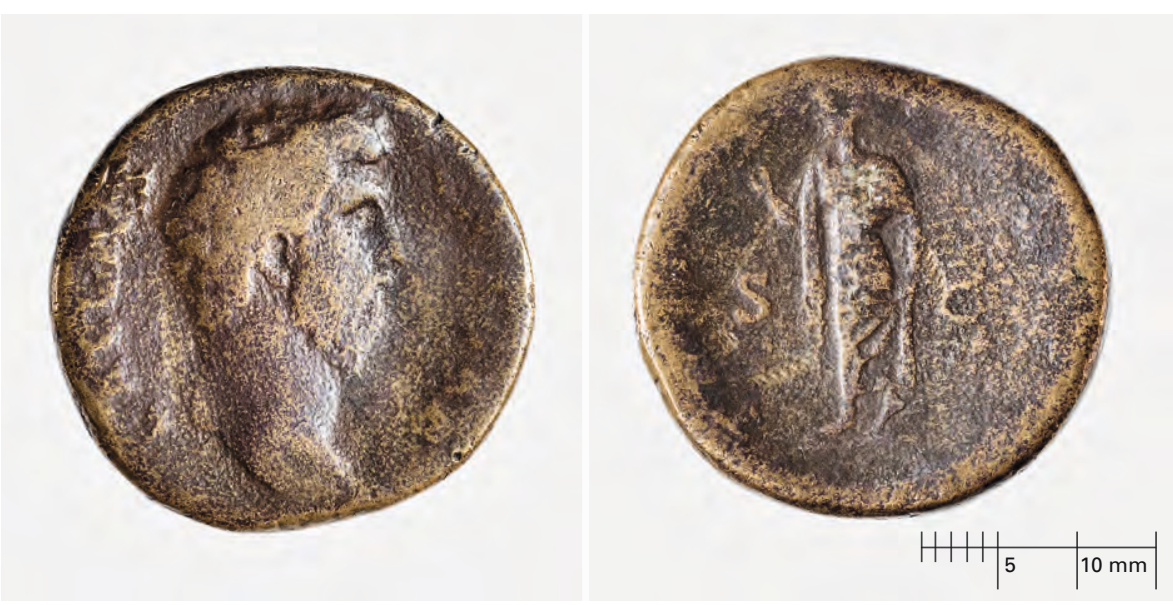

Kat.-Nr. 3: Sesterz des Hadrian

1895 wurde bei der Blackenalpkapelle ein Sesterz des Hadrians für Lucius Aelius aus der Zeit um 137 n.Chr. entdeckt. Das Objekt ist im Historischen Museum Altdorf ausgestellt.

Rom, Kaiserreich, 137 n.Chr., Sesterz. Vs. Büste des Aelius nach rechts. Rs. S C; Spes stehend. Messing. 22,28 g, 30,2 bis $28,1 \mathrm{~mm}, 360^{\circ}$. Erhaltung: A 3/3, K 2/2 (Abb. Kat.-Nr. 3).

Jahrbuch der Schweizerischen Gesellschaft für Urgeschichte 5/1912, 177. - Roubik 1979, 68-70. - Primas/Della Casa/Schmid-Sikimić 1992, 30.

\section{Kat.-Nr. 4: As des Trajan}

1976 legte Alfred Hotz einen As des von 98 bis 117 n.Chr. regierenden Trajan vor, der sich ebenfalls bei der Blackenalpkapelle fand. Das Stück blieb seinerzeit in Privatbesitz, mittlerweile ist unklar, wo sich die Münze befindet.

Rom, Kaiserreich, Trajan, 103-111 n.Chr., Prägestätte Rom, As. Vs. [IMP CAES NERVAE TRAIANO AVG GER DAC P M TR P COS V P P]; Kopf des Traian nach rechts mit Lorbeerkranz. Rs. [S P Q R OPTIMO PRINCIPI S C]; Traian zu Pferd nach rechts, Speer auf vor dem Pferd liegenden Daker stossend. RIC II, S. 282, Nr. 542.2. Kupfer. 8,41 g, 27,49 mm. Erhaltung: ---. Roubik 1979, 68. - Primas/Della Casa/Schmid-Sikimić 1992, 30.

\section{Kat.-Nr. 5: As des Augustus für Tiberius}

1984 fand Kurt Morgenthaler bei der Blackenalpkapelle einen As des Augustus für Tiberius. ${ }^{8}$ Das Objekt verblieb seinerzeit in Privatbesitz, zurzeit ist der Standort der Münze unklar.

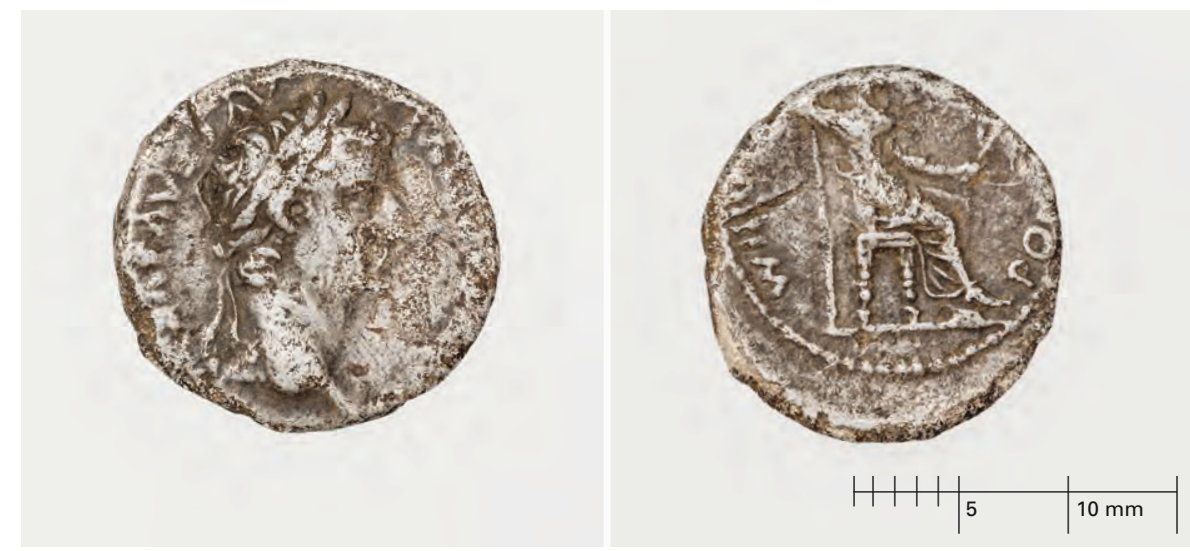

Kat.-Nr. 3

Sesterz des Hadrian Foto M. Käch, 2016

Kat.-Nr. 6 (unten) Denar des Tiberius Foto M. Käch, 2014
8 Bestimmung 1984 durch Roland Maly, Kriens. 

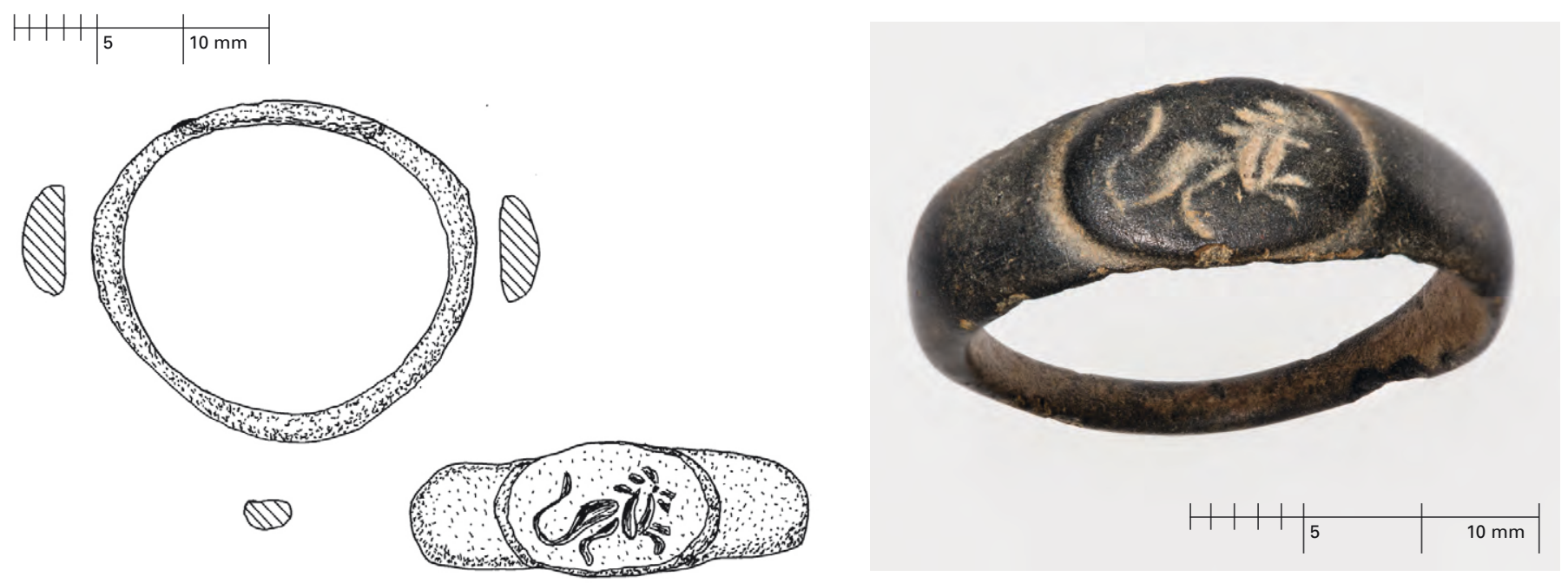

Kat.-Nr. 7

Siegelring, römisch

Zeichnung U. Leuzinger, 2014, Foto

M. Käch, 2014
Rom, Kaiserreich, Augustus für Tiberius, 13 bis 14 n.Chr., Prägestätte Lugdunum, As. Vs. [TI CAESAR AV]GVST F IMPERA[T VII]; Kopf des Tiberius nach rechts mit Lorbeerkranz. Rs. ROM [ET AVG]; Altar von Lugdunum. RIC I2, S. 58, Nr. 245. Kupfer. 6,88 g, 360. Erhaltung: ---.

Primas/Della Casa/Schmid-Sikimić 1992, 30.

\section{Kat.-Nr. 6: Denar des Tiberius}

Einen weiteren Fund im unmittelbaren Umfeld der Blackenalpkapelle machte Romano Agola am 26. Juli 2013: ein gut erhaltener Denar des in den Jahren 14 bis 37 n.Chr. regierenden Tiberius (2013.014.7) (LK 1191, 682 039/186 823, 1770 m ü.M.).

Rom, Kaiserreich, Tiberius, 14 bis 37 n.Chr., Prägestätte Lugdunum, Denar. Vs. [TI CAES]AR DIVI - AVG F AVGVS[TVS]; Kopf des Tiberius mit Lorbeerkranz nach rechts. Rs. PON[TIF - M]AXIM; weibliche Gestalt sitzt nach rechts mit langem Szepter und Zweig; einfache Abschnittslinie. RIC I2, S. $95, \mathrm{Nr}$. 30 . Silber. $3,30 \mathrm{~g}$ (ungereinigt), 17,6 bis $16,7 \mathrm{~mm}, 240^{\circ}$. Erhaltung: A 2/2, K 2/2, Einhieb auf Vs. und Rs., feine Feilspuren am Rand. Rs. dezentriert geprägt (Abb. Kat.-Nr. 6).

Die Einhieb- und Schleifspuren belegen, dass die früheren Besitzer der Münze den Silbergehalt jeweils genau prüften. Der geringe Abrieb spricht für eine kurze Umlaufzeit. Der Denar dürfte also um die Mitte des 1. Jahrhunderts n.Chr. bei der Blackenalpkapelle in den Boden gelangt sein.

\section{Kat.-Nr. 7: Siegelring}

Romano Agola entdeckte hier ausserdem auch einen Siegelring aus Bronze (2013.014.3) (LK 1191, 681 990/186 550, 1773 m ü.M.): Durchmesser max.: $23 \mathrm{~mm}$; Durchmesser min.: $20 \mathrm{~mm}$; Schiene: max. Dicke: $2 \mathrm{~mm}$; min. Dicke: $1 \mathrm{~mm}$, max. Breite: $7 \mathrm{~mm}$, min. Breite: $2 \mathrm{~mm}$. Der Ring ist 2,82 g schwer. Die Aussenseite ist glatt poliert und mit einer regelmässigen Patina überzogen, die an der Innenseite gröber ist. Auf der Ringplatte befindet sich ein ovales abgehobenes Feld von $12 \mathrm{~mm}$ Länge und $8 \mathrm{~mm}$ Breite. Darauf ist ein stilisierter Löwe mit offenem Maul eingraviert, der von links nach rechts schreitet. Die Mähne ist mit drei abstehenden kurzen Strichen sowie zwei sich nach unten ziehenden längeren Strichen dargestellt. Ein winziges Auge ist erkennbar. Die breite geschwungene Rückenlinie geht in einen s-förmig erhobenen Schwanz über. Vorne bilden zwei abstehende Striche die Vorderbeine, die dünne Bauchlinie geht in einem Winkel zu einem Hinterlauf über. 


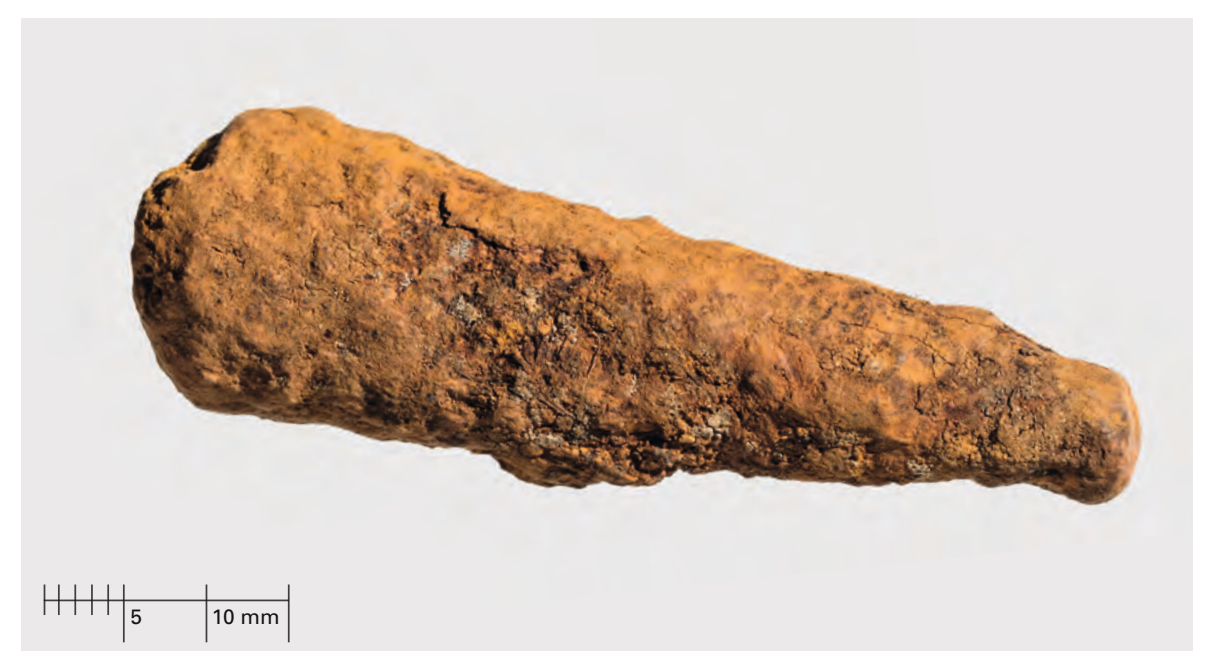

Der Ring datiert in die römische Zeit. Vergleichbare Objekte kamen beispielsweise in Augusta Raurica und Oberwinterthur zum Vorschein und datieren mehrheitlich ins 2. bis 4. Jahrhundert n.Chr. (Abb. Kat.-Nr. 7). ${ }^{9}$

\section{Mittelalter bis heute}

Die Passhöhe des Surenen ist übersät von modernem "Zivilisationsmüll», den gedankenlose Wanderer oder Jäger bei der Überquerung liegengelassen haben. Die Mehrzahl der Metalldetektor- und Lesefunde entlang der Passroute datiert daher aus der Neuzeit. Neben dem "Zivilisationsmüll», einigem Eisenschrott sowie Militaria der Schweizer Armee aus dem 20. Jahrhundert, die hier nicht näher beschrieben werden, handelt es sich vor allem um Münzen, Eisennägel, Bleikugeln sowie Knochen-, Glas- und Keramikfragmente.

Der folgende Katalog umfasst demzufolge eine Auswahl an Funden, aufgelistet nach Fundorten entlang der Passroute von Norden nach Süden. Die Faunenreste aus dem Holloch - ein versinterter Hirschwirbel - sowie mehrere Knochen von Reh und Fuchs aus der Höhle Zibegg sind im Kapitel "Höhlen und Balmen - Natürliche Schutzräume am Surenenpassweg» $\Leftrightarrow$ S. 82-101) beschrieben.

\section{Kat.-Nr. 8: Fingerring}

Beatrix Koens aus Altdorf fand am 10. August 2014 auf dem Geissrüggen (LK 1191, 686 420/188 693, 1903 m ü.M.) wenige Meter westlich des hallstattzeitlichen Gebäudegrundrisses mit dem Metalldetektor in circa $5 \mathrm{~cm}$

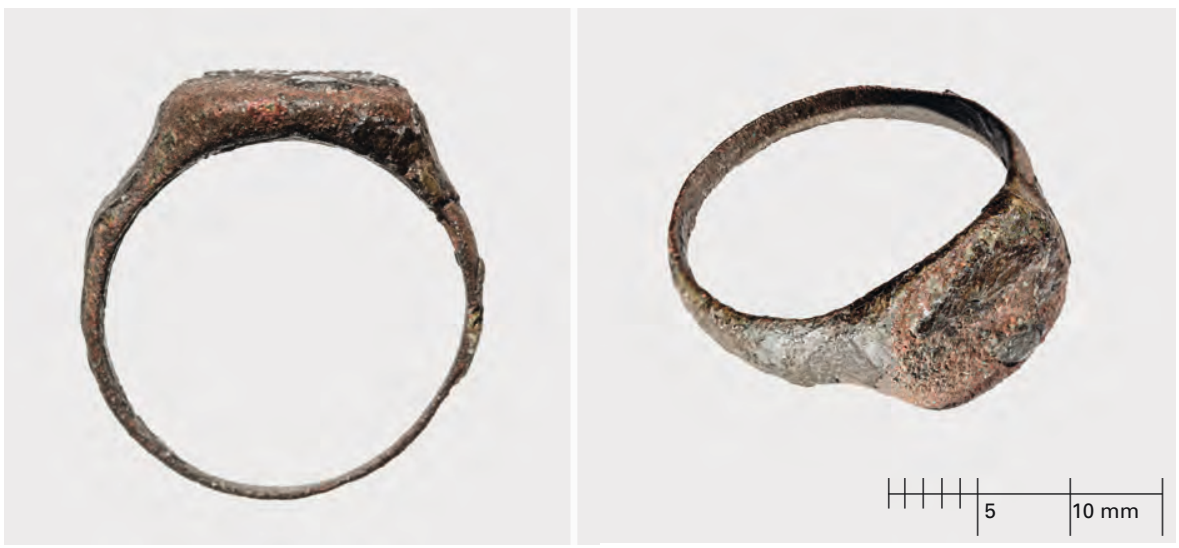

Kat.-Nr. 10

KIöppel, neuzeitlich

Foto M. Käch, 2015

Kat.-Nr. 8

Fingerring, mittelalerlich bis neuzeitlich Foto M. Käch, 2015 


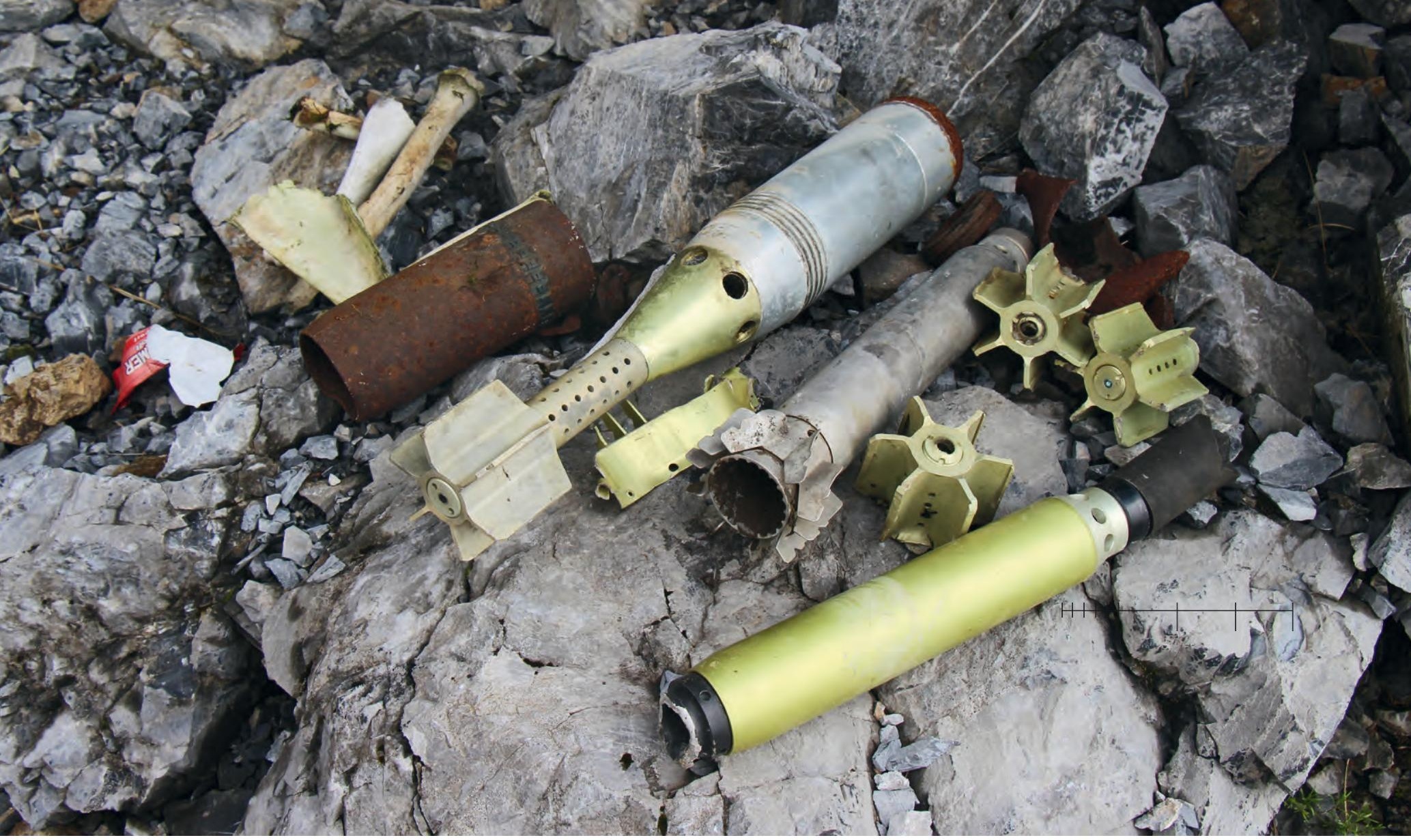

«Zivilisationsmüll» und Militaria, gefunden auf Gritschen.

Foto M. Sauter, 2014

Kat.-Nr. 9, 11 und 14 (v. I. n. r.)

Bleikugeln, neuzeitlich (wohl um 1799)

Foto M. Käch, 2015
Tiefe einen stark korrodierten Fingerring aus Buntmetall (2014.044.1.1). Der Innendurchmesser des Rings beträgt $19,5 \mathrm{~mm}$, die bandförmige Schiene ist $1 \mathrm{~mm}$ dick und hat eine Breite von 2 bis $6 \mathrm{~mm}$. Die angegossene Ringplatte ist $14 \mathrm{~mm}$ lang, $11 \mathrm{~mm}$ breit und 3,4 $\mathrm{mm}$ dick. Der Ring ist 4,32 $\mathrm{g}$ schwer. Eine Verzierung oder Gravur auf der Platte ist wegen der starken Korrosion nicht erkennbar. Alter: Mittelalter bis Neuzeit (Abb. Kat.-Nr. 8).

\section{Kat.-Nr. 9: Bleikugel}

Im Kontext der vier Wüstungen bei Nussfruttli ${ }^{10}$ entdeckte Romano Agola eine grau patinierte, etwas asymmetrische Bleikugel ohne Impaktspuren (2013.014.12.1) (LK 1191, 685 977/188 713, circa 2000 m ü.M.).

Durchmesser: $14 \mathrm{~mm}$; Gewicht: 12,39 g. Wegen des kleinen Durchmessers handelt es sich wahrscheinlich um eine Pistolenkugel. Alter: Die Kugel stammt vielleicht aus der Zeit des zweiten Koalitionskriegs, als im Rahmen des Suworow-Feldzugs zwischen dem 27. September und dem

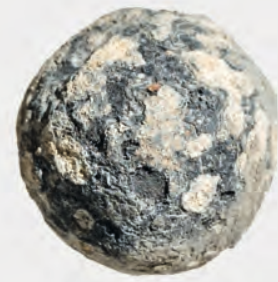

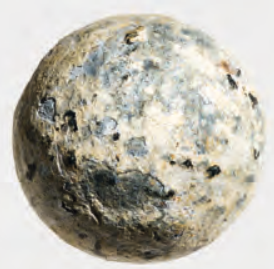

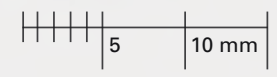

10 Sauter 2009, 64-65. 


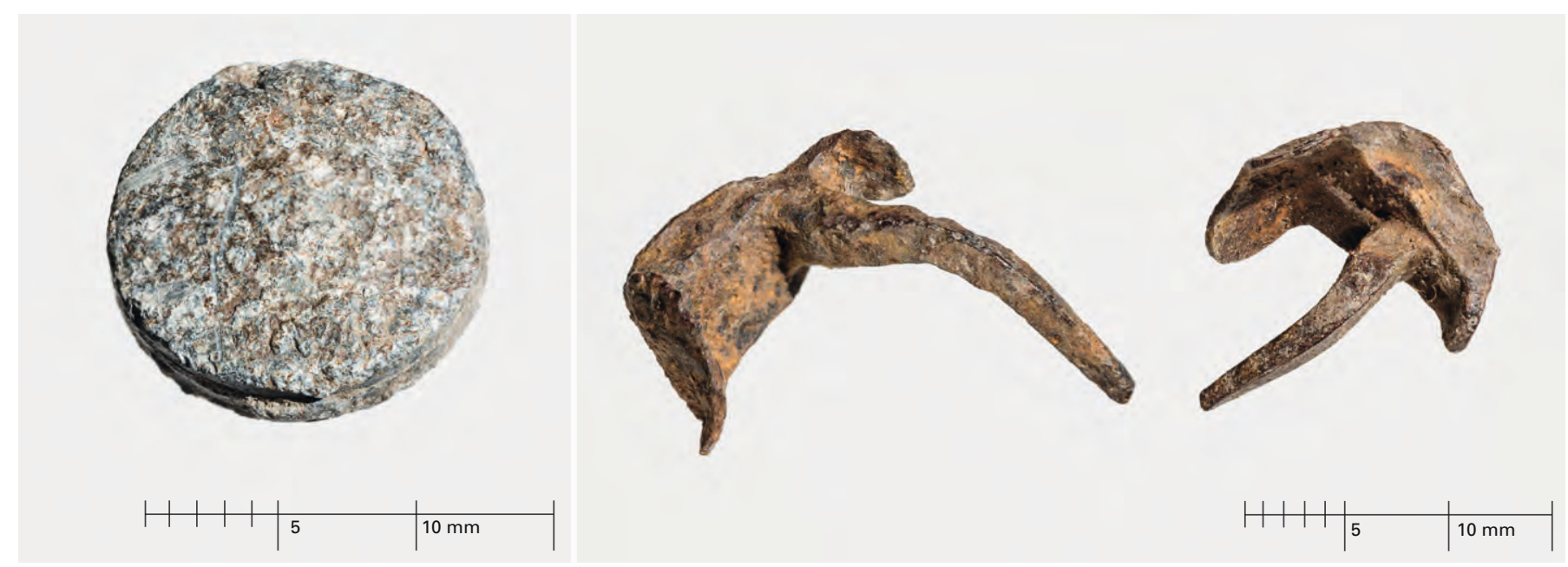

3. Oktober 1799 Teile des französischen 1. Bataillons der 38. Halbbrigade von Charles Étienne Gudin über den Surenenpass nach Altdorf abkommandiert wurden (Abb. Kat.-Nr. 9). ${ }^{11}$

\section{Kat.-Nr. 10: Klöppel}

Nur wenige Meter davon entfernt konnte Romano Agola vermutlich den von einer Glocke stammenden eisernen Klöppel bergen (2013.014.13.1) (LK 1191, 682 943/188 719, circa 2000 m ü.M.).

Das stark korrodierte Fundstück ist $65 \mathrm{~mm}$ lang, hat einen maximalen Durchmesser von $21 \mathrm{~mm}$ und ist 25,48 g schwer. Eine Aufhängung (Öse, Kerbe) ist nicht erkennbar. Alter: Neuzeit (Abb. Kat.-Nr. 10).

\section{Kat.-Nr. 11: Bleikugel}

Die Funde Kat.-Nr. 11 bis 13 machte Romano Agola am 26. Juli 2013 auf der Surenenpasshöhe: Hier fand sich eine grau patinierte, stark angewitterte Bleikugel ohne Impaktspuren (2013.014.15.1) (LK 1191, 684 479/187 823, 2291 m ü.M.).

Max. Durchmesser: 16 mm; Gewicht: 24,09 g. Der Durchmesser spricht für eine Musketenkugel. Auf der Kugeloberfläche lassen sich die Gussnaht sowie die Abtrennspuren einer Zange gut erkennen. Alter: Die Kugel dürfte in die Zeit um 1799 datieren (Abb. Kat.-Nr. 11).

\section{Kat.-Nr. 12: Plombe}

Ebenfalls von der Surenenpasshöhe stammt eine grau patinierte, flach doppelkonvexe Plombe aus grau patiniertem Blei (2013.014.16.1) (LK 1191, 684 479/187 823, 2291 m ü.M.).

Das Stück hat einen Durchmesser von 13 bis $14 \mathrm{~mm}$ und ist $5 \mathrm{~mm}$ dick, das Gewicht beträgt 4,72 g. Die Mittelnaht ist klar erkennbar. Eine beidseitige Stempelung mit umlaufendem Text lässt sich erahnen, die einzelnen Buchstaben sind jedoch nicht (mehr) lesbar. Alter: Neuzeit (Abb. Kat.-Nr. 12).

\section{Kat.-Nr. 13, 1-2: Schuhnägel}

Ausserdem fanden sich hier auch zwei handgeschmiedete Schuhnägel mit hammerförmigem Kopf und quadratischem Schaft aus Eisen (2013.014.14.1 und 2013.014.14.2) (LK 1191, 684 479/187 823, 2291 m ü.M.). Länge: 18/25 mm. Alter: 20. Jahrhundert (Abb. Kat.-Nr. 13,1-2).
Kat.-Nr. 12

Plombe, neuzeitlich

Foto M. Käch, 2015

Kat.-Nr. 13,1-2

Schuhnägel, 20. Jahrhundert Foto M. Käch, 2015 
Kat.-Nr. 15

Schuhnagel, 19. bis 20. Jahrhundert

Foto M. Käch, 2015

Kat.-Nr. 16

Schuhnagel, 19. bis 20. Jahrhundert

Foto M. Käch, 2015
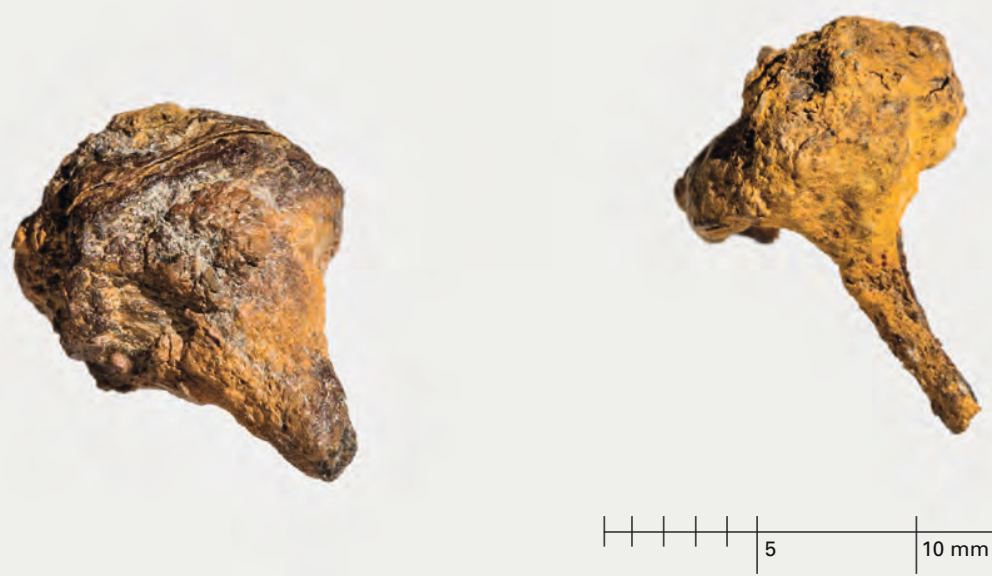

\section{Kat.-Nr. 14 - Bleikugel}

Entlang des Surenenpasswegs, zwischen der Passhöhe und der Blackenalp, konnte im Rahmen der zweiten Forschungskampagne am 4. August 2014 eine weitere grau patinierte Bleikugel ohne Impaktspuren geborgen werden (LK 1191, 683 210/186 844, 1960 m ü.M.).

Die mittige Gussnaht ist noch gut erkennbar. Durchmesser: $13 \mathrm{~mm}$, Gewicht: 11,86 g. Wegen des kleinen Durchmessers handelt es sich wahrscheinlich um eine Pistolenkugel. Alter: Die Kugel dürfte in die Zeit um 1799 datieren (Abb. Kat.-Nr. 14).

\section{Kat.-Nr. 15: Schuhnagel}

Bei der etwas unterhalb der Passhöhe auf der Engelberger Seite gelegenen Surenenschutzhütte entdeckte Romano Agola am 25. Juli 2013 einen kleinen, stark korrodierten eisernen Schuhnagel (2013.014.11.1) (LK 1191, 684 500/187 675, 2160 m ü.M.). Länge: 14 mm (Kopf: 8 mm; Schaft: 6 mm). Pyramidaler Kopf. Alter: 19. bis 20. Jahrhundert (Abb. Kat.-Nr. 15).

\section{Kat.-Nr. 16: Schuhnagel}

Ein weiterer kleiner, stark korrodierter Schuhnagel aus Eisen fand sich im Folgejahr am Surenenpasswegs zwischen der Passhöhe und der Blackenalp (LK 1191, 683 220/186 860, 1960 m ü.M.). Länge: 15 mm. Pyramidaler Kopf, Schaft viereckig. Alter: 19. bis 20. Jahrhundert (Abb. Kat.-Nr. 16).

\section{Kat.-Nr. 17: Schuhsohle/Absatzfragment}

Entlang des Surenenpasswegs zwischen der Passhöhe und der Blackenalp kam am 4. August 2014 ausserdem eine korrodierte Schuhsohlen-Absatzbefestigung aus Eisen mit Nagelloch und schwach gebogener Profilrippe zum Vorschein: Typ KTA der Schweizer Armee (LK 1191, 684 120/187 275, 2040 m ü.M.). Länge: 24 mm; Breite: 18 mm; Dicke: $6 \mathrm{~mm}$. Alter: 19. bis 20. Jahrhundert (Abb. Kat.-Nr. 17).

\section{Kat.-Nr. 18: Fingerring}

Unweit der Blackenalp entdeckte Romano Agola am 25. Juli 2013 mit dem Metalldetektor einen Fingerring aus Buntmetall (2013.014.9.1) (LK 1191, 682 042/186 825, 1790 m ü.M.).

Der Durchmesser des Rings beträgt innen 19 bis $20 \mathrm{~mm}$. Die reich mit einem dreiteiligen Flechtband verzierte bandförmige Schiene ist $4 \mathrm{~mm}$ breit 


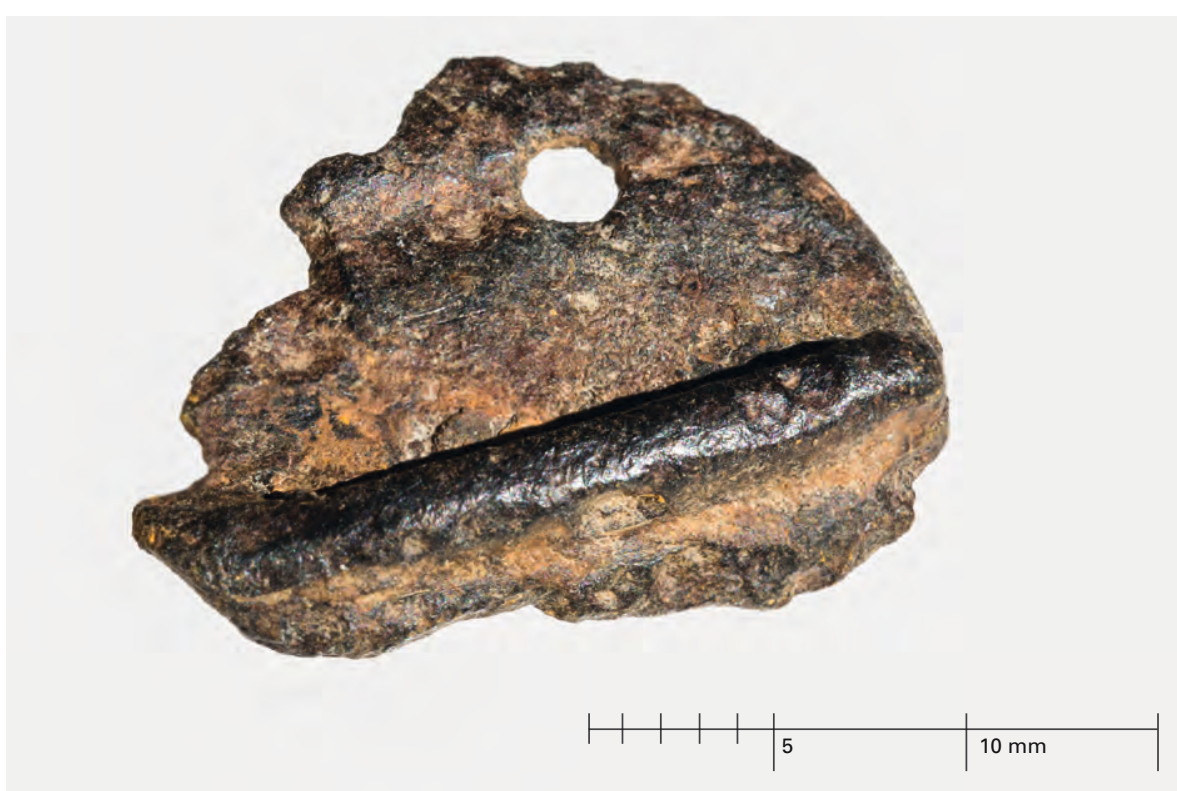

und $1 \mathrm{~mm}$ dick. Die angelötete Ringplatte besteht aus einer gegossenen Scheibe in Blütenform. Sie ist $13 \mathrm{~mm}$ lang, $12 \mathrm{~mm}$ breit und $2 \mathrm{~mm}$ dick. Die stilisierte Blüte besteht aus acht grossen Perlbuckeln, die sich regelmässig um einen zentralen Perlbuckel gruppieren. In den Aussenräumen liegen nochmals symmetrisch verteilt acht kleinere Buckel. Es ist keine Innengravur vorhanden. Der Ring ist 3,1 g schwer. Alter: Neuzeit (Abb. Kat.-Nr. 18).

\section{Funde im Kontext der 2013/14 untersuchten Wüstungen}

\section{Gritschen - Gebäude und Pferch Gritschen 1 (At.122)}

\section{Kat.-Nr. 19: Rinderknochen}

Im Pferch der Wüstung Gritschen 1 fand sich in der Sondierung 1 in $20 \mathrm{~cm}$ Tiefe eine Diaphyse eines Metapodiums eines jungen Rinds. Die Epiphysen fehlen und waren noch nicht verwachsen. Die Oberfläche ist schwach verwittert und trägt einige Bissspuren, der Knochen ist dunkelbraun patiniert. Der Knochen ist vergleichsweise schwer und noch kollagenhaltig, was nicht für ein sehr hohes Alter des Fundstücks spricht.

Länge: 157 mm; Breite: 53 mm; Dicke: 35 mm; Gewicht: 112,3 g. Alter: Neuzeit (Abb. Kat.-Nr. 19).

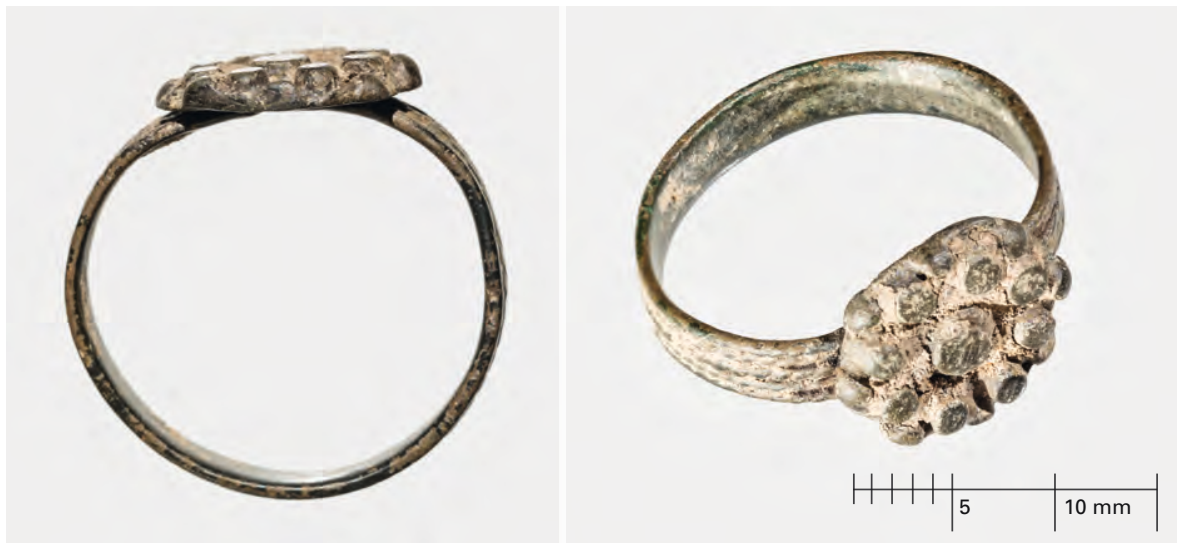

Kat.-Nr. 17

Schuhsole/Absatzfragment, 19. bis 20. Jahrhundert

Foto M. Käch, 2015

Kat.-Nr. 18

Fingerring, neuzeitlich

Foto M. Käch, 2015 
12 ETH-57592: 823 $\pm 23 B P, \delta^{13} C-24.9 \pm 1$, $A D$ 1165-1265, 2 sigma.

\section{Blackenboden - Wüstung «Pyramide» (At.106)}

\section{Kat.-Nr. 20: Eisenfragment/Scharnier?}

Innerhalb des Gebäudegrundrisses der Wüstung «Pyramide» kam ein stark korrodiertes, unbestimmbares Fragment aus Eisen zum Vorschein. Länge: 72 mm; Breite: 68 mm; Dicke: 5 mm. Alter: Neuzeit (Abb. Kat.-Nr. 20).

\section{Blackenboden - Wüstung «Massiv» (At.101)}

\section{Kat.-Nr. 21: Knochen eines Wiederkäuers}

In der Sondierung 1 in der Gebäudestruktur 2 in der Wüstung "Massiv» fand sich neben einer Feuerstelle mit Holzkohlen aus dem 12./13. Jahrhundert. ${ }^{12}$ ein kleines Kompaktafragment eines sehr schlecht erhaltenen Knochens eines kleinen Wiederkäuers. Länge: 25 mm; Breite: 12 mm; Dicke: $3 \mathrm{~mm}$. Alter: Mittelalter (nicht abgebildet).

\section{Kat.-Nr. 22: Knochen eines Wiederkäuers}

Innerhalb der "PferchartigenStruktur» Wüstung "Massiv» fand sich in Sondierung 1 in $18 \mathrm{~cm}$ Tiefe das Kompaktafragment eines intentionell aufgeschlagenen Langknochens eines kleinen Wiederkäuers. Die Oberfläche ist stark angewittert. Es lassen sich schwache Bissspuren erkennen. Länge: 47 mm; Breite: 18 mm. Alter: Neuzeit (Abb. Kat.-Nr. 22).

\section{Blacken - «Pferchartige Struktur» (At.100)}

\section{Kat.-Nr. 23: Knochen eines Wiederkäuers}

Unweit des Fundorts des bronzenen Armreifs (Kat.-Nr. 2) wurden weitere Sondierungen angelegt: In Sondierung $1 \mathrm{kam}$ in $10 \mathrm{~cm}$ Tiefe ein intentionell aufgeschlagenes Langknochenfragment eines kleinen Wiederkäuers zum

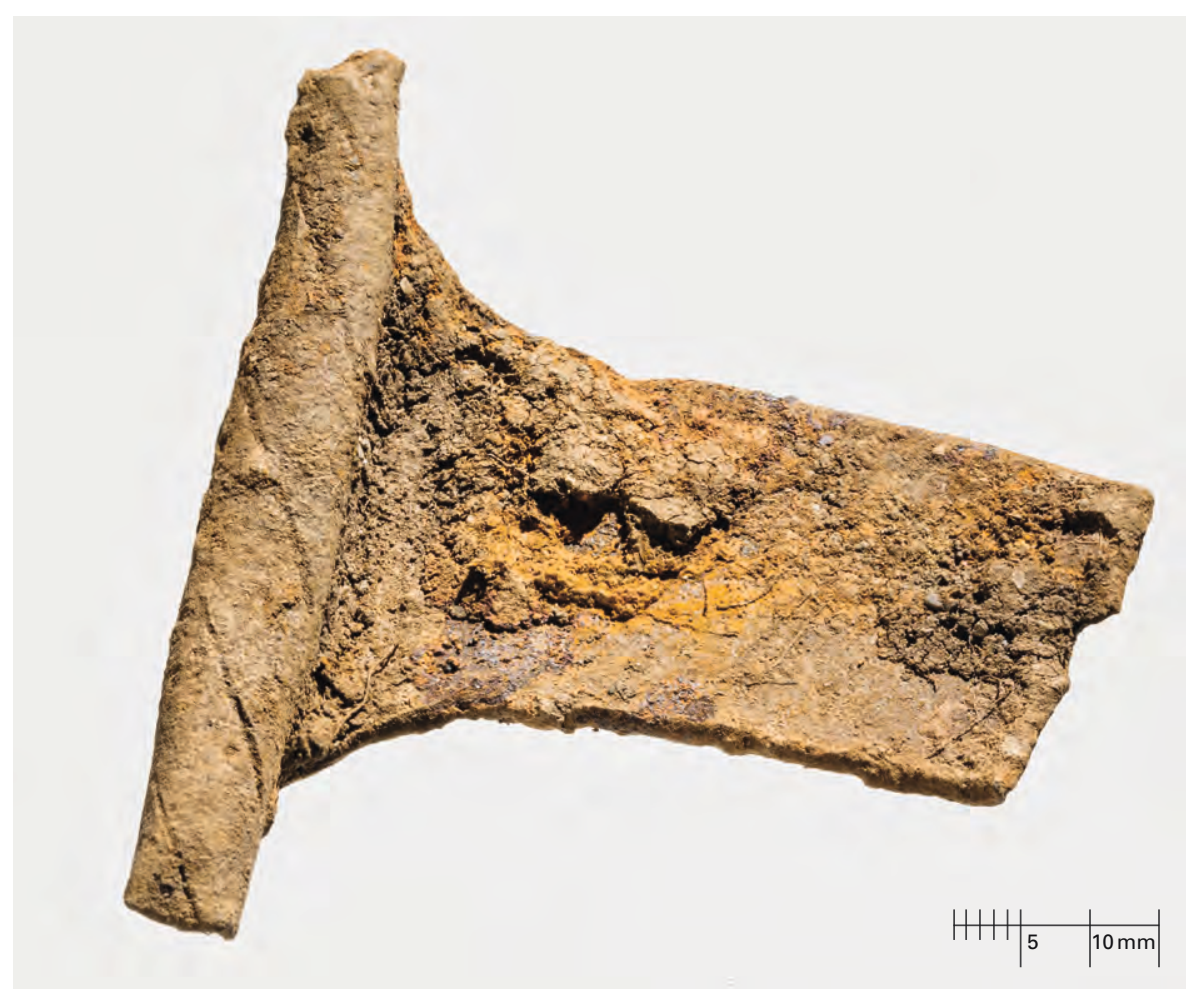




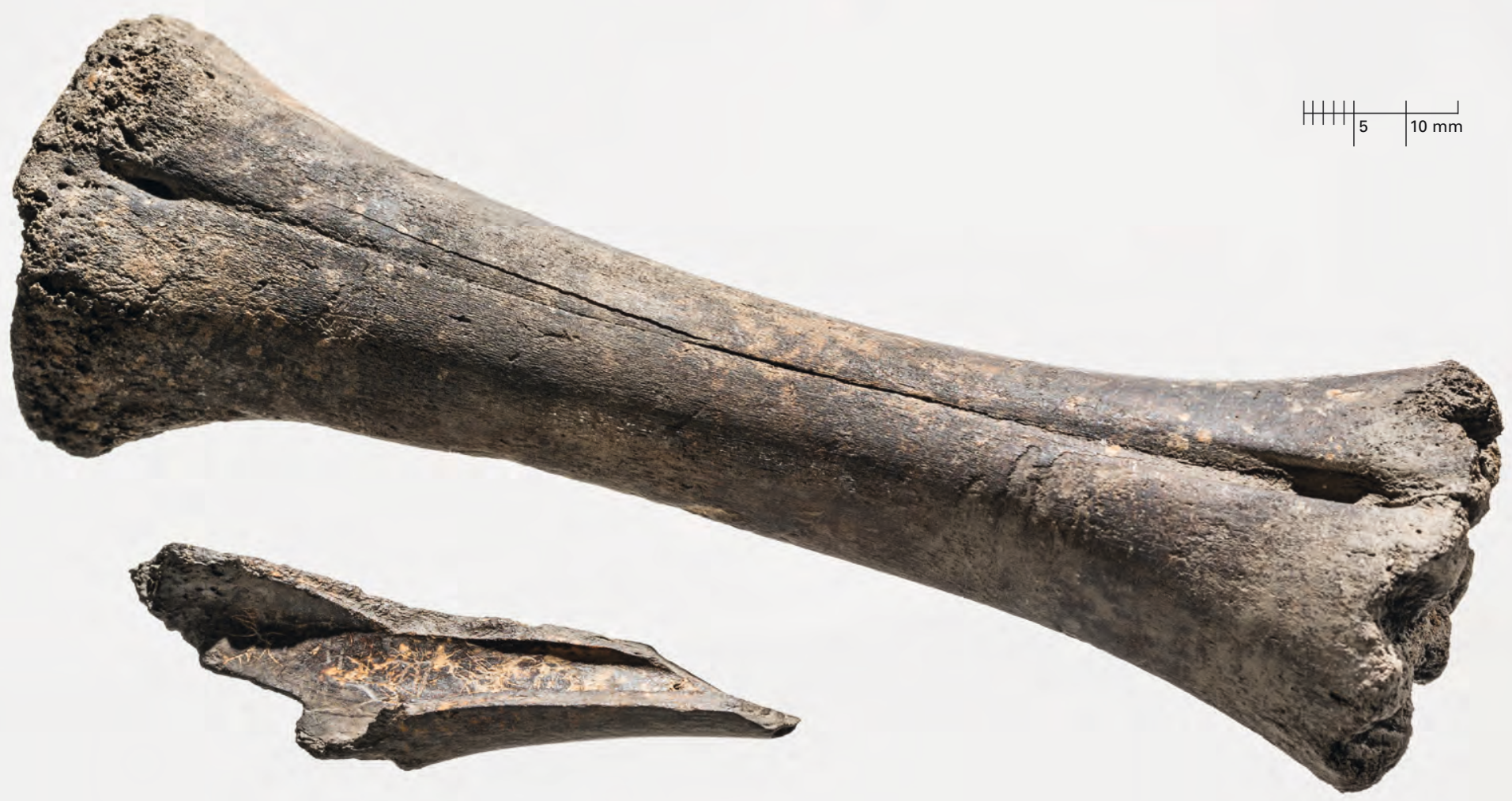

Vorschein. Die Oberfläche ist schwach verwittert, der Knochen ist dunkelbraun patiniert, an einem Ende befinden sich Bissspuren. Länge: 75 mm; Breite: 18 mm; Dicke: 8 mm. Alter: Neuzeit (Abb. Kat.-Nr. 23).

\section{Kat.-Nr. 24: Backenzahn}

In Sondierung 1 in $10 \mathrm{~cm}$ Tiefe fand sich zudem ein Backenzahn eines kleinen Wiederkäuers. Der Zahn ist dunkelbraun patiniert. Länge: $35 \mathrm{~mm}$; Breite: 19 mm; Dicke: 12 mm. Alter: Neuzeit (Abb. Kat.-Nr. 24).

\section{Kat.-Nr. 25: Knochen eines Wiederkäuers}

Ausserdem kam innerhalb der "Pferchartigen Struktur» in einem Murmeltierbau, 10 m südöstlich vom Fixpunkt, ein kleines, braun patiniertes Röhrenknochenfragment eines kleinen Wiederkäuers zum Vorschein. Länge: 22 mm; Breite: $15 \mathrm{~mm}$; Dicke: $1 \mathrm{~mm}$. Alter: 19. bis 20. Jahrhundert (nicht abgebildet).

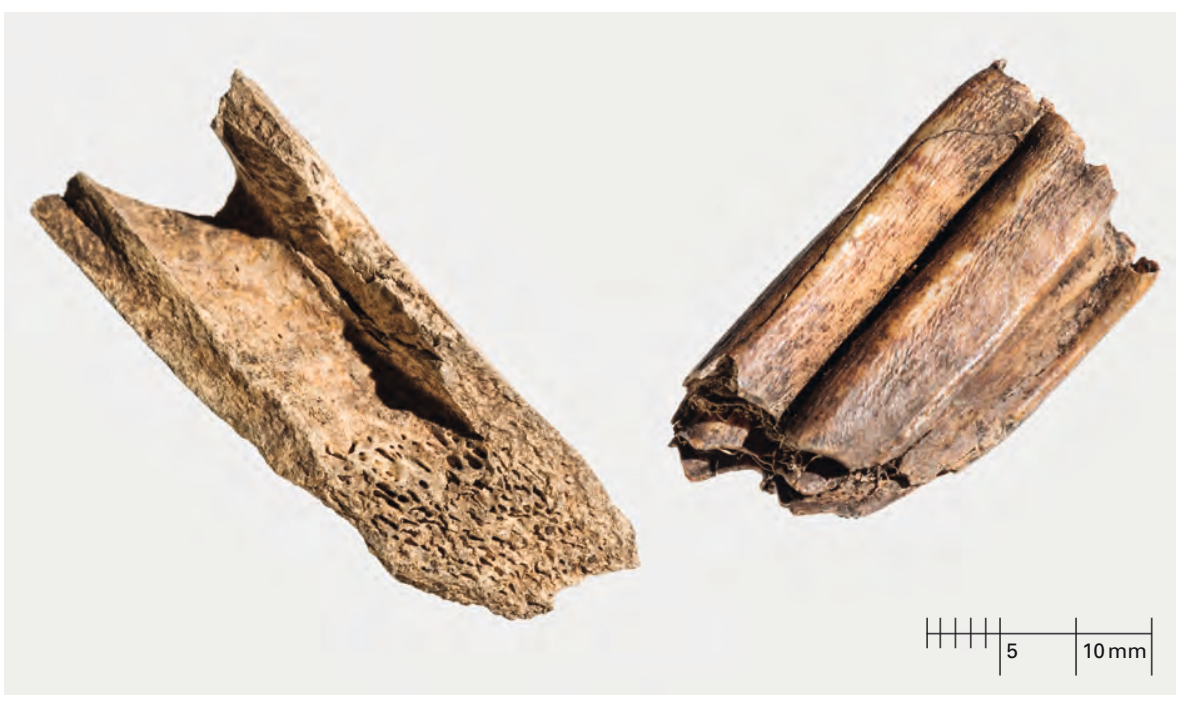

Kat.-Nr. 19

Rinderknochen, neuzeitlich Foto M. Käch, 2015

\section{Kat.-Nr. 23}

Knochenfragment, neuzeitlich Foto M. Käch
Kat.-Nr. 22

Knochenfragment, neuzeitlich Foto M. Käch, 2015

Kat.-Nr. 24

Backenzahn, neuzeitlich Foto M. Käch, 2015 
Kat.-Nr. 27

Halbbatzen, 1664

Foto M. Käch, 2015

Kat.-Nr. 28

Rechenpfennig (Jeton),

Mitte 18. Jahrhundert

Foto M. Käch, 2015
13 Die von Romano Agola geborgenen Münzen wurden alle von Stephen Doswald, Inventar der Fundmünzen der Schweiz, Bern, bestimmt. Ihm sei an dieser Stelle für seine grosse Hilfe herzlich gedankt.

14 Divo/Tobler 1987, 453, Nr. 1623a. - De Palézieux-du Pan 1909, 217, Nr. 210 Var.
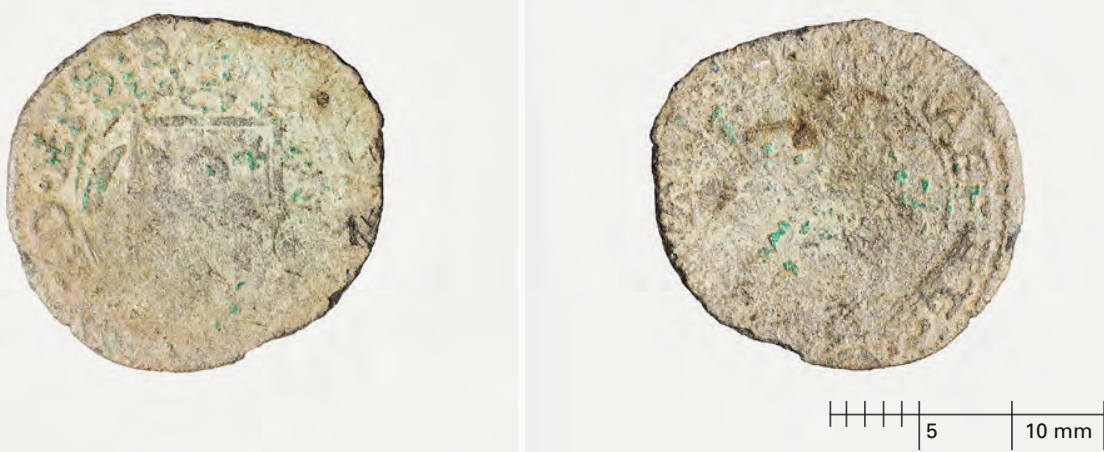

Kat.-Nr. 26: Knochen eines Wiederkäuers

Im selben Murmeltierbau wie bei Kat.-Nr. 25 lag auch ein kleines, braun patiniertes Knochenfragment eines kleinen Wiederkäuers. Länge: $24 \mathrm{~mm}$; Breite: $19 \mathrm{~mm}$; Dicke: $11 \mathrm{~mm}$. Alter: 19. bis 20. Jahrhundert (nicht abgebildet).

\section{Blackenalpkapelle St. Antonius und Wendelin}

Die unmittelbare Umgebung bei der Blackenalpkapelle lieferte zahlreiche Metalldetektor- wie auch Oberflächenfunde. Die meisten Objekte wie Nägel, Verputzreste oder Glasscherben dürfen als Bauschutt von Renovierungsarbeiten an der Kapelle bewertet werden. Auffällig ist aber der hohe Anteil an neuzeitlichen Münzen. ${ }^{13}$ Diese dürften - anknüpfend an die Tradition seit der gallorömischen Epoche - als Weihe- oder Dankesgaben an diesem sakralen Ort niedergelegt worden sein.

\section{Kat.-Nr. 27: Halbbatzen, 1664}

Bei der Blackenalpkapelle fand Romano Agola einen Halbbatzen von 1644 aus Billon (2013.014.2c) (LK 1191, 681 990/186 550, 1773 m ü.M.).

Sitten, Bistum, Adrian III. von Riedmatten (1640-1646). Vs. ADR[ ]IED 。 EPS - S; bischöfliches Familienwappen vor Schwert und Krummstab, da-

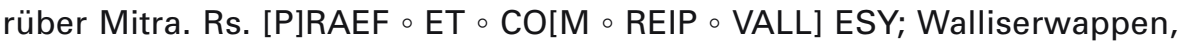
darüber Adler, zwischen die letzten beiden Ziffern der Jahreszahl $(4=4){ }^{14}$ Billon. 1,03 g (ungereinigt); 20,6 bis $18,6 \mathrm{~mm} ; 360^{\circ}$. Erhaltung: $A$ 2/2, $\mathrm{K} \mathrm{3/4}$, ausgebrochen. Möglicherweise ist ein Zwischenzeichen am Anfang und/ oder am Schluss der Umschrift auf der Vs. vorhanden (Abb. Kat.-Nr. 27).

\section{Kat.-Nr. 28: Rechenpfennig (Jeton)}

Ganz in der Nähe kam auch ein durchlochter Rechenpfennig (Jeton) aus Messing zum Vorschein (2013.014.2a) (LK 1191, 681 990/186 550, 1773 m ü.M.).

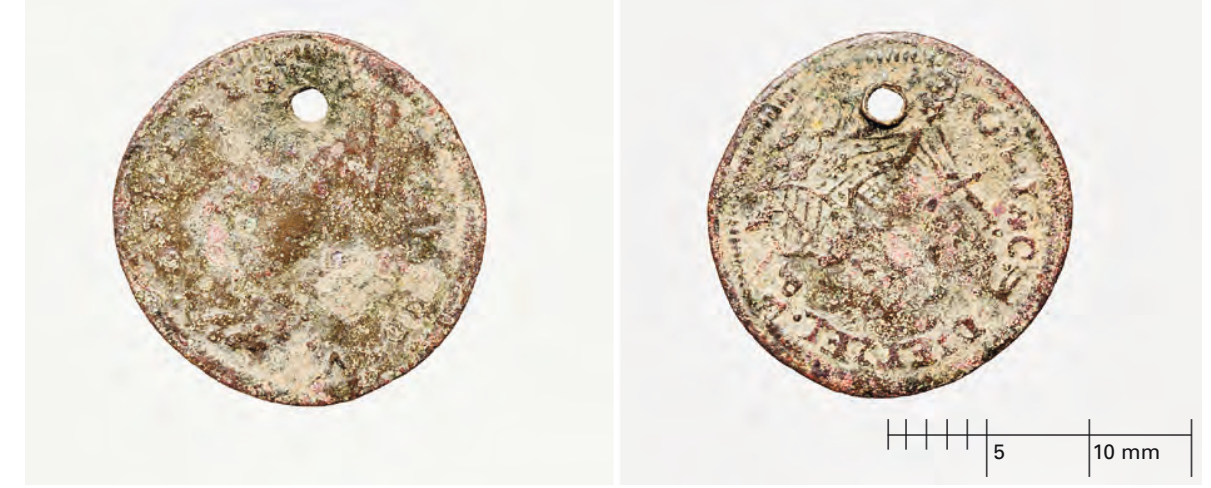



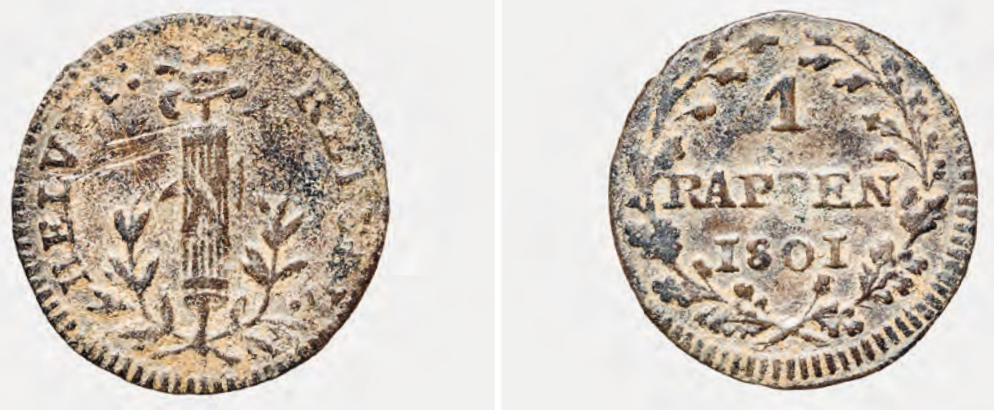

\begin{tabular}{|l|l|l|l|}
$H$ & $H$ & & \\
& &
\end{tabular} \mid

Nürnberg, Werkstatt von Johann Jacob Dietzel (Meister 1711, letztmals erwähnt 1748). Vs. LUD [ ] XV [ ] [D] - G $\circ \mathrm{FR} \circ \mathrm{E} \circ \mathrm{N} \circ \mathrm{REX}$; belorbeertes königliches Brustbild nach rechts. Rs. [I]OH $\circ I A C-D I E T Z E L \circ$; Schiff zwischen RE $=\mathrm{PF}$ (Rechenpfennig), nach links segelnd (Abb. Kat.-Nr. 28). ${ }^{15}$

Billon. $0,74 \mathrm{~g}$ (ungereinigt); 19,1 bis $18,4 \mathrm{~mm} ; 360^{\circ}$. Erhaltung: A $3 / 2$, K 2/2, gelocht von Vs. Der Jeton datiert in die Mitte des 18. Jahrhunderts.

\section{Kat.-Nr. 29: 1 Rappen, 1801}

Romano Agola barg ausserdem eine gut erhaltene 1-Rappen-Münze von 1801 aus Billon (2013.014.2b) (LK 1191, 681 990/186 550, 1773 m ü.M.).

Helvetische Republik. Vs. HELVET :- REPUBL : ; im Feld ein geschnürtes Rutenbündel zwischen zwei Lorbeerzweigen, darüber Freiheitshut mit Feder. Rs. 1 / RAPPEN / 1801, zwischen zwei zum Kranz gestellten Eichenzweigen. ${ }^{16}$ Billon. $0,51 \mathrm{~g}$ (ungereinigt); 15,4 bis $14,9 \mathrm{~mm} ; 345^{\circ}$. Erhaltung: A 1/1, K 1/1 (Abb. Kat.-Nr. 29).

\section{Kat.-Nr. 30: 1 Konkordatsbatzen, 1826}

Ein gut erhaltener Konkordatsbatzen von 1826 aus Billon ergänzt das Münzkonvolut von der Blackenalpkapelle (2013.014.1) (LK 1191, 681 990/186 550, $1773 \mathrm{~m}$ ü.M.).

Bern, Kanton. Vs. CANTON BERN $1826 / / 1 \circ$ BATZ $;$ Berner Wappen im Barockschild in einem Perlkreis, im Abschnitt Wertangabe: 1 Batz. Rs. DIE CONCORDIER. CANTONE DER SCHWEIZ; grosses verziertes, gleichschenkliges Schweizerkreuz mit einem $C$ in der Mitte und von einem Vierpass umgeben. ${ }^{17}$ Billon. $1,79 \mathrm{~g}$ (ungereinigt); 24,7 bis $24,4 \mathrm{~mm} ; 180^{\circ}$. Erhaltung: A 2/2, K 1/1 (Abb. Kat.-Nr. 30).
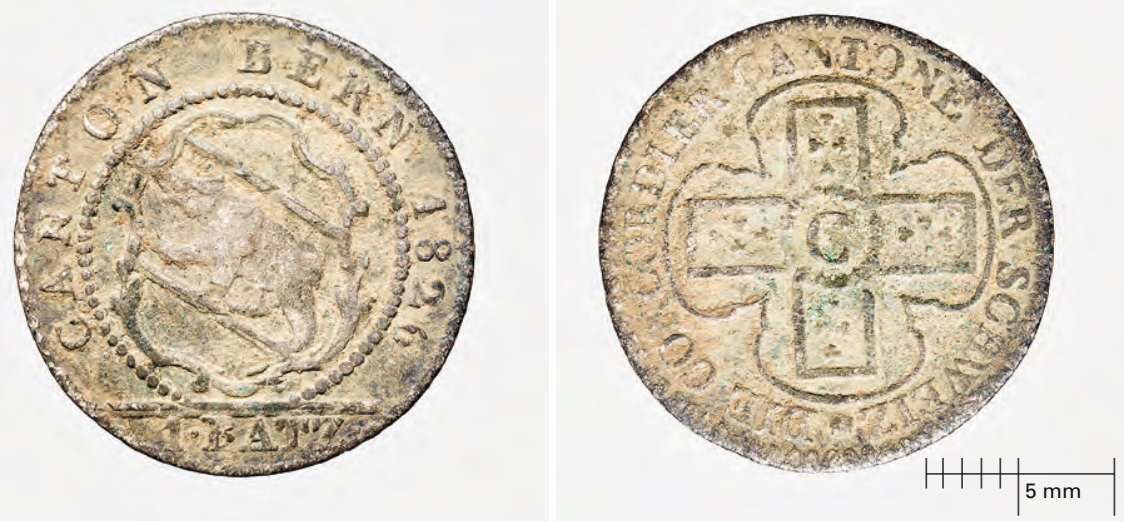

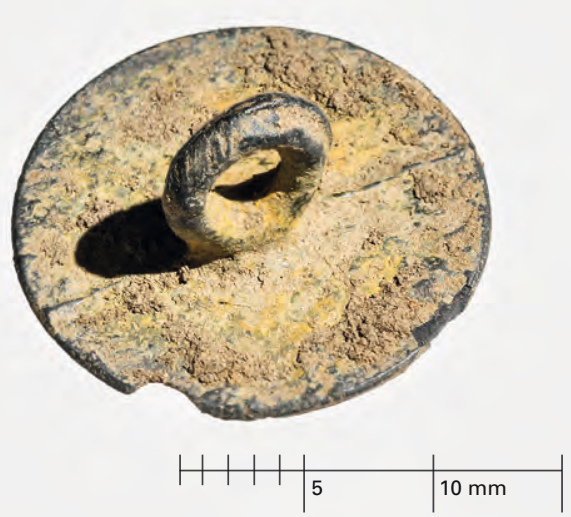

15 Mitchiner 1988, 523.

16 Divo/Tobler 1969, 17, $16 b$.

17 Divo/Tobler 1969, 34, Nr. 42a. Lohner 1846, 224, Nr. 1212.
Kat.-Nr. 29

1-Rappen-Münze, 1801

Foto M. Käch, 2015

Kat.-Nr. 31

Knopf, neuzeitlich

Foto M. Käch, 2015

Kat.-Nr. 30

Konkordatsbatzen, 1826

Foto M. Käch, 2015 
Kat.-Nr. 32

Ausgussfragment einer Glasflasche,

19. Jahrhundert

Foto M. Käch, 2015

\section{Kat.-Nr. 31: Knopf}

Bei der Blackenalpkapelle (2013.033) (LK 1191, 681 990/186 550, 1773 m ü.M.) fand Romano Agola ausserdem einen unverzierten flachen Knopf aus Buntmetall mit angelöteter schwach ovaler Öse (2013.014.4.1). Die Oberfläche des Knopfs war ursprünglich verzinnt. Durchmesser Knopfscheibe: 18 mm; Durchmesser Öse: 3,5 mm (innen). Alter: Neuzeit (Abb. Kat.-Nr. 31).

\section{Kat.-Nr. 32: Ausgussfragment einer Glasflasche}

Ein Teil des Archäologenteams untersuchte 2014 noch einmal die nähere Umgebung der Blackenalpkapelle. Unter einem Felsblock wurden mehre Funde getätigt (LK 1191, 681 990/186 570, 1773 m ü.M.). Ausgussfragment einer mundgeblasenen Flasche aus grünlich-weissem Glas, schwach irisierend. Mündungsdurchmesser (aussen): 27 bis $28 \mathrm{~mm}$; Mündungsdurchmesser (innen): 17 mm; Höhe: 62 mm. Alter: 19. Jahrhundert (Abb. Kat.-Nr. 32).

\section{Kat.-Nr. 33: Henkelfragment}

Am selben Ort fand sich auch eine Keramikhenkel (LK 1191, 681 990/186 570, $1773 \mathrm{~m}$ ü.M.). Braun glasierter zweirippiger Henkel aus oranger Keramik, Milchkrug? Länge: $43 \mathrm{~mm}$; Breite: $24 \mathrm{~mm}$; Dicke: $13 \mathrm{~mm}$. Alter: 18. bis 19. Jahrhundert (Abb. Kat.-Nr. 33).

\section{Kat.-Nr. 34: Schuhnagel}

Ebenso fand sich hier ein kleiner handgeschmiedeter Schuhnagel aus Eisen (LK 1191, 681 990/186 570, 1773 m ü.M.).

Der Nagel hat einen flach-ovalen Kopf, der quadratische Schaft ist umgeschlagen; die ursprüngliche Dicke der Ledersohle kann auf $4 \mathrm{~mm}$ geschätzt werden. Schaftlänge (rekonstruiert): 12 mm. Alter: Neuzeit (Abb. Kat.-Nr. 34).

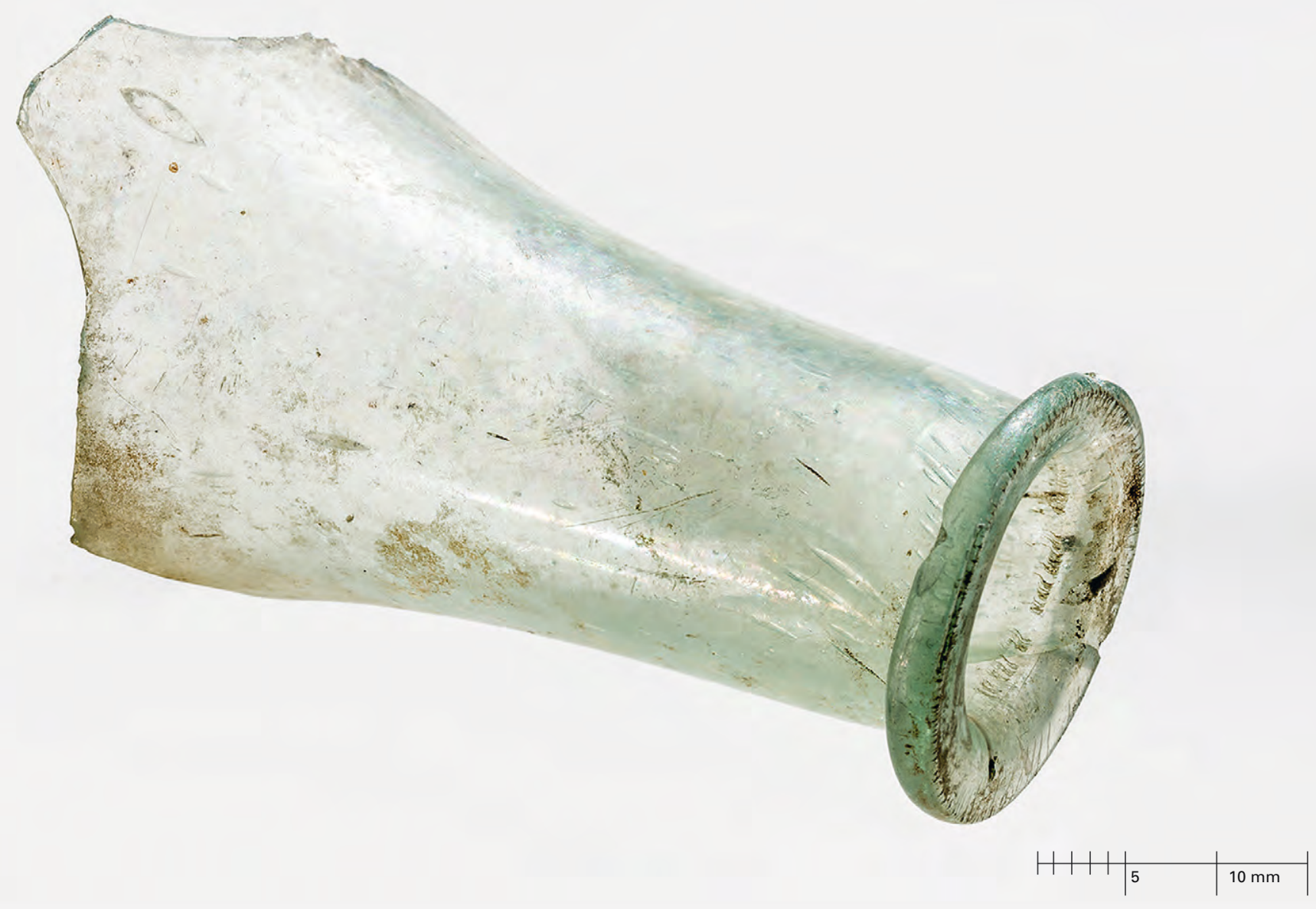



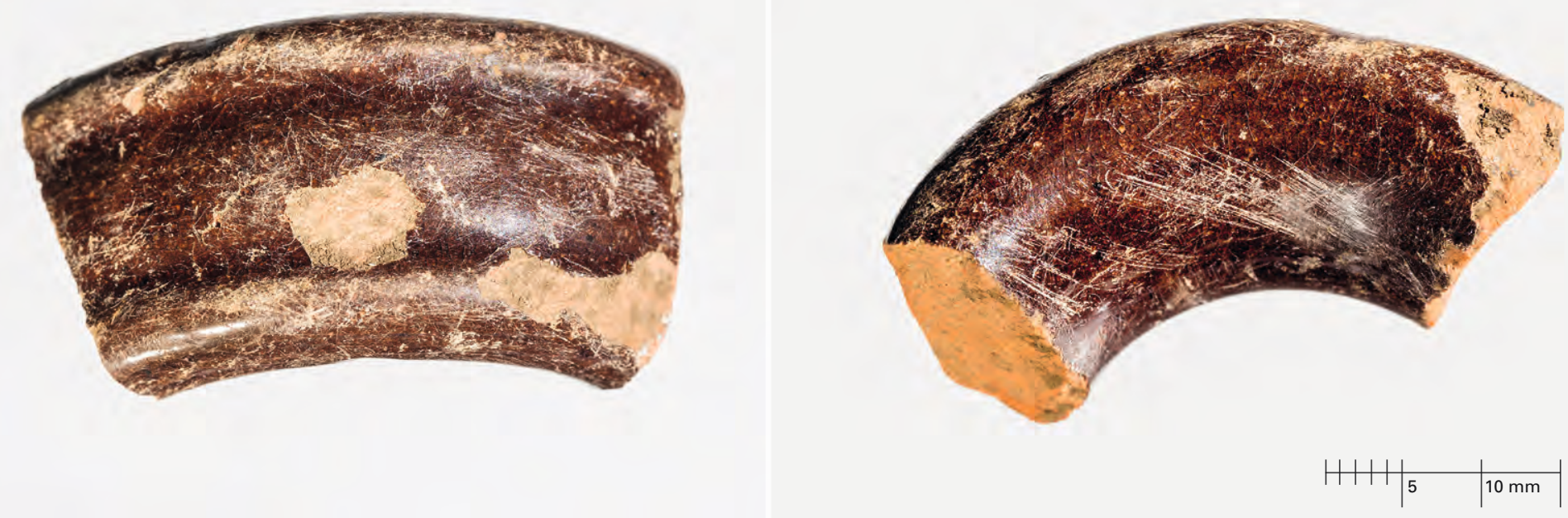

\section{Kat.-Nr. 35: Hufnagel}

Bis heute werden auf der Blackenalp Arbeitspferde gehalten - der hier vorgefundene Hufnagel könnte natürlich auch von einem Saumtier stammen (LK 1191, 681 990/186 570, 1773 m ü.M.).

Eiserner handgeschmiedeter Hufnagel mit quadratischem Kopf und rechteckigem Schaft. Länge: $43 \mathrm{~mm}$. Alter: 18. bis 20. Jahrhundert (Abb. Kat.-Nr. 35).

\section{Kat.-Nr. 36.1-5: Schindelnägel}

Die fünf Schindelnägel können eindeutig einer Kapellenrenovation zugeordnet werden. Bekannt sind Bauarbeiten in den Jahren 1919/20, 1947 und 1975 (LK 1191, 681 990/186 570, 1773 m ü.M.). ${ }^{18}$

Handgeschmiedete Schindelnägel aus Eisen mit L-förmigen Köpfen und quadratischen beziehungsweise rechteckigen Schäften. Längen: 25 bis 28 mm. Alter: 18. bis 20. Jahrhundert (Abb. Kat.-Nr. 36,1-5).

\section{Kat.-Nr. 37, 1-2: Nägel}

Auch zwei weitere Nägel dokumentieren Baumassnahmen (LK 1191, 681 990/ 186570,1773 m ü.M.).

Handgeschmiedete Nägel aus Eisen mit schmalrechteckigem/quadratischem Kopf und rechteckigem leicht gekrümmtem Schaft. Länge (gekrümmt): 87 bis 100 mm. Alter: 18. bis 20. Jahrhundert (Abb. Kat.-Nr. 37,1-2).

\section{Resultate und Vergleiche}

Das hier präsentierte Fundmaterial aus dem Gebiet entlang des Surenenpasswegs ist typisch für Lesefundinventare im Umfeld von alpinen Übergängen, wie vergleichbare Sammlungen von Albrun, Brünig, Chinzig, Alte und Neue Gemmi, Gotthard, Schnidejoch oder Simplon zeigen. In der Regel
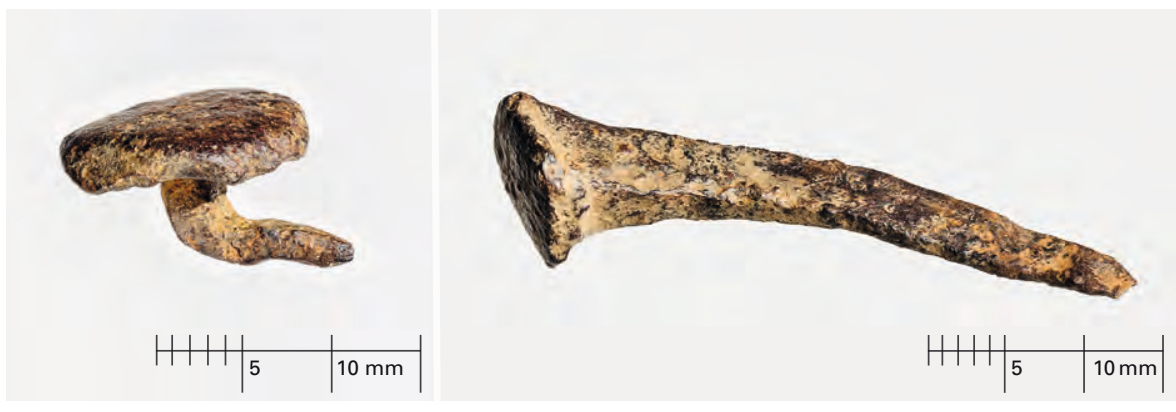

18 Sauter 2017 (im Druck).

Kat.-Nr. 33

Henkelfragment, 18. bis 19. Jahrhundert Foto M. Käch, 2015

Kat.-Nr. 34

Schuhnagel, neuzeitlich

Foto M. Käch, 2015

Kat.-Nr. 35

Hufnagel, 18. bis 20. Jahrhundert

Foto M. Käch, 2015 
19 Auf der Maur/Diaz Tabernero/ Meier Mohamed 2014, 145-197. Leuzinger 2010, 220-247. - Reitmaier 2014, 355-375. - Theune 2014.

20 Volken/Volken 2008, 391-396.

21 Suter/Hafner/Glauser 2005, 515. - Rageth/Zanier 2010, 241-283. Volken 2011, 315-388.

22 Nagy/Schwarz 2015, 172, Anm. 7. dominieren Metallobjekte, weil diese mithilfe des Metalldetektors leicht zu finden sind. Deutlich schwieriger ist das Aufspüren von Objekten aus Stein, Keramik, Knochen, Glas oder Holz. Je nach geologischem Untergrund sind gewisse Artefaktkategorien erhaltungsbedingt untervertreten oder fehlen sogar vollständig. Im sauren, kristallinen Bodenmilieu konservieren sich beispielsweise Faunenreste sehr schlecht.

Folgende Kategorien sind im Fundmaterial vertreten: Abfall, Speisereste, Verlustfunde, Militaria, Weihegaben und Bauschutt. Eine strikte Trennung zwischen Weihegaben und Verlustfunden ist nicht möglich. Die vorliegenden Schmuckstücke und Münzen dürften jedoch mehrheitlich bewusst deponiert worden sein. Dafür spricht die Konzentration im Umfeld der Blackenalpkapelle. Vermutlich befand sich an dieser Stelle bereits in vorchristlicher Zeit ein sakraler Ort, der mit dem Bau der Kapelle christianisiert wurde.

Das Fundmaterial vom Surenenpassweg umfasst eine Zeitspanne von der Bronzezeit bis gestern. Wo genau man die chronologische Grenze für archäologische Bodenfunde zieht, ist umstritten beziehungsweise unscharf. Soll man die zahlreichen Patronenhülsen und Munitionsreste der Schweizer Armee erwähnen oder den Abfall gedankenloser Wanderer? Einige Verpackungen wie Fleischkonserven, Flaschenverschlüsse oder Wurstringchen sind mittlerweile typologisch bereits nicht mehr handelsüblich oder deren Verklappung unter einem Stein nach intensivierten Umweltschutzkampagnen selten geworden. Deshalb wären diese Abfalldeponierungen eigentlich schon als charakteristische Zeitzeugen aus den ersten beiden Dritteln des 20. Jahrhunderts zu betrachten. ${ }^{19}$

Nicht weiter verwunderlich ist die relativ hohe Zahl an neuzeitlichen Schuhnägeln, die auf einem Passweg zu erwarten sind. Diese Artefaktkategorie wird in der Regel in wissenschaftlichen Publikationen stiefmütterlich behandelt, obwohl sie zusammen mit den Münzen wertvolle Hinweise auf den - allenfalls im Laufe der Zeit sich verändernden - Wegverlauf einer Passroute liefern können. ${ }^{20}$ Bei römischen Schuhnägeln ist die publizierte Datenbasis deutlich breiter. ${ }^{21}$ Auch die bei den kürzlich durchgeführten Prospektionen entlang der Brünigpassroute im Kanton Obwalden zahlreich gefundenen, eisernen Schuhnägel fanden in der Literatur bislang nur am Rande Erwähnung. ${ }^{22}$

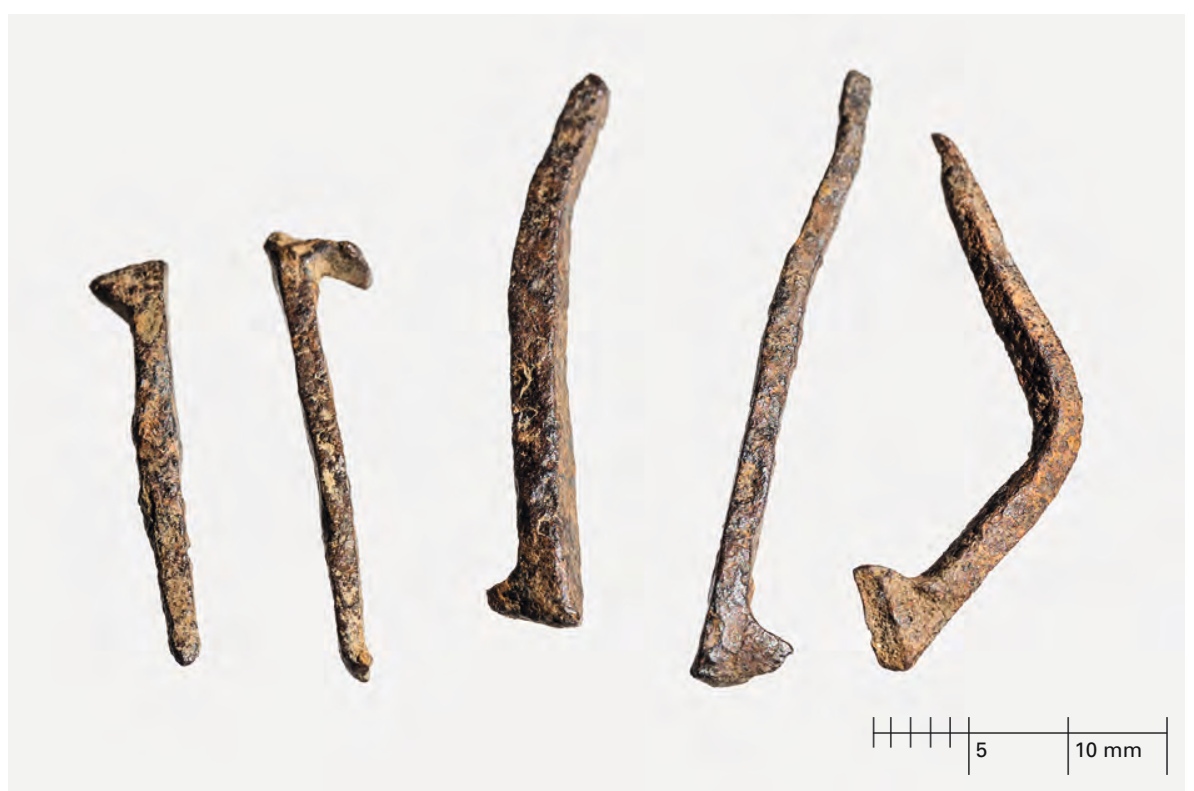

Kat.-Nr. 36, 1-5

Schindelnägel, 18. bis 20. Jahrhundert Foto M. Käch, 2015 


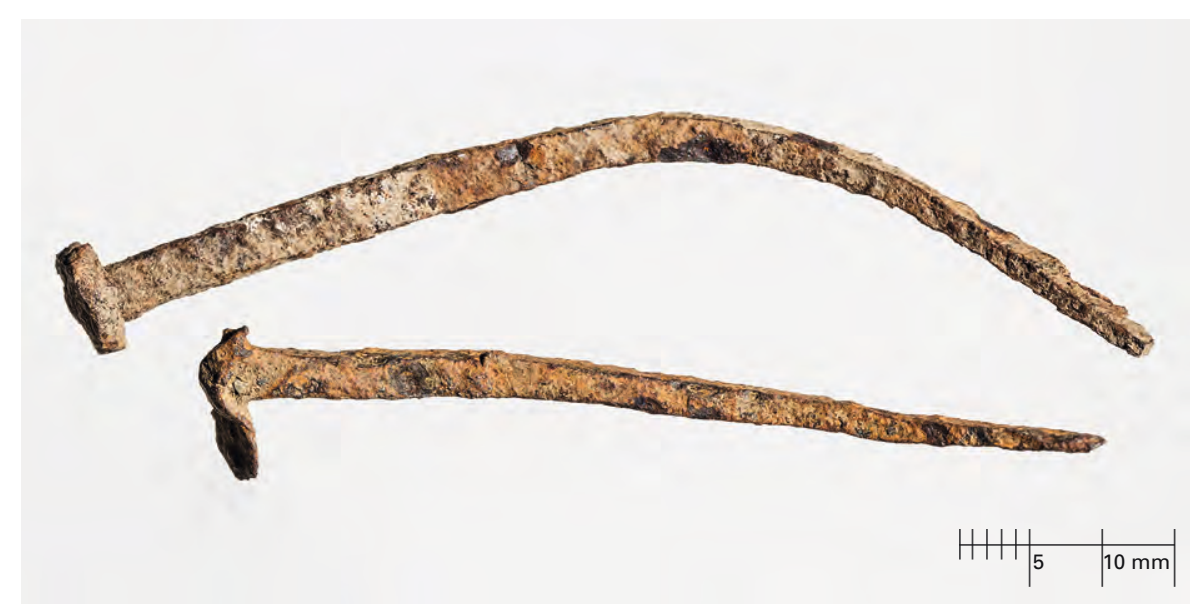

Die wenigen Faunenreste sind alle relativ jung zu datieren, da der Bodenchemismus für Tierknochen im Untersuchungsgebiet nicht optimal ist. Die Mehrzahl der in den Sondierungen geborgenen Knochen stammt von kleinen Wiederkäuern wie Schafen oder Ziegen. Aufgeschlagene Exemplare sprechen dafür, dass man neben dem Fleisch auch das fettreiche Mark konsumierte.

Agola, R. / Hochuli, S. (2014). Vom Schatzjäger zum Experten. Ein Bericht über dreissig Jahre Metalldetektor-Prospektion in der Schweiz (1983-2013). In: Tugium 30, 95-102.

Auf der Maur, C. / Diaz Tabernero, J. / Meier Mohamed, G. (2014). Archäologische Spuren einer Kulturlandschaft. Zur Nutzung und Begehung des Urserntals bei Hospental seit dem Mittelalter. In: Historisches Neujahrsblatt Altdorf, 125-197.

De Palézieux-du Pan, M. (1909). Numismatique de l'Evêché de Sion. Genf. Deschler-Erb, E. (1996). Die Kleinfunde aus Edelmetall, Bronze und Blei. In: Beiträge zum römischen Oberwinterthur - Vitudurum 7. Ausgrabungen im Unteren Bühl. Monographien der Kantonsarchäologie Zürich 27. Zürich/Egg, 13-139.

Divo, J.-P. / Tobler, E. (1969). Die Münzen der Schweiz im 19. und 20. Jahrhundert. Zürich/Luzern.

Divo, J.-P. / Tobler, E. (1987). Die Münzen der Schweiz im 17. Jahrhundert. Mit einem geschichtlichen Überblick von Prof. Dr. Boris Schneider. Zürich.

Hochuli, S. (1998). Weihe- und Verwahrfunde: Depots und Einzelfunde. In: Hochuli, S. / Niffeler, U . / Rychner, V. (Hrsg.). Die Schweiz vom Paläolithikum bis zum frühen Mittelalter, SPM III, Bronzezeit. Basel, 327-336.

Leuzinger, U. (2010). Neuzeitarchäologie. In: Benguerel, S. / Brem, H. / Hasenfratz, A. et al. (Hrsg.). Archäologie im Thurgau. In: Archäologie im Thurgau 16. Frauenfeld, 220-247. Leuzinger, U. / Sauter, M. / Haas, J.N. et al. (2014). Eine hallstattzeitliche Gebäudestruktur auf 1911 m ü.M. am Weg zum Surenenpass, Attinghausen UR, Siedlungsplatz Geissrüggen. In: Jahrbuch Archäologie Schweiz 97, 153-168.

Leuzinger, U. / Sauter, M. / Haas, J.N. et al. (2015). Spätmittelalterliche und neuzeitliche Alpnutzung zwischen Surenenpass und der Blackenalp, Gemeinde Attinghausen UR. In: Jahrbuch Archäologie Schweiz 98, 145-153.

Lohner, C. (1846). Die Münzen der Republik Bern. Zürich.

Mitchiner, M. (1988). Jetons, Medalets and Tokens. The Medieval Period and Nuremberg (Bd. 1). London.

Nagy, P. / Schwarz, P.-A. (2015). Archäologische Prospektionen im Brüniggebiet. Vorbericht zur Prospektionskampagne 2014 in Lungern OW und Meiringen BE. In: Jahrbuch Archäologie Schweiz 98, 154-174.
Kat.-Nr. 37, 1-2

Nägel, 18. bis 20. Jahrhundert

Foto M. Käch, 2015 
Pászthory, K. (1985). Der bronzezeitliche Arm- und Beinschmuck in der Schweiz. In: Prähistorische Bronzefunde, Abteilung X, 3. München.

Primas, M. / Della Casa, P. / Schmid-Sikimić, B. (1992). Archäologie zwischen Vierwaldstättersee und Gotthard. Siedlungen und Funde der ur- und frühgeschichtlichen Epochen (= Universitätsforschungen zur prähistorischen Archäologie 12). Bonn.

Rageth, J. / Zanier, W. (2010). Crap Ses und Septimer: Archäologische Zeugnisse der römischen Alpeneroberung 16/15 v.Chr. aus Graubünden. In: Germania 88, 241-283.

Reitmaier, T. (2014). Bunker, Bomber und Baracken - Historische Archäologie in Graubünden. In: Bündner Monatsblätter. Zeitschrift für Bündner Geschichte, Landeskunde und Baukultur 4, 355-375.

Riha, E. (1990). Der römische Schmuck aus Augst und Kaiseraugst. In: Forschungen in Augst 10. Augst.

Roubik, P. (1979). Ein römischer Münzfund aus Uri. In: Helvetia Archaeologica 10, 68-75.

Sauter, M. (2009). Wüstungsforschung im Kanton Uri. Brunni- und Schächental, Haldi und Surenenpass. Altdorf.

Sauter, M. (2017, im Druck). Die Kunstdenkmäler des Kantons Uri. Schächental und Unteres Reusstal (Bd. 3). Bern.

Suter, P.J. / Hafner, A. / Glauser, K. (2005). Lenk - Schnidejoch. Funde aus dem Eis - ein vor- und frühgeschichtlicher Passübergang. In: Archäologie im Kanton Bern 6. Bern, 499-522.

Theune, C. (2014). Archäologie an Tatorten des 20. Jahrhunderts. In: Archäologie in Deutschland, Sonderheft 6. Stuttgart.

Volken, M. (2011). Les clous de chaussures du site de Pfyngut: les bases d'une typochronologie. In: Paccolat, O. (Hrsg.). Pfyn/Finges. Evolution d'un terroir de la plaine du Rhône. Le site archéologique de "Pfyngut" (Valais, Suisse). In: Cahiers d'archéologie romande 121. Archaeologia Vallesiana 4. Lausanne, 315-388.

Volken, S. / Volken, M. (2008). Les clous de chaussures, témoins du cheminement des voyageurs. In: Wiblé, F. (Hrsg.). Alpis Poenina. Grand Saint-Bernard. Une Voie à Travers I'Europe. Aosta, 391-396.

Von Reding-Biberegg, R. (1895). Der Zug Suworoff's durch die Schweiz (24. Herbstbis 10. Weinmonat 1799). In: Der Geschichtsfreund 50, 1-184. 


\section{Summary: Micromorphological examinations at a Hallstatt-period settlement site}

During the excavations carried out at a Hallstatt-period building at Geisrüggen in Attinghausen in the summer of 2013 the architectural feature had yielded areas with charcoal concentrations, horizontally aligned sandstone slabs and grey soil marks which had been interpreted as hearths with remnants of ash. In order to obtain more detailed information on the layer formation and on the construction and occupation surfaces, two oriented soil samples were taken for micromorphological analysis. The thin sections prepared specifically for this optical method of analysis were examined under the microscope. The results showed that soil formation processes such as freeze-thaw cycles had had a very strong impact on the archaeological layers at this elevation (1911 $\mathrm{m}$ a.s.l.) and had obliterated many traces. Nevertheless, the micromorphological analyses allowed us to recognise certain, more compact areas at some levels, where concentrations of microcharcoal and horizontally aligned gravel suggested that they had been used by humans at some stage in the past. Remnants of ash from hearths did not survive in the acidic conditions and the localised grey soil marks in the sediment had occurred due to soil formation processes in the brown earth, caused by soil wetness under anaerobic conditions (pseudo-gleysation). 


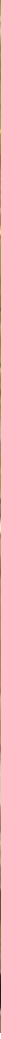

\section{Mikromorphologische Untersuchungen an einem hallstattzeitlichen Siedlungs- platz}

Während der Grabung auf dem Attinghauser Geissrüggen wurden innerhalb des hallstattzeitlichen Gebäudes zwei orientierte Bodenproben für die Mikromorphologie entnommen. Mithilfe dieser optischen Methode wollte man Hinweise auf das Bauniveau und die Aktivitätszone innerhalb der Struktur erhalten sowie die Entstehung der Schichten verstehen.

\section{Einleitung}

Im Rahmen der alpinen Wüstungsforschung im Kanton Uri fand im Sommer 2013 eine Ausgrabung in der Wüstung Siedlungsplatz Attinghausen-Geissrüggen (At.032) statt. Die Fundstelle liegt auf $1911 \mathrm{~m}$ ü.M., direkt unter dem letzten Anstieg zum Surenenpass. ${ }^{1}$ Nach dem Freilegen der verstürzten Steinsetzungen aus lokalen silikatischen Sandsteinen zeichnete sich ein annähernd rechteckiges Bauwerk mit einem Ausmass von circa 11 x 8,5 m ab. ${ }^{2}$ Während der Grabung kamen innerhalb der Mauern direkt unter dem Humushorizont mehrere auffällige Befunde zum Vorschein, die vermutlich die letzten Spuren von Siedlungsaktivitäten darstellen. Es waren einerseits lokal begrenzte, grau gefärbte Bereiche im Boden, die während der Grabung als ehemalige Feuerstellen mit Resten von Aschelagen angesprochen wurden. Anderseits trat ein mächtiges, mit einigen Holzkohlenstücken durchsetztes Lehmpaket zutage, das nahezu durchgehend in der Fläche vorhanden war. Es stellte sich die Frage, ob dies ein eingebrachter Lehmboden sein könnte oder ob es sich dabei um natürlich verlagerten Lehm handelt.

Sauter 2009, 62-63.

2 Leuzinger/Sauter/Haas et al. 2014, 158.

3 Leuzinger/Sauter/Haas et al. 2014, 157.
Unterhalb dieses Lehmpaketes konnte zudem ein Niveau gefasst werden, das mit horizontal gelagerten Steinplatten belegt war und während der Grabung als konstruierter Boden mit Gehniveau interpretiert wurde. ${ }^{3}$ 


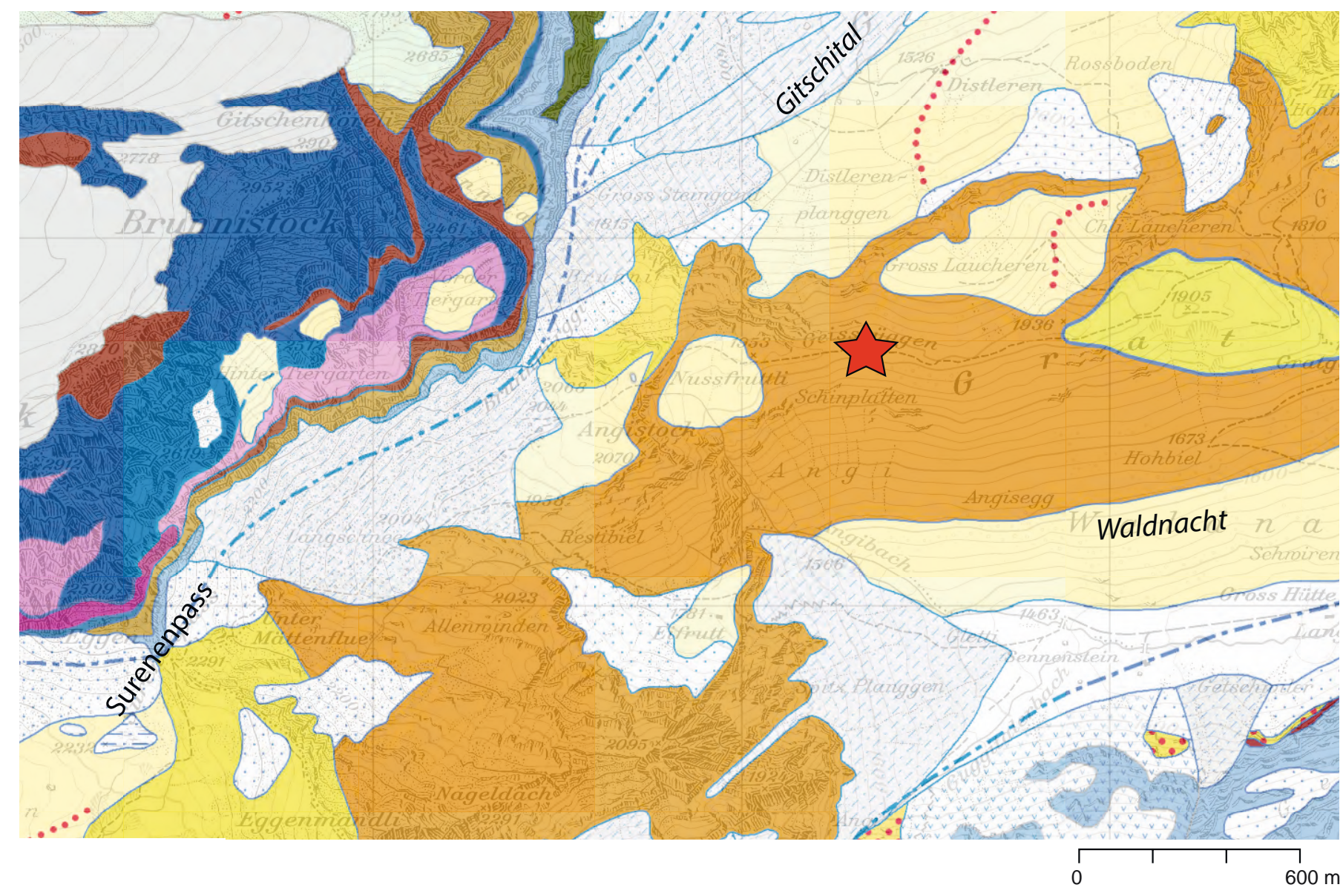

Infrahelvetikum: Nordhelvetischer Flysch, undiff. sandsteindominierte Abfolgen

(Elm-Formation bzw. «Sandstein-Dachschiefer Komplex», kann auch Taveyannnaz-Sandstein enthalten). Mergelschiefer, Kalkphyllite.

Infrahelvetikum: Nordhelvetischer Flysch, undiff., meist schieferdominiert. Enthält u.a.

Taveyannaz-Sst., Altdorfer Sst., Stad-Schiefer

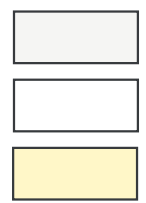

Quartär: gemischter Schuttkegel

Quartär: Moräne

Quartär: Moräne

$\begin{array}{ccc}0 & 0 \\ 0 & 0 & 0\end{array}$ Parautochthon: neritisches Eozän (Hohgant-Formation)

Parautochthon: Quinten-Formation
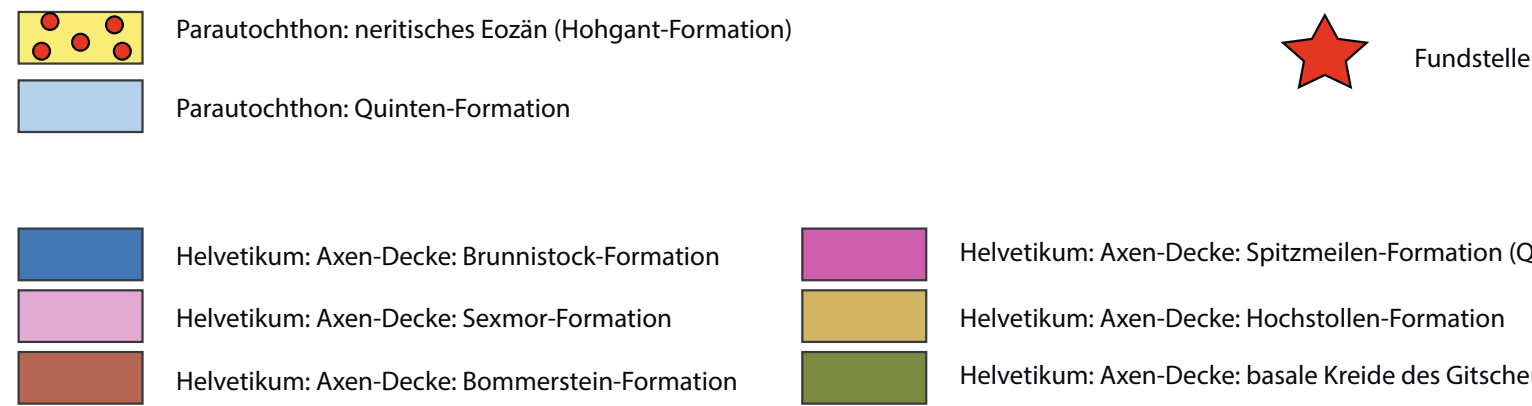

Helvetikum: Axen-Decke: Brunnistock-Formation

Helvetikum: Axen-Decke: Sexmor-Formation

Helvetikum: Axen-Decke: Bommerstein-Formation

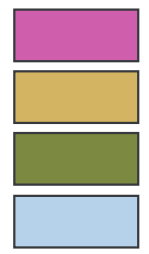

Helvetikum: Axen-Decke: Spitzmeilen-Formation (Quarzite)

Helvetikum: Axen-Decke: Hochstollen-Formation

Helvetikum: Axen-Decke: basale Kreide des Gitschen

Helvetikum: Axen-Decke: Quinten-Formation

Um die Prozesse rund um die Entstehung der Schichten besser zu verstehen sowie weitere Informationen zum Bauniveau oder zu Aktivitätszonen zu erhalten, wurde von den Ausgräbern eine mikromorphologische Untersuchung angeregt. Mithilfe dieser optischen Untersuchungsmethode lassen sich anhand von Dünnschliffen über das Gefüge und die Zusammensetzung der Sedimente Aussagen zur Entstehung der Schichten machen. Bis anhin fanden solche Untersuchungen an archäologischen Sedimenten alpiner Freilandsiedlungen nur selten statt. ${ }^{4}$ Umso mehr ist es eine Gelegenheit, den Bodentyp und die anthropogenen Einflüsse in dieser Höhenlage zu untersuchen.

4 Auf der Maur/Cornelissen/Brönnimann 2014, 37-83. 
Titelbild: Übersicht über die dünne, holzkohlehaltige "Ascheschicht" im Inneren der hallstattzeitlichen Gebäudestruktur - gut zu erkennen im Bereich des Nordpfeils.

Foto U. Leuzinger, 2013

Ausschnitt der geologischen Karte mit Darstellung des Fundorts.

Quelle: https://map.geo.admin.ch/

Steingerechter Grundriss des hallstattzeitlichen Gebäudes AttinghausenGeissrüggen mit Lage der Bodenproben M26 in der Fläche und M23 aus dem Profilsteg.

Zeichnung U. Leuzinger, E. Belz, ergänzt von C. Pümpin.
5 Gisler/Spillmann 2011, 73 - Labhart/Pfiffner/Spillmann et al. 2011, Beilage 1.

6 Gisler/Spillmann 2011, 72. - Labhart/Pfiffner/Spillmann et al. 2011, Beilage 1.

7 Renner/Zgraggen 2011, 109, Beilage 4.

\section{Geologischer und bodenkundlicher Abriss}

Der Fundort Siedlungsplatz Attinghausen-Geissrüggen (At.032) befindet sich in einer Zone, deren komplexe Geologie durch mehrere orogenetische Phasen (Gebirgsbildungsphasen) und grosse tektonische Deformationen geprägt ist ( $\Rightarrow$ S. 10-23). Das untersuchte Gebäude liegt auf einem Ost-West-verlaufenden schmalen Grat, dessen Felsuntergrund aus sehr stark gefalteten und steil gestellten Decken des Infrahelvetikums besteht. Die hier anstehenden Schichten des Nordhelvetischen Flyschs setzen sich aus einem dunkelgrauen bis grünlichen Sandstein zusammen. ${ }^{5}$ Weiter sind in unmittelbarer Umgebung Sandsteine der Bürgen-Formation und Mergelschichten der Stad-Mergel aufgeschlossen, die allesamt während des Eozäns und frühen Oligozäns, im marinen Flachwasser sowie im tieferen marinen Milieu abgelagert wurden. ${ }^{6}$

Im direkten Bereich der Fundstelle stehen harte, in grossen Blöcken aufwitternde Sandsteine an; ferner solche, die in relativ dünnen Platten aufbrechen, sowie mergelige Ablagerungen, die zu feinem Grus zerfallen. Die Feinstratigrafie dieser Formationen ist durch die extremen tektonischen Deformationen nur schematisch erkennbar und lässt sich in den oberflächlichen Aufschlüssen in der näheren Umgebung nicht eindeutig bestimmen. Der exponierte Grat des Geissrüggens auf 1911 m ü.M., der zur subalpinen Stufe gehört, wurde während der letzten grossen Vergletscherung bis auf den anstehenden Fels überprägt. Nach dem Abschmelzen der Gletscher blieben in der flachen topografischen Mulde der Fundstelle keine pleistozänen Ablagerungen erhalten. Glaziales Geschiebe und Alluvionen sind als schuttreiche Deckschichten erst auf einer topografisch deutlich tieferen Höhenstufe im Gitschital und im Tal von Waldnacht an den typischen geomorphologischen Strukturen erkennbar. ${ }^{7}$

Das Ausgangsgestein für die bodenbildenden Prozesse auf dem Geissrüggen war somit der anstehende Fels (C-Horizont), der hier unter anderem aus einem basenarmen, glimmerhaltigen Mergelschiefer und einem quarzreichen Sandstein besteht, auf dem sich Braunerde entwickeln konnte. Dieser Bodentyp tritt häufig in gemässigten humiden Klimazonen auf und ist

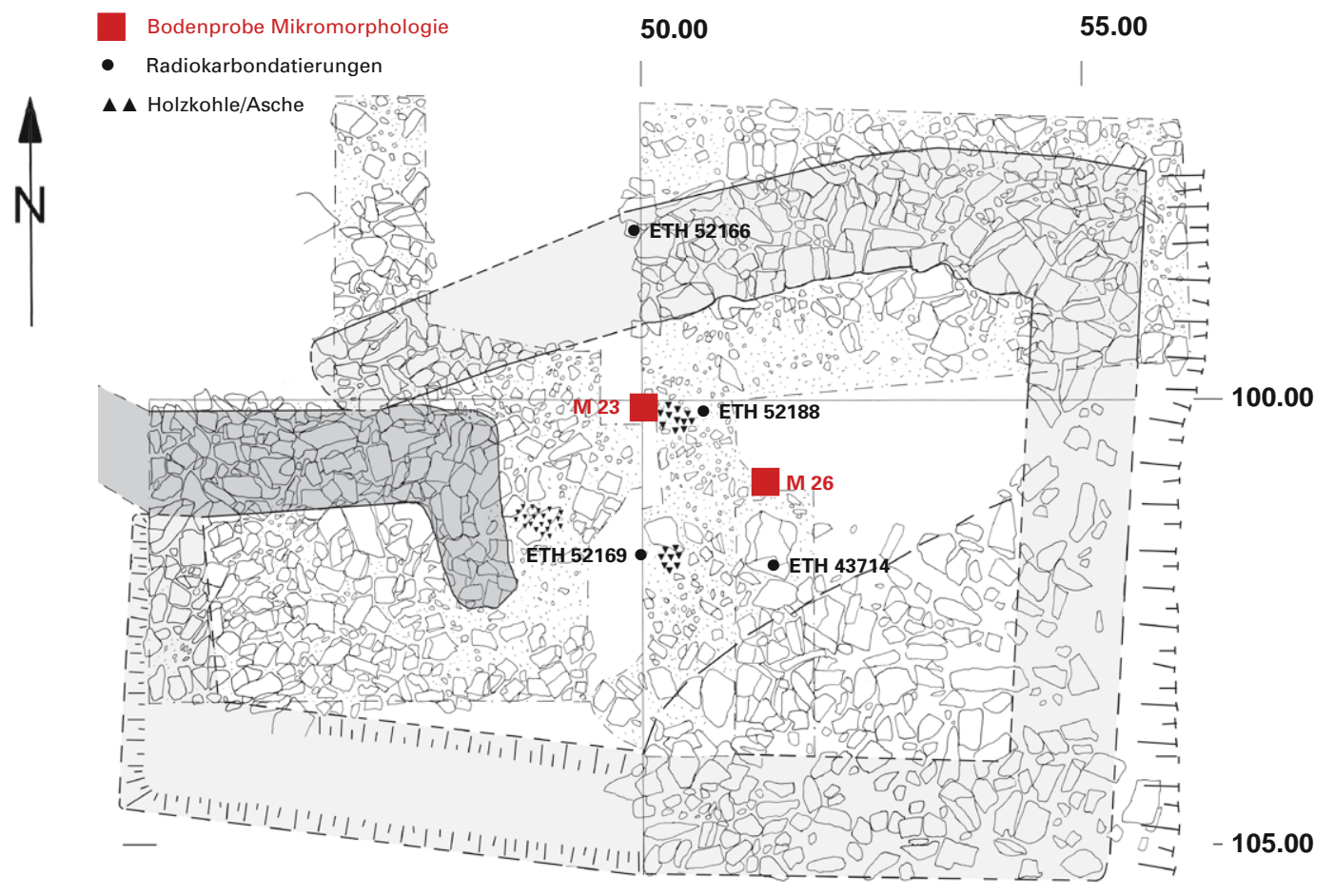




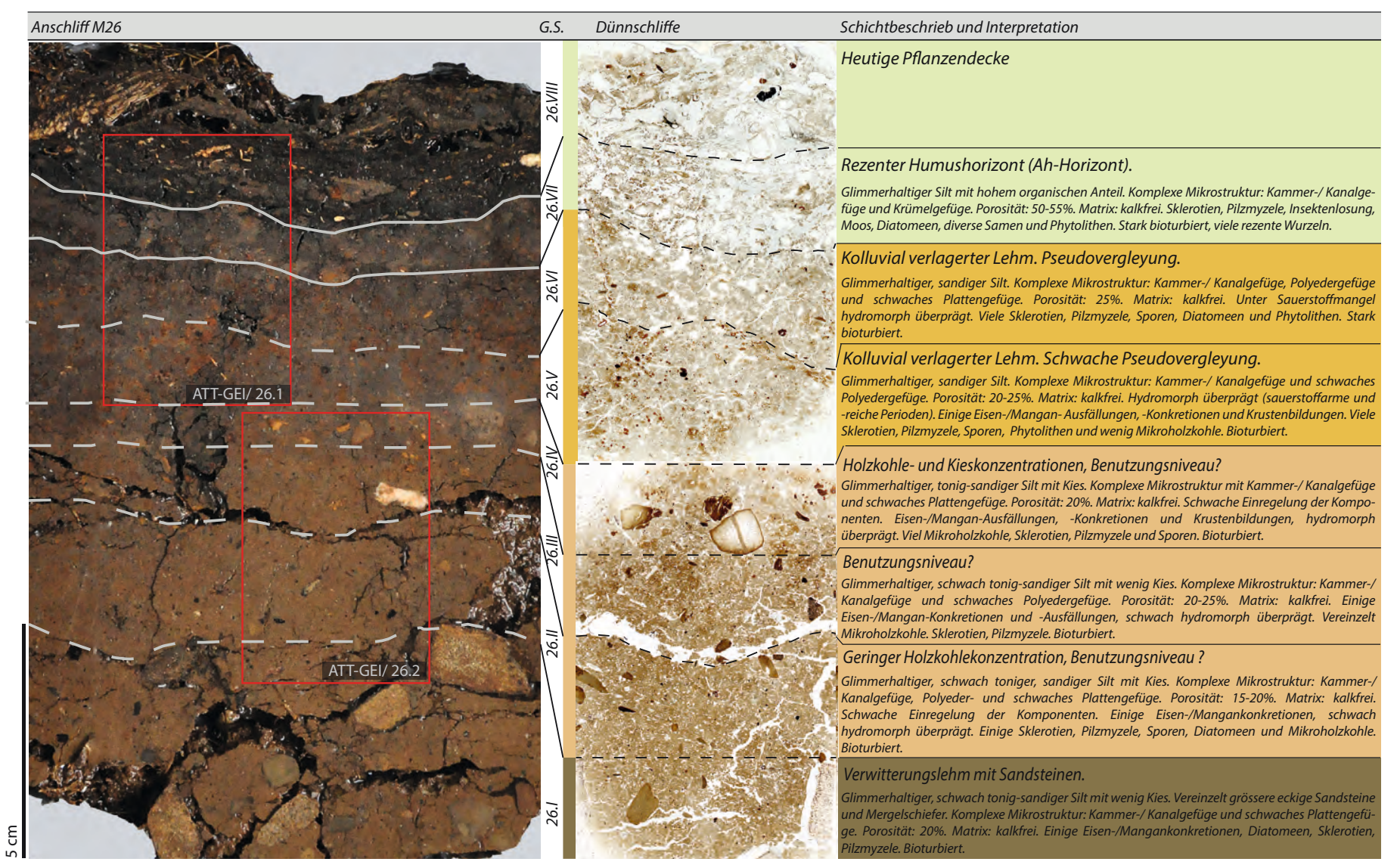

durch einen humosen Oberboden (A-Horizont) charakterisiert. Er überdeckt einen verbraunten und verlehmten Verwitterungshorizont (Bv-Horizont), der ursprünglich durch die Verwitterung des Ausgangsgesteins (C-Horizont) entstanden ist. ${ }^{8}$ Auf dem Geissrüggen führte die Verwitterung des anstehenden Gesteins zur Bildung eines orangegelben Verwitterungslehms der aus einem schwach tonigen, sandigen Silt bestand und ursprünglich eine Mächtigkeit von circa 10 bis maximal $20 \mathrm{~cm}$ aufwies. Die orange gefärbten Bereiche im Sediment sind Ausfällung von Eisen-, Mangan- und Aluminiumoxyden ${ }^{9}$, die einst vom Oberboden (A-Horizont) in die Tiefe verlagert und später durch Staunässe überprägt wurden.

Innerhalb der ausgegrabenen Gebäudestruktur lag direkt über dem anstehenden Mergelschiefer der orangefarbene Verwitterungslehm, der mit zahlreichen horizontal gelagerten Steinplatten und gelegentlich mit grösseren Holzkohlestücken durchsetzt war. Diese Schicht wurde von einem grauen, glimmerhaltigen siltigen Lehm überlagert, der eine Mächtigkeit von circa $6 \mathrm{~cm}$ aufwies und in den wiederum grössere Holzkohlestücke eingebettet waren. Darüber folgte ein 2 bis $3 \mathrm{~cm}$ mächtiger, dunkelgrau gefärbter, schwach toniger siltiger Lehm, der mit grauen und braunen siltigen Lehmaggregaten durchsetzt war und direkt unterhalb des 5 bis $10 \mathrm{~cm}$ mächtigen Humushorizontes lag. ${ }^{10}$ An gewissen Stellen konnten direkt unterhalb der Humusdecke diverse graue Zonen beobachtet werden, die eine Dicke von 2 bis $4 \mathrm{~cm}$ aufwiesen und im Rahmen der Ausgrabung als mögliche Feuerstellen mit Ascheresten angesprochen wurden. Der zum Teil direkt auf dem Verwitterungshorizont aufliegende Rohhumus (Ah-Horizont) war hauptsächlich durch eine lokale alpine Vegetation bedeckt, unter anderem mit Enzian, Wegerich, Hahnenfuss, Germer, Farn und Alpenanemone. Pflanzen wie die Brennessel, die stickstoffreiche Böden bevorzugen und als
Anschliff der Bodenprobe M26 mit den geologischen Schichten (G.S.) 26.I-26. VIII und der Position der Dünnschliffe ATT-GEI/26 sowie die tabellarisch zusammengefassten Ergebnisse der mikromorphologischen Analyse. Foto, Grafik C. Pümpin, 2016

8 Scheffer/Schachtschabel/Blume et al. 2010, 321-322. - Adhoc AG Boden 2005, 215.

9 Scheffer/Schachtschabel/Blume et al. 2010, 289, 294.

10 Leuzinger/Sauter/Haas et al. 2014, 164. 


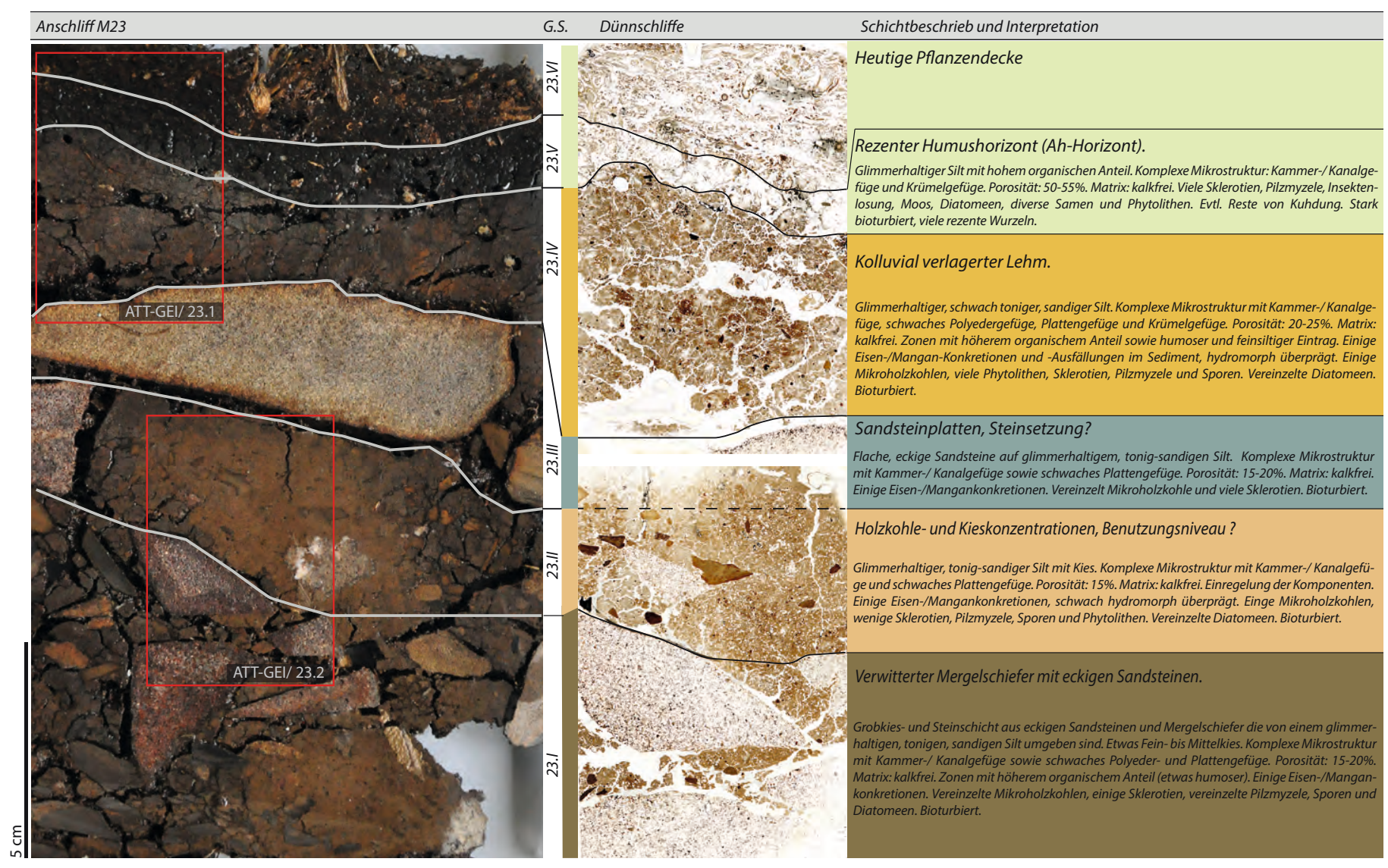

Anschliff der Bodenprobe M23 mit den geologischen Schichten (G.S.) 23.I-23.VI und der Position der Dünnschliffe ATT-GEI/26 sowie die tabellarisch zusammengefassten Ergebnisse der mikromorphologischen Analyse. Foto, Grafik C. Pümpin, 2016
Indiz für eine ehemalige alpwirtschaftliche Nutzung stehen, waren kaum vorhanden ( $\rightarrow$ S. 24-45); dies im Gegensatz zu anderen Alpwüstungen, die durch die auffälligen Bestände stickstoffliebender Pflanzengemeinschaften leicht zu erkennen sind. Das Fehlen dieser Anzeiger wurde bereits vor der Ausgrabung als Argument für ein erhebliches Alter dieser Struktur in Betracht gezogen.

Schon vor der archäologischen Untersuchung war direkt im Bereich des vermuteten Gebäudegrundrisses eine flache Geländemulde erkennbar. Für die Bewertung der mikromorphologischen Befunde stellte sich die Frage, inwieweit der Verwitterungslehm direkt vor Ort entstanden war oder ob dieser von den Rändern in die natürliche Senke eingeschwemmt oder als künstlicher Bodenbelag für das Gebäude eingebracht wurde. Somit war es wichtig, nicht nur Informationen zum möglichen Bauniveau der Struktur zu erhalten, sondern darüber hinaus auch zur Intensität der Nutzung des Gebäudes. Auch die grauen Zonen unterhalb des Humushorizontes, die vor Ort als mögliche Feuerstellen angesehen wurden, standen im Fokus der Untersuchungen. Deshalb wurde während der Ausgrabungen im Innern des Bauwerks die vollständige Abfolge der Schichten dokumentiert und anschliessend wurden zwei Bodenproben für mikromorphologische Untersuchungen entnommen.

\section{Methodik}

Die im Rahmen der Ausgrabung in Kunststoffboxen provisorisch gesicherten Sedimentproben (M26 und M23) wurden am Institut für Prähistorische und Naturwissenschaftliche Archäologie (IPNA) der Universität Basel während zwei Monaten bei Raumtemperatur im Keller schonend getrocknet, um Schwundrisse zu vermeiden. Die beiden Blöcke mit einer Grösse von 


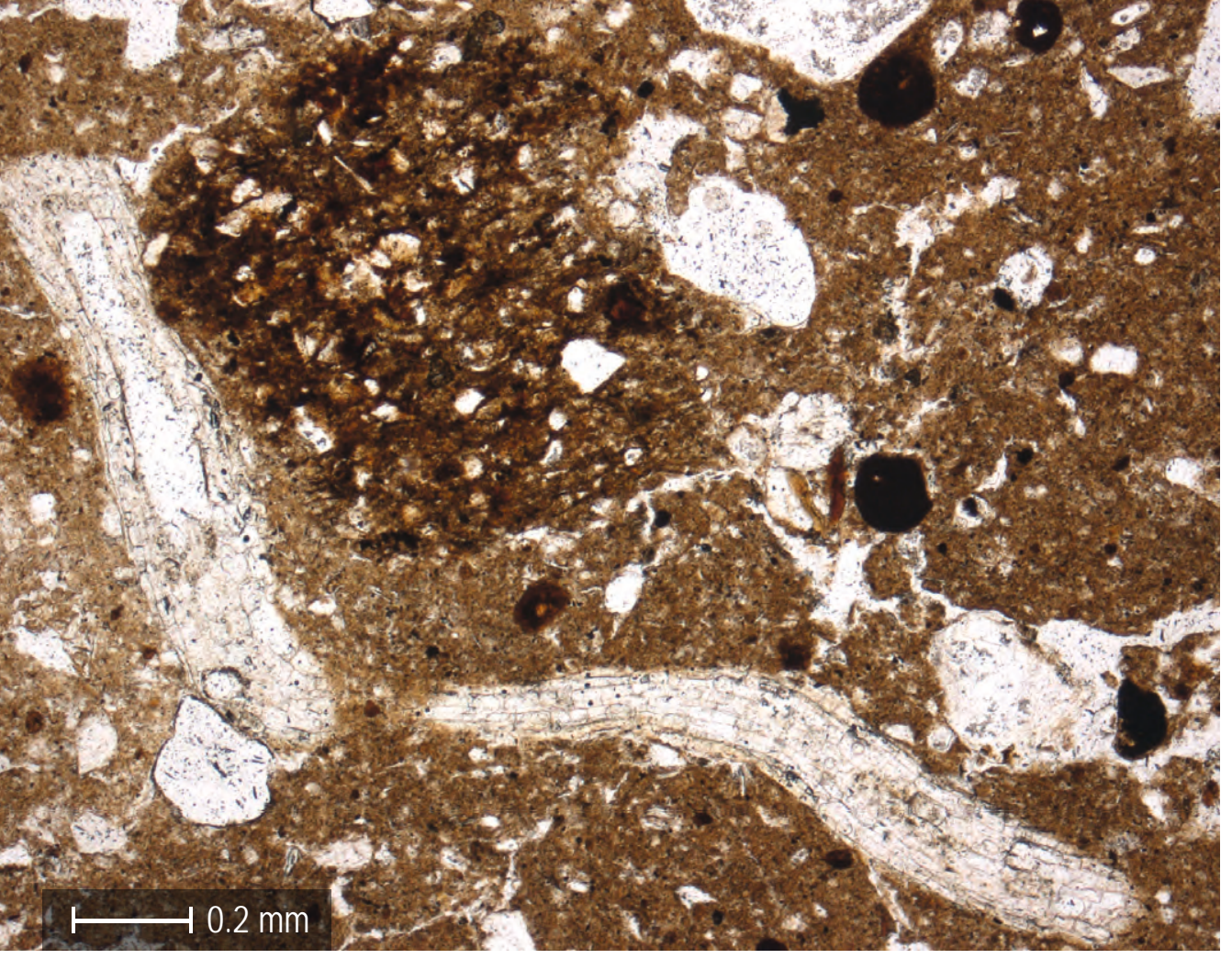

jeweils $20 \times 12 \times 10 \mathrm{~cm}$ wurden anschliessend unter Vakuum mit einem dünnflüssigen Kunstharz getränkt und nach dessen vollständiger Aushärtung mit einer Diamantsäge in mehrere dünne Tranchen von circa $1,5 \mathrm{~cm}$ Dicke aufgetrennt. An den polierten Anschliffen konnte an geeigneten Stellen entsprechend der Fragestellung die Lage der zukünftigen Dünnschliffe bestimmt werden. Insgesamt wurden vier rechteckige Blöcke der Grösse $6,5 \times 4,5 \mathrm{~cm}$ aus dem Anschliff herausausgesägt und für die Herstellung von Dünnschliffen an das Labor Geoprep der Universität Basel übergeben. ${ }^{11}$ Die Analyse und Interpretation der Dünnschliffe fanden mittels Binokular sowie Polarisationsmikroskop statt. Der Beschrieb der Sedimente wurde nach den gängigen Richtlinien der Mikromorphologie durchgeführt. ${ }^{12}$

\section{Die Schichtabfolge innerhalb des rechteckigen Bauwerks}

Die Beobachtungen der Dünnschliffanalyse werden im Folgenden zusammenfassend für beide Bodenproben, in stratigrafischer Reihenfolge von unten nach oben, vorgestellt. Die Schichtnummerierung wurde nach den geologischen Beobachtungen an den An- und Dünnschliffen definiert.

\section{Der zentrale Bereich des Gebäudes - Bodenprobe M26}

Um den Aufbau der Schichten innerhalb des Gebäudes zu verstehen, wurde aus dem zentralen Bereich der Struktur die Bodenprobe M26 entnommen. Die Untersuchungen des Sediments erlaubten eine Unterteilung der Ablagerungen in acht verschiedene Niveaus. Das natürliche Ausgangsgestein (C-Horizont) wurde bei der Entnahme der Bodenproben nicht gefasst.

Bei der tiefsten der beprobten Schichten (Schicht 26.I) handelt es sich um einen glimmerhaltigen, schwach tonigen Silt, der mit Sand und etwas Kies durchsetzt ist. Die Herkunft des Sandes sowie des Glimmers ist in der Verwitterung des lokalen Sandsteins zu sehen. Das mehrheitlich kantige Kiesmaterial besteht unter anderem aus lokalem Sandstein sowie aus Mergelschiefer. Trotz einer Porosität von circa $20 \%$ finden sich in diesem kalkfreien Sediment Eisenausfällungen in Form von runden Konkretionen sowie orangefarbene Verfärbungen, was deutlich auf Staunässe hinweist.
Detailansicht der Schicht 26.I mit einer rezenten Wurzel (gelbe Pfeile). Deutlich erkennbar sind die Zellstrukturen der Pflanze. (ATT-GEI/26.2, Durchlichtaufnahme ppl).

Foto C. Pümpin, 2016
11 An dieser Stelle sei W. Tschudin für die Herstellung der Dünnschliffe gedankt. - Beckmann 1997.

12 Bullock/Fedoroff/Jongerius et al. 1985. - Courty/Goldberg/Macphail 1989. - Goldberg/Macphail 2006. 
Detailansicht der Schicht 26.I mit feinen, länglichen horizontalen Porenräumen (rote Pfeile). In der Bildmitte liegt waagrecht ausgerichtet ein Grobsandkorn aus dunklem Mergelschiefer (ATT-GEI/26.2, ppl).

Foto C. Pümpin, 2016

Gleicher Bildausschnitt wie oben mit gekreuzten Polarisationsfiltern. In Schwarz sind die Porenräume deutlich erkennbar. Die grauen oder weissen Komponenten sind Quarzkörner, bei den dunkelbraunen Komponenten (gelbe Pfeile) handelt es sich um Eisen-/Mangankonkretionen (ATT-GEI/26.2, xpl).

Foto C. Pümpin, 2016

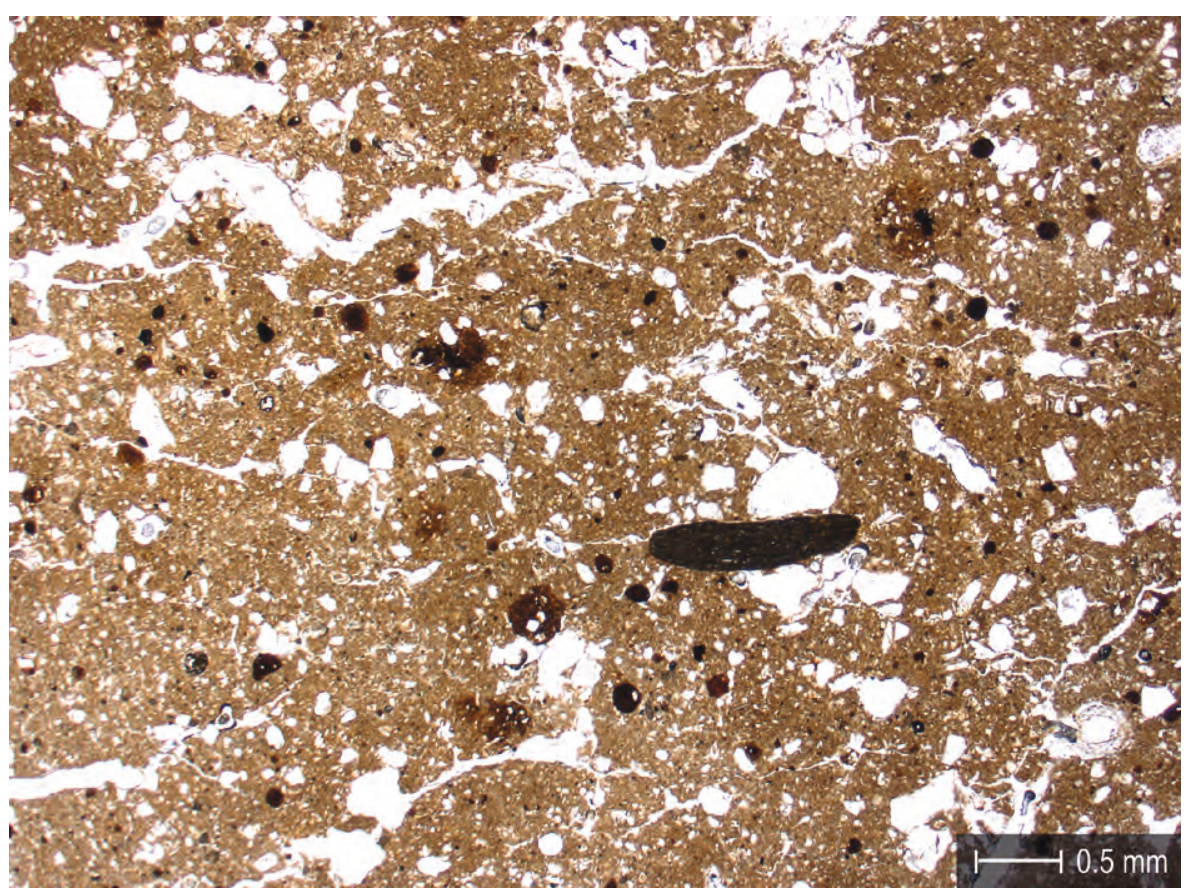

Ein Teil der Porenräume ist durch die Aktivität von Bodenfauna und rezenten Wurzeln entstanden. Diese zum Teil moderne Bioturbation hat vermutlich auch zur Verlagerung von Pilzmyzelien und Sklerotien (Kapseln mit Pilzsporen) aus den darüberliegenden Schichten geführt, die immer wieder in kleiner Anzahl in diesem Bereich des Sediments auftreten. Sie tragen zur Humusbildung bei und sind eigentliche Anzeiger für den Oberboden. ${ }^{13}$ In diesem Niveau kommen zudem längliche und horizontale Porenräume vor. Sie können sowohl durch Frost als auch durch Begehung (trampling) entstehen. ${ }^{14}$

Die Obergrenze zur Schicht 26.II ist fliessend und lässt sich einzig durch eine schwache Abnahme der Porosität und eine Zunahme an Sklerotien und Pilzsporen fassen. Die Anwesenheit von vereinzelten Kieselalgen (Diatomeen) im Sediment kann auf einen zunehmenden Grad von Nässe im

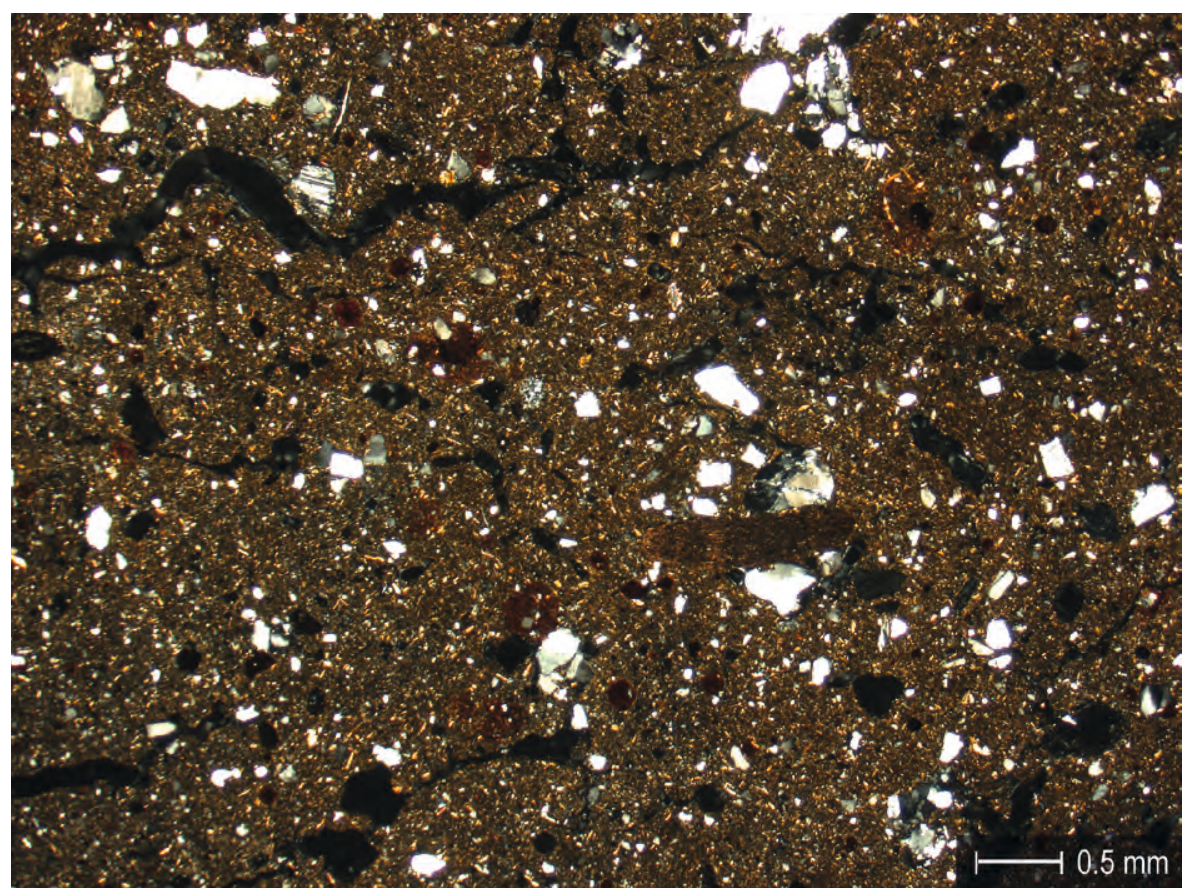

13 Babel 1975, 402. - Stoops 2003 Fig. 60.71.

14 Van Vliet-Lanoë 1985, 133. - Rentzel/ Narten 2000, 10. 

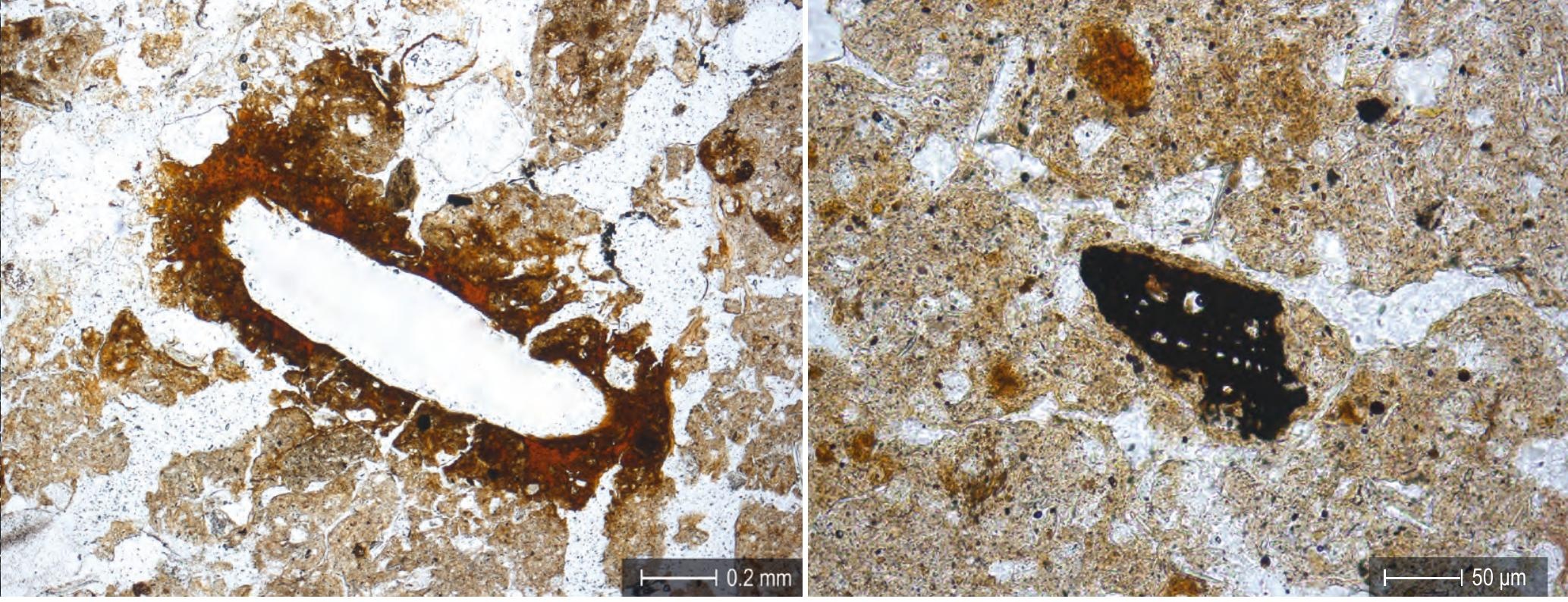

Detailaufnahme einer orangebraunen Eisen-/Mangankruste entlang eines Porenraumes in Schicht 26.IV (ATTGEI/26.2, ppl).

Foto C. Pümpin, 2016

Detailansicht einer Mikroholzkohle aus der Schicht 26.IV (ATT-GEI/26.2, ppl) in der Bildmitte.

Foto C. Pümpin, 2016
15 Scheffer/Schachtschabel/Blume et al. 2010, 294.
Bodens. ${ }^{15}$ Die markante Konzentration an Eisen- und Manganausfällungen sowie die Bildung von Eisen-/Mangankonkretionen sind typische Anzeiger für wechselfeuchte Phasen. Zusätzlich sind auch hier entlang von Porenräumen Eisen-/Mangankrusten zu erkennen. Im glimmerhaltigen, sandigen Silt sind vereinzelte pflanzliche Bestandteile aus Silikat, sogenannte Phytolithen, von subfossilen Pflanzen verteilt. Zudem sind wenige Mikroholzkohlen und vermehrt Oberbodenanzeiger wie Sklerotien, Pilzmyzelien und Pilzsporen vorhanden. Diese Ablagerung entstand aus einer Anreicherung durch Feinsedimente und vereinzelte verrundete Lehmaggregate, die ursprünglich kolluvial von den Rändern in die Mulde verlagert wurden.

Auch die darüberliegende Schicht 26. VI besteht aus kolluvial verlagertem Material und wird weiterhin von einer deutlichen hydromorphen Überprägung (Sauerstoffmangel) gekennzeichnet. In diesem Bereich nimmt die Konzentration von Eisen- und Manganausfällung deutlich ab. Die Nähe des Humushorizontes ist durch eine stärkere Durchwurzelung gekennzeichnet, was zu einer leichten Zunahme der Porosität auf 25 \% führt. Neben der Präsenz von Sklerotien und Pilzmyzelien ist in auf diesem Niveau auch ein vermehrtes Aufkommen von isolierten Phytolithen zu beobachten. Diese sind wohl durch die Verlagerung des Sediments, durch das Gefrieren und Auftauen des Bodens oder durch Bioturbationsprozesse über geringe Distanz verlagert worden. Auffallend sind auch die hier vermehrt vorkommenden Kieselalgen, die mit grosser Wahrscheinlichkeit zu den terrestrischen Arten gehören und zum Überleben kein stehendes Gewässer benötigen.

Mit einer starken Durchwurzelung von rezenten Pflanzen und einer $\mathrm{Zu}$ nahme der Porosität auf über 50 \% ist der Übergang zum modernen Humushorizont Schicht 26.VII deutlich erkennbar. Er zeigt ein typisches Krümelgefüge sowie Pflanzenreste von Moos, Samen von Erdbeeren und Gräsern sowie Spuren von Insekten.

\section{Der nördlichere Bereich des Gebäudes - Bodenprobe M23}

Im nordwestlichen Teil des Gebäudes wurde mit der Bodenprobe M23 ein Bereich mit einer grauen Zone unterhalb des Humushorizontes beprobt, die während der Ausgrabung provisorisch als aschenhaltiges Sediment interpretiert wurde. Insgesamt konnten im Profil sechs verschiedene geologische Niveaus beobachtet werden.

Das tiefste Niveau (Schicht 23.I), das direkt über dem Ausgangsgestein (Cv-Horizont) gefasst wurde, besteht aus grösseren, horizontal gelagerten, 
eckigen Sandsteinen, die in einen glimmerhaltigen, schwach tonigen, sandigen Silt eingebettet sind. In diesem Lehm kommen vermehrt Oberbodenanzeiger wie Sklerotien und Pilzmyzelien vor. Zudem verleihen Bereiche mit stark abgebautem organischem Material dem Niveau eine leicht humose und staubige Prägung. Die Ausfällungen von Eisen- und Mangankonkretionen und das Vorhandensein von vereinzelten Kieselalgen weisen darauf hin, dass das Sediment über längere Zeit einer gewissen Feuchtigkeit (Staunässe) ausgesetzt war. Vereinzelt sind auch Mikroholzkohlen nachweisbar.

Anders sieht es im darüberliegenden Niveau (Schicht 23.II) aus, wo grössere Holzkohlestücke vorhanden sind und vermehrt auch Mikroholzkohlen vorkommen. Das Sediment ist ähnlich zusammengesetzt wie Schicht 23.I, jedoch etwas kompakter. Es weist eine Porosität von $15 \%$ und eine schwache horizontale Einregelung der Kies- und Sandkomponenten auf. Auch treten feine horizontale Porenräume auf, was als Indiz für Begehung oder Überprägung durch Frost gedeutet werden kann. Verlagerungsprozesse im Sediment werden durch Bioturbation angezeigt, die zu einer Durchmischung mit Material aus dem Auswaschungshorizont geführt hat.

Überdeckt wird dieses Niveau durch grössere, horizontal liegende Sandsteinplatten (Schicht 23.III), die auf dem Lehm liegen, aus dem die Schicht 23.II zusammengesetzt ist. Die schwach tonige, siltige Matrix der Schicht unterscheidet sich nur durch eine höhere Porosität vom darunterliegenden Niveau mit einer zunehmenden Bioturbation sowie mangelnden horizontal eingeregelten Komponenten.

Die Steinplatten werden von einem circa $2,5 \mathrm{~cm}$ mächtigen siltigen Lehm überdeckt (Schicht 23.IV), der schwache Bodenbildungsprozesse in
Schicht 26.V mit rotbraunen Eisen-I Manganausfällungen im Sediment und Bildung von dunklen Eisen-/Mangankonkretionen (rote Pfeile) (ATT-

GEI/26.1, ppl).

Foto C. Pümpin, 2016

Gleicher Bildausschnitt wie links mit gekreuzten Polarisationsfiltern (ATTGEI/26.1, xpl).

Foto C. Pümpin, 2016

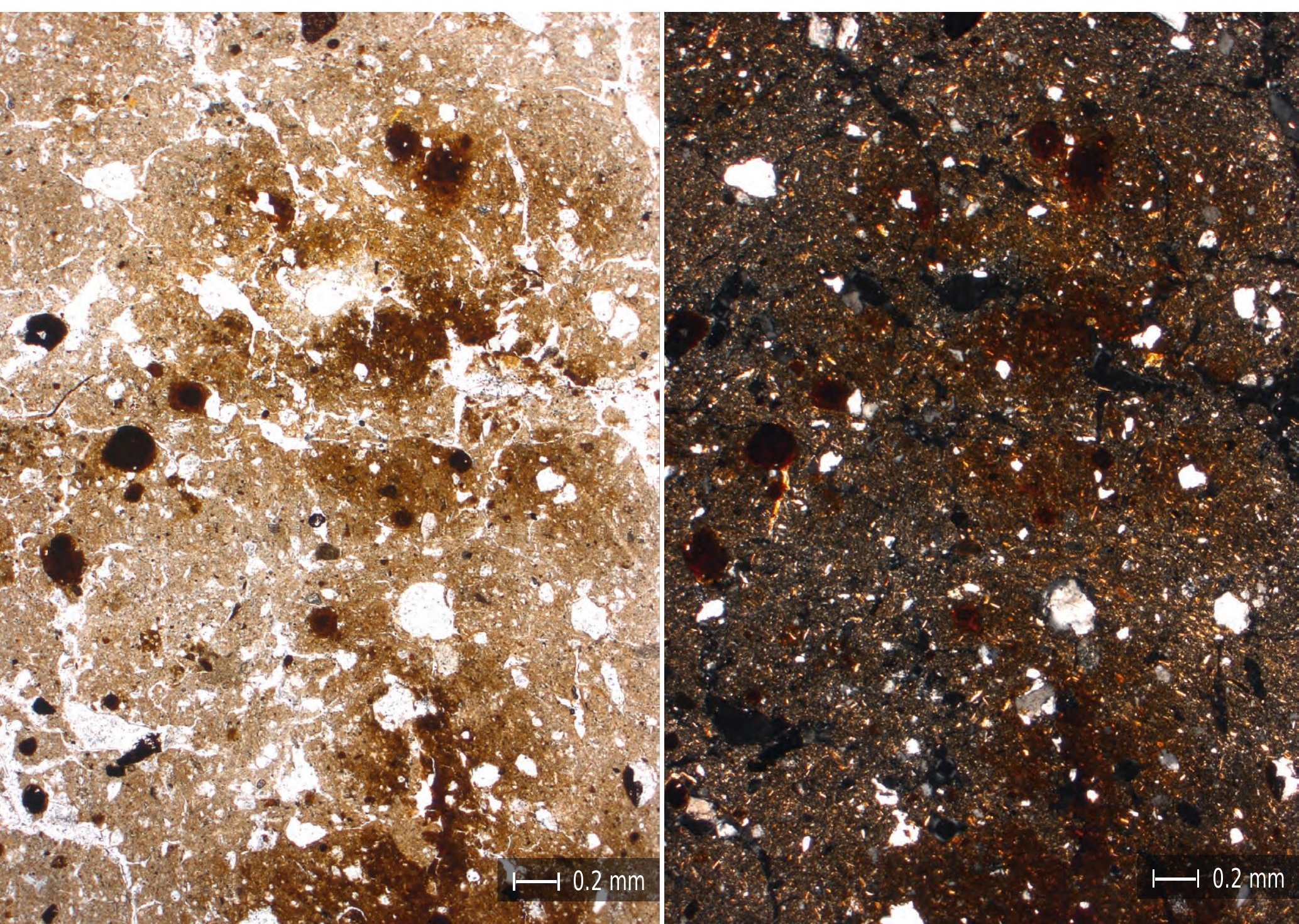


In Schicht 26.VI konnte eine Kieselalge (Diatomee) dokumentiert werden (ATTGEl/26.1, ppl).

Foto C. Pümpin, 2016

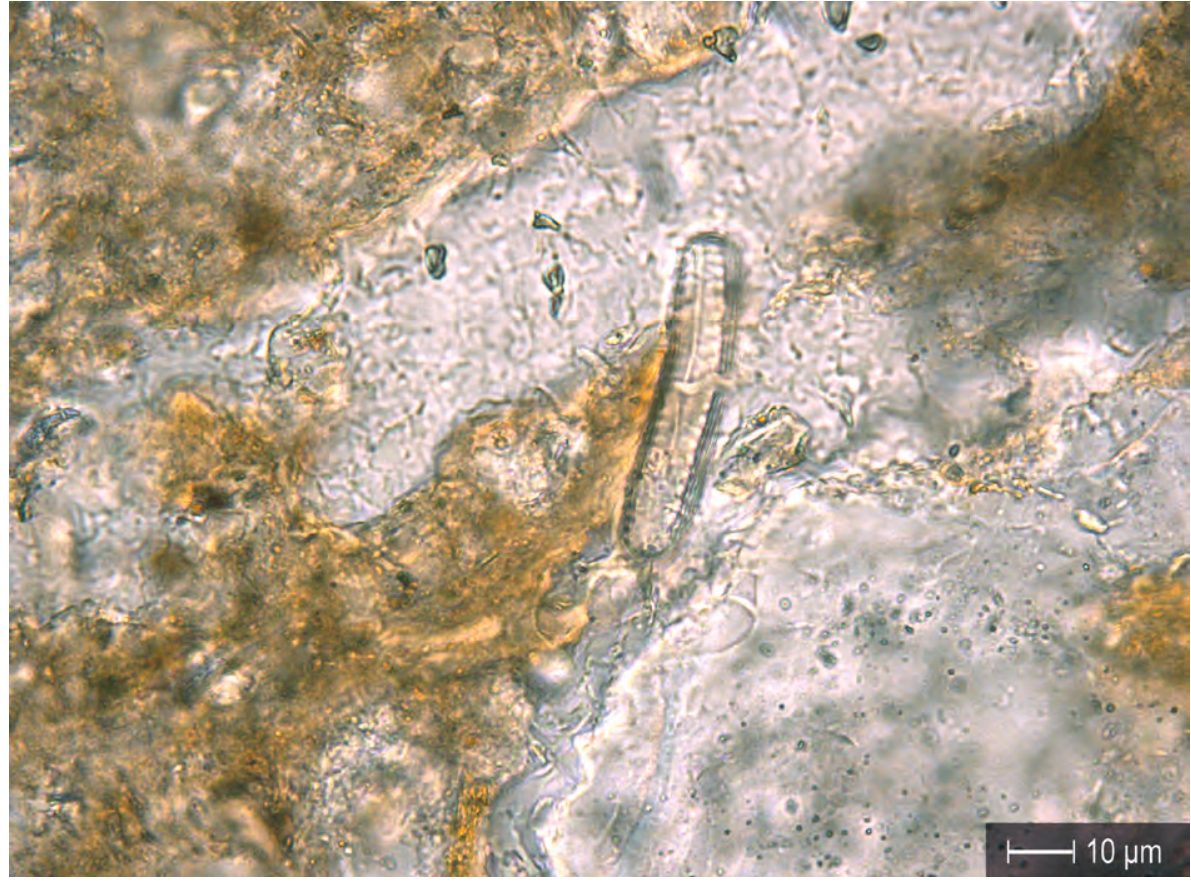

Form von Tonauswaschung aufweist. Eine komplette Ausbleichung des Sediments hat in diesem Fall nicht stattgefunden, da durch die Staunässe braunrötliche Ausfällungen von Eisen und Mangan im Sediment entstanden sind. In diesem Niveau besitzt der Lehm ein komplexes Mikrogefüge; unter anderem beobachtet man feine, horizontal verlaufende Porenräume (Plattengefüge), die höchstwahrscheinlich durch die Einwirkung von Frost entstanden sind. Ein weiteres charakteristisches Merkmal für Gefrierund Tauprozesse sind die ovalen bis linsenförmigen Lehmaggregate. Ein schwaches Krümelgefüge, hauptsächlich im oberen Bereich der Schicht, weist auf die Nähe zum Humushorizont hin. Auch die erhöhte Porosität von 20 bis $25 \%$, als Folge der modernen Durchwurzelung, hat hier zu einem typischen Gefüge von Kammern und Kanälen geführt. In gewissen Bereichen dieses Niveaus, das zudem vermehrt mit Mikroholzkohlen durchsetzt ist, stellt man eine deutliche Zunahme an stark degradierten organischen Komponenten und einen höheren Anteil an Feinsilt fest, was dem Sediment ein staubiges Antlitz verleiht. Dieses Material stammt zum Teil aus einem humosen Oberboden und wurde durch Regen oder Schneeschmelze schwach kolluvial verlagert.

Die beiden darüber folgenden Schichten 23.V und 23.VI gehören mit ihrer starken Durchwurzelung und der Erhaltung von organischem Material zur modernen Pflanzendecke.

\section{Fazit}

Die mikromorphologische Untersuchung der beiden Bodenproben innerhalb des Gebäudes auf dem Geissrüggen konnte keine eindeutigen Hinweise auf Nutzungsniveaus liefern. An beiden untersuchten Stellen konnten weder Reste von Lehmestrichen noch Hinweise auf Holzböden beobachtet werden, wobei Holz wohl aus der Brüstigegend herbeigeschafft hätte werden müssen ( $\rightarrow$ S. 24-45). Anhand der Dünnschliffe liessen sich auch keine eindeutigen Indizien für Begehung oder genutzte Oberflächen fassen. Es gibt jedoch Bereiche in den Schichten 26.II-IV und in Schicht 23.II mit Anreicherungen von horizontal ausgerichtetem Kies und einer Häufung 


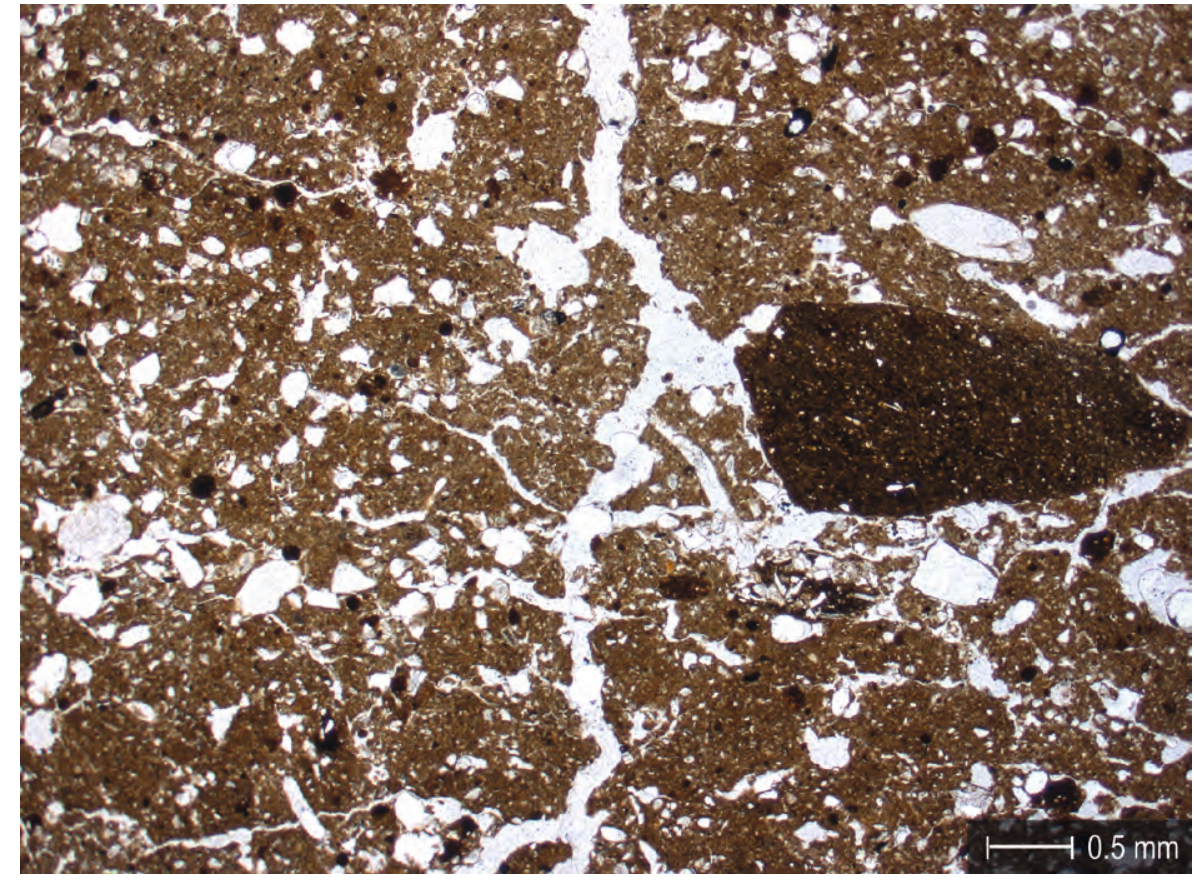

von sehr kleinen Holzkohleresten. Vereinzelt sind auch Zonen mit Bildung eines schwachen Plattengefüges, wie es für eine Begehung charakteristisch ist, vorhanden. Massgebende Hinweise für trampling, wie durch die Begehung linsenförmig ausgepresste Lehmbrocken, fehlen. Entsprechende Zonen kommen hauptsächlich in den untersten Partien der beiden Bodenproben vor. Interessanterweise liegen unterhalb dieser beiden Schichten (23.I und 26.I) horizontal ausgerichtete Steinplatten aus lokalem Sandstein, wie dies auch im Grabungsbefund über eine grössere Fläche festgestellt wurde. Da der anstehende Fels im untersuchten Gebiet aus Mergelschiefer besteht, ist anzunehmen, dass die in der Nähe anstehenden Sandsteine durch die Erbauer des Gebäudes in die Hütte eingebracht worden sind. Die Interpretation der Sandsteinplatten als Unterlage für einen Boden muss jedoch mit Vorsicht genossen werden, da die darüberliegenden Schichten keine prägnanten Benutzungsspuren aufweisen. Ein allfälliger Holzboden, der zu einem späteren Zeitpunkt wieder entfernt wurde, kann diese Spuren
Schicht 23.II weist eine Konzentration mit eingeregelten Quarzkörnern auf (rote Pfeile), die ein deutliches Niveau bilden, zusammen mit einem dunkelbraunen Fragment eines Mergelschiefers. Die länglichen, horizontalen Porenräume könnten eine Begehung der Schicht andeuten (gelbe Pfeile) (ATTGEl/23.2, ppl).

Foto C. Pümpin, 2016

Querschnitts einer rezenten Wurzel in Schicht 23.IV, aufgenommen mit gekreuzten Polarisationsfiltern (ATTGEI/23.1, xpl).

Foto C. Pümpin, 2016

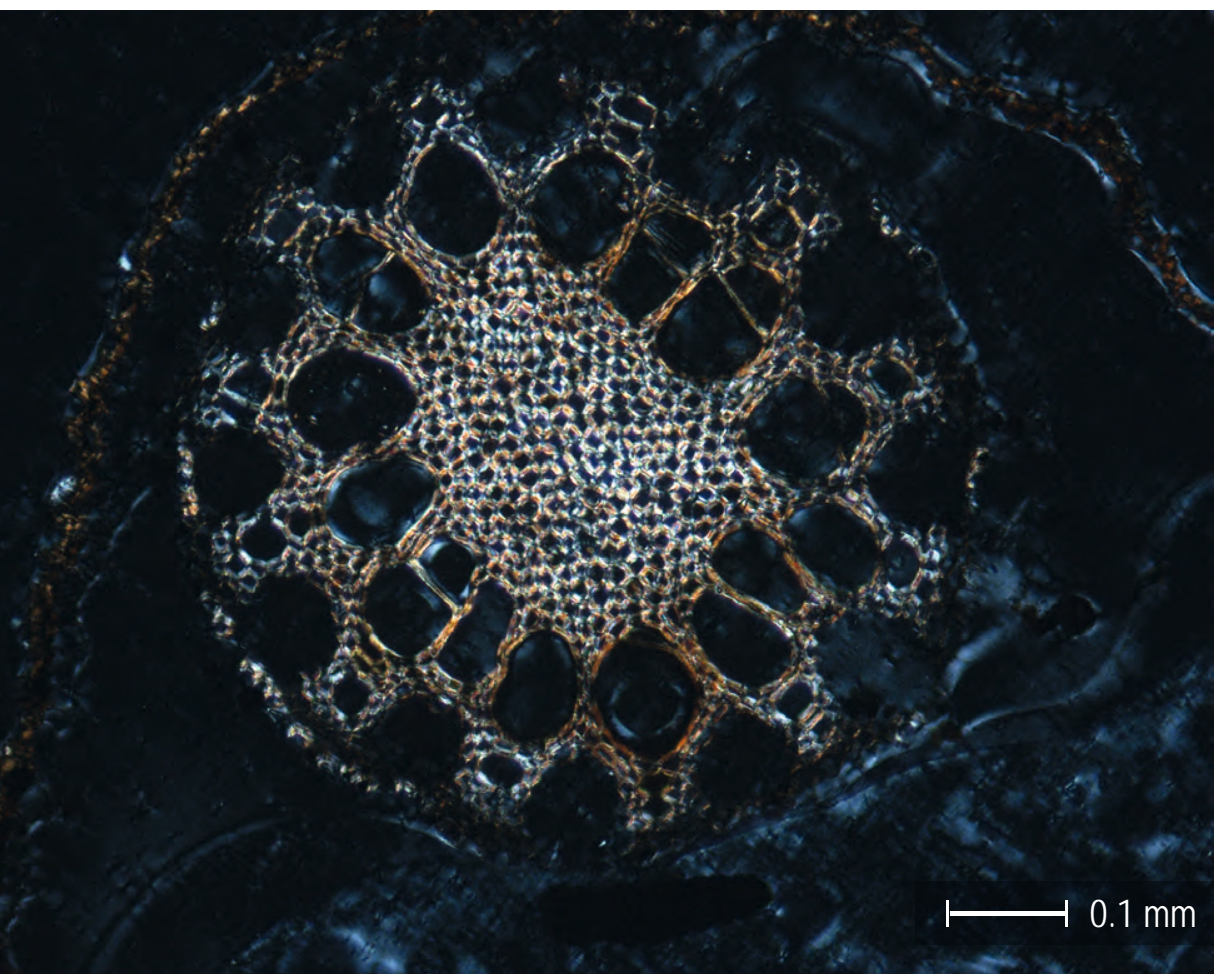


Schicht 23.IV mit schwachen Einschwemmungen von degradiertem organischem Material und Feinsilt (rote Pfeile) (ATT-GEI/23.1, ppl).

Foto C. Pümpin, 2016

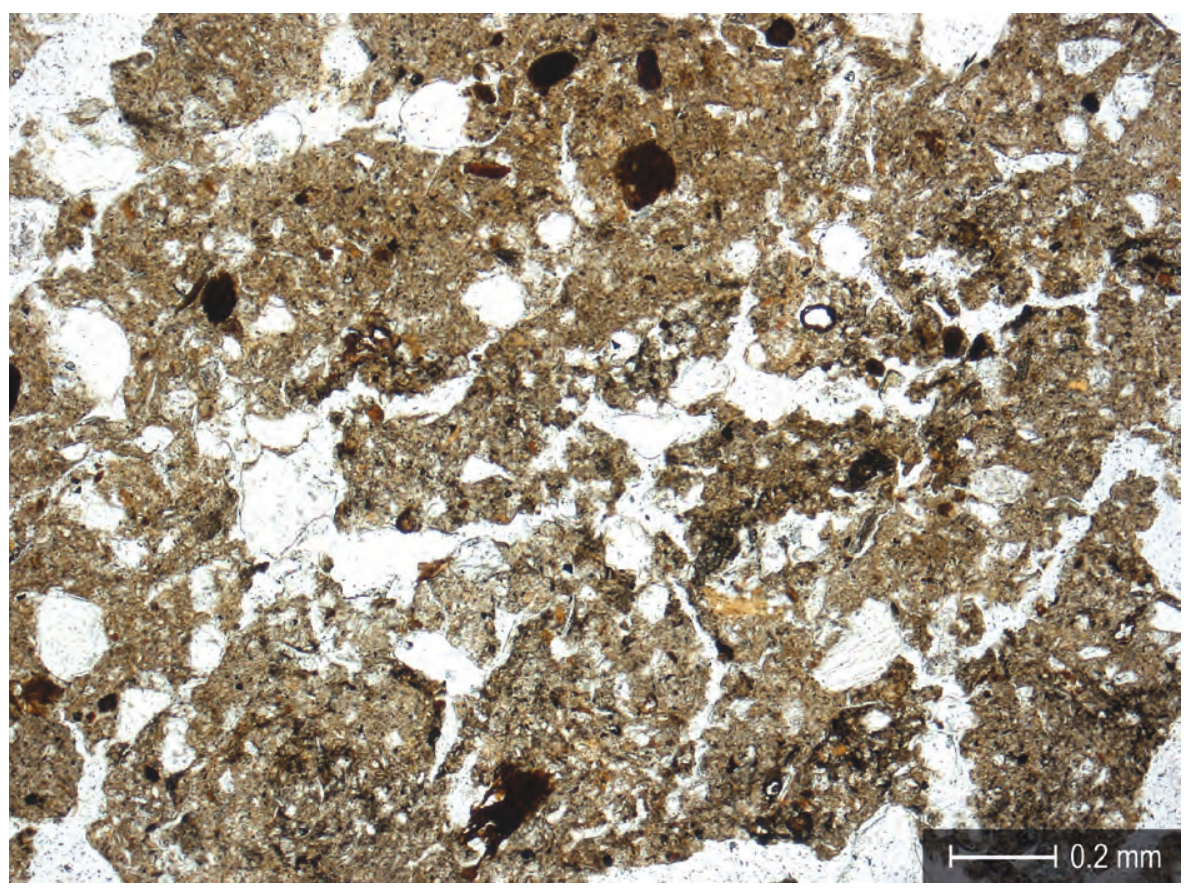

zerstört haben. Es kann aber auch sein, dass über den Steinplatten Nutzungspuren vorhanden waren, die aber durch die Tau- und Frostprozesse verwischt wurden. Diese Prozesse, die bereits während der Nutzung, aber auch in späterer Zeit auf die Schichten gewirkt haben, hinterlassen im Sediment mit der Bildung eines Plattengefüges ähnliche Spuren, wie sie bei einer intensiven Begehung des Bodens entstehen. In Schicht 23.IV konnte zudem die Bildung von ovalen bis linsenförmigen Sedimentaggregaten beobachtet werden, die ebenfalls typisch für diese Prozesse sind. Durch das wiederholte Auftauen und Gefrieren des Bodens kann es wiederum zu Verlagerungen der Komponenten kommen. Befindet sich solches am Rand einer Mulde ungeschützt durch eine Vegetationsdecke, kann das Material unter anderem durch Schneeschmelze oder Regenfälle kolluvial in die Vertiefung verlagert werden. Dabei kommt es zu feinen Einschwemmungen und zur Anreicherung von degradiertem organischem Material aus dem Oberboden mit Sklerotien und Pilzmyzelien sowie zu einer Akkumulation von Material aus dem Auswaschungs- und Verwitterungshorizont. Diese Schichten zeichnen sich zusätzlich durch eine Konzentration an Feinsilt aus, die dem Sediment einen staubigen Charakter verleihen. Diese Art von Verlagerung lässt sich in beiden Bodenproben beobachten, jedoch treten sie erst in den obersten Schichten unterhalb des Humushorizontes deutlich auf (26.V-VI und 23.IV) und könnten auf den Zerfall des Gebäudes hinweisen.

Eindeutige Feuerstellen innerhalb des Gebäudes konnten mittels mikromorphologischer Untersuchungen nicht erkannt werden. Bei den grau gefärbten Sedimenten handelt es sich um Zonen, die eine Pseudovergleyung durchgemacht haben. Dabei kommt es durch Hydromorphie im wassergesättigten Milieu und unter Sauerstoffmangel zu reduzierenden Bedingungen, was eine Graufärbung der Schichten zur Folge hat. Eine Verfärbung des Sediments durch Holzasche lässt sich ausschliessen, da Asche aus Kalziumkarbonat besteht und diese im sauren Bodenmilieu auf dem Geissrüggen seit der Hallstattzeit vollständig abgebaut worden wäre. Hinweise auf ein Feuer in unmittelbarer Nähe der Probe geben jedoch die Holz- und Mikroholzkohlereste, die in diesen Schichten immer wieder angetroffen wurden. 


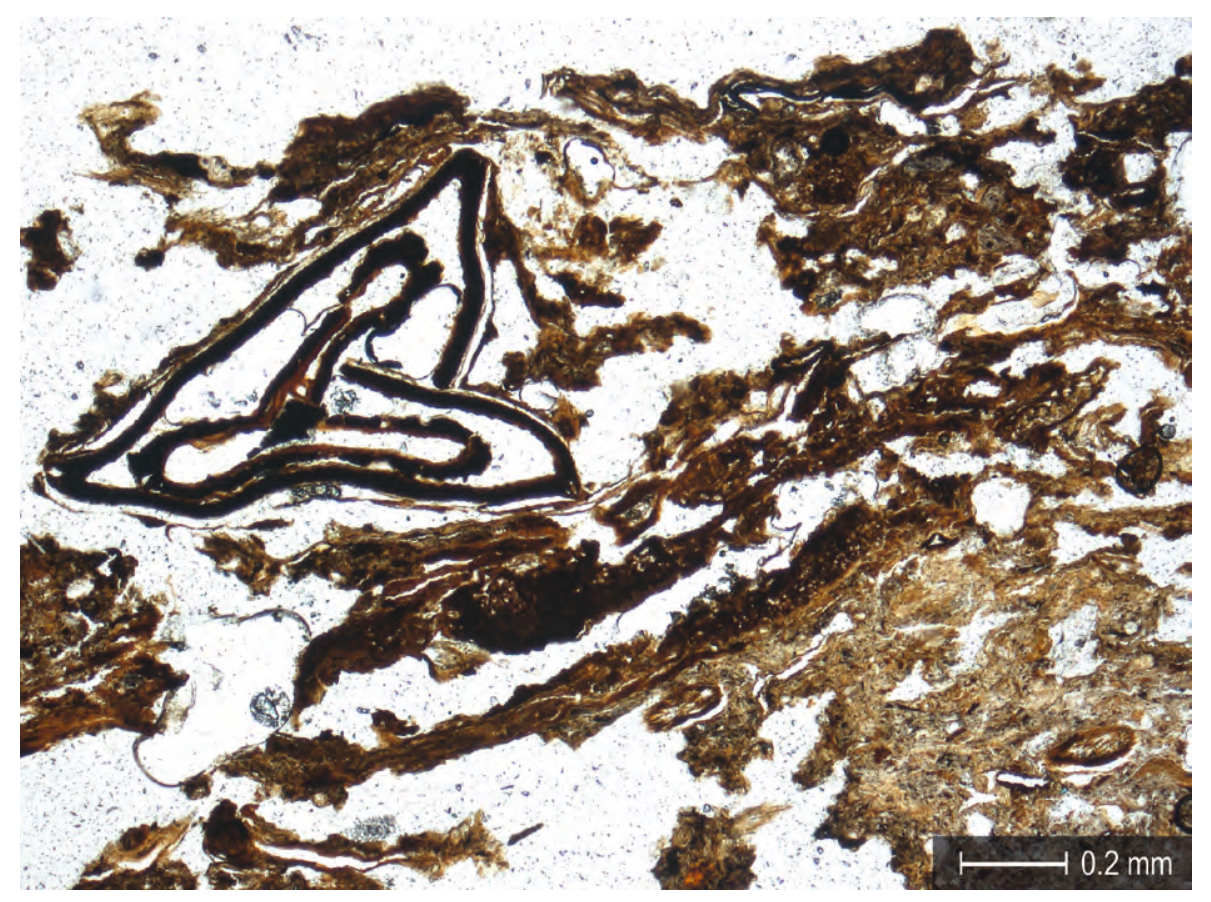

Aus der frühen Eisenzeit sind im Alpenraum massive Brandrodungen bekannt, die folgenschwere menschliche Eingriffe darstellen und zu Veränderungen der Landschaft mit massiven Erosionen der Böden führten. ${ }^{16}$ So konnten vermehrt in alpinen Gebieten, besonders in hallstattzeitlichen Befunden, Abspülsedimente beobachtet werden, die Anreicherungen von Holzkohle enthielten. ${ }^{17}$ Berücksichtigt man Ergebnisse der Pollenanalyse aus dem Moor von Brüsti, ist der Beginn der Weidewirtschaft und somit der Auflockerung des ursprünglichen Waldes schon während der Bronzezeit zu erkennen. ${ }^{18}$ Eingriffe in den Baumbestand sind jedoch erst ab der Eisenzeit, ab circa 700 v.Chr., im Pollendiagramm fassbar und nehmen massiv bis um 400 v.Chr. zu - bis hin zum teilweisen Verschwinden der Weisstanne und Fichte aus der Umgebung des Z'Graggen-Moors, das circa 2,5 km Luftlinie vom Geissrüggen entfernt liegt $(\rightarrow$ S. 24-45). Die mikromorphologische Analyse hat gezeigt, dass in den ältesten Schichten (26.I, IV und 23.II) - mit einer Häufung an Mikroholzkohlen und vereinzelt auch Makroholzkohle keine deutlich erkennbaren Einschwemmungs- oder Verlagerungsereignisse im Sediment vorhanden sind. Zudem konnten sowohl im Feldbefund als auch im Dünnschliff Steine und Kies (Schicht 26.IV) mit einem geröteten Aussensaum nachgewiesen werden, der von Hitzeeinwirkungen stammen könnte. Eine kolluviale Verlagerung des Materials ist erst in den obersten Schichten, nach der Auflassung des Gebäudes, erkennbar.

Die besonderen Bedingungen bei Fundstellen der subalpinen Höhenstufe mit den ausgeprägten klimatischen Einflüssen sind anspruchsvolle und komplexe Bodenarchive. Dazu kommt im Falle des Geissrüggens, durch die Lage auf einer Kuppe, eine geringe Überdeckung mit jüngeren Ablagerungen und dementsprechend zu einer intensiveren Verwitterung. Dadurch sind die Spuren menschlicher Aktivität entsprechend verwischt und schwierig zu interpretieren. Dennoch konnte die optische Untersuchung einige Hinweise zur Schichtgenese, zu Ablagerungsbedingungen und zur Herkunft der Verfärbungen und zu den archäologischen Befunden innerhalb des hallstattzeitlichen Gebäudes liefern.
Schicht 23.V mit einem Samen, der möglicherweise von einem Knöterich stammt (roter Pfeil) und der von degradiertem organischen Material umgeben ist (ATT-GEI/23.1, ppl).

Foto C. Pümpin, 2016
16 Patzelt 2000. - Paccolat/Moret/Taillard et al. 2011, 71-73.

17 Röpke 2006, 159. - Röpke/Stobbe/ Oeggl et al. 2011, 490-493.

18 Leuzinger/Sauter/Haas et al. 2014, 161. 
Adhoc AG Boden (Hrsg.) (2005). Bodenkundliche Kartieranleitung mit 41 Abbildungen, 103 Tabellen und 31 Listen. Hannover.

Auf der Maur, C. / Cornelissen, M. / Brönnimann, D. (2014). Die spätmesolithische und bronzezeitliche Fundstelle Hospental-Moos. Ein Einblick in das urgeschichtliche Urserntal. In: Historisches Neujahrsblatt, 37-83.

Babel, U. (1975). Micromorphology of Soil Organic Matter. In: Soil Components. Berlin, 369-473.

Beckmann, T. (1997). Präparation bodenkundlicher Dünnschliffe für mikromorphologische Untersuchungen. In: Stahr, K. (Hrsg.). Mikromorphologische Methoden in der Bodenkunde. Ergebnisse eines Workshops der DBG, Kommission VII, 9.- 11. Okt. 1995 an der Universität Hohenheim. Hohenheim, 89-103.

Bullock, P. / Fedoroff, N. / Jongerius, A. et al. (1985). Handbook for Soil Thin Section Description. (= Waine Research Publication). Wolverhampton.

Courty, M.-A. / Goldberg, P. / Macphail, R. (1989). Soils and Micromorphology in Archaeology. Cambridge.

Gisler, C. / Spillmann, P. (2011). Die mesozoisch-alttertiäre Sedimentbedeckung. In: Spillmann/Labhart/Brücker et al., 49-78.

Goldberg, P. / Macphail, R. I. (2006). Practical and Theoretical Geoarchaeology. Oxford. Labhart, T. / Pfiffner, O.A. / Spillmann, P. et al. (2011). Geologische Karte des Kantons Uri, 1: 100 000. In: Spillmann/Labhart/Brücker et al., Beilage 1.

Leuzinger, U. / Sauter, M. / Haas, J. N. et al. (2014). Eine hallstattzeitliche Gebäudestruktur auf 1911 m ü.M am Weg zum Surenenpass, Attinghausen UR, Siedlungsplatz Geissrüggen. In: Jahrbuch Archäologie Schweiz 97, 153-168.

Paccolat, O. / Moret, J.-C. / Taillard, P. et al. (2011). Evolution sédimentaire et chronologique du site. In: Paccolat, O. (Hrsg.). Pfyn/Finges. Evolution d'un terroir de la plaine du Rhône. Le site archéologique de Pfyngut (= Cahiers d'Archéologie Romande 121, Archaeologia Vallesiana 4). Lausanne, 69-96.

Patzelt, G. (2000). Natürliche und anthropogene Umweltveränderungen im Holozän der Alpen. Entwicklung der Umwelt seit der letzten Eiszeit. In: Rundgespräche der Kommission für Ökologie 18. München, 119-125.

Renner, F. /Zgraggen, A. (2011). Auf den Spuren des Reussgletschers von der Eiszeit bis zur Gegenwart. In: Spillmann/Labhart/Brücker et al., 97-134.

Rentzel, P. / Narten, G.-B. (2000). Zur Entstehung von Gehniveaus in sandig-lehmigen Ablagerungen. Experimente und archäologische Befunde. In: Jahresbericht der Archäologischen Bodenforschung des Kantons Basel-Stadt, 31-52.

Röpke, A. (2006). Der Wandel von der Natur- zur Kulturlandschaft im Hochtal von St. Antönien (Schweiz). Ein Methodenverbund aus Palynologie, Bodenkunde und Dendroökologie. Frankfurt am Main.

Röpke, A. / Stobbe, A. / Oeggl, K. et al. (2011). Late-Holocene land-use history and environmental changes at the high altitudes of St Antönien (Switzerland, Northern Alps): Combined evidence from pollen, soil and tree-ring analyses. In: The Holocene 21, 485-498.

Sauter, M. (2009). Wüstenforschung im Kanton Uri. Ergebnisse der alpinen Prospektion im Brunni- und im Schächental, auf Haldi und dem Surenenpass. Altdorf.

Scheffer, F. / Schachtschabel, P. / Blume, H.-P. et al. (2010). Lehrbuch der Bodenkunde. Heidelberg.

Spillmann, P. / Labhart, T. / Brücker W. et al. (2011). Geologie des Kantons Uri (= Naturforschende Gesellschaft Uri 24). Altdorf.

Stoops, G. (2003). Guidelines for analysis and description of soil and regolith thin sections. Soil Science Society of America. Madison.

Van Vliet-Lanoë, B. (1985). Frost effects in soils. In: Boardman, J. (Hrsg.). Soils and quaternary landscape evolution. Chichester, 117-158. 


\section{Summary: 3D by drone}

In August 2013 a team of volunteers excavated a heavily overgrown Hallstatt-period building at Geissrüggen (municipality of Attinghausen UR). The site was located on a ridge at about $1911 \mathrm{~m}$ a.s.l. next to the Surenen Pass trail, which had long connected Attinghausen UR with Engelberg OW via the Surenen Pass. In addition to conventional methods of archaeological recording, a multirotor UAV ("drone») was used to acquire low-altitude aerial photographs of the site and its immediate surroundings. The high-resolution, mostly vertical imagery was subsequently utilised to generate textured 3D models of the excavated area using an image-based modelling approach called Structure from Motion. The method uses pictures of the scene shot from various angles with off-the-shelf, non-calibrated cameras and determines the scene's three-dimensional properties by analysing the motion parallaxes. Detailed orthophotos and digital elevation models (DEMs) can then be derived from the resulting $3 D$ data. 


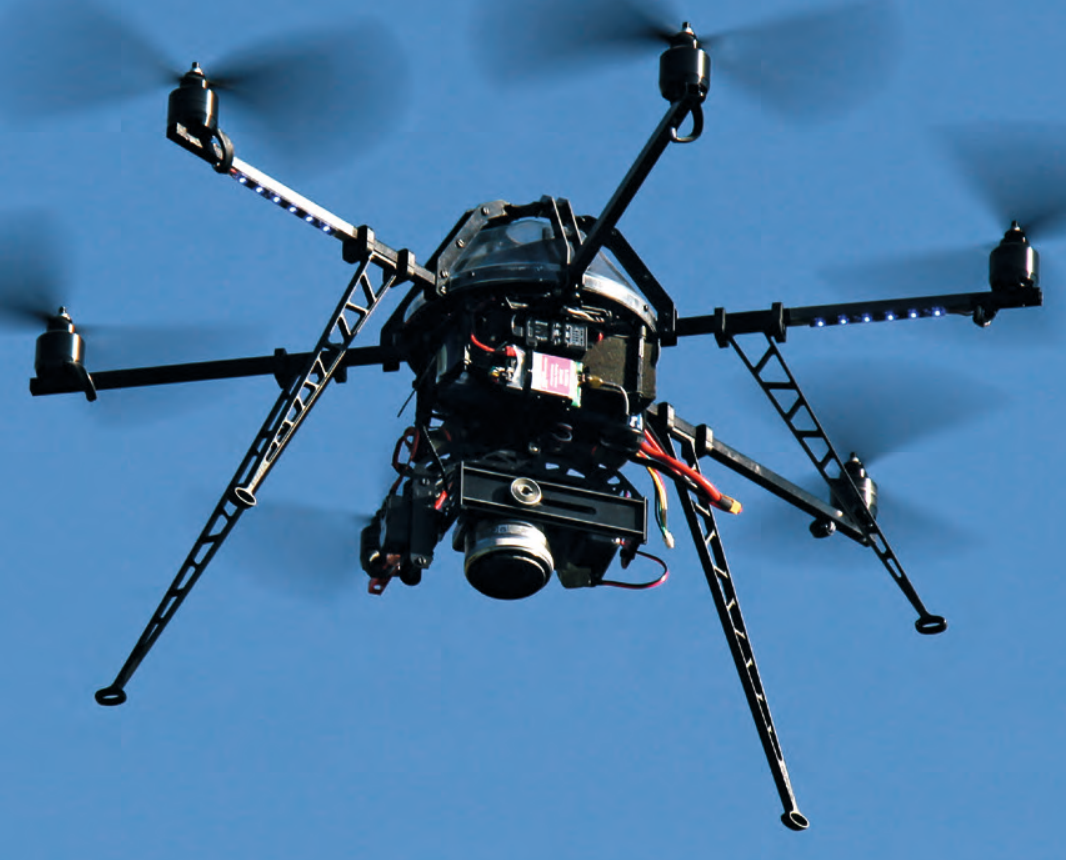

\section{D-Dokumentation mit Drohne}

Bei der Ausgrabung auf dem Attinghauser Geissrüggen kam ergänzend zu konventionellen Dokumentationsmethoden auch eine Multikopter-Drohne zur Anwendung, mit der hochauflösende Senkrechtluftbilder der Grabungsschnitte erstellt wurden. Aus dem Bildmaterial konnten detaillierte 3D-Modelle der Grabungssituation und des Umfeldes errechnet werden.

\section{Einleitung}

Der allgemeine technische Fortschritt eröffnet auch neue Möglichkeiten für die Dokumentation archäologischer Ausgrabungen. Noch vor wenigen Jahren undenkbare oder Spezialisten vorbehaltene Dokumentationsmethoden erreichen mittlerweile selbst - oder gerade - Grabungsprojekte an abgelegenen Fundorten, die ohne die sonst übliche technische Infrastruktur auskommen müssen. Dies gilt insbesondere auch für alpine Fundstellen. ${ }^{1}$ Die Kombination zweier solcher neuer Dokumentationsverfahren soll hier am Beispiel der Forschungsgrabung auf dem Geissrüggen in der Gemeinde Attinghausen vorgestellt werden. Es handelt sich um die Erstellung von Nahbereichsluftbildern mithilfe einer Multikopter-Drohne und um die anschliessende computergestützte Weiterverarbeitung der gewonnenen Luftaufnahmen zu 3D-Modellen, aus denen dokumentationsrelevante Daten wie lagetreue Orthofotos oder Digitale Oberflächenmodelle extrahiert werden können.

\section{Fotodrohnenflüge am Surenenpassweg}

Die Fundstelle Geissrüggen liegt auf einem Grat in rund 1911 m ü.M. an einem über den Surenenpass führenden historischen Weg von Attinghausen nach Engelberg. Im August 2013 wurde hier im Rahmen eines Freiwilligenprojektes ein stark einsedimentierter und überwachsener Gebäudegrundriss freigelegt und dokumentiert, der sich anhand der Radiokarbondaten

Andres/Walser 2013. - Lambers/ Zingmann 2012. - Novák/Tokarczyk/ Theiler 2012. - Ramha 2012. - Ramha 2015. - Reitmaier 2011. 


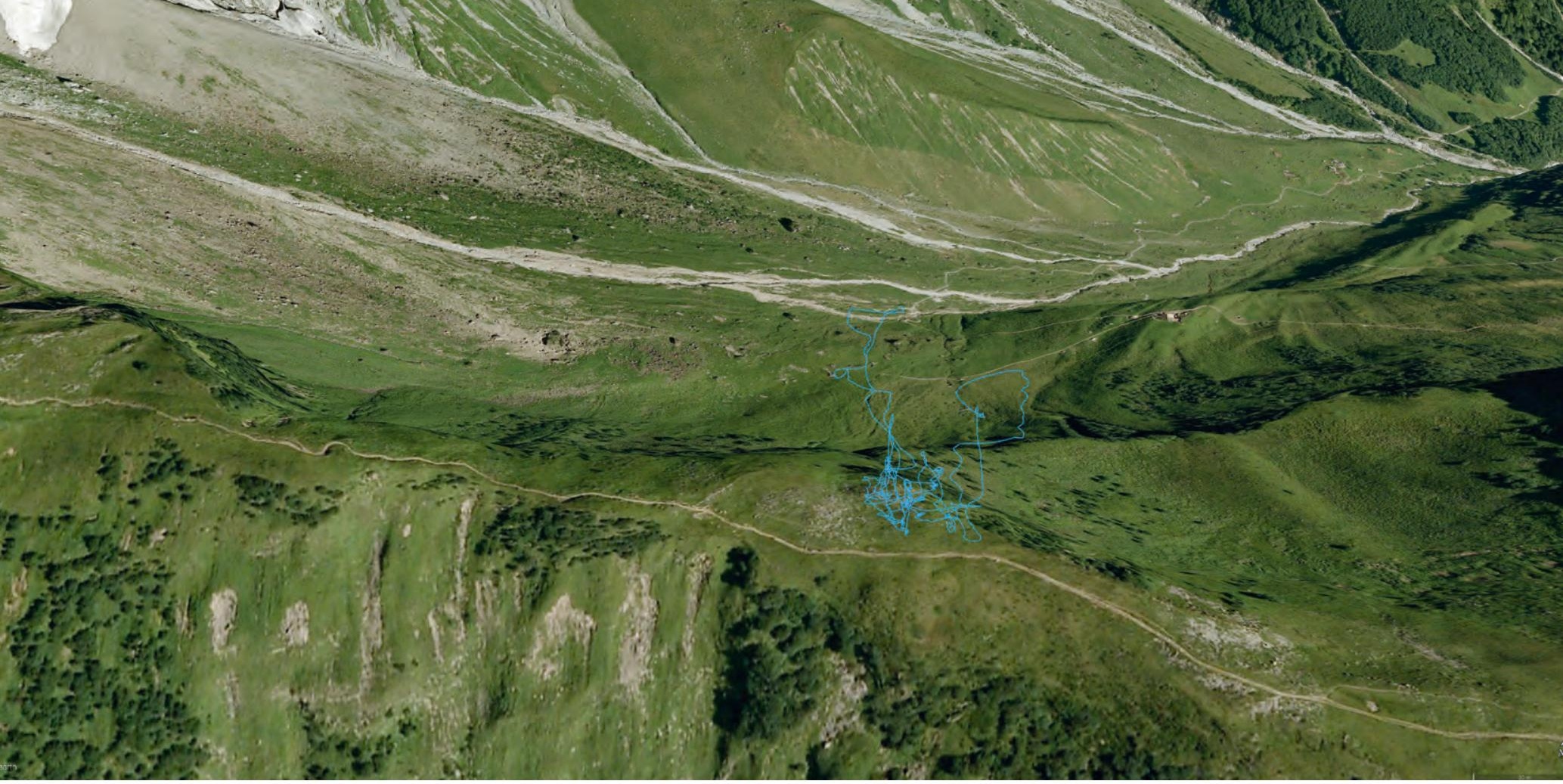

als hallstattzeitlich einordnen lässt $\left(\rightarrow\right.$ S. 124-137). ${ }^{2}$ Bereits 2012 wurden während der vorbereitenden Prospektionskampagnen mithilfe eines Hochstativs Senkrechtaufnahmen der vorgefundenen Baustrukturen gemacht ( $\rightarrow$ S. 48-67) - für die Dokumentation der eigentlichen Grabung im Jahr darauf kam ein Multikopter-UAV (engl. Unmanned Aerial Vehicle - UAV) zur Anwendung.

Unbemannte Luftfahrzeuge werden umgangssprachlich meist verallgemeinernd als Drohnen bezeichnet; im Unterschied zu Modellflugzeugen werden UAVs jedoch nicht zur Freizeitgestaltung geflogen, sondern der Einsatz erfolgt aus kommerziellen, wissenschaftlichen oder militärischen Gründen. Grössen und Bauformen sind dabei vielfältig und den Anforderungen des Einsatzes angepasst. UAVs können im Allgemeinen nicht nur über eine Funkverbindung ferngesteuert werden, sondern verfügen über die Möglichkeit, auch halb- oder vollautomatische Flüge zu absolvieren. Für diesen sogenannten autonomen Flug wird üblicherweise auf Satellitennavigationssysteme zurückgegriffen. UAVs tragen eine Nutzlast, häufig in Form von Fernerkundungssensoren, etwa Kameras, und stehen in ständiger Verbindung mit einer Bodenstation.

Eine erst seit wenigen Jahren verfügbare UAV-Variante sind die sogenannten Multikopter, mehrrotorige, elektrisch angetriebene Flugplattformen mit meist vier, sechs oder acht Propellern, die entsprechend der Anzahl ihrer Antriebe als Quadro-, Hexa- oder Oktokopter bezeichnet werden. Wie Hubschrauber, zu denen sie technisch gehören, sind sie senkrechtstart- und schwebeflugfähig. Üblicherweise sind Multikopter mit GPS ausgerüstet und damit in der Lage, auch ohne Eingreifen des Piloten die Windabdrift zu korrigieren und so präzise an einem Punkt im Raum zu schweben beziehungsweise automatisiert Routen abzufliegen. Der besonderen Eignung der Multikopter als Kameraträger wegen haben sie sich innerhalb kürzester Zeit als "Standardwerkzeug" für die Erstellung von Nahbereichsluftbildern und -videos etabliert. Sie decken mit ihren niedrigen Flughöhen kostengünstig den Bereich zwischen dem Ende der Fotoleiter und der bemannten Luftbildfotografie mit Helikoptern und Kleinflugzeugen ab. ${ }^{3}$ Und genau
Titelbild: Der sechsrotorige Hexakopter im Flug. Zwischen den Landebeinen ist die Kamerahalterung mit der nach unten gerichteten Kamera erkennbar. Foto M. Sauter, 2013

Blick gegen Nordnordwest über den Geissrüggen in der kostenfreien Geodatenbetrachtungssoftware GoogleEarth. Blau dargestellt sind die von der Drohne mitgeloggten Flugrouten der drei Bildflüge über der Grabung, die eigentlichen Grabungsschnitte befinden sich im Bereich der höchsten Logdatendichte. Bildmaterial von GeoBasis-DE/BGK, Abruf 9.2.2016, Grafik J. Reinhard, 2016

2 Leuzinger/Sauter/Haas et al. 2014.

3 Bofinger/Steffen 2014, bes. Abb. 5. 


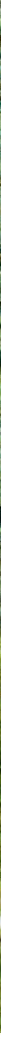

Typisches Ergebnis eines Drohnenflugs sind senkrecht aufgenommene Übersichtsbilder. Bei einer Flughöhe von $75 \mathrm{~m}$ werden mit der verwendeten Kameraausrüstung rund $110 \times 73$ m Fläche am Boden abgebildet. Die Bodenauflösung beträgt dabei circa $24 \mathrm{~mm}$ und ist damit um ein Vielfaches höher als bei konventionellen Luftbildern. Foto J. Reinhard, 2013

Die Multikopterdrohne wird für den ersten Bildflug vorbereitet. Vor dem Piloten im Gras liegt die Fernsteuerung mit dem Bildschirm für die Anzeige des per Funk übertragenen Livebilds der Kamera. Foto M. Sauter, 2013
4 Die für den Betrieb von Drohnen und Flugmodellen gültigen gesetzlichen Regelungen finden sich unter https:// www.bazl.admin.ch/bazl/de/home/gutzuwissen/drohnen-und-flugmodelle. html (14.1.2016).

5 Reinhard 2013, 179-180, Abb. 4. dieser Flughöhenbereich, der Übersicht mit hoher Bodenauflösung und Detailgenauigkeit kombiniert, ist für die fotografische Dokumentation von archäologischen Ausgrabungsflächen und Geländedenkmälern besonders geeignet. Noch 2013 als Hightech bestaunt, bevölkern Kopter in zahlreichen Grössen, Formen, Farben und Ausstattungsvarianten inzwischen die Regale der Elektronikfachmärkte ${ }^{4}$ - im Jahr 2015 galten Spielzeugkopter bereits als beliebtestes Weihnachtsgeschenk!

Für die Grabungsdokumentation auf dem Geissrüggen kam ein selbstgebauter, auf der Mikrokopter-Elektronik der deutschen Firma HiSystems basierender Hexakopter zur Anwendung. ${ }^{5}$ Als Sensor diente eine digitale Systemkamera (Sony NEX-5C) mit einer Auflösung von 14,2 Megapixeln und einem Weitwinkel-Festbrennweitenobjektiv ( $24 \mathrm{~mm}$ im Kleinbildäquivalent). Diese ist unter dem Kopter in einer beweglichen Kamerahalterung befestigt und gleicht dessen Bewegungen aus. Der Neigungswinkel der Kamera kann aber auch vom Piloten ferngesteuert verändert werden, um beispielsweise

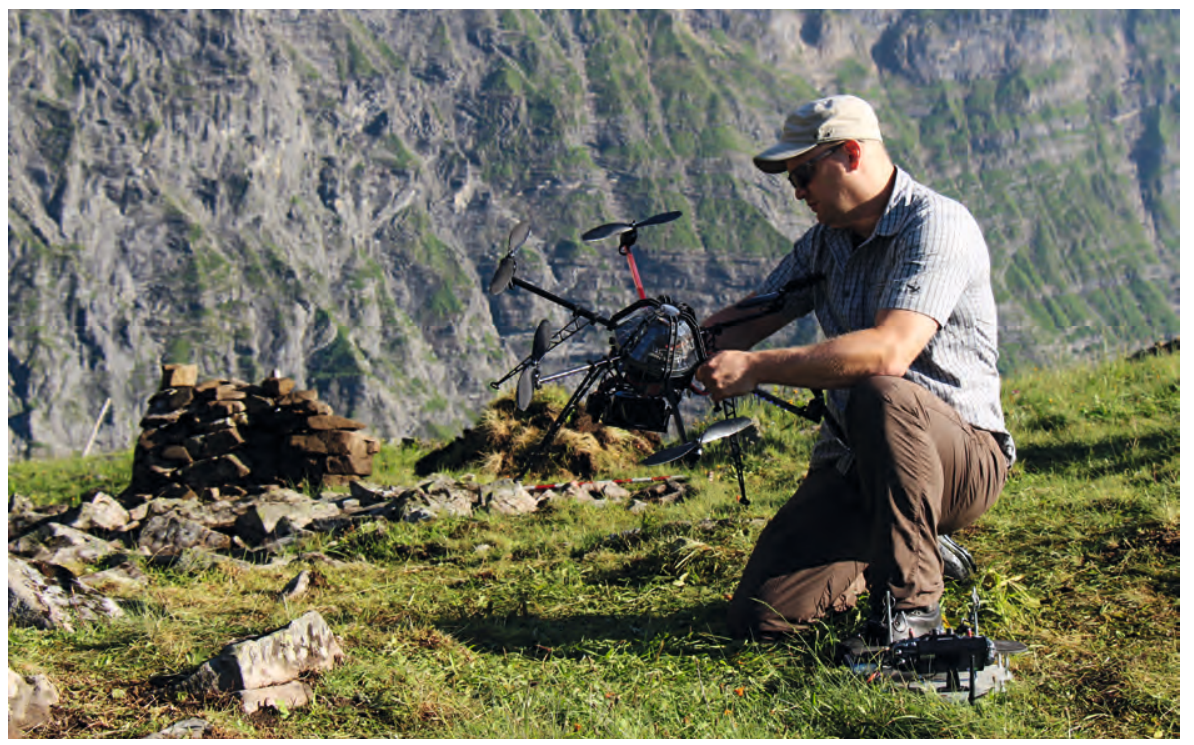


vom Senkrecht- zum Schrägbild umzuschalten. Zur Bildkontrolle und -ausrichtung wird das Vorschaubild der Kamera per Funk auf einen Bildschirm am Fernsteuerungssender des Piloten übertragen, die Auslösung der Kamera kann manuell oder automatisch erfolgen. Die hohe Flexibilität und die - verglichen mit herkömmlichen Mitteln der Überblicksfotografie auf Grabungen wie Kränen oder Feuerwehrdrehleitern ${ }^{6}$ - fast beliebige Positionierungsmöglichkeit macht Multikopter zum idealen Werkzeug für die Grabungsdokumentation. Insbesondere der für die archäologische Dokumentation häufig zentral wichtige Blick senkrecht von oben ist, vor allem bei grösseren Befunden, kaum mit anderen Mitteln zu erreichen.

Die anfängliche Befürchtung, dass die zur Verfügung stehende Anzahl von Flugakkus, deren Nachladen abseits des regulären Stromnetzes schwierig ist, ein limitierender Faktor für den Einsatz sein könnte, erwies sich vor Ort als unbegründet. Nicht leere Akkus, sondern - wie so oft in den Bergen - das Wetter diktierte die Rahmenbedingungen für die Luftbildflüge: Zwischen dem vollständigen Freilegen des Befundes und dem Tag der offenen Grabung beziehungsweise der Wiederverfüllung der Grabungsschnitte war ein Arbeitstag für die Abschlussdokumentation vorgesehen dieser fiel jedoch buchstäblich ins Wasser, der intensive Dauerregen machte

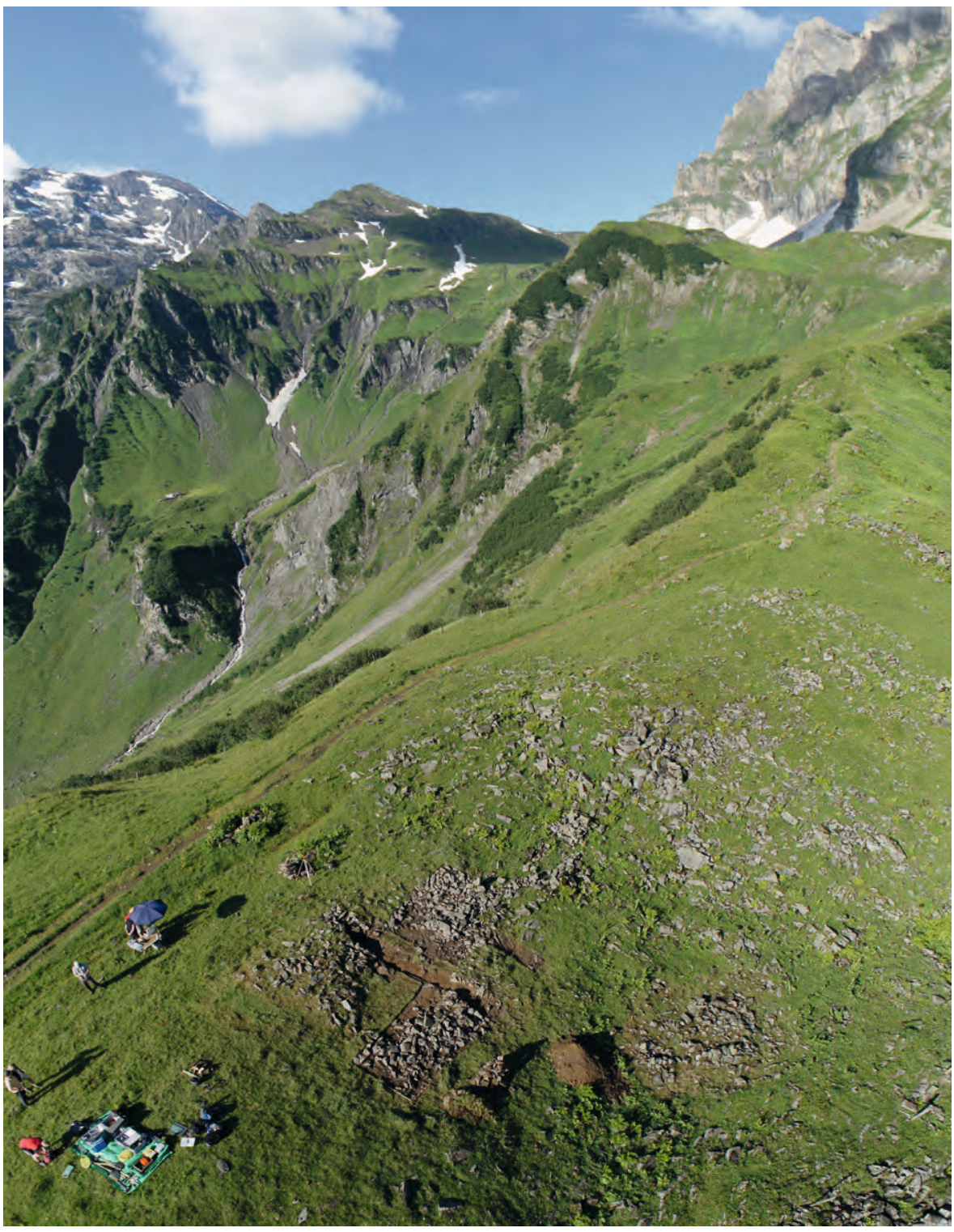

6 Vgl. Verhoeven 2009.
Aus drei Schrägaufnahmen zusammengesetztes Vertikalpanorama mit Blick nach Westen über den Geissrüggen in Richtung Surenenpass, im unteren Bilddrittel die Grabung.

Foto J. Reinhard, 2013 


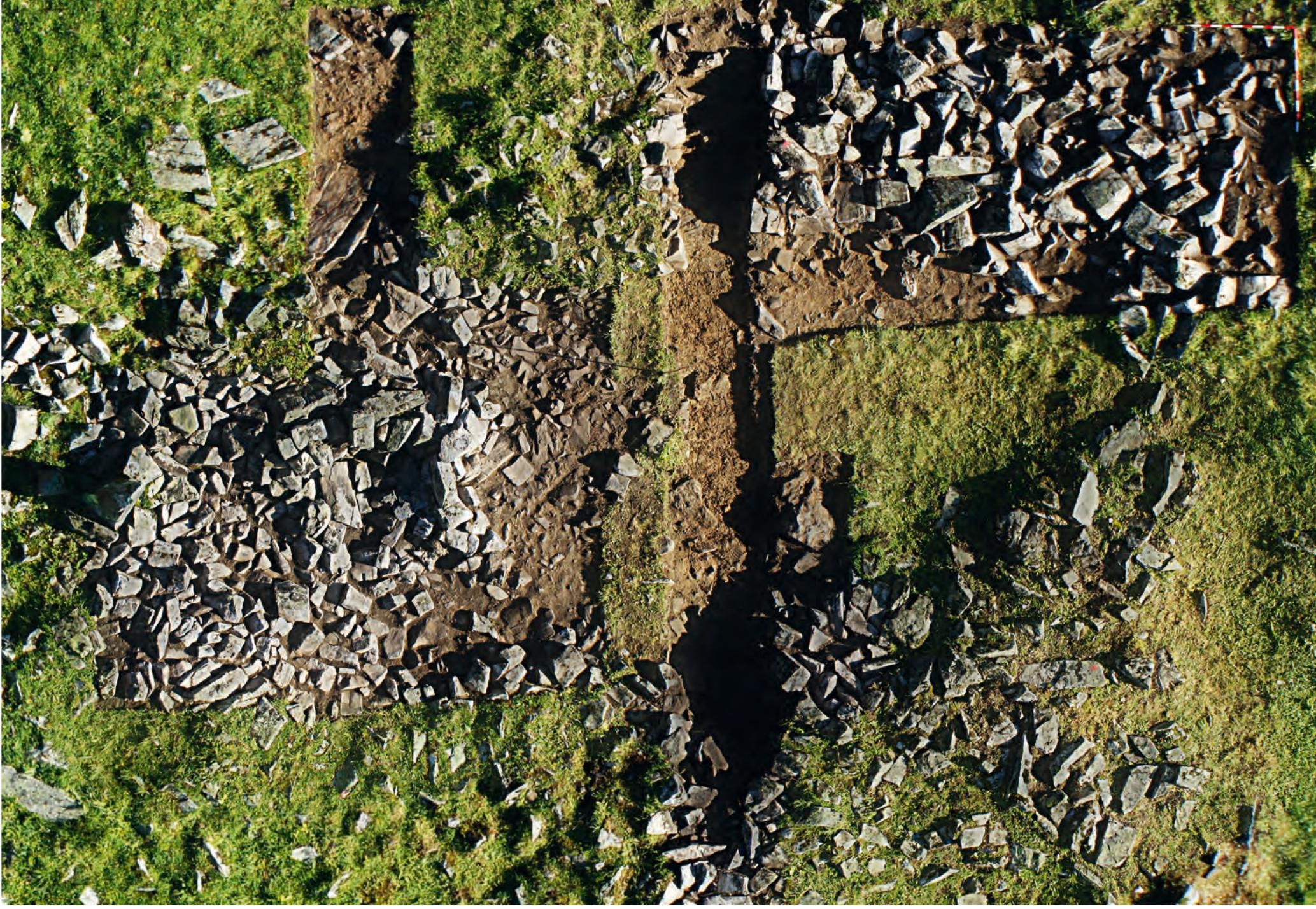

Per Structure-from-Motion errechnetes Orthofoto der Grabungsfläche auf dem Geissrüggen, genordet. Im Gegensatz zu unbearbeiteten Fotos gibt ein Orthofoto die abgebildete Fläche lagetreu und unverzerrt wieder, sodass es etwa als Fotokarte oder für Messzwecke verwendet werden kann.

Foto J. Reinhard, 2013 einen Bildflug unmöglich. Das Zeitfenster für die Luftbildflüge war damit auf den Morgen des Tags der offenen Grabung am 10. August 2013, vor dem Eintreffen der Besucher, beschränkt. In dieser Zeit konnten zwei Bildflüge von je rund 8 Minuten Dauer durchgeführt werden, bei denen in erster Linie Senkrechtbilder der Grabungsschnitte und des Umfelds der Fundstelle gemacht wurden. Die Flughöhe betrug dabei bis zu $75 \mathrm{~m}$. Noch in dieser Höhe beträgt die erreichte Bodenauflösung rund $24 \mathrm{~mm}$ pro Pixel, durch niedrigere Flughöhen ist diese bis in den Submillimeterbereich steigerbar. Zum Vergleich: Die Orthofotos der kantonalen Vermessungsämter erreichen Auflösungen von maximal $10 \mathrm{~cm}$ pro Pixel. Durch die wetterbedingte Improvisation des Einsatzzeitpunktes mussten die Bildflüge bei nicht idealen Lichtbedingungen mit morgendlich langen Schatten und den im Morgenlicht überstrahlenden hellen Steinen des Mauerversturzes stattfinden - das resultierende Bildmaterial ist dennoch sehr gut geeignet, die Grabung und ihr Umfeld sowohl in der Übersicht als auch detailgetreu zu dokumentieren. Ein weiterer zwölfminütiger Flug wurde während der Anwesenheit der Besucher auf der Grabung durchgeführt; aus Sicherheitsgründen wurde dabei nicht über den Köpfen der Besucher geflogen, sondern seitlich versetzt. Dieser Flug diente in erster Linie der Information der Besucher zur verwendeten Drohnentechnik; es entstanden jedoch auch eine Reihe von Schrägbildern der Grabungssituation, die zum Teil zu Panoramabildern zusammengefügt wurden. Auf weitere Flüge wurde verzichtet, um Konflikten mit der bemannten Luftfahrt aus dem Weg zu gehen: Es hatte sich ein Kameramann von Tele1 angekündigt, der sich per Helikopter 
auf den Geissrüggen transportieren liess ( $\rightarrow$ Buchcover). Alle Flüge verliefen vollkommen problemlos, durch die Höhenlage auf fast $2000 \mathrm{~m}$ bedingte Veränderungen im Flugverhalten gegenüber vergleichbaren Bildflügen im Mittelland konnten nicht festgestellt werden, auch die Flugzeit war nicht merkbar verkürzt.

\section{Grabungsschnitte in 3D}

Nahbereichsluftbilder eignen sich ideal als Grundlage für ein neues, ebenfalls erst seit wenigen Jahren breit verfügbares Auswerteverfahren: die Structure-from-Motion-Photogrammetrie (SfM; engl. für "Struktur aus Bewegung"). ${ }^{7}$ Wie alle photogrammetrischen Methoden zielt das Verfahren darauf ab, aus Fotografien eines Objektes - im vorliegenden Fall der Ausgrabungssituation auf dem Geissrüggen - seine räumlichen Eigenschaften abzuleiten. 3D-Photogrammetrie war noch bis vor Kurzem ein aufwendiges, kompliziertes Verfahren, dass Spezialkenntnisse und Spezialausrüstung (kalibrierte Kameras, sogenannte Messkammern, und teure Software) voraussetzte. Mit Structure-from-Motion ändert sich dies umfassend: Datengrundlage für das Verfahren sind Bildserien handelsüblicher, unkalibrierter Digitalkameras, je nach Anwendung können selbst mit Smartphonekameras brauchbare Ergebnisse erzielt werden. Auch Einzelbilder (frames) aus Videos oder gescanntes Bildmaterial, etwa alte Luftbilder oder die Fotodokumentation von Altgrabungen, können verwendet werden. Grundvoraussetzung ist lediglich eine deutliche Überlappung der einzelnen Fotos der Bildserie. Für die eigentliche Berechnung der 3D-Modelle existieren zahlreiche Softwarelösungen, die Spanne reicht von Open-Source-Anwendungen über kostenlose Freeware und Online-Dienste bis hin zu ausgefeilten Programmen, die eine detaillierte Steuerung der Modellierungsparameter ermöglichen. Im vorliegenden Fall wurde das Programm PhotoScan Professional der russischen Firma Agisoft LLC verwendet, das sich derzeit für archäologische Zwecke als "Quasi-Standard" durchgesetzt hat. SfM-Software stellt durchaus einige Ansprüche an die Rechenleistung des verwendeten Computers, insbesondere an die verfügbare Menge an Arbeitsspeicher (RAM) und die Leistungsfähigkeit der Grafikkarte, jedoch sind Spezialrechner nicht zwingend notwendig. Projekte in archäologietypischen Grössenordnungen wie die Geissrüggen-Grabungsfläche sind auch mit Standard-Hardware zu bewältigten. Bei der Verwendung von Online-Diensten ist die Bandbreite der Internetverbindung der limitierende Faktor, da das gesamte Bildmaterial auf die Server des Anbieters hochgeladen werden muss.
7 De Reu/Plets/Verhoeven et al. 2013. De Reu/De Smedt/Herremans et al. 2014. - Reinhard 2012. - Reinhard 2013, 180-186 (im Druck). Verhoeven 2011
Aus dem 3D-Modell ableitbare Daten: hochauflösendes Orthofoto (links) und Digitales Höhenmodell mit darüber gelegten Höhenlinien im Zentimeterabstand (Mitte). Die Farben geben die Höhen von tief (Blau) bis hoch (Weiss, Orange) wieder. Rechts der auf einer Handzeichnung basierende umgezeichnete Grabungsplan, zum Vergleich ebenfalls mit Höhenlinien im Zentimeterabstand. Alle drei Bildteile zeigen denselben Ausschnitt.

Grafik J. Reinhard, 2013/2016

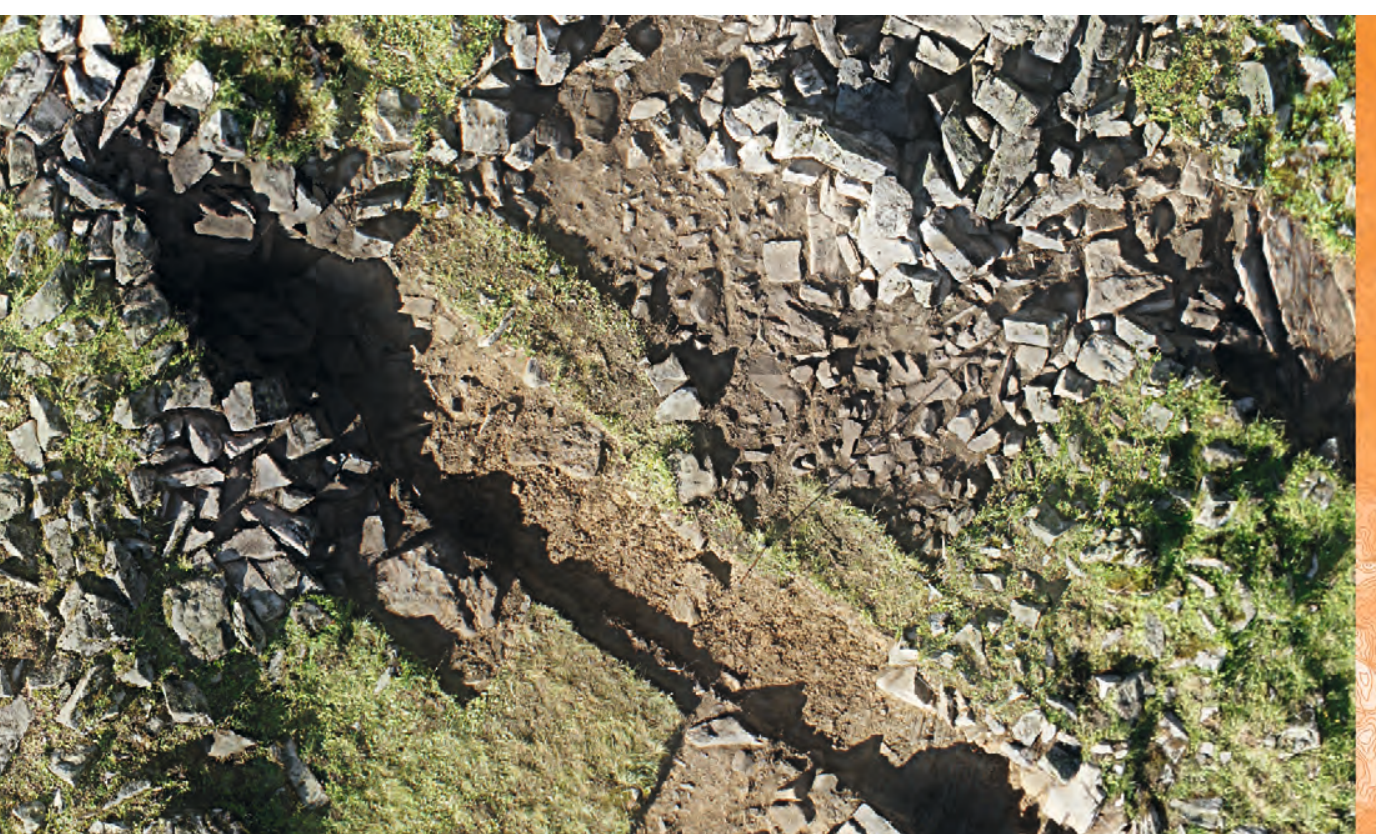




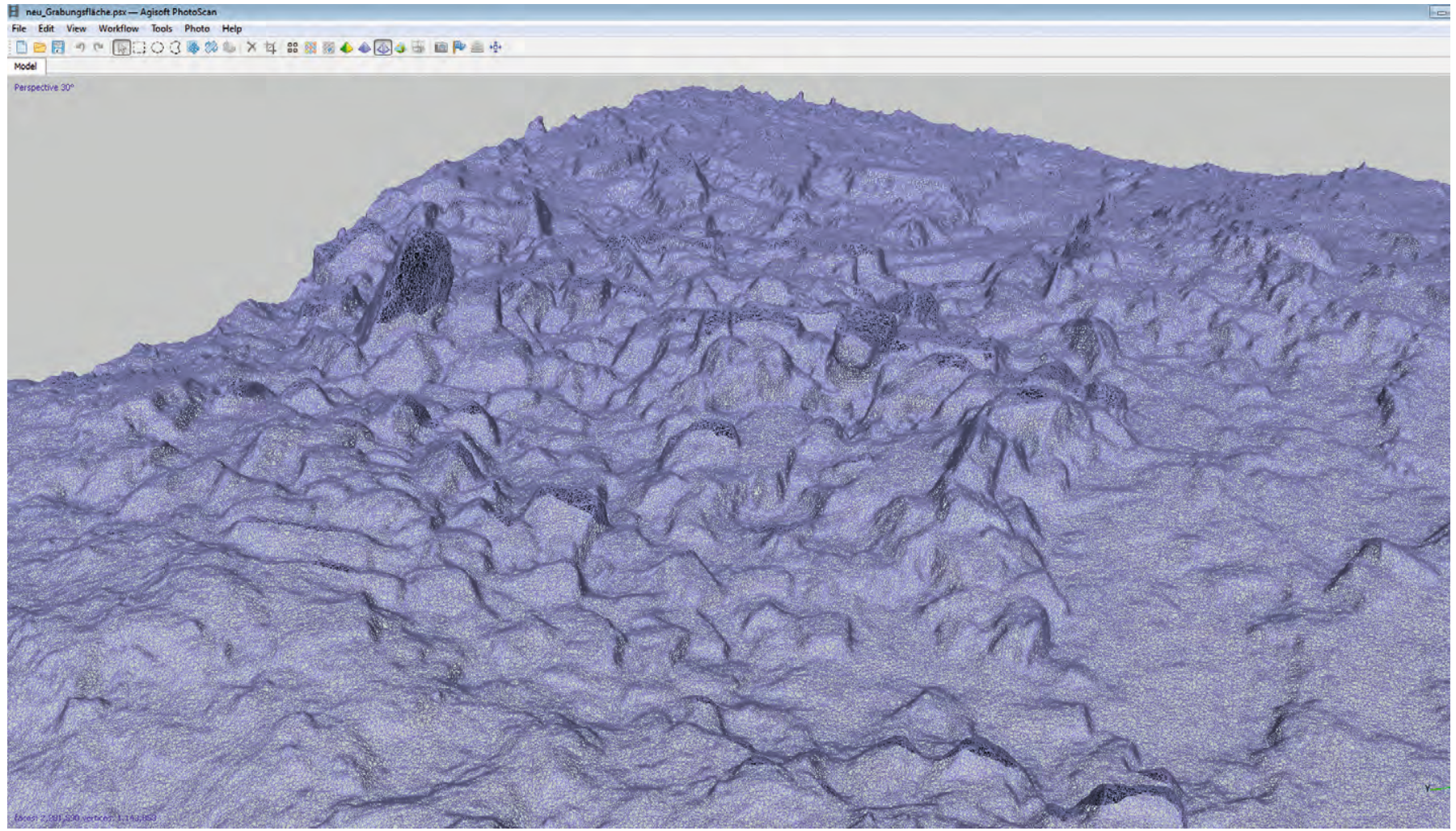

Bildschirmfoto der verwendeten SfMSoftware PhotoScan. Die dreidimensionale Oberfläche der Grabungsschnitte wird durch ein dichtes Gitternetz aus Dreiecken (mesh) wiedergegeben, deutlich sind die Formen der Steine des Mauerversturzes zu erkennen.

Grafik J. Reinhard, 2016
Das dem SfM-Verfahren zugrundeliegende Prinzip ist die Aufnahme der zu modellierenden Szene aus verschiedenen Richtungen, Winkeln und Perspektiven. Die Kamera beziehungsweise der Fotograf "bewegt» sich sozusagen um das Motiv - hierauf nimmt auch die Bezeichnung Structure-from-Motion Bezug. Vergleichbar ist dies mit der Raumwahrnehmung des Menschen: Auch diese beruht unter anderem auf den unterschiedlichen Blickwinkeln beziehungsweise Perspektiven bei der Bewegung durch die Umwelt. Die Rechenalgorithmen des SfM-Verfahrens imitieren dieses optische Prinzip.

In einem ersten Rechenschritt werden in der Bildserie Punkte identifiziert, die auf mehreren der Bilder zu sehen sind - ohne eine deutliche Überlappung der Einzelbilder ist eine 3D-Modellierung per SfM nicht möglich. Für jedes Bild werden die Kameraposition beziehungsweise der Aufnahmeort und die Blickrichtung der Kamera errechnet. Die sich daraus ergebende noch recht schüttere Punktwolke (sparse point cloud) wird in einem weiteren Schritt deutlich verdichtet (dense point cloud) und schliesslich zu einem

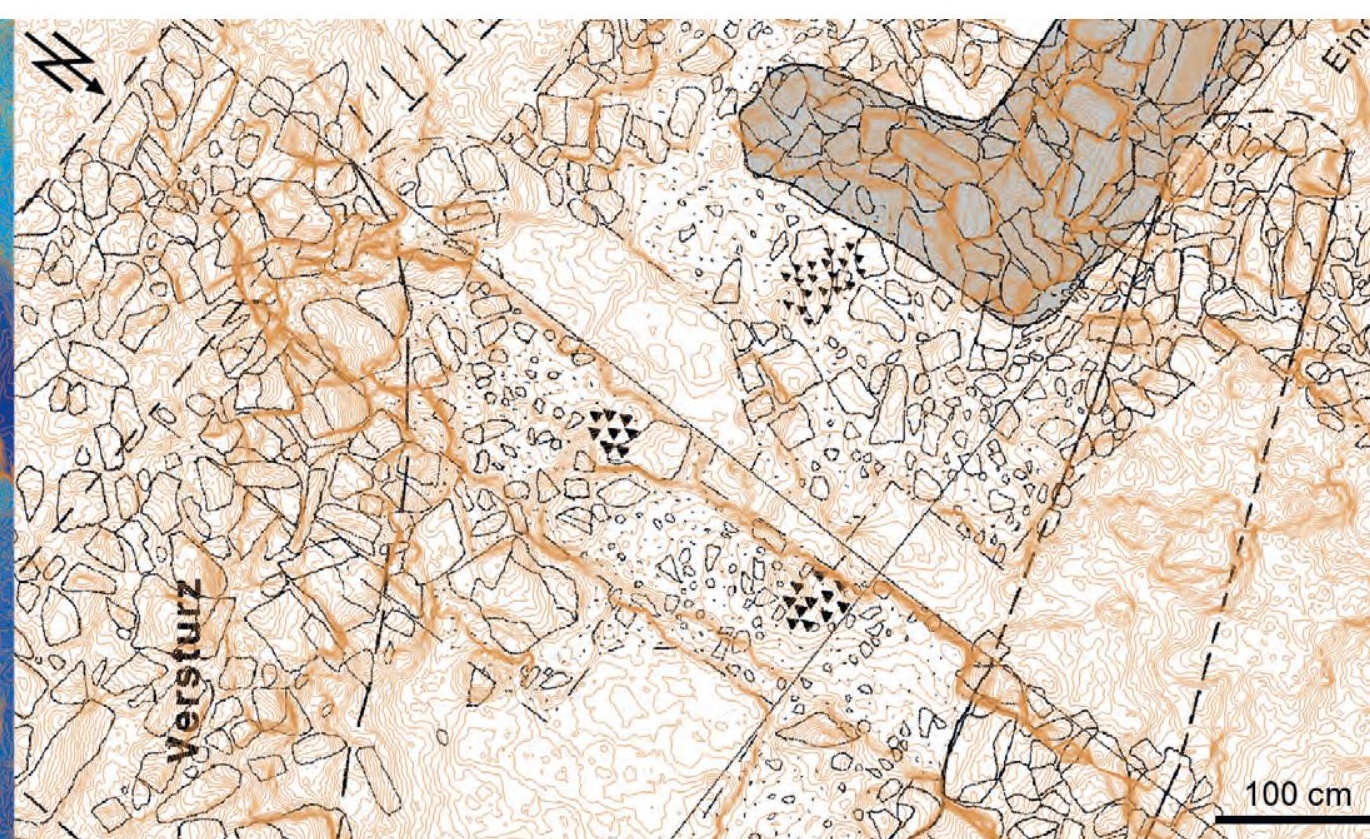




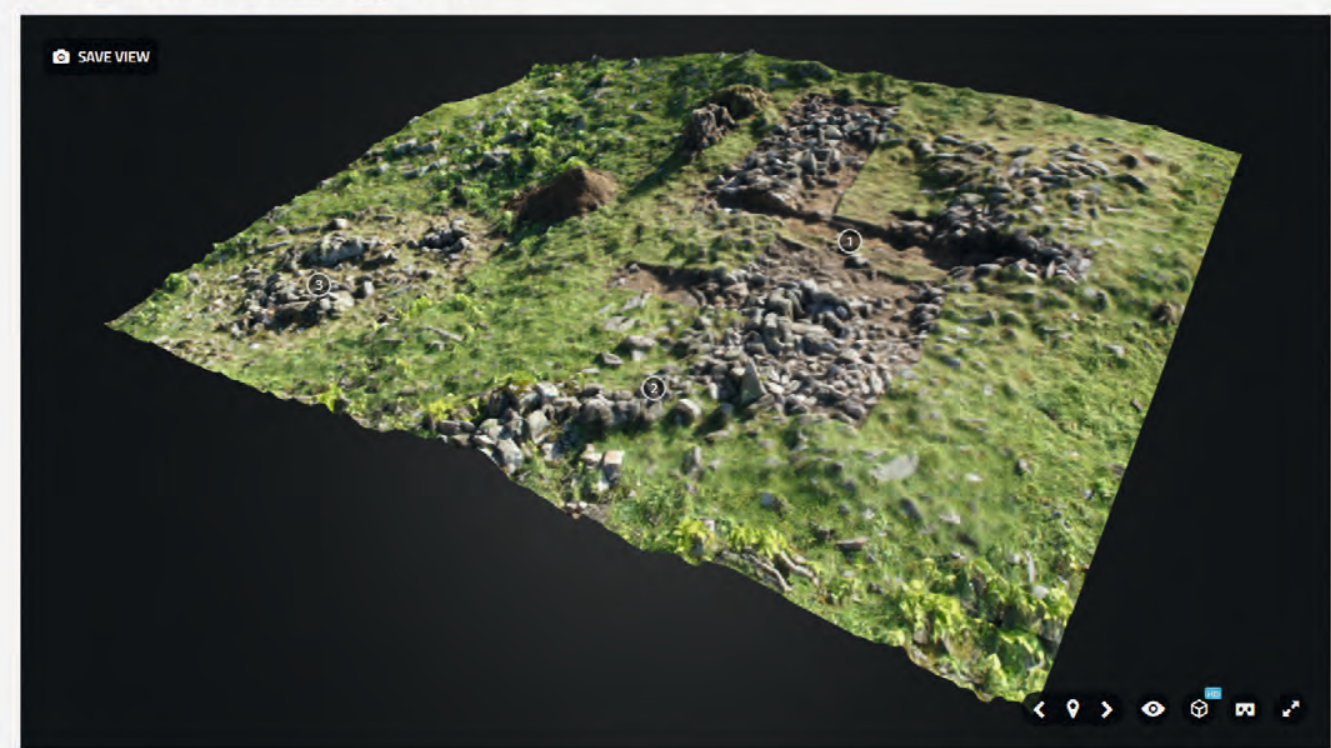

* Likes $\odot 4$ Views

0 comments

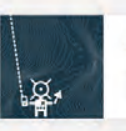

archaeobotics VIEW PROFLLE

ABOUT THIS MODE

Grabungsflache auf dem Geissrüggen, Gemeinde Attinghausen UR, während der einwöchigen Ausgrabungskampagne im August 2013. Freigelegt wurde ein Gebäudegrundriss, der ausweislich der C14-Datierungen in die altere Eisenzeit (Hallstattzeit, 750 - $450 \mathrm{v}$. Chr.) zu stellen ist. Die versturrzten Mauerzüge wurden später mit Jungeren Trockenmavern um- und Oberbaut.

Datengrundlage fur das 30-Modell list eine mit Hilfe einer Drohne aufgenommene Fotoserie.

Ein Modell mit dem unmittelbaren Umfeld der Grabungs findet sich unter httos://skfb.ly/KFRn. Literatur

U. Leuzinger / M. Sauter /f. N. Haas / R. Agola / S. Altstatter $/[\ldots .$.$] . Reinhard [...., Eine$ hallstattzeitiche Gebsudestruktur auf $1911 \mathrm{~m}$ 0.M. am Weg zum Surenenpass, Attinghausen UR. Siedlungsplatz Geissrüggen. Jahrbuch Archăologie Schweiz 97, 2014, 153-168,

(1) Published 6 days ago

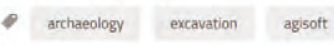

Dreiecksnetz (mesh) vermascht. Über dieses die dreidimensionale Form der fotografierten Szene wiedergebende Gitternetz kann noch eine ebenfalls aus dem Bildmaterial abgeleitete Textur gelegt werden, die dem 3D-Modell ein fotorealistisches Aussehen verleiht. Soll das fertig texturierte 3D-Modell beispielsweise in Vermessungspläne eingebunden werden, muss es noch georeferenziert, das heisst mit Koordinaten orientiert, werden. Für Fundobjekte reicht eine Skalierung, also die Angabe eines Massstabes, aus.

Ein georeferenziertes 3D-Modell hat im Vergleich zur konventionellen Grabungsdokumentation den Vorteil einer erheblich höheren Informationsdichte: Klassische Befundzeichnungen etwa zeigen den Befund auf die zweidimensionale Zeichenebene projiziert; mit eingemessenen Höhenangaben an prägnanten Stellen wird versucht, die dritte Dimension wiederzugeben. Während dies bei Profilen und flachen Grabungsplana noch ausreichen mag, ist es - auch mit tachymetrischer Vermessung oder zweidimensionaler Photogrammetrie - kaum möglich, stark dreidimensionalen Befundsituationen annähernd gerecht zu werden. Auch Fotografien geben ein Motiv zwangsläufig immer perspektivisch verzerrt wieder. Ein 3D-Modell kann dagegen räumlich, das heisst aus beliebigen Richtungen, betrachtet werden, ist der Realität also deutlich näher als eine stark abstrahierte zweidimensionale Wiedergabe. Die Auflösung des Modells ist dabei direkt von der Auflösung des Bildmaterials abhängig, das für die Modellierung verwendet wird. Typischerweise erreichen durch Structure-from-Motion erstellte 3D-Modelle Detaillierungsgrade, die um ein Vielfaches über dem im Feld mit konventionellen Mitteln Messbaren liegen; lediglich bei der Verwendung von Laserscannern sind vergleichbar dichte Punktwolken erreichbar. Die 3D-Daten sind in ganz unterschiedlichen Formaten aus der SfM-Software exportierbar, die in GIS- und CAD-Umgebungen eingebunden werden
Bildschirmfoto eines der beim OnlineHoster Sketchfab eingestellten 3DModelle der Geissrüggen-Grabung. Grafik J. Reinhard, 2016 
8 Vgl. beispielsweise Miles/Wilson/ Labrosse et al. 2015.

9 Barrettara 2013. - Heidenreich 2014, 263-264.

Bildschirmfoto eines der beim OnlineHoster Sketchfab eingestellten 3DModelle der Geissrüggen-Grabung. Durch Anklicken der Zahlen sind Informationen zum Modell abrufbar. Grafik J. Reinhard, 2016 können, wo sie als Datengrundlage für weitere Analysen dienen. Häufige Anwendungen sind dabei die Generierung von Orthofotos, von lagetreuen Bildplänen, die sich etwa als Zeichengrundlagen eignen, oder von Digitalen Höhenmodellen, aus denen beispielsweise Höhenlinien generiert werden können. Doch auch wenn eine 3D-Modellierung durchaus geeignet ist, die Grundlagen für die Grabungsdokumentation zu liefern, diese entscheidend zu verdichten und den Dokumentationsvorgang gegebenenfalls zu beschleunigen - die kritische Auseinandersetzung mit dem Befund selbst kann sie nicht ersetzen. Die Entscheidungen, die etwa beim Erstellen einer Feldzeichnung laufend getroffen werden - Wo genau verläuft die Befundgrenze? Was ist wichtig, was nicht? Zu welcher Schicht gehört dieser Stein? Was ist ein menschengemachter Befund? Was ist bereits die anstehende Geologie? -, müssen nach wie vor am Ort getroffen und in geeigneter Weise dokumentiert werden.

3D-Modelle eignen sich ideal auch für die Vermittlung komplexer dreidimensionaler Zusammenhänge im wissenschaftlichen Dialog oder etwa in der Öffentlichkeitsarbeit. ${ }^{8}$ Die in der Archäologie üblichen Grabungspläne sind für Laien häufig schwer lesbar, ein 3D-Modell erleichtert das Begreifen einer Befundsituation - im Fall eines 3D-Drucks sogar im Wortsinne! In klassischen Publikationsformaten wie Büchern, (Fach-)Zeitschriften oder Zeitungen ist die Wiedergabe von 3D-Inhalten jedoch nicht möglich - um zwischen zwei Buchdeckel zu passen, muss das 3D-Modell wieder in die zweite Dimension gebracht werden. Anders verhält es sich mit den neuen Medien: Moderne Internet-Techniken erlauben die problemlose interaktive Präsentation von 3D-Inhalten im Browser, weitgehend unabhängig vom verwendeten Endgerät. Der 3D-modellierte Fund oder Befund kann ohne Zusatzsoftware auf dem Bildschirm angezeigt und vom Betrachter durch Zoomen und Drehen von allen Seiten betrachtet werden. Eine 2012 gegründete, gut für archäologische Zwecke geeignete Präsentationsplattform ist Sketchfab (https://sketchfab.com/). ${ }^{9}$ Die Webseite übernimmt für 3D-Inhalte eine ähnliche Funktion wie Youtube für Videos. Angemeldete Benutzer können Modelle hochladen, teilen, verlinken, kommentieren, liken etc. Auch das Einbetten der 3D-Modelle in externe Webseiten ist möglich. Im Modell können Marker gesetzt werden, über die nähere Informationen abrufbar sind; auch "geführte Touren" durch das 3D-Modell können damit erstellt werden. Neu bietet Sketchfab auch eine Virtual-Reality-Funktion, mit der man

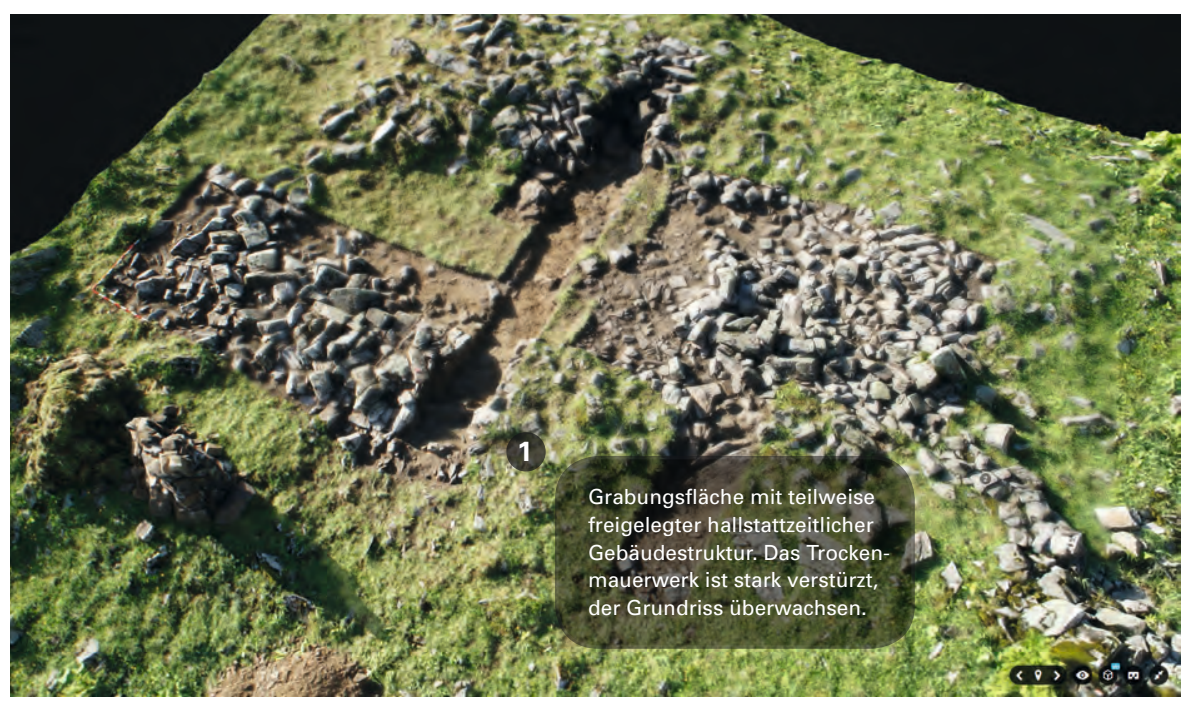




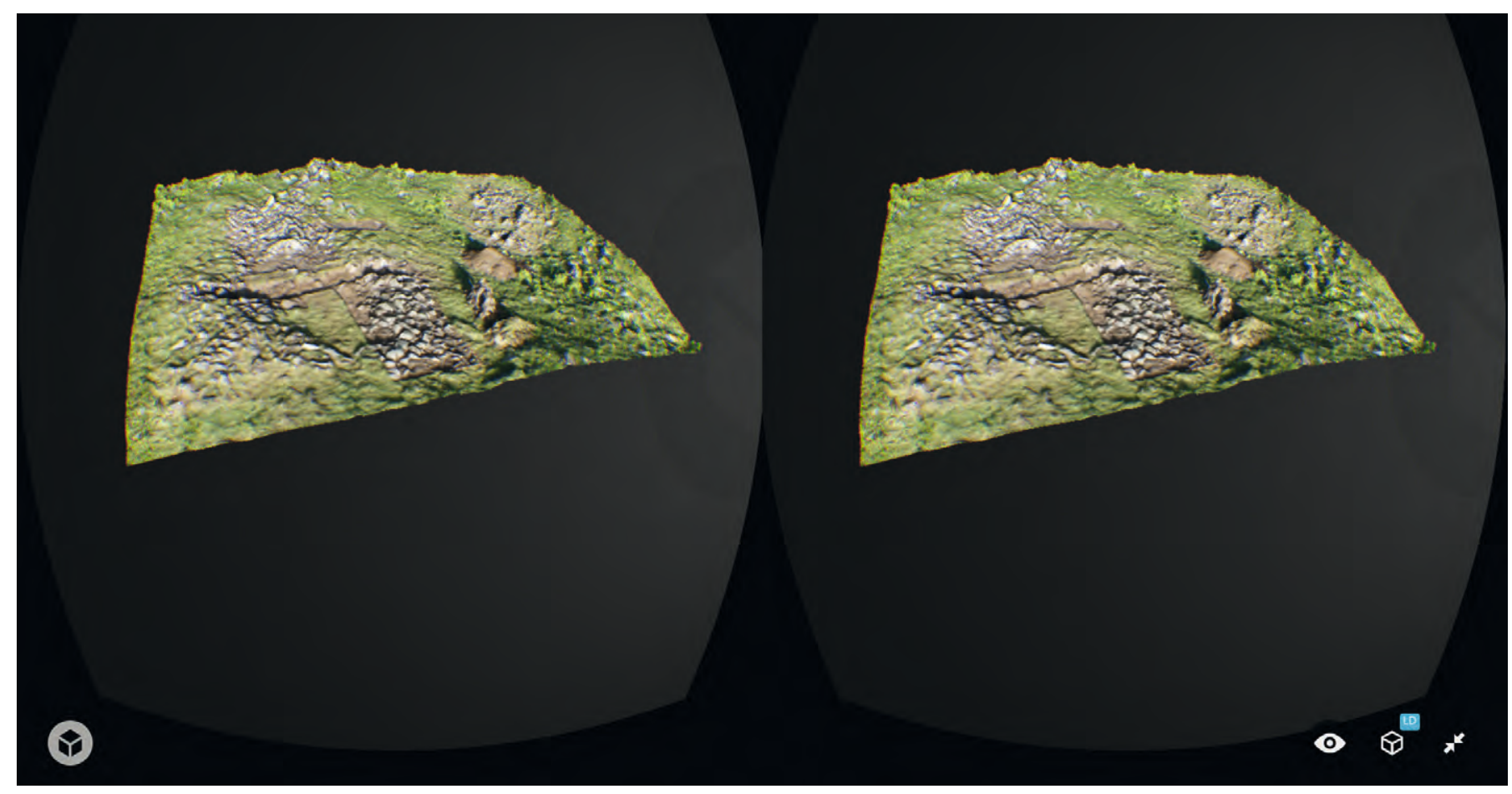

mithilfe eines Google-Cardboards, einer preiswerten Videobrille aus einem Smartphone und einer Kartonhalterung, virtuell in das 3D-Modell "eintauchen» kann. Die 3D-Modelle der Grabungssituation auf dem Geissrüggen sind abrufbar unter https://sketchfab.com/archaeobotics/folders/attinghausen-geissruggen-ur-schweiz. Der Link kann auch aufgerufen werden, indem der am Ende dieses Artikels stehende QR-Code mit einer geeigneten Smartphone-App erfasst wird. Ein virtueller, wetterunabhängiger Besuch der Grabung ist jetzt also für alle Interessierten jederzeit möglich!

Andres, B. / Walser, C. (2013). Drohnen in der alpinen Archäologie. Luftbildaufnahmen von Alpwüstungen im Oberhasli. In: Archäologie Bern 2013 - Jahrbuch des Archäologischen Dienstes des Kantons Bern 2013. Bern, 107-109.

Barrettara, M. (2013). New methods for sharing and exhibiting 3D archaeology. The Post Hole 31, (September) 2013, 8-13 (http://www.theposthole.org/read/article/218 (4.2.2016)).

Bofinger, J. / Steffen, C. (2014). Die fliegende Kamera. Neue Methoden der archäologischen Fotodokumentation aus der Luft. In: Denkmalpflege in Baden-Württemberg 43/2, 108-112.

De Reu, J. / Plets, G. / Verhoeven, G. et al. (2013). Towards a three-dimensional costeffective registration of the archaeological heritage. In: Journal of Archaeological Science 40, 1108-1121.

De Reu, J. / De Smedt, P. / Herremans, D. et al. (2014). On introducing an image-based $3 D$ reconstruction method in archaeological excavation practice. In: Journal of Archaeological Science 41, 251-262.

Heidenreich, S.M. (2014). Virtuelle Archäologie in Baden-Württemberg. Von der wissenschaftlichen Dokumentation zur öffentlichen Web-Präsentation von 3-D-Modellen archäologischer Denkmale. In: Denkmalpflege in Baden-Württemberg 43/4, 261-264. Lambers, K. / Zingman, I. (2012). Am Boden, aus der Luft, aus dem All. Prospektion archäologischer Fundstellen in der Silvretta. In: Reitmaier, T. (Hrsg.). Letzte Jäger, erste Hirten. Hochalpine Archäologie in der Silvretta (Archäologie in Graubünden Sonderheft 1). Chur, 71-85.
Bildschirmfoto eines der beim OnlineHoster Sketchfab eingestellten 3DModelle der Geissrüggen-Grabung im Virtual-Reality-Modus. Die Daten werden als Stereobild auf einem Smartphone ausgegeben und verschmelzen durch den geringen Sehabstand zu einem einzigen Bild, dass durch Bewegung des Smartphones dreh- und schwenkbar ist. Grafik J. Reinhard, 2016 
Leuzinger, U. / Sauter, M. / Haas, J.N. et al. (2014). Eine hallstattzeitliche Gebäudestruktur auf 1911 m ü. M. am Weg zum Surenenpass, Attinghausen UR. In: Jahrbuch Archäologie Schweiz 97, 153-168.

Miles, H.C. / Wilson, A.T. / Labrosse, F. et al. (2015). Alternative Representations of $3 D$-Reconstructed Heritage Data. Journal on Computing and Cultural Heritage 9/1, 4:1-4:18.

Novák, D. / Tokarczyk, P. / Theiler, P.W. (2012). Modeling the "Plan da Mattun» archaeological site using a combination of different sensors. International Archives of the Photogrammetry, Remote Sensing and Spatial Information Sciences 39-B6 [XXII ISPRS Congress, 25 August - 01 September 2012, Melbourne, Australia], 147-152 (http://www.int-arch-photogramm-remote-sens-spatial-inf-sci.net/XXXIX-B6/index.htmI (18.5.2015)).

Ramha (Hrsg.) (2012). le relevé 3D (http://www.ramha.ch/?page_id=496 (14.11.2015)). Ramha (Hrsg.) (2015). Bilan de la campagne 2015 sur le mur (dit) d'Hannibal (http:// www.ramha.ch/?p=922 (14.11.2015)).

Reinhard, J. (2012). Things on strings and complex computer algorithms. Kite Aerial Photography and Structure from Motion Photogrammetry at the Tulul adh-Dhahab, Jordan. In: AARGnews 45, 37-41.

Reinhard, J. (2013). Structure from Motion, Drohnen \& Co. Neue Wege in der Dokumentation archäologischer Ausgrabungen. In: Tugium 29, 177-188.

Reinhard, J. (im Druck). Structure-from-Motion-Fotogrammetrie mit Agisoft PhotoScan. Erste Erfahrungen aus der Grabungspraxis. In: Lieberwirth, U. / Herzog, I. (Hrsg.). Computeranwendungen und Quantitative Methoden in der Archäologie (= 4. Workshop der CAA 2013. Berlin Studies of the Ancient World).

Reitmaier, T. (2011). Alles besser als Krieg. Zum sinnvollen Einsatz ferngesteuerter Drohnen in Archäologie und Denkmalpflege. In: Amt für Kultur, Archäologischer Dienst Graubünden (Hrsg.). Vom Steinbeil bis zur Flintenkugel. Festschrift Jürg Rageth. Chur, 61-65.

Verhoeven, G. (2009). Providing an Archaeological Bird's-eye View - an Overall Picture of Ground-Based Means to Execute Low-altitude Aerial Photography (LAAP) in Archaeology. In: Archaeological Prospection 16, 233-249.

Verhoeven, G. (2011). Software Review. Taking Computer Vision Aloft - Archaeological Three-dimensional Reconstructions from Aerial Photographs with PhotoScan. In: Archaeological Prospection 18, 67-73.

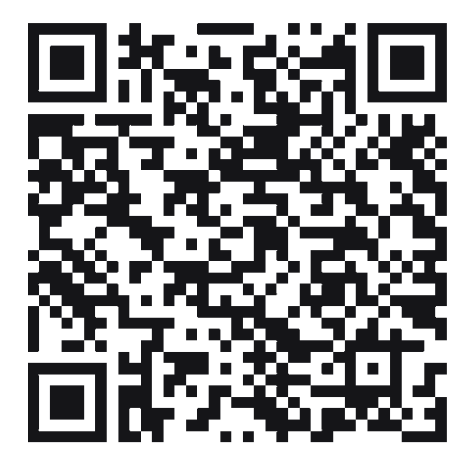




\section{Summary: Structural change - Alpine pasture on Surenen}

During a second round of surveys carried out in the summer of 2014, a further 20 disused buildings were discovered on Surenen, on the other side of the summit. The Alpine farm buildings were all located at a considerable distance from the current Surenen Pass trail in areas of higher elevation and included a wide range of construction types: rock shelters, huts, pens and enclosures. According to radiocarbon analyses carried out on charcoal fragments, two of the sites, the "Ginger City" and "Massiv" groups of buildings on Blackenboden, had already been farmed in the Middle Ages. The constructional remains, some of which were quite extensive, suggested that the terrain at this level had been used until well into Modern Times. The multitude of architectural components fit in well with the expectation that Alpine pastures north of the Schöllenen Gorge would have been owned and managed by individual families. Today, however, the Surenen area is collectively owned and managed from a central location at Blackenalp. The sites therefore document a structural change in Alpine farming, which began around 1600 and continued into the $18^{\text {th }}$ century. Cooperative cattle herding appears to have been introduced in the peripheral Alpine areas of Uri as a rationalisation measure, whilst the more favourable location of Surenen and the architectural features uncovered suggest that this change took place at a later date there. As part of this structural change, the route of the Surenen Pass trail was also altered, because it was now no longer necessary to maintain access to the areas of Blackenboden, Gritschen and Butzen, which had once been settled. 


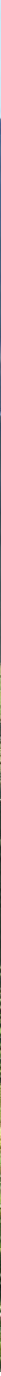

\section{Strukturwandel - Die Alpnutzung auf Surenen}

Surenen war bis im Sommer 2014 ein nahezu blinder Fleck in der Urner Wüstungsforschung: Entlang des heutigen Passwegs finden sich nur äusserst vereinzelt Ruinen von Alpgebäuden. Eine intensive Prospektionskampagne brachte nun in einigen höher liegenden Geländekammern ehemalige Siedlungsplätze ans Tageslicht. Die Fundorte datieren bis ins Hochmittelalter zurück und belegen einen alpwirtschaftlichen Strukturwandel, begleitet von einer Verlegung des Surenenpasswegs.

\section{Ausgangssituation}

Südwestlich der Surenenpasshöhe öffnet sich auf $1870 \mathrm{~m}$ ü.M der weite Talkessel von Blacken, der vom Wissberg (2739 m ü.M.), dem Wissigstock (2887 m ü.M.), dem Blackenstock (2931 m ü.M.) und dem Schlossbergmassiv (3133 m ü.M.) gefasst wird. Entlang des Surenenpasswegs, zwischen der Passhöhe und der Blackenalp, konnten bislang keine Siedlungsspuren dokumentiert werden - einzig die Balmwand auf der Passhöhe bot Passgängern einst Schutz $(\rightarrow$ S. 82-101). Die Ursprünge der heutigen Surenenschutzhütte knapp unterhalb der Passhöhe sind nicht bekannt.

Die weitläufigen Alpweiden von Surenen setzen sich im Süden auf einer Geländeterrasse auf 1680 m ü.M. mit den Alpstafeln Hobiel, Steinäbnet, Steinhütte und Usser Äbnet fort. Hier wurden wahrscheinlich die Vorgän- 


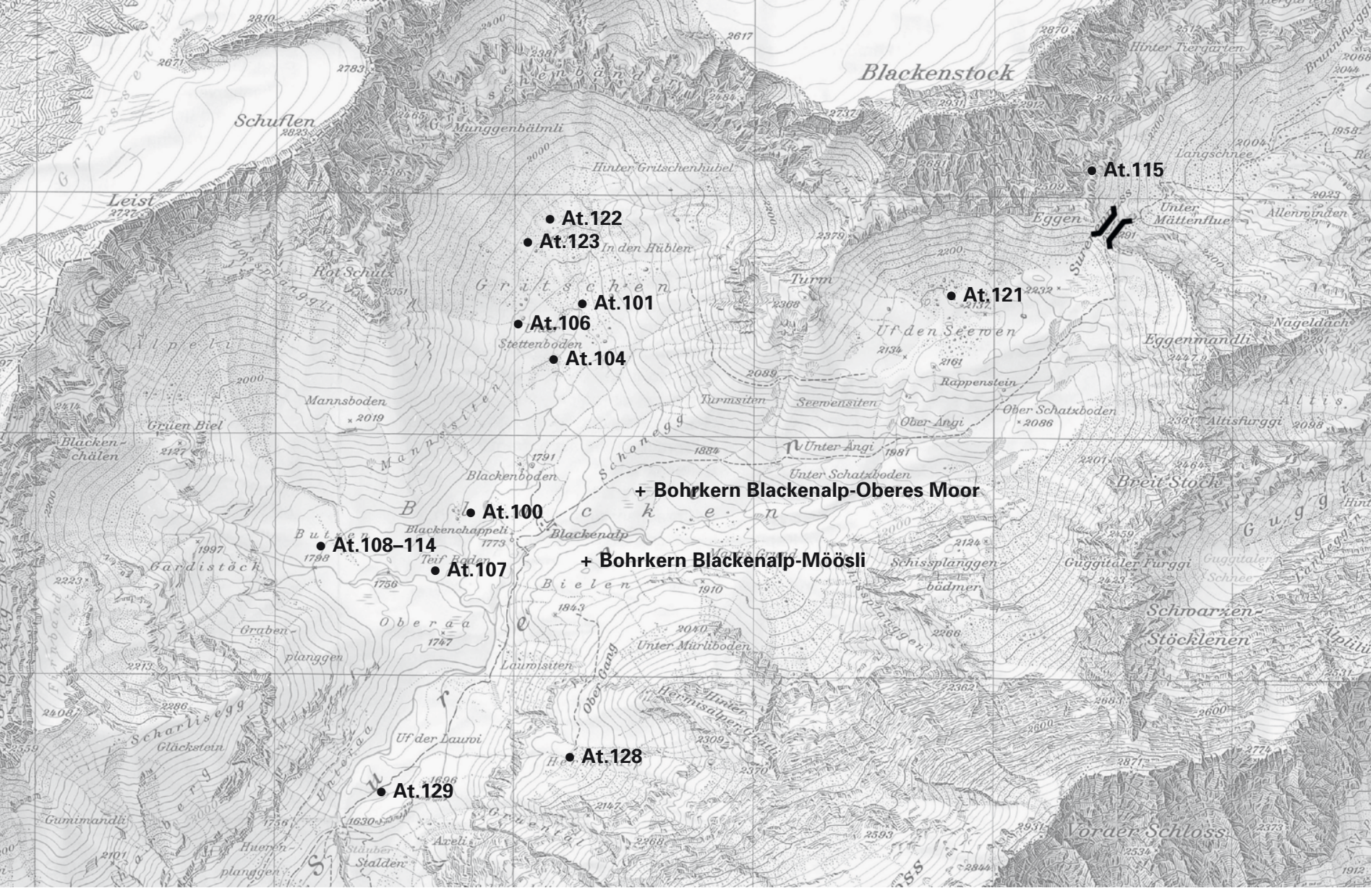

gerbauten der heutigen Alpgebäude überbaut: Anders als beispielsweise auf dem Grat finden sich keine Hinweise auf weitere ältere Alpstafel. Normalerweise hilft hier die Siegfriedkarte weiter, aber auch das 1875 entstandene Blatt Engelberg verzeichnet ausser der Blackenalp - Hütte und Stall - lediglich eine weitere gedeckte Hütte auf der peripheren Hermisalp auf 1950 m ü.M. In der Neuauflage der Siegfriedkarte von 1878 ist Letztere nicht mehr dokumentiert.

Das angrenzende Nidersurenen wird im Westen von einer steilen Fluh begrenzt. Die gegenüberliegende Talflanke ist sanft geneigt, jedoch stark von Steinschlägen betroffen. So kam der mächtige Fuchsstein, welcher auf den ersten Blick ein idealer prähistorischer Rastplatz zu sein scheint, erst im ausgehenden 19. Jahrhundert in Nidersurenen zu liegen. Damit war Surenen bis zum Sommer 2014 das an archäologischen Streufunden reichste ( $\rightarrow$ S. 184-201), zugleich jedoch das an Wüstungsplätzen ärmste Urner Alpgebiet.

Nach der erfolgreichen Grabungskampagne im Jahr 2013 auf dem Geissrüggen, bei der die Ruine eines hallstattzeitlichen Gebäudes untersucht wurde ( $\Rightarrow$ S. 122-135), führte ein Team ${ }^{1}$ von freiwilligen Experten vom 3. bis 10. August 2014 eine ausgiebige archäologische Prospektion auf Surenen durch. Ziel der Kampagne war es, die gewaltige Lücke im Forschungsstand zu schliessen und auch südwestlich der Passhöhe Wüstungsplätze, schutzbringende Abris sowie oberflächige (prä-)historische Bodenfunde zu lokalisieren - mit einigem Erfolg: Es wurden insgesamt 30 mittelalterliche bis neuzeitliche Wüstungsplätze (At.099 bis At.129) fernab des heutigen Surenenpasswegs entdeckt und dokumentiert. Die periphere Lage der inventarisierten Bauten ermöglichte eine Rekonstruktion der früheren Wirtschaftsverhältnisse und des ursprünglichen Wegverlaufs ( $\rightarrow$ S. 102-121).
Titelbild: Blackenalp - Blick von Bielen in Richtung Blackenboden und Gritschen. Foto M. Sauter, 2014

Übersicht über die Fundstellen auf Surenen.

Karte swisstopo (BA16018)
1 Team 2014: Claudia Beck, Marcel Cornelissen, Regula Gubler, Jean Nicolas Haas, Walter Imhof, Reto Jagher, Urs Leuzinger, Catherine Leuzinger-Piccand, Christine Pümpin, Marion Sauter und Pascal Stöckli, unterstützt von Caroline und Philippe Leuzinger. 
Übersicht über Uf den Seewen (2134 m ü.M.). Bauliche Massnahmen sind lediglich an einigen wenigen Felsblöcken im Steinschlagareal zu erkennen.

Foto M. Sauter, 2014

\section{At.121}

Abri sous bloc (Ansicht)

Attinghausen-Uf den Seewen

LK 1191, 688 740/187 623, 2139 m ü.M

Foto M. Sauter, 2014

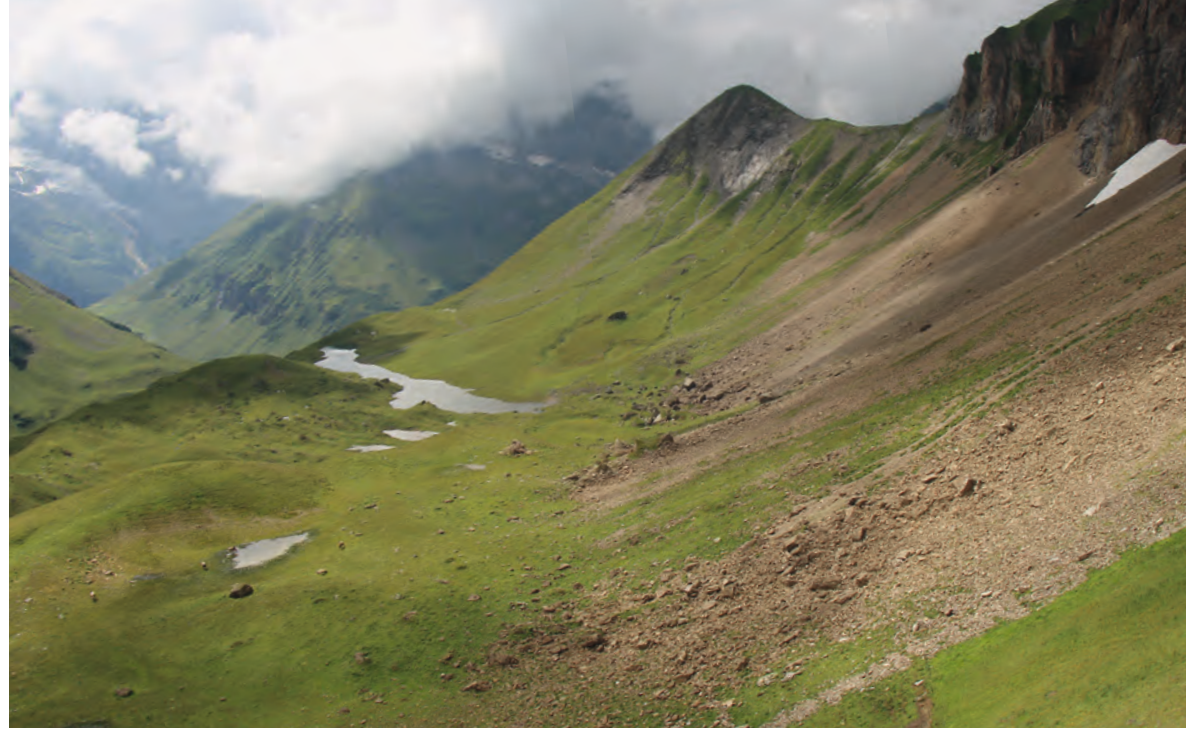

Zudem konnten zwei Torf-Bohrkerne aus dem Blackenalp-Möösli (LK 1191, 682 300/186 550, 1800 m ü.M.) und aus Blackenalp-Oberes Moor (LK 1191, 682 560/186 780, 1820 m ü.M.) für palynologische und paläoökologische Untersuchungen entnommen werden ( $\Rightarrow$ S. 24-45). Die Radiokarbondatierungen an den Torfen wurden von Irka Hajdas im Labor für lonenstrahlphysik der ETH Zürich durchgeführt. Die anthrakologischen Bestimmungen stammen von Anton Stefan Schwarz vom Institut für Botanik der Universität Innsbruck. ${ }^{2}$

\section{Uf den Seewen}

Unmittelbar unterhalb der Passhöhe lädt die Hochterrasse Uf den Seewen auf 2134 m ü.M. mit mehreren kleinen Seen zur Rast ein. Das Areal wird vom Grat zwischen dem Turm (2368 m ü.M.) und der Eggen (2509 m ü.M.) gefasst. Der Steilhang ist äusserst steinschlägig: Im Lauf der Jahrhunderte kamen zahlreiche Felsblöcke an der nördlichen Flanke von Uf den Seewen zu liegen. Wider Erwarten fanden sich hier jedoch keine nennenswerten historisch anmutenden Siedlungsspuren, obwohl andere Urner Areale in dieser Höhenlage offensichtlich eine durchaus intensive Nutzung erfuhren.

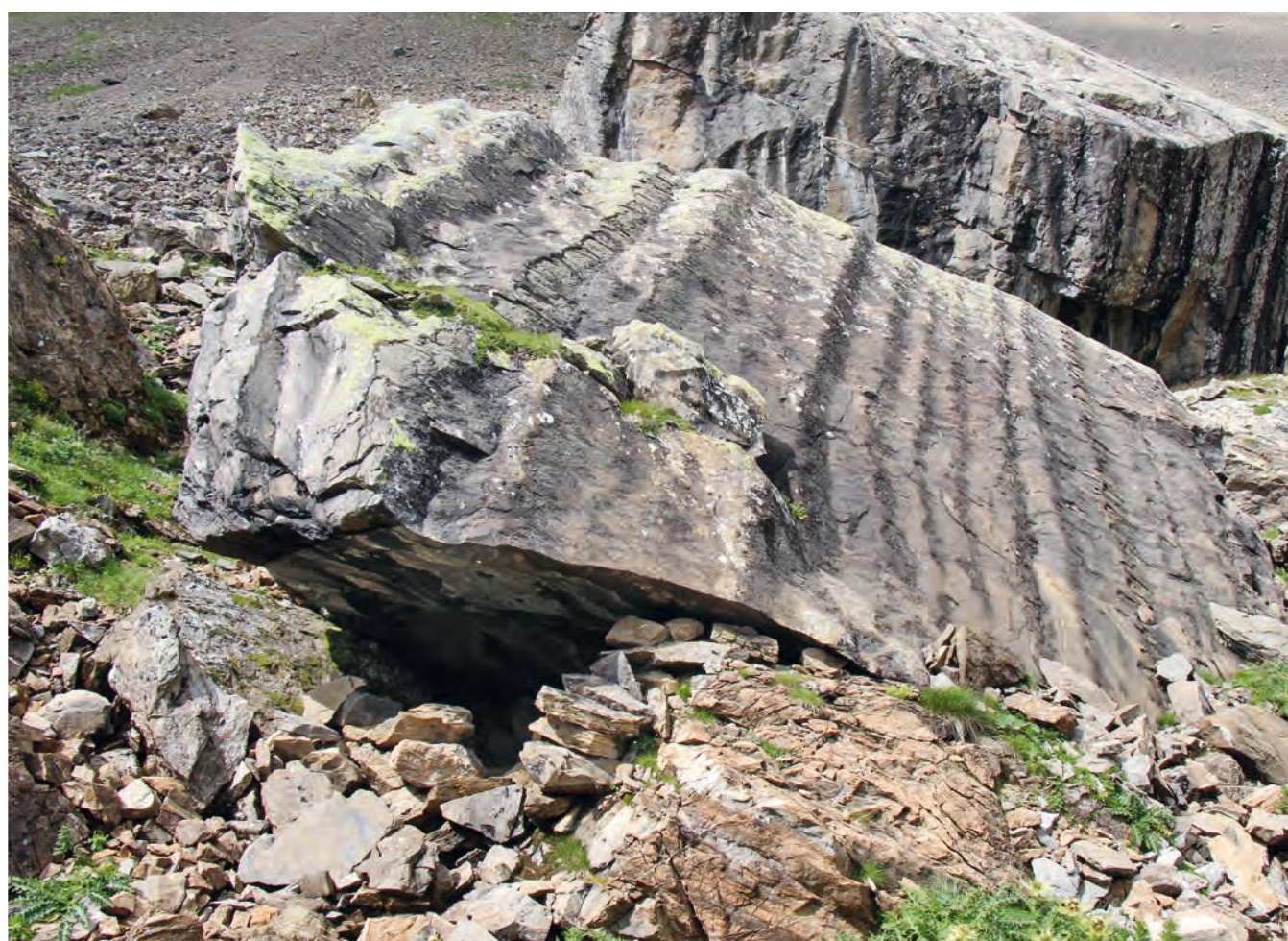

2 Leuzinger/Sauter/Haas et al. 2015. Die vollständige Dokumentation zur Prospektionskampagne 2014 befindet sich im Archiv der Denkmalpflege des Kantons Uri, Altdorf. 


\section{Uf den Seewen: Abri sous bloc (At.121)}

LK 1191, 688 740/187 623, 2139 m ü.M.

Eine einzige Felsformation ragt unter den mit jüngerem Mauerwerk und modernen Befestigungen versehenen Lagerplätzen der Jäger auf Uf den Seewen hervor: Der Block formt einen besonders gut geschützten Raum, der bis auf einen Zustieg mit Mauerwerk gefasst ist und Platz für eine Person bietet. Die heutige Mauer ist wenig akkurat geschichtet - wahrscheinlich eine Erneuerung in jüngerer Vergangenheit (Abb. At.121).

\section{Blackenboden - Gritschen}

Die Flur Gritschen liegt gut 1 km nördlich der Blackenalp, am Ende des Talkessels. Das Gelände steigt hier von 1850 auf gut 2000 m ü.M. an, ist steinschlägig und nur spärlich bewachsen. Zwischen Gritschen und der Blackenalp befindet sich der vom Stierenbach durchzogene Blackenboden, der von einem markanten Felsblock ohne erkennbare Siedlungsspuren überragt wird. Das gesamte Areal dient heute als Alpweide und ist nicht erschlossen.

\section{Gritschen: Schutzhütte und Pferch Gritschen 1 (At.122)}

LK 1191, 682 150/187 845, 1929 m ü.M.

In der Flur Gritschen verbindet eine mehrlagige Trockenmauer verschiedene grosse Felsblöcke zu einer amorphen, pferchartigen Steinsetzung. Im Innern der Struktur befindet sich ein sorgfältig gefügter Sitzstein.

In einer Felsspalte wurde eine kleine Sondierung von $10 \times 10 \mathrm{~cm}$ angelegt. In $18 \mathrm{~cm}$ Tiefe kamen zwei Knochenfragmente zum Vorschein: Das Metapodium eines jungen Rinds weist Bissspuren auf, der Langknochen eines kleinen Wiederkäuers ist aufgeschlagen und dürfte ein Speiseabfall sein. Die Anlage datiert vermutlich ins Mittelalter oder in die frühe Neuzeit (Abb. At.122).
At. 122

Schutzhütte und Pferch Gritschen 1 (Übersicht)

Attinghausen-Gritschen

LK 1191, 682 150/187 845, 1929 m ü.M.

Foto M. Sauter, 2014

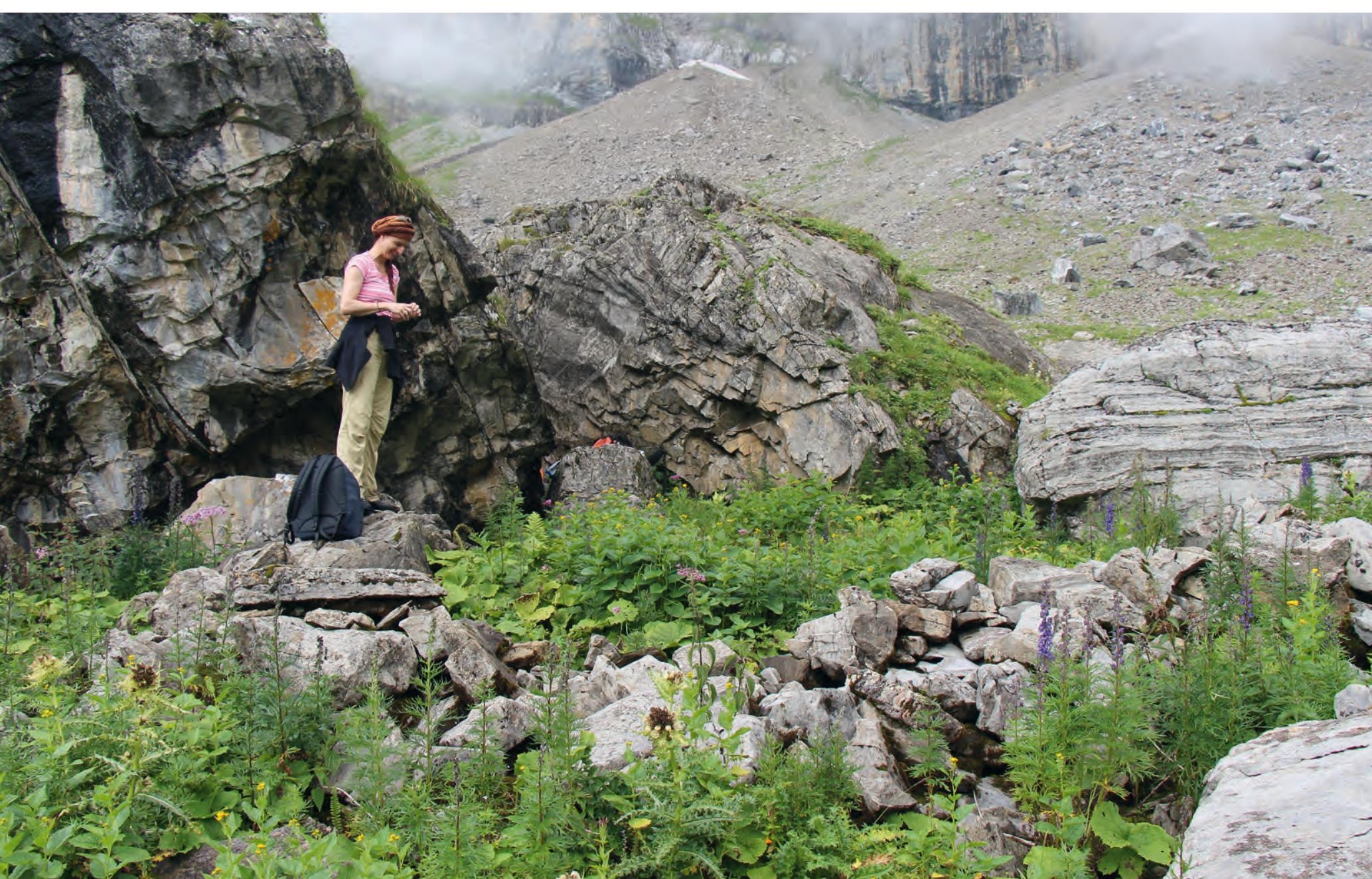


At.123

Abri sous bloc Gritschen 2 (Seitenansicht)

Attinghausen-Gritschen

LK 1191, 682 000/187 740, $1941 \mathrm{~m}$ ü.M.

Foto M. Sauter, 2014

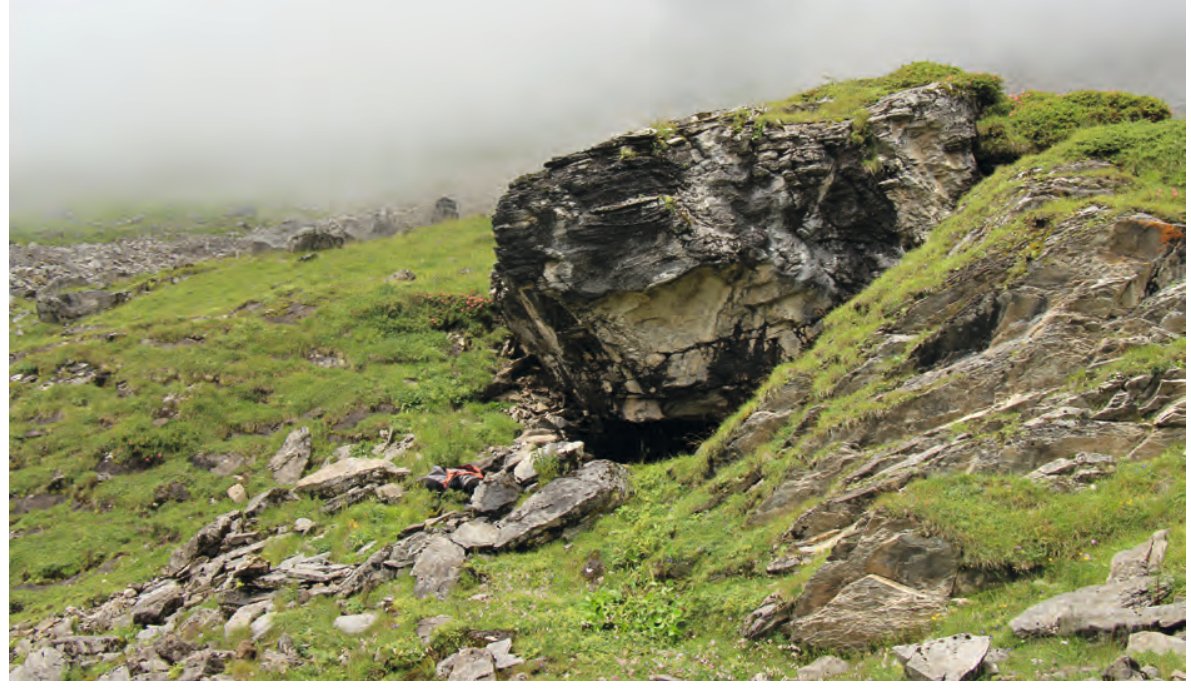

\section{Gritschen: Abri sous bloc Gritschen 2 (At.123)}

LK 1191, 682 000/187 740, 1941 m ü.M.

Etwas oberhalb der Schutzhütte Gritschen 1 befindet sich unter einem grossen verstürzten Felsen ein Abri sous bloc, der von einer mehrlagigen Trockenmauer mit seitlichem Eingang gefasst wird. Der Innenraum ist durch eine weitere Mauer unterteilt. Der vordere Bereich dieses Abri sous bloc wurde vermutlich zu einem späteren Zeitpunkt abgetieft, um eine angenehme lichte Höhe zu erreichen. Hier befinden sich mehrere Sitzplätze aus sorgfältig positionierten Steinplatten. Im hinteren Abri-Bereich kam unter einer grossen Steinplatte eine Feuerstelle zum Vorschein, an der zwei kleine Sondierungen durchgeführt wurden ( $\rightarrow$ S. 99-102). Obwohl die Radiokarbondatierung der Feuerstelle mit dem Zeitraum um 1670 bis 1940 n.Chr. ${ }^{3}$ sehr jung ausgefallen ist, dürfte der Abri sous bloc Gritschen 2 bereits im Mittelalter oder in prähistorischer Zeit genutzt worden sein. Dafür sprechen seine Grösse, seine günstige Lage und die starke Einsedimentierung des Felsblocks im spärlich bewachsenen Gelände (Abb. At.123).

\section{Blackenboden: Wüstungsplatz "Ginger City» (At. 104)}

LK 1191, 682 175/187 300, 1830 m ü.M.

Beidseitig des Stierenbachs liegt ein ausgedehnter Wüstungsplatz mit mehreren Gebäuderuinen und einem grossen Pferch. Im Zentrum von "Ginger City ${ }^{4}$ befindet sich ein 5,5 $\times 7$ m (Aussenmass) grosser, rechteckiger Bau (Haus 1) mit zwei angrenzenden, ins Gelände eingetieften Höfen, an die zwei weitere, kleine, quadratische Gebäude (Häuser 3 und 4) angefügt sind.

Das Hauptgebäude (Haus 1) wird im Norden erschlossen. Die sorgfältig gefügten zweihäuptigen Mauern sind 0,8 m dick und noch bis zu acht Steinlagen hoch erhalten. Die Südmauer ist im Verband verstürzt - allenfalls verursacht durch eine Schneelawine oder ein Erdbeben, wie es am 18. September 1601 mit Epizentrum im nur 20 km entfernten Sarnen stattfand. ${ }^{5}$ Den im Trübsee unterhalb des Titlis nachgewiesenen Sedimentdeformationen und umliegenden Hangrutschungen nach zu urteilen, müsste das Beben im nahe gelegenen Surenen ebenfalls gehörige Schäden verursacht haben. ${ }^{6}$ Zudem wurden zwei kleinere Gebäudegrundrisse (Häuser 2 und 5), die im Schutz zweier grosser Felsblöcke liegen, sowie eine Felsspalte mit Trockenmauer, die möglicherweise als Kühlkeller diente, dokumentiert. Am gegenüberliegenden Bachufer befindet sich ein etwa $13 \times 20 \mathrm{~m}$ grosser Pferch. Die stark
ETH-57595: 129 23 BP, AD 1670-1940.

4 Benannt nach dem treuen Begleiter des Archäologenteams, dem Hund Ginger der Blackenalpwirtin.

5 Schwarz-Zanetti/Deichmann/Fäh et al. 2003. - Strasser/Anselmetti/Fäh et al. 2006.

6 Glur/Stalder/Wirth et al. 2015. 


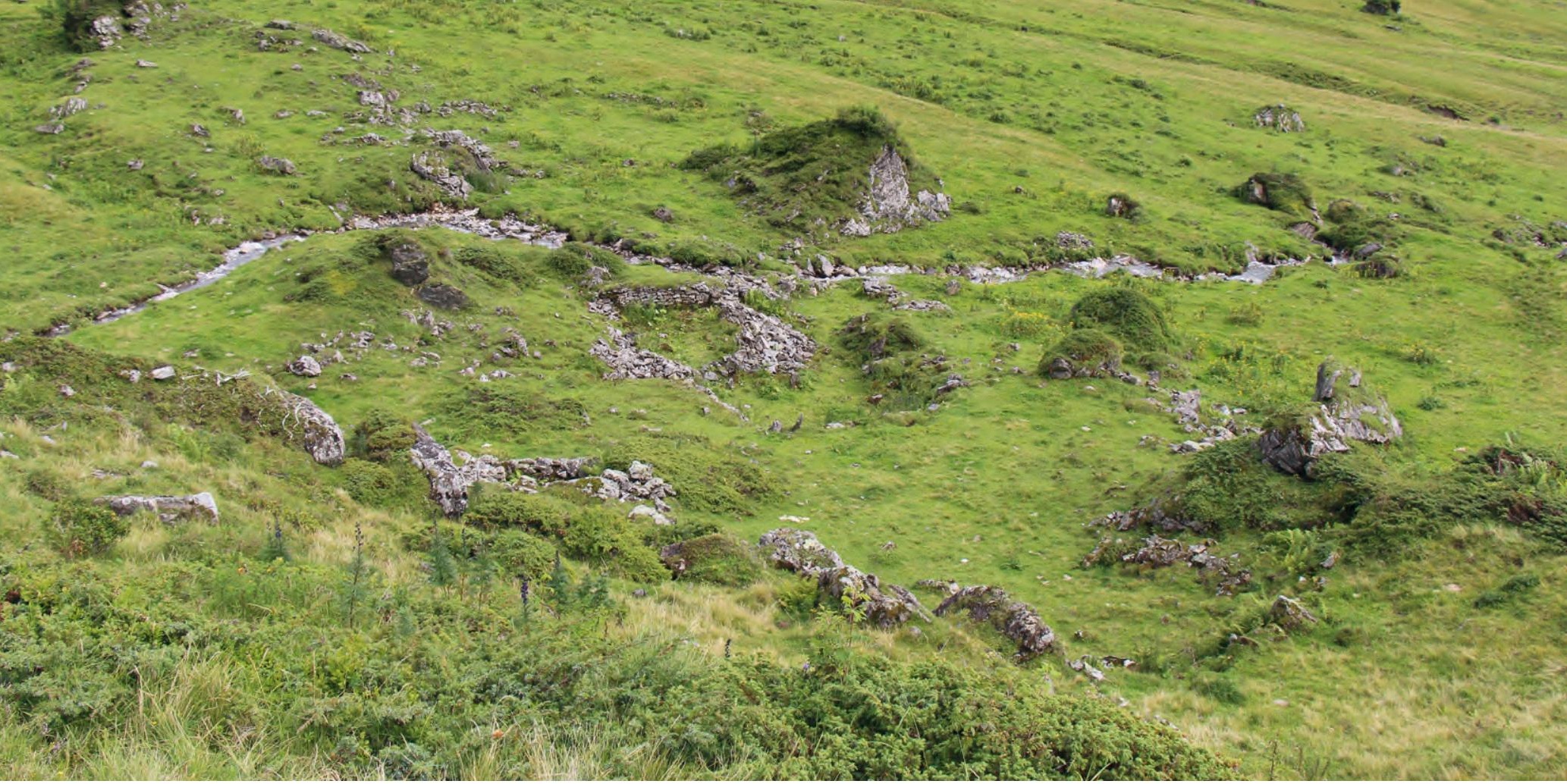

einsedimentierten Trockenmauern beziehen hier mehrere natürliche Felsblöcke in die Steinsetzung mit ein (Abb. At.123).

Im Eingangsbereich des Hauses 1 wurde unter dem Mauerversturz eine kleine Sondierung von $20 \times 20 \mathrm{~cm}$ angelegt. In $20 \mathrm{~cm}$ Tiefe kam Holzkohle zum Vorschein. Als Brennmaterial hatte man Fichten- (Picea abies) oder Lärchenholz (Larix decidua) verwendet. Probe 1 aus Gebäude 1 datiert ins Mittelalter. ${ }^{7}$ Die Grösse des Hauses 1 sowie das noch sehr gut erhaltene Mauerwerk sprechen dafür, dass diese Wüstung - trotz der mittelalterlichen Datierung - erst in der Neuzeit aufgelassen wurde (Abb. At.123).

Auch in Haus 2 brachte eine weitere kleine Sondierung unmittelbar neben dem Eingang Holzkohlen zum Vorschein: Probe 1 lieferte hier ebenfalls ein mittelalterliches Datum. ${ }^{8}$ Das für die Datierung verwendete Material stammt von einem circa $5 \mathrm{~cm}$ dicken Ast von Fichte (Picea abies) oder Lärche (Larix decidua).

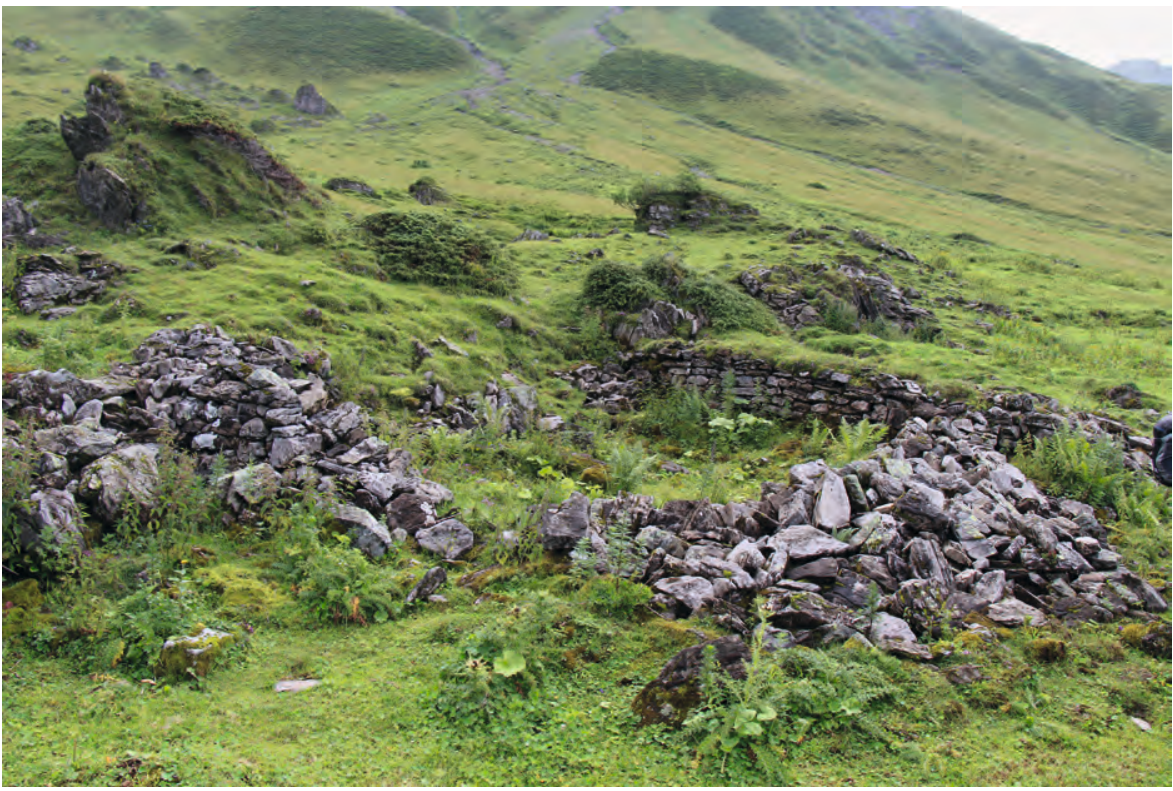

7 ETH-57593: $545 \pm 23 B P, \delta{ }^{13} C-24.2 \pm 1$, $A D$ 1310-1430, 2 sigma.

8 ETH-57594: 629 $\pm 23 B P, \delta^{13} \mathrm{C}-25.3 \pm 1$, $A D$ 1280-1400, 2 sigma.
At.123

"Ginger-City" (Übersicht) Attinghausen-Gritschen LK 1191, 682 175/187 300, 1830 m ü.M. Foto M. Sauter, 2014

\section{At.123}

"Ginger-City" - Haus 1 (Ansicht)

Attinghausen-Gritschen

LK 1191, 682 175/187 300, 1830 m ü.M.

5,5 x 7 m (Aussenmass)

Foto M. Sauter, 2014 
At.106

"Pyramide" (Ansicht)

Attinghausen-Blackenboden

LK 1191, 682 058/187 483, 1887 m ü.M.

$6 \times 2$ m (Innenmass)

Foto R. Jagher, 2014

\section{At. 106}

"Pyramide" (Grundriss)

Attinghausen-Blackenboden

LK 1191, 682 058/187 483, 1887 m ü.M.

Zeichnung P. Stöckli, U. Leuzinger, 2014

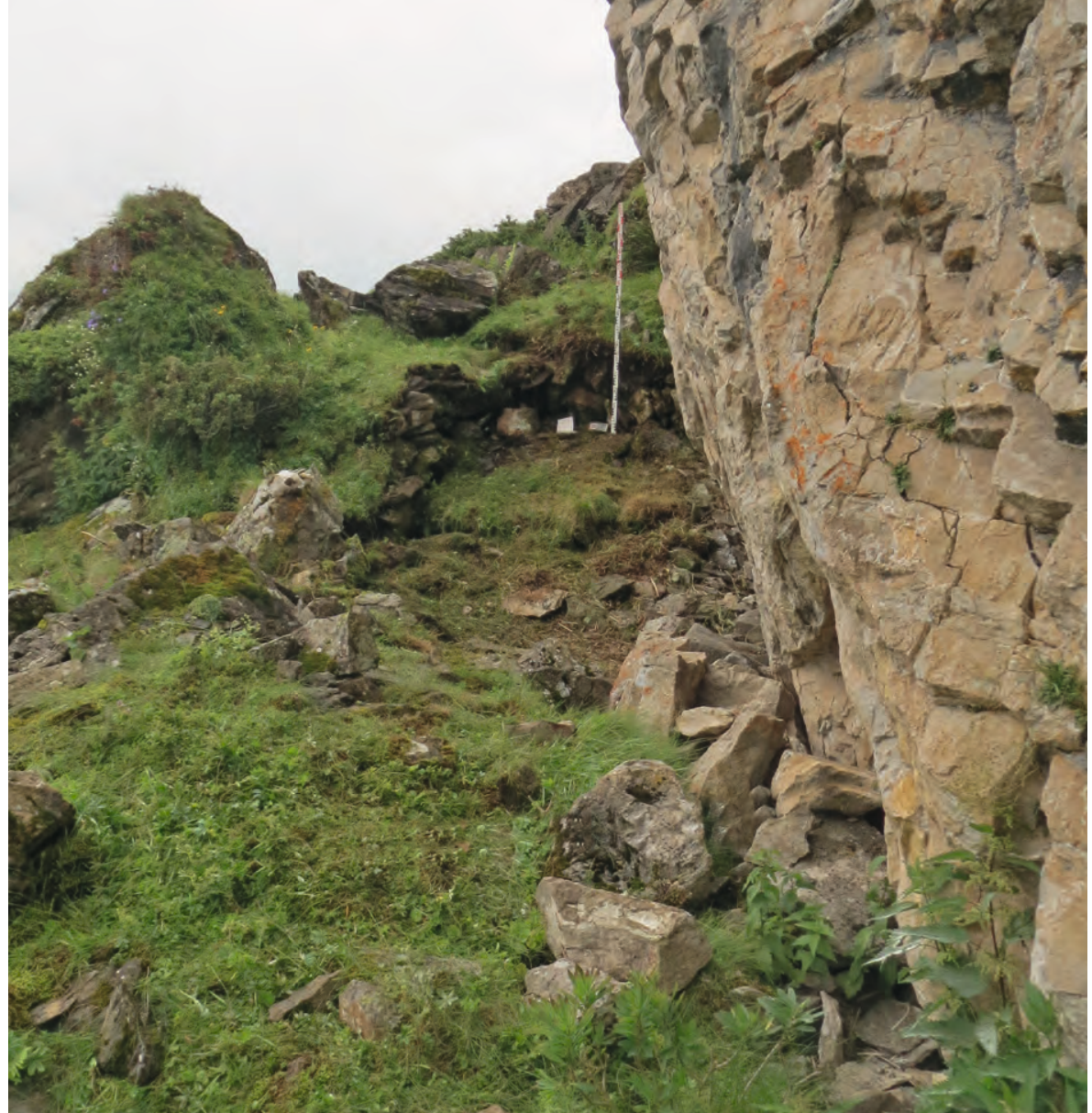

\section{Blackenboden: Wüstung «Pyramide» (At.106)}

LK 1191, 682 058/187 483, 1887 m ü.M.

Unter einem sehr grossen, pyramidenförmigen Block befindet sich ein $2 \times 6 \mathrm{~m}$ grosses rechteckiges Gebäude (Innenmass) aus mehrlagigem, stark einsedimentiertem Trockenmauerwerk. Der Eingang liegt im Nordosten, unmittelbar an der Felswand. Eine kleine Sondierung im Eingangsbereich lieferte zwar keine Holzkohle, dafür ein unbestimmbares neuzeitliches Eisenstück.

Etwas unterhalb des Gebäudefragments liegt ein 8,5 × 8,5 m grosser, polygonaler Pferch. Möglicherweise gehört zu dieser Wüstung auch ein kleiner überhängender Block, der als Milchkeller oder Materiallager gedient haben könnte. Die Siedlungsstrukturen datieren typologisch wahrscheinlich ins Mittelalter oder in die Neuzeit (Abb. At.106).

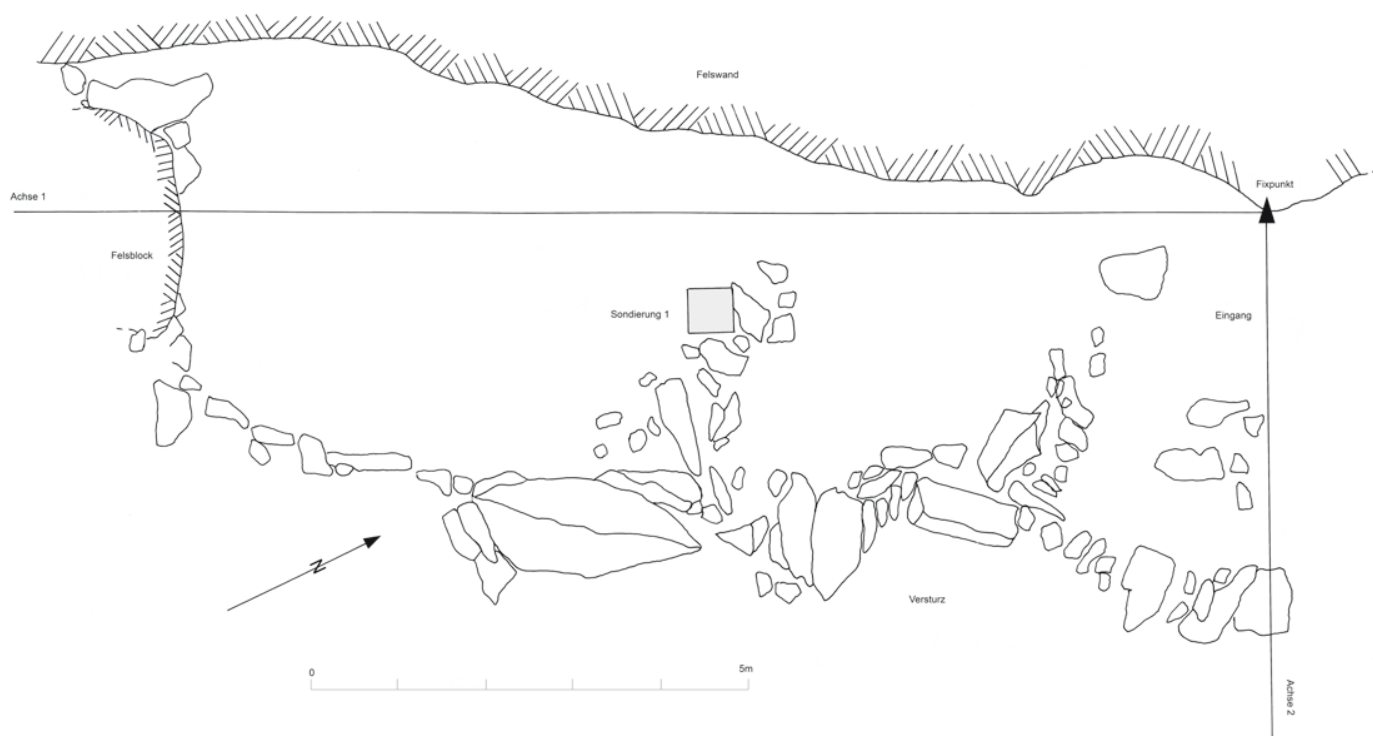




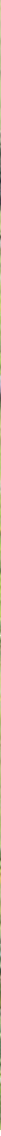

\section{Blackenboden: Wüstung «Massiv» (At.101)}

LK 1191, 682 240/187 500, 1860 m ü.M.

Die Wüstung «Massiv» besteht aus zwei stark einsedimentierten Gebäuderuinen, die übereck angeordnet sind, sowie zahlreichen umliegenden Lesesteinhaufen (Abb. At.101).

Haus 1 hat einen nahezu quadratischen Grundriss von $5 \times 6$ m (Aussenmass). Die Lage der hangwärts verkippten, teilweise im Verband stehenden Mauer spricht für ein zerstörendes Lawinenereignis oder allenfalls für ein Erdbeben. Der Eingang befindet sich im Nordosten. Eine kleine Sondierung im Eingangsbereich lieferte keine Holzkohle. Unter den Versturzsteinen kam in der nordwestlichen Gebäudeecke das Skelett eines etwa zweijährigen Rinds zum Vorschein. Die noch kollagenhaltigen Knochen weisen einen guten Erhaltungszustand auf, was dafür spricht, dass das Rind erst in jüngster Zeit verscharrt worden ist (Abb. At.101).

Haus 2 liegt am Fuss eines Felsblocks. Das Gebäude mit rechteckigem Grundriss von 4,5 ×6 m (Aussenmass) besteht aus äusserst massiven 1,2 $\mathrm{m}$ dicken Trockenmauern. Der Eingang liegt im Osten, am Felsblock. Unmittelbar daneben wurde eine kleine Sondierung von $20 \times 20 \mathrm{~cm}$ angelegt. Unter den Versturzsteinen kamen in $20 \mathrm{~cm}$ Tiefe Holzkohle sowie ein Knochen eines kleinen Wiederkäuers zum Vorschein. Wie die Radiokarbonanalyse zeigte, datiert die Feuerstelle ins 12 . oder 13 . Jahrhundert. ${ }^{9}$ Als Brennholz hatte Fichte (Picea abies) oder Lärche (Larix decidua) gedient.

\section{Blacken: «Pferchartige Struktur» (At.100)}

LK 1191, 681 990/186 665, 1777 m ü.M.

Unweit der Blackenalpkapelle befindet sich eine stark einsedimentierte, u-förmige Trockenmauer mit integrierten grossen Steinblöcken. Sie umschliesst eine Fläche von rund $26 \mathrm{~m}$ Länge und $25 \mathrm{~m}$ Breite. Die Unterbrechung der Mauer liegt im Südosten. Im Innern der Struktur erhebt sich ein steiniger Hügel. Bei der zentralen, flachen Felsplatte (Fixpunkt) auf der
At.101

Wüstung «Massiv» (Übersicht) Attinghausen-Blackenboden LK 1191, 682 240/187 500, 1860 m ü.M. Foto R. Jagher, 2014
$9 E T H-57592: 823 \pm 23 B P, \delta{ }^{13} C-24.9 \pm 1$, $A D$ 1165-1265, 2 sigma. 
At. 101

Wüstung Massiv, Haus 1 (Grundriss) Attinghausen-Blackenboden

LK 1191, 682 240/187 500, 1860 m ü.M.

$5 \times 6$ m (Aussenmass)

Zeichnung U. Leuzinger, E. Belz, 2015

At.100

«Pferchartige Struktur» (Übersicht)

Attinghausen-Blacken

LK 1191, 681 990/186 665, 1777 m ü.M.

circa 26 x 25 m

Foto M. Sauter, 2013
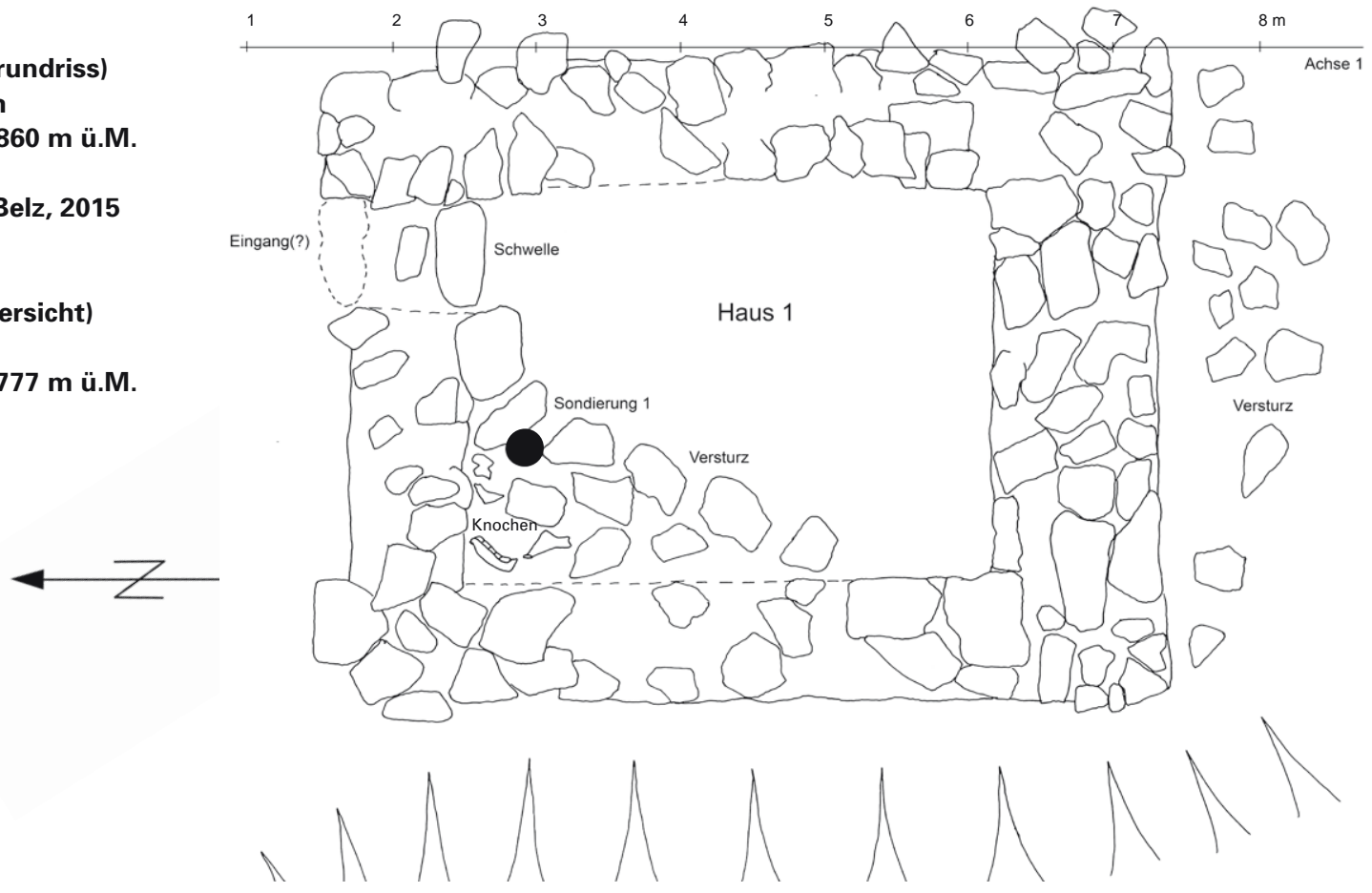

Hügelkuppe wurde im Sommer 2013 ein vermutlich prähistorischer Armreif aus Bronze entdeckt ( $\Rightarrow$ S. 139). 2014 wurde hier die 0,5 51 m grosse Sondierung 1 angelegt. Ausser einem aufgeschlagenen Knochen eines kleinen Wiederkäuers und einem Zahn (Schaf/Ziege) kamen jedoch keine Funde oder Holzkohlen zu Tage ( $\boldsymbol{G}$ S. 148).

Die Funktion und die Datierung dieser eindrucksvollen Anlage sind bislang unklar. Für einen Pferch müsste die Mauer eigentlich geschlossen sein, denkbar wäre allerdings eine Steinausbeute beim Bau der Blackenalpkapelle - sollte die Steinsetzung älter sein. Erwähnung fand die im Kern mittelalterliche Blackenalpkapelle erstmals im Jahr $1635 \mathrm{im}$ Erstfelder Jahrzeitbuch. ${ }^{10}$ Zudem ist eine Umfriedung entlang des Hügelfusses für einen Viehpferch nicht sinnvoll. Vielleicht wollte man die Tiere mit der Trockenmauer daran

10 Pfarrarchiv Erstfeld B 4.7.6/1. - Sauter 2017 (im Druck).

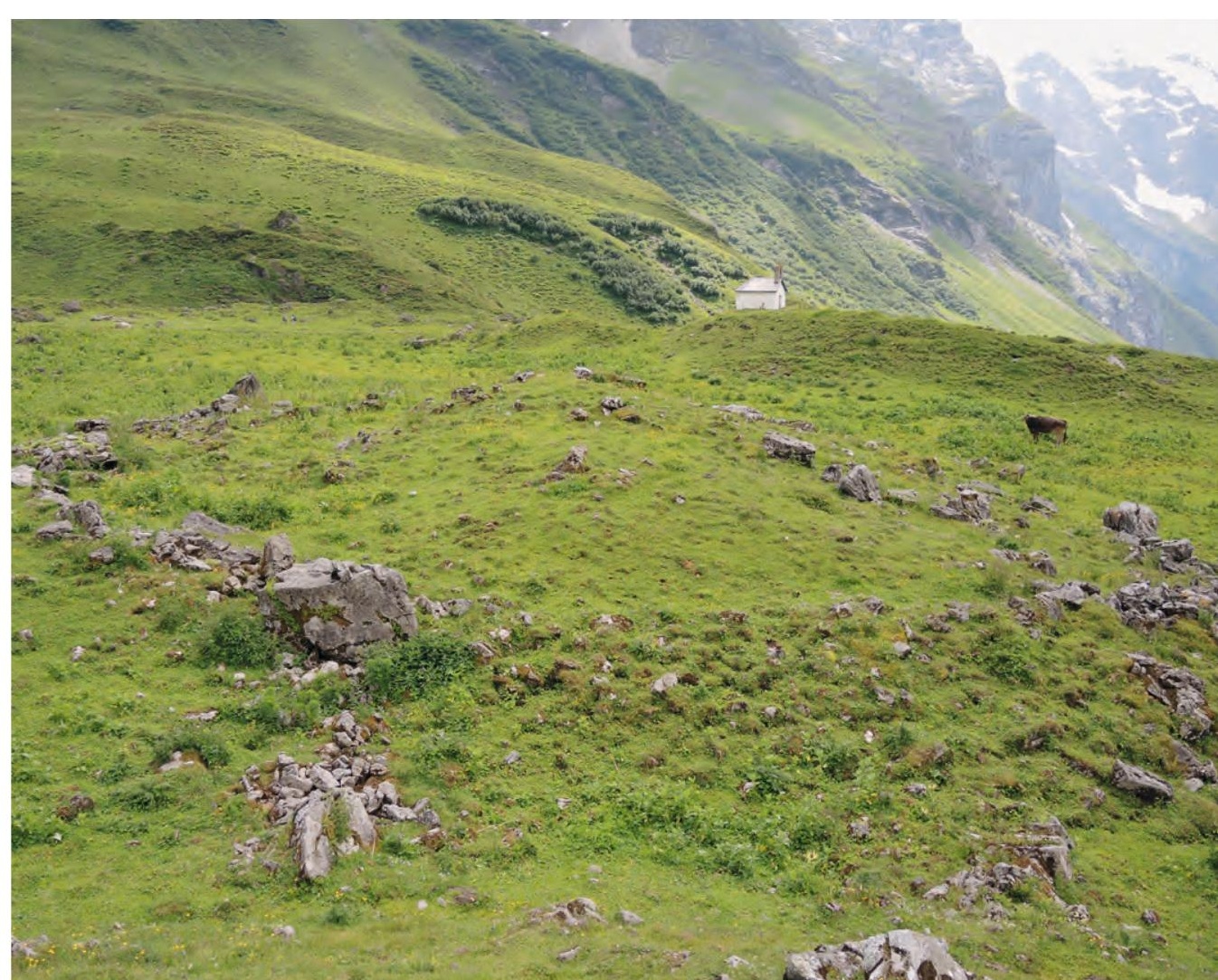




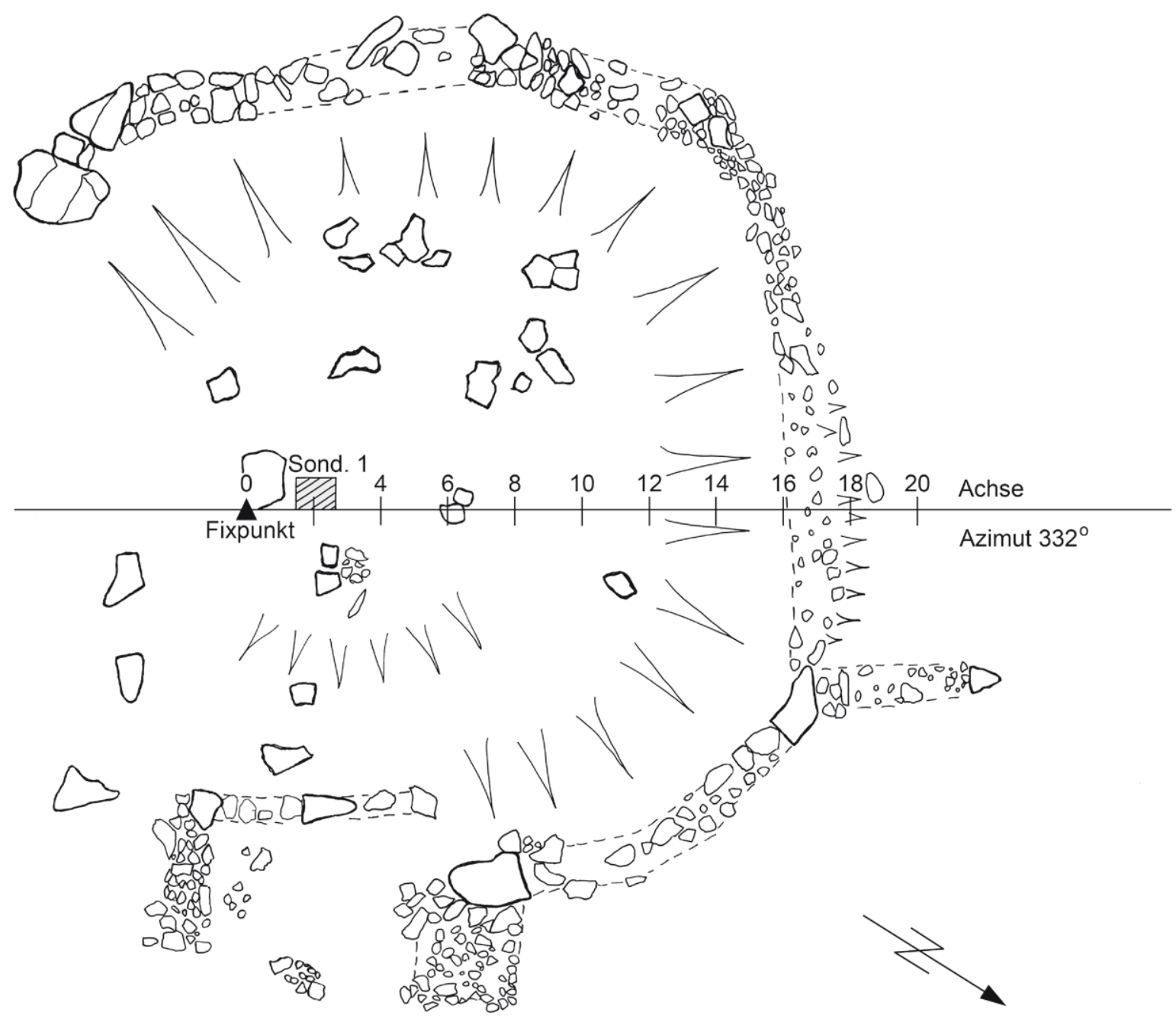

hindern, den Hügel zu beweiden? Für einen Kultplatz spräche vielleicht die Niederlegung des Bronzearmreifs, der aber auch einfach verloren gegangen sein könnte. Es gibt bislang jedoch keine archäologische Indizien, die für einen kultischen Charakter der "Pferchartigen Struktur» sprechen würden (Abb. At.100).

At. 100

"Pferchartige Struktur" (Grundriss) Attinghausen-Blacken

LK 1191, 681 990/186 665, $1777 \mathrm{~m}$ ü.M. circa $26 \times 25 \mathrm{~m}$

Zeichnung U. Leuzinger, E. Belz, 2014

\section{Teif Boden: Wasserwüstung (At.107)}

LK 1191, 681 740/186 500, 1750 m ü.M.

Auf dem an den Blackenboden im Süden angrenzenden Teif Boden befindet sich ein rechteckiger Gebäudegrundriss mit aufgehendem Trockenmauerwerk und einer Stützmauer gegen den Bachlauf hin. Vor dem Eingang des Hauses liegt eine gut erhaltene Terrassierung. Die Wüstung wurde nicht vermessen. Der Siedlungsplatz dürfte ins Mittelalter oder in die Neuzeit datieren, wenngleich die Lage am Bachlauf typologisch ungewöhnlich ist - für einen Kühlkeller ist die Anlage sehr gross (ABB At.107).

\section{Fundstellen Butzen}

Butzen liegt gut $1 \mathrm{~km}$ westlich der Blackenalp auf $1800 \mathrm{~m}$ ü.M. in einem Ost-West-orientierten Kessel, der vom Grat zwischen Wissigberg (2627 m ü.M.) und Rot Schutz (2351 m ü.M.) begrenzt wird. Die periphere, sanft geneigte Alpweide wird von mehreren Zuflüssen des Stierenbachs durchzogen. Die vorgefundenen Wüstungen zeichnen sich fast alle durch starken Moosbewuchs aus, einige sind mit Lägerflora bewachsen. Die Strukturen wurden nicht eingemessen. 
At.107

Wasserwüstung (Aufsicht)

Attinghausen-Teif Boden

LK 1191, 681 740/186 500, $1750 \mathrm{~m}$ ü.M.

Foto M. Sauter, 2014

At. 108

Hüttli Butzen 1

Attinghausen-Butzen

LK 1191, 681 311/186 452, 1800 m ü.M.

Foto M. Sauter, 2014

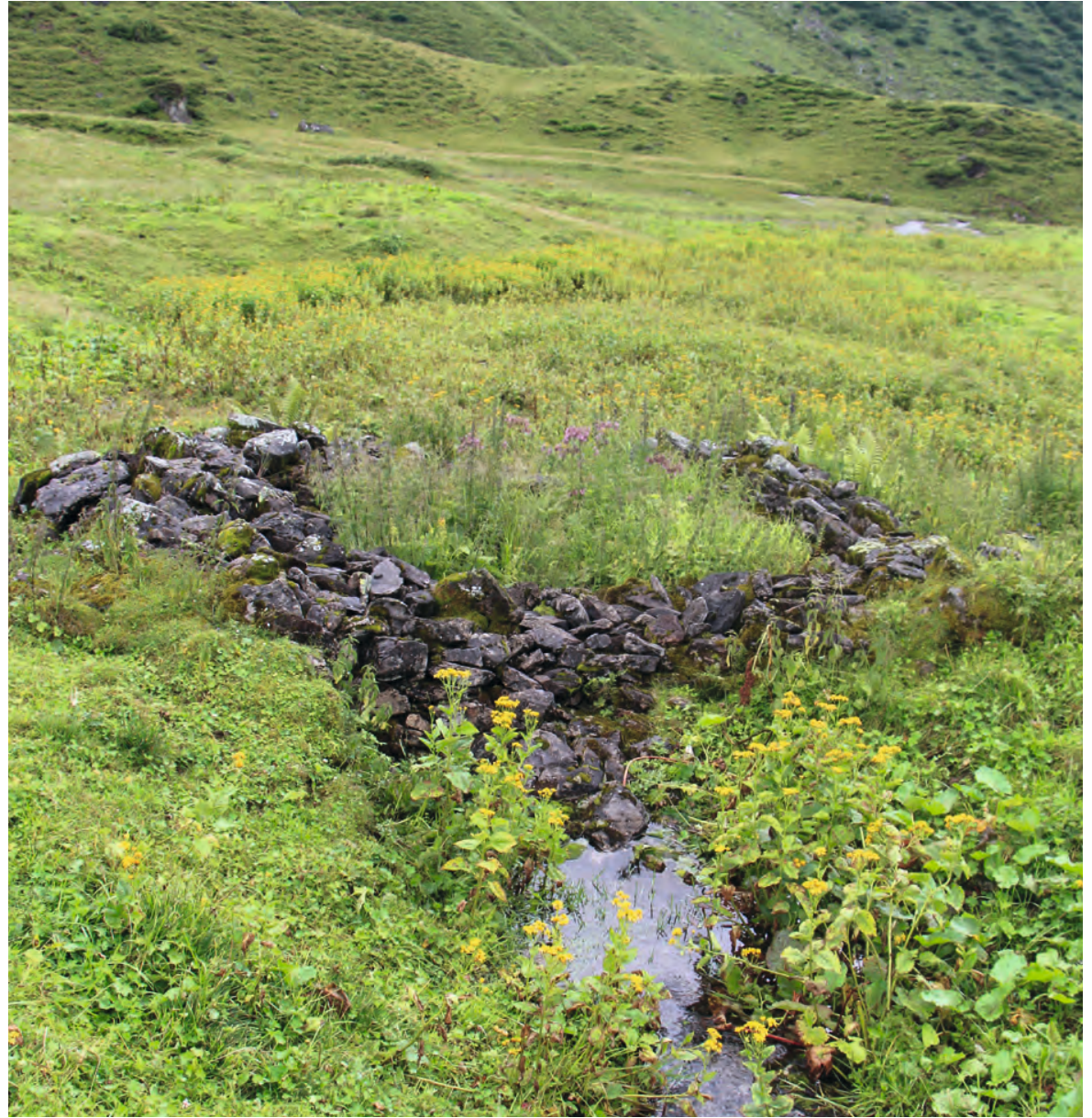

\section{Butzen: Hüttli Butzen 1 (At.108)}

LK 1191, 681 311/186 452, 1800 m ü.M.

Der nahezu quadratische Gebäudegrundriss ist hangseits im Norden und im Westen eingetieft. Die Nordmauer integriert einen Felsbrocken und endet vor einem schräg ansteigenden Felsen. Der Eingang ist talseits, in der Mittelachse der Struktur, zu suchen. Das zweihäuptige Mauerwerk hat sich teilweise in mehreren Lagen erhalten. Typologische Datierung: Mittelalter oder Neuzeit (Abb. At.108).

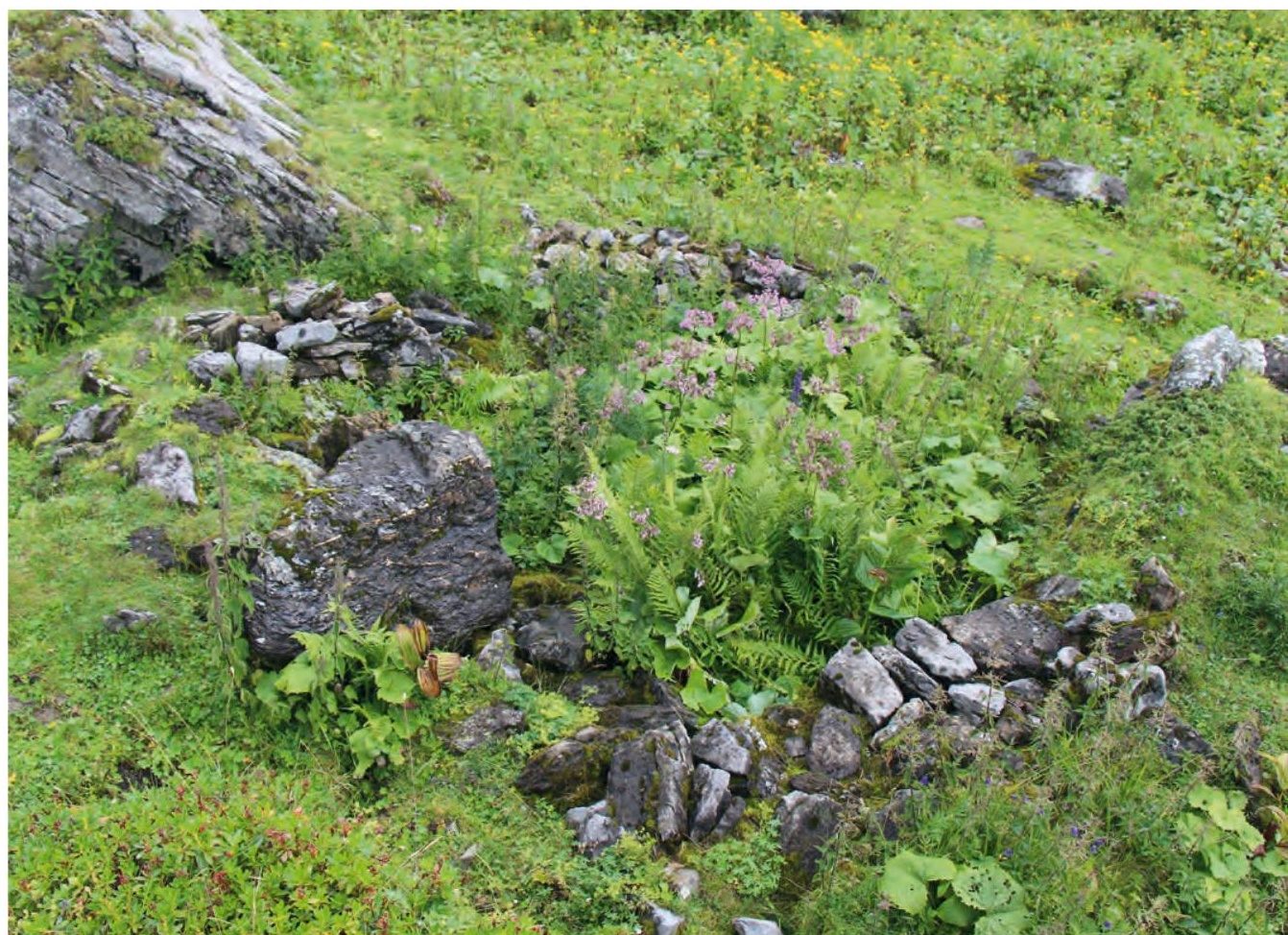


At.114

Abri sous bloc mit Pferch? (Ansicht) Attinghausen-Butzen

LK 1191, 681 318/186 427, 1800 m ü.M.

Foto M. Sauter, 2014

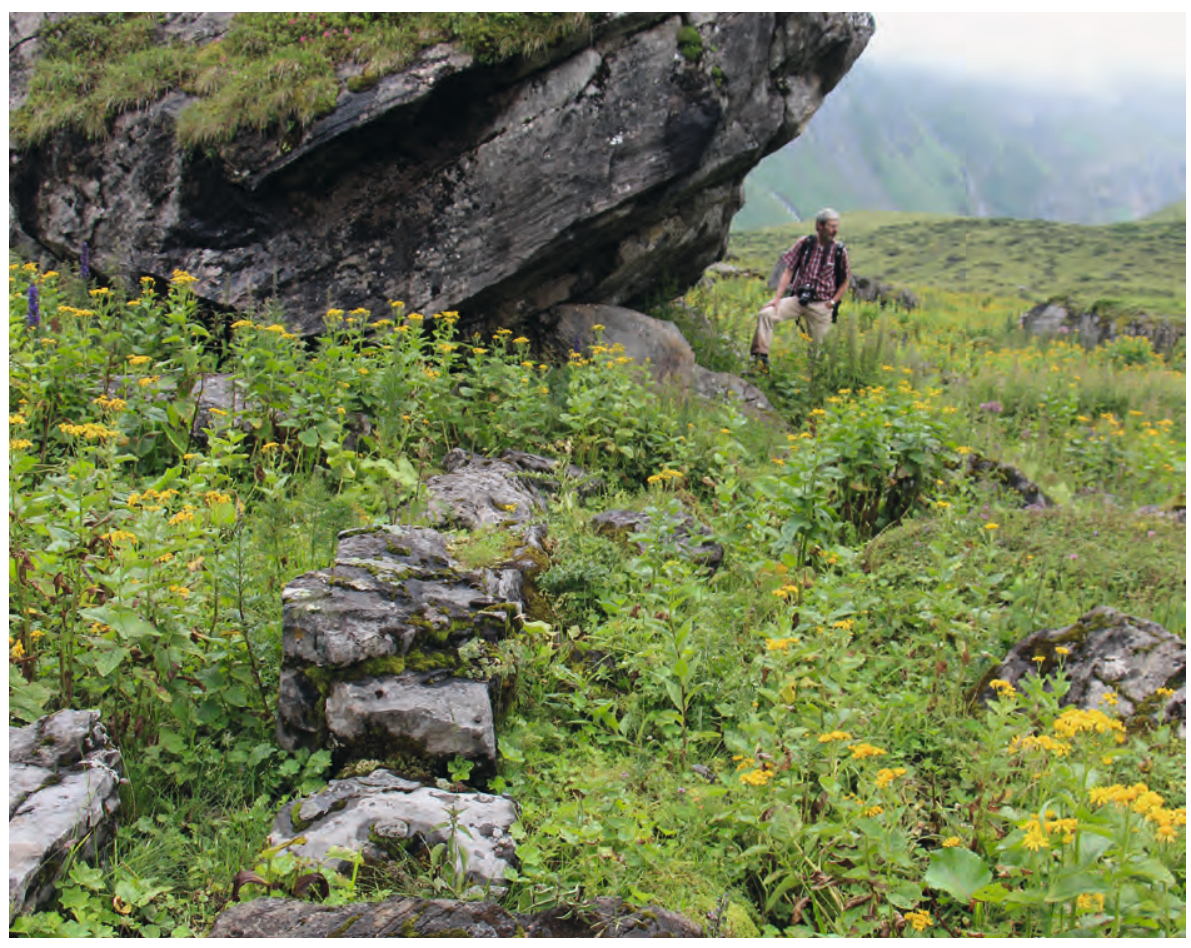

Butzen: Hüttli Butzen 4 (At.111)

LK 1191, 681 318/186 427, 1800 m ü.M.

Dieses Gebäude erhob sich im Schutz eines nahezu senkrecht aufragenden Felsblocks. Das mehrlagige Trockenmauerwerk ist kaum einsedimentiert und intergiert einige grössere Steine. Der Eingang ist an der Ostseite, unmittelbar am Felsen, zu suchen. Auszugehen ist von einer an den Felsen angelehnten Pultdachdeckung. Die reiche Lägerflora bezeugt, dass das Vieh diesen geschützten Bereich nach wie vor aufsucht.

Die Datierung eines solchen Fundorts hängt davon ab, wann der Felsblock ins Tal gestürzt ist. Hinweis auf eine jahrhundertelange Lagerung bietet hier der starke Bewuchs. Daher kann von einer frühen, mittelalterlichen, Nutzung dieses Platzes ausgegangen werden. Wahrscheinlich wurde die Wüstung in jüngerer Vergangenheit weiterhin von Hirten oder Jägern als Schutzhütte verwendet, entsprechend ergänzt und instand gehalten.

\section{Butzen: Lager (At.113)}

LK 1191, 681 318/186 427, 1800 m ü.M.

Unter der auskragenden Verdachung eines Felsblocks befindet sich eine Steinsetzung, die einen kleinen Lagerraum umschliesst. Das Mauerwerk reicht bis knapp unter das schützende Felsdach. Der Eingang liegt talseits, an der Ostecke (Abb. At.113).

\section{Butzen: Abri sous bloc mit Pferch? (At.114)}

LK 1191, 681 318/186 427, 1800 m ü.M.

Ein grosser, schräg aufragender Felsblock überdeckt vollständig eine Steinsetzung aus groben Steinbrocken. Unmittelbar angrenzend befinden sich Mauerzüge, die eventuell von einem Pferch stammen. Im Unterschied zum Hüttli Butzen 4 ist dieser Felsblock kaum einsedimentiert und daher ebenso wie der markante Fuchsstein in Nidersurenen, der im ausgehenden 19. Jahrhundert ins Tal stürzte, wohl kein mittelalterlicher oder gar prähistorischer Lagerplatz (Abb. At.114). 


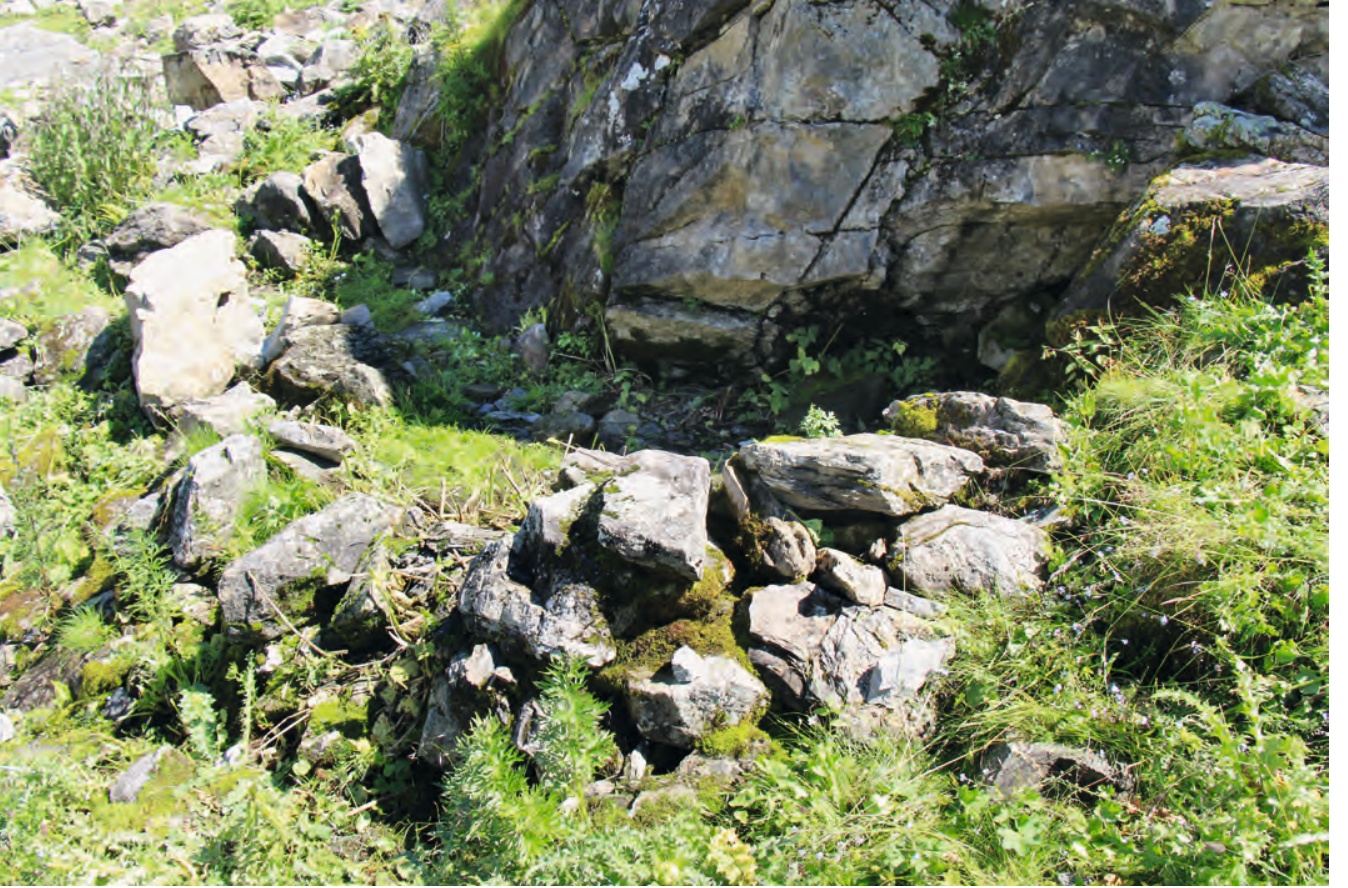

\section{Weitere Fundstellen}

\section{Hermisalp: Hermis-Hüttli (At.128)}

LK 1191, 682 272/185 656, 1950 m ü.M.

Unter einem grossen, schwach überhängenden Felsblock befindet sich ein rechteckiger Gebäudegrundriss. Das Trockenmauerwerk ist bis zu drei Lagen hoch erhalten. Die Innenmasse betragen lediglich 1,5 $\times 4 \mathrm{~m}$. Der Eingang liegt im Nordwesten. Das Gebäude weist einen sorgfältig gefügten Plattenboden auf. Zwei kleine Sondierungen von $20 \times 20 \mathrm{~cm}$ erbrachten keinerlei anthropogene Spuren. An der Südostseite des Blocks wurde ein weiterer kleiner, $1 \times 1 \mathrm{~m}$ messender Raum dokumentiert, der wegen seiner geringen Grösse allenfalls als Materiallager zu deuten ist. Das umliegende Gelände ist sehr steil. Vermutlich wurde die Hermisalp immer nur mit Schafen bestossen.

Trotz ihrer geringen Grösse ist die Hütte in der Siegfriedkarte (BI. Engelberg, 1875) eingetragen und war demnach damals noch in einem benutzbaren Zustand. In der Neuauflage von 1878 ist der kleine Bau dann jedoch nicht mehr dokumentiert (Abb. At.128).

\section{Uf der Lauwi: Zweiräumiger Bau (At.129)}

LK 1191, 681 467/185 523, 1660 m ü.M.

Wenige Meter östlich des Wanderwegs liegt auf vergleichsweise ebenem Terrain ein etwa $6 \times 8 \mathrm{~m}$ grosses Geviert. Das 0,8 bis $1 \mathrm{~m}$ breite Trockenmauerwerk ist teilweise bis zu drei Lagen hoch erhalten. In der Nordwestecke zeichnet sich eine Wandzunge ab, die eine kleine Kammer abteilt. Die Eingangssituation im Südwesten ist unklar.

Der Bau liegt unweit nordöstlich der Abzweigung des Surenenpasswegs in Richtung Stäfeli und Engelberg, flankiert vom Stierenbach und einem kleineren, auf der Hermisalp entspringenden Bachlauf. Die gute Wasserversorgung dürfte Fluch und Segen zugleich gewesen sein: Das Areal war sicherlich häufig überschwemmt. Der wohl in der Neuzeit errichtete Bau ist weit und breit die einzige anthropogen erstellte Struktur.
At.128

Hermis-Hüttli (Ansicht)

Attinghausen-Hermisalp

LK 1191, 682 272/185 656, 1950 m ü.M.

1,5 x 4 m (Innenmass)

Foto M. Sauter, 2014 


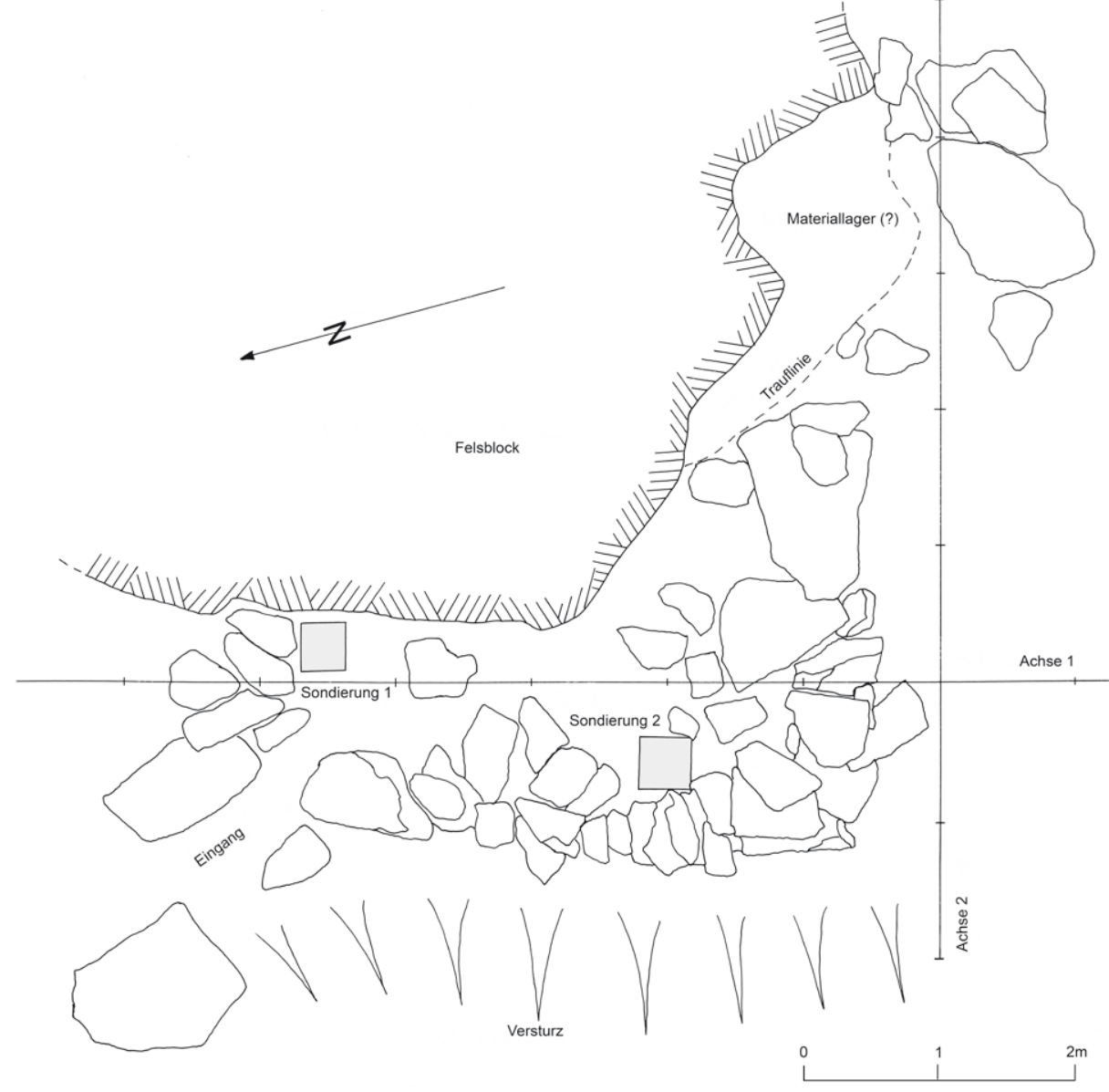

11 Stadler-Planzer 2013, 17-18.

12 Püntener 1908, 105.

13 Hinweis vom Rinderhirt Kari Muheim.

\section{Wirtschaftsformen - Strukturwandel}

Im Kanton Uri wurden im 16. Jahrhundert erste Rinderhirten eingerichtet. Dies ist als Rationalisierungsmassnahme zu bewerten: Um den Milchertrag zu steigern, blieben die guten und näher gelegenen Alpen fortan den Milchkühen vorbehalten, die Rinder wurden auf periphere Alpweiden getrieben. Dieser Prozess war wahrscheinlich Anfang des 18. Jahrhunderts abgeschlossen. ${ }^{11}$ Für Surenen existieren keine Quellen. Die vergleichsweise gute Lage und die Grösse dieser Rinderhirte spricht jedoch für einen späte vollständige Ablösung der Einzelalpung.

Bis etwa 1700 sömmerten demnach die Urner Bergbauern ihre eigenen Viehherden südwestlich des Surenenpasses in Form der Einzelalpung. Für die damit verbundene Käseproduktion benötigten sie eine angemessene Infrastruktur wie Hütten mit Feuerstellen, Pferche, Kühl- und Käsekeller sowie "Gaumerhüttli» - Schutzhütten für Hirten. Alle genannten Bautypen wurden nachgewiesen, auch wenn im Einzelfall die ursprüngliche Funktion der aufgedeckten Reste nicht immer eindeutig belegt werden kann. Die nachweisliche Nutzung von Fichten- und Lärchenholz als Brennmaterial in den spätmittelalterlichen Siedlungsplätzen "Ginger City" und "Massiv» lässt vermuten, dass in dieser Zeit in der nahen Umgebung - im Gegensatz zu heute - noch reichlich Nadelbäume bis auf circa 1900 m ü.M. wuchsen.

Die Siegfriedkarte verzeichnet auf Gritschen und Butzen keine gedeckten Hütten mehr, demzufolge müssen diese spätestens im frühen 19. Jahrhundert aufgegeben worden sein. Das neue alpgenossenschaftliche Zentrum wurde auf Blacken eingerichtet, unweit der im Kern mittelalterlichen Alpkapelle. Die Siegfriedkarte dokumentiert hier in den Jahren 1875 bis 1878 zwei Gebäude, von 1899 bis 1942 lediglich noch eine Alphütte - Wohngebäude und Stall waren unter einem Dach vereint, was für den Kanton Uri eher untypisch ist. ${ }^{12}$ Die heutige Alphütte und ein Lawinenschutzwall wurden 1993 errichtet. Als Steinbruch diente der ehemalige Pferch, er wurde undokumentiert abgebaut. ${ }^{13}$ 


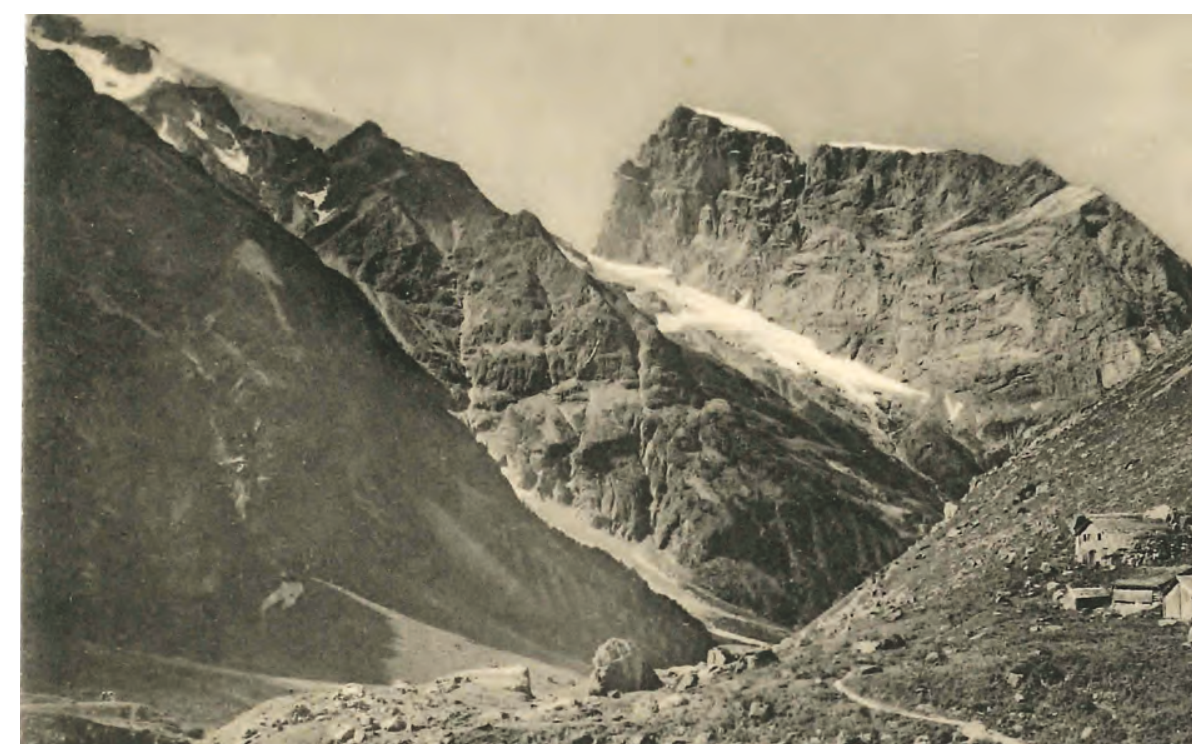

Die vertikale und chronologische Abfolge der Blackenalp sowie der wüst gefallenen Alpstafel "Ginger City" und "Massiv» in den Fluren Blackenboden und Gritschen scheinen damit nicht mit den Auswirkungen der Kleinen Eiszeit (1350 bis 1850) zusammenzuhängen. Zwar liegen die bisher ältesten nachgewiesenen Gebäude der Wüstung "Massiv» 30 m höher als die Bauten der Wüstung "Ginger City", diese wurden jedoch auch während der Kleinen Eiszeit weiterhin genutzt. Die Auflassung des obersten Stafels folgte offensichtlich ebenfalls dem Strukturwandel.

Und der Strukturwandel geht weiter - bis heute. Seit 1893 subventioniert der Bund die Alpwirtschaft, erliess aber auch zahlreiche Vorschriften zu Produktionsbedingungen und zum Tierwohl. Schon bald mussten die alpwirtschaftlichen Gebäude angepasst werden. ${ }^{14}$ Die Modernisierung drückt sich auch in der zunehmenden Elektrifizierung und einer verbesserten Erschliessung aus, vor allem in Luft- und Transportseilbahnen.

Die Rinderhirte Surenen umfasste im Jahr 1900 insgesamt 457 Rinder und 609 Schafe. ${ }^{15}$ Ein Höhepunkt wurde im Jahr 1990 mit 759 Rindern erreicht. Heute (2015) werden auf den fünf (Nider-)Surener Alpstafeln Blacken, Hobiel, Stäfeli, Steinäbnet und Usser Äbnet - 175 Milchkühe gesömmert. Der Surener Rinderhirte wacht ausserdem noch über 562 Rinder sowie über 638 Schafe. 6 Schweine und 2 Pferde ergänzen die insgesamt fast 1200 Tiere umfassende Herde. Die Urner Herden sind längst um auswärtigen Viehbestand ergänzt. Viele Kleinbetriebe wurden/werden aufgegeben oder zusammengelegt, schlecht erschlossene Alpen aufgegeben. ${ }^{16}$ Viele Alpbetriebe haben Personalprobleme - dabei ist gerade unter den extremen Arbeitsbedingungen der Alpwirtschaft Erfahrung und lokales Wissen von Nöten. Neuerliche Strukturwandel stehen bevor. ${ }^{17}$

\section{Fazit}

Nirgendwo sonst im Urner Prospektionsgebiet liegen die Wüstungen so weit von den etablierten Saumpfaden entfernt wie auf Surenen. Dies legt eine Verlegung des Surenenpasswegs nahe, die mittels eines vorgefundenen Wegfragments, das von Uf den Seewen in Richtung Gritschen führt, auch belegt werden kann ( $\rightarrow$ S. 102-121).

Die archäologische Prospektionskampagne im Sommer 2014 lieferte zwar keine neuen prähistorischen Funde. Nach wie vor ist eine Begehung des
Surenen - Blick über die Alp Stäfeli in Niedersurenen in Richtung Titlis. Mangels touristischer Bedeutung existieren nur wenige historische Ansichtskarten des Untersuchungsgebiets. Diese zeigt den alten Surenenpassweg. Ansichtskarte, um 1900 (Staatsarchiv Uri)
14 Furrer 2015, 13

15 Püntener 1908, 104. - Aufstellung Blackenalp

16 Muheim 2015, 215.

17 Furrer 2015, 50. 
Surenenpasses in ur- und frühgeschichtlicher Zeit lediglich durch die bereits publizierten Lesefunde belegt: eine bronzene Gewandnadel, ein bronzener Armreif sowie römische Münzen und ein antiker Siegelring. ${ }^{18}$ Die Prospektionskampagne erlaubte es jedoch, die auffällige Fundlücke an mittelalterlichen Wüstungen auf der Engelberger Seite des Surenenpasses zu füllen sowie den alpwirtschaftlichen Strukturwandel und die damit einhergehende Verlegung des Passwegs archäologisch zu dokumentieren. Jede grosse Geländekammer - Butzen, Blackenboden/Gritschen sowie Hermisalp - hatte ursprünglich ein eigenes alpwirtschaftliches Zentrum mit verschiedenen Hüttenplätzen. Die Nutzung von Fichten- und Lärchenholz als Brennmaterial in den spätmittelalterlichen Siedlungsplätzen "Ginger City" und "Massiv» lässt vermuten, dass Surenen bis in die Neuzeit hinein bewaldet war.

Furrer, B. (2015). Vom Steinhaufen zum Molkenbad. Spurensuche in Urner Alpgebäuden. In: Hirtler, C. (Hrsg.). Hirt, Tinner und Fugibootschä. Urner Berglandwirtschaft früher, heute, morgen. Altdorf, 13-59.

Glur, L. / Stalder, N.F. / Wirth, S.B. et al. (2015). Alpine lacustrine varved record reveals summer temperature as main control of glacier fluctuations over the past 2250 years. In: The Holocene 25/2, 280-287.

Leuzinger, U. / Sauter, M. / Haas, J.N. et al. (2014). Eine hallstattzeitliche Gebäudestruktur auf 1911 m ü.M. am Weg zum Surenenpass, Attinghausen UR, Siedlungsplatz Geissrüggen. In: Jahrbuch Archäologie Schweiz 97, 153-168.

Leuzinger, U. / Sauter, M. / Haas, J.N. et al. (2015). Spätmittelalterliche und neuzeitliche Alpnutzung zwischen Surenenpass und der Blackenalp, Gemeinde Attinghausen UR. In: Jahrbuch Archäologie Schweiz 98, 145-153.

Muheim, K. (2015). Wir haben Hunderte Kubikmeter Schutt abgeräumt. In: Hirtler, C. (Hrsg.). Hirt, Tinner und Fugibootschä. Urner Berglandwirtschaft - früher, heute, morgen. Altdorf, 210-215.

Primas, M. / Della Casa, P. / Schmid-Sikimić, B. (1992). Archäologie zwischen Vierwaldstättersee und Gotthard. Siedlungen und Funde der ur- und frühgeschichtlichen Epochen (= Universitätsforschungen zur prähistorischen Archäologie 12). Bonn.

Püntener, A. (1908). Alpinspektions-Bericht der Korporation Uri 1905-1908. Altdorf. Sauter, M. (2017, im Druck). Die Kunstdenkmäler des Kantons Uri. Schächental und unteres Reusstal (Bd. 3). Bern.

Schwarz-Zanetti, G. / Deichmann, N. / Fäh, D. et al. (2003). The earthquake in Unterwalden on September 18, 1601: A historico-critical macroseismic evaluation. In: Eclogae Geologicae Helvetiae 96, 441-450.

Stadler-Planzer, H. (2013). Die Urner Allmendgenossenschaft von den Anfängen bis 1888. In: Korporation Uri (Hrsg.). Korporation Uri. Altdorf, 9-21.

Strasser, M. / Anselmetti, F.S. / Fäh, D. et al. (2006). Magnitudes and source areas of large prehistoric northern Alpine earthquakes revealed by slope failures in lakes. In: Geology 34, 1005-1008.

Die Grabungsergebnisse wurden erstmals in Leuzinger/Sauter/Haas et al. 2015 publiziert. Der vorliegende Bericht ist überarbeitet und um einige Abbildungen ergänzt.

18 Primas/Della Casa/Schmid-Sikimić 1992, 221-228. - Leuzinger/Sauter/ Haas et al. 2014, 164-166. 

Anhang 


\section{Ulrike Gollnick M.A.}

Ulrike Gollnick (*1968) studierte an den Universitäten Augsburg und Freiburg im Breisgau Kunstgeschichte, Klassische Archäologie und Geschichte. Während des Studiums tätig am Landesdenkmalamt Baden-Württemberg, seit 1996 beschäftigt im atelier d'archéologie médiévale in Moudon, seit 2004 dessen Leiterin. Archäologische Grabungen und Bauuntersuchungen mit Schwerpunkt der Kathedrale in Lausanne sowie Blockbauten in der Zentralschweiz. Seit Herbst 2015 Inhaberin von BAB Gollnick, Bauforschung-Archäologie-Beratung in Schwyz.

\section{Prof. Dr. Jean Nicolas Haas}

Jean Nicolas Haas (*1961) studierte Botanik, Palynologie und Paläo-Ethnobotanik an der Universität Basel. Er war als Wissenschaftler in Toronto, Leiden und Kopenhagen tätig und ist seit 2000 Professor für Botanik und Paläoökologie an der Universität Innsbruck. Ausserdem gehört er dem wissenschaftlichen Beirat des Instituts Écologie et Environnement des Centre National de la Recherche Scientifique in Frankreich an. Seine Forschungsschwerpunkte sind die Rekonstruktion der Biodiversität auf der Nordhemisphäre seit der letzten Eiszeit, die Quantifizierung von vergangenen Klimaschwankungen sowie das Verständnis der jahrtausendealten, anthropogenen und viehwirtschaftlichen Nutzung des Alpenraums.

Team: Dr. Notburga Wahlmüller, Sara Altstätter, Dr. Benjamin Dietre und Dr. Anton Stefan Schwarz (Institut für Botanik, Universität Innsbruck/Österreich) sowie Dr. Irka Hajdas (ETH Zürich).

\section{Walter Imhof}

Walter Imhof (*1957) ist ausgebildeter Primarlehrer und unterrichtet seit 1979 in der Gemeinde Muotathal. Er ist Mitglied der Arbeitsgemeinschaft Höllochforschung AGH und befasst sich mit Knochenfunden aus Höhlen, alpiner Wüstungsforschung und der Erforschung von natürlichen Unterständen. Mitwirkung an Forschungsprojekten zur Archäologie und Archäozoologie der Urschweiz. Autor verschiedener fachspezifischer Publikationen.

\section{PD Dr. habil. Urs Leuzinger}

Urs Leuzinger (*1966) studierte Ur- und Frühgeschichte an den Universitäten Basel, Bern und Innsbruck. Er ist stellvertretender Kantonsarchäologe und Konservator des Museums für Archäologie des Kantons Thurgau. Seine Forschungsschwerpunkte sind die Pfahlbauarchäologie sowie die frühe Besiedlung des Alpenraums. Er war wissenschaftlicher Berater der erfolgreichen TV-Sendungen Pfahlbauer von Pfyn und Steinzeit - das Experiment. Seit 2007 ist er Dozent an der Leopold-Franzens-Universität Innsbruck.

\section{Dipl. phil. II Christine Pümpin}

Christine Pümpin $\left({ }^{*} 1975\right)$ studierte an der Universität Basel Ur- und Frühgeschichte, Geologie, Zoologie und Anthropologie. Spezialisierung während des Studiums in Geoarchäologie mit Schwerpunkt Mikromorphologie. Seit 2003 wissenschaftliche Mitarbeiterin in der geoarchäologischen Abteilung des Instituts Integrative, Prähistorische und Naturwissenschaftliche Archäologie (IPNA) der Universität Basel. Forschungsinteressen sind unter anderem Untersuchungen von Schichtbildungsprozessen und menschlichen Aktivitäten im archäologischen Kontext anhand von Bodendünnschliffen. 


\section{Jochen Reinhard M.A.}

Jochen Reinhard (*1977) hat in Göttingen, im polnischen Łódź, in Freiburg im Breisgau und in Basel Ur- und Frühgeschichte, Anthropologie und Völkerkunde studiert und mit einer Arbeit über das Altneolithikum abgeschlossen. Seit 2009 wissenschaftlicher Mitarbeiter des Amtes für Denkmalpflege und Archäologie im Kanton Zug. Teilnahme an zahlreichen Grabungsprojekten in Deutschland, Frankreich, Jordanien, Israel und der Schweiz. Ein Interessenschwerpunkt ist die Integration moderner Technologien in die archäologische Feldforschung.

\section{Dr. Marion Sauter M.A.}

Marion Sauter $\left({ }^{*} 1970\right)$ hat an der Fachhochschule Stuttgart und der Universität Karlsruhe Architektur, Kunstgeschichte, Baugeschichte und Soziologie studiert. Promotion über frühbarocke Bautypologie. Tätig unter anderem im Deutschen Architekturmuseum Frankfurt am Main und an der Fachhochschule Stuttgart. Seit 2006 Dozentin für Architekturgeschichte an der Hochschule Luzern - Technik \& Architektur. Seit 2008 Denkmalinventarisation im Kanton Uri. Forschungsprojekte zur Kulturgeschichte der Urschweiz und zur alpinen Archäologie.

\section{Dr. Peter Spillmann}

Peter Spillmann (*1963) hat an der ETH Zürich Geologie studiert. Promotion über die Geologie im südlichen Berninagebirge. Autor des Kartenblatts Piz Bernina, Geologischer Atlas der Schweiz M 1:25.000. Seit 1995 Mitarbeit bei der Firma GEOTEST AG in Altdorf und Horw. Praktischer Geologe in den Bereichen Rohstoffe, Umwelt, Naturschutz, Gewässerschutz, Geothermie, Altlasten und Abfälle. Präsident der Naturforschenden Gesellschaft Uri. Leiter des Redaktionsteams der Publikation Geologie des Kantons Uri. 


\section{Prospektionskampagnen mit Studierenden der Hochschule Luzern - Technik \& Architektur, 2009-2012}

\section{Printmedien}

- NEUE URNER ZEITUNG. Studenten suchen Urner Spuren (12.8.2009)

- URNER WOCHENBLATT. Auf den Spuren der prähistorischen Urner Älpler (12.8.2009)

- URNER WOCHENBLATT. Eindrucksvolle Funde aus vergangener Zeit (15.8.2009)

- URNER WOCHENBLATT. Architekturhistorikerin Marion Sauter arbeitet an einem Inventar verlassener Alphütten in Uri (22.8.2012)

\section{Restaurierung Burgruine Attinghausen 2011/12}

\section{Printmedien}

- URNER WOCHENBLATT. Attinghauser Wahrzeichen wird restauriert Burgruine: 460000 Franken wird ins Bauwerk aus dem 13. Jahrhundert investiert (21.3.2012)

- NEUE URNER ZEITUNG. Ruine wird vor Zerfall gerettet (21.3.2012)

- NEUE URNER ZEITUNG. Die bekannte Burgruine ist wieder offen (25.9.2012)

\section{Grabung Geissrüggen, 2013}

\section{Radio und Fernsehen}

- RADIO Sunshine (7.8.2013)

- RADIO RETE UNO (7.8.2013)

- TELE1-NACHRICHTEN (10.8.2013)

- RADIO DRS1 LIVE. Aufsteller des Tages (8.8.2013)

\section{Printmedien}

- NEUE URNER ZEITUNG. Fundstelle wird genauer geprüft (11.7.2013)

- URNER WOCHENBLATT. Surener Alpgeschichte wird neu erforscht (20.7.2013)

- NEUE URNER ZEITUNG. Sensationeller Fund auf der Alp Surenen Forscher entdecken 2700-jährige Hütte (7.8.2013)

- URNER WOCHENBLATT. Auf der Suche nach dem ältesten Alpgebäude - Schreibt der Geissrüggen Schweizer Alpgeschichte? (7.8.2013)

- BOTE DER URSCHWEIZ. Die älteste Alphütte der Zentralschweiz entdeckt (8.8.2013)

- BLICK. 2500 Jahre alte Hütte entdeckt (8.8.2013)

- URNER WOCHENBLATT. 150 Personen besuchen Surenen-Grabung (14.8.2013)

\section{Online}

- NEUE URNER ZEITUNG. Grabung am Weg zum Surenenpass (11.7.2013)

- NEUE URNER ZEITUNG. Forscher entdecken 2700-jährige Hütte (6.8.2013) 
- NEUE LUZERNER ZEITUNG. Forscher entdecken 2700-jährige Hütte (6.8.2013)

- URNER WOCHENBLATT. Attinghausen - Auf der Suche nach dem ältesten Alpgebäude (6.8.2013)

- BLICK. 2500 Jahre alte Hütte entdeckt (7.8.2013)

- LE NOUVELLISTE. Une cabane de montagne vieille de 2700 ans découverte en Suisse centrale (7.8.2013)

- 20MIN. Découverte d’ une des plus vieilles cabanes des Alpes (7.8.2013)

- LE MATIN. Ils découvrent la plus vieille cabane des Alpes (7.8.2013)

- TICINONEWS. UR. scoperto rifugio alpino di 2500 anni fa (7.8.2013)

- SÜDOSTSCHWEIZ. Steht die älteste Alphütte in der Urschweiz? (7.8.2013)

- KLOSTERSERZEITUNG. Steht die älteste Alphütte in der Urschweiz? (7.8.2013)

- BAUBLATT. 2700 Jahre alte Alphütte bei Attinghausen entdeckt (7.8.2013)

- BOTE DER URSCHWEIZ. Steht die älteste Alphütte in der Urschweiz? (7.8.2013)

- SWISSINFO. UR. scoperto rifugio alpino di 2500 anni fa (7.8.2013)

- SCHWEIZERBAUER. In Uri wird die älteste Alphütte der Zentralschweiz vermutet (7.8.2013)

- MOBILEBLUEWIN. Forscher vermuten in Uri älteste Alphütte der Zentralschweiz (7.8.2013)

- SILVRETTAHISTORICA. Alphütte in Uri macht Val Fenga Konkurrenz (10.8.2013)

\section{Prospektionskampagne Blackenalp, 2014}

\section{Printmedien}

- URNER WOCHENBLATT. Archäologische Forschung geht weiter (2.8.2014)

- NEUE URNER ZEITUNG. Alte Urner Siedlung entdeckt (3.8.2014)

- NEUE URNER ZEITUNG. Forscherteam empfängt Besucher (6.8.2014)

- URNER WOCHENBLATT. Archäologen werden auf Urner Alp fündig (13.8.2014) 
(C)2016, Marion Sauter und LIBRUM Publishers \& Editors, Hochwald (Schweiz)

Alle Rechte vorbehalten. All rights reserved.

Konzeption und Redaktion

Lektorat

Übersetzung

Layout
Marion Sauter

Miriam Seifert-Waibel, Urs Leuzinger und Jean Nicolas Haas

Sandy Hämmerle

Marion Sauter, unterstützt von Manuel Gächter

\section{DLIBRUMOPEN}

www.LIBRUMopen.com

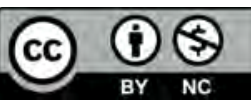

Surenenpass - Archäologie und Geschichte in Attinghausen by Marion Sauter is licensed under a Creative Commons Attribution-NonCommercial 4.0 International License.

www.creativecommons.org

ISBN

DOI

Buchcover
978-3-9524542-1-3

$10.19218 / 3952454213$

Grabung Attinghausen-Geissrüggen. Foto J. Reinhard, 2013 
In den Jahren 2009 bis 2013 führten Marion Sauter und Walter Imhof im Kanton Uri Prospektionskampagnen mit Studierenden der Hochschule Luzern - Technik \& Architektur durch. Ziel war es, alpine Wüstungen zu inventarisieren. Der Geissrüggen in Attinghausen (1911 m ü.M.), eine von über $\mathbf{7 0 0}$ Fundstellen, wurde für eine archäologische Forschungsgrabung ausgewählt. Ein Team freiwilliger Experten brachte hier die Überreste eines hallstattzeitlichen Gebäudes zum Vorschein.

Den Kern dieses Bandes bildet die Dokumentation der Prospektionskampagnen und der Grabung unter der Leitung von Urs Leuzinger, die interdisziplinär begleitet wurden: Palynologie, Radiokarbondatierungen, Mikromorphologie und Anthrakologie. Ergänzt werden die alpinen Forschungsergebnisse um einen Beitrag aus dem Tal, einer Untersuchung der Burgruine Attinghausen.

Between 2009 and 2013 Marion Sauter and Walter Imhof carried out prospection surveys in Canton Uri with students from the Lucerne School of Engineering and Architecture. The project aimed to compile an inventory of deserted Alpine villages. Of the more than 700 sites the Geissrüggen in Attinghausen (1911 $\mathrm{m}$ a.s.l.) was the one chosen for an archaeological research excavation, during which a team of volunteer experts uncovered the remains of a Hallstatt-period building.

The core contents of this volume are the records compiled during the prospection surveys and the excavation carried out under the direction of Urs Leuzinger. The project was also monitored by an interdisciplinary team of specialists in the fields of palynology, radiocarbon dating, micromorphology and anthracology. The Alpine research results are complemented by a report from the valley concerning the examination of the Attinghausen castle ruins.

www.librum-publishers.com

\section{HOCHSCHULE LUZERN}

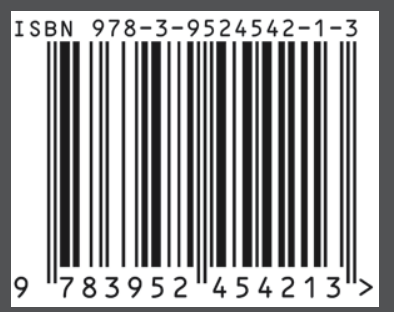

Technik \& Architektur

FH Zentralschweiz

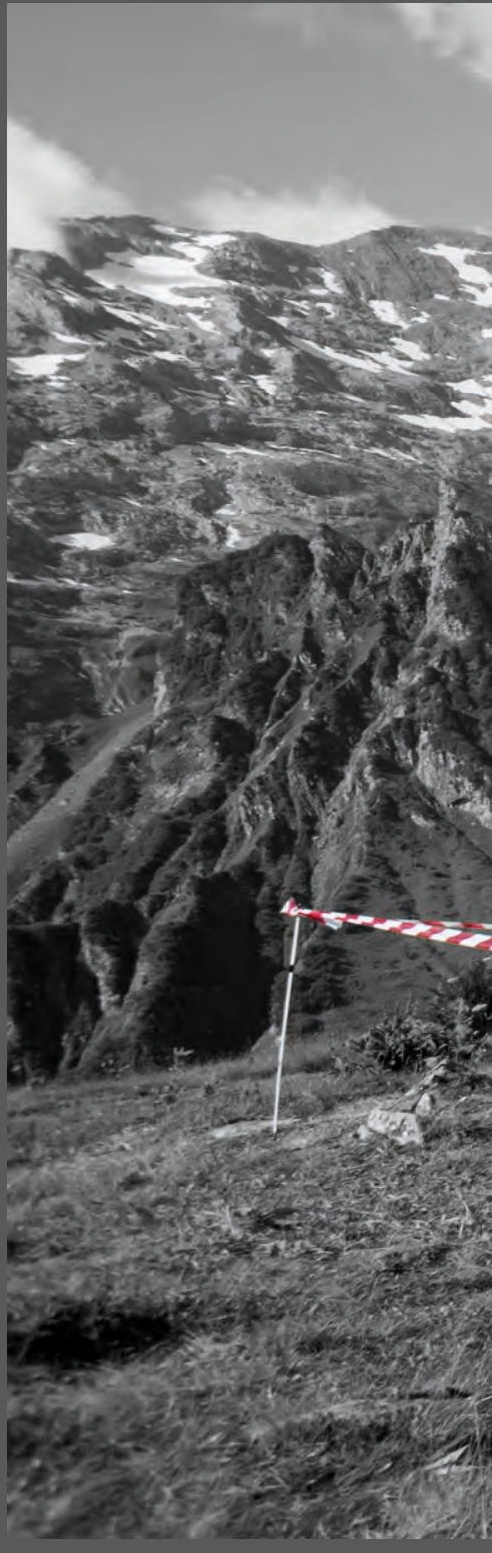


This publication is also available open-access on

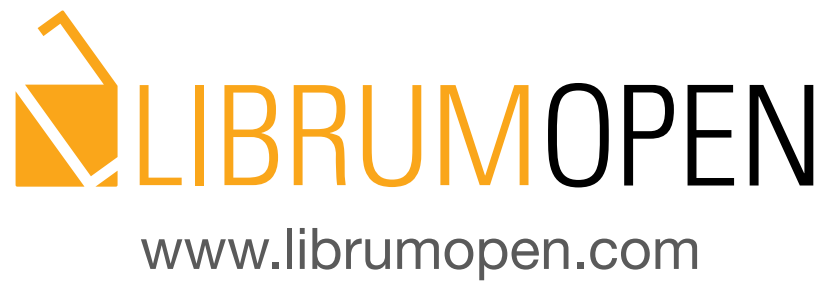

or as printed version at

\section{SLIBRUMSTORE www.librumstore.com}

